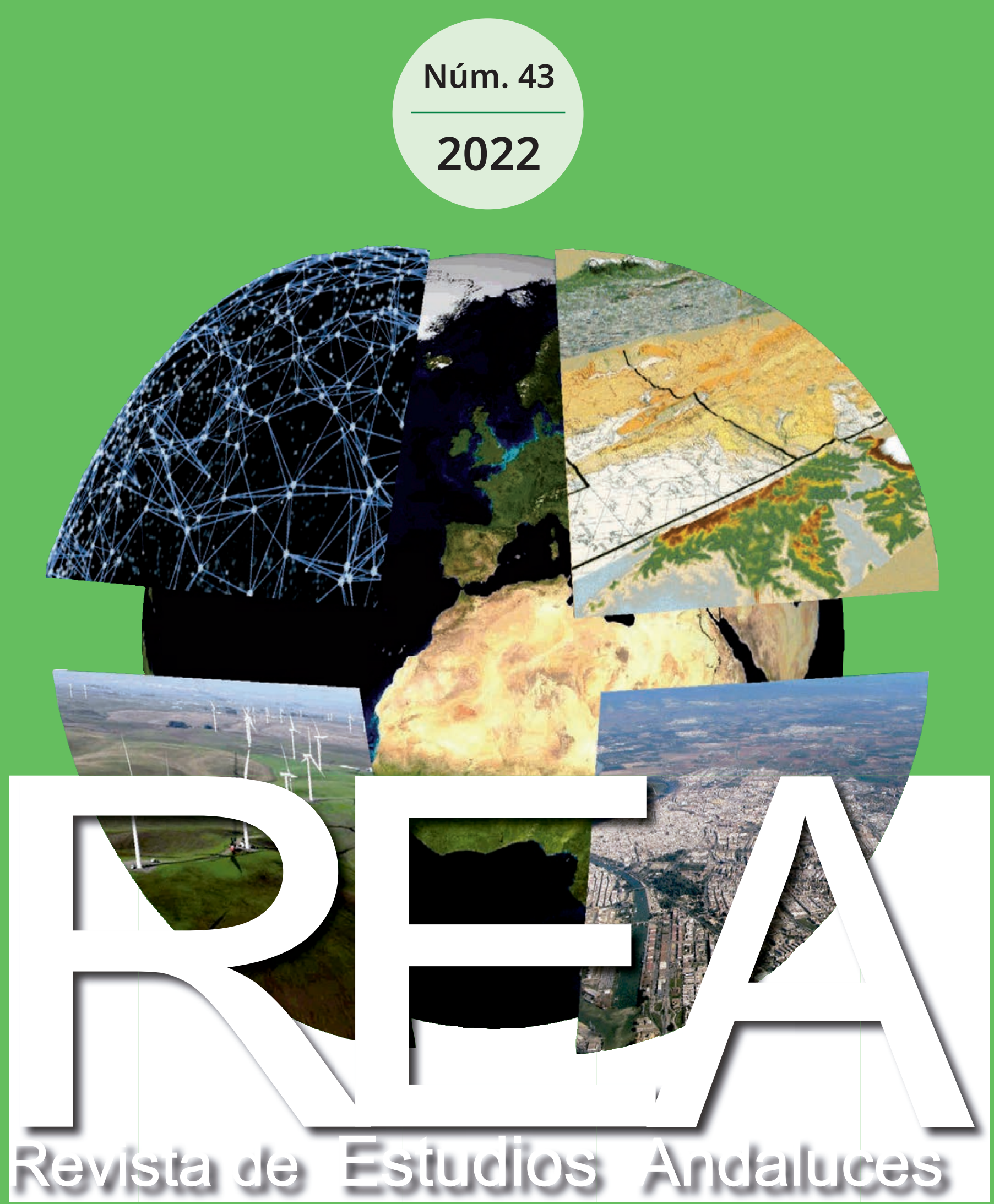

Universidad de Sevilla

Editorial Universidad de Sevilla

https://editorial.us.es/es/revistas/revista-de-estudios-andaluces https://revistascientificas.us.es/index.php/REA

ư eus

Editorial Universidad de Sevilla 


\section{Equipo Editorial}

Directora/Editora de la Revista

Rosa María JORDA BORRELL, Universidad de Sevilla (Sevilla), España.<borrell@us.es>

Secretaría de Revisión, Redacción y Edición

Francisca Ruiz Rodríguez, Universidad de Sevilla (Sevilla), España.<fruiz@us.es> Inmaculada España Rios, Universidad de Sevilla (España), España.<irios@us.es>

Editores Adjuntos (2022)

Rubén Ibán Díaz Parra, Universidad de Sevilla (Sevilla), España.<ibandiaz@us.es> Marco Garrido Cumbrera, Universidad de Sevilla (Sevilla), España.<mcumbrera@us.es> Reyes Gonzalez Relaño, Universidad de Sevilla (Sevilla), España.<rgrelano@us.es> Enrique López Lara, Universidad de Sevilla (Sevilla), España.<elopezl@us.es>

Angel Luis Lucendo Monedero, Universidad de Sevilla (Sevilla), España.<angeluis@us.es>

Consejo de Redacción

Juan Manuel Barragán Muñoz, Universidad de Cádiz (Cádiz), España.<juan.barragan@uca.es> Roberto Bustos Cara, Universidad Nacional del Sur (Bahía Blaca), Argentina.<usbustos@uns.edu.ar> Rafael Cámara Artiga, Universidad de Sevilla (Sevilla), España.<rcamara@us.es>.

Javier Esparcia Pérez, Universidad de Valencia (Valencia), España.<javier.esparcia@uv.es> Cayetano Espejo Marín, Universidad de Murcia (Murcia), España.<cespejo@um.es> Javier Gutiérrez Puebla, Universidad Complutense de Madrid (Madrid), España.<javiergutierrez@ghis.ucm> Enrico Ivaldi, Università degli Studi di Genova (Genova), Italia.<Enrico.ivaldi@unige.it> Stefania Mangano, Universita' Degli Studi Di Genova (Genova), Italia.<stefania.mangano@unige.it> Juan Antonio Márquez Dominguez, Universidad de Huelva (Huelva), España.<antonio@uhu.es> M. Paula Mendes, Universidade de Lisboa (Lisboa), Portugal.<mpaulamendes@tecnico.ulisboa.pt> Pietro Piana, Università degli Studi di Genova (Genova), Italia.<pietro.piana@edu.unige.it> Jorge Olcina Cantos, Universidad de Alicante (Alicante), España.<jorge.olcina@ua.es> Fermín Rodríguez Gutiérrez, Universidad de Oviedo (Oviedo), España.<farragut@ uniovi.es> María Asunción Romero Díaz, Universidad de Murcia (Murcia), España.<arodi@um.es> Marco Antonio Sandoval Estrada, Universidad de Concepción (Concepción), Chile.<masandov@udec.cl> Jesús Ventura Fernández, Universidad de Sevilla (Sevilla), España.<jventura@us.es>

Consejo Asesor

Alberto Capacci, Universidad de Génova (Génova), Italia

Gabriel Cano García, Universidad de Sevilla (Sevilla), España

Francisco Javier Contreras Diaz, Universidad Autónoma de Zacatecas (Zacatecas), México

Fernando Díaz del Olmo, Universidad de Sevilla (Sevilla), España

Dominik Faust, Technische Universität Dresden (Dresden), Alemania

Rubén Camilo Lois González, Universidade de Santiago de Compostela (Santiago de Compostela), España

Andrés García Lorca, Universidad de Almería (Almería), España

Karolina Golemo, Uniwersytet Jagielloński "Universidad Jaguelónica"(Cracovia), Polonia

Javier Martín Vide, Universidad de Barcelona (Barcelona), España

Ricardo Méndez Gutierrez del Valle, Instituto de Economía, Ga y Población CSIC (Madrid), España

Adriano Rovira Pinto, Universidad Austral (Valdivia), Chile

Kamal Targuisti El Khalifi, Université Andelmalek Essaadi (Tetouan), Marruecos

José Vallés Ferrer, Universidad Loyola Andalucía (Sevilla), España

Revista de Estudios Andaluces (REA). Núm. 43, febrero (2022)

Edita: Editorial de la Universidad de Sevilla (Sevilla), España.

(c) Editorial Universidad de Sevilla 2022

https://editorial.us.es/es/revistas/revista-de-estudios-andaluces

https://revistascientificas.us.es/index.php/REA

Periodicidad Bianual (febrero, Julio)

Depósito Legal: SE-221-1984

ISSN: 0212-8594

ISSN-e: $2340-2776$

DOI: https://dx.doi.org/10.12795/rea.2022.i43

Diseño Portada: Ángel Luis Lucendo Monedero

Maquetación: Referencias Cruzadas - referencias.maquetacion@gmail.com

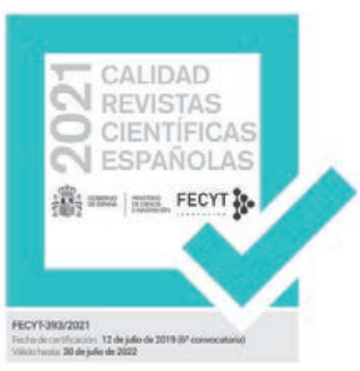

(®) $\Theta \Theta$ Licence Creative Commons Attribution-NonCommercial-NoDerivatives 4.0 International (CC BY-NC-ND 4.0) 


\section{ÍNDICE}

Proceso de gentrificación de un espacio degradado convertido en escaparate cultural. El caso del Centro Histórico de Málaga / Gentrification process of a degraded space turned into a cultural showcase. The case of the Historic Center of Malaga

Hugo Castro-Noblejas $\odot$ 0000-0002-8975-7506

Juan Francisco Sortino-Barrionuevo $\bigcirc$ 0000-0002-3643-4228

Sergio Reyes-Corredera 0 0000-0002-2760-6489

https://dx.doi.org/10.12795/rea.2022.i43.01

Patrimonio nuclear del sur de España. Diagnóstico y propuestas / Nuclear heritage of the south of Spain. Diagnosis and proposals

Juan Antonio Muñoz-Castillo $\odot$ 0000-0002-9755-5541

Jorge Olcina-Cantos $\odot$ 0000-0002-4846-8126

https://dx.doi.org/10.12795/rea.2022.i43.02 .

Classificação do sistema de trilhas da unidade de conservação Parque Estadual Mata do PauFerro, Areia, Paraíba, Brasil / Trail system classification of the conservation unit Pau-Ferro Forest State Park, Areia, Paraíba, Brazil / Clasificación del sistema de senderos de la unidad de conservación del Parque Estatal Forestal de Pau-Ferro, Areia, Paraíba, Brasil

Valéria Raquel Porto de Lima $10000-0001-7744-3502$

Jean Oliveira-Campos $\odot$ 0000-0002-2874-754X

https://dx.doi.org/10.12795/rea.2022.i43.03

Resiliencia del mercado turístico urbano ante la crisis de la COVID-19. El caso de Málaga / Resilience of the urban tourist market in the face of the COVID-19 crisis. The case of Malaga

Beatriz Benítez-Aurioles $\bigcirc$ 0000-0002-4224-9184

https://dx.doi.org/10.12795/rea.2022.i43.04

Does a visit to a blue-green space evoke positive feelings? Blue and green spaces survey in Shkodra' Lake, Albania / ¿Evocan sentimientos positivos las visitas a un espacio verde y azul? Encuesta sobre espacios azules y verdes, en el lago Shkodra, Albania

Samel Kruja $\odot$ 0000-0003-2717-138X

Olta Braçe $10000-0001-6335-5085$

https://dx.doi.org/10.12795/rea.2022.i43.05

Políticas públicas ambientales y desarrollo turístico sostenible en las áreas protegidas de Ecuador I Environmental public policies and sustainable tourism development in Ecuador's protected areas

Iván Mendoza-Montesdeoca @ 0000-0001-7632-144X

Manuel Rivera-Mateos $₫ 0000-0003-2780-380 X$

Yamil Doumet-Chilán @ 0000-0003-4295-5270

https://dx.doi.org/10.12795/rea.2022.i43.06 
La importancia de las capacidades dinámicas en el replanteamiento de una ventaja competitiva innovadora. Estudio de caso en empresas tecnológicas cordobesas / The importance of dynamic capabilities in the reformulation of an innovative competitive advantage. Case study of Cordoba technology companies

María Amalia Trillo-Holgado $10000-0002-1626-8066$

Carolina León-Urban $\odot$ 0000-0002-3862-6784

Rocío López-Caballero $\odot$ 0000-0003-2701-9951

https://dx.doi.org/10.12795/rea.2022.i43.07

Cambios observados y proyectados en los tipos de regímenes bioclimáticos de Argentina / Observed and projected changes in the types of bioclimatic regimes in Argentina

Valeria Soledad Duval $\odot$ 0000-0001-9048-3058

Rafael Cámara-Artigas $\odot 0000-0003-1046-3749$

https://dx.doi.org/10.12795/rea.2022.i43.08

Transporte aéreo y pandemia de la COVID-19: ¿Hacia un cambio de trayectoria en la red aeroportuaria española? / Air transportation and the COVID-19 pandemic: Towards a change of the path in the spanish airport network?

Roberto Díez-Pisonero $\odot$ 0000-0002-7817-628X

Cándida Gago-García @ 0000-0003-2315-7943

https://dx.doi.org/10.12795/rea.2022.i43.09

Tendencias de investigación en Geografía Económica. Estudio bibliométrico de la Web of Science (1920-2020) / Research trends in Economic Geography. Bibliometric study of the Web of Science (1920-2020)

María Pilar Alonso-Logroño $₫ 0000-0002-4327-623 X$

Nuria Bautista-Puig $\bigcirc 0000-0003-2404-0683$

https://dx.doi.org/10.12795/rea.2022.i43.10

Etude de la dynamique spatio-temporelle de la forêt des Ait Daoud ou Ali (Haut Atlas central, Maroc) en utilisant les techniques géospatiales / Study of the spatio-temporal dynamics of the Ait Daoud ou Ali (Central High Atlas, Morocco) Forest using geospatial techniques / Estudio de la dinámica espacio-temporal del bosque de Ait Daoud ou Ali (Alto Atlas Central, Marruecos) mediante técnicas geoespaciales

Aïman Hili $₫ 0000-0003-2220-6360$

Rachid Bissour $\odot$ 0000-0002-5391-9921

Farid Jaa $\odot 0000-0002-7158-5080$

Hanane Reddad $\odot$ 0000-0002-6238-165X

Yassine El Jouhary $\bigcirc$ 0000-0002-1534-4944

https://dx.doi.org/10.12795/rea.2022.i43.11 


\section{INDEX}

\section{Summary of Articles}

Gentrification process of a degraded space turned into a cultural showcase. The case of the Historic Center of Malaga

Hugo Castro-Noblejas $\odot$ 0000-0002-8975-7506

Juan Francisco Sortino-Barrionuevo $00000-0002-3643-4228$

Sergio Reyes-Corredera $10000-0002-2760-6489$

https://dx.doi.org/10.12795/rea.2022.i43.01

Nuclear heritage of the south of Spain. Diagnosis and proposals

Juan Antonio Muñoz-Castillo $\odot$ 0000-0002-9755-5541

Jorge Olcina-Cantos $\odot$ 0000-0002-4846-8126

https://dx.doi.org/10.12795/rea.2022.i43.02

Trail system classification of the conservation unit Pau-Ferro Forest State Park, Areia, Paraíba, Brazil

Valéria Raquel Porto de Lima $\odot 0000-0001-7744-3502$

Jean Oliveira-Campos $₫$ 0000-0002-2874-754X

https://dx.doi.org/10.12795/rea.2022.i43.03

Resilience of the urban tourist market in the face of the COVID-19 crisis. The case of Malaga

Beatriz Benítez-Aurioles $10000-0002-4224-9184$

https://dx.doi.org/10.12795/rea.2022.i43.04

Does a visit to a blue-green space evoke positive feelings? Blue and green spaces survey in Shkodra' Lake, Albania

Samel Kruja $\odot$ 0000-0003-2717-138X

Olta Braçe $10000-0001-6335-5085$

https://dx.doi.org/10.12795/rea.2022.i43.05

Environmental public policies and sustainable tourism development in Ecuador's protected areas

Iván Mendoza-Montesdeoca $\bigcirc$ 0000-0001-7632-144X

Manuel Rivera-Mateos $₫$ 0000-0003-2780-380X

Yamil Doumet-Chilán @ 0000-0003-4295-5270

https://dx.doi.org/10.12795/rea.2022.i43.06 
The importance of dynamic capabilities in the reformulation of an innovative competitive advantage. Case study of Cordoba technology companies

María Amalia Trillo-Holgado @ 0000-0002-1626-8066

Carolina León-Urban $\odot$ 0000-0002-3862-6784

Rocío López-Caballero $\odot$ 0000-0003-2701-9951

https://dx.doi.org/10.12795/rea.2022.i43.07

Observed and projected changes in the types of bioclimatic regimes in Argentina

Valeria Soledad Duval $\odot$ 0000-0001-9048-3058

Rafael Cámara-Artigas $₫$ 0000-0003-1046-3749

https://dx.doi.org/10.12795/rea.2022.i43.08

Air transportation and the COVID-19 pandemic: Towards a change of the path in the spanish airport network?

Roberto Díez-Pisonero $\odot$ 0000-0002-7817-628X

Cándida Gago-García @ 0000-0003-2315-7943

https://dx.doi.org/10.12795/rea.2022.i43.09

Research trends in Economic Geography. Bibliometric study of the Web of Science (1920-2020)

María Pilar Alonso-Logroño $10000-0002-4327-623 X$

Nuria Bautista-Puig $\odot$ 0000-0003-2404-0683

https://dx.doi.org/10.12795/rea.2022.i43.10

Study of the spatio-temporal dynamics of the Ait Daoud ou Ali (Central High Atlas, Morocco) Forest using geospatial techniques

Aïman Hili $\odot$ 0000-0003-2220-6360

Rachid Bissour $10000-0002-5391-9921$

Farid Jaa $\bigcirc 0000-0002-7158-5080$

Hanane Reddad $10000-0002-6238-165 X$

Yassine El Jouhary $₫$ 0000-0002-1534-4944

https://dx.doi.org/10.12795/rea.2022.i43.11 
Artículos

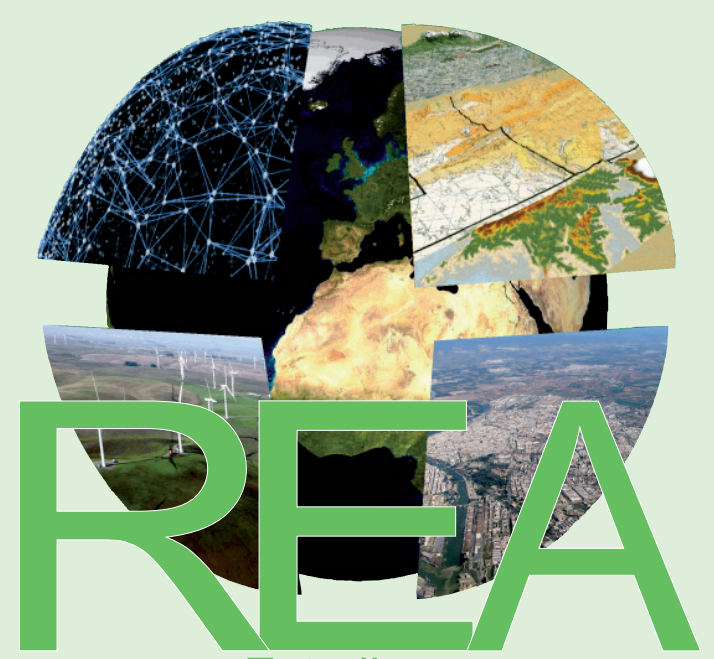

Revista de Estudios Andaluces 


\title{
Proceso de gentrificación de un espacio degradado convertido en escaparate cultural. El caso del Centro Histórico de Málaga
}

\section{Gentrification process of a degraded space turned into a cultural showcase. The case of the Historic Center of Malaga}

\author{
Hugo Castro-Noblejas \\ hugocastro@uma.es@0000-0002-8975-7506 \\ Juan Francisco Sortino-Barrionuevo \\ francis.sortino@uma.es @0000-0002-3643-4228 \\ Sergio Reyes-Corredera \\ sergioreyes@uma.es @ 0000-0002-2760-6489
}

Departamento de Geografía. Facultad de Filosofía y Letras. Universidad de Málaga. Campus Teatinos. Bulevar Louis Pasteur s/n. 29071 Málaga, España

\section{INFO ARTÍCULO}

Recibido: 11-06-2021

Revisado: 02-10-2021

Aceptado: 05-10-2021

\section{PALABRAS CLAVE}

Gentrificación
Centro urbano
Procesos urbanos
Transformación residencial
Málaga

\section{KEYWORDS}

\section{Gentrification}

Urban center

Urban processes

Residential transformation Malaga

\section{RESUMEN}

El Centro Histórico de Málaga ha estado sufriendo una serie de profundas transformaciones arquitectónicas, funcionales y sociales en las últimas décadas. Estos procesos no han sido analizados aún de forma sistemática, pese a que el estudio de los procesos urbanos como el de la gentrificación es un tema de máxima actualidad. Este trabajo pretende determinar si el Centro Histórico de Málaga ha presentado un proceso de gentrificación desde el último tercio del siglo XX hasta inicios del siglo XXI. Se ha procedido a la obtención de una serie de indicadores demográficos, socioeconómicos e inmobiliarios y al análisis de los mismos. Los resultados obtenidos indican la existencia de un proceso de gentrificación avanzado. Este estudio establece la base para una vía de investigación más amplia de este espacio urbano malagueño.

\begin{abstract}
The Historic Center of Malaga has been undergoing a series of profound architectural, functional and social transformations in recent decades. These processes have not yet been systematically analysed, despite the fact that the study of urban processes such as gentrification is a very present field of academic research. This work aims to determine if the Historic Center of Malaga has presented a gentrification process from the last third of the 20th century to the beginning of the 21st century. The results were obtained and analysed on the basis of a selection of demographic, socio-economic and property indicators that facilitate the identification of this urban phenomenon. The results obtained indicate the existence of an advanced gentrification process. This study establishes the basis for a broader avenue of investigation of this Malaga urban space.
\end{abstract}




\section{INTRODUCCIÓN}

El deterioro y la posterior transformación de los centros históricos urbanos ha sido un fenómeno generalizado al que se han enfrentado numerosas ciudades. Las causas de esta situación tienen su origen en la evolución social, económica y cultural derivadas de la crisis del modelo de producción fordista y el estado de bienestar keynesiano desde la década de 1970. Como reacción, las ciudades iniciaron un proceso de empoderamiento de lo local que fue el centro del debate económico (Brenner, 2004, Kazepov, 2010), en detrimento del tradicional modelo de centralismo estatal.

La gentrificación ha sido uno de los tres procesos de cambio predominantes en la ciudad junto con la relegación y la periurbanización (Donzelot, 2004). A ellos se suma otro más reciente, la turistificación, con los que mantiene distintas relaciones según la ciudad y la perspectiva con la que se analice (Sequera \& Nofre, 2018). La gentrificación consiste en el desplazamiento de la población originaria de un barrio deteriorado y la ocupación de este por una población con un mayor nivel económico, suponiendo esta sustitución una renovación urbana que va acompañada de inversiones y mejoras tanto en las viviendas, que son renovadas o rehabilitadas, como en el área afectada: comercios, equipamientos y servicios. Esto implica cambios en el mercado del suelo y de la vivienda, donde desempeñan un papel decisivo los agentes del suelo: los propietarios, los promotores, las administraciones públicas, las entidades financieras, así como los ocupantes. En conjunto, el fenómeno supone una mayor estima por las áreas renovadas y una recuperación del valor simbólico de los centros urbanos, a expensas de una ruptura del tejido urbano preexistente.

Las consecuencias que se perciben en el mercado de la vivienda son: el aumento del precio de la propiedad, tanto renovada como no renovada; la reducción de las tasas de ocupación de la vivienda y la menor densidad de población del área afectada, así como la transformación de la modalidad de ocupación en alquiler por la de ocupación en propiedad de grupos de rentas más altas que cambian la estructura económica y física de dichas áreas.

Una de las herramientas institucionales principales de esta transformación urbana ha sido convertir a la cultura en el recurso central de la producción de la riqueza (García, 2004), bien a través de estrategias vinculadas a la construcción de imagen para el atractivo turístico (branding o city marketing), bien como una industria o sector para el desarrollo económico, las denominadas "ciudades creativas" (Sánchez et al., 2012). En las últimas décadas este fenómeno ha supuesto el denominado giro local de la política cultural hacia la «estrategia emprendedora de los gobiernos locales» (Harvey, 1989) que en grandes ciudades como Birmingham, Glasgow o Barcelona ha traído consigo su promoción como capitales regionales con ambiciones internacionales. Estas dinámicas, que han supuesto una ruptura con las antiguas formas en la que se concebía la cultura -crear una identidad nacional o integrar diferentes expresiones culturales-, han convertido a las ciudades impulsoras en entes autónomos, responsables últimos de sus procesos de crecimiento y de sus consecuencias derivadas. Dichas estrategias planteadas para el desarrollo de sectores económicos vinculados con la producción de bienes culturales incluyen una serie de servicios culturales que impulsan el atractivo turístico y comercial. Algunas de las actuaciones han sido la recuperación patrimonial de los centros urbanos, la creación de instituciones y equipamientos culturales - museos, centros culturales - o la organización de grandes eventos transformadores (Evans, 2001). En definitiva, son proyectos que relacionan directamente la política cultural con la promoción económica (Gray, 2007), convirtiendo la cultura en un eje de desarrollo económico imprescindible (Scott, 1997).

Tras estudiar el proceso de gentrificación en otras ciudades y observar el cambio sufrido en el distrito denominado el "SoHo" (Borondo, 2015) en la propia ciudad de Málaga, la presente investigación tiene como objetivo principal mostrar los patrones de gentrificación que aparecen en el Centro Histórico del municipio y que se manifiestan tanto en la configuración de los edificios, su estado, su apariencia, así como en la funcionalidad que ofrecen. Para ello se ha analizado un cuerpo de variables demográficas, socioeconómicas, de equipamiento e infraestructuras.

Un objetivo secundario es el de aportar a la producción científica centrada en los procesos urbanos la visión geográfica con una contribución transversal a escala microterritorial de detalle, que considera aspectos sociales, económicos y ambientales. Integra así las perspectivas que también abordan esta temática: la Sociología, la Antropología y la Urbanística, como indica Mendoza (2016). 


\section{ANTECEDENTES}

Tras la acuñación del término gentrificación por Glass (1964), cuando se empezaba a repetir el patrón en Londres, se puede destacar la labor conceptual de Smith (1979), Zukin (1987) o Van Weesep (1994), entre otros que, al mismo tiempo de definir el concepto de gentrificación, van identificando las limitaciones y problemática que presenta dicho proceso. En la actualidad los estudios van desde la discusión sobre si la gentrificación debe ser apoyada, controlada, restringida o prevenida (Nickayin et al., 2020), pasando por los que analizan los efectos sociales de esta, como el efecto negativo en la salud de los más vulnerables (Mehdipanah et al., 2018), hasta los que tratan de diferenciarla y relacionarla con otros procesos como la turistificación (Sequera \& Nofre, 2018).

En el caso de España, los estudios se inician a comienzos de la década del 2000. Se han identificado distintas tipologías, según los actores y las transformaciones del sistema productivo: gentrificación y migración transnacional en el caso de Madrid (Martínez \& Leal, 2008; Pérez-Agote et al. (Eds.), 2010), Barcelona (Sargatal, 2000), ambas ciudades (Sorando \& Leal, 2019) o Bilbao (Cavia et al., 2008); gentrificación turística con influencia pública (García \& Díaz, 2008) en ciudades como Valencia (Prytherch \& Boira, 2009), Bilbao (Vicario \& Martínez, 2003), Sevilla (Jover \& Díaz-Parra, 2020) o Palma de Mallorca, con políticas del programa europeo Urban (Morell, 2009); gentrificación productiva y comercial en el caso de la ría de Bilbao (Rodríguez \& Vicario, 2005), el Poble Nou barcelonés (Marrero, 2003; Boixader, 2004) o el centro de Sevilla (Jover, 2019) y gentrificación simbólica y de producción cultural, destacando los estudios de Lavapiés, Malasaña y Chueca en Madrid (Sequera, 2010) y, en menor medida, de Barcelona o Bilbao. En el caso del Centro Histórico de Málaga, que ha sufrido una vertiginosa rehabilitación en las últimas décadas, no se han encontrado trabajos que estudien dichos cambios.

La evolución histórica de los instrumentos de planeamiento regulador del crecimiento y dinámica de Málaga comienza con el Plan General de Ordenación Urbana (PGOU) de 1971, un plan expansivo y desarrollista que fomentó el binomio construcción-turismo en una etapa de crisis a escala internacional (Rubio, 2003). Paralelamente, el Centro Histórico fue declarado Bien de Interés Cultural (BIC) en 1971, figura de protección y reconocimiento que no adquiere valor vinculante por la Ley de Patrimonio Histórico Español hasta 1985.

Durante las décadas de 1980 y 1990 la nueva interpretación de la ciudad consolidada como producto supuso una ruptura con el modelo existente de ciudad expansionista, siendo el objetivo de este "nuevo urbanismo" la conservación y el desarrollo de una ciudad articulada que mejore la vida de sus habitantes (Rubio, 1986). Este giro se trasladó a la nueva legislación y planificación. A partir de ese momento, gracias al artículo 11 de la Ley de Patrimonio, se le concede al Núcleo Histórico la aplicación provisional del mismo régimen de protección previsto para los BIC ya declarados. Esto conlleva la obligación por parte del municipio donde se encuentre el BIC de realizar un Plan Especial de Protección (PEP) del área incoada (art. 20). En 1988 se aprobó un Plan Especial que también incorporaba un Plan de Reforma Interior. Un PEP tiene la capacidad de modificar el PGOU que esté en vigencia, mientras que un Plan Especial de Reforma Interior (PERI) puede realizar todas las transformaciones urbanas que se quiera en el área de su actuación, pero siempre acogiéndose a la normativa que dicte el PGOU.

En la década de 1990 hay un giro en la planificación urbana clásica al cobrar importancia, de forma complementaria, los planes estratégicos como fruto del nuevo paradigma posmoderno. Parte de los proyectos urbanísticos de la ciudad, que tienen como objetivo el desarrollo turístico con el Plan Urbano del Centro Histórico, se fundamentan en la política de la Unión Europea. Las actuaciones propuestas en este documento bien podrían encuadrarse en un Plan de Excelencia Turística. El PGOU de 1995 se basó en un ciclo de inversiones público-privadas, centrando los esfuerzos de la administración local en la promoción de la ciudad como producto y dirigiendo las inversiones al crecimiento de la misma. La consecuencia de esta política generó graves problemas en el Casco Histórico, con una población envejecida y el abandono de la vivienda; la tendencia a la marginación de su población; la pérdida de su funcionalidad por la deslocalización productiva y la crisis comercial; la inseguridad ciudadana; la mala comunicación de los medios de transporte, a los que hay que añadir el incremento de los precios en el régimen de alquiler que explican el proceso llamado turistificación (López-Padilla, 2020). 


\section{METODOLOGÍA}

\section{1. Área de Estudio}

Málaga se sitúa al sur de la península Ibérica, en el litoral mediterráneo, siendo el sexto municipio español por población total con 574.654 habitantes, según el Padrón de 2019. Su estructura metropolitana se caracteriza por la existencia de numerosos centros de actividad que conforman la aglomeración urbana de la Costa del Sol. La ciudad opera como centro intermodal de comunicaciones, siendo cabecera económica y cultural de este sistema urbano regional.

A partir de 1960 la ciudad creció de forma rápida y desordenada al cobrar fuerza la nueva actividad turística. La población se duplicó en 20 años gracias a los flujos inmigratorios de índole económica y climática, sin disponer de unos niveles adecuados de infraestructuras, equipamientos urbanos y zonas verdes. Este crecimiento ha supuesto en el Área Metropolitana que el consumo de suelo en los últimos 25 años haya crecido exponencialmente. Esta expansión llevó, de forma indirecta, a la degradación del Centro Histórico debido a la oferta de una vivienda mejor dotada y con mayor equipamiento público amparada en la democratización del automóvil. Además, a falta de un instrumento de planeamiento regulador del crecimiento y dinámica de la ciudad, se produjeron importantes pérdidas del patrimonio del Centro Histórico por el interés de construir vivienda "de promoción". A partir de mediados de 1990, con la puesta en marcha de la Iniciativa Comunitaria Urban, se iniciaron los trabajos de recuperación del espacio público del Centro Histórico, incentivándose la rehabilitación de la edificación y la transformación comercial.

Para el presente estudio (ver figura 1) se han considerado las unidades administrativas siguientes, teniendo como referencia los límites de la antigua ciudad musulmana: los distritos censales de 2906701, 2906702 y 2906703. Cuando ha sido posible, se ha profundizado hasta la escala de unidad sección censal: 2906701001 (Mercado de Atarazanas), 2906701002 (entorno de Calle Larios), 2906702001 (Alcazaba-Paseo del Parque), 2906703001 (área central), 2906703002 (entorno de la Plaza de San Pedro) y 2906703003 (entorno del Palacio de Valdeflores). Según el Instituto Nacional de Estadística (INE), a 1 de enero de 2019 la población total de esta delimitación es de 5.417 habitantes.

Para el análisis de la transformación de los locales comerciales se ha empleado otra delimitación del área de estudio levemente distinta. Se trata de una unidad elaborada por DonDeNegocios (2016), coincidente con el sector intramuros medieval. Según los datos recogidos por DonDeNegocios en 2016, la superficie total es de 41,5 hectáreas, dentro de las cuales se localiza un total de 1.082 parcelas catastrales, de las que 54 son solares sin edificar o inmuebles en ruina. Además, comprende un total de 175 calles y plazas con una morfología muy diversa (desde callejones de apenas 20 metros de longitud, como Concejal Agustín Moreno o Ángel Ganivet, hasta calles como Carretería o Granada, de hasta medio kilómetro).

\subsection{Fuentes de información y selección de variables}

Se presenta a continuación la tabla 1 de variables con su fuente de procedencia, antes de explicar su importancia en el análisis de la gentrificación.

Para facilitar el análisis de los resultados, las variables empleadas se han estructurado en tres epígrafes: variables demográficas, variables socioeconómicas y variables del inmobiliario y espacios públicos. Tomando como referencia a Rubiales (2014), el orden en que se disponen estas agrupaciones no es casual. En primer lugar, empleando criterios de jerarquización social de la población a nivel de secciones censales, se recogen unos primeros indicios de gentrificación en la zona de estudio; posteriormente, se profundiza en las características socioeconómicas de la población, poniendo particular interés en la población que llega y sale del área de estudio. Por último, se reconoce la transformación urbanística que acompaña a los indicios previos mediante las variables del inmobiliario y espacios públicos. 


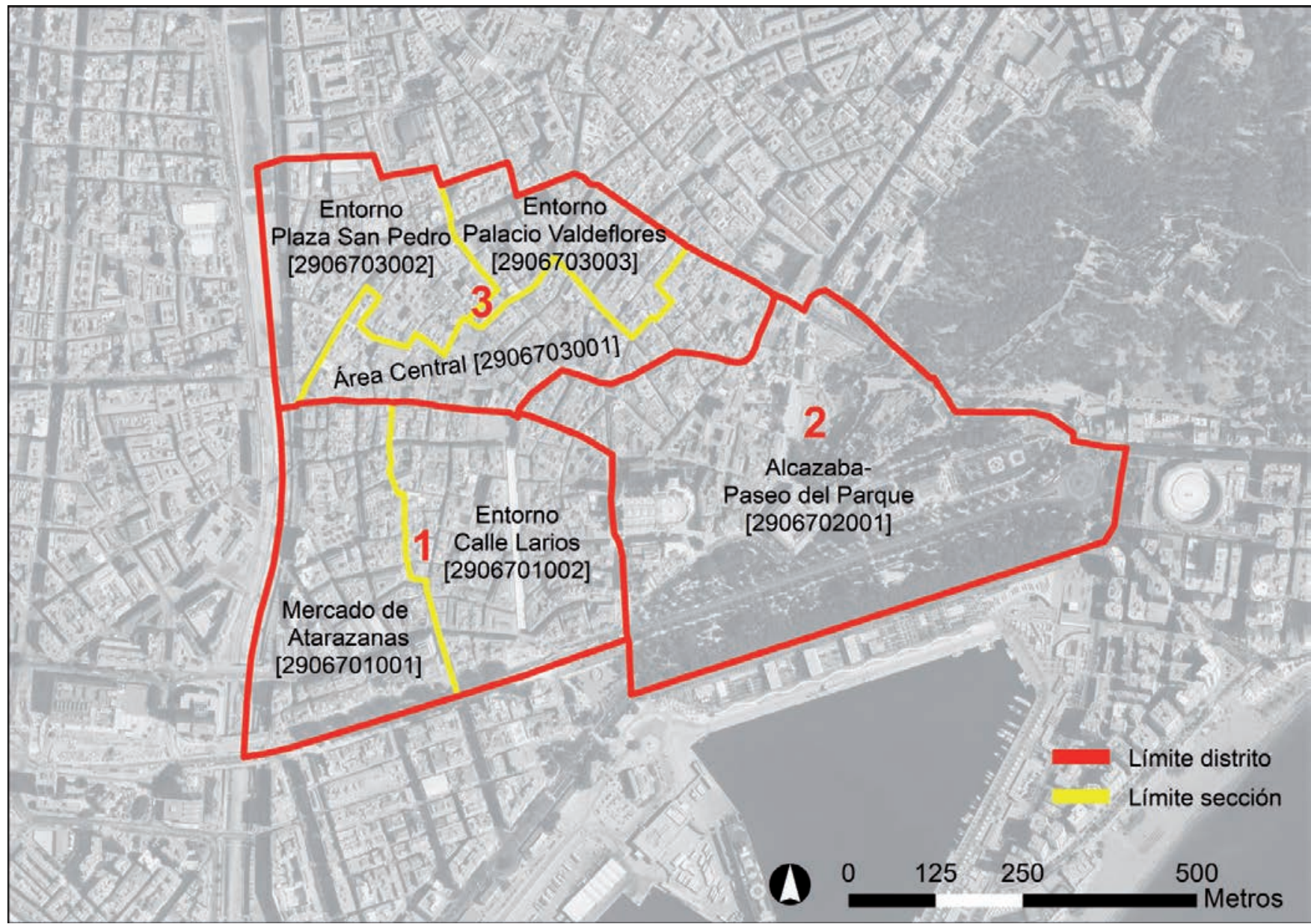

Figura 1. Secciones censales circunscritas al trazado de la antigua muralla musulmana. Fuente: Elaboración propia.

Tabla 1. Variables y sus fuentes de procedencia.

\begin{tabular}{|c|c|c|}
\hline Temática & Variables & Fuentes \\
\hline \multirow{4}{*}{$\begin{array}{l}\text { Demografía y } \\
\text { socioeconomía }\end{array}$} & $\begin{array}{l}\text { Evolución del tamaño y estructura de } \\
\text { la población }\end{array}$ & $\begin{array}{l}\text { Censo de población (2011) y Padrón (2019). } \\
\text { Instituto Nacional de Estadística (INE) }\end{array}$ \\
\hline & Evolución del volumen de extranjeros & $\begin{array}{l}\text { Censos de población (2001 y 2011) y Padrón } \\
\text { (2019). Instituto Nacional de Estadística (INE) }\end{array}$ \\
\hline & Tasa de riesgo de pobreza & Martín, García y Fernández (2012) \\
\hline & Índice de Gini & Martín, García y Fernández (2012) \\
\hline \multirow{5}{*}{$\begin{array}{l}\text { Parque de viviendas y } \\
\text { hogar }\end{array}$} & Precio del suelo construido & $\begin{array}{l}\text { Analistas económicos de Andalucía (2016). } \\
\text { Ocaña (2010). TINSA (2020) }\end{array}$ \\
\hline & Proceso de rehabilitación y demolición & $\begin{array}{l}\text { Edifeicios (2019). Oficina de Rehabilitación del } \\
\text { Centro Histórico de Málaga (2012). }\end{array}$ \\
\hline & Año de construcción de las viviendas & $\begin{array}{l}\text { Censo de población (2011). Instituto Nacional de } \\
\text { Estadística (INE) }\end{array}$ \\
\hline & Estado del edificio & $\begin{array}{l}\text { Censos de población (2001 y 2011). Instituto } \\
\text { Nacional de Estadística (INE). Martínez, García, } \\
\text { Maya, Rodríguez y Checa (1996) }\end{array}$ \\
\hline & Tamaño de la vivienda & $\begin{array}{l}\text { Censos de población (2001 y 2011). Instituto } \\
\text { Nacional de Estadística (INE) }\end{array}$ \\
\hline
\end{tabular}




\begin{tabular}{|c|c|c|}
\hline Temática & Variables & Fuentes \\
\hline & Estructura del hogar & $\begin{array}{l}\text { Censos de población ( } 2001 \text { y } 2011 \text { ). Instituto } \\
\text { Nacional de Estadística (INE). Jurado (2006). Ley } \\
\text { (1996) }\end{array}$ \\
\hline & Régimen de tenencia & $\begin{array}{l}\text { Censos de población (2001 y 2011). Instituto } \\
\text { Nacional de Estadística (INE). Ocaña (2010). } \\
\text { Sargatal (2000) }\end{array}$ \\
\hline \multirow[b]{2}{*}{ Servicios y equipamientos } & Evolución del comercio y hostelería & \multirow{2}{*}{$\begin{array}{l}\text { DonDeNegocios (2019). Clasificación Nacional de } \\
\text { Actividades Económicas (CNAE). OMAU (2015). } \\
\text { Fundaciones Picasso y Thyssen (2015-2019). }\end{array}$} \\
\hline & $\begin{array}{l}\text { Infraestructuras, equipamientos y } \\
\text { servicios }\end{array}$ & \\
\hline
\end{tabular}

Fuente: Elaboración propia.

\subsubsection{Variables demográficas y socioeconómicas}

Un primer acercamiento a la dinámica demográfica del área de estudio se basa en la evolución temporal de la población a escala sección censal entre 1981 y 2019. Puesto que el dato de 1991 no está disponible a este nivel de desagregación espacial, se optó por calcular su valor aproximado mediante un proceso de interpolación. Tras comparar los coeficientes de determinación de varias ecuaciones, se optó por la ecuación polinómica de segundo grado, que presentaba el mejor ajuste de todas las opciones estudiadas. Para el mismo período se midió la evolución de la estructura demográfica mediante la razón de los valores de las distintas cohortes de población para los años 2001, 2011 y 2019.

Los procesos urbanos objeto de estudio afectan teóricamente en mayor medida a los inmigrantes laborales, puesto que tienden a concentrarse en el parque de viviendas de baja calidad, como reflejo de su escasa capacidad de elección. De ahí el análisis de la evolución del volumen de extranjeros para el período 2001-2019. Se aplicó a los valores obtenidos el coeficiente de localización para expresar la relación entre la presencia de los extranjeros en el Centro Histórico y la proporción de extranjeros del total del municipio con respecto a la población total de Málaga. El análisis de estas tres variables se basó en los datos del censo de 1981, 2001 y 2011 y del padrón de 2019.

La tasa de riesgo de pobreza expresa el porcentaje de hogares municipales situados por debajo del nivel mínimo de renta, conocido como umbral de pobreza, por debajo del cual se considera que resulta difícil mantener unas condiciones de vida aceptables en el contexto social en el que se vive. Para el establecimiento de la línea de pobreza relativa se toma el umbral de referencia de la Unión Europea, correspondiente al $60 \%$ de la renta mediana, es decir, la que ocupa la posición central de la distribución existente de la renta (Martín et al. (2012). La información disponible es de 2011.

Para medir la desigualdad en los ingresos de la población se ha empleado el índice de Gini. Se trata de un coeficiente normalizado en el que los valores oscilan entre 0 y 100, donde 0 se corresponde con la perfecta igualdad (todos tienen los mismos ingresos) y 100 se corresponde con la perfecta desigualdad (una persona tiene todos los ingresos y los demás, ninguno). La información disponible es de 2011.

\subsubsection{Caracterización y evolución del parque de viviendas y el hogar}

El precio del suelo construido, medido en $€ / \mathrm{m}^{2}$, permite diagnosticar la deseabilidad de la zona de estudio para residir. Se ha interpretado la evolución temporal de 2001-2012.Directamente vinculado va el proceso de demolición-rehabilitación y la antigüedad de la vivienda. Se ha interpretado una secuencia anual de planos desde 1956 hasta 2016 en la que se contabilizan las demoliciones. No solo permite identificar la extensión total transformada, sino que, además, permite reconocer los distintos ritmos de alteración del Centro Histórico por zonas. Para ello, se ha tomado como base la bibliografía de los Antecedentes y se ha confrontado con los resultados del resto de las variables. 
Para establecer la antigüedad se ha optado por el año de construcción de las viviendas, tomando como unidad la vivienda. Se ha realizado la razón de los valores de las secciones censales entre el valor total del ámbito de estudio para los años 2001 y 2011.

En la misma línea, la evolución en el estado del edificio permite detectar si hay un proceso de abandono y reformas. Se ha realizado la razón de los valores de las distintas entidades entre el valor total para los años 2001 y 2011. Se toma como unidad de medida el edificio. Se han suprimido los datos de "no consta/no aplicable".

El tamaño de la vivienda ejemplifica el cambio de modelo residencial en el caso del parque de viviendas renovado. Tomando como unidad la vivienda, se ha averiguado la razón de los valores de las distintas secciones censales entre el valor total para los años 2001 y 2011. De forma consecuente, esto afecta a la estructura del hogar, que tiende a reducirse a la vez que el tamaño de la vivienda. Se ha realizado la razón de los valores de las secciones censales entre el valor total del área de estudio para los años 2001 y 2011.

Por último, el régimen de tenencia puede cambiar junto con los condicionantes anteriores, aunque también puede ser por la influencia de la turistificación. Empleando como unidad la vivienda, se ha aplicado la razón de los valores de las distintas secciones censales entre el valor total del ámbito de estudio para los años 2001 y 2011.

\subsubsection{Variables sobre los servicios y equipamientos}

La evolución en la oferta del comercio y la hostelería en el Centro Histórico de Málaga para el período 2001-2016 ejemplifica la forma de vida desarrollada en dicho espacio urbano. Las actividades económicas recogidas en los locales comerciales del área de estudio se han ordenado según la Clasificación Nacional de Actividades Económicas de España (CNAE-2009). Se han desagregado las actividades económicas a una escala de 2 y 3 dígitos, dependiendo de la claridad de la actividad económica de un local para su adscripción a un grupo determinado.

Posteriormente, siguiendo los cálculos realizados en el trabajo de referencia, se ha calculado la evolución del número de locales para cada grupo de actividades, expresándolo mediante un índice en base 100.

Igualmente, la incorporación de infraestructuras, equipamientos y servicios vinculados al ocio cultural son propios de la gentrificación cultural (Vila, 2016). Se opta por un recuento de estos componentes urbanos considerando la evolución en términos absolutos, cualitativos y su distribución espacial, mediante trabajo de campo. Esta tarea ha requerido una elaboración específica puesto que la aproximación cuantitativa realizada se apoya en datos publicados por la Administración en sus diferentes escalas administrativas: estatal, autonómica y municipal.

\section{RESULTADOS}

Los resultados obtenidos en este apartado se presentan mediante el análisis de las variables expuestas en la metodología. Por un lado, las vinculadas con la población y sus características socioeconómicas; por otro, las relacionadas con las peculiaridades del parque de viviendas y, por último, las pertenecientes a infraestructuras, equipamientos y servicios.

\subsection{Variables demográficas}

Como se puede observar en la figura 2, en la etapa intercensal (1981-2001) el sector Centro mantiene la línea de declive poblacional iniciada con anterioridad. Desde finales de la década de 1990 se pasa a una estabilización e, incluso, se reconoce una leve recuperación durante la década del 2000. Este comportamiento demográfico responde, en la primera etapa descrita, al proceso de desplazamiento indirecto generado por la degradación del Centro Histórico y, en la segunda, al inicio de un incremento de la deseabilidad del Centro Histórico en proceso intenso de rehabilitación. 
En el período de 2011 a 2019 se retoma la dinámica de decrecimiento. Tras haber alcanzado un nivel alto de deseabilidad para nuevos residentes, el Casco Antiguo ha ido cobrando una orientación funcional cada vez mayor hacia el ocio, particularmente al asociado al turismo (ver apartado de locales y centros culturales). Este proceso, al que se le denomina turistificación, puede explicar el reciente retorno del decrecimiento. Si se contrasta con la tendencia del conjunto del municipio, que está marcada por un proceso de crecimiento no constante, pero sí continuo, queda confirmada la teoría de que el área de estudio ha sufrido ciertos procesos urbanos particulares.

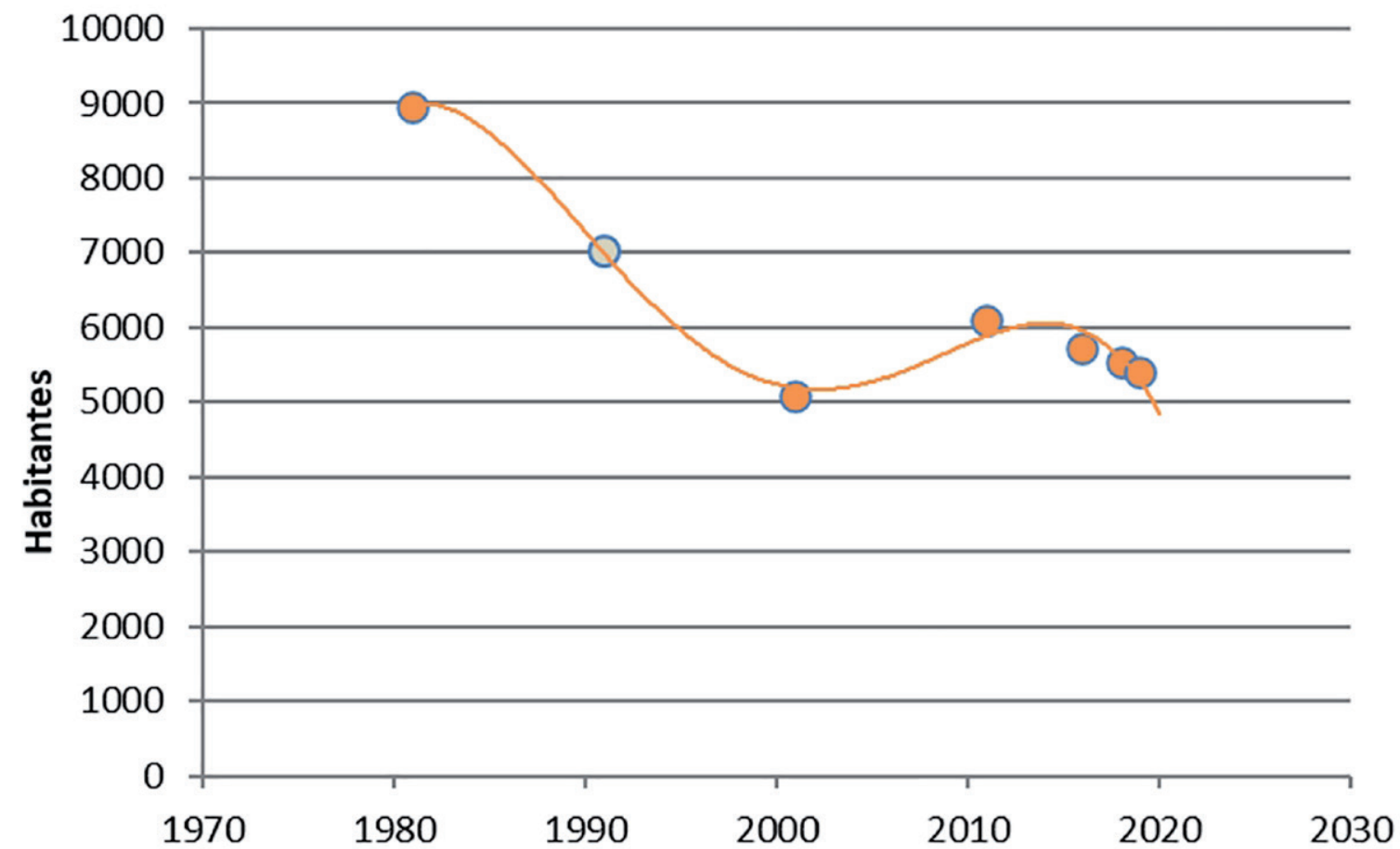

Figura 2. Evolución de la población en el Centro Histórico en el período 1981-2019. Fuente: Censo de Población 2011 y Padrón (2019), INE. Elaboración propia. *Sin datos del año 1991 (en gris).

Para profundizar en las variaciones de la estructura demográfica es igualmente importante conocer los cambios en los contingentes de la población. Tomando como referencia la figura 3, en la década de 2001 a 2011 la estructura de población se ha ensanchado por las cohortes de mediana edad, mientras que la cumbre de la pirámide de población indica que el grupo de mayor edad ha perdido presencia en la estructura de población en dicha década. Se puede identificar un proceso de rejuvenecimiento de la población, en parte debido a la reactivación de la cohorte de 0-4 años y, en parte, por la población joven de las cohortes 25-29 y 30-34, por lo que se deduce la llegada de población de fuera de dicha área de estudio. Este fenómeno refleja cómo las condiciones del mercado cambiaron en este período: si bien Ocaña (2010) señala cómo el Centro Histórico de Málaga aparecía en las décadas anteriores como un área poco propicia al afincamiento de hogares jóvenes de clase media urbana, parece evidente que hay un cambio en la demanda, en parte debido al reajuste de la oferta del parque de viviendas del Centro, que se tratará más adelante.

Otro de los rasgos que cambia del 2001 al 2011 es el particular desequilibrio en la sex ratio de la cohorte de 25-29, que aparece muy descompensada, con predominio de sexo masculino (138 hombres por mujer). En 2011 se equilibra dicha descompensación, lo que hace intuir un cambio en el origen y el nivel socioeconómico de la población. 


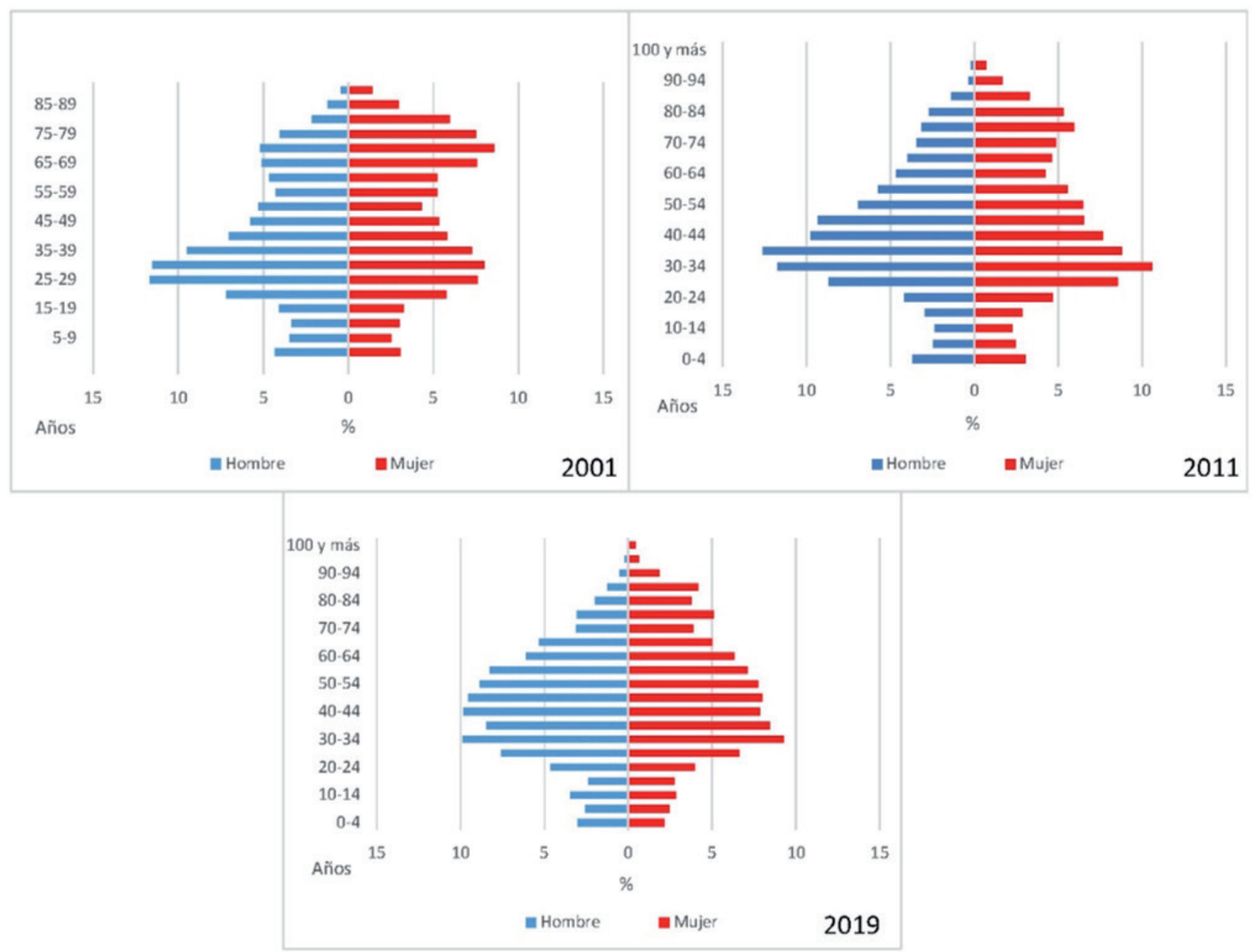

Figura 3. Pirámides de población del Centro Histórico en 2001, 2011 y 2019. Fuente: Censo de Población, INE (2001 y 2011) y Padrón INE (2019). Elaboración propia.

En ambos censos se refleja una predominancia de la población masculina hasta las cohortes de 50-54 y 55-59. Más allá de dicha edad, la mayor esperanza de vida es femenina. Un patrón que se repite es el incremento del peso de la población en proporción y en valores absolutos de las cohortes 25-29 a 35-39, que se explica por la discontinuidad creada por su tamaño con respecto al de las cohortes más jóvenes y viejas. En 2019 la estructura de población (figura 3) presenta un cambio de ocupación del parque de viviendas casi completo. Ya no quedan apenas residentes de la anterior generación y la mayor parte de la población se concentra entre los 25 y 59 años, población adulta sin hijos en su mayoría, con ocupaciones del hogar que van de la vivienda unipersonal a las compartidas por varios adultos. Cada vez se muestra como un sitio menos atractivo para los hogares de familias.

La estructura de población de 2019 refleja la falta de reposición de la población que reside en el área estudiada. La cohorte de población de mayor importancia sigue siendo la de 30 a 34 años, aunque la disminución de nuevos residentes jóvenes hace que se genere una meseta en la población de adultos en edad madura hasta los 59 años. La base se estrecha cada vez más, lo que refleja que los jóvenes que se instalan en esta zona urbana no tienen por prioridad la conformación de familias debido a dificultades económicas y a otras preferencias vitales (tendencia compartida con el resto del municipio).

La mayor transformación se puede observar en la sección 2906703001 (Área Central) en el período 20012011 donde se ensancha particularmente para los contingentes de 30-34 años y también de 35-39 años, lo que supone alrededor del $15 \%$ de la población total. Resulta llamativa la mayor presencia de mujeres en la cohorte de 30-34 años debido, probablemente, a la procedencia de los extranjeros, aunque no se puede precisar con 
el nivel de desagregación de los datos obtenidos. Además, se estrecha más que en otras secciones la proporción de población anciana. En este caso, parece que la llegada de población se dio de forma más intensa antes del 2001. La figura 4 permite identificar de forma sintética las particularidades de la estructura demográfica del Centro Histórico al compararla con la estructura demográfica del conjunto municipal de Málaga.

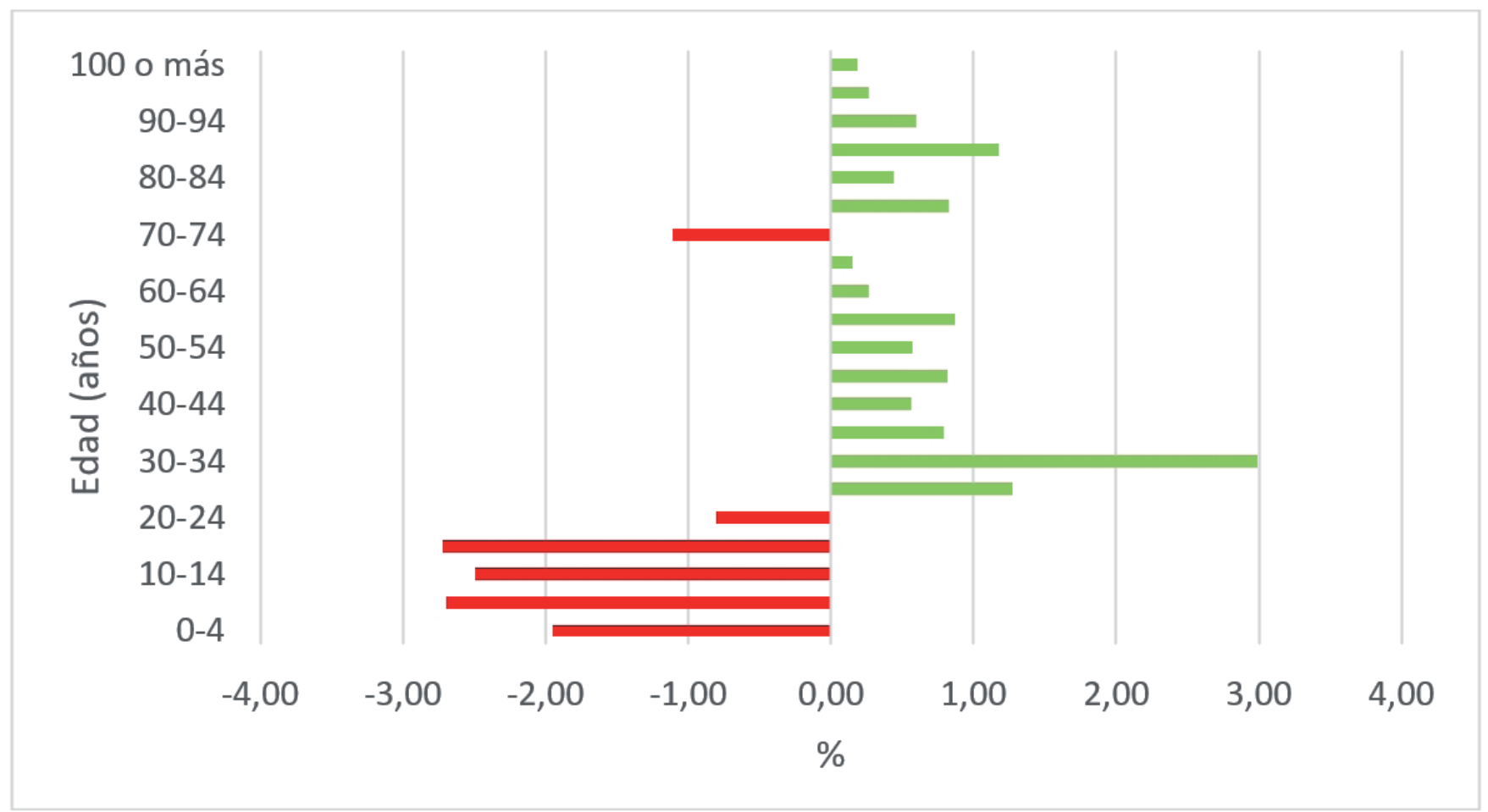

Figura 4. Diferencia de predominancia proporcional de la población por cohortes en el centro Histórico con respecto al conjunto de Málaga. 2019. Fuente: Padrón 2019, INE. Elaboración propia.

El área de estudio muestra comparativamente una mayor presencia de la población adulta entre las cohortes 25-29 y 65-69 años, así como de las cohortes de mayor edad de 75 años en adelante. La nota discordante de la cohorte de 70-74 años, con un peso mucho menos importante en el Centro Histórico, puede ser el último indicador del proceso de gentrificación que expulsó a la población de esta franja de edad y que atrajo a otra más joven después del proceso de rehabilitación/reforma/renovación. Estos resultados demuestran que la tendencia al rejuvenecimiento de la población entre 2001 y 2011 se estancó en la siguiente década. Como se infiere de estos datos, siguen instalándose adultos jóvenes, aunque no configuran hogares clásicos y es mucho menos habitual que tengan hijos.

Como se observa en las pirámides de población, la estructura demográfica está muy influenciada por la presencia de extranjeros. Las tablas 2 y 3 permiten reconocer la proporción de extranjeros en el Centro Histórico, en relación con la proporción municipal, para los años 2001, 2011 y 2019.

Los intervalos elaborados para esta variable toman como referencia el valor medio municipal. Mientras que en el 2001 solo la zona occidental del área del Centro Histórico, las secciones censales 2906701001 y 2906703003, presentaba una mayor proporción relativa de extranjeros, en 2011 se podía reconocer cómo todo el Centro Histórico había pasado a convertirse en un espacio diferenciado espacialmente para la residencia de extranjeros.

A lo largo de las dos últimas décadas, el conjunto de las secciones incluidas muestra una importante presencia de extranjeros, aunque ha ido fluctuando su distribución. Los rasgos de especialización que se observaban en 2001 se han suavizado, lo que supone que determinadas zonas del Centro han dejado de constituirse como guetos para colectivos extranjeros, como fue el caso de los habitantes africanos en la sección 2906701001 o la de asiáticos en la sección 2906703001. 
Tabla 2. Proporción de extranjeros por secciones. Años 2001, 2011 y 2019.

\begin{tabular}{|l|c|c|c|c|c|c|}
\hline \multirow{2}{*}{ Sec. Censal } & \multicolumn{2}{|c|}{2001} & \multicolumn{2}{|c|}{2011} & \multicolumn{2}{c|}{2019} \\
\cline { 2 - 7 } & N. ${ }^{\circ}$ & $\%$ & N. ${ }^{\circ}$ & $\%$ & N. ${ }^{\circ}$ & $\%$ \\
\hline 2906701001 & 113 & 11,2 & 276 & 23,9 & 203 & 18,9 \\
\hline 2906701002 & 40 & 5,5 & 126 & 15,4 & 96 & 14,8 \\
\hline 2906702001 & 35 & 4,6 & 131 & 15,9 & 117 & 16,8 \\
\hline 2906703001 & 54 & 7,3 & 201 & 19,8 & 234 & 25,1 \\
\hline 2906703002 & 46 & 6,1 & 191 & 20,4 & 151 & 19,4 \\
\hline 2906703003 & 112 & 10,2 & 396 & 29,4 & 333 & 25,8 \\
\hline C. Histórico & 400 & 7,9 & 1321 & 21,7 & 1134 & 20,9 \\
\hline Málaga & 10087 & 1,9 & 47925 & 8,4 & 46490 & 8,1 \\
\hline
\end{tabular}

Fuente: Censos de Población de 2001 y de 2011. Padrón continuo 2019. Elaboración propia.

Tabla 3. Coeficiente de localización según la región de origen de los extranjeros. 2001, 2011 y 2019.

\begin{tabular}{|c|c|c|c|c|c|c|c|c|c|c|c|c|}
\hline \multirow{2}{*}{ Sec. Censal } & \multicolumn{3}{|c|}{ África } & \multicolumn{3}{|c|}{ América } & \multicolumn{3}{|c|}{ Asia } & \multicolumn{3}{|c|}{ Europa } \\
\hline & 2001 & 2011 & 2019 & 2001 & 2011 & 2019 & 2001 & 2011 & 2019 & 2001 & 2011 & 2019 \\
\hline 2906701001 & 10,8 & 3,1 & 1,6 & 2,9 & 3,7 & 2,3 & 0,0 & 1,4 & 2,5 & 4,6 & 3,5 & 2,9 \\
\hline 2906701002 & 0,0 & 0,4 & 0,6 & 2,1 & 1,5 & 2,2 & 4,2 & 0,9 & 1,7 & 5,9 & 2,4 & 2,6 \\
\hline 2906702001 & 1,3 & 0,5 & 0,5 & 2,3 & 1,3 & 1,9 & 1,4 & 0,2 & 0,9 & 3,7 & 2,7 & 3,0 \\
\hline 2906703001 & 2,0 & 1,2 & 1,1 & 4,5 & 2,6 & 2,3 & 8,3 & 1,4 & 5,7 & 4,2 & 3,3 & 3,5 \\
\hline 2906703002 & 3,7 & 1,7 & 1,6 & 1,8 & 3,1 & 1,9 & 2,7 & 4,0 & 0,9 & 3,9 & 2,0 & 3,4 \\
\hline 2906703003 & 9,9 & 6,0 & 2,7 & 3,3 & 4,5 & 2,7 & 3,7 & 3,3 & 2,3 & 3,0 & 4,3 & 2,8 \\
\hline
\end{tabular}

Fuente: Censo de Población (INE) 2001 y 2011. Padrón 2019 (INE). Elaboración propia.

Casi veinte años después se pierde este aspecto segregador, aunque continúa siendo un área con una comunidad extranjera proporcionalmente abultada. Como resultado, las estructuras de población de las secciones se equilibran en cuanto al sexo. No obstante, se observa cómo ha habido un repunte de concentración de asiáticos y de europeos, siendo la sección céntrica de 2906703001 la que presenta los resultados más llamativos. Se deduce que los extranjeros han sido uno de los principales factores rejuvenecedores de la estructura demográfica, aunque directamente no se puede conocer dicha información. Este aumento de extranjeros se ha producido en la práctica totalidad de las divisiones administrativas inframunicipales. En consecuencia, sus niveles de diferenciación residencial tienden a ser bajos y, no solo no han aumentado, sino que, al contrario, la evidencia de la que disponemos indica que se han reducido en la mayor parte de los casos, y no solo en Andalucía (Domínguez et al., 2010; Natera, 2012).

En el caso de la tasa de riesgo de pobreza, conviene precisar que los datos analizados se corresponden con una unidad territorial de mayor extensión, que incluye el sector al norte de las calles Carretería y Álamos. Por lo tanto, es un valor orientativo que permite aproximarnos a la realidad zonal. Siguiendo la tabla 4, la tasa de riesgo de pobreza es de 20,32 \% con respecto al umbral de Málaga. Según las unidades territoriales establecidas por Martín et al. (2012), no es una de las. zonas con riesgo más alto, aunque queda muy lejos del 
valor de la unidad territorial Litoral Este, que presenta el más bajo (8,44\%). Es un resultado lógico, teniendo en cuenta que probablemente el proceso de gentrificación se halle ya avanzado.

Tabla 4. Tasa de riesgo de pobreza. 2011.

\begin{tabular}{|l|c|}
\hline \multicolumn{1}{|c|}{ Unidad territorial } & Tasa de riesgo (\%) \\
\hline Municipio de Málaga & 19,92 \\
\hline Centro & 20,32 \\
\hline Litoral Este & 8,44 \\
\hline Litoral Oeste & 21,17 \\
\hline Nordeste & 24,74 \\
\hline Noroeste & 21,50 \\
\hline
\end{tabular}

Fuente: Martín et al. (2012). Elaboración propia.

El índice de Gini de 2011 permite apreciar una situación de elevada desigualdad en la unidad territorial del Centro Histórico (32,14\%), siendo solo superada por el sector urbano del Nordeste $(32,66 \%)$, cuando la media del municipio de Málaga es 31,54\%, (ver tabla 5). El valor alto de intradesigualdad de la zona de estudio es un indicador del contraste de nivel socioeconómico de sus habitantes, un fenómeno habitual en ámbitos donde está teniendo lugar un cambio en la tipología socioeconómica de su población residente, en este caso donde aún permanecían reductos de los habitantes de clase popular primigenia, pero, a su vez, ya se estaban instalando habitantes de mayor poder adquisitivo.

Tabla 5. Índice de Gini. 2011.

\begin{tabular}{|l|c|}
\hline \multicolumn{1}{|c|}{ Unidad territorial } & Índice de Gini \\
\hline Municipio de Málaga & 31,54 \\
\hline Centro & 32,14 \\
\hline Litoral Este & 26,68 \\
\hline Litoral Oeste & 28,83 \\
\hline Nordeste & 32,66 \\
\hline Noroeste & 29,40 \\
\hline
\end{tabular}

Fuente: Martín et al. (2012). Elaboración propia.

\subsection{Caracterización y evolución del parque de viviendas}

El sector de la vivienda continúa siendo un pilar fundamental de la actividad productiva malagueña pese a su pérdida de peso relativo en la estructura económica en los últimos años (CIEDES, 2012). La importancia del sector inmobiliario en Málaga se debe a la privilegiada situación de la capital de la Costa del Sol y sus bondades climáticas, siendo un gran atractivo para españoles y extranjeros que quieren vivir o fijar una segunda residencia.

En la década de 1990 el incremento de la demanda de vivienda condujo a un crecimiento del precio del suelo construido. En esta situación se produjo un doble proceso, según Rubio (2003): las antiguas viviendas fueron compradas en el mercado de segunda mano por familias de rentas bajas. Este proceso generó un elevado número de transacciones, contribuyendo a la elevación de los precios de la vivienda usada y en régimen de alquiler. En segundo lugar, se incrementó el número de viviendas perdidas por morosidad, lo 
que supuso el empeoramiento de las condiciones de habitación de numerosas familias. En este contexto, la demanda viró hacia las viviendas unifamiliares de la periferia con mejores servicios, en detrimento de los inmuebles urbanos antiguos. Sin embargo, la puesta en valor del Centro Histórico desde finales de la década de 1990 ha propiciado un incremento en la deseabilidad del centro y ha disparado los precios, como se refleja en la tabla 6. Esta variación de los precios afecta a la estructura de los hogares, que tiende a reducir su tamaño por el nuevo tipo de demanda potencial.

Tabla 6. Precio medio de la vivienda libre (€/m²). Años 2001, 2007 y 2012.

\begin{tabular}{|c|c|c|}
\hline Año & Centro histórico & Municipio de Málaga \\
\hline 2001 & $2261 *$ & $958^{\star *}$ \\
\hline 2007 & 2900 & 2425 \\
\hline 2012 & 2701 & 1470 \\
\hline
\end{tabular}

Fuente. Analistas económicos de Andalucía, 2016. *Ocaña, 2010. Elaboración propia. **TINSA, 2020.

El desplazamiento de la población originaria, el principal elemento que caracteriza a la gentrificación, se puede reconocer de forma directa a través de la demolición de bienes residenciales.

Observando la secuencia cronológica de demoliciones desde 1956 (figura 5), se puede observar que desde la década de 1970 las demoliciones se convierten en una práctica habitual, cuando aún no se habían iniciado los procesos de reforma.

Desde la década de 1980 se acelera este proceso de rehabilitación mediante políticas como el Decreto 2/1985 que dejaba al margen el hasta entonces habitual régimen de alquiler congelado. Este régimen era considerado un obstáculo para que el propietario del inmueble pudiese rehabilitarlo. Posteriormente le seguiría la Ley 29/1994 de Arrendamientos Urbanos.

Además, hasta 1994 las intervenciones municipales no habían incentivado la rehabilitación edificatoria, el alquiler de viviendas y, en definitiva, la regeneración urbana porque el mercado de inmuebles era poco transparente y restringido y había ausencia de expectativas claras del Casco Histórico. Desde 1995, la coordinación del PEPRI con las recién creadas Iniciativa Comunitaria Urban de la actual Unión Europea y el Plan Estratégico supusieron el arranque de una época de acciones rehabilitadoras y de reformas. El período 1997-2011 acumula un 41,3\% del total de las demoliciones ejecutadas en el período 1956-2016, resultando particularmente intenso.

Como se demuestra en la figura 6, las cuantiosas inversiones procedentes de la oficina de rehabilitación del Centro Histórico de Málaga en el período 2003-2009, se cortaron bruscamente con la crisis, repercutiendo en el ritmo de demoliciones, como se puede observar en la figura 5. Este fenómeno demuestra la importancia de la iniciativa pública en este proceso, por lo menos en el inicio del s. XXI.

Los datos presentados en la tabla 7 y figura 7 evidencian el intenso proceso de transformación en el Centro Histórico, particularmente entre 2002 y 2011. En este período se acumula más de un tercio de las viviendas construidas de la unidad de estudio. Al comparar los valores con los del conjunto de Málaga, mucho más bajos en este período, se puede reconocer en el Centro Histórico la particular situación de demanda en el mercado de la vivienda. También se reconoce la relativa parálisis del Centro Histórico en las décadas de 1960 a 1980, que indica Rubio igualmente (2003). Este patrón cronológico coincide con el abandono previo a la renovación de las áreas urbanas que acusan la gentrificación.

Se detectan dos situaciones relevantes. Por un lado, observando los datos de la tabla 7, los edificios de las secciones 2906701001, 2906701002 y 2906702001 presentan un estado general algo mejor que el resto del Centro Histórico, con escasos edificios en situación "ruinosa", aunque presentan valores comparativamente similares de edificios en estado "malo" y "deficiente". Por otro, la situación es aún peor en las secciones del distrito 2906703, con valores altos de edificios en estado "ruinoso" y con tan solo algo más de la mitad $(58,16 \%)$ de las construcciones en buen estado. 

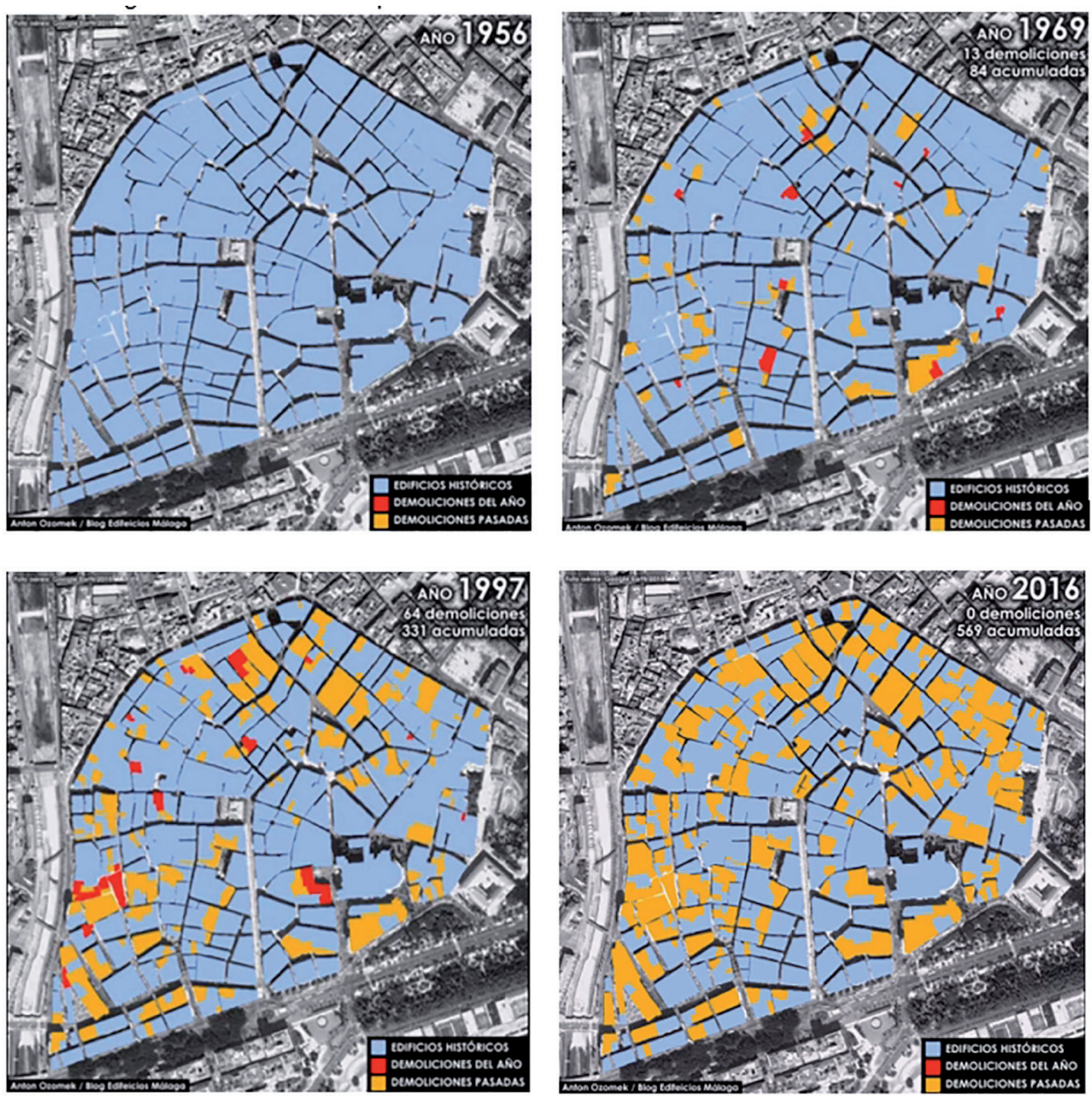

Figura 5. Evolución en el proceso de demolición de los edificios del Centro histórico. Fuente: Edificios Málaga (2016).

Si se cruzan estos resultados con los valores derivados del coeficiente de localización de la población extranjera, se observa cómo la comunidad extranjera africana, asociada a la inmigración económica y a las actividades productivas de poca cualificación y bajo nivel salarial (Martínez, García, Maya, Rodríguez y Checa, 1996), se halla especializada espacialmente en las secciones donde hay mayor presencia de edificios en mal estado y donde más común es el régimen de tenencia de alquiler. Se aprecia una evolución positiva para 2011 que lleva incluso a que una sección censal, la 2906703002, presente todos sus edificios en buen estado por encima de la media del municipio. Sin embargo, las 2906701001 y 2906703003 , de las que se tiene información, presentan valores aún mejorables, con importante peso de edificios en estado "malo" (2906701001) o "deficiente". Al cruzar dicha información con la de la presencia de población extranjera para los años 2001 y 2011, se puede extraer una correlación imperfecta entre mala situación del edificio y mayor proporción de extranjeros, presentándose los valores más elevados de ambas categorías en las secciones más occidentales, 2906701001 y 2906703003 , que bordean el río Guadalmedina. 


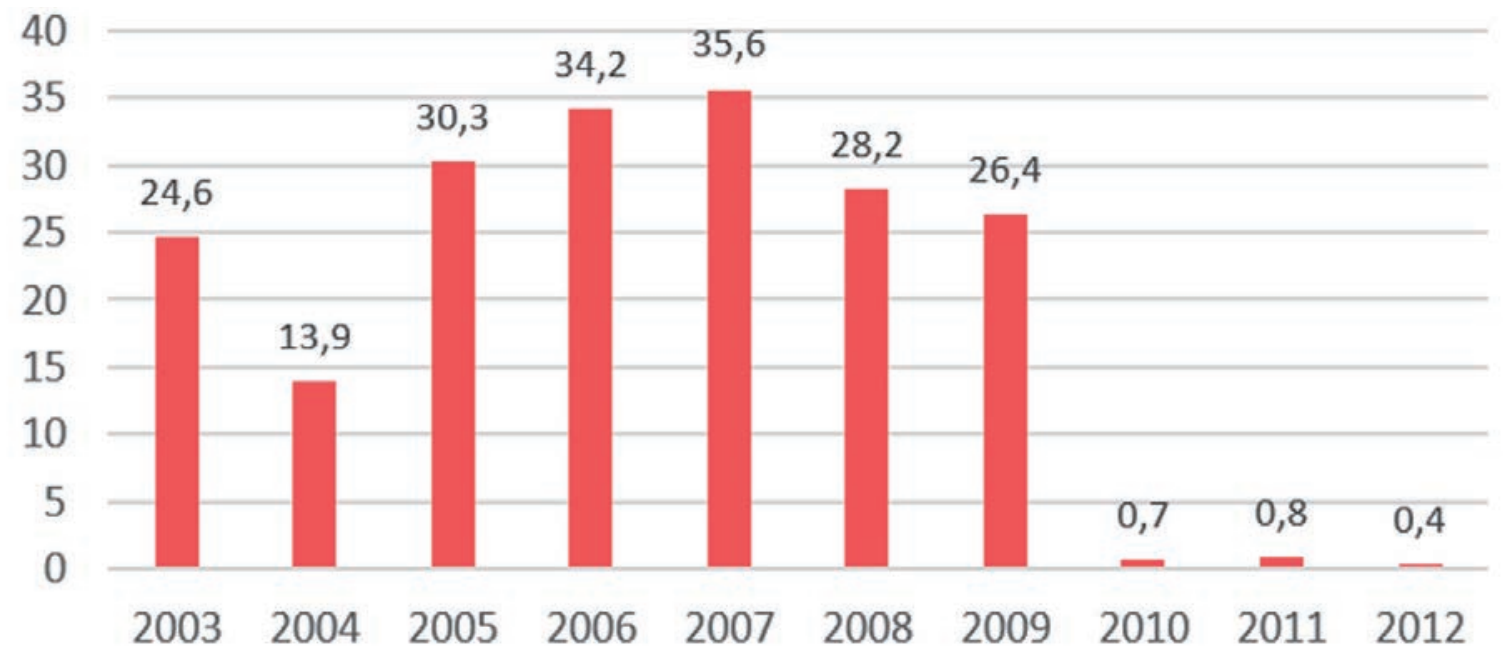

Figura 6. Evolución de la inversión en actuaciones de la oficina de rehabilitación del Centro Histórico de Málaga (millones de €). Fuente: Oficina de Rehabilitación de Centro histórico de Málaga. Elaboración propia.

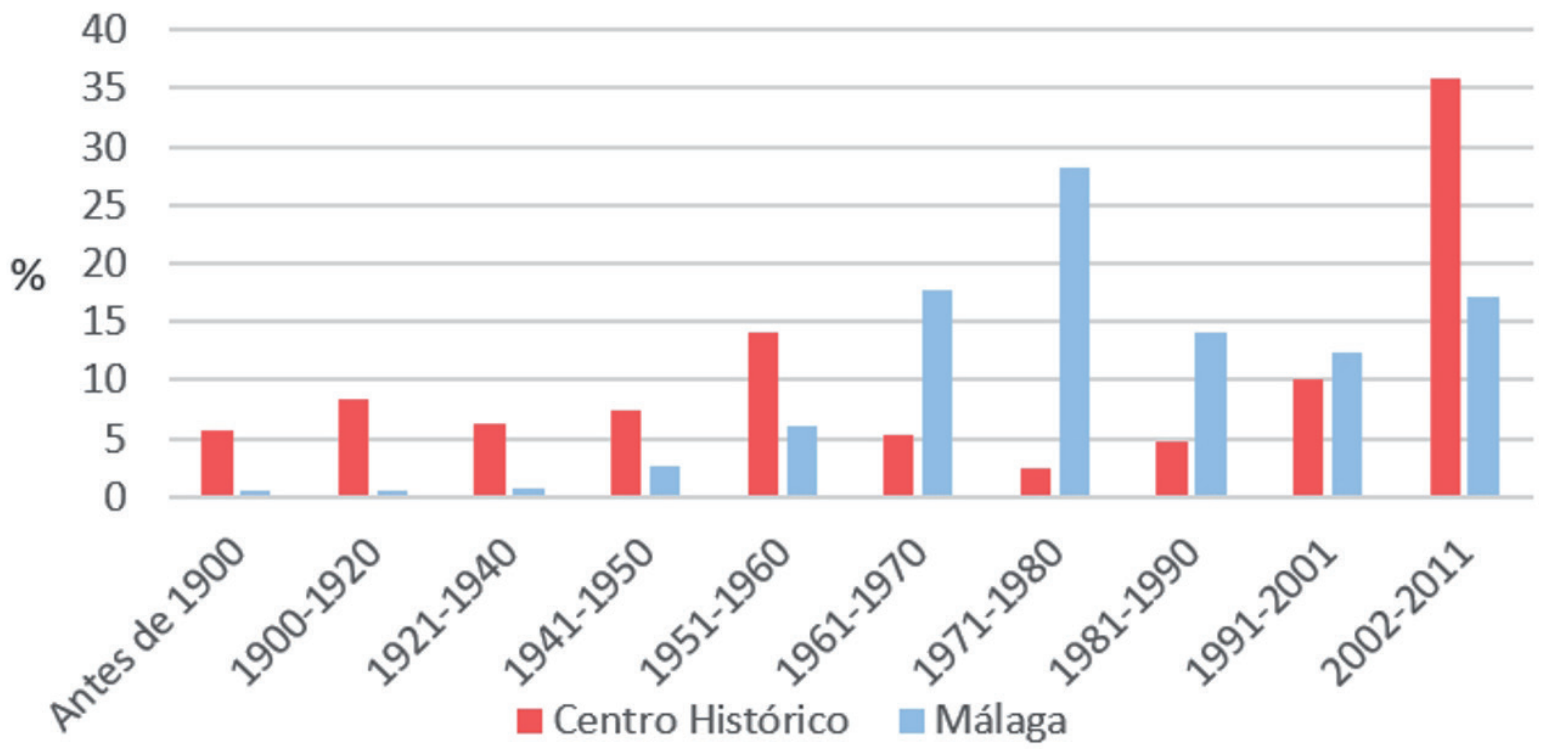

Figura 7. Proporción de viviendas según su antigüedad. Centro Histórico y municipio de Málaga. Fuente: Censo de Población 2011, INE. Elaboración propia.

En la década de 2001 a 2011 (tabla 8), la sección 2906703003 y, en menor medida, la sección 2906701001 , presentan una abultada proporción de viviendas de hasta $45 \mathrm{~m}^{2}$. Concretamente, en el año 2001 se puede destacar el peso algo inusual de viviendas de menos de $45 \mathrm{~m}^{2}$. En el Centro Histórico representa el $10 \%$ del parque de viviendas, mientras que el $25 \%$ del total presentan $60 \mathrm{~m}^{2}$ o menos. El incremento proporcional de viviendas de reducidas dimensiones coincide con el proceso de renovación del parque inmobiliario en este período.

Una vez caracterizado el parque de viviendas, interesa analizar la forma en que es habitado. La estructura del hogar en el 2001 para las distintas secciones presenta un patrón claro (tabla 9). El tipo de hogar "pareja sin hijos" es el más habitual (26,4\%), seguido de hogares unipersonales. En el caso de los hogares unipersonales es particularmente abundante la clase de "Mujer sola de 65 años o más". Esta situación puede deberse a la mayor longevidad de la mujer y al efecto de la Guerra Civil sobre la población masculina. Este fenómeno también se refleja en las pirámides de población (figura 3). 
Esta tendencia pasó a cambiar en la década del 2000. La mayor proporción de régimen de tenencia de alquiler en el Centro Histórico es utilizada por un colectivo complejo de individuos de distinto origen y perfil social con dificultad para el acceso a la propiedad, como es el de los inmigrantes. Estos se insertan precariamente en el mercado laboral o incluso no tienen legalizada su residencia, recurriendo a un sector urbano céntrico de bajo precio (Ocaña, 2010). Se observa una tendencia clara si se toman como referencia las dos secciones censales de las que se tienen datos en el 2011 (tabla 10).

El régimen "en propiedad" en el Centro Histórico se ha incrementado progresivamente, lo que responde a la ocupación del parque de viviendas por una comunidad de rentas más altas (Sargatal, 2000). Se trata de una tendencia propia de los procesos de gentrificación. Si bien es cierto que en el resto de Málaga la propiedad privada ha sido más significativa en las últimas décadas que en el Centro Histórico. Se puede establecer una cierta relación entre un mayor número de extranjeros, un peor estado del edificio y una mayor presencia del régimen de alquiler.

Con respecto a la oferta comercial y los equipamientos culturales, en el año 2001 el equipo consultor de DonDeNegocios censó 1.626 puntos de actividad existentes a nivel de calle en todos los edificios del Centro Histórico. En 2017 el censo final reflejó 1.617 puntos de actividad. Uno de cada tres locales permanece inalterado en cuanto a emplazamiento y denominación durante el periodo 2001-2017, mientras que los dos tercios restantes de negocios no han resistido el paso de estos quince años. Según DonDeNegocios, “De los 1.331 locales activos en la actualidad, 644 se encuadran en el apartado comercial (48,4\%), 477 en el hostelero $(35,8 \%)$ y 210 en 'otros servicios' (15,8\%); mientras que, de los 1.313 locales activos en el año 2001, 779 eran comerciales (59,3\%), 304 hosteleros $(23,2 \%)$ y 230 de 'otros servicios' $(17,5 \%)$ ". Por lo tanto, la evolución del periodo 2001-2017 muestra un significativo retroceso en el peso relativo del sector comercio (-17,3\%) y del sector de otros servicios $(-8,7 \%)$, mientras que el sector hostelero experimenta un muy notable incremento (+56,9\%). De este modo, si en el año 2001 había una proporción de 2,6 locales comerciales por cada local hostelero, dieciséis años después, esta ratio se ha visto reducida de forma muy notable, hasta situarse en 1,4 comercios por cada establecimiento dedicado a hostelería.

Para entender el significado de estas cifras y de su evolución es necesario ponerlas en relación con los promedios autonómicos, provinciales o de algunos municipios concretos. En 2016 Andalucía presenta una ratio de 2,2 locales comerciales (frente a 2,5 en 2001); la provincia de Málaga de 1,8 (frente a 2,0 en 2001) y el municipio de Málaga de 2,5 (frente a 3,1 en 2001). Por el contrario, solo los municipios de muy elevada actividad turística muestran ratios ligeramente inferiores al de la almendra histórica: Benalmádena, Torrox, Nerja (los tres con 1,1), Torremolinos $(1,2)$ o Fuengirola $(1,4)$, que apenas han experimentado cambios significativos desde el año 2001.

Tabla 7. Estado del edificio por secciones censales. 2001 y 2011.

\begin{tabular}{|l|c|c|c|c|c|c|c|c|}
\hline \multirow{2}{*}{\multicolumn{1}{|c}{ Sec. censal }} & \multicolumn{2}{|c|}{ Ruinoso } & \multicolumn{2}{c|}{ Malo } & \multicolumn{2}{c|}{ Deficiente } & \multicolumn{2}{c|}{ Bueno } \\
\cline { 2 - 10 } & 2001 & 2011 & 2001 & 2011 & 2001 & 2011 & 2001 & 2011 \\
\hline 2906701001 & 0,00 & 0,00 & 4,27 & 3,87 & 12,17 & 27,07 & 83,56 & 68,51 \\
\hline 2906701002 & 0,21 & S.D & 5,65 & S.D & 15,48 & S.D & 78,66 & S.D \\
\hline 2906702001 & 0,00 & S.D & 1,11 & S.D & 5,01 & S.D & 93,88 & S.D \\
\hline 2906703001 & 4,30 & S.D & 1,04 & S.D & 36,50 & S.D & 58,16 & S.D \\
\hline 2906703002 & 1,10 & 0,00 & 7,71 & 0,00 & 14,05 & 0,00 & 77,13 & 100,00 \\
\hline 2906703003 & 2,29 & 0,00 & 11,01 & 0,00 & 40,37 & 17,39 & 46,33 & 82,61 \\
\hline 29067 (municipio) & 0,96 & 0,02 & 1,71 & 0,79 & 7,90 & 3,43 & 89,44 & 95,75 \\
\hline
\end{tabular}

Fuente: Censos de Población 2001 y 2011, INE. Elaboración propia. *S.D.: sin datos. 
Tabla 8. Tamaño de la vivienda en $\mathrm{m}^{2} .2001$ y 2011.

\begin{tabular}{|c|c|c|c|c|c|c|c|c|c|c|c|c|c|c|}
\hline \multirow{2}{*}{ Sec. Censal } & \multicolumn{2}{|c|}{$<45$} & \multicolumn{2}{|c|}{$46-60$} & \multicolumn{2}{|c|}{$61-75$} & \multicolumn{2}{|c|}{$76-90$} & \multicolumn{2}{|c|}{$91-105$} & \multicolumn{2}{|c|}{$106-120$} & \multicolumn{2}{|c|}{$>121$} \\
\hline & 2001 & 2011 & 2001 & 2011 & 2001 & 2011 & 2001 & 2011 & 2001 & 2011 & 2001 & 2011 & 2001 & 2011 \\
\hline 2906701001 & 8,8 & 25,3 & 10,1 & S.D & 12,5 & 26,3 & 20,9 & 15,8 & 23,5 & 32,6 & 12,3 & S.D & 11,9 & S.D \\
\hline 2906701002 & 9,8 & S.D & 8,9 & 64,6 & 9,2 & 35,4 & 15,0 & S.D & 20,9 & S.D & 7,4 & S.D & 28,8 & S.D \\
\hline 2906702001 & 5,8 & S.D & 7,2 & S.D & 13,9 & S.D & 17,3 & 100 & 17,6 & S.D & 15,0 & S.D & 23,1 & S.D \\
\hline 2906703001 & 11,3 & 29,0 & 21,2 & 71,0 & 8,2 & S.D & 21,8 & S.D & 10,8 & S.D & 12,2 & S.D & 14,4 & S.D \\
\hline 2906703002 & 7,4 & S.D & 12,3 & S.D & 8,0 & S.D & 24,2 & S.D & 14,8 & S.D & 11,7 & 45,0 & 21,7 & 55,0 \\
\hline 2906703003 & 12,8 & 37,4 & 18,8 & 40,7 & 15,9 & S.D & 22,7 & S.D & 9,1 & 22,0 & 7,6 & S.D & 13,3 & S.D \\
\hline 29067 & 4,0 & 3,7 & 9,4 & 9,8 & 25,3 & 26,0 & 31,3 & 31,8 & 14,6 & 12,8 & 6,8 & 6,7 & 8,7 & 9,2 \\
\hline
\end{tabular}

Fuente: Censos de Población 2001 y 2011, INE. Elaboración propia. *S.D: sin datos.

Tabla 9. Proporción de los distintos tipos de hogar. 2001 y 2011.

\begin{tabular}{|c|c|c|c|c|c|c|c|c|c|c|c|c|c|c|c|c|}
\hline \multirow[t]{2}{*}{ Sección censal } & \multicolumn{2}{|c|}{$\begin{array}{l}\text { Mujer sola } \\
\text { menor de } \\
65 \text { años }\end{array}$} & \multicolumn{2}{|c|}{$\begin{array}{c}\text { Hombre } \\
\text { solo menor } \\
\text { de } 65 \text { años }\end{array}$} & \multicolumn{2}{|c|}{$\begin{array}{l}\text { Mujer sola } \\
\text { de } 65 \text { años } \\
\text { o más }\end{array}$} & \multicolumn{2}{|c|}{$\begin{array}{l}\text { Hombre de } \\
65 \text { o más } \\
\text { años }\end{array}$} & \multicolumn{2}{|c|}{$\begin{array}{l}\text { Padre o madre que } \\
\text { convive con algún/ } \\
\text { todos los hijos }\end{array}$} & \multicolumn{2}{|c|}{$\begin{array}{l}\text { Pareja sin } \\
\text { hijos }\end{array}$} & \multicolumn{2}{|c|}{$\begin{array}{l}\text { Pareja con } \\
\text { hijos }\end{array}$} & \multicolumn{2}{|c|}{$\begin{array}{l}\text { Otro tipo de } \\
\text { hogar }\end{array}$} \\
\hline & 01 & 11 & 01 & 11 & 01 & 11 & 01 & 11 & 01 & 11 & 01 & 11 & 01 & 11 & 01 & 11 \\
\hline 2906701001 & 10,1 & 19,1 & 14,3 & 41,4 & 13,8 & S.D & 4 & S.D & 0,9 & S.D & 26,4 & 21,7 & 5,9 & 11,5 & 24,6 & 6,4 \\
\hline 2906701002 & 10,1 & S.D & 10,7 & S.D & 17,2 & 9 & 3,7 & S.D & 1,8 & S.D & 26,7 & 48,9 & 6,1 & 42,1 & 23,6 & S.D \\
\hline 2906702001 & 10,4 & S.D & 11,8 & S.D & 16,5 & S.D & 3,8 & 20 & 1,7 & 20 & 24,9 & 38,9 & 8,4 & 41,1 & 22,5 & S.D \\
\hline 2906703001 & 9,6 & S.D & 14,7 & 20,9 & 15,3 & S.D & 3,1 & S.D & 3,1 & S.D & 28 & 53,5 & 6,8 & 8,5 & 19,3 & 17,1 \\
\hline 2906703002 & 9,7 & S.D & 10 & S.D & 17,7 & S.D & 2,3 & 27,3 & 1,4 & 27,3 & 27,6 & 24,2 & 7,7 & 48,4 & 23,6 & S.D \\
\hline 2906703003 & 7 & 9,23 & 16,1 & 8,1 & 12 & S.D & 2,6 & S.D & 4,2 & S.D & 23,7 & 14,6 & 10,7 & 32,3 & 23,7 & 35,8 \\
\hline 29067 & 4,4 & 2,4 & 4,7 & 2,6 & 6,9 & 2,8 & 1,6 & 10,4 & 2,2 & 10,4 & 21 & 13,8 & 18,6 & 50,4 & 40,5 & 17,5 \\
\hline
\end{tabular}

Fuente: Censos de Población 2001 y 2011, INE. Elaboración propia. *S.D.: sin datos.

Diez años después, dicho patrón se rompe y se pueden identificar distintas tendencias. En las secciones 2906701002 y 2906703001 el tipo de hogar con mayor presencia es el de la "pareja sin hijos". Mientras que las secciones 2906702001, 2906703002 y 290673003 muestran otro modelo, en el que las "parejas con hijos" ha crecido fuertemente con respecto al 2001. Este último modelo es una tendencia creciente en todo el Centro Histórico y en el conjunto del municipio. Por último, se puede reconocer un tercer tipo de hogar en la sección censal 2906701001, en el que destacan los hogares unipersonales de menos de 65 años. Este último modelo puede tratarse de una consecuencia del proceso de rehabilitación de las viviendas y la disminución del tamaño de esta, junto a la propia inercia de la sociedad (Jurado, 2006).

Se puede establecer una tendencia clara al comparar los censos de 2001 y 2011: el rejuvenecimiento de la estructura de los hogares, desapareciendo progresivamente el hogar de clase "una mujer de 65 o más años" que ha sido sustituido por el de "pareja sin hijos". Si se cruza este resultado con el de la evolución 
en la estructura de la población, se puede identificar un fenómeno propio de un área urbana gentrificada. Según Ley (1996), el hogar de clase media es habitualmente sin hijos, frecuentemente solteros, con una edad inferior a los 35 años, empleados en el sector de servicios avanzados: profesionales y técnicos, generalmente asalariados, muy demandados y con elevados patrones de consumo. Este grupo, asociado a un nivel de cualificación y un rango de ingresos elevado, aumenta en tamaño e importancia en la ciudad postindustrial, a partir de los cambios propios del sistema de regulación posfordista. En conclusión, se puede hablar de un decrecimiento del tamaño medio del hogar.

Desde la década de 1980 se trató de ampliar la oferta de viviendas de alquiler para equilibrar el mercado inmobiliario mediante políticas liberalizadoras (Decreto 2/1985), lo que se refleja en el más equilibrado régimen de tenencia en 2001 (tabla 10). Esta política supuso la reducción en la importancia del alquiler congelado y la promoción del alquiler libre, que hasta entonces había estado bastante restringido.

Un análisis a diferentes escalas (tabla 11) ofrece los siguientes resultados, clasificados siguiendo la CNAE. A nivel de ramas, se han incrementado los locales asociados a las ramas I (Restaurantes y puestos de comida), Q (Actividades sanitarias) y S (Otros servicios personales). La rama de actividades I ha crecido fuertemente como resultado del incremento en importancia del turismo en el sistema productivo de Málaga, pasando a acaparar prácticamente un tercio de todos los locales (32\%). En 2016 se erige como el subgrupo de actividad más grande del Centro Histórico, en detrimento de las tiendas de confección de moda. Mientras, las ramas Q y S se han incrementado como consecuencia del incremento del nivel de vida y de la mayor preocupación por el cuidado personal. El resto de las ramas, G (Comercio al por menor), K (Servicios financieros, excepto seguros y fondos de pensiones) y L (Actividades inmobiliarias) se han reducido drásticamente. En el caso de las ramas $\mathrm{G}$ y $\mathrm{K}$ el descenso está muy asociado al cambio de funcionalidad del Centro Histórico que ha perdido su carácter residencial. A esto se suma la tendencia creciente a la concentración de la oferta comercial en los centros comerciales periféricos (Rubio, 2003). En el caso de la rama $L$, el descenso se debe en mayor medida a la crisis inmobiliaria relacionada con la crisis económica iniciada en el 2008. Al desagregar las actividades se pueden identificar diferentes tendencias. Dentro del grupo $\mathrm{G}$ se incrementa el número de tiendas de complementos $\mathrm{y}$, sobre todo, el de souvenirs, que presenta una tasa de crecimiento para el período 2001-2016 de un 766, 7\%. En ambos casos es un reflejo de la demanda de los turistas. Menos destacable es el descenso de pubs debido a un cambio en las preferencias de ocio, a diferencia del resto de establecimientos de restaurantes y otros puestos de restauración. Por último, el rápido incremento en el número de centros culturales y de sus visitantes (figura 8, tabla 12) mantiene una relación directa con la evolución en la tipología de los establecimientos comerciales y hosteleros.

Tabla 10. Proporción de viviendas según su régimen de tenencia. 2001 y 2011.

\begin{tabular}{|l|c|c|c|c|c|c|}
\hline \multirow{2}{*}{ Sección censal } & \multicolumn{2}{|c}{ Propiedad } & \multicolumn{2}{c|}{ Alquiler } & \multicolumn{2}{c|}{ Otro régimen } \\
\cline { 2 - 7 } & $\mathbf{2 0 0 1}$ & $\mathbf{2 0 1 1}$ & $\mathbf{2 0 0 1}$ & $\mathbf{2 0 1 1}$ & $\mathbf{2 0 0 1}$ & $\mathbf{2 0 1 1}$ \\
\hline 2906701001 & 47,69 & 55,63 & 47,47 & 37,32 & 4,84 & 7,04 \\
\hline 2906701002 & 33,13 & S.D & 56,13 & S.D & 10,74 & S.D \\
\hline 2906702001 & 50,87 & S.D & 42,77 & S.D & 6,36 & S.D \\
\hline 2906703001 & 41,08 & S.D & 49,01 & S.D & 9,92 & S.D \\
\hline 2906703002 & 47,01 & S.D & 48,43 & S.D & 4,56 & S.D \\
\hline 2906703003 & 35,68 & 42,4 & 60,16 & 52,8 & 4,17 & 4,8 \\
\hline 29067 & 64,63 & 80,17 & 9,61 & 12,94 & 25,76 & 6,89 \\
\hline
\end{tabular}

Fuente: Censo de Población 2011, INE. Elaboración propia. 
Tabla 11. Evolución de los locales comerciales y hosteleros (2001-2016).

\begin{tabular}{|c|c|c|c|c|c|c|c|}
\hline Actividad & Descripción & Subtipos & 2001 & 2016 & $2001 \%$ & $2016 \%$ & $\begin{array}{l}\text { Evolución } \\
\text { (índice 100) }\end{array}$ \\
\hline \multirow{7}{*}{ G } & & Artes. y Decor. Hogar & 55 & 35 & 11,3 & 9,1 & 63,6 \\
\hline & & Bazar de electrónica & 21 & 8 & 4,3 & 2,1 & 38,1 \\
\hline & & Bricojardín y mascotas & 25 & 8 & 5,1 & 2,1 & 32 \\
\hline & & Calzado & 48 & 41 & 9,9 & 10,7 & 85,4 \\
\hline & & Complementos & 24 & 40 & 4,9 & 10,4 & 166,7 \\
\hline & Comercio al por menor & Confección & 204 & 167 & 41,9 & 43,5 & 81,9 \\
\hline & & Farmacia & 22 & 11 & 4,5 & 2,9 & 50 \\
\hline & & Joyería y relojería & 61 & 29 & 12,5 & 7,6 & 47,5 \\
\hline & & Librería & 24 & 19 & 4,9 & 4,9 & 79,2 \\
\hline & & Souvenirs & 3 & 26 & 0,6 & 6,8 & 866,7 \\
\hline \multicolumn{3}{|c|}{ Subtotal } & 487 & 384 & 100 & 100 & 78,9 \\
\hline \multirow[t]{5}{*}{ I } & $\begin{array}{l}\text { Restaurantes y puestos de } \\
\text { comida }\end{array}$ & Restaurante-bar & 81 & 186 & 27,5 & 44,6 & 229,6 \\
\hline & & Pub & 109 & 89 & 36,9 & 21,3 & 81,7 \\
\hline & & Café-bar & 60 & 67 & 20,3 & 16,1 & 111,7 \\
\hline & & Cafetería-heladería & 31 & 47 & 10,5 & 11,3 & 151,6 \\
\hline & & Comida rápida & 14 & 28 & 4,7 & 6,7 & 200 \\
\hline \multicolumn{3}{|c|}{ Subtotal } & 295 & 417 & 100 & 100 & 141,4 \\
\hline K & $\begin{array}{l}\text { Servicios financieros, ex- } \\
\text { cepto seguros y fondos de } \\
\text { pensiones }\end{array}$ & Servicios Bancarios & 40 & 25 & 100 & 100 & 62,5 \\
\hline $\mathrm{L}$ & Actividades inmobiliarias & Agencia inmobiliaria & 20 & 11 & 100 & 100 & 55 \\
\hline Q & Actividades sanitarias & Servicios médicos & 11 & 20 & 100 & 100 & 181,8 \\
\hline \multirow[t]{2}{*}{ S } & Otros servicios personales & Peluquería & 20 & 23 & 100 & 100 & 115 \\
\hline & Resto de actividades & & 430 & 424 & 100 & 100 & 98,6 \\
\hline \multicolumn{3}{|c|}{ Total } & 1303 & 1304 & & & \\
\hline
\end{tabular}

Fuente: DonDeNegocios. Elaboración propia.

La orientación funcional del Centro como un área de ocio, ofreciendo el entorno histórico urbano como el escenario de un producto dirigido a los turistas, ha repercutido en la oferta de los locales comerciales y hosteleros. La tensión creciente en los últimos años generada por los visitantes a causa de las externalidades negativas como el incremento del ruido, la suciedad, el aumento del coste de vida o la falta de armonía funcional entre residentes y la oferta de servicios supone la disminución de la calidad de habitabilidad para los residentes. Esta situación puede explicar la tendencia al descenso de la población en el último lustro, pese a la elevada deseabilidad. 


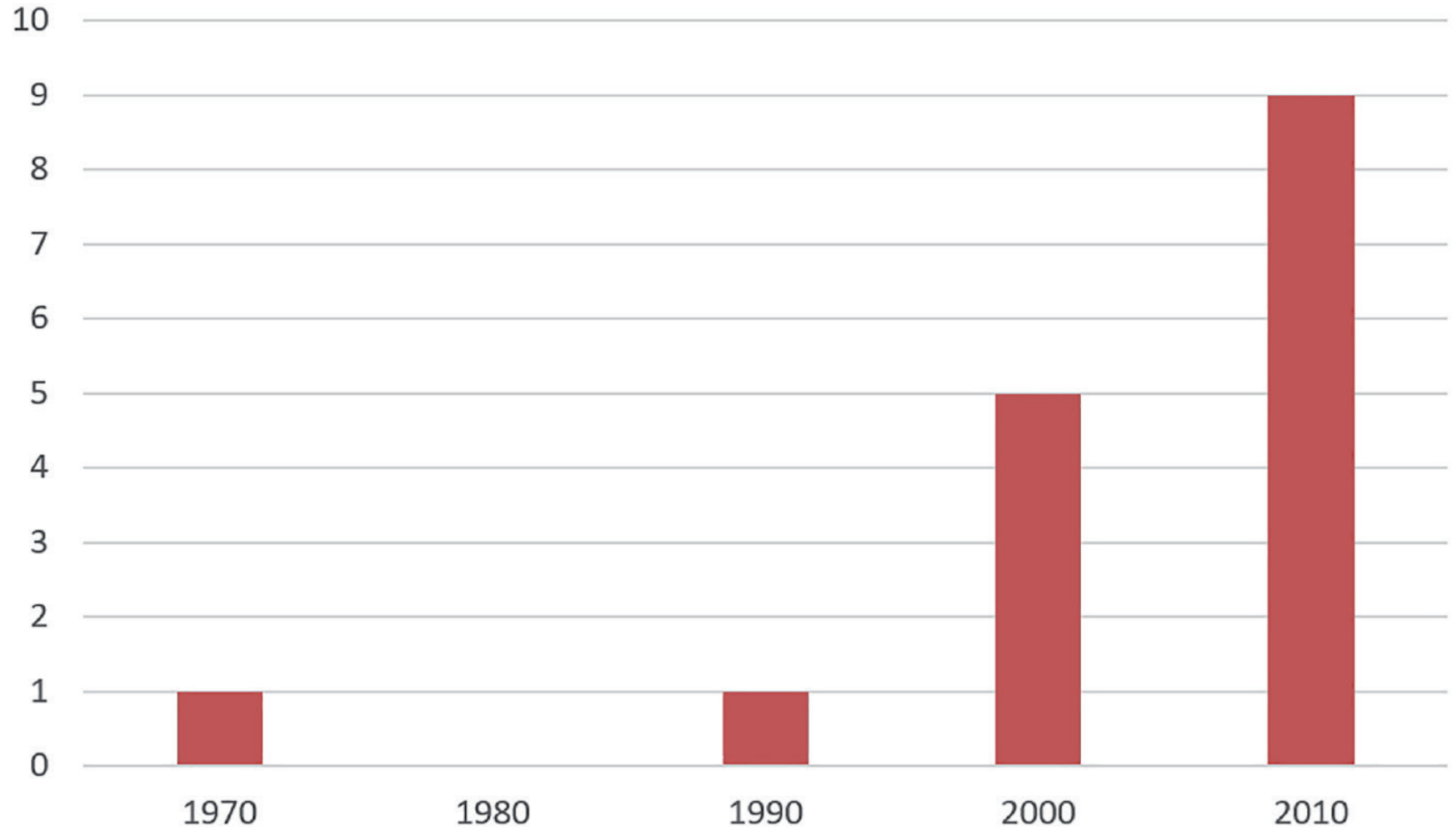

Figura 8. Número de centros culturales según su década de apertura. Fuente: Trabajo de campo. Elaboración propia.

Tabla 12. Evolución en el número de visitas de algunos importantes centros culturales.

\begin{tabular}{|c|c|c|c|}
\hline AÑO & MUSEO PICASSO & CASA NATAL PICASSO & MUSEO C. THYSSEN \\
\hline 2004 & 383.819 & - & - \\
\hline 2007 & 340.688 & 114.009 & 154.523 \\
\hline 2010 & 345.742 & 130.095 & 158.567 \\
\hline 2013 & 406.465 & 110.766 & 170.373 \\
\hline 2016 & 558.033 & 130.608 & 120.789 \\
\hline 2019 & 703.807 & 1207 \\
\hline
\end{tabular}

Fuente: OMAU (2015). Fundaciones Picasso y Thyssen (datos de 2015 a 2019). Elaboración propia.

\section{DISCUSIÓN Y CONCLUSIONES}

El proceso de gentrificación ha sido uno de los fenómenos urbanos más explorados a escala tanto internacional como nacional. Pese a ello, la ciudad de Málaga, una de las más importantes del litoral mediterráneo, carecía de una investigación que confirmase este fenómeno urbano en su Centro Histórico. La amplia serie de variables utilizadas en la investigación evidencia un proceso avanzado de gentrificación en el Centro Histórico de Málaga desde el último tercio del siglo XX hasta inicios del siglo XXI.

Para alcanzar esta conclusión, se ha elaborado una metodología en la que se tratan de reflejar todas las dimensiones del proceso de gentrificación en el espacio urbano. Desde la dimensión demográfica, se muestra este proceso con las fluctuaciones en el tamaño total de la población, con una tendencia negativa de la que no se ha recuperado con la creciente presencia del turismo en la zona y con la transformación 
de la estructura de población, tendente a un rejuvenecimiento y a una mayor presencia de habitantes extranjeros, patrón repetido en otras grandes ciudades occidentales globalizadas como Barcelona (Sargatal, 2000; López-Gay, 2018) o Madrid (Sorando \& Leal, 2019). Estas fluctuaciones demográficas se producen de forma simultánea a las variaciones en la condición socioeconómica de los habitantes, donde se observan valores bastante elevados de desigualdad, según el índice de Gini y la tasa de riesgo de pobreza en 2011, que reflejan los contrastes propios de una gentrificación sin finalizar, en una etapa económica marcada por la crisis del 2008 (Sorando \& Leal, 2019). Por otro lado, las transformaciones del parque de viviendas reflejan asimismo patrones como la reducción del tamaño del hogar asociado al incremento del precio del suelo, las numerosas demoliciones $y$, en su lugar, nuevas construcciones, que significan el paso de un parque de viviendas particularmente degradado a uno en buenas condiciones, en un contexto de rehabilitación intensivo. Esto se traduce en un fenómeno propio de la gentrificación, el incremento de la brecha de la renta, por el aumento de la diferencia entre la renta capitalizada del suelo dado su uso actual (precio previo del suelo) y la renta potencial del suelo que puede ser capitalizada mediante un nuevo aprovechamiento de este (Smith, 1987). Por último, este conjunto de transformaciones ha interactuado favoreciendo una evidente metamorfosis funcional del área de estudio, que se refleja en la tipología de la actividad comercial y en el incremento de la restauración y hostelería, como se ha detectado en el Centro Histórico de Sevilla (Jover, 2019); así como en el creciente equipamiento cultural impulsado por las administraciones públicas, emulando propuestas planificadoras similares a las de Bilbao (Angulo-Baudin et al., 2017) o Londres (Davidson, 2008) y que deriva en una pérdida de identidad urbana, ya identificada en la ciudad de Málaga (García et al., 2019). De forma consecuente, las inversiones público-privadas han favorecido la continuidad en la expulsión indirecta de los grupos de menores ingresos, que no pueden acceder a la propiedad debido a la gentrificación y, posteriormente también, a la turistificación del Centro Histórico. Este fenómeno se refleja en el aumento del número de viviendas vacías y el precio de las viviendas o el cambio de negocios y equipamientos que sufren las familias de clase trabajadora cuando su barrio se transforma, como ha ocurrido en Londres (Davidson \& Lees, 2005).

A lo largo de esta investigación se ha detectado la dificultad para obtener información de variables socioeconómicas como el índice de Gini y la tasa de riesgo de pobreza, solo disponibles para 2011 y para una escala de distrito, o las carencias de información de numerosas variables en el censo de 2011 a escala de sección censal. Esta problemática está causada por el conflicto de intereses entre las administraciones a la hora de generar y publicar datos precisos, que puedan documentar los efectos de las políticas de gentrificación, frecuentemente impulsadas por la propia Administración (García \& Díaz, 2008). En el caso español, la generación de figuras ocupacionales fuertemente imprecisas como los autónomos (Carabaña \& González, 1992); la ausencia de datos sobre la composición ocupacional (pero no de nacionalidad) en las estadísticas sobre centros educativos; la ausencia de datos sobre ocupaciones (pero no sobre nacionalidad) en la Estadística de Variaciones Residenciales (EVR) o los recientes cambios en el censo, son limitaciones que dificultan la investigación sobre la gentrificación.

Se comprueba que el Centro Histórico de Málaga se ha convertido en un escaparate cultural, tal y como lo han promovido las entidades públicas desde las últimas décadas del siglo XX, con el fin de reconvertir el modelo productivo del Centro Histórico. Sin embargo, esta estrategia ha propiciado un intenso proceso de gentrificación con los desequilibrios territoriales que conlleva, y que ha derivado y favorecido otros procesos más recientes como el de turistificación.

El proceso de gentrificación no se manifiesta de forma homogénea espacialmente. Las secciones centrales muestran un proceso de gentrificación más temprano y tenue que las secciones de la margen izquierda del río Guadalmedina 2906701001 (Área del Mercado de Atarazanas) y 2906703003 (Entorno del Palacio de Valdeflores). Estas dos últimas zonas sufren un proceso muy intenso de transformación entre finales de la década de 1990 y principios de la década del 2000. Dichos cambios se reflejan demográficamente en una población rejuvenecida, masculina y con mayor proporción de extranjeros que las otras secciones, así como por el acelerado proceso de demoliciones y rehabilitaciones del parque residencial.

Como señala García Bujalance (2016), la ciudad es el espacio en el que se desarrolla la cotidianeidad y afecta a la manera de vivir de las comunidades humanas. Sin embargo, la ciudad se ha transformado en un 
simple contenedor de productos de consumo mediante el proceso de gentrificación, siendo el urbanismo el instrumento al servicio de esta democratización de la banalidad, en la que la preservación de las sociabilidades de los habitantes no ha sido el objetivo principal. En este proceso se ha expulsado a los elementos que le confieren una vida auténtica global a este ámbito urbano fuera del circuito de consumo. Un territorio sin habitantes está abocado a perder su identidad. Por estas razones, el trabajo de reconocimiento de esta realidad puede suponer el primer paso para una mejor planificación y gestión urbana del Centro Histórico de Málaga.

La detección en el presente estudio de otros procesos urbanos posteriores como la turistificación abre la oportunidad para abordarlos en futuras investigaciones. Para comprender mejor las profundas transformaciones territoriales que se están produciendo en la ciudad y las consecuencias que pueden tener a medio y largo plazo, sería interesante diferenciar y valorar las relaciones entre ambos fenómenos. Además, se abre una vía de investigación sobre gentrificación que amplíe la unidad de estudio a los barrios circundantes del Centro Histórico.

\section{Declaración responsable y conflicto de intereses}

Los autores declaran que no existe ningún conflicto de interés con relación a la publicación de este artículo. Los tres autores han participado en la fase de investigación del artículo y los procesos de revisión requeridos para elaborar su versión final.

\section{REFERENCIAS}

Angulo-Baudin, W., Klein, J.L. \& Tremblay, D.G. (2017). Potencial y límites de las estrategias culturales de reconversión urbana: El caso de Bilbao. Finisterra, Revista Portuguesa de Geografia, LII, 105, 49-78. https://doi.org/10.18055/Finis8966

Boixader, J. (2004). Nuevas tecnologías y renovación urbana: luces y sombras del distrito 22@ Barcelona. Scripta Nova, VIII, 170 (34).

Borondo Cañizares, L. (2015). El Soho de Málaga: aprovechamiento turístico en un territorio creativo [Trabajo Final de Grado, Universidad de Málaga].

Brenner, N. (2009). Urban governance and the production of new state spaces in Western Europe, 1960-2000. In The disoriented state: Shifts in governmentality, territoriality and governance (pp. 41-77). Springer. https://doi. org/10.1007/978-1-4020-9480-4_3

Carabaña, J. \& González, J.J. (1992). Encuesta de estructura, conciencia y biografía de clase. Informe técnico. Comunidad de Madrid, Consejería de Economía.

Cavia, B., Gatti, G., de Albéñiz, I. M. \& Seguel, A. G. (2008). Crisis of the social and emergence of sociality in the new scenarios of identity. The San Francisco district of Bilbao. Papeles del CEIC, 2, 1-35.

Davidson, M. (2008). Spoiled mixture: where does state-ledpositive'gentrification end? Urban Studies, 45(12), $2385-2405$. https://doi.org/10.1177/0042098008097105

Davidson, M. \& Lees, L. (2005). New-build ‘gentrification'and London's riverside renaissance. Environment and planning A, 37(7), 1165-1190. https://doi.org/10.1068/a3739

DonDeNegocios Marketing (2019). Evolución del comercio y la hostelería en el Centro Histórico de Málaga 2001-2016. https://www.dondenegocios.com/single-post/2016/05/31/Evoluci\%C3\%B3n-del-comercio-y-la-hosteler\%C3\%ADa-en-el-Centro-Hist\%C3\%B3rico-de-M\%C3\%A1laga-20012016-1

Domínguez Mújica, J., Parreño Castellano, J. M. \& Díaz Hernández, R. (2010). Inmigración y ciudad en España: integración versus segregación socio-territoriales. Scripta Nova, 14 (331).

Donzelot, J. (2004). La ville à trois vitesses: relégation, périurbanisation, gentrification. Esprit (1940-), (263), 14-39.

Edifeicios Málaga (2019). Cronomapa del expolio del BIC Centro Histórico de Málaga 1957-2016. https://www.youtube.com/ watch?v=POfu $2 \mathrm{gmLz} 8 \mathrm{U}$ 
Evans, G. (2002). Cultural planning: An urban renaissance? Routledge. https://doi.org/10.4324/9780203459744

Fundación CIEDES (2012). Evolución del mercado inmobiliario en Málaga y perspectivas de futuro. http://ciedes.es/images/ stories/Cuadernos/Cuaderno13.pdf

García Bujalance, S. (2016). Las nuevas cartografías del territorio. JUSTICE: Journal of Urban Smart Transdisciplinarity and International City Studies, 1(2), 7-14.

García, B. (2004). Cultural policy and urban regeneration in Western European cities: lessons from experience, prospects for the future. Local economy, 19(4), 312-326. https://doi.org/10.1080/0269094042000286828

García Herrera, L., Barrera-Fernández, D. \& Scalici, M. (2019). Touristification in historic cities: Reflections on Malaga. Revista de Turismo Contemporâneo, 7(1), 93-115. https://doi.org/10.21680/2357-8211.2019v7n1ID16169

García Herrera, L. \& Díaz Rodríguez, M. (2008). El proceso de elitización: investigaciones y temas de análisis en la Geografía española (1999-2008). Scripta Nova, 12 (270), 1-16.

Glass, R. (1964) Aspects of change. In The Gentrification Debates A Reader; Routledge; pp. 19-30.

Gray, C. (2007). Commodification and instrumentality in cultural policy. International journal of cultural policy, 13(2), 203215. https://doi.org/10.1080/10286630701342899

Harvey, D. (1989). From managerialism to entrepreneurialism: the transformation in urban governance in late capitalism. Geografiska Annaler: Series B, Human Geography, 71(1), 3-17. https://doi.org/10.1080/04353684.1989.11879583

Jover Báez, J. (2019). Geografía comercial de los centros históricos: entre la gentrificación y la patrimonialización. El caso de Sevilla. Boletín de la Asociación de Geógrafos Españoles, (82). https://doi.org/10.21138/bage.2788

Jover, J. \& Díaz-Parra, I. (2020). Gentrification, transnational gentrification and touristification in Seville, Spain. Urban Studies, 57(15), 3044-3059. https://doi.org/10.1177/0042098019857585

Kazepov, Y. (Ed.). (2010). Rescaling social policies: towards multilevel governance in Europe (Vol. 38). Ashgate Publishing, Ltd.

López-Gay, A. (2018). Cambio en la composición social y gentrificación en Barcelona: una mirada a través de los flujos migratorios y residenciales. Papers: Regió Metropolitana de Barcelona: Territori, estratègies, planejament, (60), 80-93. https://raco.cat/index.php/PapersIERMB/article/view/339242/430202

Marrero Guillamón, I. (2003). ¿Del Manchester Catalán al Soho Barcelonés? La renovación del barrio de PobleNou en Barcelona y la cuestión de la vivienda. Scripta Nova, VII (146).

Jurado Guerrero, T. (2006). El creciente dinamismo familiar frente a la inflexibilidad del modelo de vivienda español. Cuadernos de Información Económica, 193, 117-126.

Ley, D. (1996). The new middle classes and the remaking of the central city. Oxford University Press.

López Cano, D. (1984). Sociodemografía de los barrios malagueños. Ayuntamiento de Málaga.

López Padilla, M. D. (2020). Procesos actuales de turistificación en la ciudad de Málaga. Boletín de la Real Sociedad Geográfica, (CLV), 107-140. http://orcid.org/0000-0001-6477-9269

Martín Reyes, G., García Lizana, A. \& Fernández Morales, A. (2012). La distribución de la renta en la ciudad de Málaga. Índice de Gini, curva de Lorenz y pobreza en 2011. OMAU, Ayuntamiento de Málaga.

Martínez, A. \& Leal, J. (2008). La segregación residencial, un indicador espacial confuso en la representación de la problemática residencial de los inmigrantes económicos: el caso de la Comunidad de Madrid. ACE: Architecture, City and Environment, 8, 53-64. http://dx.doi.org/10.5821/ace.v3i8.2457

Martínez, M., García, M., Maya, I., Rodríguez, S. \& Checa, F. (1996). La integración social de los inmigrantes africanos en Andalucía. Necesidades y recursos. Consejería de Asuntos Sociales. Junta de Andalucía.

Mehdipanah, R., Marra, G., Melis, G. \& Gelormino, E. (2018). Urban renewal, gentrification and health equity: a realist perspective. The European Journal of Public Health, 28(2), 243-248. https://doi.org/10.1093/eurpub/ckx202

Mendoza, F. (2016). La gentrificación en los estudios urbanos: una exploración sobre la producción académica de las ciudades. Cadernos Metrópole, 18 (37), 697-719. https://doi.org/10.1590/2236-9996.2016-3704

Morell, M. (2009). Fent barri: heritage tourism policy and neighbourhood scaling in Ciutat de Mallorca. Etnográfica, 13, 343-372. https://doi.org/10.4000/etnografica.1136

Natera, J. (2012). Población extranjera en el municipio de Málaga. Evolución de sus niveles de diferenciación residencial y de sus pautas de distribución espacial (2003/2010). Scripta Nova, XVI (413). https://doi.org/10.1344/sn2012.16.14774

Nickayin, S. S., Halbac-Cotoara-Zanfir, R., Clemente, M., Chelli, F. M., Salvati, L., Benassi, F. \& Morera, A. G. (2020). “Qualifying Peripheries" or "Repolarizing the Center": A Comparison of Gentrification Processes in Europe. Sustainability, 12(21), 9039. https://doi.org/10.3390/su12219039 
Ocaña, C. (2010). Estudio de diagnóstico de la población urbana y su relación con la vivienda en Málaga. Ayuntamiento de Málaga. OMAU (2015). Análisis del turismo en Málaga. Málaga, España. OMAU.

Pérez-Agote, A., Tejerina, B. \& Barañano, M. (2010). Barrios multiculturales. Relaciones interétnicas en los barrios de San Francisco (Bilbao) y Embajadores/Lavapiés (Madrid). Trotta.

PEPRI Centro de Málaga (1998). http://urbanismo.malaga.eu/urbanismo/plangeneral/pgmom/memorias_y_normativas/normativas/pepri_centro/indice_pepri.htm

Prytherch, D. \& Boira, J. (2009). City profile: Valencia. Cities, 26 (2), 103-115. https://doi.org/10.1016/j.cities.2008.11.004

Rodríguez, A. \& Vicario, L. (2005). Innovación, Competitividad y Regeneración Urbana: los espacios retóricos de la" ciudad creativa" en el nuevo Bilbao. Ekonomiaz: Revista vasca de economía, (58), 262-295.

Rubiales, M. (2014). ¿Medir la gentrificación? Epistemologías, metodologías y herramientas de investigación de carácter cuantitativo y mixto. Working Paper Series. Contested Cities.

Rubio, A. (1986). Geografía aplicada y centro histórico: la experiencia de Málaga ciudad. Jornadas de Geografía y Urbanismo. Junta de Castilla y León.

Rubio, A. (2003). Málaga, de ciudad a metrópolis. Asociación Provincial de Constructores y Promotores de Málaga.

Sánchez, M.A, Rius, J. \& Zarlenga, M. (2012). ¿Ciudad creativa y ciudad sostenible?: Un análisis crítico del “modelo BarceIona" de políticas culturales. Revista Crítica de Ciências Sociais, (99), 31-50. https://doi.org/10.4000/rccs.5101

Sargatal, M. (2000). El estudio de la gentrificación. Revista Bibliográfica de Geografía y Ciencias Sociales, 5 (228).

Scott, A. J. (1997). The cultural economy of cities. International journal of urban and regional research, 21(2), 323-339. https://doi.org/10.1111/1468-2427.00075

Sequera, J. (2010). Prácticas distintivas y control urbano como mecanismos de gestión de las conductas. El caso de Lavapiés (Madrid). En C. Cornejo, J. Sáez \& J. Prada (eds.), Ciudad, territorio y paisaje: reflexiones para un debate multidisciplinario. CSIC.

Sequera, J. \& Nofre, J. (2018). Shaken, not stirred: New debates on touristification and the limits of gentrification. City, 22(5-6), 843-855. https://doi.org/10.1080/13604813.2018.1548819

Smith, N. (1979). Toward a theory of gentrification a back to the city movement by capital, not people. Journal of the American planning association, 45(4), 538-548. https://doi.org/10.1080/01944367908977002

Smith, N. (1987). Gentrification and the Rent Gap. Ann. Assoc. Am. Geogr., 77, 462-465. https://doi.org/10.1111/j.1467-8306.1987.tb00171.x

Sorando, D. \& Leal, J. (2019). Distantes y desiguales. Reis: Revista española de investigaciones sociológicas, (167), $125-147$. http://dx.doi.org/10.5477/cis/reis.167.125

Van Weesep, J. (1994). Gentrification as a research frontier. Progress in Human Geography, 18 (1), 74-83. https://doi. org/10.1177/030913259401800107

Vicario, L. \& Martínez Monje, M. (2003). Another' Guggenheim effect'? The generation of a potentially gentrifiable neighbourhood in Bilbao. Urban studies, 40(12), 2383-2400. https://doi.org/10.1080/0042098032000136129

Vila Márquez, F. (2016). La (in) esperada gentrificación cultural. El caso Barcelona. Periférica Internacional, (17) $285-297$. https://revistas.uca.es/index.php/periferica/article/view/3283

Zukin, S. (1987). Gentrification: culture and capital in the urban core. Annual review of sociology, 13(1), 129-147. https:// doi.org/10.1146/annurev.so.13.080187.001021 


\title{
Patrimonio nuclear del sur de España. Diagnóstico y propuestas
}

\author{
Nuclear heritage of the south of Spain. Diagnosis and proposals \\ Juan Antonio Muñoz-Castillo \\ juanantonio.munoz@iesaverroes.org @ 0000-0002-9755-5541 \\ Departamento de Geografía e Historia. Instituto de Educación Secundaria "Averroes" de Córdoba. \\ C/ Motril, s/n. 14013 Córdoba, España \\ Jorge Olcina-Cantos \\ jorge.olcina@ua.es @ 0000-0002-4846-8126 \\ Departamento de Análisis Geográfico Regional y Geografía Física. Universidad de Alicante. \\ Campus de San Vicente del Raspeig s/n. 03690 Alicante, España
}

\section{INFO ARTÍCULO}

Enviado: 21/10/2021

Revisado: 06/12/2021

Aceptado: 24/12/2021

PALABRAS CLAVE

Patrimonio nuclear

Andalucía

Badajoz

Uranio

Residuos radiactivos

\section{KEYWORDS}

Nuclear heritage

Andalucía

Badajoz

Uranium

Radioactive wastes

\begin{abstract}
RESUMEN
El presente trabajo es una puesta al día del patrimonio nuclear existente en el sur de España. Las antiguas minas de uranio, las fábricas de combustible nuclear, los almacenes de residuos nucleares o los lugares afectados por accidentes nucleares tienen un conjunto de posibilidades por encima de su relación con la actividad del uranio. Se analiza y valora el estado de las instalaciones nucleares existentes en el sur de España que forman un conjunto patrimonial que merece atención institucional y puede tener oportunidades para su trasformación en recurso de aprovechamiento docente o turístico. Del análisis detallado de cada elemento del objeto de estudio, se ha pasado a establecer el diagrama de fortalezas y debilidades del conjunto. El patrimonio nuclear analizado sufre una estigmatización que se debe revertir a partir de una serie de acciones conducentes al desarrollo de las localidades afectadas, en una serie de acciones conducentes de modo sostenible a integrarles en sus entornos regionales.
\end{abstract}

\begin{abstract}
This paper is an update of the existing nuclear heritage in southern Spain. Old uranium mines, nuclear fuel factories, nuclear waste warehouses or places affected by nuclear accidents have a set of possibilities beyond their relation to uranium activity. The state of existing nuclear facilities in southern Spain, which form a heritage complex that deserves institutional attention and may have opportunities for its transformation into a resource for educational or tourist use, is analyzed and valued. From the detailed analysis of each element to the object of study, the diagram of strengths and weaknesses of the whole has been established. This suffers a certain stigmatization that should be reverted in a series of actions conducive in a sustainable way to comprehensiveness in their regional environments.
\end{abstract}




\section{INTRODUCCIÓN}

El patrimonio nuclear puede entenderse como el "conjunto formado por las infraestructuras mineras de producción y transformación de minerales de uranio, así como la obtención de energía nuclear, junto con aquellas zonas destinadas a la gestión de sus residuos, y las que, por cualquier circunstancia anómala, se hayan visto afectadas por el uranio, sus derivados y la radiactividad de una u otra manera" (Muñoz Castillo, 2020) ${ }^{1}$.España es un país uranífero, que por cuenta de las muy dispares políticas energéticas practicadas en las últimas cuatro décadas, no ha sabido aprovechar las potencialidades de este recurso energético. Pese a la limitada existencia de centrales nucleares en el territorio español -7 reactores activos entre Tarragona, Cáceres y Guadalajara-, en el sur de España se ha generado un notable patrimonio nuclear en forma de minas, fábricas de uranio, proyectos de centrales nucleares, así como zonas afectadas por radiactividad debida a distintos accidentes y causas. En este sentido, el sur de España es singular, porque las centrales nucleares, propiamente dichas, no constituyen lo esencial de su patrimonio nuclear, como si lo es, en la mitad septentrional de la península Ibérica.

El conjunto de organismos públicos gestores de todo aquello relacionado con la energía nuclear (JIA-EPALE, Junta de Investigaciones Atómicas-Sociedad Anónima de Estudios y Patentes de Aleaciones Especiales /JEN, Junta de Energía Nuclear/CSN, Consejo de Seguridad Nuclear /CIEMAT, Centro de Investigaciones Energéticas, Medioambientales y Tecnológicas /ENRESA, Empresa Nacional de Residuos Radiactivos, S.A.) ha tenido una intervención directa en la gestión de este conjunto de recursos. Sin embargo, es necesario realizar un análisis crítico de la situación actual del patrimonio nuclear. Para ello, la ciencia geográfica y especialmente, la geografía regional, aporta método y herramientas de análisis muy indicadas para llevar a cabo esta labor a fin de obtener una visión de conjunto (física, paisajística-ambiental, población, economía) sobre una realidad que, en el fondo, es bastante desconocida y que se ha prestado a visiones predeterminadas por juicios a favor o en contra, donde no cabía término medio. La realidad territorial actual de las áreas que cuentan con infraestructuras nucleares en el sur de España es la de un conjunto de lugares afectados por esta serie de actividades que, por lo común, han quedado marcados de forma negativa.

Debe recordarse que, en la actualidad, España cuenta con una potencia instalada en energía nuclear que supera los $7.000 \mathrm{MW}$, que generan el $21 \%$ de la producción de energía eléctrica. Por encima del debate sobre la necesidad actual de la energía nuclear, que ha tornado en una cuestión de calado ideológico, es necesario elaborar un análisis geográfico que permita sacar conclusiones que señalen las potencialidades de unos lugares unidos por el aprovechamiento tradicional de un recurso mineral, el uranio, bien por su producción o por la gestión de sus residuos. El análisis geográfico regional se muestra como la disciplina útil para la configuración y constitución de un corpus que permita elaborar aproximaciones posteriores de carácter más específico.

No son nada numerosos los trabajos sobre patrimonio nuclear, desde los supuestos que aborda esta investigación. Generalmente se han analizado las propias centrales nucleares como elemento central del patrimonio nuclear de un territorio. Es el caso de Francia, donde las centrales nucleares, como principales elementos del patrimonio nuclear, han sido objeto de aproximaciones en ocasiones no específicamente académicas, como las de Mathieu (2020), Bezat (2021) y Wakim (2021), sin olvidar el amplio material de la web pnc-france.org, o los trabajos recientemente publicados en el portal de especialización ambiental "Reporterre". En Alemania, destaca el trabajo de Mihm (2019) sobre el "indeseable patrimonio" nuclear.

En España, el patrimonio minero ha merecido diversos trabajos donde se señala su valor como patrimonio y recurso potencialmente utilizable en la promoción turística de una localidad o ámbito comarcal. Son destacados los trabajos de Cañizares $(2011,2013)$, sobre las minas de Almadén o los parques mineros como recurso turístico, el de Pérez Macías et al. (2016) sobre las minas de Río Tinto (Huelva), Romero Silva (2019)

1 Vid. Muñoz Castillo, J.A. (2020). Patrimonio Nuclear del Sur de España. Un estudio geográfico (Tesis doctoral inédita). En este trabajo no se incluyen las centrales nucleares dentro del patrimonio nuclear que, por lo demás, son elementos principales de la actividad de producción energética en España y si forman parte del mismo, como elementos básicos del mismo, en la mitad norte de nuestro país. 
sobre el inicio de la siderurgia en Málaga o las investigaciones de Espejo Marín (2002) relativas a la producción de electricidad de origen nuclear, que desarrolló a primeros de siglo; sin olvidar el trabajo de Gonzalvo Salas et al. (2018) sobre Vandellós.

El uranio ha sido empleado desde la antigüedad para diferentes usos, aunque no fue aislado hasta 1789 por Martin H. Klaproth. Se ha empleado, tradicionalmente, en la artesanía del vidrio y la cerámica. Durante los siglos XIX y XX se fueron descubriendo los distintos minerales uraníferos, así como sus principales yacimientos para extracción. Del mismo modo, se le fueron dando distintas utilidades asociadas a su potencial energético y a la radiactividad. En España fue el ingeniero cordobés Antonio CarboneII-Trillo Figueroa ${ }^{2}$ (1885-1947) el primero en hallar minerales uraníferos en 1917-18. Se reconocen hasta 76 mineralizaciones uraníferas en España, 32 en rocas plutónicas (y en general, las más susceptibles de tener rentabilidad económica), 20 en rocas metamórficas y otras 22 en rocas sedimentarias. En la zona objeto del presente estudio, 6, 9 y 2 respectivamente. Bastante desiguales y con una rentabilidad mínima en general a excepción de los yacimientos de El Cabril, Cardeña y la Sierra de Andújar. A estos antiguos yacimientos ya clausurados, se pueden sumar la antigua Fábrica de Uranio de Andújar "General Hernández Vidal", la Fábrica "experimental" de ENUSA en La Haba (Badajoz) y la Central Nuclear nunca desarrollada de Valdecaballeros. También el entorno de la diputación (pedanía) de Palomares, sita en el municipio almeriense de Cuevas de Almanzora, escenario del importante accidente aéreo-nuclear ocurrido en 1966 (figura 1).

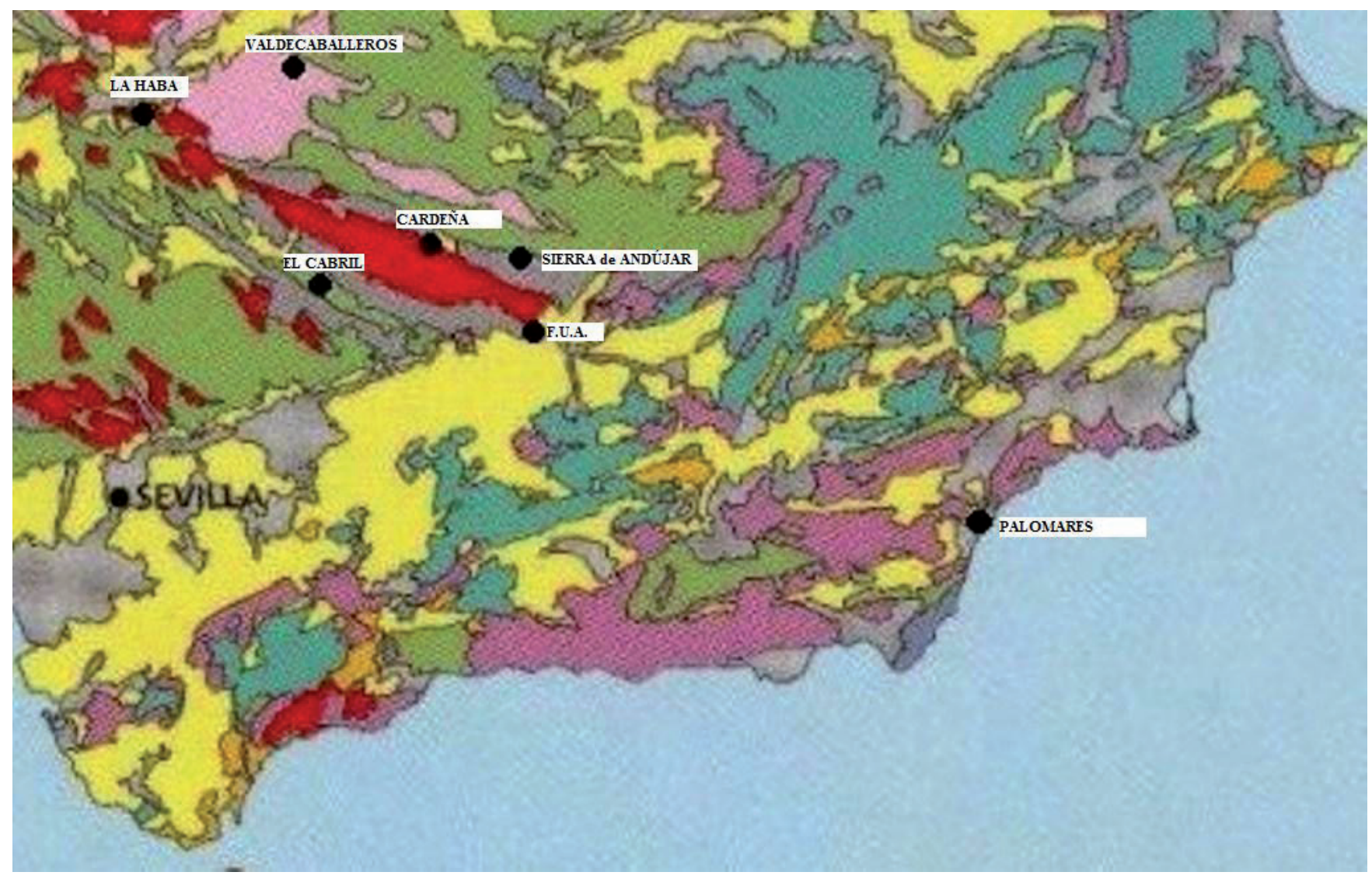

Figura 1. Cartograma geológico con localización de los lugares patrimonio nuclear objeto de estudio. Fuente: Elaboración propia sobre base cartográfica del IGME (Mapa Geológico de España). 
El proceso de fabricación del combustible nuclear de uranio -el precipitado de diuranato de amonio o "yellow cake"- implica una serie de procedimientos fisicoquímicos con hasta trece fases distintas desde la extracción en la mina hasta la neutralización de estériles, envasado y distribución del producto final a las centrales nucleares. La energía nuclear es, en la actualidad, una pieza importante en el mix de producción energética de España (20-25\%) (Espejo, 2001, 2002). Y a pesar de las controversias que conlleva su desarrollo y uso, el reemplazo a corto plazo que supone el cierre previsto de las centrales nucleares en España, resulta complejo en el contexto de precios altos de la energía que se registra a comienzos de la tercera década del presente siglo, debido al aumento de precios del gas natural, procedente para el caso español de Argelia y Rusia (gasoducto europeo). Espejo Marín y Capel Molina (2007) analizaron la implantación de las nuevas centrales de ciclo combinado (gas natural) en España, más eficientes desde el punto de vista energético y menos contaminantes. Entre los años 2002 y 2006, se construyeron 21 centrales de ciclo combinado, con una potencia de $15.175 \mathrm{MW}$, el doble de la capacidad nuclear existente en España y por tanto suficiente para la sustitución de las centrales térmicas tradicionales y las nucleares que se fueran cerrando. Otra cuestión, como se ha señalado, es el coste de producción energética, debido al alto precio del gas natural y a la obligación de reducción de emisiones impuesta por Europa para 2030 y 2050, en su marco de actuación para el cumplimiento del Acuerdo de París (2014). De manera que, la cuestión nuclear se convierte en un tema de debate y actuación importante para los próximos años, dentro de la estrategia energética a medio plazo (horizonte 2050) de España, por definir.

Recordemos que la energía nuclear de uso para satisfacción de demandas energéticas en España tiene sus antecedentes en el Decreto de 4 de octubre de $1945^{3}$ que nacionalizó la minería del uranio, que al cabo de diez años se desarrolló, fundamentalmente en yacimientos de Soria, Salamanca, Cáceres, Badajoz, Córdoba y Jaén, con dos ramas: la militar, con el denominado "Proyecto Islero" (1964-1984) (Valverde y Carpintero, 2016) y la civil, que tuvo tres etapas principales. A saber: la de los reactores "experimentales" CORAL, ARGOS y ARBI, la de las centrales de "primera generación" (Garoña, Zorita, Vandellós I) y las de las centrales en uso o de "segunda generación" (Almaraz, Trillo, Vandellós II y Cofrentes). Como señala Espejo (2002), "en 1984, de acuerdo con el contenido del Plan Energético Nacional aprobado dicho año, fueron paralizadas las obras de las cinco centrales nucleares que se hallaban en fase de construcción: Lemóniz I y II en Vizcaya con una potencia de $930 \mathrm{MW}$ cada una, Valdecaballeros I y II en Badajoz con 975 MW de potencia unitaria, y Trillo II en Guadalajara con 1.041 MW". Esta decisión adquirió resolución definitiva con la aprobación de la moratoria nuclear de 1986 que, de no haberse aplicado, podría haber llevado a España, país uranífero y con potencial nuclear ${ }^{4}$ a poseer en su territorio la respetable cifra de treinta reactores nucleares (Fernández-Arias et al., 2021), además de haber asegurado, a corto plazo (horizonte 2030) la demanda de energía eléctrica en el contexto de cambio energético impuesto por la Unión Europea para el cumplimiento de los objetivos de reducción de emisiones de gases de efecto invernadero (principalmente CO2) incluidos en el Acuerdo de París de 2014. Mientras, la minería fue decayendo a partir de 1970, hasta quedar reducida a pocos yacimientos, en concreto el polémico caso, a cielo abierto, de Retortillo (Salamanca), paralizado por las deficiencias en la documentación presentada ante la Junta de Castilla y León el día 12 de abril de 20215, y otros proyectos aún por concluir.

El presente estudio tiene como objetivos principales: a) delimitar las infraestructuras que integran el patrimonio nuclear en el sur de España; b) realizar un diagnóstico del estado de las mismas, sin olvidar el recorrido histórico que explica su evolución y situación actual; c) elaborar unas propuestas de actuación para poner en valor este patrimonio nuclear, que minimice la percepción, generalmente negativa, que acompaña a estos espacios en relación con la peligrosidad asociada al uranio.

3 BOE, 19 de octubre de 1945.

4 Esta afirmación está basada en el estudio del Plan Nuclear de la JEN de 1971.

5 Vid. documentación en la página del Congreso de los Diputados (www.congreso.es). 


\section{FUENTES Y MÉTODO}

Las fuentes empleadas para la realización del presente trabajo han sido, básicamente, dos: a) documentales, con revisión de ensayos e informes en cada uno de los elementos que componen el patrimonio nuclear del sur peninsular; b) de campo con visita a los lugares estudiados en este trabajo, que ha servido para tener un contacto directo con el medio natural y la sociedad de cada uno de los emplazamientos analizados, donde se han realizado entrevistas personales con la población local.

Por tanto, la hipótesis de partida del presente trabajo se puede formular del modo siguiente: "en distintos lugares de Andalucía y la provincia de Badajoz se encuentran una serie de lugares e infraestructuras relacionados con la minería del uranio, la industria de transformación de éste, la producción de energía nuclear y las consecuencias de accidentes relacionados con éstos, que, aparte los estigmas con respecto a su entorno, merecen un análisis geográfico.

El método de trabajo ha sido inductivo: a partir del análisis particular y detallado de los elementos que componen el patrimonio nuclear del sur de España, se ha realizado un diagnóstico detallado de su estado actual. Todo ello orientado a la elaboración de propuestas que permitan revalorizar estos espacios en la actualidad. Una pieza fundamental en este análisis ha sido, como se ha señalado, el trabajo de campo y las entrevistas personales con las poblaciones locales realizadas en los distintos territorios componentes del objeto de estudio (Andújar, Cardeña, El Cabril, Palomares, La Haba y Valdecaballeros).

Se realizaron un total de cincuenta entrevistas en los emplazamientos de patrimonio nuclear señalados, siguiendo el siguiente patrón de consulta6:

1. Relación con el elemento estudiado.

2. Conocimiento de los efectos de la radiactividad.

3. Conocimiento de potenciales víctimas de la radiactividad.

4. Relación laboral con las infraestructuras (si la hubiera).

5. Relación con los responsables de las mismas (si la hubiera).

6. Visión propia de lo realizado hasta el momento con el elemento estudiado.

7. Propuestas sobre lo que se debería hacer (si proceden).

8. Razonamientos sobre lo que no se debería haber hecho (si así procede).

9. Cualquier otra cuestión (o cuestiones específicas) del elemento estudiado.

En los casos de Andújar, Cardeña y El Cabril, hubo un notable paralelismo entre trabajos de campo y de documentación que derivaron en los resultados plasmados en el presente artículo. Sin embargo, en el estudio de los elementos de patrimonio nuclear de la provincia de Badajoz se realizaron primero las visitas de campo y se confirmaron las hipótesis de trabajo derivadas de estos encuentros con la documentación consultada con posterioridad.

Debe señalarse que las jornadas de campo se realizaron, básicamente, en meses de pandemia (mayo-septiembre de 2020) con lo que hubo que adaptar la programación de las visitas a las restricciones de movilidad y aforos en los destinos visitados. E, igualmente, ha ocurrido con las visitas a archivos provinciales y locales para la consulta de documentación sobre los distintos lugares que integran el patrimonio nuclear del sur de España, que hubo de adaptarse a las difíciles condiciones de la situación sanitaria vivida en nuestro país a lo largo del año 2020. Se han consultado los siguientes archivos:

- Archivo personal de D. José Soto Cepas, con documentación proporcionada en Andújar, de modo presencial.

- Biblioteca Histórica del Instituto de Educación Secundaria "Séneca".

6 La realización de los cuestionarios no tuvo la misma respuesta en todos los lugares objeto de estudio. La escasa población y muy envejecida existente en algunas localidades y la negativa a hablar de esta cuestión, en numerosas ocasiones, dificultó el trabajo de campo realizado para desarrollar este estudio. 
El resto de documentación de archivo se ha consultado en modo on-line:

- Archivos de la revista Estratos, disponibles en la web de ENRESA.

- Archivos del CIEMAT, disponibles en la web homónima.

- Base de datos Dialnet de la Universidad de La Rioja.

- $\quad$ Base de datos Latindex.

- Base de datos Academia.edu.

Una parte de publicaciones empleadas en la redacción de este trabajo fueron descargadas on-line. Aquellas que no lo fueron, se encuentran en las bibliotecas personales de los autores.

\section{RESULTADOS: DIAGNÓSTICO DEL PATRIMONIO NUCLEAR EN EL SUR DE ESPAÑA.}

Se presenta, a continuación, el diagnóstico del patrimonio nuclear del sur de España. Se han analizado 6 elementos tales como minas, fábricas, almacenes y áreas afectadas por radiactividad sobrevenida:

- Las minas de la Virgen de la Cabeza y la FUA en Andújar.

- Las minas de Cardeña-El Cerezo.

- El depósito de almacenamiento nuclear de El Cabril

- Palomares.

- Valdecaballeros.

- La Haba.

En su conjunto, son localidades de las Comunidades Autónomas de Andalucía y Extremadura que, salvo en la localidad de Palomares, sufren en los últimos años los efectos de la despoblación del interior peninsular y de la pérdida de actividad económica relacionada con la actividad nuclear (López, 1998). Aunque en su mayoría presentan una riqueza natural y de paisaje que otorga un potencial de desarrollo para actividades de ocio (tabla 1).

Tabla 1. Datos básicos de las localidades con Patrimonio Nuclear del sur de España.

\begin{tabular}{|c|c|c|c|}
\hline Localidad & Población (2020) & $\begin{array}{c}\text { Actividad económica } \\
\text { principal }\end{array}$ & Valores del territorio \\
\hline Andújar (Andalucía) & 36.615 & Servicios, construcción & $\begin{array}{l}\text { Paisaje de olivar. Patrimonio } \\
\text { monumental. Parque } \\
\text { Natural Sierra de Andújar }\end{array}$ \\
\hline Cardeña (Andalucía) & 1.471 & Agricultura, servicios & $\begin{array}{l}\text { Riqueza paisajística } \\
\text { (dehesas). Parque Natural } \\
\text { Sierra de Cardeña y Montoro }\end{array}$ \\
\hline $\begin{array}{l}\text { El Cabril. Hornachuelos } \\
\text { (Andalucía) }\end{array}$ & 4.480 & $\begin{array}{l}\text { Agricultura. } \\
\text { Depósito nuclear }\end{array}$ & $\begin{array}{l}\text { Paisaje natural. Parque } \\
\text { Natural de la Sierra de } \\
\text { Hornachuelos. } \\
\text { Actividad cinegética }\end{array}$ \\
\hline $\begin{array}{l}\text { Palomares. Cuevas de } \\
\text { Almanzora (Andalucía) }\end{array}$ & $\begin{array}{c}14.455 \\
\text { (1.996 en el núcleo de } \\
\text { Palomares) }\end{array}$ & $\begin{array}{l}\text { Servicios. Construcción. } \\
\text { Turismo. Agricultura de } \\
\text { vanguardia }\end{array}$ & $\begin{array}{l}\text { Playas. Patrimonio } \\
\text { monumental }\end{array}$ \\
\hline $\begin{array}{l}\text { Valdecaballeros } \\
\text { (Extremadura) }\end{array}$ & 1.065 & Servicios. Turismo & $\begin{array}{l}\text { Embalse de García Sola. } \\
\text { Reserva de la Biosfera de la } \\
\text { Siberia }\end{array}$ \\
\hline La Haba (Extremadura) & 1.219 & Servicios. Turismo & Patrimonio monumental \\
\hline
\end{tabular}

Fuente: INE eInstituto de Estadística y Cartografía de Andalucía. Elaboración propia. 
En todos los casos, la actividad nuclear ha marcado la evolución socioeconómica contemporánea de estas localidades. En la mayoría de ellos, generando puestos de trabajo directos e ingresos que se perderán una vez cesada la actividad, sometiendo a estas localidades a años de depresión económica que apenas se ha podido recuperar por el desarrollo de la actividad de servicios y turismo de interior. Asimismo, tras el cese de esa actividad, la población se ha desplazado a las cabeceras comarcales o provinciales. Incluso, los efectos de la radiactividad sobre la salud de los habitantes han tenido efectos funestos para la perdida de vitalidad demográfica. En el caso de Palomares, tras años de estigma debido al accidente nuclear sobrevenido, la actividad de la construcción, el turismo y la agricultura de vanguardia desarrollada en las tres últimas décadas ha impuesto una dinámica económica importante.

\subsection{Andújar: las minas de la Virgen de la Cabeza y la FUA}

Se trata de un patrimonio doble: por un lado, las minas situadas al noroeste del Santuario de Ntra. Sra. de la Cabeza (Navalasno, Montealegre, Raso de los Machos y la Virgen), activas entre 1955 y 1970, pero selladas y restauradas en 1996; y por otro, la Fábrica de Uranio de Andújar (FUA) “General Hernández Vidal”, a las afueras de Andújar y activa entre 1959 y 1981, desmantelada, sellada y restaurada entre 1991-94. Si es destacable la labor de ENRESA en las labores de sellado de las minas antedichas-situadas dentro del Parque Natural de las Sierras de Andújar-, la tragedia humana generada por la FUA, situada al lado del río Guadalquivir y de la propia ciudad isturgitana, trasciende los considerables problemas medioambientales generados por la carencia de medidas de protección radiológica, tanto para los trabajadores como para el entorno (Muñoz Castillo, 2021).

Las minas uraníferas de la Sierra de Andújar-Virgen de la Cabeza se encuentran sobre un relieve herciniano, con escasa población y actividades económicas (forestal, cinegética y ganadera). De ellas se extrajo pecblenda y torbernita. Por el contrario, la antigua FUA se encuentra sobre un relieve plio-pleistoceno, aluvial, con gran potencialidad agronómica e inmediato a Andújar, que es una localidad que presenta todos los estándares de una "agrociudad" (figura 2). Si la antigua zona minera presenta escasísima población, la población de Andújar, junto con sus otros poblados de colonización y pedanías, presenta en la actualidad una escasa dinámica demográfica. Es un trasunto de la evolución de la población de la España interior.

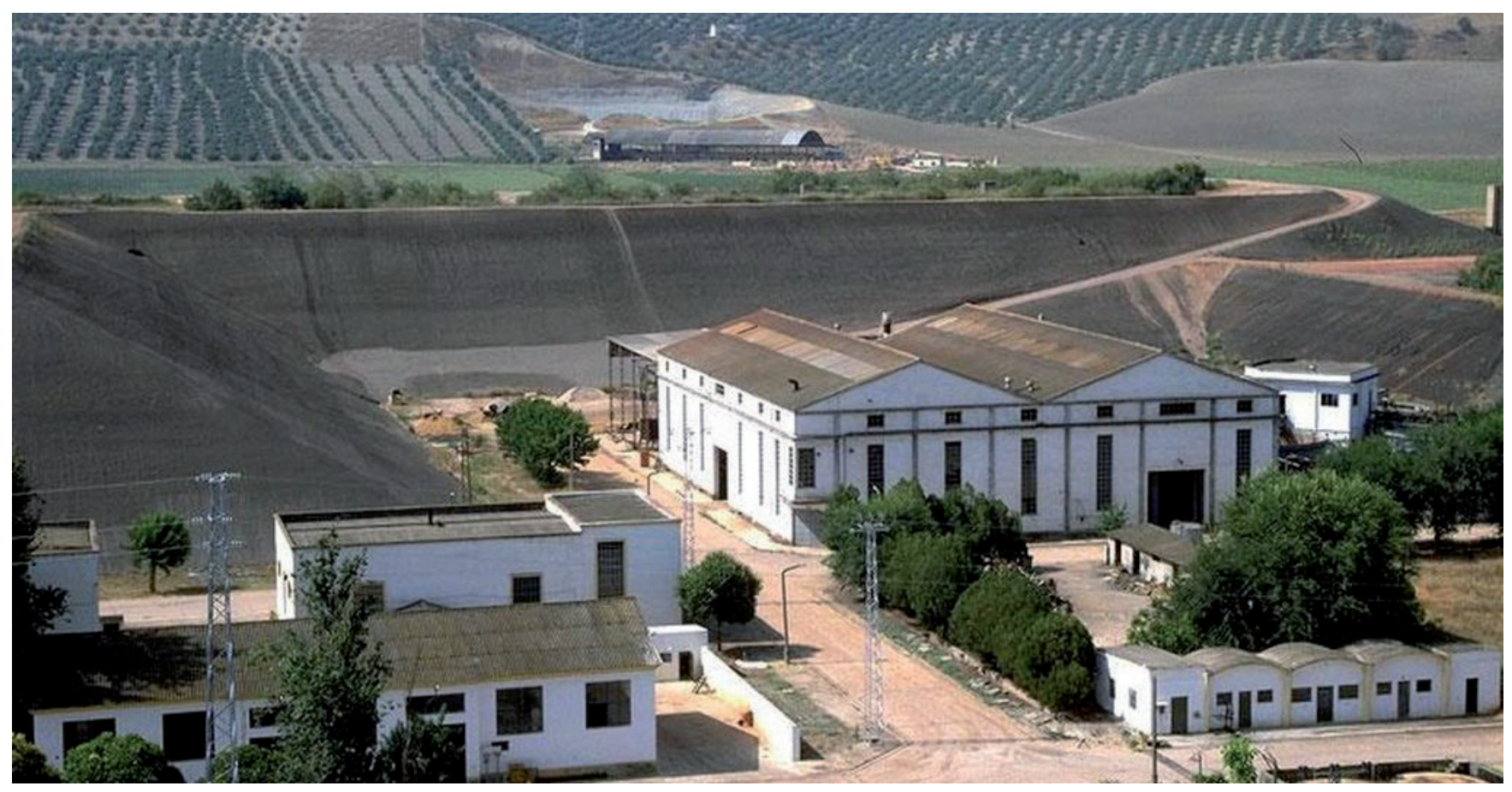

Figura 2. Imagen de la Fábrica de Uranio de Andújar -FUA-, en la actualidad. Fuente: www.vivajaen.es 
Andújar y su término municipal son "una comarca en sí misma". De transición entre la Sierra, su piedemonte, el Valle del Guadalquivir y la Campiña. Con una gran variedad de usos del suelo y dinámicas de aprovechamiento económico. En consecuencia, la dedicación de la primera a la ganadería, explotaciones forestales y cinegéticas, el uso variado de la segunda, destacando el uso como "segundas residencias", la oleicultura en piedemonte y campiña, la agricultura del valle y la dedicación mixta del entorno de Andújar.

La minería tuvo una tradición previa en Andújar, concluida con el cierre de las minas de uranio en 1970. No hubo proyectos de instalar la FUA a bocamina. Sin embargo, ésta se ubicó en un lugar con una proyección logística excelente, pero con una palmaria inaptitud en lo radiológico, a orillas del río Guadalquivir sobre suelos aluviales. La FUA “General Hernández Vidal" se proyectó y creó entre 1955-58, operando desde 1959 a julio de 1981(Muñoz Castillo, 2017). Tuvo 126 trabajadores y 8 técnicos. Siempre la dirigió el Dr. Manuel Perarnau. Se convirtieron en yellow cake ${ }^{7}$ minerales procedentes de la Sierra de Andújar, Cardeña, El Cabril y desde 1965 a 1975, La Haba. También se obtuvo algo de cobre de la torbernita. El propio libro del Dr. Perarnau alude a las altísimas dosis de radiactividad en ciertas fases del proceso ${ }^{8}$. No era la única carencia. Había más:

1. Carencia de comedor laboral, instalado después en el que hasta entonces había sido almacén de los bidones de "yellow cake", sin descontaminación previa alguna.

2. Ausencia de lavandería, instalada mucho tiempo después, por lo que gran cantidad de polvo radiactivo pasó a la red de aguas potables de Andújar al lavarse las ropas laborales en las casas de los trabajadores.

3. Falta de equipos de protección adecuados para los trabajadores. Los testimonios sobre esta realidad son abundantes, así como el hechode que "sólo se sacaban cuando había alguna visita importante" .

4. El propio trato del Dr. Perarnau y sus subordinados técnicos sobre el personal, calificado como "despótico" por los escasos supervivientes.

El primer fallecido por males relacionados con la exposición a la radiactividad se registró en 1970. Desde entonces, el goteo fue continuado hasta hoy, en su mayor parte por enfermedades oncológicas. Cuando se cerró la FUA en 1981, 30 trabajadores fueron enviados a la planta de ENUSA en La Haba. A excepción de algunos empleados que fueron dedicados a tareas de mantenimiento y un reducido número de técnicos que fueron enviados a Madrid, la mayor parte de los trabajadores fueron despedidos (Utrera Cardeñas, 2009).

Entre 1988 y 1991, la FUA estuvo en situación de casi abandono. Y, si bien sus labores de restauración y sellado se llevaron a cabo entre 1991 y 1994, las de las antiguas minas se llevaron a cabo en 1996, espoleadas por estar dentro de un Parque Natural. La antigua FUA, conocida como "La Escombrera", sigue en fase de vigilancia radiológica, prorrogada después de $2017^{10}$. Hasta hoy, son escasísimas las publicaciones técnicas de ENRESA que abordan la historia y evolución de la FUA y las actividades llevadas a cabo. Es un tema incómodo que no interesa publicitar. De las minas ya no queda nadie. Se intenta disimular o maquillar de una manera u otra, pero queda como ejemplo de lo que no se debe hacer a la hora de poner en marcha una fábrica de concentrados de uranio, ni en el momento de su desmantelamiento y sellado; y lo mismo cabe señalar del propio cierre de las antiguas minas.

\subsection{Las minas de Cardeña-El Cerezo}

El caso cardeñero está muy conectado al anterior. Sus minas pertenecen, como las de la Sierra de Andújar, a la cadena de batolitos y culms de Sierra Morena, de milenario aprovechamiento minero. Los pozos

7 Nombre común utilizado para el precipitado de diuranato de amonio, empleado como combustible en las centrales nucleares de fisión.

8 Vid. Perarnau (1966), pág. 9.

9 Afirmaciones obtenidas en el trabajo de campo realizado para la elaboración de este artículo.

10 Estaba previsto su cambio en esta fecha, pero las mediciones de ENRESA y el CSN aconsejaron ampliarla. 
uraníferos, situados en torno a la antigua aldea del Cerezo, fueron los de El Cano, San Valentín y Ovejo, batolíticos (figura 3). Más distanciado, el de Trapero, sobre el culm. De ellos se extrajeron pecblenda, coffinita y torbernita, tratados en la FUA de Andújar. Su actividad se desarrolló entre 1953 y 1968 y en 1970. Después concluyó. Hasta 1998 no se emprendieron las labores de restauración y sellado de las minas, quizá las que más quedaron influidas por los proyectos estadounidenses UMTRA ${ }^{11}$.

Son suelos muy pobres, análogos a los de la sierra de Andújar, adehesados a finales de la Edad Moderna y de escaso aprovechamiento más allá del ganadero extensivo. La actividad minera influyó directamente en la dinámica demográfica y migratoria de Cardeña y de modo particular desde 1970 hasta hoy. Ni siquiera el acicate de la creación del Parque Natural de las Sierras de Cardeña y Montoro en 1989, así como los proyectos asociados al desarrollo sostenible de la zona, han podido revertir esta tendencia. La escasa actividad actual de Cardeña se sustenta en una economía mixta, de base más ganadera que agrícola, y con escasísimos servicios.

Las minas cardeñesas de uranio fueron estudiadas desde principios del siglo XX por el ingeniero Antonio Carbonell Trillo-Figueroa. El primer uranio que se transformó en la Facultad de Ciencias de Madrid, en 1952, procedía de pozos de Cardeña. Los mineros del uranio cardeñés fueron bien tratados por sus jerarcas de la Junta de Energía Nuclear (JEN), pues se les reconocieron sus enfermedades laborales-silicosis y exposición a la radiactividad-, aparte ser trasladados a otras explotaciones uraníferas como Saelices el Chico, Albalá y La Haba. Sin embargo, el desmantelamiento, sellado y restauración de las antiguas minas fueron muy tardíos: en 1998-99, de modo análogo al caso de la sierra de Andújar, y animados por la consideración de Parque Natural de los terrenos de las antiguas minas.

Los estudios sobre las minas de Cardeña son sumamente escasos; incluso los de carácter técnico, editadas por ENRESA. Sería conveniente dar una mejor difusión a este elemento del patrimonio que ha quedado, en general, bien restaurado y reintegrado en el paisaje y protegido bajo la figura de Parque Natural.

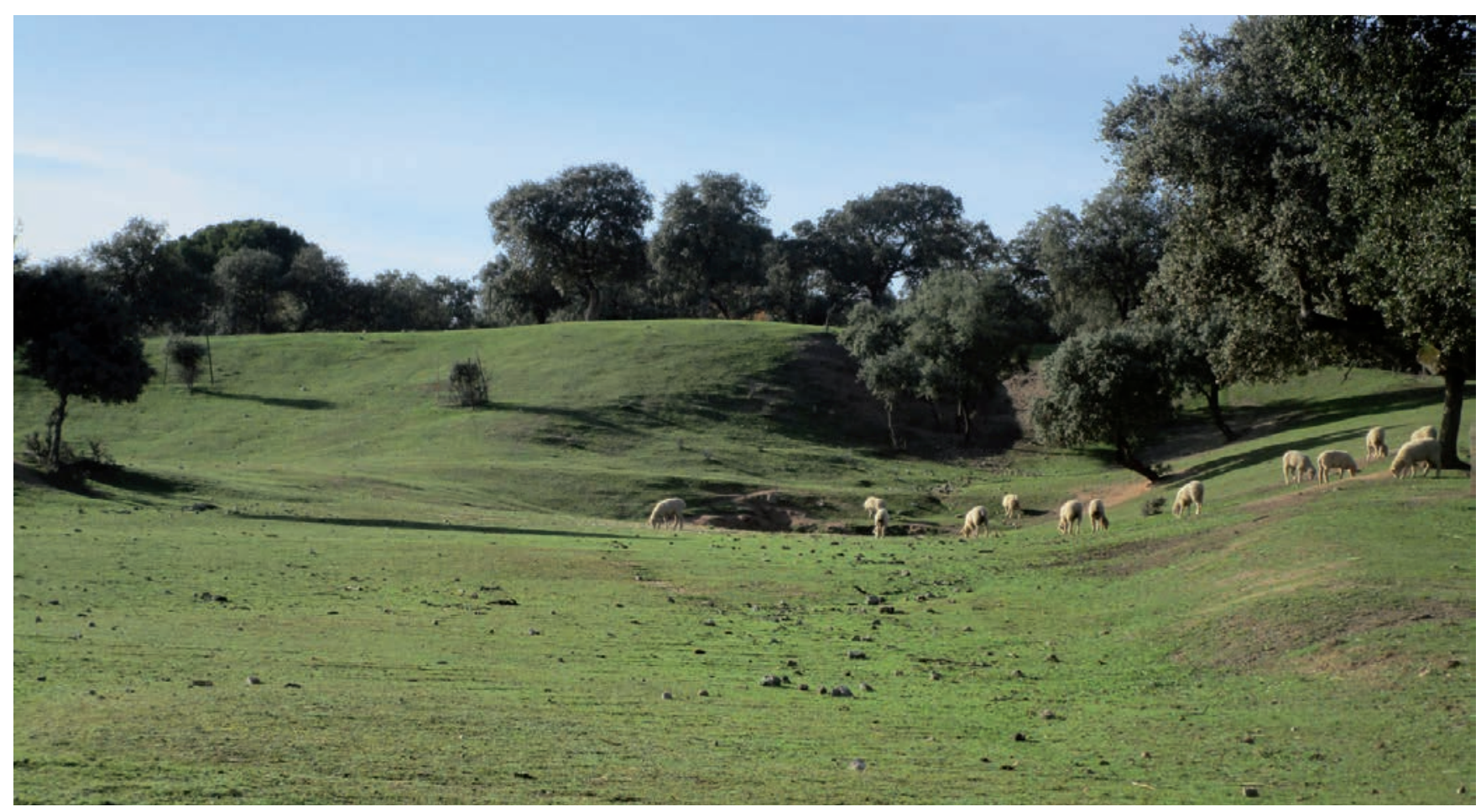

Figura 3. Aspecto actual de la antigua bocamina de El Cano (Cardeña), restaurada y vuelta a sus usos pastoriles tradicionales. Fuente: Autor (Muñoz, diciembre 2020).

11 Siglas de Uranium Mines Tailing Remedial Action (Acción de Reforma de Explotaciones Mineras de Uranio), conjunto de proyectos aprobados desde los años sesenta del siglo pasado por el DOE de los Estados Unidos. 


\subsection{El Cabril: principal activo del Patrimonio Nuclear del Sur de España}

El Cabril, se sitúa al noroeste de la provincia de Córdoba. Ese es el nombre del Almacén Centralizado de Residuos Radiactivos de ENRESA, enclavado en la finca homónima, en la ladera oriental de la Sierra Albarrana. Es el principal activo del Patrimonio Nuclear del Sur de España, habida cuenta que ha mantenido un siglo de actividades relacionadas con la minería del uranio y la gestión de los residuos nucleares generados por las distintas actividades en las que se emplean metales radiactivos (Muñoz, 2010).

En origen fueron distintas minas y cortas de uranio, berilo y micas, desde su descubrimiento en 1918 por el ingeniero, empresario e intelectual cordobés Antonio Carbonell Trillo-Figueroa hasta el cierre por la Junta de Energía Nuclear (JEN) de la Mina Beta en 1961 (Muñoz, 2012). Con posterioridad, a partir de esa misma fecha, se acondicionó para almacenamiento de residuos radiactivos en distintos emplazamientos de la finca, con una especialización e incremento de las medidas de seguridad y protección radiológica, cada vez mayores y mejores, por su propio carácter, no sólo industrial, sino de I+D+i propio y todo ello reforzado si cabe aún más, por ser el único almacenamiento de residuos radiactivos que hay en España, mientras que no se lleve a cabo la infraestructura para el almacenamiento y gestión de los residuos de alta actividad, tanto en modo temporal de combustible (ATC) como con carácter permanente(AGP), que son de extrema necesidad (Enresa, 1986-2019).

El Cabril se asienta sobre un zócalo precámbrico y caledoniano dispuesto en bandas de dirección NO-SE, bordeado por formaciones hercínicas, bastante abarrancadas. La pobreza de los suelos (inceptisoles) ha limitado mucho las actividades al pastoreo, la minería, la caza y la explotación forestal (figura 4). Además, su población ha sido por lo general escasa y dispersa. No en vano, con respecto a las localidades que lo rodean, hay un desierto demográfico cuyo centro es El Cabril. No hay población estable en un radio de acción superior a los 15 kilómetros. Y las localidades del entorno pierden población de modo continuado (Muñoz, 2020).

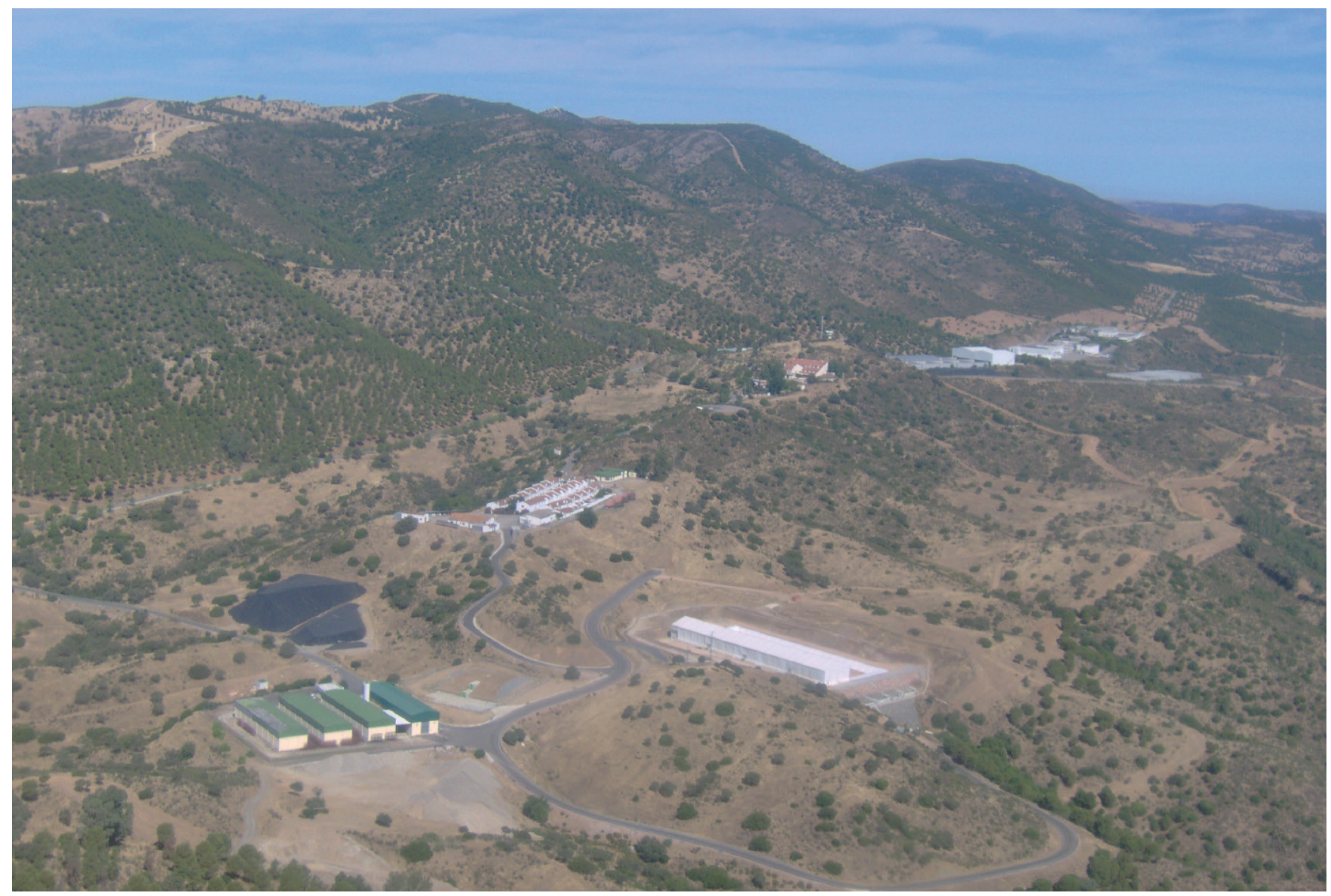

Figura 4. Vista de las instalaciones del Almacén Centralizado de Residuos Radiactivos de El Cabril (Córdoba). Fuente: Autor (Muñoz, junio 2020). 
El Almacenamiento Centralizado de Residuos de Muy Baja, Baja y Media Actividad de ENRESA en Sierra Albarrana-El Cabril es, sin duda alguna, la principal instalación industrial de alta tecnología del noroeste de la provincia de Córdoba. Su actividad se inicia con la extracción de berilos y micas de modo discontinuo desde 1918, y de modo continuado a partir de 1939 por iniciativa privada de BRESA, y, con posterioridad, por parte de EPALE-pública-, en las minas del Cabril y La Coma. Sin embargo, son las minas Beta (activa hasta 1961) y la cantera Diéresis (activa hasta 1975) las más productivas, tanto de micas como, en mucha menos medida, de uranio. Este uranio fue tratado en la FUA "General Hernández Vidal" hasta 1975. Gestionado por la JEN desde 1961 a 1984, el primer almacenamiento fueron las propias galerías de la mina Beta. Con posterioridad, se crearon los primeros almacenamientos temporales y permanentes -la antigua central térmica del Cabril-, y los módulos que hoy en día son temporales, al sur del emplazamiento actual. A partir de 1990 se crearon los módulos de almacenamiento principales, puestos en marcha en 1992. Hasta nuestros días se han creado otras tres celdas más para el almacenamiento de residuos nucleares de muy baja actividad, denominados "celdas 29, 30 y 31". Desde el año 2016, El Cabril limitó parcialmente la recogida de residuos hasta su ampliación aprobada12 en marzo de 2020, con otro módulo -“C"- y la llamada "celda 32".

La actividad de investigación y desarrollo, en los años de funcionamiento del almacén, ha sido constante y resulta francamente positiva, tanto por las aportaciones de tecnología para consumo propio, como por el ejemplo que suponen a nivel internacional. En su Complejo Tecnológico, las investigaciones, incluso las no estrictamente relacionadas de modo directo con la actividad nuclear, son continuas (Echag (ed.), 2000). Es un banco de pruebas, no sólo para mejorar las técnicas ya en uso, sino el futuro ATC, que se tendrá que desarrollar en las condiciones técnicas y de seguridad necesarias. Y esta consideración se puede aplicar al necesario AGP español que tendrá que desarrollarse en el futuro. Y, sin embargo, pese a las innegables actividades científicas, de gestión de residuos y de divulgación educativa (más de 7.000 visitas anuales), algo no acaba de producirse dentro de la política de comunicación de la empresa. Y ello porque sigue existiendo un desconocimiento importante de la instalación en el conjunto del país, así como un sesgo negativo sobre su funcionamiento. Presenta un potencial de recursos vinculados al ocio y las actividades deportivas, educativas y turístico-ambientales muy notable. Es, con mucho, la mejor instalación del Patrimonio Nuclear del Sur de España, por el volumen de actividad que desarrolla y su potencial como centro de innovación.

\subsection{Palomares: las secuelas del "broken arrow"13" español del 17 de enero de 1966}

La localidad de Palomares ${ }^{14}$ se sitúa al sureste del término municipal de Cuevas de Almanzora (NE de la provincia de Almería). No presenta en su subsuelo rocas ni minerales uraníferos. Tampoco ha tenido ninguna instalación nuclear de importancia significativa. Y, sin embargo, se ha incluido entre los lugares objeto de análisis en el presente trabajo por los hechos que exponemos a continuación:

En la mañana del 17 de enero de 1966 durante una rutinaria acción de repostaje en el aire de un bombardero "B52" y su avión-nodriza "KC 135" se produjo un choque entre éstos, que se incendiaron y estallaron en el aire. Aparte de las once muertes ocurridas en el acto de la tripulación de ambos aviones, cuatro bombas termonucleares " $\mathrm{H}$ " del modelo "B24", cayeron del avión "B52" con sus respectivas cargas de plutonio. Tres se pudieron recuperar rápidamente; la cuarta, al cabo de 80 días, gracias a la pericia de un pescador catalán ${ }^{15}$ avecindado en la cercana localidad murciana de Águilas (Álvarez de Toledo, 2002). Transcurrido más de medio siglo después sigue habiendo un número bastante considerable de parcelas que tras haber sido descontaminadas por la USAF en el propio año de 1966, y con posterioridad, por JEN/CIEMAT/ENRESA,

12 ENRESA pasó a depender del MITECO en 2019. Sin embargo, la suspensión del proyecto de ATC de Villar de Cañas supuso la contrapartida de la ampliación de El Cabril a partir de marzo de 2020.

13 Término utilizado en el lenguaje militar estadounidense para designar los accidentes en los que se produce pérdida de armamento nuclear por el motivo que sea.

14 Como pedanía que es, allí recibe el nombre de "diputación".

15 Francisco Simó Orts, desde entonces, Paco "el de la Bomba", tarraconense dedicado a la pesca del gambón rojo. 
siguen valladas y sometidas a vigilancia radiológica por presentar partículas de plutonio y altas dosis de radiactividad (figura 4).

El espacio geográfico de Palomares es una zona de contrastes entre paisajes naturales y entornos fuertemente antropizados. Sierra Almagrera, antigua zona minera, es un continuo espartizal, mientras las zonas bajas alternan zonas de invernaderos, arboricultura y núcleos urbanos o diseminados. Aparte, agroindustrias, zonas logísticas o la fábrica de Deretil en la cercana Villaricos. La población en estos municipios se ha triplicado en menos de tres décadas, debido a la demanda de la agricultura bajo plástico, y en menor medida, el turismo. Una tercera parte de la población actual (1883 hab. en 2020) son inmigrantes. Palomares y su entorno ya tenían una economía mixta antes del accidente, que ha ido modificándose. No obstante, a día de hoy, la principal actividad sigue siendo la agricultura intensiva de alto rendimiento, incluso en el entorno de las parcelas expropiadas por el CIEMAT y vigiladas por éste -y antes, por la JEN- desde 1966 al detectarse altos niveles de radiactividad.

Las parcelas en las que cayeron las tres bombas fueron valladas y descontaminadas por tropas de la USAF durante casi un año (figura 5). Se informó de modo tamizado sobre el accidente, ocultándose inicialmente su carácter nuclear. Mientras se expropiaban y vallaban parcelas contaminadas, se llevaron a cabo los acuerdos entre la JEN y el DOE estadounidense-los denominados acuerdos "Otero-Hall"-, para descontaminar la zona. Además, se llevó a cabo la operación propagandística del baño en la playa del entonces ministro de Información y Turismo, Manuel Fraga, y del embajador americano. El acuerdo JEN-DOE fue conocido como “Proyecto Indalo" y permitió la descontaminación de las parcelas afectadas y el traslado a almacenamientos nucleares de EE.UU. de los bidones con residuos. Primero a Savannah River y después, a Yucca Mountain. El Proyecto Indalo finalizó por parte estadounidense en 2009. Pero en 2015, conocida ya la extensión y entidad del "aerosol de plutonio" en la Sierra Almagrera, se firmó un nuevo acuerdo -el acuerdo "García Margallo-Kerry"que prevé la implementación de dinero para la descontaminación de las parcelas afectadas por el accidente de 1966, tanto en Palomares como en la Sierra Almagrera.

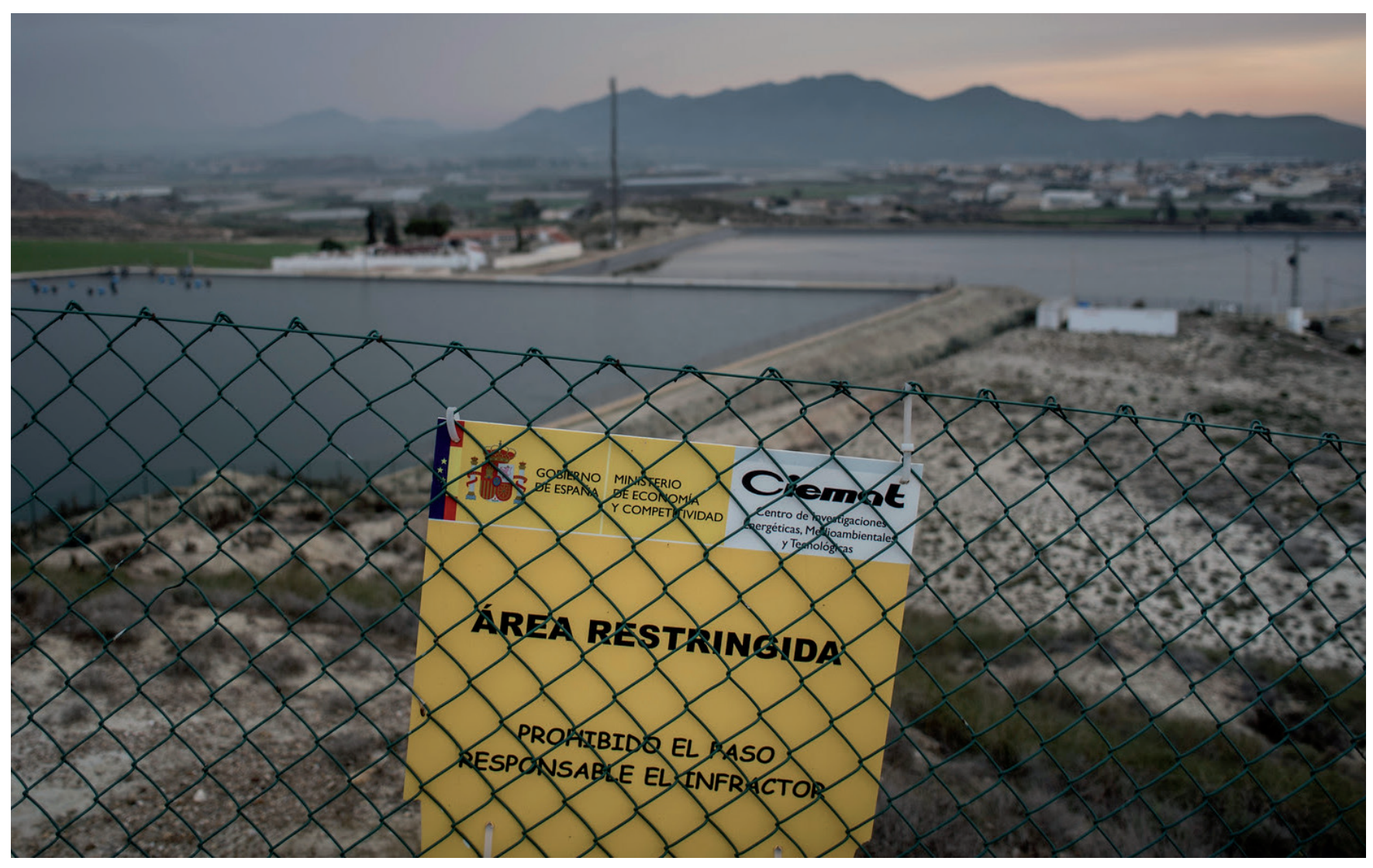

Figura 5. Balsas de Los Algarrobones, cerca de la localidad de Palomares. Fuente: Autor (Muñoz, 2018). 
Pese a expropiarse en principio 8 hectáreas, lo cierto es que hasta el día de hoy, alrededor de 150 personas han presentado trazas de plutonio en sangre (Muñoz, 2020). Y que, algunas han enfermado y muerto por causa de patologías compatibles con la exposición a la radiactividad. La desinformación fue muy considerable entonces (Herrera Plaza, 2019). Las mediciones de la JEN, tras la extracción, envasado y envío a los EE. UU. de los $25.000 \mathrm{~m}^{3}$ de residuos de tierra y elementos contaminados por parte de la USAF y la USN, han proseguido hasta hoy día. Y como consecuencia, se han perimetrado, vallado, expropiado y sometido a vigilancia otras parcelas. La evolución del tratamiento de las zonas contaminadas ha sido notable en el caso de Palomares. De hecho, la evolución tecnológica del propio conglomerado nuclear español permitió hallar en 2009 el "aerosol" o "pluma" de plutonio en Sierra Almagrera (Menéndez Suárez, 2016), y aunque tarde, permitió su perimetrado, vallado y expropiación. Pero a los residentes en la localidad de Palomares se les ha estigmatizado por los peligros de la radiactividad. "Oficialmente" no hay relación entre la exposición al plutonio y las enfermedades, pero en las "diputaciones" siempre se comenta. Junto con El Cabril, Palomares ha sido y es el otro gran banco de pruebas de los efectos de las radiaciones por distintas causas. Se han seguido llenando bidones con tierra contaminada, enviándose a los EE.UU., pero sería deseable mayor transparencia en la gestión de los residuos.

\subsection{Valdecaballeros: la central nuclear non nata de la Siberia Extremeña}

Valdecaballeros se encuentra al noroeste de la Siberia Extremeña, junto al río Guadiana embalsado por la presa de García de Sola. Es un pequeño pueblo agroganadero, sobre dos cuestas, entre dehesas y repoblaciones de pinos y eucaliptos, tranquilo, en el que, entre 1975 y 2001 se planteó un gran proyecto que, de no haber sido por la moratoria nuclear de 1986 y el Reglamento de Instalaciones Eléctricas de 1994, habría constituido un gran revulsivo para el desarrollo de esta zona, muy atrasada y bastante poco poblada: las Cuatro Villas ${ }^{16}$. Ese proyecto consistió en la construcción de una central nuclear con dos reactores, a once kilómetros al norte del pueblo.

La instalación se encuentra sobre un relieve silíceo, dispuesto en bandas paralelas entre sí, que permite un aprovechamiento limitado, agroganadero, que, sin embargo, no está acompañado de otros sectores que, sin lugar a duda, habrían permitido el asentamiento de más población (Púa, 2013). Es una de las comarcas más afectadas por el éxodo rural y la emigración de la segunda mitad del siglo pasado, con escasísima población joven, lo que hace que la disponibilidad de servicios sea mínima. En definitiva, una comarca subdesarrollada (Prieto y García Dory, 2018).

Las obras de la central (figura 6) comenzaron en 1975 y llegaron a tener hasta cuatro mil trabajadores a la vez en la misma. Valdecaballeros vivió su propia metamorfosis urbanística. Sin embargo, la moratoria nuclear de 1986, con el primer reactor a punto de empezar a funcionar, supuso el inicio de incertidumbres que llevaron a la parada de la obra en 1991. En 2001 se desmanteló la maquinaria de la central, a excepción de los transformadores, utilizados para dos parques solares creados años después, que no cumplen las expectativas de desarrollo para una comarca tan necesitada. En definitiva, a Valdecaballeros "le mataron el futuro" sin pensar en alternativas creíbles (Tertsch, 2001; Naredo, 2017).

\subsection{La Haba: Ias minas que mataron a un pueblo}

Un ejemplo más trágico que el mencionado de Valdecaballeros, -dentro del conjunto de instalaciones del "Patrimonio Nuclear del Sur de España"-, es el de la localidad de La Haba, situada en el límite entre las comarcas pacenses de las Vegas Altas y La Serena. A este pequeño pueblo, que hoy día vive de la dehesa y sus productos -sobre todo la actividad ganadera-, junto con el éxodo rural y la emigración a Francia y Alemania, se le sumó la gran tragedia de una minería de uranio mal gestionada. Desde las primeras calicatas de 1953

16 Valdecaballeros, Talarrubias, Herrera del Duque y Castilblanco. 
al cierre de la mina a cielo abierto "Marilozana" (figura 7) y la planta "experimental" de ENUSA en 1991, fueron 38 años de una relativa "fiebre del uranio" en una comarca de amplia tradición minera. Explotadas en sistema de galerías desde 1962-63 las minas del Lobo y el Pedregal, con posterioridad se cometió el considerable error de abrir la mina "Marilozana" a cielo abierto, con el evidente riesgo radiológico. También hay fuentes que señalan que en una de las galerías de las antiguas minas del Lobo-concretamente en la "Lobo 7"- se enterró el reactor nuclear "JEN 1" de La Moncloa (Madrid) cuando sufrió el accidente en 1973.

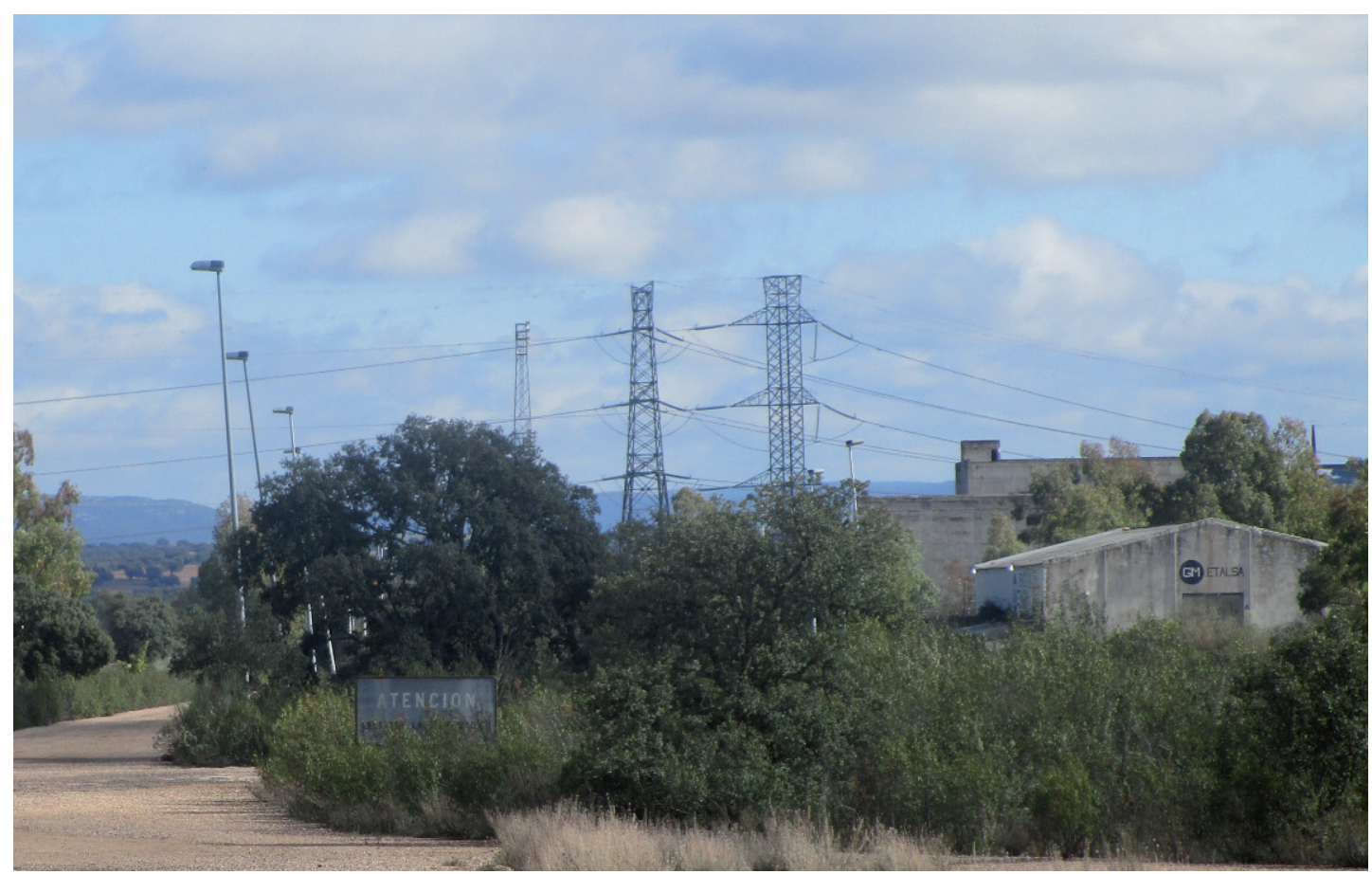

Figura 6. Estado de abandono actual de la antigua Central de Valdecaballeros. Fuente: Autor (Muñoz, 2018).

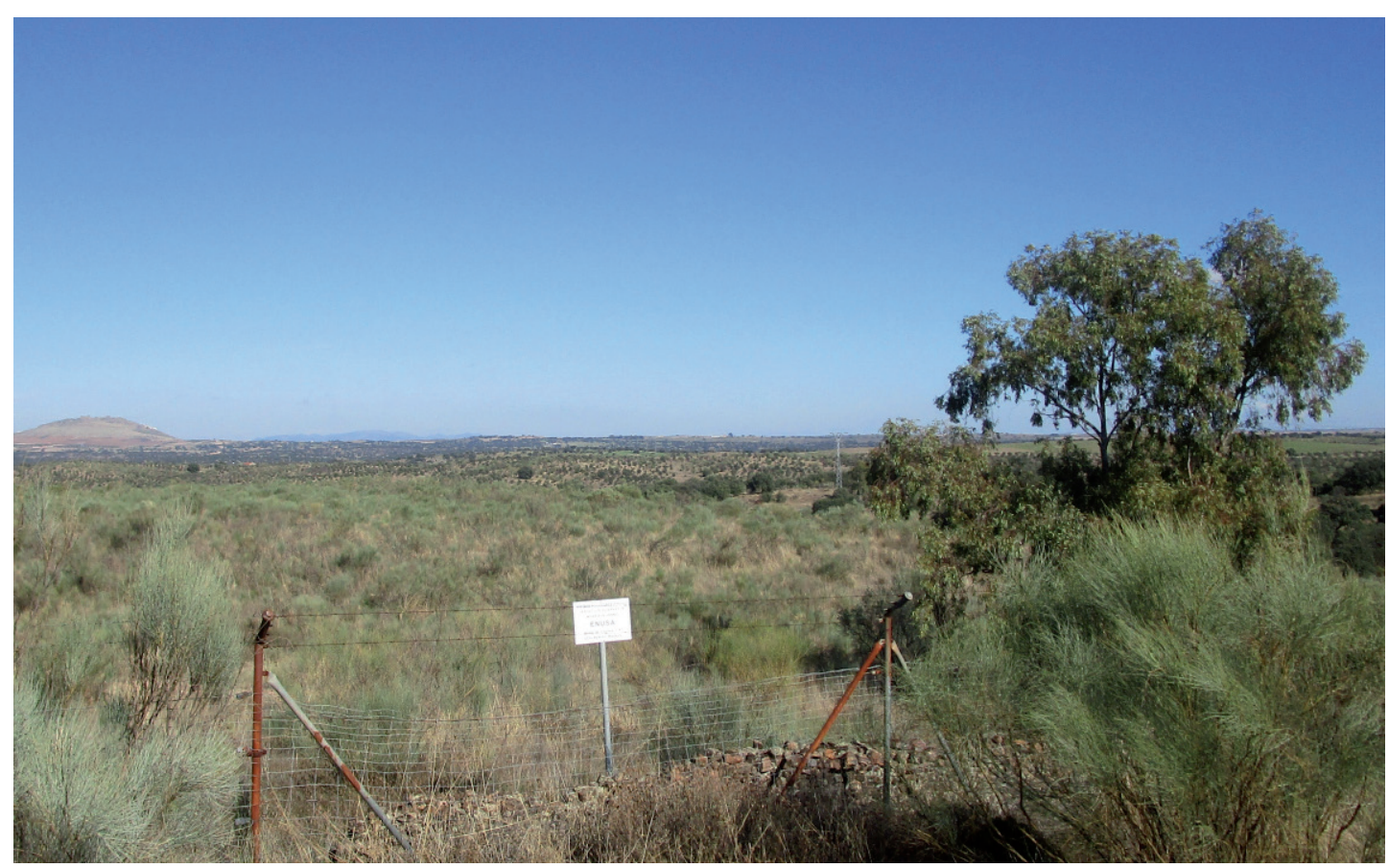

Figura 7. Imagen de la antigua mina Marilozana, una vez sellada. Fuente: Autor (Muñoz, 2020). 
Hasta 1975, el mineral de uranio se trasladó en camiones a Magacela, y desde allí, en tren, hasta la FUA "General Hernández Vidal" de Andújar. Del análisis de campo realizado, sobresale el hecho de que la población de La Haba es muy reacia a hablar "del uranio". Muchos jabeños consideran que "el uranio ha matado al pueblo". El análisis de los datos poblacionales consultados, en estadísticas y de forma directa17, muestra que un porcentaje cercano al $40 \%$ de la población ha fallecido joven, todos de enfermedades oncológicas, relacionadas con la exposición al uranio y la radiactividad. La Fábrica "experimental" de ENUSA en La Haba funcionó desde 1975 a 1991. Almacenó bidones radiactivos hasta 1993, cuando ya deberían haber concluido las labores de desmontaje, descontaminación y restauración paisajística del conjunto, la cual no se llevó a cabo hasta varios años más tarde, entre 1997 y 1998. Y, sin embargo, lo que ha permanecido en la memoria colectiva, cada vez más pequeña y mermada de los jabeños, ha sido su propia tragedia personal, con casi la mitad de los habitantes muertos por cánceres relacionados con la radiactividad. Pese a la rapidez de ENRESA en llevar a cabo las labores de desmantelamiento, descontaminación, sellado y vigilancia de las antiguas minas y fábrica de uranio, lo cierto es que la peor cara de la minería del uranio diezmó a este pequeño pueblo pacense. En definitiva, Valdecaballeros y La Haba son dos ejemplos de fracaso en la política y gestión "nuclear" en España: en la primera localidad se quedaron sin central nuclear y sin futuro; en la segunda, sin almacén y sin salud tras el final de la minería del uranio.

\section{DISCUSIÓN Y CONCLUSIONES}

En el presente estudio se ha puesto de manifiesto la evolución histórica reciente, la realidad actual y el valor del patrimonio nuclear del sur de España. Un conjunto de infraestructuras, equipamientos y paisajes que sufren una estigmatización por la peligrosidad asociada al uranio. En el análisis de las localizaciones del patrimonio nuclear sobresalen los aspectos siguientes:

- El estudio del caso doble de Andújar -minas en la sierra y FUA en sus afueras-, muestra resultados evidentes de lo señalado (estigmatización de un territorio) a partir del estudio de las minas y su trayectoria, y del análisis del tema tabú que representa la tragedia de la FUA, con sus consecuencias hasta nuestros días. Existen evidentes analogías entre las minas cardeñesas en torno a la Venta del Cerezo y las del entorno norte y noroccidental del Santuario de Nuestra Señora de la Cabeza, en la Sierra de Andújar.

- La evolución experimentada por El Cabril ha sido destacada en las últimas décadas. Esta localidad ha pasado de lugar de minas de uranio, mica y berilo a sede del Almacenamiento Centralizado de Residuos Radiactivos de muy baja a media actividad en España. Por su importancia y significación, tras algunos años relegado a un segundo plano por el truncado proyecto del ATC (2013-2020), El Cabril, es el principal activo de ENRESA/CIEMAT, y tiene aún nuevas posibilidades, con el desarrollo de actividades deportivas y ambientales.

- En Palomares se han analizado las labores llevadas a cabo a través del "Proyecto Indalo", destacando las iniciativas positivas que han permitido ir mejorando la percepción de esta localidad como área destacada de desarrollo agrario de vanguardia y turístico residencial, desde que ocurrió el accidente aéreo de efectos nucleares en 1966.

- Muy distinto es el caso de la provincia de Badajoz, que ha vivido dos realidades diametralmente opuestas. Por un lado, en Valdecaballeros se alumbró la gran esperanza de dejar atrás su multisecular escaso desarrollo con el proyecto de la central nuclear no desarrollada finalmente, lo que ha dado lugar a un futuro bastante incierto. Por otro, el caso de La Haba donde a la "fiebre del uranio" extraído de sus minas y transformado en su fábrica "experimental" de ENUSA siguió el cese de actividad en 1991 y posterior tragedia de las muertes motivadas por el contacto con distintos elementos radiactivos. 
De acuerdo con lo expuesto en el presente estudio, los dos mejores ejemplos de experimentación y de desarrollo de I+D+i son el Almacén Centralizado de Residuos de Muy Baja, Baja y Media Actividad de El Cabril y el conjunto de parcelas acotadas y sometidas a vigilancia radiológica en el entorno de Palomares y la Sierra Almagrera. Ambas zonas muestran la evolución y optimización de los conocimientos en tratamiento y gestión de residuos radiactivos (Alonso et al., 1989).

A modo de síntesis, se presentan las fortalezas y debilidades principales de los elementos del Patrimonio Nuclear del sur de España analizados en el presente estudio (tabla 2).

Tabla 2. Fortalezas y debilidades de los elementos del Patrimonio Nuclear del Sur de España.

\begin{tabular}{|l|l|l|}
\hline \multicolumn{1}{|c|}{ Lugar } & \multicolumn{1}{|c|}{ Fortalezas } & \multicolumn{1}{c|}{ Debilidades } \\
\hline Andújar: minas y FUA & $\begin{array}{l}\text { Minas: Parque Natural. } \\
\text { FUA: Localización. }\end{array}$ & $\begin{array}{l}\text { Minas: Despoblación. } \\
\text { FUA: Medio físico. }\end{array}$ \\
\hline Cardeña. & Parque Natural. & $\begin{array}{l}\text { Despoblación que impide desarrollar } \\
\text { proyectos. }\end{array}$ \\
\hline El Cabril & Excelente infraestructura de I+D+i & $\begin{array}{l}\text { Despoblación y distancia de núcleos } \\
\text { de población. }\end{array}$ \\
\hline Palomares & $\begin{array}{l}\text { Cercanía a la costa y a núcleos de } \\
\text { población importantes. Buenas } \\
\text { condiciones climáticas para el turismo } \\
\text { yla agricultura }\end{array}$ & $\begin{array}{l}\text { Variaciones en la cantidad de radiación } \\
\text { ("pluma”). }\end{array}$ \\
\hline Valdecaballeros & Gran disponibilidad de suelo y aguas. & $\begin{array}{l}\text { lu estándares propios de una región } \\
\text { escasamente desarrollada. }\end{array}$ \\
\hline La Haba & ZePA, buena situación intercomarcal. & $\begin{array}{l}\text { Despoblación, así como extrema } \\
\text { dependencia de Don Benito-Villanueva } \\
\text { de la Serena. }\end{array}$ \\
\hline
\end{tabular}

Fuente: Elaboración propia.

Las administraciones (estatal y regionales) han hecho escasas propuestas de actuación para poner en valor este innegable patrimonio y revertir la carga onerosa que ha supuesto para estas localidades, fomentando una diversificación más que necesaria en sus, en general, magras posibilidades de desarrollo sostenible. En efecto, a nivel oficial, la ausencia de iniciativas para la promoción del Patrimonio Nuclear del Sur de España, que, como tales reconozcan la condición de esas infraestructuras, es palmaria. Basta recorrer las localidades y lograr entablar conversación alusiva al pasado y patrimonio nuclear de las mismas para sacar sus conclusiones: más allá de las labores de vigilancia de ENRESA, no hay prácticamente nada. Se podría haber hecho más para la promoción socioeconómica de estos espacios. De ahí la necesidad de proponer actuaciones.

Considerando el hándicap de la radiactividad, cuya vigilancia debe ser constante, en algunas de las localidades afectas al Patrimonio Nuclear del Sur de España, sí se podrían emprender infraestructuras similares a las ya existentes en Almadén (Cañizares, 2011 a y b, 2013), así como el fomento de las ya existentes como las creadas en Palomares, que están sin desarrollar en los últimos años, por distintos motivos.

La investigación acometida en este trabajo es novedosa por el conjunto de instalaciones que aborda: antiguas minas de uranio, fábricas de refinado de uranio desmanteladas, un almacén de residuos radiactivos y una central nuclear "non nata"; todo ello con el método de trabajo del análisis geográfico.

Por último, como resultado del análisis-diagnóstico realizado en el presente trabajo, se presentan una serie de propuestas para el fomento y valorización del Patrimonio Nuclear del Sur de España, se incluye la siguiente tabla pormenorizando los distintos elementos que lo integran, así como las posibles opciones para su dinamización como recursos para la reactivación turística o, en general, socioeconómica de las áreas de estudio (tabla 3). 
Tabla 3. Propuestas de actuación en las instalaciones del patrimonio nuclear del sur de España, analizadas en el presente estudio.

\begin{tabular}{|c|c|c|}
\hline LOCALIDAD & ELEMENTO DEL PATRIMONIO NUCLEAR & PROPUESTAS de ACTUACIÓN \\
\hline Andújar & Antiguas minas y FUA ("Ia Escombrera"). & $\begin{array}{l}\text {-Modificación del sellado de la FUA siempre que } \\
\text { no implique más problemas radiológicos con } \\
\text { idea de potenciar proyectos ya existentes. } \\
\text {-Recurso didáctico para la enseñanza }\end{array}$ \\
\hline Cardeña & Antiguas minas de uranio & $\begin{array}{l}\text {-Conclusión de proyectos a medio desarrollar } \\
\text { para la valoración de la localidad. } \\
\text {-Valorización del rico entorno natural e } \\
\text { integración de la mina como elemento turístico } \\
\text { visitable }\end{array}$ \\
\hline El Cabril & $\begin{array}{l}\text { Antiguas minas de uranio y } \\
\text { Almacenamiento de RRNN de ENRESA }\end{array}$ & $\begin{array}{l}\text {-Creación de un Centro de Interpretación } \\
\text { adecuado al nivel de las instalaciones. } \\
\text {-Potenciación de las actividades de investigación } \\
\text { e innovación en el propio centro. }\end{array}$ \\
\hline Palomares & $\begin{array}{l}\text { Parcelas afectadas por el accidente aéreo- } \\
\text { nuclear de } 1966 .\end{array}$ & $\begin{array}{l}\text {-Vigilancia y adecuación de las parcelas afectadas } \\
\text { a sus posibles utilidades. } \\
\text {-Recurso didáctico para la enseñanza }\end{array}$ \\
\hline Valdecaballeros & Central nuclear "non nata" & $\begin{array}{l}\text {-Necesidad de un plan de promoción económica } \\
\text { de la localidad. } \\
\text {-Promoción turística de la Reserva de la Biosfera } \\
\text { de La Siberia } \\
\text {-Recurso didáctico para la enseñanza }\end{array}$ \\
\hline La Haba & $\begin{array}{l}\text { Antiguas minas de uranio y fábrica de } \\
\text { combustible nuclear desmantelada. }\end{array}$ & $\begin{array}{l}\text {-Valorización del patrimonio monumental como } \\
\text { elemento turístico. } \\
\text {-Recurso didáctico para la enseñanza }\end{array}$ \\
\hline
\end{tabular}

Fuente: Elaboración propia.

Son iniciativas y propuestas que se consideran necesarias para poner en valor el patrimonio nuclear del sur de España, relacionadas con la promoción turística y la educación. Por su parte, la combinación entre desarrollo sostenible y energía nuclear es posible, siempre y cuando los procesos sean llevados a cabo con las adecuadas condiciones de seguridad y protección para evitar fugas radiactivas, es posible. A corto y medio plazo, la energía nuclear va a seguir siendo una pieza fundamental del mix energético de nuestro país, en el contexto de cambio climático y necesidad de reducción de emisiones.

La investigación, como se ha señalado, analiza instalaciones que no han sido tratadas en trabajos anteriores, desde la disciplina geográfica: antiguas minas de uranio, fábricas de refinado de uranio desmanteladas, un almacén de residuos radiactivos y una central nuclear que finalmente no se llevó a cabo. Se pueden encontrar enfoques aproximados en algunas investigaciones realizadas sobre valorización y propuestas hechas con el patrimonio minero e industrial de Almadén (Cañizares, 2011 a y b, 2013, 2020), la Sierra Almagrera (Menéndez, 2016) y Riotinto (Pérez et al., 2016). Con ellas comparte la necesidad de integrar estos espacios del patrimonio nuclear en los circuitos de las visitas turísticas y de la educación ambiental en las localizaciones estudiadas. No podemos olvidar el interesante trabajo de Espejo Marín (2002), que en su momento señaló la necesidad de profundizar en el estudio general de la "geografía de la energía nuclear en España", que es un esfuerzo todavía sin realizar en España y con el que este trabajo ha intentado profundizar a partir del estudio de casos locales destacados. En otros países, como Francia, el concepto de "patrimonio nuclear", así como su estudio, ha merecido artículos iniciales a partir de 2020 (Mathieu, 2020; Wakim, 2021), si bien con un carácter más de reportaje que de análisis patrimonial como aborda este trabajo.

Como ha ocurrido en otros lugares de nuestro país, en los que se ha puesto en valor equipamientos relacionados con la actividad minera desarrollada en épocas pasadas, las localidades del sur de España que integran el patrimonio nuclear, presentan potencialidad para llevar a cabo acciones que fomenten el 
desarrollo local y comarcal. En este caso, además, se unen paisajes "de lo nuclear" que tienen belleza y potencialidad como recurso didáctico y de ocio. Es importante conocer la evolución histórica, la realidad actual y las propuestas de futuro de los lugares del patrimonio nuclear del sur de España. Con el estudio abordado, desde la perspectiva geográfica, de los distintos lugares que lo integran, de sus características, de sus fortalezas, debilidades y posibilidades de cara al desarrollo futuro de sus entornos territoriales, se ha pretendido la visibilización de una realidad que, sin duda, merece aproximaciones más detalladas desde las disciplinas histórica y sociológica. El presente trabajo pretende abrir nuevas vías de análisis de un patrimonio, poco valorado en nuestro país, debido a la percepción negativa que subyace a lo nuclear. Porque el desconocimiento de la realidad territorial de estas localidades surgidas o desarrolladas en relación con los recursos, objetos o con proyectos de generación de energía nuclear conduce a conclusiones tendenciosas que solo la investigación científica puede aclarar.

\section{Agradecimientos}

A quienes creyeron en las posibilidades de un trabajo como éste. Y, de modo particular, a los miembros del Tribunal ante el que se defendió la Tesis Doctoral que dio lugar a este y otros artículos, por sus notables aportaciones.

\section{Declaración responsable y conflicto de intereses}

Los autores declaran que no existe ningún conflicto de interés con relación a la publicación de este artículo. Los dos autores han participado en la organización de contenidos, en la selección de la metodología empleada, en la revisión bibliográfica y han revisado y corregido las diferentes versiones del manuscrito. La idea original de la investigación y el trabajo de campo ha sido realizado por Juan Antonio Muñoz Castillo.

\section{REFERENCIAS}

Alonso, L., Iñarra, I., Cancio, D \& del Potro, R. (1989). Residuos radiactivos. Ministerio de Obras Públicas y Transportes. Álvarez de Toledo. L.I. (2002). Palomares. Memoria.UNED.

Bezat, J.M. (2021, 19 de abril). Le nucléaire peut-il être considéré comme un investissement durable, au même titre que les énergies renouveables? Le Monde. https://www.lemonde.fr/idees/article/2021/04/19/nucleaire-la-guerre-fait-rage-a-l-approche-d-une-decision-de-bruxelles-sur-les-technologies-labellisees-vertes_6077235_3232.html

Cañizares Ruiz, Ma C. (2011a). Patrimonio, parques mineros y turismo en España. Cuadernos de Turismo, 27, $133-154$. https://doi.org/10.6018/turismo

Cañizares Ruíz, Ma C. (2011b). Protección y defensa del patrimonio minero en España. Scripta Nova, 15, 348-386. https:// raco.cat/index.php/ScriptaNova/article/view/241319

Cañizares Ruiz, Ma C. (2013). Patrimonio, minería y rutas en el Valle de Alcudia y Sierra Madrona (Ciudad Real). Estudios Geográficos, 74 (275), 409-437. https://doi.org/10.3989/estgeogr.201315

Cañizares Ruiz, M ${ }^{a}$ C. (2020). Visibilidad del patrimonio minero en algunos geoparques españoles. Documents d́ Análisi Geográfica, 66 (1),109-131. https://doi.org/10.5565/rev/dag.556

Echagüe Méndez de Vigo, G. (ed.) (2000). Residuos radiactivos y su percepción pública. Ilustre Colegio de Físicos.

Enresa (1986-2019). Planes de I+D y Planes de $I+d+i$. Documentos.

Espejo Marín, C. (2001). El sector eléctrico español en la prensa escrita. Cuadernos Geográficos de la Universidad de Granada, 31(S), 203-220. https://doi.org/10.30827/cuadgeo.v31i0.1949

Espejo Marín, C. (2002). La producción de electricidad de origen nuclear en España. Boletín de la Asociación de Geógrafos Españoles, 33, 65-77. https://bage.age-geografia.es/ojs/index.php/bage/article/view/415

Espejo Marín, C. (2002). L'energie electronucleaire en I’Espagne. Annales de Geographie, 625, 319-328. https://doi. org/10.3406/geo.2002.2088 
Espejo Marín, C. \& Capel Molina, J.J. (2007). El gas en la producción de electricidad en España. Nimbus. Revista de Climatología, Meteorología y Paisaje, 19-20, 71-98.

Fernández-Arias, P., Cuevas, A. \& Vergara, D. (2021). Controversia nuclear en España: la central nuclear de Lemóniz. Revista Iberoamericana de Ciencia, Tecnología y Sociedad-CTS, 16(46), 199-218

Gonzalvo Salas, C., Zuaznabar Uzkudun, G. \& Ródenas García, J.F. (2018). Centrales Nucleares y Patrimonio: El caso de la central nuclear de Vandellós-I(Tarragona). E-rph: Revista electrónica de Patrimonio Histórico, 23, 1-23. https://doi. org/10.30827/e-rph.v0i23.17862

Herrera Plaza, J. (2019). Silencio y deslealtades: el accidente de Palomares desde la Guerra Fría hasta hoy. Laertes.

López Ontiveros, A. (coord.) (1998). Geografía de Andalucía. Ariel.

Mathieu, B. (2020, 15 de julio). Patrimoine nucléaire: les "papys" entrent en résistance por sauver la "fierté nationale".

Ĺ Express. https://lexpansion.lexpress.fr/actualite-economique/patrimoine-nucleaire-les-papys-entrent-en-resistance-pour-sauver-la-fierte-nationale_2130400.html.

Menéndez Suárez, C. (2016). La minería en la Sierra de Almagrera (Almería) y el ferrocarril minero del barranco Jaroso. De re metallica, 27, 1-19.

Mihm, A. (2019, 11 de mayo). Das ungeliebte Erbe des Atomstroms. Frankfurter Allgemeine. https://www.faz.net/aktuell/ wirtschaft/klima-nachhaltigkeit/wohin-mit-dem-atommuell-das-ungeliebte-erbe-des-atomstroms-16480139.html (Consultado, agosto 2020).

Muñoz Castillo, J.A. (2010). El Cabril. Estudio Geográfico [Memoria de Licenciatura, Universidad de Córdoba].

Muñoz Castillo, J.A. (2012). Antonio Carbonell, mucho más que el creador de El Cabril. Séneca Digital. Córdoba.

Muñoz Castillo, J.A. (2013). El bosque-galería de El Cabril: un paisaje entre lo natural y lo antropizado. Iberian.

Muñoz Castillo, J.A. (2016). Patrimonio Nuclear del Sur de España. Un objeto necesitado de estudio. Argentaria, $14,94-98$.

Muñoz Castillo, J.A. (2017). La Fábrica de Uranio de Andújar: hablan los trabajadores. Argentaria, 17, 58-64.

Muñoz Castillo, J.A. (2020). Patrimonio Nuclear del Sur de España. Un estudio geográfico [Tesis Doctoral, Universidad de Alicante].

Muñoz Castillo, J.A. (2021). Patrimonio Nuclear del Sur de España. Unas conclusiones sobre el caso doble de Andújar: las minas y la Fábrica de Uranio de Andújar "General Hernández Vidal". Argentaria, 24,1-8.

Naredo, J.M. (2017). Extremadura saqueada en perspectivas. Encrucijadas, 17.

Perarnau Perramón, M. (coord.) (1966). Fábrica de Uranio de Andújar General Hernández Vidal. JEN.

Pérez Macías, J.A., Delgado Domínguez, A., Pérez López, J.M. \& García Delgado, F.J. (eds.) (2016). Río Tinto. Historia, patrimonio minero y turismo cultural. Fundación Río Tinto. Publicaciones de la Universidad de Huelva.

Prieto, D. \& García-Dory, F. (2018). Dominación y (neo)extractivismo: 40 años de "Extremadura saqueada". Matadero, col. "Campo adentro".

Púa, C. (2013). Extremadura: Ia Siberia, sus personajes y sus costumbres. Castilblanco, Ed. del Autor.

Reporterre, le quotidien de Í ecologie. Varios números. https://reporterre.net

Romero Silva, J.C. (2019). La minería del distrito Marbella-Ojén (Serranía de Ronda): la razón de la Málaga industrial del primer tercio del siglo XIX De re metallica, 32, 47-60.

Tertsch, H. (2001, 7 de enero). Valdecaballeros, la central del nunca jamás. Diario El País. https://elpais.com/diario/2001/01/07/sociedad/978822004_850215.html

Utrera Cardeñas, P. (2009). El sueño de Franco, la pesadilla de Andújar. Los damnificados de la FUA. Plaza Vieja.

Velarde, G. \& Carpintero, N. (2016). Proyecto Islero: cuando España pudo desarrollar armas nucleares, Córdoba. Guadalmazán (grupo Almuzara).

Wakim, N. (2021, 16 de febrero). Montebourg, Accoyer et Chevènement unis pour la défense du patrimoine nucléaire français. Le Monde. https://www.lemonde.fr/economie/article/2021/02/15/montebourg-accoyer-et-chevenement-unis-pour-la-defense-du-patrimoine-nucleaire-francais_6070042_3234.html 


\title{
Classificação do sistema de trilhas da unidade de conservação Parque Estadual Mata do Pau-Ferro, Areia, Paraíba, Brasil
}

\author{
Trail system classification of the conservation unit Pau-Ferro Forest State Park, \\ Areia, Paraíba, Brazil
}

\section{Clasificación del sistema de senderos de la unidad de conservación del Parque Estatal Forestal de Pau-Ferro, Areia, Paraíba, Brasil}

\author{
Valéria Raquel Porto de Lima \\ valeriaraquelportodelima@servidor.uepb.edu.br @ 0000-0001-7744-3502 \\ Universidade Estadual da Paraíba. Rua Baraúnas, 351 \\ Bairro Universitário - Campina Grande-PB. CEP 58429-500 Brasil \\ Jean Oliveira-Campos \\ jean.oliveira@academico.ufpb.br @ 0000-0002-2874-754X \\ Universidade Federal da Paraíba. Cidade Universitária \\ João Pessoa-PB. CEP 58051-900 Brasil
}

\section{INFO ARTÍCULO}

Recebido: 21-11-2021

Revisado: 13-12-2021

Aceito: 24-12-2021

\section{PALAVRAS-CHAVE:}

Mata Atlântica

Unidade de Conservação

Parque

Sistema de trilhas

\section{KEYWORDS:}

Atlantic Forest

Conservation Unit

Park

Track system

\begin{abstract}
RESUMO
A Unidade de Conservação (UC) Parque Estadual Mata do Pau-Ferro está localizada no município de Areia, estado da Paraíba, Nordeste do Brasil. A UC não possui um sistema de trilhas detalhado. Diante do exposto, o presente artigo elaborou um mapeamento das trilhas mais usadas pelos turistas que frequentam o Parque. Os procedimentos metodológicos consistiram no registro das coordenadas das trilhas usando um Sistema de Posicionamento Global - GPS e capturas fotográficas dos principais atrativos ao longo dos trajetos. Além disso, com o uso do software ArcGIS 10.2, as variáveis ambientais declividade, condições de terreno, cobertura vegetal e drenagem foram somadas para obter as classes de dificuldade das trilhas, usando como referências Silva (2016), Silva, Lima \& Panchaud (2016), e Silva \& Palhares (2020). Como resultado, foram mapeadas 4 trilhas, 2 integrações e 4 pontos principais que funcionam como atrativos turísticos. Em relação às classes de dificuldade das trilhas, $67,41 \%$ do sistema de trilhas foi classificado como "fácil", contexto que evidencia potencial para receber um público diverso de visitantes.
\end{abstract}

\begin{abstract}
The Mata do Pau-Ferro State Park Conservation Unit (UC) is located in the municipality of Areia, state of Paraíba, Northeastern Brazil. UC does not have a detailed trail system. In light of the above, this article drew up a mapping of the most used trails by tourists who frequent the Park. The methodological procedures consisted of recording the coordinates of the trails using a Global Positioning System - GPS and photographic captures of the main attractions along the paths. Also, using ArcGIS 10.2 software, the environmental variables slope, terrain conditions, vegetation cover and drainage were added to obtain the difficulty classes of the trails, using as references Silva (2016), Silva, Lima \& Panchaud (2016) and Silva \& Palhares (2020). As a result, 4 trails, 2 integrations and 4 main points that function as tourist attractions were mapped. Regarding the difficulty classes of the trails, $67.41 \%$ of the trail system was classified as "easy", a context that shows the potential to receive a diverse public of visitors.
\end{abstract}


PALABRAS CLAVE:

Bosque Atlántico

Unidad de Conservación

Parque

Sistema de senderos

\section{RESUMEN}

La Unidad de Conservación (UC) del Parque Estatal Forestal de Pau-Ferro está ubicada en el municipio de Areia, estado de Paraíba, noreste de Brasil. Esta no cuenta con un sistema de senderos detallado. Por lo tanto, asumiendo la ausencia de un mapa de identificación de senderos este trabajo realizó un mapeo de los senderos que son más utilizados por los turistas que frecuentan el Parque. Los procedimientos metodológicos consistieron en registrar las coordenadas de los senderos mediante un Sistema de Posicionamiento Global - GPS y captura fotográfica de los principales atractivos a lo largo de los senderos. Se utilizó el software ArcGIS 10.2 para evaluar las variables ambientales pendiente, condiciones del terreno, cobertura vegetal y drenaje que se agregaron para obtener los niveles de dificultad de los senderos, con base en las referencias de Silva (2016), Silva et al. (2016) y Silva \& Palhares (2020). Como resultado, se mapearon 4 senderos, 2 integraciones y 4 puntos principales que funcionan como atractivos turísticos. En cuanto a las clases de dificultad de los senderos, el $67,41 \%$ del sistema de senderos se clasificó como "fácil", contexto que muestra el potencial para recibir un público diverso de visitantes.

\section{INTRODUÇÃO}

A implantação de unidades de conservação para resguardar a biodiversidade constitui a principal reação do homem frente à degradação dos ecossistemas no Brasil e no mundo (Myers et al., 2000; Primack \& Rodrigues, 2001; Aguiar et al., 2013). O principal instrumento jurídico de criação das Unidades de Conservação no Brasil é a Lei 9.985, de 2000, que instituiu o Sistema Nacional de Unidades de Conservação (SNUC), do qual estabelece parâmetros e categorias de manejo com diferentes graus de proteção, dividindo as áreas em Unidades de Proteção Integral e Unidades de Uso Sustentável.

A categoria Parque encontra-se no grupo das unidades de Proteção Integral, cujo objetivo básico é preservar a natureza, sendo permitido apenas o uso indireto de seus recursos naturais, atividades educacionais, científicas e recreativas. Segundo descrição realizada por Diaz del Olmo e Molina Vázquez (1985), para os parques nacionais da Andalucia, os Parques brasileiros seguem os mesmos princípios.

O contexto de criação de Unidades de Conservação (UCS) no Brasil é permeado por conflitos que materializam o interesse de diversos agentes envolvidos, como representantes do setor público e privado. Desse modo, a gestão de Unidades de Conservação é um desafio, principalmente no tocante ao controle das atividades que se desenvolvem dentro e nas áreas próximas as UCs, e são detentoras de potencial para perturbar os ecossistemas protegidos.

No estado da Paraíba, entre as unidades conservação da Mata Atlântica, o Parque Estadual Mata do Pau-Ferro, no município de Areia, abriga um dos maiores fragmentos, sendo um dos mais representativos da região Nordeste (Tabarelli \& Santos, 2004). Trata-se de um fragmento de Floresta Estacional Semidecidual Montana (Floresta Ombrófila), situado na vertente leste do planalto da Borborema, em condição de refúgio ou brejo de altitude (Veloso et al., 1991; Ab'Saber, 2003; Tabarelli \& Santos, 2004; Bétard et al., 2007; Medeiros \& Cestaro, 2019).

Em função das características ambientais, o Parque Estadual Mata do Pau-Ferro é um importante atrativo turístico da microrregião do Brejo Paraibano, além de fornecer proteção aos ecossistemas remanescentes (Marques et al., 2019; Santos et al., 2020). Embora tenha tamanha importância, a UC ainda não possui um detalhado do sistema de trilhas, conforme é atestado em seu Plano de Manejo, o que desfavorece a divulgação da área, bem como o cumprimento dos objetivos que levaram a sua criação (Santos et al., 2020). Tal aspecto se deve em parte à escassez de recursos para gestão e manutenção das estruturas físicas da área protegida.

O Plano de Manejo da UC não apresenta o mapeamento das trilhas, tampouco a extensão das mesmas, demonstrando que a atividade de visitação ocorre em condições informais, isto é, sem a infraestrutura e orientações necessárias. Essa conjuntura inviabiliza mensurar e estimar os impactos da referida atividade na unidade, posto que não se sabe ao certo onde ocorre.

Por tratar-se de um importante ponto turístico do Brejo Paraibano, a elaboração de tal produto pronunciará, de forma mais assertiva o potencial turístico, e suscitará a realização de pesquisas e práticas 
de educação ambiental, pontos, estes, que se encontram entre os objetivos perseguidos pela categoria Parque. Mediante o exposto, o presente artigo se propõe a mapear as trilhas do Parque Estadual Mata do Pau-Ferro e as classes de dificuldade delas, com vistas a fornecer contribuições no que diz respeito ao levantamento das potencialidades turísticas e divulgação da importância da área para proteção da biodiversidade.

\section{REFERENCIAL TEÓRICO}

A criação de áreas protegidas a partir do século XX, teve como um dos principais objetivos resguardar a biodiversidade, sendo esse um mecanismo para que as sociedades reajam aos cenários de degradação ambiental (Dorst, 1973; Primack \& Rodrigues, 2001; Juras, 2010). O marco moderno do estabelecimento de áreas protegidas, foi a criação do Parque Nacional de Yellowstone, nos Estados Unidos, em março de 1872. A partir do feito, o conceito de proteção da natureza progressivamente espalhou-se por todo o mundo, e, no Brasil, o início da política de áreas protegidas teve início em 1937, com a criação do Parque Nacional de Itatiaia (Brasil, 2007; Godoy \& Leuzinger, 2015).

Na mesma década também foram criadas duas áreas de proteção, a saber, o Parque Nacional do Iguaçu e o Parque Nacional Serra dos Órgãos, ambos no ano de 1939. Assim, tal contexto coloca o Brasil entre os países que mais tardaram no estabelecimento de políticas de áreas protegidas (Morsello, 2001; Medeiros, 2006).

Nas décadas seguintes instrumentos legais possibilitaram a criação de novas tipologias de áreas protegias. Entre eles, a Lei 4.771, de 15 de setembro de 1965, conhecida como Código Florestal, a Lei $n^{\circ}$ 5.197, de 3 de janeiro de 1967, conhecida como Código de Fauna, a Lei no 6.513, de 20 de dezembro de 1977, a Lei $n^{\circ}$ 6.902, de 27 de abril de 1981, o Decreto $n^{\circ}$ 89.336, de 31 de janeiro de 1984, a criação do Instituto Brasileiro de Meio Ambiente e dos Recursos Naturais Renováveis, em 1989 e o Decreto n 98.897, de 30 de janeiro de 1990 (Brasil, 2007; Pureza et al., 2015).

Em vista dos avanços, o país finda a década de 1990 com uma variedade de categorias de áreas protegidas, a exemplo dos parques nacionais, florestas nacionais, estações ecológicas, áreas de proteção ambiental, reservas ecológicas, áreas de relevante interesse ecológico e reservas particulares do patrimônio natural (Morsello, 2001; Drummond et al., 2010).

Apenas no século XXI, o país consegue a criação de um sistema para gestão das áreas protegidas, o Sistema Nacional de Unidades de Conservação da Natureza - SNUC, instituído pela Lei n 9.985, de 18 de julho de 2000, que passa a estabelecer os critérios e as normas para a criação, implantação e gestão de unidades de conservação, estabelecendo um novo panorama acerca das áreas protegidas no país (Brasil, 2007, 2011). Mesmo com o expressivo avanço, se comparado a outros períodos em que não existiam estratégias ou políticas de conservação e preservação da natureza no Brasil, os desafios para manter as UC já criadas nas esferas federal, estadual e municipal são inúmeros, sobretudo na atual conjuntura política vivenciada no Brasil.

Para Castro Júnior, Coutinho e Freitas (2009) a lei é o resultado do trabalho de mais de duas décadas de trabalho, visto que a primeira proposta foi realizada ainda em 1979, e só em 1992 uma versão foi enviada ao Congresso Nacional, onde tramitou por oito anos, suscitando debates. Os debates abrangiam ambientalistas, proprietários de terra, populações tradicionais e setores produtivos com interesse no manejo dos recursos naturais, dessa forma, mesmo antes de sua promulgação, o SNUC gerou variados conflitos entre as partes interessadas.

O SNUC é composto por dois grupos de Unidades de Conservação, Unidades de Proteção Integral e Unidades de Uso Sustentável. O grupo de Proteção Integral tem por objetivo preservar a natureza, mantendo os ecossistemas livres das perturbações antrópicas, admitindo apenas o uso indireto dos recursos naturais, tendo a categoria Parque de domínio nacional, estadual e municipal como a mais representativa (Brasil, 2020). Os parques visam a preservação dos ecossistemas naturais e beleza cênica, permitindo a realização de atividades, como pesquisa científica, educação ambiental, recreação e turismo ecológico (Brasil, 2011). 
Ressalta-se, no entanto, que a realização de pesquisas bem como a visitação pública estão sujeitas a normas e restrições estabelecidas pelo órgão gestor e pelo Plano de Manejo da unidade.

O Plano de Manejo trata-se de um documento de caráter multidisciplinar, que inclui estudos do meio biótico, abiótico e social (Diegues, 2008; Brasil, 2011). Suas características são variáveis, e no conjunto visam orientar as atividades desenvolvidas no território da Unidade de Conservação. Em sua estrutura, o plano também aponta os procedimentos para implantação de estruturas físicas na unidade de conservação, com vistas para a melhoria no quadro de gestão (Ibama, 2002; Souza, Vieira \& Silva, 2015).

Nesse sentido, se mostra um dos principais recursos de orientação para a atividade de turística, especialmente no diz respeito a capacidade das trilhas, estruturas, intervalos de tempo e normas de conduta. A visitação em parques nacionais é essencial para o arrecadamento de recursos financeiros, que, por sua vez, podem ser empregados na gestão dessas áreas. A prática propicia ao turista a oportunidade de conhecer, entender e valorizar a biodiversidade (Canto-Silva \& Silva, 2017; Gomes \& Cunha, 2018). Para tanto, se faz necessário a instalação de uma infraestrutura básica para atender os turistas e conduzi-los durante a passagem pela Unidade de Conservação - contexto em que as trilhas se mostram imprescindíveis, em função das possibilidades oferecidas, como a interpretação ambiental e contato dos visitantes com o ambiente protegido (Robim \& Tabanez, 1993; Rezende \& Cunha, 2014; Costa et al., 2019).

Em face do papel desempenhando pelas trilhas nas Unidades Conservação, se torna fundamental oferecer aos visitantes informações básicas a respeito do leito das trilhas, como orientações de conduta, sinalização, mapas de trajetos, pontos de referência, distâncias e medidas a serem adotadas, em casos de acidentes e graus de dificuldade, considerando as características ambientais e o esforço físico a ser dispensado na realização (Silva et al., 2016; Silva \& Palhares, 2020).

Sendo um dos principais atrativos das áreas protegidas, e também responsável pelo deslocamento entre pontos da paisagem, as trilhas necessitam de um preciso monitoramento ambiental, haja vista que provocam alterações no sistema ambiental (Figueiró \& Coelho Netto, 2009; Boquimpani-Freitas et al., 2020). Além do que, a falta de planejamento pode levar as trilhas a receberem números de visitantes que ultrapassam o recomendando para as características ambientais apresentadas, ocasionando pressões superiores à capacidade de suporte, causando consequências danosas à biodiversidade (Primack \& Rodrigues, 2001; Rangel et al., 2013).

Nesse contexto, Sistemas de Informações Geográficas - SIGs, ao permitirem a integração de dados ambientais e a representação espacial de fenômenos, podem ser utilizados para fins de gestão, especialmente visando o mapeamento das trilhas, seus atrativos, e obstáculos (Decanini, 2001; Silva et al., 2016). O mapeamento, por sua vez, possibilita o planejamento da capacidade de suporte das trilhas e antecipação de possíveis impactos causados pela visitação, considerando a distribuição das trilhas e dos ecossistemas da área protegida.

O uso de SIGs torna-se oportuno em um contexto onde as Unidades de Conservação apresentam escassez de pessoal para atividades de campo (Drummond et al., 2010; Godoy \& Leuzinger, 2015), pois, apesar da relevância das unidades de conservação para o país, são enfrentadas inúmeras dificuldades. Dentre elas, encontram-se a escassez de recursos financeiros e falta de pessoal qualificado para manejo, fiscalização e gerenciamento (Brasil, 2007; Simões, 2008).

Parte das dificuldades que assolam a gestão das áreas protegidas no país, é resultado da falta reconhecimento da importância das mesmas para a manutenção da biodiversidade. Frente a isso, faz-se necessária uma maior atuação do Poder Público na resolução dos conflitos que se instalam, bem como na conscientização da população acerca da importância dessas áreas para conservação da biodiversidade, oferta de serviços ecossistêmicos, e também para o desenvolvimento social, econômico e cultural, alicerçado nas bases da sustentabilidade (Ganem \& Drummond, 2010; Medeiros et al., 2011). 


\section{METODOLOGIA}

O município de Areia está localizado no estado da Paraíba, assentado na borda úmida do Planalto da Borborema em condição de Brejo de Altitude, área de exceção que apresentam maior umidade em relação ao espaço onde está inserida - característica que favorece a manutenção da formação florestal da Mata Atlântica, sendo, portanto, considerado como uma área de refúgio florestal (Andrade \& Lins, 1964; Ab'Sáber, 2003; Medeiros \& Cestaro, 2019) em meio a uma condição de semiaridez, caracterizada pela vegetação de Caatinga, uma formação florestal tropical seca (Pennington et al., 2004), que ocupa 9\% do território brasileiro.

O Parque Estadual Mata do Pau-Ferro está localizado na zona rural do município, apresentando uma área de 607,96 hectares, onde abriga um fragmento florestal, o qual constitui um dos mais extensos remanescentes de Mata Atlântica do estado (Tabarelli \& Santos, 2004) (mapa 1). A área protegida foi criada em 19 de outubro de 1992, como Reserva Ecológica e recategorizada para a categoria parque de domínio estadual, através do Decreto Estadual n 26.098, de 04 de agosto de 2005, passando a constituir o Parque Estadual Mata do Pau-Ferro (Decreto $n^{\circ} 26.098$, de 04 de agosto de 2005, 2005).

O território municipal está inserido nos domínios da bacia hidrográfica do rio Mamanguape, apresentando rios intermitentes, com padrão de drenagem dendrítico (Campos \& Lima, 2020). O relevo é predominantemente forte ondulado, com solos profundos e mediamente férteis, estando a sede municipal situada a aproximadamente 620 metros de altitude (Beltrão et al., 2005), enquanto a vegetação é composta predominantemente por fisionomias da Mata Atlântica, ocorrendo também porções de Caatinga nas extremidades a noroeste do município. Segundo a classificação climática de Köppen, o clima municipal é do tipo As, quente e úmido com chuvas de outono e inverno (Paraíba, 1985).

Os levantamentos florísticos mostram que a Unidade de Conservação comporta pelo menos quatro espécies vulneráveis ou ameaçadas de extinção, pau-d'arco-roxo (Handroanthus impetiginosus (Mart. ex DC.) Mattos), sucupira (Bowdichia virgilioides Kunth), cedro (Cedrela fissilis Vell.) e pau-ferro (Erythroxylum pauferrense Plowman), sendo esta última endêmica do Brejo de Altitude onde se encontra o Parque (SFB, 2019; H. A. Santos et al., 2020). Esse arranjo evidencia a necessidade de esforços para proteção dos ecossistemas do Parque e de suas áreas vizinhas.

Observado o exposto, para o desenvolvimento do trabalho na Unidade de Conservação foram utilizados os seguintes materiais: imagem de radar com Modelo Digital de Terreno - MDE com resolução de 12,5 m ALOS/PALSAR; imagem do satélite Sentinel-2, sensor MSI, datada de novembro de 2019 (período com menor cobertura de nuvens na área de estudo) adquirida gratuitamente na plataforma Sentinel Hub; base cartográfica do Brasil, Nordeste, Paraíba e do município de Areia no formato shapefile; polígono no formato shapefile da Unidade de Conservação disponibilizado pela SUDEMA; aparelho de GPS portátil modelo Etrex Garmin Vista; aplicativo Android GPS Essentials versão 4.4.27; câmera fotográfica; e softwares ArcGIS versão $10.2^{\circledR}$ e Excel.

Os trabalhos de campos ocorreram nos dias 10, 11 e 29 de agosto de 2019 e 10 março de 2020. Com o auxílio de um guia turístico local, foram percorridas todas as trilhas e realizado registro fotográfico dos principais atrativos ao longo dos trajetos. Todas as trilhas, assim como todos os atrativos foram gravados no GPS portátil e também no GPS Essentials de forma automática. A visita de março foi realizada no intuito de verificar atualizações sofridas pelas trilhas.

Os dados do GPS foram manipulados no software ArcGIS para elaboração do mapa de trilhas, enquanto as trilhas do aplicativo foram utilizadas para validação das mesmas. Posteriormente, os percursos das trilhas foram sobrepostos com mapas de altitude e declividade gerados a partir do MDE, e, posteriormente, feita a extração das informações que foram utilizadas para elaboração de gráficos.

Para mapear as classes de dificuldades apresentadas pelas trilhas, foi utilizada a metodologia adaptada por Silva (2016), Silva, Lima e Panchaud (2016), e Silva e Palhares (2020), que está baseada na atribuição de notas, sobreposição e somatório das variáveis ambientais declividade, cobertura vegetal, condições de terreno e drenagem da água, com uso de geoprocessamento, de modo a verificar os graus de dificuldade das trilhas. 
Para tanto, com uso do ArcGIS, as variáveis declividade, cobertura vegetal, condições de terreno e drenagem da água foram divididas em classes, posteriormente receberam notas de 1 a 4 e foram reclassificadas em muito fácil, fácil, moderada e difícil - conforme as dificuldades que oferecem para realização das trilhas (tabela 1). A declividade e drenagem foram obtidas a partir do processamento do MDE no software ArcGIS, esta última foi gerada a partir das curvas de nível do terreno. As áreas mais baixas do terreno onde se encontram os cursos de água receberam a maior nota, dado que o escoamento é lento e pode afetar a realização das trilhas, enquanto as áreas mais altas do modelado local, onde a drenagem se apresenta rápida e livre, receberam a menor nota.

As informações da cobertura vegetal foram obtidas a partir da classificação supervisionada de uma imagem de satélite do Sentinel - 2, no software ArcGIS, com uso do classificador Maximum Likelihood, onde foram encontradas as seguintes classes: vegetação alta, vegetação média e vegetação baixa. As condições do terreno, por sua vez, foram obtidas a partir da cobertura vegetal, tendo em vista que os obstáculos encontrados na superfície das trilhas referem-se, na área de estudo, às árvores caídas, sendo estas mais frequentes nas áreas de vegetação alta.

Todas as variáveis ambientais foram geradas no formato raster, e após a atribuição das notas, foi realizado o somatório das mesmas com o uso do ArcGIS. Posteriormente, o produto obtido do somatório foi reclassificado com base nas notas finais e convertido para o formato shapefile (tabela 2).

Por fim, o arquivo shapefile, com as classes de dificuldade, foi utilizado para recortar as trilhas mapeadas, permitindo verificar as classes de dificuldade encontradas nas mesmas e os percentuais de distância que ocupam no sistema de trilhas da área protegida.

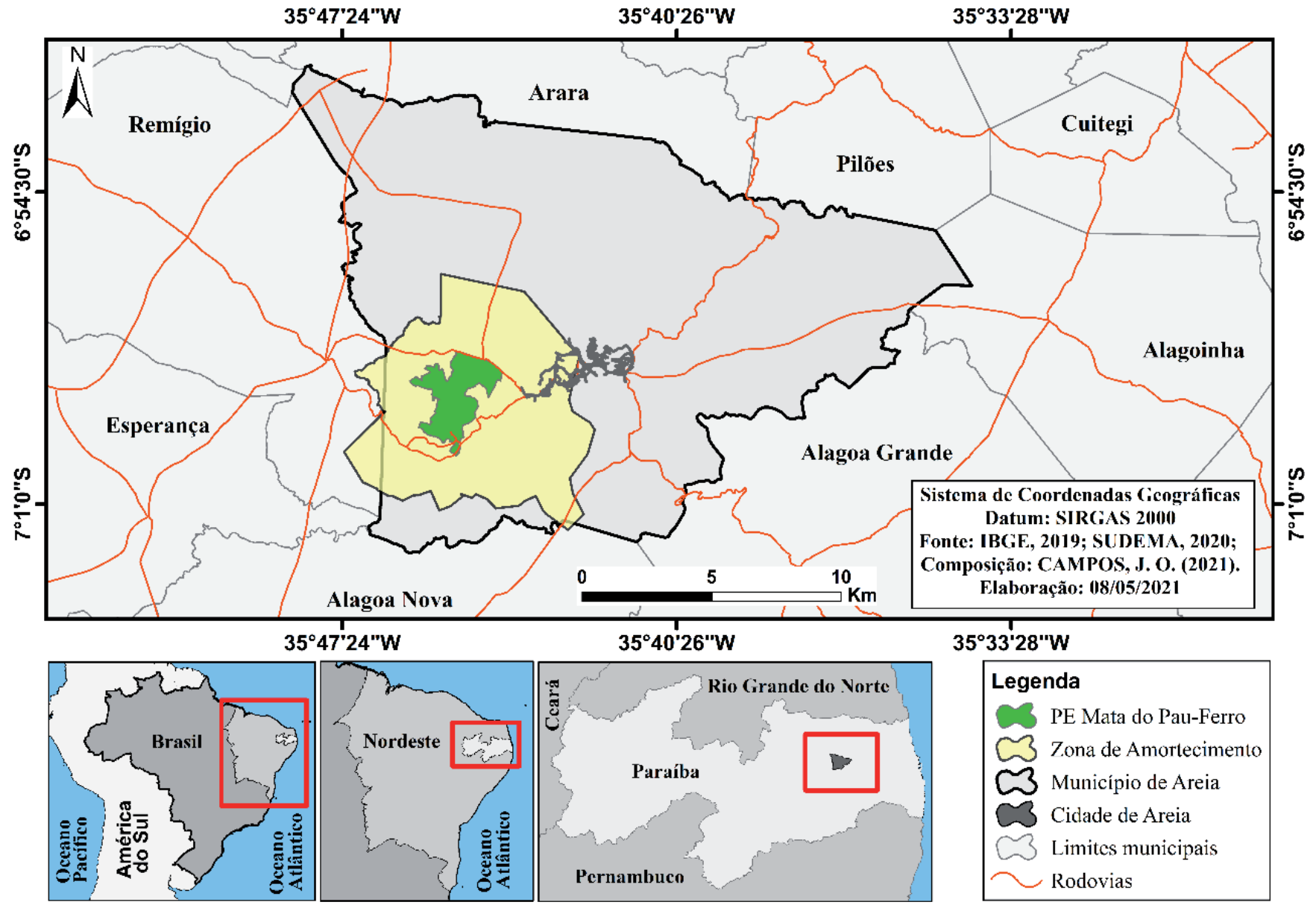

Mapa 1. Localização do Parque Estadual Mata do Pau-Ferro no município de Areia - PB.

Fonte: Elaboração própria. 
Tabela 1. Variáveis ambientais, notas e reclassificações atribuídas

\begin{tabular}{|c|c|}
\hline VARIÁVEIS AMBIENTAIS & NOTAS E RECLASSIFICAÇÕES \\
\hline Declividade & $\begin{array}{l}\text { A inclinação do terreno foi dividida nos seguintes intervalos: relevo suave }(0-10 \%) \text {, relevo } \\
\text { ondulado (10-20\%), relevo forte-ondulado ( } 20-30 \%) \text { e relevo montanhoso (>30\%). Os } \\
\text { intervalos, por sua vez, receberam as seguintes notas e reclassificações: } 2 \text { - fácil, } 3 \text { - } \\
\text { moderado, } 4 \text { - difícil e, } 5 \text { - muito difícil. }\end{array}$ \\
\hline $\begin{array}{l}\text { Condições } \\
\text { do terreno }\end{array}$ & $\begin{array}{l}\text { As condições do terreno referem-se aos obstáculos encontrados. Em função disso, adotou- } \\
\text { se as condições: superfície lisa, superfície com poucos obstáculos, superfície com muitos } \\
\text { obstáculos e superfície muito irregular/trechos de ascensão. As mesmas receberam as } \\
\text { seguintes notas e reclassificações: } 2 \text { - fácil, } 3 \text { - moderado, } 4 \text { - difícil e, } 5 \text { - muito difícil. }\end{array}$ \\
\hline $\begin{array}{l}\text { Cobertura } \\
\text { vegetal }\end{array}$ & $\begin{array}{l}\text { Neste critério adotou-se classes generalizadas de cobertura vegetal, expressas em } \\
\text { vegetação alta, vegetação média, vegetação baixa e trecho sem vegetação. As classes } \\
\text { receberam as seguintes notas e reclassificações: } 1 \text { - muito fácil, } 2 \text { - fácil, } 3 \text { - moderado e, } \\
4 \text { - difícil. }\end{array}$ \\
\hline Drenagem & $\begin{array}{l}\text { A drenagem está relacionada à presença de água nas trilhas, por isso foram adotadas as } \\
\text { classificações: drenagem natural rápida e drenagem natural lenta ou impedida, as mesmas } \\
\text { receberam as seguintes notas e reclassificações: } 2 \text { - fácil e } 3 \text { - moderado. }\end{array}$ \\
\hline
\end{tabular}

Fonte: Adaptado de Silva (2016) e Silva et al. (2016).

Tabela 2. Intervalos utilizados para classificação dos graus de dificuldade

\begin{tabular}{|c|l|}
\hline INTERVALOS & \multicolumn{1}{|c|}{ CLASSES DE DIFICULDADE } \\
\hline Entre 7 e 9 & Muito fácil \\
\hline$>9$ a 11 & Fácil \\
\hline$>11$ a 13 & Moderada \\
\hline$>13$ a 15 & Difícil \\
\hline$>15$ a 17 & Muito difícil \\
\hline
\end{tabular}

Fonte: Adaptado de Silva (2016) e Silva et al. (2016).

\section{RESULTADOS E DISCUSSÕES}

A estrutura verificada ao longo do trabalho realizado na Unidade de Conservação, indica a existência de diversos conflitos: a falta de fiscalização, isto é, o não reconhecimento dos limites da área por parte de moradores locais, abertura de trilhas não planejadas, e a manutenção da agropecuária em pontos específicos da área protegida. Esses conflitos, por sua vez, podem enfraquecer a visitação, tendo em vista a dificuldade de controle dos órgãos gestores sobre quem acessa os espaços protegidos (Figueiró \& Coelho Netto, 2009; Costa et al., 2019; Pereira et al., 2019; Silva \& Palhares, 2020). A supressão dos conflitos, por outro lado, pode evidenciar as particularidades ambientais e favorecer a visitação.

No total foram mapeadas 4 trilhas, 2 integrações que conectam as trilhas e 4 pontos principais da paisagem que funcionam como atrativo turístico (mapa 2). As trilhas mapeadas foram Trilha Inicial, Trilha do Cumbe, Trilha das Flores e Trilha da Barragem, enquanto as integrações mapeadas recebem o nome de Integração 1 e Integração 2. Os pontos atrativos, portanto, são Munguba, Cachoeira, Barragem e Casarão. A nomenclatura das trilhas e dos atrativos foram atribuídos pelas comunidades tradicionais que estão assentadas no entorno da UC. 
Durante a visitação, os turistas selecionam as trilhas através da quilometragem ou de um atrativo, como a Barragem. Em função disso, as integrações, possibilitam percursos alternativos no intuito de aumentar as distâncias. Como aqui são apresentadas apenas as extensões das trilhas, para mensurar a extensão total percorrida pelo visitante é necessário realizar a soma das distâncias percorridas, considerando o ponto de início, a trilha selecionada e o percurso de volta.

A maior parte dos visitantes enquadra-se como estudantes da Educação Básica, professores, turistas experientes, moradores locais, pesquisadores e moradores locais (Pereira et al., 2019; Campos \& Lima, 2020; Santos et al., 2020). E conforme o Plano de Manejo, os grupos de visitantes não devem ultrapassar 50 pessoas e devem estar acompanhados por guias autorizados, além disso é necessário um intervalo de 30 minutos entre cada um deles (Santos et al., 2020).

Ao longo das trilhas, na maior parte do tempo o campo de visão dos visitantes é limitado pelos caules e copas das árvores, sendo comum o avistamento de aves e mamíferos. O solo, por sua vez, aparece sem cobertura vegetal na maior parte do trajeto, sendo também verificados trechos com cobertura orgânica, como plântulas, folhas, galhos, frutos e dejetos de animais que habitam a área. Ocorrem também trechos a céu aberto, onde o campo de visão é ampliado, esses, no entanto, estão situados nas clareiras localizadas na porção central do Parque, bem como na porção sul, onde a vegetação possui menor porte. No período chuvoso da região, que ocorre entre fevereiro e julho, a execução das trilhas torna-se dificultosa em função da presença de água nas trilhas e da superfície do solo que se torna escorregadia, aumentando o risco de acidentes.

A Trilha Inicial é o percurso que possui menor extensão, funciona como o início de todas as trilhas, uma vez que é compartilhada, com início no Centro de Turismo Jonas Camelo de Souza, que está localizado na entrada do Parque (mapa 2 e figura 1). No centro é possível realizar agendamentos para a realização de trilhas guiadas, bem como conhecer sobre a duração das mesmas e os atrativos turísticos encontrados no percurso. Os guias locais residem na própria comunidade e recebem formação para a condução de visitantes na Unidade de Conservação.

A Trilha do Cumbe é a segunda menor trilha, apresentando extensão de 0,168 km, ao mesmo tempo, em que possui a menor variação de declividade e altitude (figura 2). Geralmente é escolhida por visitantes que procuram caminhadas rápidas e públicos de excursões escolares, além de tratar-se de uma das primeiras trilhas abertas e controladas da Unidade de Conservação, sendo a única que apresenta uma placa com indicação do nome e orientações aos visitantes. A chegada na trilha se dá através da Integração 1 ou do percurso inicial da Trilha das Flores, conforme o mapa 2.

Na margem desta trilha recebe destaque a munguba (figura 3), indivíduo de Eriotheca macrophylla (K.Schum.) A.Robyns, espécie vegetal nativa da Mata Atlântica (Santos et al., 2020), considerado um dos pontos de parada da trilhada, principalmente para registro fotográfico, em vista que indivíduos desse porte são escassos em decorrência do desmatamento nas áreas adjacentes da unidade.

Assim, a trilha das Flores, inicialmente, é direcionada para o leste e posteriormente projeta-se para o sul após decorridos mil metros, onde se conecta com a Trilha da Barragem. A altitude da trilha varia entre 520 e 640 metros, ao passo que a declividade se distribui entre 0 e 50\%, o que demonstra a existência de declives significativos no percurso de 2,452 km (figura 4). Essa trilha encontra-se situada em uma das áreas onde a vegetação se apresenta de forma mais densa na Unidade de Conservação, por isso é escolhida por pesquisadores para a realização de estudos sobre a biodiversidade (Santos et al., 2020).

Por fim, a Trilha da Barragem é maior entre as trilhas da Unidade de Conservação, possui 4,580 km de extensão, tendo início na parte norte e encerrando na porção sul do Parque (mapa 2). Ao mesmo tempo, pode ser iniciada ao sul e finalizada ao norte no Centro de Turismo. Esta, apresenta a maior variação de altitude dentre as trilhas (480 a $620 \mathrm{~m}$ ), porém menor variação na declividade, quando comparada a Trilha das Flores (figura 5). A declividade é um fator importante na sustentabilidade das trilhas, estando diretamente associada com a vulnerabilidade a erosão. Portanto, os percursos podem ser avaliadas do ponto de vista da declividade, com vistas a priorizar trilhas onde se verificam os menores percentuais para grupos maiores de visitantes (Marion \& Wimpey, 2017). 


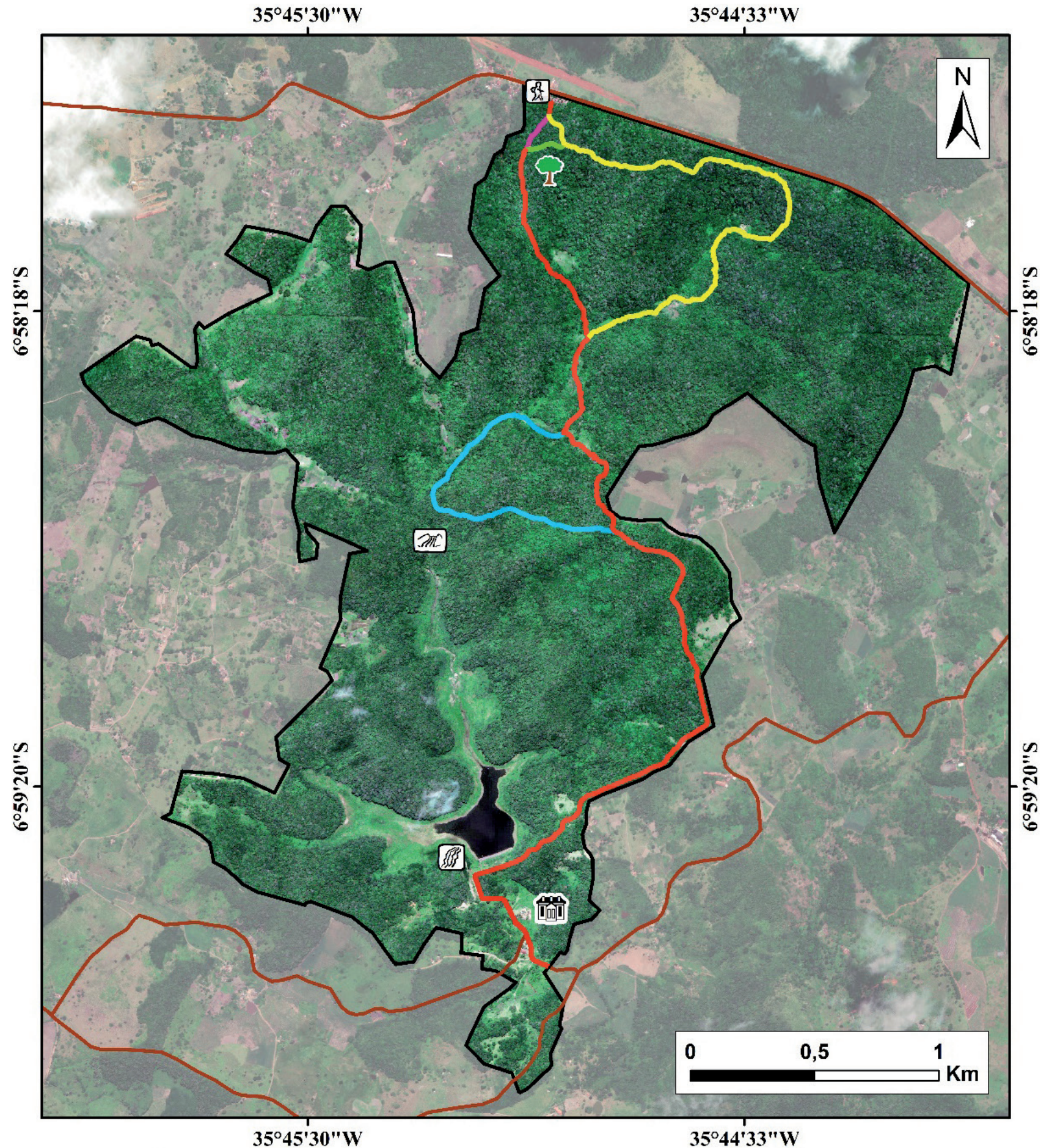

\begin{tabular}{|l|c|}
\hline \multicolumn{1}{|c|}{ Trilha } & Comprimento $(\mathbf{k m})$ \\
\hline Trilha Inicial & $\mathbf{0 , 0 5 2}$ \\
\hline Trilha do Cumbe & $\mathbf{0 , 1 6 8}$ \\
\hline Integração 1 & $\mathbf{0 , 1 7 2}$ \\
\hline Integração 2 (Bifurcação) & 1,544 \\
\hline Trilha das Flores & $\mathbf{2 , 4 5 2}$ \\
\hline Trilha da Barragem & $\mathbf{4 , 5 8 0}$ \\
\hline
\end{tabular}

\begin{tabular}{|c|c|}
\hline 87 & Centro de Turismo \\
\hline & Munguba \\
\hline $\mathrm{OMC}$ & Cachoeira \\
\hline 埩 & Barragem \\
\hline 可䅇 & Casarão \\
\hline
\end{tabular}

\begin{tabular}{|} 
Início das Trilhas \\
Integração 1 \\
Trilha do Cumbe \\
Integração 2 (Bifurcação) \\
Trilhas das Flores \\
Trilha da Barragem \\
Rodovias \\
PE Mata do Pau-Ferro
\end{tabular}

Mapa 2. Trilhas do Parque Estadual Mata do Pau-Ferro. Fonte: Elaboração própria. 


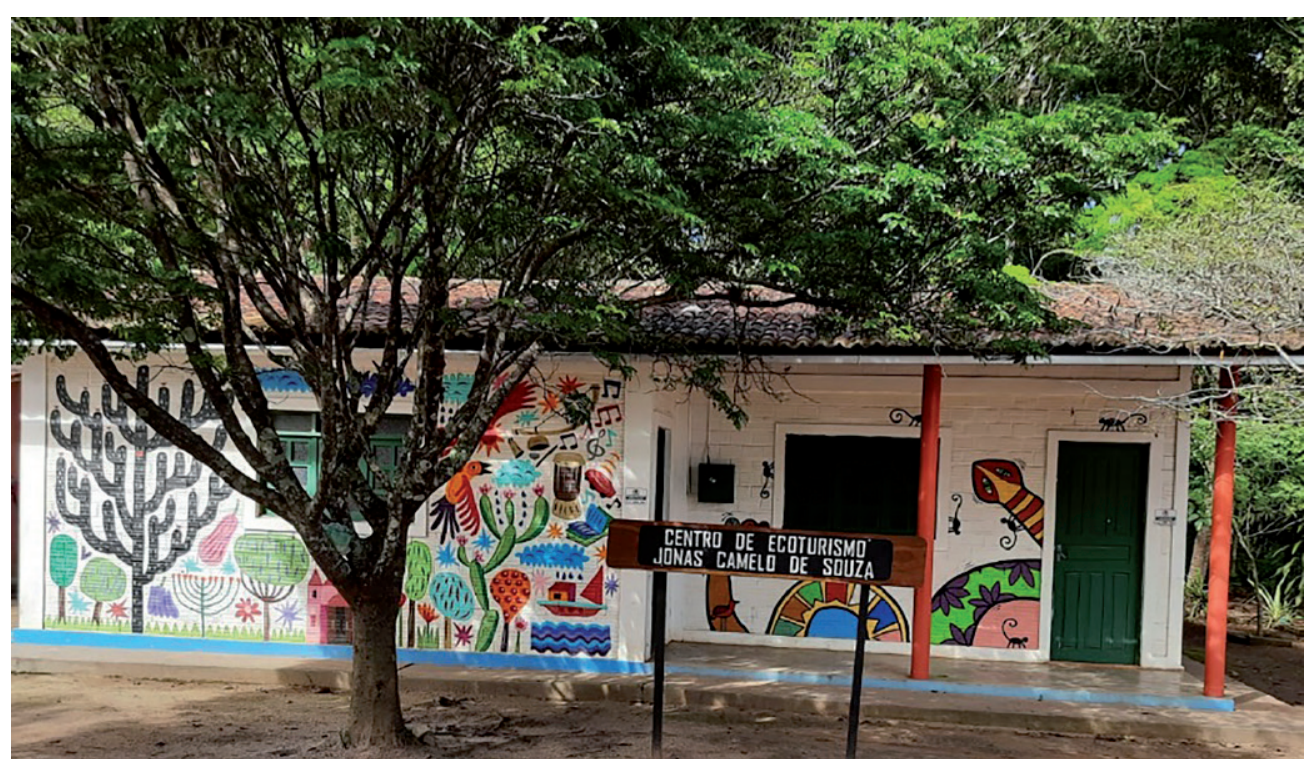

Figura 1. Centro de Turismo Jonas Camelo de Souza. Fonte: Elaboração própria.

(A) Hipsometria - Trilha do Cumbe

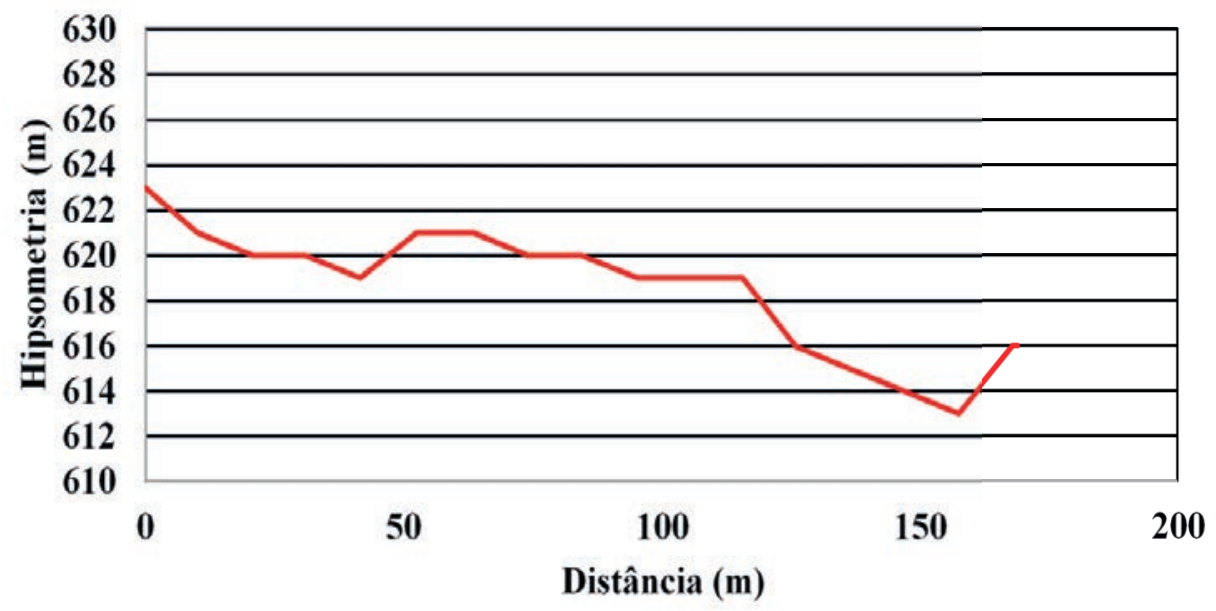

(B) Declividade - Trilha do Cumbe

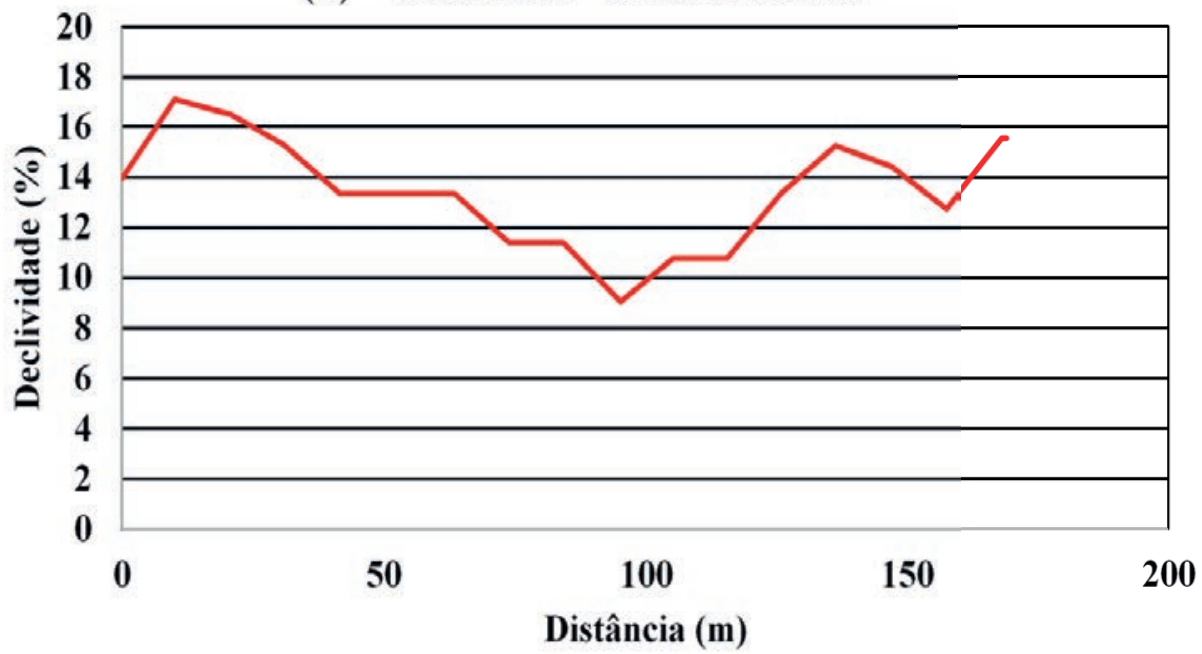

Figura 2. Hipsometria e declividade da Trilha do Cumbe. Fonte: Elaboração própria. 


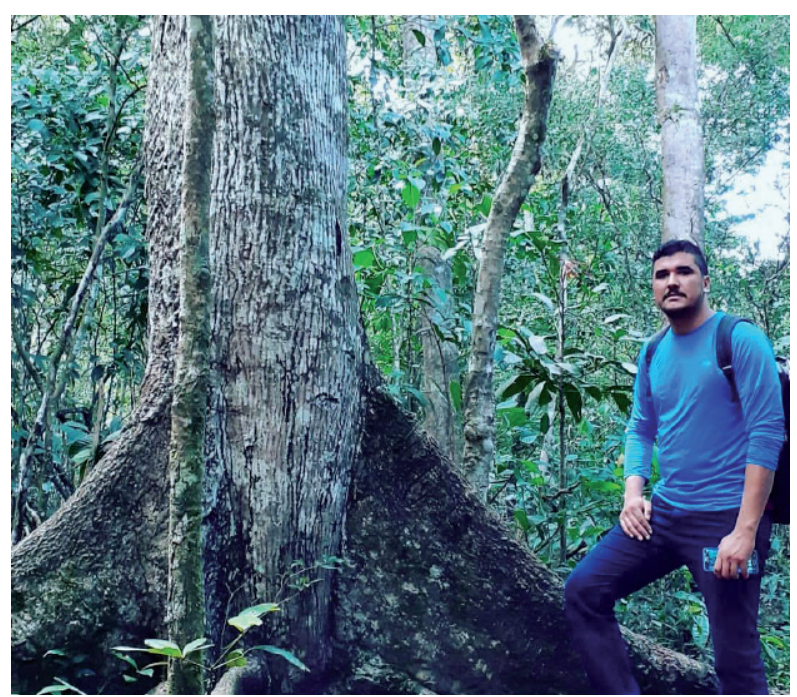

Figura 3. Munguba na margem da Trilha do Cumbe. Fonte: Elaboração própria.

(A) Hipsometria - Trilha das Flores

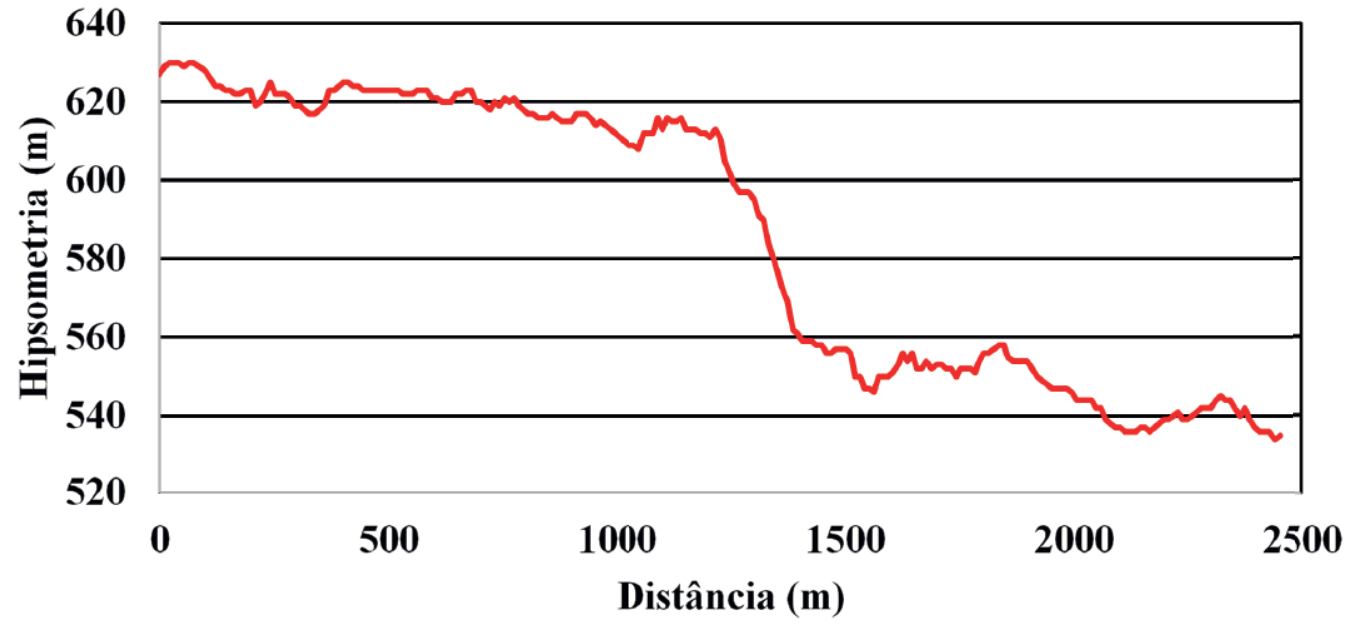

(B) Declividade - Trilha das Flores

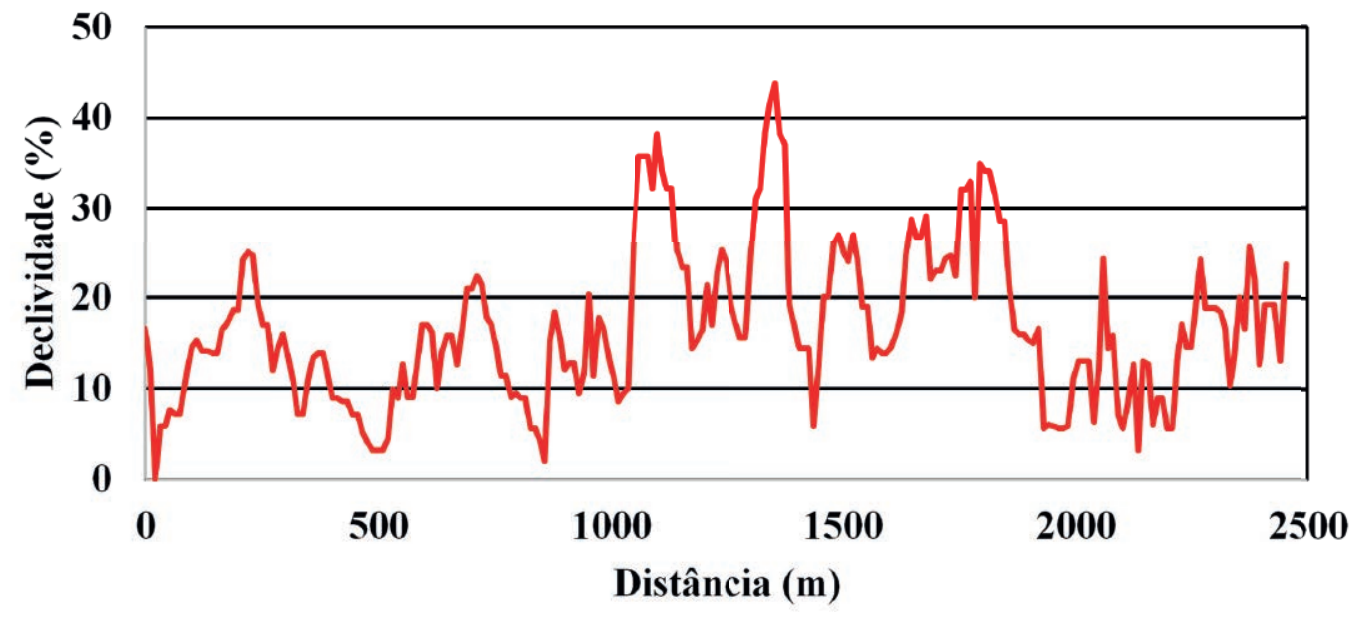

Figura 4. Hipsometria e declividade da Trilha das Flores. Fonte: Elaboração própria. 
$\mathrm{Na}$ Trilha da Barragem são encontrados os pontos Barragem e Casarão - o primeiro trata-se do reservatório hídrico Vaca Brava, que abastece Areia e municípios circunvizinhos e dá nome a trilha (figura 6A), enquanto o segundo é uma construção oriundas dos engenhos que estavam instalados na localidade antes da implantação da área protegida (figura 6B e 6C).

\section{(A) Hipsomteria - Trilha da Barragem}

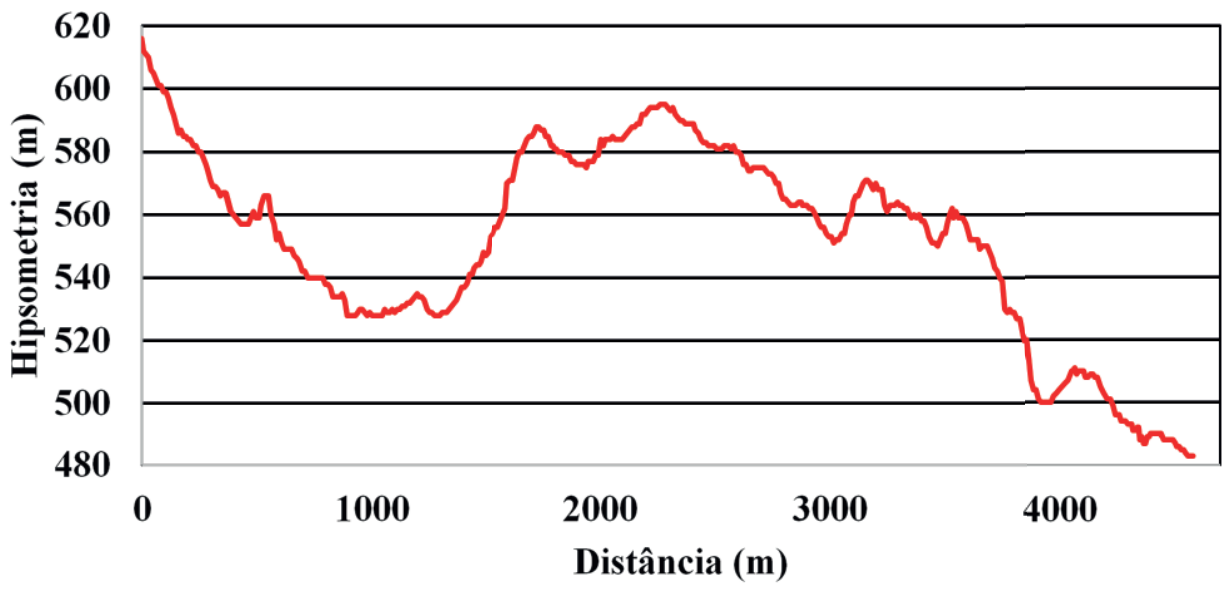

(B) Declividade - Trilha da Barragem

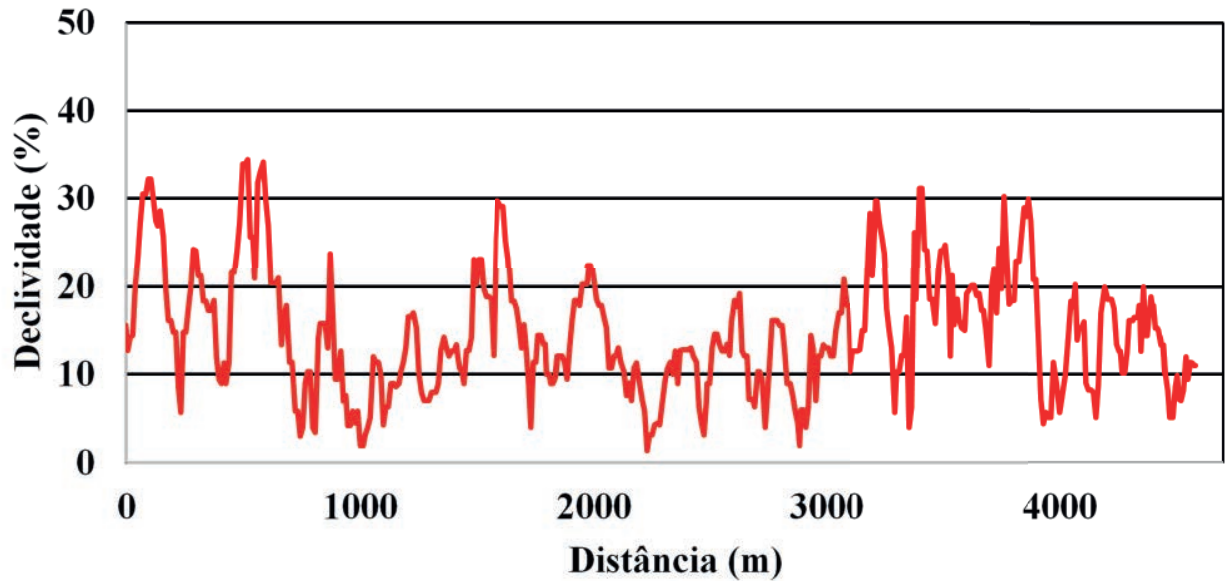

Figura 5. Hipsometria e declividade da Trilha da Barragem. Fonte: Elaboração própria.

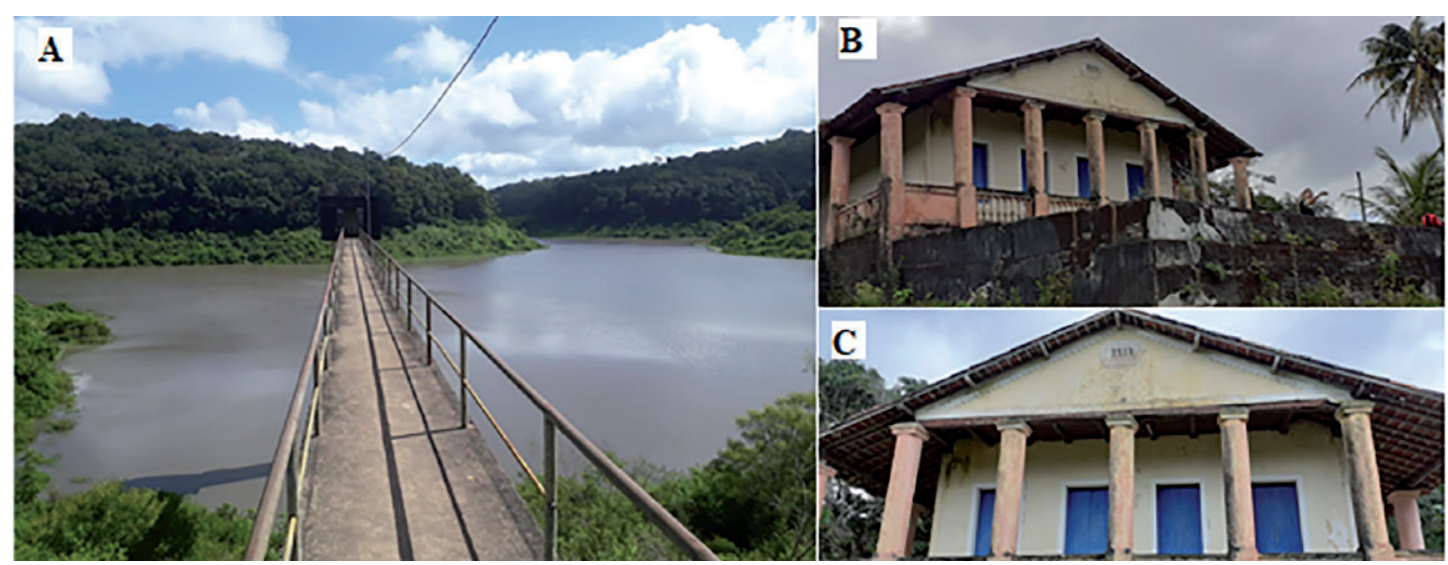

Figura 6. Atrativos turísticos encontrados na Trilha da Barragem: A - Barragem Vaca Brava; B e C - Casão. Fonte: Elaboração própria. 
Em relação às integrações, a Integração 1 situa-se na porção norte do Parque, próximo à Trilha Inicial, e possibilita a conexão entre as demais trilhas mapeadas. Assim como o trecho inicial da Trilha das Flores, é utilizada como parte da Trilha do Cumbe, o que permite estender o comprimento da trilha. Essa integração possui a menor extensão, à medida que a Integração 2, localizada na parte central do Parque, detém maior extensão.

A Integração 2, apesar de ser um percurso alternativo que permite estender a Trilha da Barragem, constitui o terceiro trajeto mais extenso do Parque. A porção onde está situada é pouco explorada do ponto de vista turístico, além disso, ao longo da sua extensão tem seu campo de visão limitado pelas árvores. Essa integração dá acesso ao atrativo da Cachoeira (figura 7), que se refere a uma queda d'água que se forma no rio Vaca Brava, situado na porção central do Parque, durante o período chuvoso, voltando a secar após esse período.

Mesmo sendo uma área protegida, o espaço da cachoeira é frequentemente acessado por moradores locais e visitantes sem guias para atividades de lazer, fato do qual se confirma pela presença de embalagens e resíduos orgânicos e inorgânicos encontrados. A presença de resíduos também foi constatada nas trilhas do Parque por Silva et al. (2006) e Pereira et al. (2019), o que demonstra ser uma ocorrência comum na unidade.

Em relação às classes de dificuldade apresentadas pelas trilhas, as mesmas foram obtidas por meio da sobreposição das variáveis ambientais no software ArcGIS. O mapa 03 mostra a espacialização das classes de dificuldade apresentadas por cada variável ambiental em acordo com as notas que lhe foram atribuídas. No mapa é possível verificar o produto final obtido a partir do somatório das variáveis, que, por sua vez, também se encontra reclassificado com as classes de dificuldade finais.

Com base no mapa 3, verifica-se que a declividade possui a maior variação das classes de dificuldade, uma vez que nela encontra-se representadas quatro das cinco classes adotadas. Por outro lado, as condições do terreno e a drenagem apresentam a menor variação de classes, apenas duas. Em seguida, a cobertura expõe três classes, com predominância de "muito fácil". A classe de dificuldade "moderado" se expressou em todas as variáveis ambientais, ao passo que a classe "muito difícil" está manifestada apenas na declividade.

Em razão de se manifestar apenas em uma das variáveis, a classe não é verificada no resultado do somatório, pois sua manifestação depende da soma de notas altas. Situação semelhante é atestada para a classe "muito fácil", a qual se encontra expressa somente na cobertura vegetal. No entanto, como depende das menores notas, a mesma está representada no produto final. O produto do somatório após convertido para o formato shapefile possibilitou recortar as trilhas em diferentes classes de dificuldade, conforme o mapa 4.

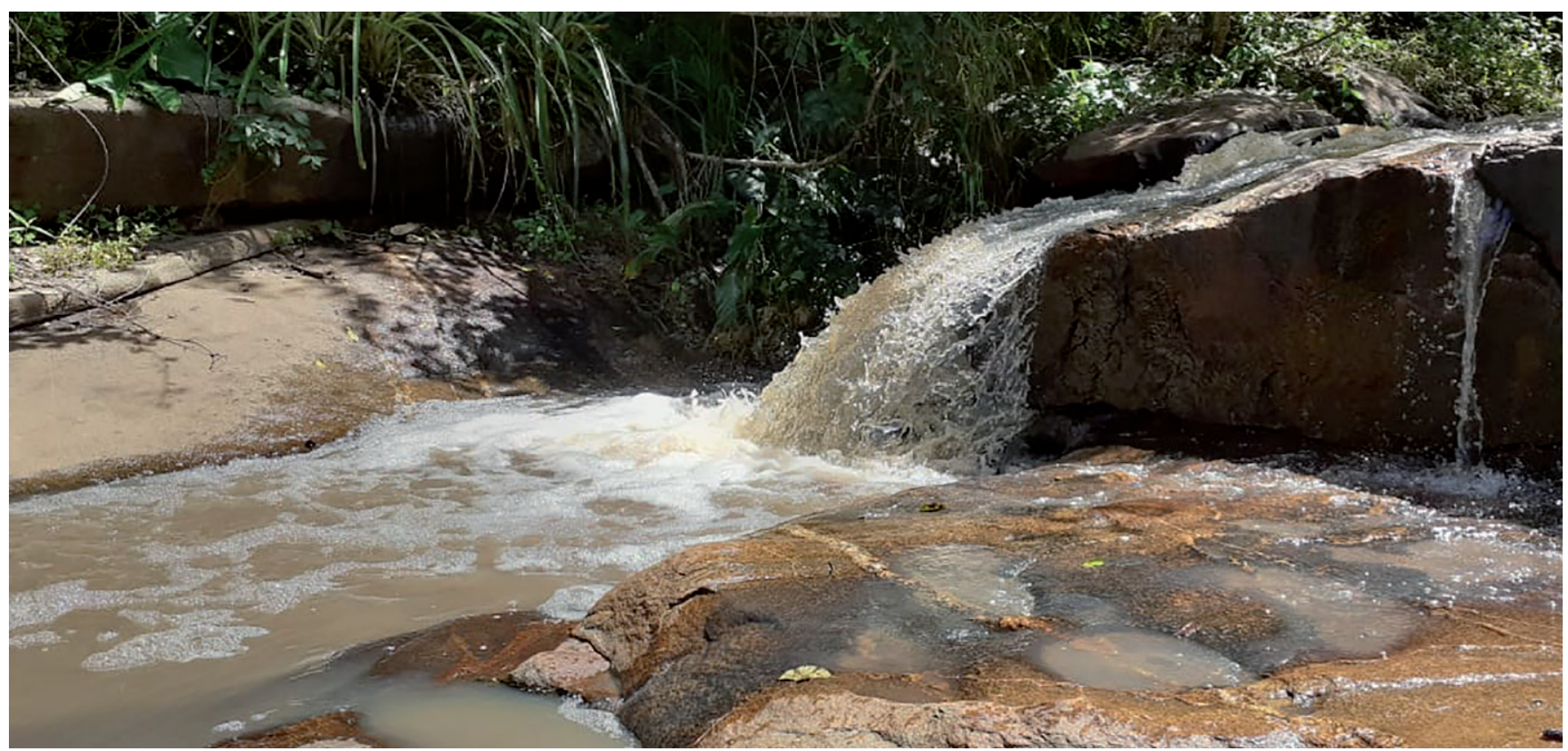

Figura 7. Cachoeira encontrada próximo da Integração 2 no período chuvoso. Fonte: Elaboração própria. 

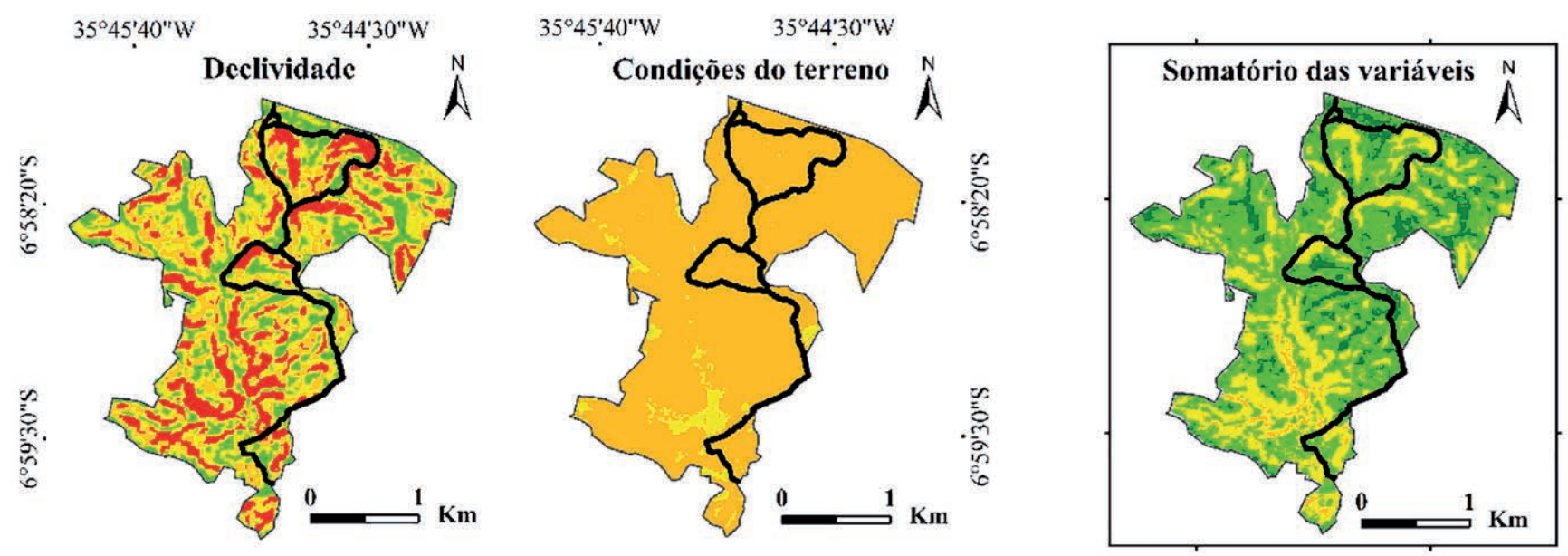

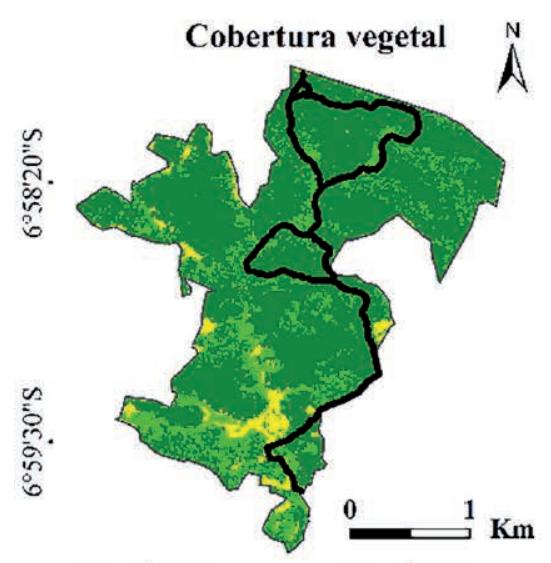

$35^{\circ} 45^{\circ} 40^{\prime \prime} \mathrm{W}$

$35^{\circ} 44^{\prime} 30^{\prime \prime} \mathrm{W}$

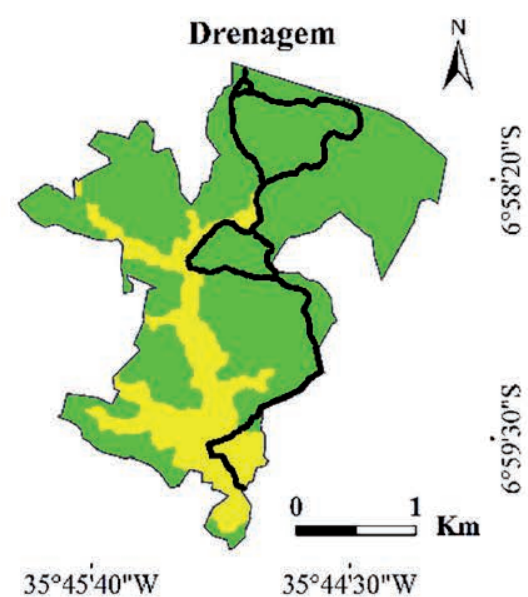

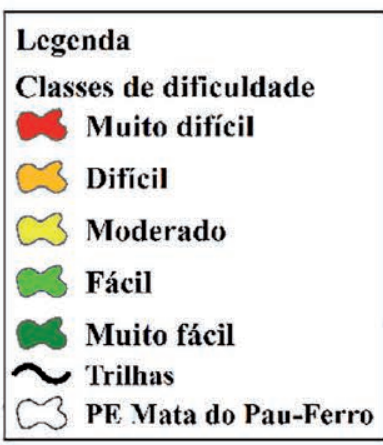

Sistema de Coordenadas Geográficas Datum: SIRGAS 2000

Fonte: SUDEMA (2020)

Composiẹāo: CAMPOS, J. O. (2021).

Mapa 3. Variáveis ambientais utilizadas na geração das classes de dificuldade das trilhas. Fonte: Elaboração própria.

A distância ocupada por cada classe de dificuldade nas trilhas, bem como o percentual de cada classe no sistema de trilhas é apresentado na tabela 3. A Trilha Inicial apresentada as classes "muito fácil" e "fácil", e ambas distam 0,003 e 0,049 km, respectivamente. As mesmas classes são observadas para a Trilha do Cumbe e a Integração 1, na primeira possuem distância de 0,056 e 0,112 km, enquanto na segunda possuem 0,047 e 0,098 km. Nos três percursos mencionados, ocorreu a predominância da classe "fácil".

Tabela 3. Distâncias ocupadas por cada classe de dificuldade nas trilhas do Parque.

\begin{tabular}{|l|c|c|c|c|c|c|c|c|}
\hline $\begin{array}{c}\text { Classes de } \\
\text { dificuldade }\end{array}$ & $\begin{array}{c}\text { Trilha } \\
\text { Inicial }\end{array}$ & $\begin{array}{c}\text { Trilha do } \\
\text { Cumbe }\end{array}$ & $\begin{array}{c}\text { Integração } \\
1\end{array}$ & $\begin{array}{c}\text { Integração } \\
2\end{array}$ & $\begin{array}{c}\text { Trilha das } \\
\text { Flores }\end{array}$ & $\begin{array}{c}\text { Trilha } \\
\text { da Barragem }\end{array}$ & Total (km) & \% \\
\hline Difícil & 0 & 0 & 0 & 0,012 & 0 & 0 & 0,012 & 0,13 \\
\hline Moderado & 0 & 0 & 0 & 0,518 & 0,259 & 0,655 & 1,431 & 15,96 \\
\hline Fácil & 0,049 & 0,112 & 0,098 & 0,879 & 1,629 & 3,278 & 6,046 & 67,41 \\
\hline Muito fácil & 0,003 & 0,056 & 0,074 & 0,135 & 0,564 & 0,647 & 1,479 & 16,49 \\
\hline Total $(\mathbf{k m})$ & $\mathbf{0 , 0 5 2}$ & $\mathbf{0 , 1 6 8}$ & $\mathbf{0 , 1 7 2}$ & $\mathbf{1 , 5 4 4}$ & $\mathbf{2 , 4 5 2}$ & $\mathbf{4 , 5 8 0}$ & $\mathbf{8 , 9 6 9}$ & $\mathbf{1 0 0 , 0 0}$ \\
\hline
\end{tabular}

Fonte: Elaboração própria. 


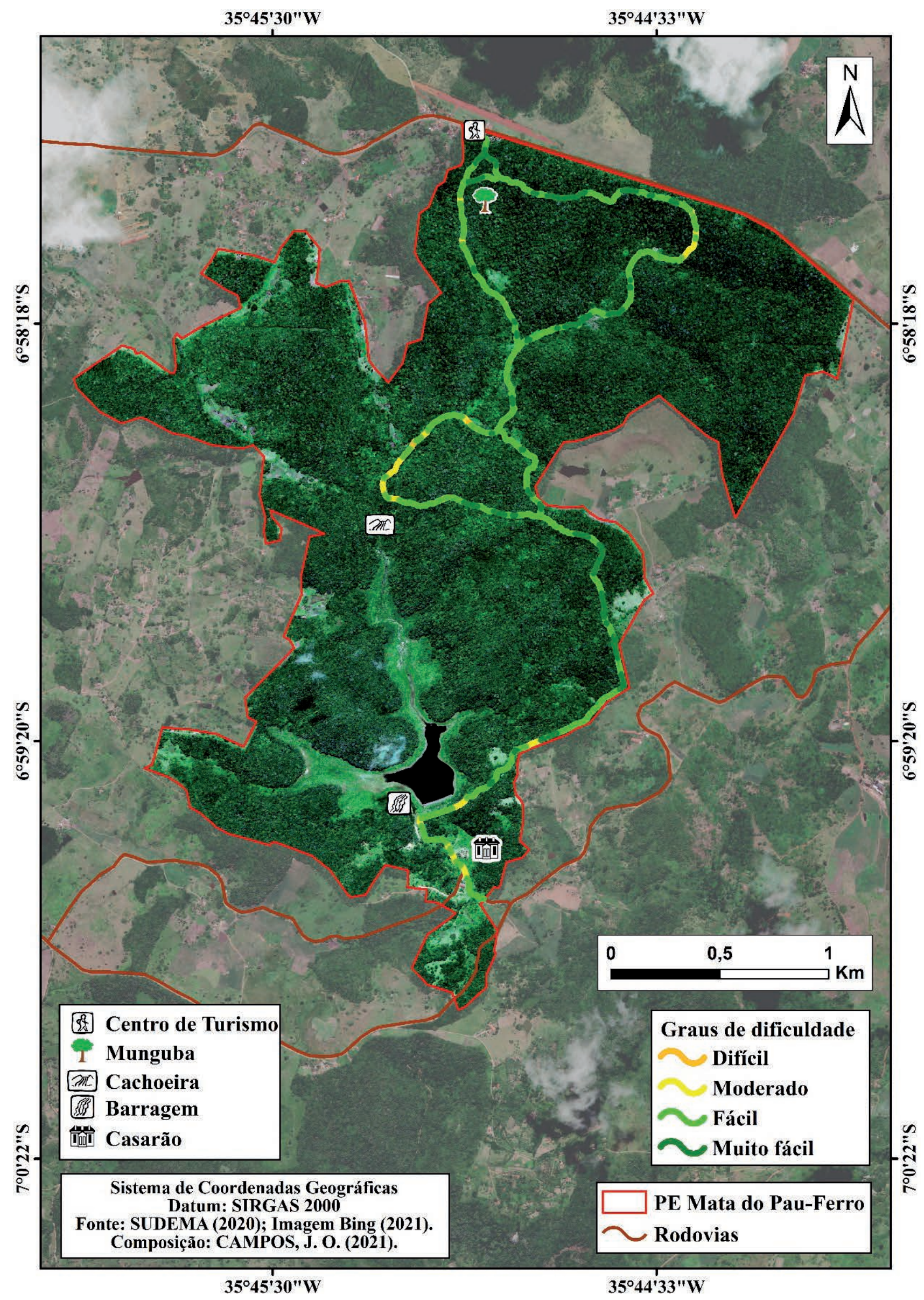

Mapa 4. Classes de dificuldade das trilhas do Parque. Fonte: Elaboração própria. 
$\mathrm{Na}$ Integração 2 são verificadas quatro classes de dificuldade, e, do mesmo modo que as trilhas anteriores, a maior parte da trilha é classificada como "fácil", compreendendo a distância de 0,879 km. Na Trilha das Flores a classe "difícil" está ausente, assim como na Trilha da Barragem, em que, seguindo a tendência verificada nas demais trilhas, a classe "fácil" abrange a maior quilometragem em ambas, somando 1,629 e $3,278 \mathrm{~km}$, na devida ordem.

A partir da análise da tabela 3, constata-se que o maior percentual das trilhas do Parque é classificado como "fácil", haja vista que a classe compreende $67,41 \%$ do sistema de trilhas. A classe "muito fácil" ocupa $16,49 \%$, e se manifesta de forma expressiva nas porções norte e sudeste. Os percursos classificados como moderado ocupam 15,96\% e ocorrem majoritariamente na parte central e sul da área. Por outro lado, os percursos classificados como "difícil" possuem a menor representatividade em termos de distância, ocupando apenas $0,13 \%$ do sistema, tendo sua ocorrência restrita à porção central, onde se localiza a Integração 2 .

Percentuais divergentes foram encontrados por Silva e Palhares (2020), no Parque Estadual Serra do Cabral, em Minas Gerais, onde os autores verificaram que a classe "difícil" é a mais representativa da Trilha do Mirante, abrangendo $45 \%$ da mesma, ao passo que as classes "moderado", "fácil" e "muito fácil", ocupam $35 \%, 18 \%$ e $3 \%$, respectivamente.

Silva (2016) mapeando trilhas no Parque Nacional do Itatiaia, verficou que a Trilha das Prateleiras possui predominância da classe "muito difícil", na qual constitui $45,4 \%$ de sua extensão, enquanto na Trilha das Agulhas Negras a classe "fácil" é a mais representativa, com um percentual de $46,9 \%$, sendo o resultado que mais se aproxima dos percentuais verficados no presente estudo. A maior ocorrência das classes "muito fácil" e "fácil" nas trilhas demonstra que as mesmas podem receber um público diverso de visitantes, desde iniciantes até os mais experientes. Tal realidade é de suma importância, pois permite que novos visitantes sejam atraídos, aumentando o público divulgador dos atributos naturais e beleza cênica da paisagem.

A predominância da classe de dificuldade fácil também releva a não exigência de condicionamento físico para o tráfego. No entanto, como a classe se encontra distribuída em fragmentos no sistema de triIhas, há que observar se as classes de dificuldade que se apresentam no intermeio delas não constituem obstáculos aos visitantes. Reforça-se a recomendação, quando tratar-se da porção central do Parque, onde ocorre a classe difícil, embora em menor percentual. Ao mesmo tempo, se faz importante anunciar que, durante eventos de chuva ou período chuvoso na região, os graus de dificuldade das trilhas constatados podem não condizer com a realidade em decorrência de dinâmicas condicionadas pelas variáveis ambientais, tais como: aumento da calha dos rios de cortam o Parque, risco de queda de árvores, exposição à chuva e maior risco de acidente devido ao solo escorregadio, principalmente em trechos de maior declividade.

O mapeamento das trilhas em conjunto com os atributos morfométricos do terreno e a classificação da dificuldade, aqui apresentados, podem ser utilizados para planejar a capacidade de suporte e as atividades que podem ser desenvolvidas ao longo das trilhas, pois é possível observar como as trilhas se distribuem na unidade e os gradientes de altitude e declividade que experimentam - aspectos estes que influenciam na distribuição dos seres vivos e na erosão dos solos. Além disso, a espacialização das classes de dificuldade possibilita aos visitantes maiores informações sobre as trilhas, o que oportuniza a escolha da trilha mais adequada aos seus interesses.

No mapeamento foram desconsideradas as trilhas que não são mantidas pelos guias, pois são trilhas não controladas que ocorrem em toda a unidade, abertas por moradores locais para fins turísticos, conflito que se pronuncia em virtude da baixa fiscalização nos limites da área, decorrente da baixa disponibilidade de recursos para gestão. Diante disso, a divulgação das informações geradas sobre o sistema de trilhas pode auxiliar na formalização da atividade de visitação no Parque, possibilitando que os visitantes priorizarem as trilhadas mapeadas ao invés de trilhas alternativas, sem trajeto conhecido.

A priorização das trilhas mapeadas ao invés de trilhas não controladas, por parte dos visitantes, pode contribuir para a redução da abertura de novos percursos, em razão da menor procura. Desse modo, serão evitados maiores impactos sobre os ecossistemas (Decanini, 2001; Boquimpani-Freitas et al., 2020). Além disso, as trilhas não controladas poderão ser desativadas, em virtude do desuso e experimentar a regeneração da vegetação afetada. 
A formalização de um sistema de trilhas é de fundamental importância, não só do ponto de vista turístico, mas também no que se refere às perturbações ecológicas, pois a manutenção e criação de novos trajetos pode ocasionar e intensificar a propagação dos efeitos de borda para áreas interioranas dos fragmentos florestais, levando à redução na qualidade ambiental (Figueiró \& Coelho Netto, 2009; Mitchell et al., 2015; Campos et al., 2018).

Dito isso, a exibição dos mapas de trilhas no Centro de Turismo e em mídias digitais locais, juntamente com a disponibilidade dos guias, poderá decisivamente encaminhar a atividade de visitação no Parque para caminhos voltados à conservação e ao desenvolvimento social, econômico e cultural. Apesar do conhecimento das perturbações causadas por trilhas em Unidades de Conservação (Rangel et al., 2013; Costa et al., 2019), oportunizar as comunidades locais a desenvolverem atividades turísticas associadas às mesmas, surge como uma das formas mais efetivas para resolução dos conflitos que se manifestam, além de fortalecer o intercâmbio entre órgão gestor e sociedade civil.

\section{CONCLUSÕES}

O Parque Estadual Mata do Pau-Ferro possui um sistema composto por 4 trilhas, 2 integrações e quatro pontos na paisagem que funcionam como atrativos turísticos principais, em que maior parte dos percursos são classificados como fácil, isto é, não demandam maiores esforços físicos para sua realização. Além disso, o Parque encontra-se circundado por moradores que desenvolvem atividades econômicas sustentáveis associadas a Unidade de Conservação, a exemplo do ecoturismo, com possibilidade de expansão para maior número de pessoas.

Essa conjuntura reforça o potencial turístico da Unidade da Conservação para receber diversos grupos de visitantes simultaneamente, e se consolidar como um dos espaços mais apropriados para realização de visitação e trilha interpretativa no estado da Paraíba, além de contribuir para a renda dos moradores locais. Tais aspectos são reforçados por se tratar de um dos maiores remanescentes de Mata Atlântica do estado em Brejo de Altitude, e abrigar espécies ameaçadas de extinção. Nesse caminho, a divulgação da importância da área, o aumento no número de visitantes e implantação de estruturas adequadas à manutenção da visitação podem suscitar recursos financeiros e novas perspectivas para proteção da área em questão.

Do ponto de vista da gestão, as informações geradas podem ser utilizadas para planejamento da capacidade de suporte das trilhas, bem como da suscetibilidade das mesmas à erosão, com vistas a proporcionar uma melhor experiência aos visitantes e, ao mesmo tempo, minimizar os impactos da atividade sobre os ecossistemas. A visitação, além de estar voltada aos objetivos propostos para a categoria Parque, permite a conscientização ambiental através do contato com os ecossistemas, evidenciando a necessidade do trabalho conjunto entre sociedade civil e órgão gestor para uma efetiva gestão da área protegida.

\section{Declaração responsável e conflito de interesses}

Os autores declaram não haver conflito de interesse em relação à publicação deste artigo. Os dois autores contribuíram igualmente nos seguintes pontos: revisão bibliográfica, desenho metodológico, trabalho de campo e redação do artigo.

\section{REFERÊNCIAS}

Ab'Sáber, A. N. (2003). Os domínios de natureza no Brasil: potencialidades paisagísticas. Ateliê Editorial.

Aguiar, P. C. B., Moreau, A. M. S. S. \& Fontes, E. O. (2013). Áreas Naturais Protegidas: Um Breve Histórico Do Surgimento Dos Parques Nacionais E Das Reservas Extrativistas. Revista Geográfica de América Central, 1(50), 195-213. https:// www.redalyc.org/articulo.oa?id $=451744541007$ 
Andrade, G. O. \& Lins, R. C. (1964). Introdução ao estudo dos "Brejos"Pernambucanos. Arquivos do Instituto de Ciências da Terra da Universidade de Recife, 2, 21-34.

Beltrão, B. A., Morais, F., Mascarenhas, J. C., Miranda, J. L. F., Junior, L. C. S. \& Mendes, V. A. (Orgs.). (2005). Projeto cadastro de fontes de abastecimento por água subterrânea estado de Paraíba: diagnóstico do município de Areia. CPRM/PRODEEM.

Bétard, F., Peulvast, J.-P. \& Sales, V. C. (2007). Caracterização morfopedólogica de uma serra úmida no semi-árido do Nordeste brasileiro: o caso do maciço de Baturité-CE. Mercator - Revista de Geografia da UFC, 6(12), 107-126. http:// www.mercator.ufc.br/mercator/article/view/49

Boquimpani-Freitas, L., Costa, N. M. C. da \& Pereira, R. A. (2020). Caracterização e análise da declividade das trilhas do Parque Nacional da Tijuca: subsídios para a gestão da visitação. Geosul, 35(75), 556-579. https://doi.org/10.5007/1 982-5153.2020v35n75p556

Brasil (2007). Informe nacional sobre áreas protegidas no Brasil. MMA.

Brasil (2011). SNUC: Lei $n^{\circ}$ 9.985, de 18 de julho de 2000; Decreto $n^{\circ}$ 4.340, de 22 de agosto de 2002; Decreto $n^{\circ} 5.746$, de 5 de abril de 2006. Plano Estratégico Nacional de Áreas Protegidas: Decreto n 5.758, de 13 de abril de 2006. MMA.

Brasil (2020). Cadastro Nacional de Unidades de Conservação: Unidades de Conservação por Bioma. MMA.

Campos, J. O. \& Lima, V. R. P. (2020). Proposta de Zoneamento Ambiental para o Parque Estadual Mata do Pau Ferro, Paraíba, Brasil. Physis Terrae - Revista Ibero-Afro-Americana de Geografia Física e Ambiente, 2(1), 19-46. https://doi. org/10.21814/physisterrae.2425

Campos, J. O., Santos, J. S., Salvador, M. S. S. \& Lima, V. R. P. (2018). Análise e propagação dos efeitos de borda no Parque Estadual Mata do Pau-Ferro, Areia-PB. Revista Geográfica Acadêmica, 12(2), 21-36. https://revista.ufrr.br/rga/article/ view/5103

Canto-Silva, C. R. \& Silva, J. S. (2017). Panorama da visitação e da condução de visitantes em Parques brasileiros. Revista Brasileira de Pesquisa em Turismo, 11(2), 365-386. https://doi.org/10.7784/rbtur.v11i2.1286

Castro Júnior, E., Coutinho, B. H. \& Freitas, L. E. (2009). Gestão da biodiversidade e áreas protegidas. In A. J. T. Guerra \& M. C. N. Coelho (Orgs.), Unidades de Conservação: abordagens e características geográficas (p. 25-65). Bertrand Brasil.

Costa, P. G., Pimentel, D. de S., Simon, A. V. S. \& Correia, A. R. (2019). Trilhas Interpretativas para o Uso Público em Parques: desafios para a Educação Ambiental. Revista Brasileira de Ecoturismo (RBEcotur), 12(5), 818-839. https://doi. org/10.34024/rbecotur.2019.v12.6769

Decanini, M. M. (2001). SIG no Planejamento de trilhas no Parque Estadual de Campos do Jordão. Revista Brasileira de Cartografia, 53, 97-110. http://www.rbc.Isie.unb.br/index.php/rbc/article/download/202/185

Decreto n²6.098, de 04 de agosto de 2005, Diário Oficial [do] Estado da Paraíba 2 (2005). https://www.jusbrasil.com.br/ diarios/44314636/doepb-05-08-2005-pg-2?ref=next_button

Diaz del Olmo, F. \& Molina Vezquez, F. (1985). Parques naturales andaluces: una estrategia de conservacion y desarrollo en regiones deprimidas. Revista de Estudios Andaluces, (4), 147 - 156. https://doi.org/10.12795/rea.1985.i04.08

Diegues, A. C. (2008). O mito moderno da natureza intocada (6 ed). Hucitec: Nupaub - USP/CEC.

Dorst, J. (1973). Antes que a natureza morra: por uma ecologia política (R. Buongermino (trad.)). Edgard Blucher.

Drummond, J. A., Franco, J. L. A. \& Oliveira, D. (2010). Uma análise sobre a história e a situação das unidades de conservação no Brasil. In R. S. Ganem (Org.), Conservação da Biodiversidade Legislação e Políticas Públicas (p. 341-386). Câmara dos Deputados, Edições Câmara.

Figueiró, A. S. \& Coelho Netto, A. L. (2009). Impacto ambiental ao longo de trilhas em áreas de floresta tropical de encosta: Maciço da Tijuca Rio de Janeiro - RJ. Mercator, 8(16), 187-200. https://doi.org/10.4215/RM2009.0816.0015

Ganem, R. S. \& Drummond, J. A. (2010). Biologia da conservação: as bases científicas da proteção da biodiversidade. In Roseli Senna Ganem (Org.), Conservação da Biodiversidade Legislação e Políticas Públicas (p. 11-46). Câmara dos Deputados, Edições Câmara.

Godoy, L. C. R. C. \& Leuzinger, M. D. (2015). O financiamento do Sistema Nacional de Unidades de Conservação no Brasil: Características e tendências. Revista de Informação Legis/ativa - RIL, 52(206), 223-243. https://www12.senado.leg.br/ ril/edicoes/52/206/ril_v52_n206_p223.pdf

Gomes, P. O. \& Cunha, A. A. (2018). A importância da visitação nos parques nacionais e a geração de recursos financeiros. Revista Cenário, 6(10), 112-125. https://doi.org/10.26512/revistacenario.v6i10.18899

Ibama (2002). Roteiro metodológico de planejamento: Parque Nacional, Reserva Biológica, Estação Ecológica. IBAMA. 
Juras, I. da A. G. M. (2010). Instrumentos para a conservação da biodiversidade. In R. S. Ganem (Org.), Conservação da Biodiversidade Legislação e Políticas Públicas (p. 223-284). Câmara dos Deputados, Edições Câmara.

Marion, J. L. \& Wimpey, J. (2017). Assessing the influence of sustainable trail design and maintenance on soil loss. Journal of Environmental Management, 189, 46-57. https://doi.org/10.1016/j.jenvman.2016.11.074

Marques, A. D. L., Costa, C. R. G. \& Moura, D. C. (2019). Parque Estadual Mata do Pau Ferro (Areia - Paraíba): Zona de Amortecimento e espaços de conflitos. Geoambiente On-line, 34, 1-18. https://doi.org/10.5216/revgeoamb.v0i34.52282

Medeiros, J. F. \& Cestaro, L. A. (2019). As diferentes abordagens utilizadas para definir brejos de altitude, áreas de exceção do Nordeste brasileiro. Sociedade e Território, 31(2), 97-119. https://doi.org/10.21680/2177-8396.2019v31n2ID16096

Medeiros, R. (2006). Evolução das tipologias e categorias de áreas protegidas no Brasil. Ambiente \& Sociedade, 9(1), 41-64. https://doi.org/10.1590/S1414-753X2006000100003

Medeiros, R., Young, C. E. F., Pavese, H., Araújo, F. F. S., Pereira, G. S., Rodrigues, C. G. O., Valverde, Y., Pinto, E. M., Stein, B., Gurgel, H. C., Santos, F. R. P. dos \& Neves, L. H. (2011). Unidades de conservação e desenvolvimento: a contribuição do SNUC para economia nacional. In R. Medeiros \& F. F. S. Araújo (Orgs.), Dez anos do Sistema Nacional de Unidades de Conservação da Natureza: lições do passado, realizações presentes e perspectivas para o futuro (p. 55-88). MMA.

Mitchell, M. G. E., Suarez-Castro, A. F., Martinez-Harms, M., Maron, M., McAlpine, C., Gaston, K. J., Johansen, K. \& Rhodes, J. R. (2015). Reframing landscape fragmentation's effects on ecosystem services. Trends in Ecology \& Evolution, 30(4), 190-198. https://doi.org/10.1016/j.tree.2015.01.011

Morsello, C. (2001). Áreas protegidas públicas e privadas: seleção e manejo. Annablume.

Myers, N., Mittermeier, R. A., Mittermeier, C. G., da Fonseca, G. A. B. \& Kent, J. (2000). Biodiversity hotspots for conservation priorities. Nature, 403(6772), 853-858. https://doi.org/10.1038/35002501

Paraíba. (1985). Atlas geográfico do Estado da Paraíba. Grafset.

Pereira, T. F., Campos, J. O., Pereira, M. R. S. \& Lima, V. R. P. (2019). Ecoturismo e os impactos ambientais no Parque Estadual Mata do Pau-ferro, Areia, Paraíba. Revista Geotemas, 9(1), 128-143. https://doi.org/10.33237/geotemas. v9i1.3382

Pennington, R. T., Lavin, M., Prado, D. E., Pendry, C. A., Pell, S. K. \& Butterworth, C. A. (2004). Historical climate change and speciation: neotropical seasonally dry forest plants show patterns of both Tertiary and Quaternary diversification. Philosophical Transactions of the Royal Society of London. Series B: Biological Sciences, 359(1443), 515-538. https://doi. org/10.1098/rstb.2003.1435

Primack, R. B. \& Rodrigues, E. (2001). Biologia da conservação. E. Rodrigues.

Pureza, F., Pellin, A. \& Padua, C. (2015). Unidades de Conservação: fatores e personagens que fizeram a história das categorias de manejo. Matrix.

Rangel, L. de A., Guerra, T. J. A., Brizzi, R. R. \& Souza, H. S. (2013). O uso de trilhas em unidades de conservação: o caso da Apa de Cairuçu, Paraty - RJ. Geografia, 22(1), 79-93. https://doi.org/10.5433/2447-1747.2013v22n1p79

Rezende, V. L. \& Cunha, F. L. (2014). OS DESAFIOS DO USO DE TRILHAS EM UNIDADES DE CONSERVAÇÃO. Periódico Eletrônico Fórum Ambiental da Alta Paulista, 10(3), 29-41. https://doi.org/10.17271/198008271032014839

Robim, M. D. J. \& Tabanez, M. F. (1993). Subsídios para implantação da Trilha Interpretativa da Cachoeira - Parque Estadual de Campos do Jordão. Revista Instituto Florestal, 5(1), 65-89.

Santos, H. A., Costa, E. G., Araújo, H. F., Mendonça, J. D. L. \& Silva, T. C. F. (2020). Plano de manejo do Parque Estadual Mata do Pau-Ferro. Editora UNIESP.

Santos, S. S., Pedrosa, K. M., Andrade, E. S., Silva, J. S., Rodrigues, E. F. \& Xavier, W. J. F. (2020). Trilhas interpretativas utilizadas como recurso pedagógico: formação e informação no ensino básico. Revista Brasileira de Gestão Ambiental e Sustentabilidade, 7(16), 749-769. https://doi.org/10.21438/rbgas(2020)071621

SFB. (2019). Inventário Florestal Nacional: principais resultados: Paraíba. MAPA.

Silva, G. G. L. (2016). Classificação do grau de dificuldade de trilhas : uso de geotecnologias na elaboração de um modelo aplicado ao Parque Nacional do Itatiaia, Brasil [Dissertação (Mestrado em Ciências)]. Programa de Pós-Graduação em Turismo, Escola de Artes, Ciências e Humanidades, Universidade de São Paulo - USP.

Silva, G. G. L., Lima, T. C. \& Panchaud, L. (2016). Mapeamento e Classificação do Grau de Dificuldade da Trilha do Rancho Caído, Parque Nacional do Itatiaia (RJ). Revista Brasileira de Ecoturismo (RBEcotur), 9(2), 250-272. https://doi. org/10.34024/rbecotur.2016.v9.6443 
Silva, M. C., Queiroz, J. E. R., Araujo, K. D. \& Pazera Jr, E. (2006). Condições ambientais da Reserva Ecológica Estadual da Mata do Pau-Ferro, Areia - PB. Geografia, 15(1), 51-63. http://www.uel.br/revistas/uel//index.php/geografia/article/ view/6644/6001

Silva, T. N. \& Palhares, R. H. (2020). Parque Estadual Serra do Cabral em Minas Gerais: classificação do grau de dificuldade da trilha do mirante. Revista Cerrados, 18(02), 512-535. https://doi.org/10.46551/rc24482692202027

Simões, L. L. (2008). Unidades de conservação: conservando a vida, os bens e os serviços ambientais. WWF - Brasil.

Souza, J. L., Vieira, C. L. \& Silva, D. C. B. (2015). Roteiro metodológico para elaboração de plano de manejo para Reservas Particulares do Patrimônio Natural. Brasília - DF: Instituto Chico Mendes de Conservação da Biodiversidade, 2015. 86p. Instituto Chico Mendes de Conservação da Biodiversidade.

Tabarelli, M. \& Santos, A. M. M. (2004). Uma breve descrição sobre a história natural dos Brejos Nordestinos. In K. C. PORTO, J. J. P. CABRAL, \& M. TABARELLI (Orgs.), Brejos de altitude em Pernambuco e Paraíba: história natural, ecologia e conservação (p. 17-24). MMA.

Veloso, H. P., Rangel Filho, A. L. R. \& LIMA, J. C. A. (1991). Classificação da vegetação brasileira, adaptada a um sistema universal. IBGE. 


\title{
Resiliencia del mercado turístico urbano ante la crisis de la COVID-19. El caso de Málaga
}

\section{Resilience of the urban tourist market in the face of the COVID-19 crisis. The case of Malaga}

\author{
Beatriz Benítez-Aurioles \\ bbaurioles@uma.es@0000-0002-4224-9184 \\ Facultad de Ciencias Económicas y Empresariales. Universidad de Málaga. \\ Calle El Ejido, 6. 29013 Málaga, España
}

\section{INFO ARTÍCULO}

Recibido: $14 / 11 / 2021$

Revisado: $16 / 12 / 2021$

Aceptado: 24/12/2021

\section{PALABRAS CLAVE}

Resiliencia

Turismo urbano

COVID-19

Hoteles

Airbnb

Impactos

\section{KEYWORDS}

Resilience

Urban tourism

COVID-19

Hotels

Airbnb

Impacts

\begin{abstract}
RESUMEN
Este artículo tiene como objetivo verificar la resiliencia del turismo urbano ante la crisis de la COVID-19 e identificar sus rasgos principales, tomando como referencia la ciudad de Málaga. Se utilizará el enfoque metodológico que proporciona el análisis económico para analizar la dinámica que se ha registrado en el mercado de alojamientos, tanto convencionales (hoteles) como el de viviendas turísticas de alquiler a corto plazo. Los datos se refieren a indicadores de demanda, de oferta y de precios para el periodo comprendido entre septiembre de 2018 y el mismo mes del año 2021. Los resultados del análisis evidencian claros signos de recuperación del mercado turístico a partir de la primavera de 2021. Más concretamente, se constata el protagonismo que adquieren los residentes en España en la demanda de alojamiento hotelero. Asimismo, en el mercado peer-to-peer se confirma que, meses después del levantamiento de las restricciones a la movilidad, se superaron los niveles de actividad alcanzados antes de la pandemia. Sobre esa base, parece pertinente reabrir y replantear el debate sobre la capacidad de carga de las ciudades y la conveniencia de regular el mercado de alojamientos turísticos.
\end{abstract}

\section{ABSTRACT}

This article aims to verify the resilience of urban tourism in the face of the COVID-19 crisis, and identify its main features, taking the city of Malaga as a reference. The methodological approach provided by the economic analysis will be used to analyze the dynamics that have been registered in the accommodation market, both conventional (hotels) and short-term rental tourist housing. The data refer to demand, supply and price indicators for the period between September 2018 and the same month in 2021. The results of the analysis show clear signs of recovery in the tourism market as of spring 2021. More specifically, the role that residents of Spain acquire in the demand for hotel accommodation is confirmed. Likewise, in the peer-to-peer market, it is confirmed that, months after the lifting of mobility restrictions, the activity levels reached before the pandemic were exceeded. On this basis, it seems pertinent to reopen and rethink the debate on the carrying capacity of cities and the advisability of regulating the tourist accommodation market. 


\section{INTRODUCCIÓN}

Las crisis turísticas han sido, relativamente, frecuentes. A veces han afectado a destinos concretos cuando, por ejemplo, se han producido ataques terroristas (Corbet et al., 2019), desastres naturales (Rosselló et al., 2020), o cuando ha crecido la incertidumbre política o económica (Benítez-Aurioles, 2019a; Benítez-Aurioles, 2021a). Asimismo, en las dos últimas décadas se han registrado crisis globales como consecuencia de los ataques terroristas del 11 de setiembre de 2001 (Blake \& Sinclair, 2003), de la propagación del virus del síndrome respiratorio agudo grave (SARS) en 2003 (McKercher \& Chon, 2004), o de la Gran Recesión de 2007 (Pechlaner \& Frehse, 2010). Ahora bien, ninguna de ellas es comparable con la crisis turística que ha provocado la COVID-19 que ha sido responsable del peor año en la historia del turismo (UNWTO, 2021). En efecto, para tratar de contener la expansión del virus, a principios de 2020, se generalizaron las restricciones a los movimientos de personas, las cuarentenas, los encierros y la prohibición de los viajes. En esas condiciones, el colapso de la industria turística fue inevitable.

En el caso concreto de España, tras la declaración del estado de alarma, en marzo de 2020 se suspendió la apertura al público de los establecimientos de alojamiento turístico. En mayo se flexibilizaron algunas medidas, aunque, debido a las restricciones a la movilidad, la actividad hotelera siguió siendo mínima durante los meses de verano. Además, ante la aparición de nuevos rebrotes y medidas restrictivas, dicha actividad fue muy escasa también en los últimos meses del año (Exceltur, 2021). El resultado fue que 2020 fue un año nefasto para el turismo en España. En 2021, en cambio, el progresivo avance de la vacunación y el levantamiento de las restricciones que se habían decretado permitieron, en cierta medida, la recuperación de la actividad turística que empezó a demostrar la resiliencia que había tenido en el pasado (Benítez-Aurioles, 2020a).

En este contexto, el objetivo de este artículo es analizar la capacidad de recuperación del turismo urbano ante la crisis de la COVID-19, tomando como referencia la ciudad de Málaga. Consideraremos el turismo urbano en el mismo sentido que lo hace la Organización Mundial del Turismo: “Un tipo de actividad turística que tiene lugar en un espacio urbano con sus atributos inherentes caracterizados por una economía no agrícola basada en la administración, las manufacturas, el comercio y los servicios y por constituir nodos de transporte". Y añade: "Los destinos urbanos ofrecen un espectro amplio y heterogéneo de experiencias y productos culturales, arquitectónicos, tecnológicos, sociales y naturales para el tiempo libre y los negocios" (UNWTO, 2019).

A partir de aquí este trabajo se organiza en los siguientes apartados. En primer lugar, presentaremos el marco teórico en el que se sitúa. A continuación, expondremos la metodología. Más adelante, se dedicará un epígrafe a la presentación y la discusión de los resultados. Terminaremos con las conclusiones.

\section{MARCO TEÓRICO}

A principios de la década de los noventa, Ashworth (1992) planteó la siguiente pregunta: ¿Hay un turismo urbano? Su respuesta se articulaba en torno a tres afirmaciones que, por entonces, necesitaban demostración empírica. La primera era que el turismo urbano existe y que puede ser estudiado de forma autónoma. La segunda se refería a que el turismo urbano no había recibido suficiente atención por parte de los investigadores. Y la tercera sostenía que el turismo urbano era lo suficientemente importante como para justificar su estudio. Pues bien, trascurridas tres décadas, se ha acumulado suficiente evidencia que demuestra no sólo que el turismo urbano existe, sino que tiene la importancia suficiente para merecer un tratamiento específico tanto a nivel académico como político, social y económico.

La configuración de un marco teórico coherente y maduro para el análisis del turismo urbano empezó a gestarse a medida que las ciudades comenzaron a dejar de ser simples gateways para consolidarse como destinos, tanto para los que viajaban por motivos de negocio como para aquellos que lo hacían por placer (Zheng et al., 2020). Es cierto que, tal como señaló Ashworth (2003), durante algún tiempo los que estudiaban el turismo desatendieron las ciudades y los que estudiaban las ciudades desatendieron el turismo. De hecho, antes de la década de los ochenta del siglo pasado, la investigación sobre turismo urbano estaba 
fragmentada y no se reconocía como un campo de investigación independiente (Edwards et al., 2008). No obstante, en los últimos años el panorama ha cambiado de forma sustancial y la literatura específica sobre el turismo urbano ha experimentado un enorme crecimiento. Así, por ejemplo, una búsqueda del topic "urban tourism" en la base de datos Web of Science (WOS) concentra casi el $80 \%$ de todos los documentos encontrados en los últimos diez años. Incluso, desde 2015 se publica una revista por la editorial Emerald dedicada específicamente a la investigación sobre el turismo urbano: International Journal of Tourism Cities.

El interés académico por el turismo urbano fue creciendo a medida que también lo hacía el fenómeno objeto de estudio. En este sentido, la importancia que alcanzó el turismo en determinadas ciudades aumentó la presión de los turistas sobre ciertos entornos urbanos lo que provocó la aparición de protestas de la población local (Smith et al., 2019), el inicio de la difusión de términos como overtourism o turismofobia (Namberger et al., 2019; UNWTO, 2018), y el rechazo de los residentes hacia el mercado peer-to-peer (p2p) de alojamientos turísticos (Ikeji \& Nagai, 2020). Precisamente, el desarrollo de este mercado, gracias a plataformas como Airbnb, es fundamental para entender la dimensión que ha alcanzado el turismo urbano y el debate social que ha generado (Oskam, 2020), donde se han puesto de manifiesto ciertos conflictos entre los actores implicados (Comendador-Sánchez et al., 2021).

Entre la abundante literatura que se ha generado en torno al mercado p2p de alojamientos turísticos (Dann et al., 2019; Dolnicar, 2019; Guttentag, 2019; Hati et al., 2021; Ozdemir \& Turker, 2019; Prayag \& Ozanne, 2018; Sainaghi, 2020) tiene un especial interés la relacionada con los distintos impactos que se han documentado. Por un lado, nos encontramos con investigaciones que han confirmado sus interacciones con otros mercados como el de alojamientos convencionales (hoteles) (Benítez-Aurioles, 2019b) o el de alquiler y compraventa de viviendas (Benítez-Aurioles \& Tussyadiah, 2020). Por otro, se han analizado, desde distintas perspectivas, los efectos externos negativos en zonas residenciales en forma de ruidos, atascos y escasez de aparcamiento, así como los problemas que supone la gestión de residuos, entre otras cuestiones (Gurran \& Phibbs, 2017). En torno a estos temas siguen abiertas algunas discusiones en el ámbito académico. No obstante, el debate sobre la pertenencia del mercado p2p, en general, y de Airbnb, en particular, como la plataforma que lidera el alquiler de viviendas a corto plazo en el mundo, a la denominada sharing economy o economía compartida o colaborativa parece resuelto. En efecto, en un principio se había argumentado que Airbnb es "prácticamente sinónimo de economía colaborativa" (Schor, 2016). Sin embargo, algunos consideraron relevante aclarar si Airbnb es parte de la economía colaborativa (Reinhold \& Dolnicar, 2018). Lógicamente, cualquier consideración sobre este tema dependerá de lo que se entienda por economía colaborativa. En este contexto, si aceptamos que Airbnb es una organización con fines de lucro que cobra una comisión sobre los precios de alquiler cuando los propietarios reciben huéspedes, entonces pertenecería a lo que Belk (2014) denomina pseudo-sharing economy. Es obvio que, a pesar de los esfuerzos de Airbnb por presentarse como representante de la economía colaborativa y promotora de experiencias solidarias (Benítez-Aurioles, 2018a), la realidad es que las transacciones se realizan en el mercado e implican un flujo de dinero que compensa la prestación de un servicio. De esta forma, Airbnb habría de considerarse como una plataforma que busca el beneficio comercial (Oskam \& Boswijk, 2016; Hajibaba \& Dolnicar, 2018).

En cuanto a los usuarios de las plataformas (anfitriones y huéspedes) existe una amplia gama de contribuciones, muchas de las cuales se basan en encuestas, que demuestran que, por un lado, la demanda de alojamiento en el mercado p2p se explica, entre otros factores, por razones económicas (Camilleri \& Neuhofer, 2017; Guttentag, 2015; Möhlmann, 2015; Priporas et al., 2017; Tussyadiah, 2016; Tussyadiah \& Pesonen, 2016; Tussyadiah \& Zach 2017; Wiles \& Crawford, 2017; Wu et al., 2017) y, por otro, desde el punto de vista de la oferta, también se ha dejado clara la importancia de las motivaciones económicas (Deale \& Crawford, 2018; Ikkala \& Lampinen, 2014; Karlsson \& Dolnicar, 2016).

Sobre la base anterior, el marco teórico pertinente para el análisis del mercado turístico urbano, con independencia del peso que pudieran tener los intercambios en el mercado p2p, sería el análisis económico en donde los agentes reaccionan a los incentivos maximizando sus funciones de utilidad o de beneficio. Este enfoque no es óbice para que una comprensión global del turismo urbano exija una perspectiva más amplia y, en particular, el concurso de otras ciencias sociales (Ashworth \& Page, 2011; Hocevar \& Bartol, 2021). Ahora bien, el marco teórico que aplicamos se justifica por la idea de que para entender los cambios que 
ha provocado la crisis de la COVID-19 en el mercado turístico urbano son adecuados los argumentos que proporciona el análisis económico.

Se plantea, por tanto, la conveniencia de apoyar el estudio del turismo urbano en el análisis de la oferta, de la demanda y de los precios como vectores básicos que determinan el funcionamiento de cualquier mercado. Esta aproximación tiene más interés en la medida en que el propio turismo urbano esté demostrando resiliencia ante la crisis de la COVID-19 y el mercado, en consecuencia, muestre síntomas de recuperación. A partir de ahí, adquirirían un nuevo impulso los debates previos a la pandemia sobre la capacidad de carga turística de algunas ciudades. En este contexto, resulta pertinente determinar, en primer término, si el turismo urbano se está recuperando y, si es así, en qué medida se están reproduciendo las características que tenía antes de la pandemia. Este artículo pretende avanzar en esa línea.

\section{METODOLOGÍA}

De acuerdo con lo expuesto en el apartado anterior, el análisis que proponemos exige información sobre las variables básicas que definen el funcionamiento de los mercados: oferta, demanda y precios. Para el mercado de alojamientos turísticos convencionales el Instituto Nacional de Estadística (INE) facilita una serie de datos relativamente completos (González \& Velasco, 2021). En particular, la Encuesta de Ocupación Hotelera proporciona, por el lado de la demanda, información sobre el número de viajeros, pernoctaciones y estancia media, y, por el lado de la oferta, se pueden consultar, entre otras variables, el número estimado de establecimientos abiertos, plazas, y grados de ocupación. Asimismo, se suministra información sobre el empleo en el sector (INE, 2019). El hecho de que los datos tengan una desagregación mensual y por puntos turísticos, es decir, por municipios en los que la concentración de la oferta turística es muy significativa, hacen que sean, particularmente, apropiados para el análisis que pretendemos. Adicionalmente, para el tratamiento de algunas variables relacionadas con la rentabilidad del sector hotelero se ha utilizado el barómetro que publica Exceltur (2021).

Por el contrario, el conocimiento del mercado p2p de alojamientos turísticos sigue tropezando con la escasez de estadísticas oficiales, aunque el INE (2021a) proporciona de forma experimental una estimación de la ocupación en alojamientos turísticos a partir de datos de plataformas digitales. No obstante, en el momento de redactar este trabajo el último dato disponible se refiere a diciembre de $2019 \mathrm{y}$, por tanto, sobre esa base no es posible analizar los efectos que ha causado la COVID-19. En estas circunstancias, la alternativa se encuentra en la recogida de información, a través de técnicas de scraping, de los anuncios publicados por plataformas que facilitan la comercialización del alquiler de viviendas a corto plazo, como Airbnb.

La elección de Airbnb para aproximarnos al conocimiento del mercado p2p de alojamientos turísticos se basa en la indiscutible posición de liderazgo que ha alcanzado entre las plataformas dedicadas a la comercialización de viviendas particulares a corto plazo (Hajibaba \& Dolnicar, 2018). En 2017 ya tenía más capacidad de alojamiento que el conjunto de las cinco principales cadenas hoteleras del mundo (Hartmans, 2017). Y en 2021 alcanzó más de 7 millones de anuncios de alojamientos repartidos por unas 100.000 ciudades de, prácticamente, todos los países del mundo (Deane, 2021). Las previsiones apuntan a que esas cifras seguirán aumentando en los próximos años (Gassmann et al., 2021).

Pues bien, existen iniciativas privadas, como AirDNA (2021) o InsideAirbnb (2021), que recopilan los datos que caracterizan a la oferta de Airbnb y los ponen a disposición de los interesados. En particular, la base de datos que proporciona InsideAirbnb (2021) ha sido frecuentemente utilizada para la investigación académica (Dann et al., 2019) ya que contiene una información muy completa para un amplio conjunto de ciudades del mundo. No obstante, al margen de ciertas críticas puntuales (Alsudais, 2021), posee algunas limitaciones destacables. Así, los datos no suelen estar disponibles a intervalos regulares sino en determinadas fechas lo que, a veces, dificulta hacer comparaciones sobre la evolución temporal de mercados concretos. Además, se trata básicamente de datos que caracterizan a la oferta de los alojamientos. En este punto conviene precisar que existe evidencia de que la demanda en el mercado $p 2 p$ se suele concentrar en una parte de la oferta y que un elevado porcentaje de alojamientos anunciados no reciben solicitudes de reserva y, por tanto, no son 
ocupados (Benítez-Aurioles, 2020b). Los precios, en consecuencia, no son precios a los que se realizan los intercambios, sino que son, más bien, el reflejo de la disposición a ofrecer de los anfitriones.

Por otro lado, la base de datos de InsideAirbnb no permite conocer de forma directa el grado de ocupación de los alojamientos por lo que la información relativa a la demanda solo puede deducirse por métodos indirectos. Por ejemplo, de acuerdo con Airbnb (2021a) solo los huéspedes que han completado una estancia pueden dejar su evaluación. Por tanto, es posible utilizar el número de evaluaciones como proxy de la ocupación efectiva de cada alojamiento (Hu \& Lee, 2020). Es necesario señalar que, según las normas establecidas por Airbnb (2021a), los huéspedes disponen de 14 días desde la fecha de salida para enviar su evaluación, con lo que es posible que se produzca un cierto desfase entre el número de evaluaciones y el mes en el que, efectivamente, se ha ocupado el alojamiento que, en cualquier caso, no afecta a su capacidad como indicador de la evolución de la demanda.

Para el análisis de los precios hemos seleccionado los anuncios que tenían al menos 5 evaluaciones. De esta manera, intentamos asegurar que se trata de alojamientos que no sólo han sido comercializados en el mercado, sino que no lo han sido de forma esporádica. Sobre esa base, y de acuerdo con los resultados de investigaciones previas (Benítez-Aurioles, 2018b; Wang \& Nicolau, 2017) se han seleccionado las variables que contiene la tabla 1.

Tabla 1. Descripción de las variables.

\begin{tabular}{|l|l|}
\hline \multicolumn{1}{|c|}{ Variable } & \multicolumn{1}{c|}{ Descripción } \\
\hline In P & Logaritmo natural del precio \\
\hline AC & Número máximo de huéspedes \\
\hline EH & 1 si se trata de una vivienda completa (0 si no) \\
\hline DI & Distancia en kilómetros al centro de la ciudad \\
\hline SH & 1 si el anfitrión posee la etiqueta Superhost $(0$ si no) \\
\hline In L & Logaritmo natural del número de anuncios por anfitrión \\
\hline IB & 1 si la opción reserva instantánea está activada $(0$ si no) \\
\hline NR & Número de evaluaciones que posee el anuncio \\
\hline
\end{tabular}

A partir de esas variables realizaremos la siguiente estimación donde el subíndice se refiere a cada alojamiento y e el término de error:

$$
\ln P_{i}=\beta_{1} A C_{i}+\beta_{2} E H_{i}+\beta_{3} D I_{i}+\beta_{4} S H_{i}+\beta_{5} \ln L_{i}+\beta_{6} I B_{i}+\beta_{7} N R_{i}+\beta_{0}+e_{i}
$$

Lo previsible es que los alojamientos tengan un precio más elevado a medida que crece el número de huéspedes potenciales. Asimismo, cabe esperar que los alojamientos que consisten en una vivienda completa tengan un precio superior respecto a los que ofrecen una habitación privada o compartida.

Por otro lado, Airbnb otorga el distintivo de Superhost a aquellos anfitriones que, en promedio, han obtenido una calificación general de no menos de 4,8 estrellas (sobre 5), responden, al menos, al 90\% de los mensajes en un plazo máximo de 24 horas, consiguen, al menos, 10 visitas por año, y solo cancelan reservas en circunstancias excepcionales (Airbnb, 2021b). Cabría suponer que los esfuerzos invertidos por los anfitriones para obtener (y mantener) la etiqueta Superhost son compensados por los mayores ingresos derivados de la mayor disposición a pagar de los huéspedes (Liang et al., 2017). Por tanto, debería existir una relación directa entre el precio del alojamiento y el distintivo Superhost.

Por último, se ha demostrado que los anfitriones profesionales (aquellos que ofrecen más de un alojamiento) son capaces de adaptar sus precios de manera más eficiente ante las fluctuaciones de la demanda 
y que suelen cobrar precios mayores por sus alojamientos (Li et al., 2019). Por tanto, también cabría esperar que a medida que crece el número de anuncios por anfitrión también aumentará el precio.

Análogamente, existe evidencia de que, en términos generales, cuanto mayor sea la distancia que separa el alojamiento del centro de la ciudad sus precios decrecen (Benítez-Aurioles, 2018c). Por último, se ha confirmado de forma reiterada que el número de evaluaciones se correlaciona negativamente con el precio de los alojamientos (Gibbs et al., 2018; Magno et al., 2018) lo que, en principio, podría ser una consecuencia lógica de la ley de la demanda: ceteris paribus, a medida que disminuye el precio crece la demanda.

El ámbito de estudio es la ciudad de Málaga. La elección se basa, de entrada, en la importancia que, en términos absolutos, tiene su actividad turística entre las ciudades españolas. De acuerdo con el informe elaborado por Exceltur (2017), con datos referidos a 2016, la ciudad de Málaga ocupaba el quinto lugar, tras Barcelona, Madrid, Sevilla y Valencia, entre las 22 ciudades españolas analizadas, según el número de plazas de alojamientos turísticos (hoteles más viviendas p2p); y se situó en el cuarto lugar, tras Barcelona, Madrid y Valencia, entre las ciudades de más de 500 mil habitantes según el ranking de competitividad turística. Para 2019 se estimó que el impacto económico total del turismo en la ciudad de Málaga estaría cercano a los 3 mil millones de euros (Observatorio turístico de la ciudad de Málaga, s.f.). Si tenemos en cuenta que, según el INE (2021b) la renta total de la ciudad ascendía, en 2018, a algo más de 6 mil millones de euros, el impacto económico del turismo en la ciudad podría estar cercano al $50 \%$. En términos de empleo, en cambio, las 34.500 personas dedicadas a la actividad turística supondrían algo más del $12 \%$ de los trabajadores afiliados a la seguridad social en la ciudad (Ayuntamiento de Málaga, 2021). En cualquier caso, con independencia de las discrepancias que puedan surgir respecto a las estimaciones realizadas, parece evidente que el turismo en la ciudad de Málaga tiene un peso destacable que la sitúan entre los destinos turísticos urbanos más importantes de España.

Otro elemento que hace que el análisis del turismo urbano en Málaga posea un especial interés se refiere al peso que tiene, en esta ciudad, el mercado p2p de alojamientos turísticos. Algunas estimaciones la situaban, con datos de 2017, como la ciudad española donde la penetración de Airbnb (camas ofrecidas por Airbnb respecto a camas hoteleras) era más elevada (Jiménez et al. 2021). Por consiguiente, dado el papel que ha desempeñado dicho mercado en la consolidación del turismo urbano, la ciudad de Málaga constituye un caso representativo y oportuno para el análisis de la resiliencia del turismo urbano ante la crisis de la COVID-19.

En cuanto al ámbito temporal hemos tomado como referencia el periodo comprendido entre septiembre de 2018 y el mismo mes del año 2021, es decir, antes de la pandemia y una vez que el sector turístico ha dado muestras de recuperación. No obstante, es necesario advertir que, dada la excepcionalidad que se vivió durante algunos meses de la pandemia, no siempre dispusimos de datos para todos los meses del periodo señalado, lo que ha provocado cierta discontinuidad en las series analizadas.

\section{RESULTADOS Y DISCUSIÓN}

La información disponible y las peculiaridades de cada mercado hacen aconsejable diferenciar el análisis de los resultados obtenidos para los hoteles y para los de Airbnb.

\subsection{Hoteles}

La figura 1 recoge la evolución mensual de algunos indicadores de demanda del sector hotelero en la ciudad de Málaga. No se dispone de datos entre abril y junio de 2020 debido a la situación que supuso la declaración del estado de alarma el 14 de marzo que se prolongó hasta el 21 de junio. En cualquier caso, se aprecia un comportamiento claramente diferenciado antes y después de la vigencia del estado de alarma. Entre septiembre de 2018 y marzo de 2020, tanto los viajeros como las pernoctaciones de los residentes en el extranjero superaron ampliamente a las de los nacionales. De hecho, en septiembre de 2018 y de 2019 los residentes en 
el extranjero supusieron más del doble, tanto en términos de viajeros como de pernoctaciones registradas en los hoteles, que los nacionales. En septiembre de 2020, en cambio, eran los residentes en España los que duplicaban, en ambas variables, a los extranjeros. Al final del periodo las series se aproximan, aunque seguían siendo mayoría los viajeros y las pernoctaciones de los españoles. El comportamiento observado al final del periodo considerado es similar al registrado en el último trimestre de 2019: fuerte caída en el número de viajeros y pernoctaciones de los extranjeros, por motivos estacionales, e incremento en el de los españoles.

En definitiva, cuando en julio de 2020 se recupera la información estadística los turistas residentes en España superan a los residentes en el extranjero. Es decir, es la demanda turística nacional la que protagoniza la recuperación que experimenta el sector y que resulta aún más evidente desde mayo de 2021. Es cierto que, desde entonces, también se aprecia un aumento tanto en el número de viajeros como de pernoctaciones de los extranjeros, aunque sin alcanzar los niveles previos a la pandemia. En cambio, el número de viajeros y de pernoctaciones de los nacionales experimentan crecimientos importantes superando, incluso, las cifras de los años precedentes. Así, el número de viajeros y de pernoctaciones en agosto de 2021 de los residentes en España supusieron las más altas de la historia. Y si comparamos los datos de viajeros y pernoctaciones de septiembre de 2021 con los del mismo mes de 2019, los de los extranjeros disminuyeron en un $48 \%$ y en un $39 \%$, respectivamente, mientras que los de los nacionales aumentaron en un $15 \%$ y en un $45 \%$ respectivamente.

Esta evidencia refuerza la idea de que la pandemia ha favorecido la sustitución de los viajes internacionales por los nacionales lo cual está en línea con otros estudios previos. Por ejemplo, Cooper (2003) observó que, ante la epidemia del SARS de 2003, los turistas japonenses evitaron ciertos destinos, pero no dejaron de viajar y, en consecuencia, optaron por los viajes interiores. Más recientemente, para el caso de España, Benítez-Aurioles (2021b) demostró que, como consecuencia de la pandemia de la COVID-19, había disminuido el número de viajes al extranjero mientras que creció el de los realizados dentro de España y, más concretamente, los que tenían como destino la propia Comunidad Autónoma de residencia del turista. Todo lo cual acredita la capacidad del turismo nacional para compensar la caída del turismo internacional al menos en España (Arbulú et al., 2021).

Otro dato relevante se refiere al aumento de la estancia media total que alcanzó los 2,61 días en agosto de 2021. Esta cifra es la más alta desde, al menos, 2005 y es uno de los elementos que está caracterizando la resiliencia del turismo en los entornos urbanos lo cual proporciona pistas, no sólo para la gestión de los establecimientos hoteleros, sino también para las campañas de promoción puestas en marcha en el ámbito público.

Por otro lado, los indicadores de oferta representados en la figura 2 confirman la recuperación del mercado a partir de mediados de 2021. El número de habitaciones estimadas alcanzó en agosto y septiembre de 2021 sus máximos históricos, lo que sugiere que, no sólo se produjo la reapertura de establecimientos hoteleros que habían cerrado durante la pandemia, sino que también hubo nuevas incorporaciones al mercado. El hecho de que, a pesar de ese crecimiento en el número de habitaciones estimadas, su grado de ocupación también haya crecido se explica, lógicamente, por la recuperación de la demanda turística. El resultado final fue un aumento del empleo que, en pocos meses, casi se triplica al pasar de los 589 en febrero de 2021 a los 1.589 en septiembre de ese mismo año, muy próximo al nivel alcanzado antes de la pandemia. Este es otro dato que confirma la resiliencia del turismo urbano en la ciudad de Málaga ante la crisis de la COVID-19.

Finalmente, la figura 3 recoge la evolución de la tarifa media diaria (ADR, Average Daily Rate) y de los ingresos por habitación disponible (RevPAR, Revenue per Available Room). El ADR representa los ingresos medios diarios por habitación ocupada. La información estadística se recupera en octubre de 2020 y, desde marzo de 2021, se aprecia una subida sostenida del ADR que se hace, particularmente, intensa durante julio y agosto. En septiembre de 2021 vuelve a disminuir, siguiendo la pauta de los años anteriores. El hecho de que el ADR haya experimentado elevaciones importantes los meses en los que, precisamente, aumentó tanto la demanda como la oferta de habitaciones, es una evidencia que justifica, aún más, la resiliencia que ha demostrado el turismo urbano en Málaga tras la pandemia. Además, de acuerdo con el análisis económico más elemental, la subida de los precios de las habitaciones, si se incrementa la oferta, solo puede explicarse por un incremento aún mayor de la demanda que, tal como se ha señalado, recibió un impulso decisivo por parte de los residentes en España. 
Beatriz Benítez-Aurioles / REA N. 43 (2022) 71-88
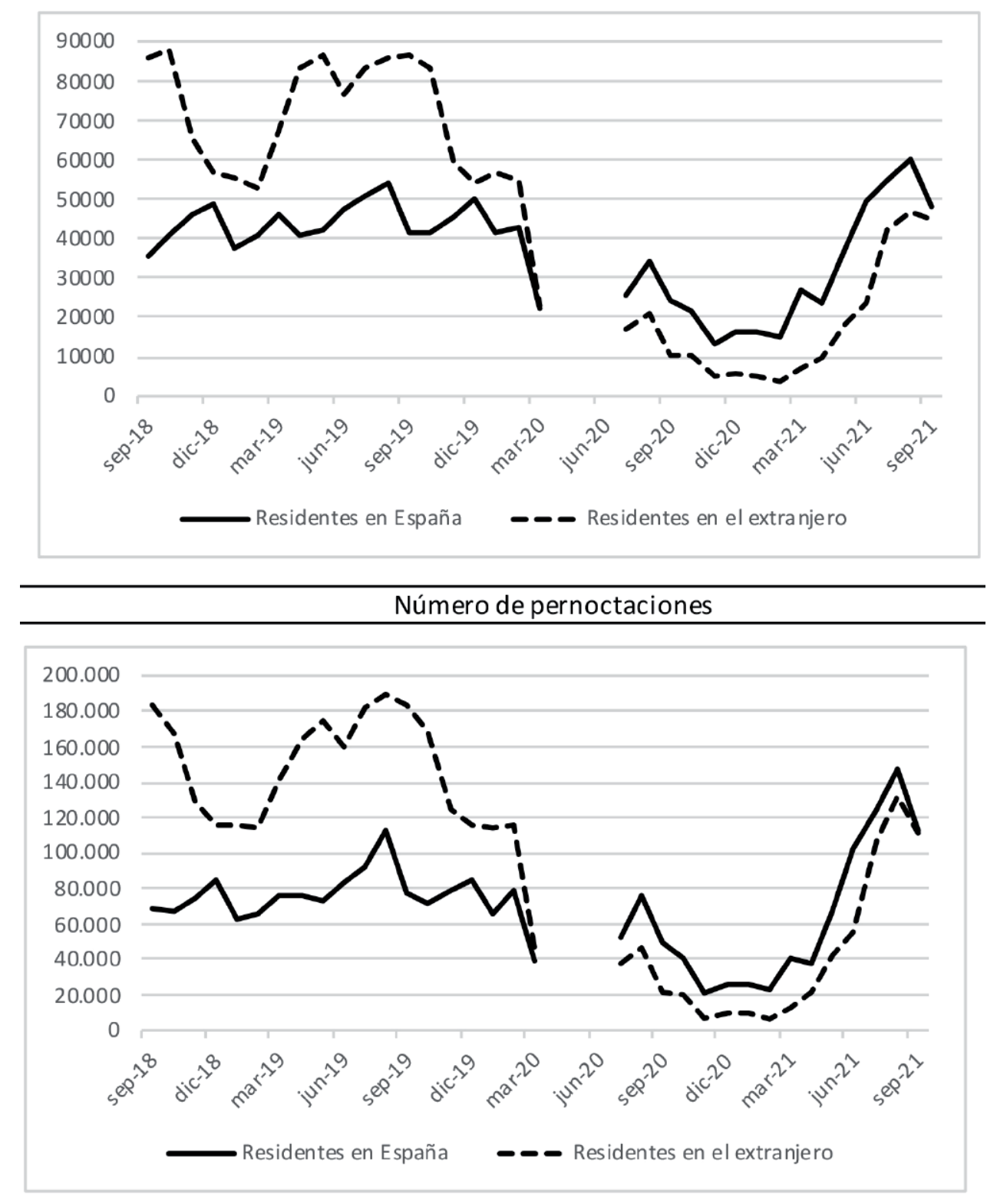

Estancia media (días)

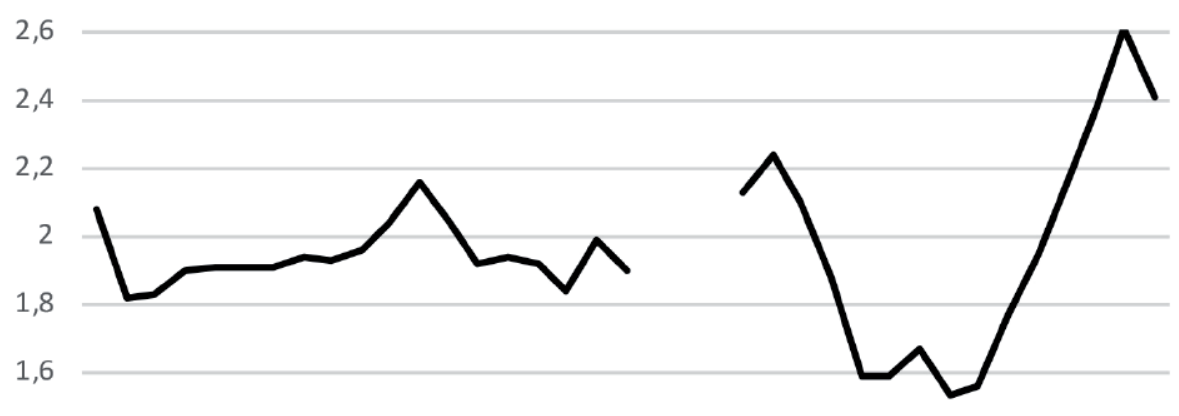

1,4

1,2

1

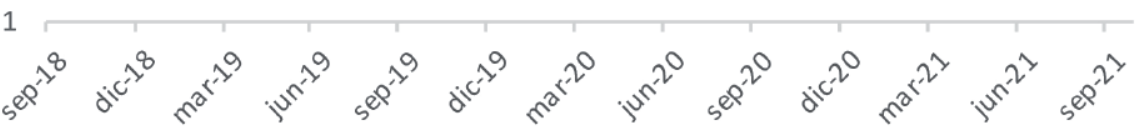

Figura 1. Indicadores de demanda en el sector hotelero en la ciudad de Málaga.

Fuente: Elaboración propia a partir de INE (2021c).

(c) Editorial Universidad de Sevilla 2022 | Sevilla, España| CC BY-NC-ND 4.0 | e-ISSN: 2340-2776 | doi: https://dx.doi.org/10.12795/rea.2022.i43.04 
Beatriz Benítez-Aurioles / REA N. 43 (2022) 71-88
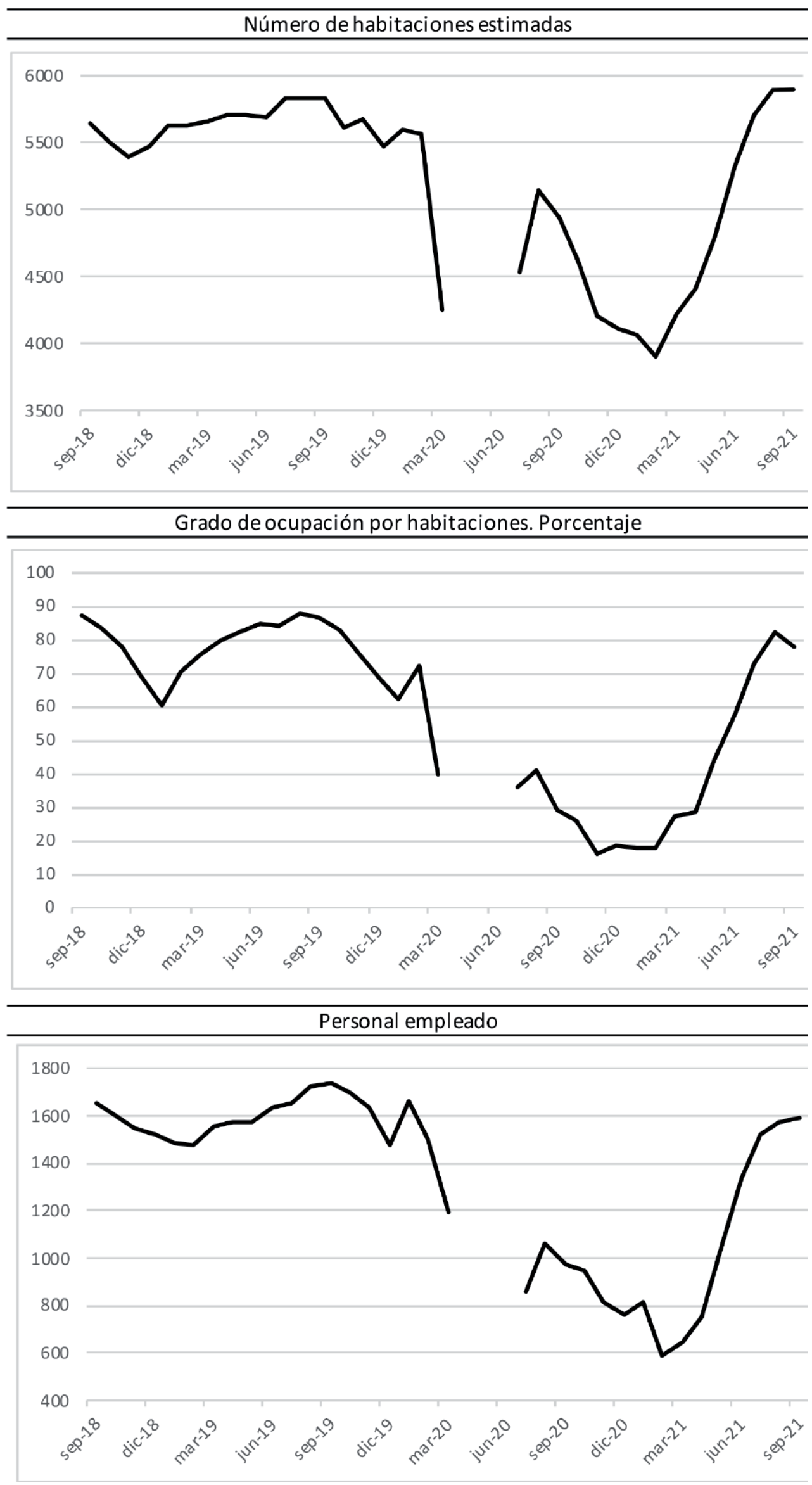

Figura 2. Indicadores de oferta en el sector hotelero en la ciudad de Málaga. Fuente: Elaboración propia a partir de INE (2021c).

(c) Editorial Universidad de Sevilla 2022 | Sevilla, España| CC BY-NC-ND 4.0 | e-ISSN: 2340-2776 | doi: https://dx.doi.org/10.12795/rea.2022.i43.04 
La RevPAR, por su parte, es uno de los indicadores básicos de rentabilidad hotelera y es, simplemente, el producto del ADR y de la ocupación por habitación. Lógicamente, su evolución está condicionada por esas dos variables. Pues bien, desde febrero de 2021 el RevPAR ha tenido crecimientos medios mensuales en torno al $40 \%$, lo cual está en línea con los resultados comentados anteriormente.
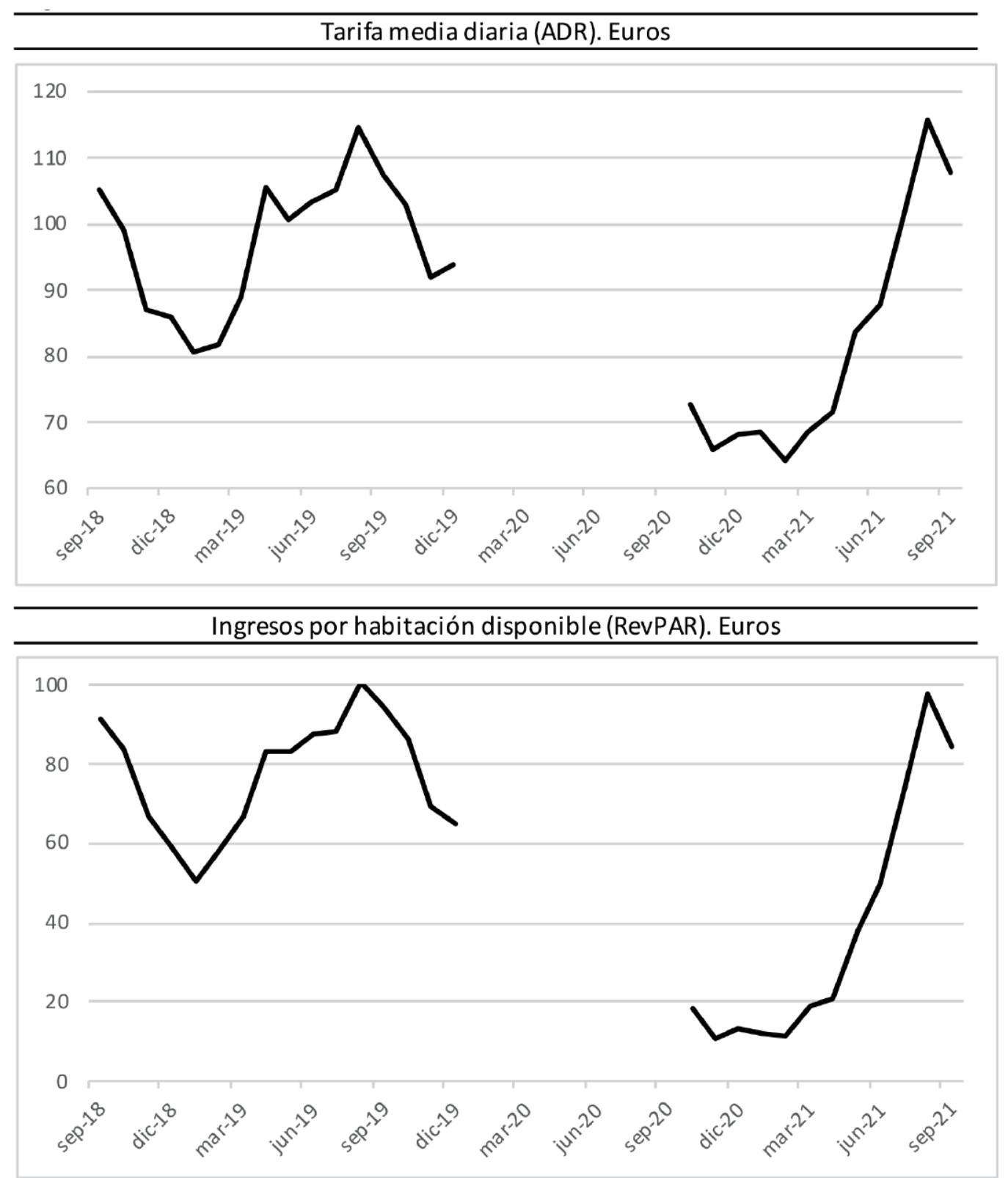

Figura 3. Indicadores de rentabilidad. Fuente: Elaboración propia a partir de INE (2021c).

\subsection{Airbnb}

Respecto al comportamiento del mercado p2p, en general, y de la comercialización de alojamientos a través de Airbnb, en particular, se tomará como indicador de la demanda la evolución en el número de evaluaciones que obtuvieron los anuncios que estaban activos el 30 de septiembre de 2021. En la figura 4 observamos, en consonancia con lo detectado para la demanda hotelera, la práctica ausencia de movimientos durante los meses de abril, mayo y junio de 2020, la leve recuperación durante el verano de ese mismo año, la subsiguiente disminución de la demanda, en buena medida por motivos estacionales, y, finalmente, una 
evidente expansión a partir de mayo de 2021. De hecho, el número de evaluaciones registradas en agosto de 2021 duplica las del año anterior, y la de septiembre de 2021 está muy próxima a la del mismo mes de 2019, antes de la pandemia. Estos datos apuntan a que la resiliencia del turismo urbano en la ciudad de Málaga no se limitó al mercado convencional (hoteles) sino que se manifiesta también en el mercado p2p. Sobre esa base, es previsible que se planteen de nuevo los debates que estaban abiertos antes de la pandemia sobre los efectos que provoca la expansión del mercado p2p en las ciudades.

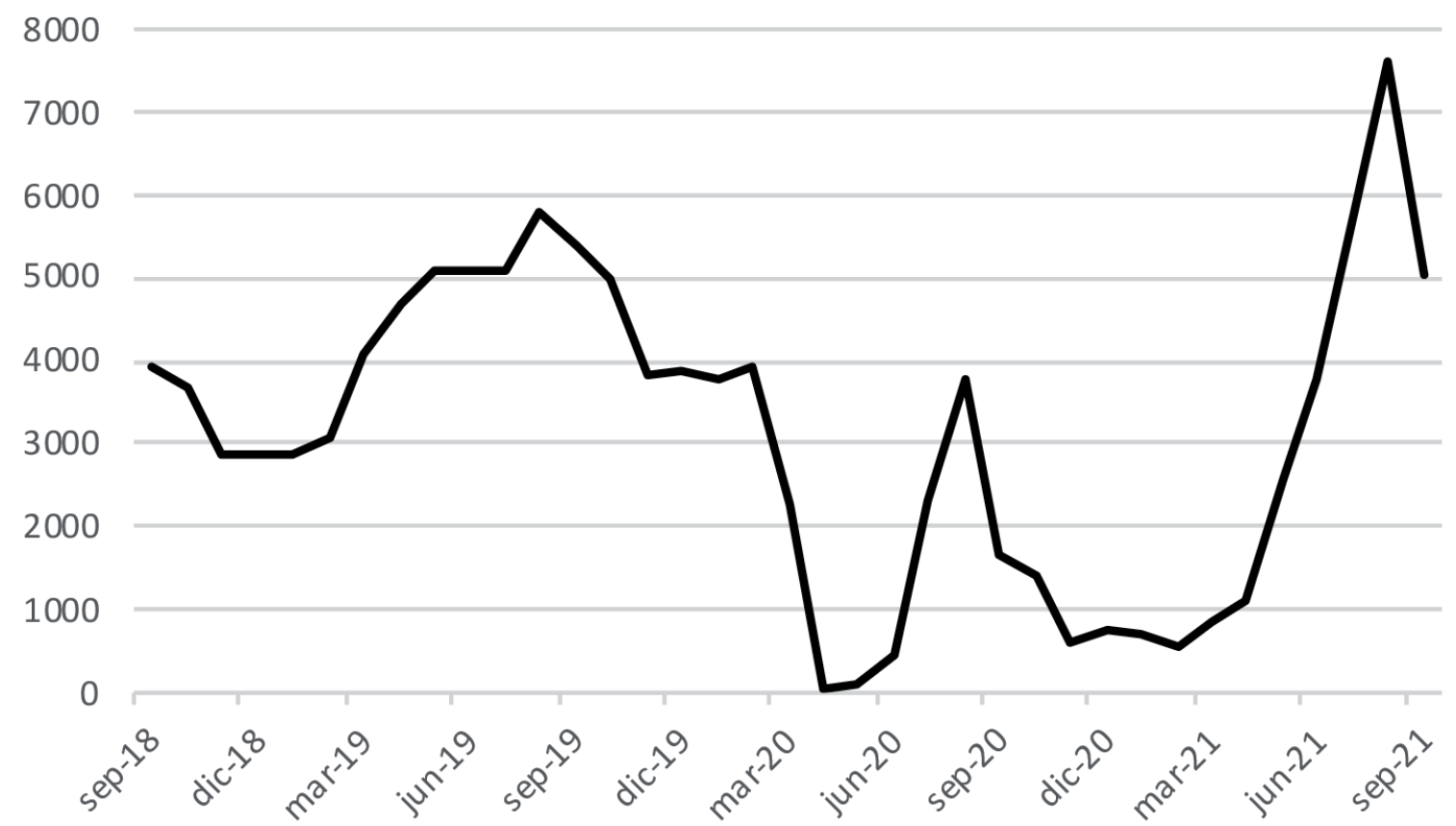

Figura 4. Evolución del número de evaluaciones de los anuncios activos el 30 de septiembre de 2021. Fuente: Elaboración propia a partir de InsideAirbnb (2021).

Por el lado de la oferta la información disponible nos permite un ejercicio de estática comparativa con los datos de scrapings realizados a los anuncios de Airbnb en la ciudad de Málaga el 1 de septiembre de 2019 y el 30 de septiembre de 2021. Así, a partir de los datos de la tabla 2, se observa que la oferta de alojamientos disminuyó. Los anuncios lo hicieron en 363 (un 6\%) y el número de huéspedes que potencialmente pueden ser alojados en 2.557 (un 10\%). Es posible que, dadas las reducidas barreras de entrada y salida que posee la oferta en este mercado, durante la pandemia se haya producido una reducción de la oferta que aún no se haya recuperado. En principio, esta flexibilidad es mayor que la que tienen los alojamientos convencionales lo que, en última instancia, le permite ciertas ventajas competitivas (Einav et al., 2016).

Ahora bien, el hecho de que la oferta de alojamientos en el mercado p2p sea menor no equivale necesariamente a una reducción efectiva del mercado. Los datos de los que hemos podido disponer no permiten distinguir qué alojamientos han salido del mercado o si se ha producido un trasvase de la oferta de viviendas desde el alquiler a corto plazo hacia el alquiler a largo plazo como, a nivel general, han sugerido Dolnicar y Zare (2020). No obstante, de acuerdo con la lógica económica, cabe plantear la hipótesis de que la reducción de la oferta se haya producido, precisamente, en los alojamientos menos rentables, es decir, los menos demandados. Aquí conviene recordar que existe evidencia de que un elevado porcentaje de alojamientos en el mercado p2p apenas son demandados (Benítez-Aurioles, 2020a). Sobre esa base, es posible que, ante la recuperación de la demanda, se haya producido una utilización más intensa de los alojamientos disponibles con lo que, en última instancia, la presión turística que ejerce el mercado p2p pueda estar recuperando los niveles que tenía antes de la pandemia. Esta conjetura viene avalada por el hecho de que el número medio de evaluaciones entre los anuncios que estaban activos el 30 de septiembre de 2019 y habían recibido, al 
menos, una evaluación, era 35, mientras que, entre los anuncios activos el 30 de septiembre de 2021, había subido a 42. Es decir, habría menos alojamientos, pero con un grado de ocupación mayor.

Tabla 2. Indicadores de oferta en el mercado peer-to-peer.

\begin{tabular}{|l|c|c|c|}
\hline & 1-Sep-19 [1] & 30-Sep-21 [2] & [2]-[1] \\
\hline Número de anuncios & 6.019 & 5.656 & -363 \\
\hline Número de huéspedes potenciales & 25.543 & 22.986 & -2.557 \\
\hline \% alojamientos completos & 84,4 & 85,8 & 1,4 \\
\hline Número de anfitriones & 2.610 & 2.297 & -313 \\
\hline \% anuncios ofrecidos por profesionales & 70,2 & 72,7 & 2,5 \\
\hline \% de Superhosts & 22,2 & 24,3 & 2,1 \\
\hline \% de reserva instantánea & 76,6 & 66,5 & $-10,1$ \\
\hline
\end{tabular}

Fuente: Elaboración propia a partir de InsideAirbnb (2021).

En cuanto al tipo de alojamientos ofrecidos se consolida la oferta de viviendas completas que crecen levemente hasta alcanzar el $85,8 \%$ del total de la oferta, lo cual confirma la idea de que Airbnb, más que una plataforma que permite compartir el espacio sobrante en una vivienda, está dedicada a la comercialización del alquiler de viviendas completas a corto plazo (Gyódi, 2019).

El número de anfitriones se redujo durante el periodo considerado en un $12 \%$ y, al mismo tiempo, creció el porcentaje de anuncios ofrecidos por anfitriones que posee más de un alojamiento, y el de los que tenían la etiqueta Superhosts, lo cual es compatible con una mayor profesionalización del mercado. En muchos casos, la oferta es realizada por empresas que gestionan de forma integral el alquiler de los apartamentos en nombre de los verdaderos propietarios. Por ejemplo, Luckey es una empresa que fue adquirida por la propia Airbnb en diciembre de 2018 y que por una comisión del $20 \%$ se encargan de todo el proceso, desde la gestión de la entrada y salida de los huéspedes hasta la limpieza y el mantenimiento de los alojamientos (Luckey, 2021).

También es destacable la reducción en algo más de 10 puntos del porcentaje de reservas que pueden realizarse de forma instantánea, lo cual podría ser indicativo del mayor interés de los anfitriones por seleccionar el tipo de turista que recibe. Este dato merece una reflexión adicional ya que, desde Airbnb (2021c) se ha promocionado la opción de reserva instantánea, igual que existe en los alojamientos convencionales, ante la evidencia de que la posibilidad de que sea necesaria la confirmación del anfitrión para validar la reserva pueda estar facilitando la discriminación de algunas minorías étnicas (Edelman et al., 2017) o de personas con una determinada orientación sexual (Ahuja \& Lyons, 2017). No obstante, con la información disponible no es posible determinar las razones por las que ha disminuido el porcentaje de anuncios de Airbnb que, en la ciudad de Málaga, permiten una reserva instantánea, aunque cabe la posibilidad de que esté relacionado con la búsqueda por parte de los anfitriones de una mayor seguridad sanitaria tras la pandemia.

Por último, para el análisis de la formación de los precios en el mercado p2p de alojamientos turísticos, los datos disponibles nos han permitido estimar la ecuación [1] antes (1 de septiembre de 2019) y después de la pandemia (30 de septiembre de 2021). En ambos casos, el poder explicativo del modelo es similar $(R 2=0,51)$. Asimismo, los parámetros que acompañan a algunas variables no solo mantienen los signos esperados, sino que su valor es, prácticamente, el mismo. Así ocurre con el número máximo de huéspedes que potencialmente pueden ser alojados (AC), con la vivienda completa (EH), y con el número de evaluaciones por anuncio (NR). La constante también mantiene el mismo valor. La distancia (DI), en cambio, parece perder relevancia: mientras que antes de la pandemia tiene el signo esperado con elevada significación estadística, después pierde la significación estadística y su influencia en la determinación de los precios de los alojamientos. No obstante, quizás los cambios más reseñables se hayan producido en los parámetros de las 
variables relacionadas con los anfitriones y su política de reserva. En este sentido, pierde influencia la etiqueta Superhost (SH) mientras que lo gana el número de anuncios por anfitrión (Ln L). Asimismo, es destacable el cambio de signo del parámetro relacionado con la reserva instantánea (IB) que pasa a ser positivo al final del periodo. Probablemente, estos cambios estén relacionados con la mayor importancia que han adquirido los oferentes profesionales en el mercado $\mathrm{p} 2 \mathrm{p}$.

Tabla 3. Resultados de la regresión de la ecuación [1].

\begin{tabular}{|c|c|c|}
\hline & 1-Sep-19 & 30-Sep-21 \\
\hline AC. Número máximo de huéspedes & $0,12 * * *$ & $0,12 * * *$ \\
\hline EH. Vivienda completa & $0,61 * * *$ & $0,61 * * *$ \\
\hline DI. Distancia en kilómetros a plaza Constitución & $-0,013 * * *$ & 0,003 \\
\hline SH. Superhost & $0,06 * * *$ & $0,03 * *$ \\
\hline Ln L. Logaritmo del número de anuncios por anfitrión & $0,015 * * *$ & $0,043 * * *$ \\
\hline IB. Reserva instantánea & $-0,03 *$ & $0,07 * * *$ \\
\hline NR. Número de evaluaciones por anuncio & $-0,001 * * *$ & $-0,001 * * *$ \\
\hline Constante & $3,16 * * *$ & $3,16 * * *$ \\
\hline N. Número de observaciones & 3.589 & 3.263 \\
\hline R2-ajustado & 0,51 & 0,51 \\
\hline
\end{tabular}

\section{CONCLUSIONES}

La pandemia de la COVID-19 ha provocado una crisis sin precedentes que ha afectado, con especial intensidad, al turismo. No obstante, el progresivo avance de la vacunación y la eliminación de las restricciones a la movilidad permitieron que la actividad turística empezara a dar señales de recuperación. En este contexto, el análisis de la resiliencia del turismo urbano, que ha recibido una creciente atención desde el punto de vista académico, tiene una especial relevancia dado el debate abierto, antes de la pandemia, sobre la presión que estaba ejerciendo el turismo en determinadas ciudades. El caso de Málaga es una buena referencia, no sólo por la importancia absoluta y relativa que posee la actividad turística en la generación de renta y de empleo, sino por el peso que tiene el mercado p2p de alojamientos turísticos que ha sido, frecuentemente, señalado como el catalizador de impactos negativos asociados al overtourism.

Entre los diversos enfoques metodológicos que pueden adoptarse para el estudio del turismo urbano, el marco teórico que proporciona el análisis económico resulta pertinente para conocer los vectores básicos que condicionan el funcionamiento del mercado turístico, es decir, la demanda, la oferta y los precios. Asimismo, dadas las diferencias que existen entre el mercado de alojamientos convencionales y el mercado p2p de alquiler de viviendas a corto plazo, es conveniente un análisis separado.

Tomando como base la Encuesta de Ocupación Hotelera del INE, el análisis del mercado de alojamientos convencionales ha mostrado evidentes signos de recuperación a partir de los meses de abril y mayo de 2021. En este sentido, es destacable la resiliencia demostrada por el turismo urbano, al menos en la ciudad de Málaga, y el protagonismo adquirido por el turismo nacional. En efecto, todo apunta a que los residentes en España sustituyeron los viajes internacionales por los nacionales con lo que, a diferencia de lo que ocurría antes de la pandemia, ha superado al turismo realizado por los extranjeros, tanto en términos de viajeros como de pernoctaciones hoteleras. Adicionalmente, aumentó, hasta alcanzar cifras históricas, la 
estancia media en los hoteles de la ciudad lo que podría conectarse con el cambio del comportamiento que ha propiciado el turista nacional.

Otros indicadores, como el número de habitaciones estimadas, su grado de ocupación o el personal empleado por los hoteles, confirman la resiliencia del sector desde la primavera de 2021. El hecho de que se haya producido, a partir de entonces, una subida del ADR y del RevPAR hace pensar que la intensidad en la recuperación de la demanda, ha compensado el incremento de la oferta, y, en consecuencia, es lo que explica la subida de los precios en el mercado de alojamientos convencionales.

Por su parte, el mercado p2p de alojamientos turísticos también demuestra unos patrones de resiliencia similares al del mercado convencional y, más concretamente, una fuerte recuperación de la demanda partir de mayo de 2021. Asimismo, un análisis más concreto de la oferta confirma la preponderancia de la comercialización de viviendas completas y el de los anfitriones que ofrecen más de un alojamiento. Es decir, parece fortalecerse la tendencia hacia un mercado en el que la oferta está en manos de profesionales que, básicamente, se dedican al alquiler de viviendas completas a corto plazo, lo que, en última instancia, podría explicar ciertos cambios en el proceso de formación de precios tras la pandemia.

De acuerdo con lo anterior, se constata la resiliencia del turismo urbano, al menos en la ciudad de Málaga, tanto en el mercado convencional (hoteles) como en el mercado p2p (Airbnb). Además, las características de esta recuperación tienen algunas implicaciones prácticas tanto para el ámbito privado como público. Así, el protagonismo que ha tenido el turismo nacional en la demanda turística de alojamientos en los hoteles y la prolongación de la estancia puede servir de base para la articulación, por parte de los gestores privados, de campañas de promoción especialmente orientadas a los turistas residentes en España. Por otro lado, el resurgimiento del mercado $\mathrm{p} 2 \mathrm{p}$ de alojamientos turísticos reabre el debate sobre la capacidad de carga de las ciudades y la pertinencia de su regulación.

\section{Agradecimientos}

La autora agradece los comentarios y sugerencias de dos evaluadores anónimos, así como la labor del equipo editorial de la Revista de Estudios Andaluces. En cualquier caso, los errores y carencias que pudiera tener este artículo son de exclusiva responsabilidad de la autora.

\section{Declaración responsable y conflicto de intereses}

La autora garantiza la autoría y originalidad del artículo, y asume la plena y exclusiva responsabilidad por los daños y perjuicios que pudieran producirse como consecuencia de reclamaciones de terceros respecto del contenido, autoría o titularidad del contenido del mismo. Asimismo, la autora declara que no existe ningún conflicto de interés con relación a la publicación de este artículo.

\section{REFERENCIAS}

Ahuja, R. \& Lyons, R. (2017). The Silent Treatment: LGBT Discrimination in the Sharing Economy, Trinity Economics Papers tep1917. Trinity College Dublin, Department of Economics. https://www.tcd.ie/Economics/TEP/2017/tep1917.pdf

Airbnb (2021a). Evaluaciones de alojamientos. https://www.airbnb.es/help/article/13/evaluaciones-de-alojamientos?_set_ bev_on_new_domain=1602779486_mIqcHLyDNsehfobD

Airbnb (2021b). Superhost: un premio a los mejores anfitriones. https://www.airbnb.es/d/superhost

Airbnb (2021c). Cómo utilizar la Reserva inmediata. https://www.airbnb.es/help/article/1510/c\%C3\%B3mo-utilizar-la-reserva-inmediata

AirDNA (2021). Vacation Rental Data to Set You Apart. Insights to Keep You Ahead. https://www.airdna.co/ 
Alsudais, A. (2021). Incorrect data in the widely used Inside Airbnb dataset. Decision Support Systems, 141, 113453. https:// doi.org/10.1016/j.dss.2020.113453

Arbulú, I., Razumova, M., Rey-Maquieira, J. \& Sastre, F. (2021). Can domestic tourism relieve the COVID-19 tourist industry crisis? The case of Spain. Journal of Destination Marketing \& Management, 20, 100568. https://doi.org/10.1016/j. jdmm.2021.100568

Ashworth, G. J. (1992). Is there an urban tourism? Tourism Recreation Research, 17(2), 3-8. https://doi.org/10.1080/02508 281.1992.11014645

Ashworth, G. \& Page, S. J. (2011). Urban tourism research: Recent progress and current paradoxes. Tourism Management, 32(1), 1-15. https://doi.org/10.1016/j.tourman.2010.02.002

Ayuntamiento de Málaga (2021). Plan estratégico turismo de Málaga 2021-2024. http://s3.malagaturismo.com/files/933/933/plan-estrategico-turismo-2021-2024-def.pdf

Belk, R. (2014). Sharing versus pseudo-sharing in Web 2.0. The Anthropologist, 18(1), 7-23. https://doi.org/10.1080/0972 0073.2014 .11891518

Benítez-Aurioles, B. (2018a). Estrategias de comunicación: Airbnb versus hoteles/Communication strategies: Airbnb versus hotels. Revista Internacional de Relaciones Públicas, 8(16), 47-66. http://dx.doi.org/10.5783/RIRP-16-2018-04-4766

Benítez-Aurioles, B. (2018b). Why are flexible booking policies priced negatively? Tourism Management, 67, 312-325. https://doi.org/10.1016/j.tourman.2018.02.008

Benítez-Aurioles, B. (2018c). The role of distance in the peer-to-peer market for tourist accommodation. Tourism Economics, 24(3), 237-250. https://doi.org/10.1177/1354816617726211

Benítez-Aurioles, B. (2019a). Barcelona's peer-to-peer tourist accommodation market in turbulent times: terrorism and political uncertainty. International Journal of Contemporary Hospitality Management, 31(12), 4419-4437. https://doi. org/10.1108/IJCHM-01-2019-0090

Benítez-Aurioles, B. (2019b). Is Airbnb bad for hotels? Current Issues in Tourism, 1-4. https://doi.org/10.1080/13683500.2 019.1646226

Benítez-Aurioles, B. (2020a). Tourism Resilience Patterns in Southern Europe. Tourism Analysis, 25(4), 409-424. https://doi. org/10.3727/108354220X16010020096118

Benítez-Aurioles, B. (2020b). The exhaustion of the herding effect in peer-to-peer accommodation. Tourism Economics, 1354816620946537. https://doi.org/10.1177/1354816620946537

Benítez-Aurioles, B. (2021a). Uncertainty and tourism. A regional approach. Investigaciones Turísticas, 22, 52-68. https:// doi.org/10.14198/INTURI2021.22.3

Benítez-Aurioles, B. (2021b). El turismo interior en España ante la crisis de la COVID-19. Boletín económico de ICE, Información Comercial Española, 3139, 43-53. https://doi.org/10.32796/bice.2021.3139.7285

Benítez-Aurioles, B. \& Tussyadiah, I. P. (2020). What Airbnb does to the housing market. Annals of Tourism Research, 103108. https://doi.org/10.1016/j.annals.2020.103108

Blake, A. \& Sinclair, M. T. (2003). Tourism crisis management: US response to September 11. Annals of Tourism Research, 30(4), 813-832. https://doi.org/10.1016/S0160-7383(03)00056-2

Camilleri, J. \& Neuhofer, B. (2017). Value co-creation and co-destruction in the Airbnb sharing economy. International Journal of Contemporary Hospitality Management, 29(9), 2322-2340. https://doi.org/10.1108/IJCHM-09-2016-0492

Comendador-Sánchez, A., Santos-Pavón, E. \& Hernández-Ramírez, J. (2021). Players, interests and public policies in relation to tourist rental housing in Spain (2010-2019). Complexity and multiple conflicts. Journal of Tourism Analysis: Revista de Análisis Turístico (JTA), 28(1), 1-21. https://doi.org/10.53596/jta.v28i1.373

Cooper, M. (2006). Japanese tourism and the SARS epidemic of 2003. Journal of Travel \& Tourism Marketing, 19(2-3), 117131. https://doi.org/10.1300/J073v19n02_10

Corbet, S., O'Connell, J. F., Efthymiou, M., Guiomard, C. \& Lucey, B. (2019). The impact of terrorism on European tourism. Annals of Tourism Research, 75, 1-17. https://doi.org/10.1016/j.annals.2018.12.012

Dann, D., Teubner, T. \& Weinhardt, C. (2019). Poster child and guinea pig-insights from a structured literature review on Airbnb. International Journal of Contemporary Hospitality Management, 31(1), 427-473. https://doi.org/10.1108/ IJCHM-03-2018-0186 
Deale, C. S., \& Crawford, A. (2018). Providers' perceptions of the online community marketplace for lodging accommodations. Tourism and Hospitality Research, 18(4), 470-477. https://doi.org/10.1177/1467358416682067

Deane, S. (2021). 2021 Airbnb Statistics: Usage, Demographics, and Revenue Growth. https://www.stratosjets.com/blog/ airbnb-statistics/

Dolnicar, S. (2019). A review of research into paid online peer-to-peer accommodation: Launching the Annals of Tourism Research curated collection on peer-to-peer accommodation. Annals of Tourism Research, 75, 248-264. https://doi. org/10.1016/j.annals.2019.02.003

Dolnicar, S. \& Zare, S. (2020). COVID19 and Airbnb-Disrupting the disruptor. Annals of Tourism Research, 83, 102961. https://doi.org/10.1016/j.annals.2020.102961

Edelman, B., Luca, M., \& Svirsky, D. (2017). Racial discrimination in the sharing economy: Evidence from a field experiment. American Economic Journal: Applied Economics, 9(2), 1-22. https://doi.org/10.1257/app.20160213

Edwards, D., Griffin, T. \& Hayllar, B. (2008). Urban tourism research: developing an agenda. Annals of Tourism Research, 35(4), 1032-1052. https://doi.org/10.1016/j.annals.2008.09.002

Einav, L., Farronato, C. \& Levin, J. (2016). Peer-to-peer markets. Annual Review of Economics, 8, 615-635. https://doi. org/10.1146/annurev-economics-080315-015334

Exceltur (2017). Monitor de competitividad turística de los destinos urbanos españoles. Urbantur 2016. https://www.exceltur. org/

Exceltur (2021). Barómetro de la rentabilidad de los destinos turísticos españoles. https://www.exceltur.org/wp-content/ uploads/2021/02/Baro\%CC\%81 metro-Rentabilidad-y-el-Empleo-Enero-Diciembre-2020.pdf

Gassmann, S.-E., Nunkoo, R., Tiberius, V. \& Kraus, S. (2021). My home is your castle: forecasting the future of accommodation sharing. International Journal of Contemporary Hospitality Management, 33(2), 467-489. https://doi.org/10.1108/ IJCHM-06-2020-0596

Gibbs, C., Guttentag, D., Gretzel, U., Morton, J. \& Goodwill, A. (2018a). Pricing in the sharing economy: A hedonic pricing model applied to Airbnb listings. Journal of Travel \& Tourism Marketing, 35(1), 46-56. https://doi.org/10.1080/10548 408.2017.1308292

Gurran, N. \& Phibbs, P. (2017). When tourists move in: how should urban planners respond to Airbnb? Journal of the American Planning Association, 83(1), 80-92. https://doi.org/10.1080/01944363.2016.1249011

Guttentag, D. (2015). Airbnb: disruptive innovation and the rise of an informal tourism accommodation sector. Current issues in Tourism, 18(12), 1192-1217. https://doi.org/10.1080/13683500.2013.827159

Guttentag, D. (2019). Progress on Airbnb: a literature review. Journal of Hospitality and Tourism Technology. https://doi. org/10.1108/JHTT-08-2018-0075

Gyódi, K. (2019). Airbnb in European cities: Business as usual or true sharing economy?. Journal of Cleaner Production, 221, 536-551. https://doi.org/10.1016/j.jclepro.2019.02.221

Hajibaba, H. \& Dolnicar, S. (2018). Airbnb and its Competitors. En S. Dolnicar (Ed.) Peer-to-Peer Accommodation Networks: Pushing the boundaries (pp. 63-76). Oxford: Goodfellow Publishers. https://dx.doi.org/10.23912/97819113965123604

Hartmans, A. (2017). Airbnb now has more listings worldwide than the top five hotel brands combined, BusinessInsider. https://www.businessinsider.com/airbnb-total-worldwide-listings-2017-8

Hati, S. R. H., Balqiah, T. E., Hananto, A. \& Yuliati, E. (2021). A decade of systematic literature review on Airbnb: the sharing economy from a multiple stakeholder perspective. Heliyon, 7(10), e08222. https://doi.org/10.1016/j.heliyon.2021. e08222

Hocevar, M. \& Bartol, T. (2021). Mapping urban tourism issues: analysis of research perspectives through the lens of network visualization. International Journal of Tourism Cities. 7(3), 818-844. https://doi.org/10.1108/IJTC-05-2020-0110

Hu, M. R. \& Lee, A. D. (2020). Airbnb, COVID-19 Risk and Lockdowns: Global Evidence. https://papers.ssrn.com/sol3/ papers.cfm?abstract_id=3589141

Ikeji, T. \& Nagai, H. (2020). Residents' attitudes towards peer-to-peer accommodations in Japan: Exploring hidden influences from intergroup biases. Tourism Planning \& Development, 18(5), 491-509. https://doi.org/10.1080/2156831 6.2020 .1807400

Ikkala T. \& Lampinen A. (2014) Defining the Price of Hospitality: Networked Hospitality Exchange via Airbnb. CSCW, Baltimore, 173-176. https://doi.org/10.1145/2556420.2556506 
INE (2019). Encuesta de Ocupación Hotelera. Metodología. https://ine.es/daco/daco42/ocuphotel/meto_eoh.pdf

INE (2021a). Estimación de la ocupación en alojamientos turísticos a partir de datos de plataformas digitales. https://ine.es/ experimental/ocupacion/experimental_ocupacion.htm

INE (2021b). Indicadores Urban Audit para Ciudades. https://www.ine.es/jaxiT3/Tabla.htm?t=30140

INE (2021c). Encuesta de Ocupación Hotelera. https://ine.es/dyngs/INEbase/es/operacion.htm?c=Estadistica_C\&ci$\mathrm{d}=1254736177015 \&$ menu=ultiDatos\&idp=1254735576863

InsideAirbnb (2021). Get the Data. http://insideairbnb.com/get-the-data.html

Jiménez, J. L., Ortuño, A. \& Pérez-Rodríguez, J. V. (2021). How does AirBnb affect local Spanish tourism markets?. Empirical Economics, 1-31. https://doi.org/10.1007/s00181-021-02107-2

Karlsson, L. \& Dolnicar, S. (2016). Someone's been sleeping in my bed. Annals of Tourism Research, 58, 159-162. https:// doi.org/10.1016/j.annals.2016.02.006

Li, J., Moreno, A. \& Zhang, D. J. (2019). Agent Pricing in the Sharing Economy: Evidence from Airbnb. In M. Hu (Ed.) Sharing Economy (pp. 485-503). Cham: Springer. https://doi.org/10.1007/978-3-030-01863-4_20

Liang, S., Schuckert, M., Law, R. \& Chen, C-C. (2017). Be a 'Superhost': The importance of badge systems for peer-to-peer rental accommodations. Tourism Management, 60, 454-465. https://doi.org/10.1016/j.tourman.2017.01.007

Luckey (2021). Gestión de apartamentos turísticos en Airbnb. https://luckey.es/

Magno, F., Cassia, F.\& Ug olini, M. M. (2018). Accommodation prices on Airbnb: effects of host experience and market demand. The TQM Journal, 30(5), 608-620. https://doi.org/10.1108/TQM-12-2017-0164

Martín, E. G. \& Gimeno, M. V. (2021). Encuestas de Ocupación en Alojamientos Turísticos. Índices de Precios e Indicadores de Rentabilidad del Sector Hotelero. Indice: Revista de Estadística y Sociedad, (80), 26-32. http://www.revistaindice.com/numero80/p26.pdf

McKercher, B. \& Chon, K. (2004). The over-reaction to SARS and the collapse of Asian tourism. Annals of Tourism Research, 31(3), 716-719. https://doi.org/10.1016/j.annals.2003.11.002

Möhlmann, M. (2015). Collaborative consumption: determinants of satisfaction and the likelihood of using a sharing economy option again. Journal of Consumer Behaviour, 14(3), 193-207. https://doi.org/10.1002/cb.1512

Namberger, P., Jackisch, S., Schmude, J. \& Karl, M. (2019). Overcrowding, overtourism and local level disturbance: how much can Munich handle?. Tourism Planning \& Development, 16(4), 452-472. https://doi.org/10.1080/21568316.201 9.1595706

Observatorio turístico de la ciudad de Málaga (s.f.). Enero 2019 - Diciembre 2019. http://s3.malagaturismo.com/files/974/974/presentacion-observatorio-turistico-ciudad-de-malagaene19dic19100320-2.pdf

Oskam, J. \& Boswijk, A. (2016). Airbnb: the future of networked hospitality businesses. Journal of Tourism Futures, 2(1), 22-42. https://doi.org/10.1108/JTF-11-2015-0048

Oskam, J. A. (2020). Commodification of the 'Local' in Urban Tourism: The Airbnb Contradiction. En J. A. Oskam (Ed.) The Overtourism Debate, Emerald Publishing Limited, Bingley (pp. 151-170). https://doi.org/10.1108/978-1-83867-487820201011

Ozdemir, G. \& Turker, D. (2019). Institutionalization of the sharing in the context of Airbnb: a systematic literature review and content analysis. Anatolia, 30(4), 601-613. https://doi.org/10.1080/13032917.2019.1669686

Pechlaner, H. \& Frehse, J. (2010). Financial crisis and tourism. En R. Conrady \& M. Buck (Eds.) Trends and Issues in Global Tourism 2010 (pp. 27-38). Berlin, Heidelberg: Springer. https://doi.org/10.1007/978-3-642-10829-7_4

Prayag, G. \& Ozanne, L. K. (2018). A systematic review of peer-to-peer (P2P) accommodation sharing research from 2010 to 2016: progress and prospects from the multi-level perspective. Journal of Hospitality Marketing \& Management, 27(6), 649-678. https://doi.org/10.1080/19368623.2018.1429977

Priporas, C. V., Stylos, N., Rahimi, R. \& Vedanthachari, L. N. (2017). Unraveling the diverse nature of service quality in a sharing economy: A social exchange theory perspective of Airbnb accommodation. International Journal of Contemporary Hospitality Management, 29(9), 2279-2301. https://doi.org/10.1108/IJCHM-08-2016-0420

Reinhold, S. \& Dolnicar, S. (2018). The Sharing Economy. In S. Dolnicar (Ed.) Peer-to-Peer Accommodation Networks: Pushing the boundaries (pp. 15-26). Oxford: Goodfellow Publishers. http://dx.doi.org/10.23912/9781911396512-3600

Rosselló, J., Becken, S. \& Santana-Gallego, M. (2020). The effects of natural disasters on international tourism: A global analysis. Tourism Management, 79, 104080. https://doi.org/10.1016/j.tourman.2020.104080 
Sainaghi, R. (2020). The current state of academic research into peer-to-peer accommodation platforms. International Journal of Hospitality Management, 89. https://doi.org/10.1016/j.ijhm.2020.102555

Schor, J. (2016). Debating the sharing economy. Journal of Self-Governance and Management Economics, 4(3), 7-22. https:// doi.org/10.22381/jsme4320161

Smith, M. K., Sziva, I. P. \& Olt, G. (2019). Overtourism and resident resistance in Budapest. Tourism Planning \& Development, 16(4), 376-392. https://doi.org/10.1080/21568316.2019.1595705

Tussyadiah, I. P. (2016). Factors of satisfaction and intention to use peer-to-peer accommodation. International Journal of Hospitality Management, 55, 70-80. https://doi.org/10.1016/j.ijhm.2016.03.005

Tussyadiah, I. P. \& Pesonen, J. (2016). Impacts of peer-to-peer accommodation use on travel patterns. Journal of Travel Research, 55(8), 1022-1040. https://doi.org/10.1177/0047287515608505

Tussyadiah, I. P. \& Zach, F. (2017). Identifying salient attributes of peer-to-peer accommodation experience. Journal of Travel \& Tourism Marketing, 34(5), 636-652. https://doi.org/10.1080/10548408.2016.1209153

UNWTO (2018). 'Overtourism'? Understanding and managing urban tourism growth beyond perceptions. Madrid: UNWTO. https://doi.org/10.18111/9789284420070

UNWTO (2019), Definiciones de turismo de la OMT, OMT, Madrid, https://doi.org/10.18111/9789284420858

UNWTO (2021). 2020: Worst year in tourism history with 1 billion fewer international arrivals. https://www.unwto.org/ news/2020-worst-year-in-tourism-history-with-1-billion-fewer-international-arrivals

Wang, D. \& Nicolau, J. L. (2017). Price determinants of sharing economy based accommodation rental: A study of listings from 33 cities on Airbnb.com. International Journal of Hospitality Management, 62, 120-131. https://doi.org/10.1016/j. ijhm.2016.12.007

Wiles, A. \& Crawford, A. (2017). Network hospitality in the share economy: Understanding guest experiences and the impact of sharing on lodging. International Journal of Contemporary Hospitality Management, 29(9), 2444-2463. https:// doi.org/10.1108/IJCHM-08-2016-0453

Wu, J., Zeng, M. \& Xie, K. L. (2017). Chinese travelers' behavioral intentions toward room-sharing platforms: The influence of motivations, perceived trust, and past experience. International Journal of Contemporary Hospitality Management, 29(10), 2688-2707. https://doi.org/10.1108/IJCHM-08-2016-0481

Zheng, W., Ji, H., Lin, C., Wang, W. \& Yu, B. (2020). Using a heuristic approach to design personalized urban tourism itineraries with hotel selection. Tourism Management, 76, 103956. https://doi.org/10.1016/j.tourman.2019.103956 


\title{
Does a visit to a blue-green space evoke positive feelings? Blue and green spaces survey in Shkodra' Lake, Albania
}

\author{
¿Evocan sentimientos positivos las visitas a un espacio verde y azul? \\ Encuesta sobre espacios azules y verdes, en el lago Shkodra, Albania \\ Samel Kruja \\ samel_kruja@universitetipolis.edu.al (1) 0000-0003-2717-138X \\ Polis University. Rr. Bylis 12, Tirane-Durres Highway, Km 5.1051 Tirana, Albania
}

\author{
Olta Braçe \\ oltabrace@msn.com @ 0000-0001-6335-5085 \\ Polytechnical University of Tirana. Rr. Muhamet Gjollesha, 54, Tirana, Albania
}

\section{INFO ARTÍCULO}

Received: 02/11/2021

Revised: 05/01/2022

Accepted: 09/01/2022

\section{KEYWORDS}

Blue space

Green space

Urban planning

Health

Mood

Well-being

\begin{abstract}
People living in urban areas must face several challenges to improve their health and well-being.

The purpose of this research is to further explore how the use of urban blue and green spaces is related to the people's mood feelings when visiting these spaces. A cross-sectional study is carried out with an adult sample population in Albania with people between 16-74 years old by an online survey. Respondents have been asked to complete the survey via the platform Google Form, from April to May 2021. The questionnaire included questions related to socio-economic characteristics, urban green and blue spaces (GBS), and self-reported feelings information. After the validation and cleaning process, a representative sample (95\% level of confidence) of 530 respondents was obtained. Descriptive statistics were used to analyze indicators such as (1) sociodemographic characteristics; (2) frequency of visits in GBS in the last 4 weeks; (3) time spending during the visit; (4) activities carried out during the visit; (5) type of accompaniment; (6) the reason for not visiting GBS and the quality of GBS. The SPSS software platform was used for the statistical analyses. The frequency, percentage, mean and standard deviation calculations were used to calculate data from the sample. The Chi-square test was used to examine the relationship between the frequency of visits in blue space and the people' mood. The study shows a significant relationship among the frequency of visits of blue and green spaces and positive mood feelings.
\end{abstract}

\section{RESUMEN}

Las personas que viven en zonas urbanas se enfrentan a varios retos para mejorar su salud y bienestar.

El propósito de esta investigación es explorar más a fondo cómo el uso de los espacios azules y verdes urbanos está relacionado con el estado de ánimo de las personas cuando visitan estos espacios. Para ello se realizó un estudio transversal de una muestra de población adulta en Albania de entre 16 y 74 años mediante una encuesta en línea a través de la plataforma Google Form entre abril y mayo de 2021. El cuestionario incluía preguntas relacionadas con las características socioeconómicas, los espacios verdes y azules urbanos, e información sobre los sentimientos autodeclarados. Tras el proceso de validación y depuración, se obtuvo una muestra representativa (nivel de confianza del 95\%) de 530 encuestados. También, se utilizaron estadísticas descriptivas para analizar indicadores como: (1) las características sociodemográficas; (2) la frecuencia de las visitas en espacios azules y verdes en las últimas 4 semanas; (3) el tiempo empleado durante la visita; (4) las actividades realizadas durante la visita; (5) el tipo de acompañamiento; (6) el motivo de no visitar EVA y la calidad de EVA. 


\begin{abstract}
Para los análisis estadísticos se utilizó el software SPSS, realizando cálculos de frecuencia, porcentaje, media y desviación estándar. Se utilizó la prueba de Chi-cuadrado para examinar la relación entre la frecuencia de las visitas al espacio azul y el estado de ánimo de las personas. Como resultado, el estudio mostró una relación significativa entre la frecuencia de las visitas a los espacios azules y verdes y el estado de ánimo positivo.
\end{abstract}

\title{
1. INTRODUCTION
}

\subsection{The role of natural environment}

Cities have historically adapted their shape in response to the challenges of public health. Actually, cities are home to over half of the world's population, and it is estimated that by 2050, the number of people living in cities will have increased by around 2.5 billion (American Psychological Association, 2005). Over $60 \%$ of the metropolitan areas that will exist by 2050 are expected to be built, implying that enormous additional infrastructure requirements would be required, notably in Asia and Africa (Hartig et al., 2014). At the same time, current cities throughout the world are aging and in desperate need of infrastructural upgrades. Infrastructures are critical for human well-being and economic progress. They offer water, electricity, food, shelter, transportation and communication, waste management, and public spaces (European Commission Directorate, 2015). However, when considered as a whole, these seven infrastructure sectors impose a significant environmental burden and have a significant influence on human health. These consequences are dominated by urban needs; cities account for over $70 \%$ of worldwide greenhouse gas (GHG) emissions (American Psychological Association, 2005).

Stanley Milgram began his seminal study on urban psychology on a positive note, claiming that "cities have great appeal because of their variety, eventfulness, possibility of choice, and the stimulation of an intense atmosphere that many individuals find a desirable background to their lives" (Von der Lippe et al., 2005). Cities, he added, provide "unparalleled opportunities" for face-to-face engagement and conversation (Von der Lippe et al., 2005). Living in a city may be advantageous for people since it allows the formation of social networks and access to a variety of services, including health care, but cities also confront a number of issues related to health and well-being of people. In his work, Milgram emphasized psychology's contribution to comprehending the experience of city living. He highlighted overload as a psychological notion that can be used to connect objective urban conditions like high population density to observable behaviors like incivility. These viewpoints are valuable for informing urban psychology study.

Urbanism promotes numerous changes in human behavior that influence their health since smoking, traffic injuries, mortality and adult obesity are prevalent in existing cities (World Health Organization, 1998). A stressful and fast-moving environment, high noise levels, unhealthy lifestyles such reduced physical activity, poor nutrition habits, alcohol and tobacco consumption, and accelerated living reduce well-being and physical and mental health of urban dwellers (Galea \& Vlahov, 2005). By 2030, depression is anticipated to be the main cause of Disability Adjusted Life Years (DALYs) in middle to high-income nations (World Health Organization, 2004), with urbanization playing a key part in this direction (Goryakin et al., 2017). However, in addition to the numerous health and wellbeing benefits of living in cities (Dye, 2008; Godfrey \& Julien, 2005), the urbanism faces many health challenges such as smog, water contamination, respiratory diseases (Benjamin et al., 2017; Samet et al., 2000; Taylor-Gooby, 2004; Tong \& Chen, 2002), heart diseases (Mustafi et al., 2012), and gastro-intestinal disorders (Brunekreef \& Holgate, 2002).

However, urban environments contain facilities that may help in reducing the severe health consequences of city living. Because many chronic diseases are avoidable, there has been a need for reasonable measures taken by population and government to minimize risk or mitigate damages from smoking, physical inactivity, alcohol consuming, and an unhealthy diet (Bauer et al., 2014). Due to the great benefits provided by nature, in both theoretical and practical aspects during the last two decades, there has been an increasing interest in ecological, nature-based health-promoting initiatives (Hartig et al., 2014). The construction, protection, maintenance, and growth of blue and green areas (BGS) are the goals of new strategies. 
Urban planners and public health authorities are becoming increasingly interested in reducing the harmful consequences of the built environment on population health and well-being (Bailey, Anderson \& Cox, 2021; Edwards \& Tsouros, 2006; Ewing, 2005; Popkin, Duffey \& Gordon-Larsen, 2005). By minimizing air pollution, promoting physical exercises, and lowering mental and emotional tension, parks and other 'natural habitats' within cities can assist to mitigate some of these risks (Hartig \& Kahn, 2016; Hartig et al., 2014). Previous evidence from various studies shows that people who live in areas surrounding with green spaces have better health conditions (Maas et al., 2006; Mitchell \& Popham, 2007; Seresinhe et al., 2015); such as a decrease in heart and lung diseases (Vitorio et al., 2017; Kardan et al., 2015; Maas et al., 2009); a low level of diabetes (Astell-Burt et al., 2014) and some cancers (Demoury et al., 2017); favorable mental health and wellbeing (Gascon et al., 2015; White et al., 2013); good reproductive outcomes (Dadvand et al., 2012); and, eventually, fewer deaths (Demoury et al., 2017; Gascon et al., 2016; Mitchell \& Popham, 2008; Takano et al., 2002; Villeneuve et al., 2012). Proximity to aquatic environments, also known as 'blue spaces,' such as coastlines, lakes, and rivers, has also been shown to have similar positive effects (Gascon et al., 2017; Volker \& Kistemann, 2011; Wheeler et al., 2012), particularly for mental health and wellbeing (Gascon et al., 2017; Volker \& Kistemann, 2011; Wheeler et al., 2012; De Bell et al., 2017; Nutsford et al., 2016). The importance of proximate access to natural habitats has received less attention (Grahn \& Stigsdotter, 2003) and some few studies are based on objective assessments (De Vries et al., 2003).

Understanding what wellbeing entails is essential before considering how blue spaces may play a role in its creation. In global conceptualizations, wellbeing is frequently emphasized as a multidimensional state linked to a country's economic, social, cultural, and environmental output (Daykin et al., 2018). A subjective sensation of feeling 'well' or 'excellent' is referred to as wellbeing on a local level, a concept that encompasses the physical, social, environmental, educational, spiritual, emotive, and neurobiological components of a person's life (Liamputtong et al., 2012), which it is become a popular partner to blue space. It might refer to an interior condition that is difficult to categorize yet palpable to the person experiencing it. It's also becoming more common as a description for what a community considers to be a decent existence. While it is admirable to adjust wellness to local situations and settings, as Loera-González (2016) mentions, it is also critical to ensure that the "diversity of viewpoints within a social group" (p. 241) are uncovered in these communal perceptions. It's possible that a combination of various and context-dependent methods of conceptualizing wellbeing, as well as how this idea expanded perceptions of health without diseases to a comprehensive theory involving physical, social, environmental, educational, spiritual, affective, and cognitive dimensions of life (Liamputtong, Fanany, \& Verrinder, 2012), has contributed to it becoming such a popular companion to blue space.

Environmental experiences, including recycling, submitting petitions for environmental conservation, and using public transportation have been shown to have significant correlations with pro-environmental behavior (Finger, 1994; Nord, Luloff \& Bridger 1998). There have been substantial associations established between the frequency of visits to forest regions and self-reported pro-environmental acts including, making donations to environmental organizations and practicing ecologically conscious consumption (Teisl \& O'Brien, 2003). According to Pyle (1978), the elimination of direct touch with the natural world has resulted in a cycle of indifference and a lack of care for ecological concerns, the natural environment, and animals. Previous study has indicated that both direct and indirect exposure with the natural environment especially during childhood, is essential for creating significant connections with the natural environment promoting positive values regarding it (Trougakos et al., 2020; Leaf et al., 1996; Kellert, 2002).

\subsection{The benefits of green and blue spaces in human health and wellbeing}

The US Environmental Protection Agency (EPA) defines green spaces as the land that is partly or completely covered with grass, trees, shrubs, or other vegetation which includes parks, community gardens, and cemeteries (US Environmental Protection Agency, 2017) whereas blue urban open spaces encompass "large-scale, normally natural water bodies connected to the ocean, such as seas, bays, gulfs, lagoons or estuaries, flowing inland water bodies like rivers, streams or canals of different sizes, flow rates, turbulence and transported sediments, 
stagnant inland water bodies like lakes, ponds, pools or basins of different size and turbidity and other urban blue elements which are not water bodies, such as geysers or waterfalls" (Völker et al., 2018).

Interactions with nature have been shown to improve psychological well-being (Kaplan 1995), improve mood (Hartig et al., 2003, Barton \& Pretty, 2010, Roe \& Aspinall, 2011), increase focus (Hartig et al., 2003; Ottosson \& Grahn, 2005), and lower level of stress and anxiety (Hartig et al., 2003; Ottosson \& Grahn, 2005). The reasons of poor mental health are numerous and complex (Kinderman et al. 2015), and cultural and socioeconomic variations between locations may impact how people respond to natural interactions (Keniger et al., 2013). Nature is likely to have an impact on mental balance by a series of functions (Shanahan et al., 2015b). According to the attention-restoration theory (Kaplan, 1995), the nature aids in the improvement of mental collapse that occurs during cognitive functioning and necessitates the sustained maintenance of directed attention, whereas the stress-reduction theory claims that natural environments aid in reducing subjectively aversive physiological states, including stress (Ulrich et al. 1991). Both corresponding theories show that exposure to nature promotes mental health by reducing rumination, increasing cognition functioning, and lowering stress (Berman et al., 2012; Jiang et al., 2014; Tyrväinen et al., 2014; Bratman et al. 2015). The access to BGS is related with improvement health outcomes through several of mechanisms, psychological restoration, (White et al., 2013), noise mitigation, (Hystad, et al., 2014), heat and humidity regulation, (Kingsley et al., 2019), increased social relations, and cohesion (Van den Berg et al., 2019) and increased physical activity (Thompson et al., 2012). BGS has been connected to physical and psychological advantages due to their purported impact on physical activity (Morris, 2003). In general, BGS are underutilized as a resource for physical exercise. As a result, there is significant potential for improving population health through more visits and active use of BGS.

A range of factors impact personal and societal health and well-being, including place, or the physical surroundings in which they live (Marmot \& World Health Organization, 2013). Healthy places, or locations that aid in the advertising, maintenance, and restoration of better health, are increasingly recognized, and the relevance of green and blue spaces for health and wellbeing is becoming more widely recognized. Recognizing the links between green space and human health, the United Nations (UN) Sustainable Development Goals (SDGs) expressly state to "provide universal access to safe, inclusive, and accessible green and public spaces, particularly for women and children, older people, and people with disabilities" by 2030. Green spaces have the capacity to inhibit 'upstream' problems, which is more efficient than dealing with 'downstream' issues of poor human health and wellbeing, according to the belief that they provide cultural ecosystem services that encourage human health and wellbeing in a wider environmental context (Martin et al., 2020). On the other hand, outdoor water habitats or blue spaces are receiving increasing interdisciplinary interest and awareness for its cultural ecological functions and potential health benefits (Chen \& Yuan, 2020).

Green spaces are thought to provide health advantages through encouraging physical exercise, contact with nature, and social interaction, according to a paradigm built based on existing studies (Lachowycz \& Jones, 2013). We will discuss numerous ways in which the utilization of blue and green areas can promote human health in the following sections.

Green environments have also been demonstrated to have mental health advantages in studies. It has been discovered that having them and having access to them is linked to improved mental health (Sturm \& Cohen, 2014; Wood et al., 2017). Stress is all too typical in today's world, is a proven risk factor for mental illnesses like depression (Cohen et al., 2007). According to studies, public green spaces might help people relax. Evidence suggests that spending more time in green areas is linked to lower stress levels as measured by cortisol and a decreased risk of psychological distress (Ward Thompson et al., 2012; Astell-Burt et al., 2013). Exposure to green areas is associated to decreased stress levels and pleasant feelings due to physiological reactions of a relaxed state (Hazer et al., 2018; Honold et al., 2016).

The mentally and physically healing benefits of interaction with the natural environment, pollution reduction, and possibilities for social connections and physical activity are all possible causative factors (Pretty et al., 2005). Some studies of the links between green space and human health have been founded on evolutionary concepts, which explain why humans have an inherent need for nature. We are naturally calmer and less anxious when we visit green settings (Kellert S, 1995). These advantages can be achieved through 
purposeful contacts with nature (such as visiting local green spaces or spending time in a garden), accidental encounters (such as going to the store), or indirectly while not physically present in nature (such as observing it through a window) (Keniger et al., 2013). Because the natural area surrounding the home is the nature that most people will meet on a daily basis, all three forms of nature interactions will contribute considerably to people's daily nature experience.

The research supporting a link between blue space availability and health, on the other hand, is limited and inconsistent (Gascon et al., 2015). Despite this, research utilizing population census data from England found that persons who lived near the coastline were more likely to be in excellent health (White et al., 2014). Using English panel data, researchers discovered that living fewer than 5 kilometers from the seaside improved both general and mental health when compared to living further away (White et al., 2013a). Both studies, however, did not include inland surface waters. Other studies, which included surface waterways alongside coastal waters, found no link among mental health and the quantity of blue space or its accessibility (De Vries et al., 2003; Triguero-Mas et al., 2015). Nonetheless, empirical, and qualitative research shows that using blue spaces in urban areas has a favorable impact on both physical and mental health. Even though most studies have concentrated on coastal environments, there is an expanded literature that investigates the impact of inland surface waters (Finlay et al., 2015), which found that people who witnessed urban blue scenes experienced higher levels of restorativeness than those who witnessed other scenes. Several studies have demonstrated that blue space, particularly turbulent water bodies, can protect and promote health by masking road noise (Jeon et al., 2010) and mitigate summertime temperatures (Völker et al., 2018).

In addition, blue space exposure has been connected to enhanced health and well-being in terrestrial settings, including non-water-based physical activity (Vert et al., 2019), reduced psychological distress from water observation (Nutsford et al., 2016), and social engagement in waterside regions (De Bell et al., 2017). Therefore, although the empirical value of these factors is unknown the presence of water and the status of waterside regions, such as route quality or open space availability, play a vital part on health and well-being benefits. De Bell et al., (2017) developed a healing blue space experience transdisciplinary model along the seaside based on four overlapping therapeutic experience dimensions: symbolic, accomplishing, immersive, and social (pg. 58). These dimensions are useful for identifying a range of components that are relevant to a broader leisure research regarding coastal locations and the interaction between people and ways that promote and restrict wellbeing.

Living near water, promotes the creation of shared spaces as well as a sense of association, devotion, individuality, and social interactions (Völker \& Kistemann, 2012). Furthermore, appealing seaside leisure activities like swimming and surfing have been found to offer significant cognitive and physiological advantages. Another study on outdoor swimming recommends focusing on health as a process of affection and emotion, with swimming considered as a "healing activity" (Foley, 2017).

Blue space advantages can be connected to several ecosystem services, such as water purification, fish production, nutrient cycling, and leisure activities (Costanza et al., 2017). Since the introduction of the European Union's Water Framework Directive (Directive/2000/60/EC), policymakers have placed a greater emphasis on measuring the economic value of freshwater ecosystem services.

In reality, understanding the economic value of freshwater ecosystem services is a critical component of establishing socially optimum water resource management strategy (Llopis-Albert et al., 2018). Anyhow, because freshwater ecosystem services usually create non-market benefits, experimentally assessing their economic value is difficult (McDougall et al., 2020). Financial experts have developed a range of ways for evaluating non-market advantages in recent years, the majority of which rely on individuals expressed or disclosed preferences (Mitchell and Carson, 1989). By monitoring real-world behavior and relating it to the number and/or quality of environmental resources such as rivers and forests, revealed preference techniques can estimate economic values.

To evaluate economic values, customer behavior in correctly constructed hypothetical markets is examined utilizing expressed preference approaches (Hanley \& Czajkowski, 2019). Because most individuals are unfamiliar with fictitious markets and non-market items, stated preference judgments are typically 
confusing (Butler \& Loomes, 2007). When people's attitudes toward environmental improvements are characterized by uncertainty, research reveals that respondents prefer to provide a variety of economic value statements rather than a single value statement in expressed preference questionnaires (Mahieu et al., 2017). Anxiety and mood disorders, such as depression, are predicted to cost Europe $€ 187.4$ billion per year in economy's production (Gustavsson et al. 2012, Olesen et al. 2012). This emerging problem is at least partly related to the growing distance between people and nature because of more urbanized and sedentary lifestyles (Miller, 2005; Soga \& Gaston, 2015). Understanding and capitalizing on the processes through which natural surroundings deliver psychological advantages has the capacity to be a unique and cost-effective strategy for lowering the pervasiveness of various mental illnesses (Hartig et al. 2014, Shanahan et al. 2015).

Even though the relationship among blue and green spaces and human health is complicated in every country, understanding of its dynamics, as well as amounts of information and data on health and wellbeing, as well as access to green and blue spaces, vary. The goal of this study is to bridge the gap between (1) understanding complex relationship among blue and green spaces, and positive effects on mood feelings in the Shkodra' population, and (2) describing its complicated dynamics. In Albania, studies that relate the impact of blue and green spaces on the population's wellbeing has been limited and poorly explored.

\section{METHODOLOGY}

\subsection{Study area}

Shkodra is an ancient town of 2500 years old and one of the most important cities of Albania. It is situated in the northwest of Albania at a latitude $42^{\circ} 4^{\prime} \mathrm{N}$, and longitude $19^{\circ} 31^{\prime} \mathrm{E}$, with a surface area of $872,71 \mathrm{~km}^{2}$. According to INSTAT data (2021) on 1st January, the Shkodra' municipality has a population of 200,007 inhabitants where $48,6 \%$ are men and $51,4 \%$ are women (INSTAT, 2020).

The lake of Shkodra with $369 \mathrm{~km}^{2}$ (figure 1), the largest lake in Albania and Montenegro, is located on the west of the city of Shkodra and serves as a border between the two countries (Sadori et al., 2014), with $149 \mathrm{~km}$ of it belongs to Albania. Both countries put their decisions and procedures for managing this region into action, using national legislation and international accords to preserve this area. The Albanian side of Shkodra' Lake and the green areas surrounding, is a protected area and one of the most important national and international ecosystems, proclaimed Managed Nature Reserve as well as Ramsar Area (Albanian Government Decision No.684, dated 11/02/2015, while the Montenegrin side is proclaimed National Park in 1983 (Government Report, 2020).

This area also has an essential value in terms of hydrology and ecology thanks to the lake's connection with the large hydrographic network of the Balkan, through the Drin River and the Adriatic Sea through the Buna River (Sadori et al., 2014). The Shkodra' Lake basin is dominated by a Mediterranean climate with an annual solar radiation potential of $2054 \mathrm{~km} / \mathrm{m}^{2}$, which qualifies it as an area of high ecological value (Darwall et al., 2014). Shkodra' Lake represents a complex of habitats with 420 different species (Petkovic, 1981; Hindak \& Hindakova, 2000; Rakocevic, 2001; Miho \& Witkowski, 2005; Dhora, 2005).

The shoreline of Shkodra' Lake is picturesque, with plenty of peninsulas and islets that resemble wetlands. The lake frames the historic and artistic town of Shkodra, a tranquil and relaxing environment, reflecting the effect of the water that elegantly surrounds it. It is also rich in cultural and historical monuments, which stretch along an important part of this managed nature reserve. Many visitors pass through the impressive Buna River delta to reach Lake Shkodra. Many others choose to take a cycling tour to fully immerse themselves in the natural environment of the area. During the summer, several lakeside resorts offer excellent alternatives to visitors thanks to their clear waters and proximity to the city. Visitors should not miss the waterfront restaurants offering the famous Carp fish in a variety of meals (figure 2). 

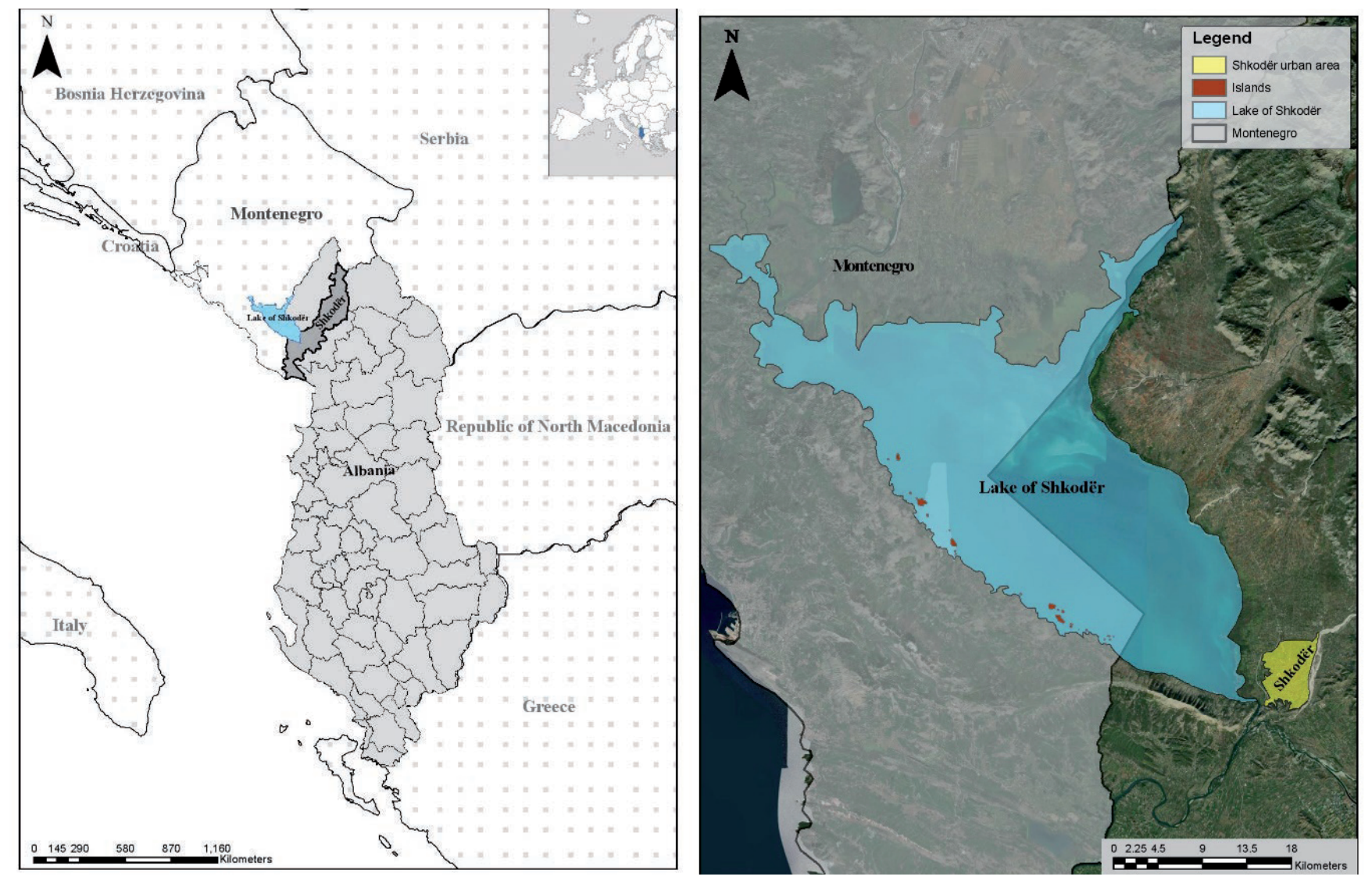

Figure 1. Location of Shkodra' Lake. Source: Author.
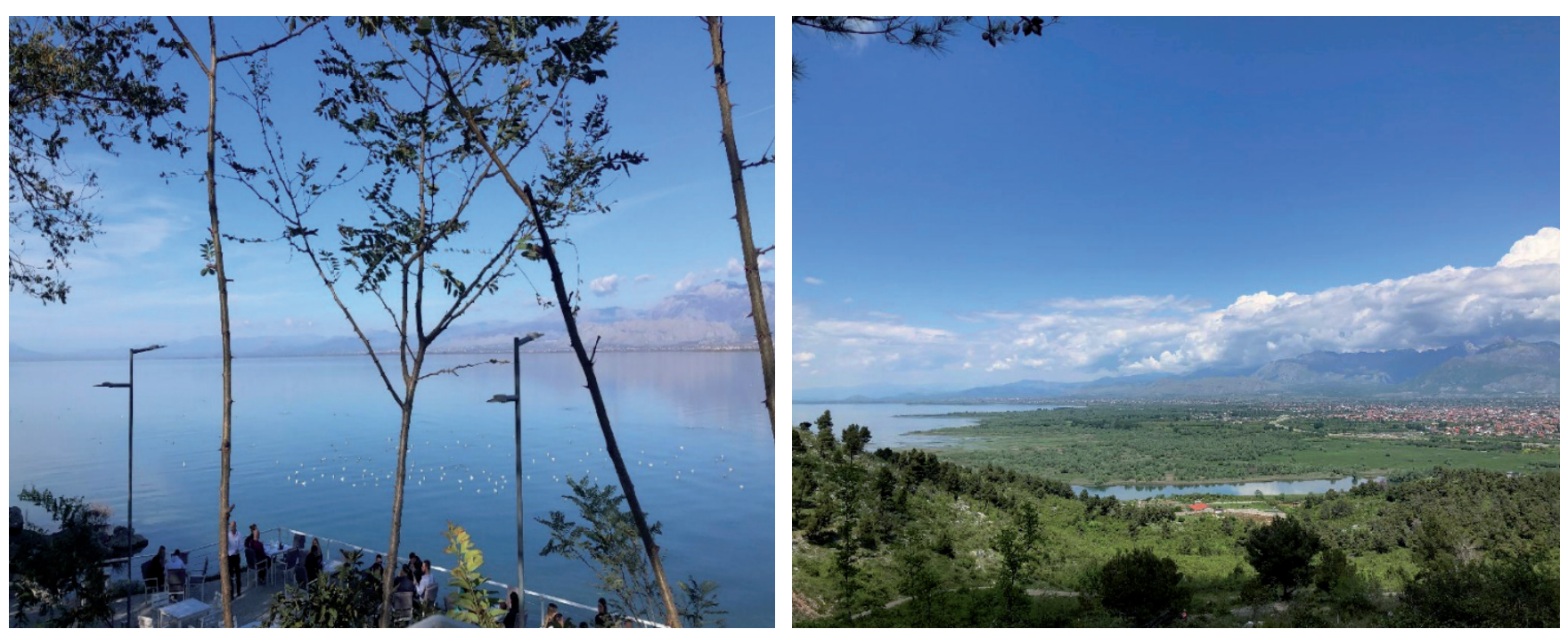

Figure 2. Waterfront view of Shkodra' Lake. Source: Author.

\subsection{Survey}

Population data presented in this paper are preliminary data extracted from an online cross-sectional survey on BGS carried out in Shkodra' city. Respondents have been asked to complete the survey via the platform Google Form, from April to May 2021. During this period, Albania was open to all citizens and visitors, with some restrictions in place, such as masks required outside and inside certain buildings and institutions, 
no gatherings of more than 50 people, and public movement prohibited from 10:00 p.m. to 5:00 a.m. The questionnaire used in the study was prepared by an interdisciplinary panel formed by urban planner, geographer, psychologist, and environmental scientist. The questionnaire provided 68 questions, designed in 3 main sections: 1) General information, 2) Natural environment information, 3) Self-reported health information. To improve the clarity of the questions before launching the survey, a pilot study was conducted. After the validation and cleaning process, a representative sample (95\% level of confidence) of 530 respondents was obtained. This survey targeted people over 16 years old and was disseminated to the public using social media platforms.

\subsection{Variables}

\subsubsection{Socio-demographic characteristics}

In the first part of the survey, the participants were asked to report information related to their gender (female, male), age (in years) categorized in following groups: 16-31, 32-48, 49-64, >65, marital status (married, single, divorced, in a relationship, widowed), education level (no formal education, primary school, high school, university (completed), following university studies), job status (employed, unemployed, temporary sick leave, permanently sick, disabled, retired, student homemaker), and years leaving in Shkodra.

\subsubsection{Visits at a blue-green space}

In the second section, the participants provided information related to their visits to a blue-green space by answering the following questions: "In the last 4 weeks, how many times have you visited the Shkodra' Lake? (Not at all in the last four weeks, once or twice in the last four weeks, once a week, several times a week", "How much time approximately do you spend during your visits? (in minutes)", "What kind of activity do you realized during the visit? (Quiet activities (e.g., reading, meditating), cycling, walking with a dog, walking or playing with children, eating or drinking, swimming, fishing, running/physical activity, boating (canoeing, kayaking)", "With who are you visiting Shkodra' Lake (alone, children, friends, parents (mother/father, grandma/grandpa), wife/husband or boyfriend/girlfriend), "If you have not visited the Shkodra' Lake, what has been the reason for that? (Do not have time, this area is too crowded, this area is too far from my home, never thought about it", "Overall, how would you describe the quality of Shkodra' Lake (Very good, good, neither good nor bad, bad, very bad)".

\subsubsection{Mood feelings}

The information about the emotional people's mood after the visit in a green-blue space was extracted from the question: “How did you feel after visiting Shkodra' Lake? (I felt safe, I felt tranquillity, I felt part of nature, I was satisfied with the visit)".

\subsection{Statistical Analyses}

Descriptive statistics were used to analyze such as indicators (1) sociodemographic characteristics (age, gender, marital status, level of education and job status, years living in Shkodra; (2) frequency of visits in BGS in the last 4 weeks; (3) time spending during the visit; (4) activities carried out during the visit; (5) type of accompaniment; (6) the reason for not visiting BGS and the quality of BGS. The SPSS software platform was used for the statistical analyses. The frequency, percentage, mean and standard deviation calculations were used to calculate data from the sample. The Chi-square test was used to analyze association of visits frequency in blue-green space with the people' mood. There exists any statistical significance when $\mathrm{p}$-value was $\mathrm{P}<0.05$. 


\section{PRELIMINARY RESULTS}

As shown in Table 1, according to the analysis of the sociodemographic variables, the mean age of the respondents was $30.32 \pm 12.971$. It can be observed that the population sample was young, with $63.4 \%$ between 16 and 31 years old, $23.4 \%$ between 32 and 48 years old, $12.6 \%$ between 49 and 64 years old, and only $0.6 \%$ over 65 years old, including $76.2 \%$ of women and $23.8 \%$ of men.

Regarding employment status, $55.8 \%$ were working at the time of the survey, $30.2 \%$ were students, $1.9 \%$ were unemployed, $1.1 \%$ were homemakers followed by $0.8 \%$ retired, and $0.2 \%$ disabled. It is interesting to remark that only $14.7 \%$ of the respondents had not visited Shkodra' Lake during the last four weeks of whom $43.5 \%$ for lack of time, 37.1\% for living too far from this area, and only 3.8\% for describing it as an overpopulated area.

In terms of frequency of visits to Shkodra' Lake, 30.9\% had visited once or twice in the last four weeks, $28.1 \%$ several times a week, $26.2 \%$ had visited only once a week and $14.7 \%$ had not made any visits in the last four weeks.

Concerning the type of accompaniment during the visits, 37.9\% visited Shkodra Lake with friends, $14.2 \%$ with wife/husband or boyfriend/girlfriend, $13.4 \%$ with children, $8.5 \%$ with parents, $5.8 \%$ with another adult, and $2.8 \%$ alone. In their visits, the respondents spent approximately 60 minutes at the Shkodra' Lake BGS as follows: $31.1 \%$ cycling, $18.3 \%$ consuming food and drink, $8.9 \%$ walked or played with children, $4.3 \%$ engaged in quiet activities (e.g., reading, meditating), $0.8 \%$ walked with a dog, $0.6 \%$ went swimming and $0.2 \%$ used this time for fishing.

In terms of quality, $46.6 \%$ of the people who had visited during the last 4 weeks rated this area as good quality, $29.8 \%$ rated it as acceptable, $14.8 \%$ considered Shkodra' Lake as very good quality and only $7.5 \%$ thought that the quality of this area was bad or very bad.

Table 1. Sample of socio-demographic, and other variables related with visits in Shkodra' Lake, Albania ( $N=530)$.

\begin{tabular}{|c|c|c|c|}
\hline \multicolumn{2}{|c|}{ Sociodemographic variables } & \multicolumn{2}{|l|}{ Visits at Shkodra' Lake } \\
\hline Variables & Mean \pm SD/ n (\%) & Variables & Mean \pm SD/ n (\%) \\
\hline \multicolumn{2}{|l|}{ Gender $\mathbf{N}=530$} & $\begin{array}{l}\text { Visiting Shkodra' Lake during the last } 4 \\
\text { weeks } N=530\end{array}$ & \\
\hline Female & $404(76.2)$ & Not at all in the last four weeks & $78(14.7)$ \\
\hline \multirow[t]{2}{*}{ Male } & $126(23.8)$ & Several times a week & $149(28.1)$ \\
\hline & & Once a week & $139(26.2)$ \\
\hline Age group $\mathrm{N}=530$ & $30.32 \pm 12.971$ & Once or twice in the last four weeks & $164(31)$ \\
\hline $16-31$ & $336(63.4)$ & $\begin{array}{l}\text { Time spending during the visit } \mathrm{N}=452 \\
\text { (in minutes) }\end{array}$ & (72.43 38.737) \\
\hline $32-48$ & $124(23.4)$ & Activities carried out during the visit & \\
\hline $49-64$ & $67(12.6)$ & Quiet activities (e.g., reading, meditating) & $23(4.3)$ \\
\hline$>65$ & $3(0.6$ & Cycling & $165(31.1)$ \\
\hline \multicolumn{2}{|c|}{ Marital status $\mathrm{N}=530$} & Walking with a dog & $4(0.8)$ \\
\hline Married & $29(5.5)$ & Walking or playing with children & $47(8.9)$ \\
\hline Single & $297(56.0)$ & Eating or drinking & $97(18.3)$ \\
\hline Divorced & $7(1.3)$ & Swimming & $3(0.6)$ \\
\hline Widowed & $180(34.0)$ & Fishing & $1(0.2)$ \\
\hline
\end{tabular}




\begin{tabular}{|c|c|c|c|}
\hline \multicolumn{2}{|c|}{ Sociodemographic variables } & \multicolumn{2}{|c|}{ Visits at Shkodra' Lake } \\
\hline Variables & Mean \pm SD/ n (\%) & Variables & Mean \pm SD/ n (\%) \\
\hline Neither of these & $4(0.8)$ & Other & $6(1.2)$ \\
\hline Prefer not to answer & $12(2.4)$ & Running/Physical activity & $104(23)$ \\
\hline \multicolumn{2}{|l|}{ Education level $\mathbf{N}=530$} & Boating (canoeing, kayaking) & $2(0.4)$ \\
\hline Primary school & $3(0.6)$ & \multicolumn{2}{|l|}{ Type of accompaniment $\mathrm{N}=452$} \\
\hline High school & $117(22)$ & Wife/Husband or Boyfriend/Girlfriend & $75(16.5)$ \\
\hline University (completed) & $257(48.5)$ & Children & $71(15.7)$ \\
\hline Following university studies & $153(28.9)$ & Friends & $201(44.4)$ \\
\hline \multicolumn{2}{|l|}{ Job status $\mathrm{N}=530$} & Another adult & $31(6.8)$ \\
\hline Employed & $296(55.8)$ & Parents & $45(9.9)$ \\
\hline Unemployed & $63(11.9)$ & Other & $14(3.0)$ \\
\hline Disabled & $1(0.2)$ & Alone & $15(3.3)$ \\
\hline Retired & $4(0.8)$ & \multicolumn{2}{|l|}{ Reason for not visiting the lake $\mathbf{N}=78$} \\
\hline Student & $160(30.2)$ & This area is overpopulated & $3(3.8)$ \\
\hline Homemaker & $6(1.1)$ & This area is too far from my home & $29(37.1)$ \\
\hline \multirow[t]{9}{*}{ Years leaving in Shkodra } & \multirow[t]{9}{*}{$28.22 \pm 14.557$} & I have no time & $34(43.5)$ \\
\hline & & I have never thought about this area & $1(1.2)$ \\
\hline & & Other & $11(14.1)$ \\
\hline & & \multicolumn{2}{|l|}{$\begin{array}{l}\text { Quality of Shkodra' Lake } \\
\mathrm{N}=452\end{array}$} \\
\hline & & Neither good, nor bad & $135(29.8)$ \\
\hline & & Bad & $31(6.8)$ \\
\hline & & Good & $211(46.6)$ \\
\hline & & Very bad & $8(1.7)$ \\
\hline & & Very good & $67(14.8)$ \\
\hline
\end{tabular}

Source: Own elaboration.

In terms of mood after the visits to Shkodra Lake, there are significant differences between positive feelings with the visit ( $p=0.032)$ and feeling part of nature $(p=0.004)$. It is generally observed that regardless of the frequency of visits $87.6 \%$ felt tranquility and $87.6 \%$ felt safe (table 2 ). 
Table 2. Association of visits in Shkodra' Lake with the mood feelings ( $N=452)$.

Association of visits in Shkodra' Lake with mood feelings

\begin{tabular}{|c|c|c|c|c|c|}
\hline Variables & $\begin{array}{c}\text { Once a week } \\
139(30.8 \%)\end{array}$ & $\begin{array}{c}\text { Once or twice a } \\
\text { week } \\
164(36.2 \%)\end{array}$ & $\begin{array}{c}\text { Several times a } \\
\text { week } \\
149(33 \%)\end{array}$ & $\begin{array}{c}\text { Total } \\
452(100 \%)\end{array}$ & $p$ value \\
\hline
\end{tabular}

I was satisfied with the visit

\begin{tabular}{|c|c|c|c|c|c|}
\hline Agree & $122(87.8)$ & $7(5.0)$ & $116(77.9)$ & $382(84.5)$ & \\
\hline Neither agree nor disagree & $10(7.2)$ & $7(4.3)$ & $11(7.4)$ & $28(6.2)$ & $0.032 *$ \\
\hline Disagree & $7(5.0)$ & $13(7.9)$ & $22(14.8)$ & $42(9.3)$ & \\
\hline \multicolumn{6}{|l|}{ I felt part of nature } \\
\hline Agree & $127(91.4)$ & $141(6.0)$ & $112(75.2)$ & $380(84.1)$ & \\
\hline Neither agree nor disagree & $6(4.3)$ & $8(4.9)$ & $16(10.7)$ & $30(6.6)$ & $0.004^{*}$ \\
\hline Disagree & $6(4.3)$ & $15(9.1)$ & $21(14.1)$ & $42(9.3)$ & \\
\hline \multicolumn{6}{|l|}{ I felt tranquility } \\
\hline Agree & $127(91.4)$ & $144(87.8)$ & $125(83.9)$ & $396(87.6)$ & \\
\hline Neither agree nor disagree & $6(4.3)$ & $5(3.0)$ & $5(3.4)$ & $16(3.5)$ & \\
\hline Disagree & $6(4.3)$ & $15(9.1)$ & $19(12.8)$ & $40(8.8)$ & 0.157 \\
\hline \multicolumn{6}{|l|}{ I felt safe } \\
\hline Agree & $89(64.0)$ & $115(70.1)$ & $91(61.1)$ & $295(65.3)$ & \\
\hline Neither agree nor disagree & $18(12.9)$ & $18(11.0)$ & $17(11.4)$ & $53(11.7)$ & \\
\hline Disagree & $32(23.0)$ & $31(18.9)$ & $41(27.5)$ & $104(23.0)$ & 0.432 \\
\hline
\end{tabular}

$* \mathrm{P}<0.05$

Source: Own elaboration.

\section{DISCUSSION AND CONCLUSIONS}

The current study found a correlation between people's mood and visits to blue and green spaces (BGS), in a way that people who visited Shkodra' Lake more frequently demonstrated higher positive feelings. Therefore, the results of this study confirm the results acquired from previous studies claiming the benefits of visits to BGS on mood and well-being of people (White et al., 2013; Su Sugiyama et al., 2008; Pretty et al., 2005).

Although there are studies that affirm that visiting green spaces has beneficial impact on physical and mental health (White et al., 2013) and helps us to be more relaxed and less stressed (Kellert, 1995), there is noticeable a lack of studies in the Mediterranean area in general (Braçe et al., 2020) and Albania in particular, that would provide knowledge on the impact of BGS on the population health and well-being.

The objective of this study is to bring a general review on the potential health and well-being benefits of BGS exposure as in the case of Shkodra's lake (Albania). The results of this study show that $85.3 \%$ of the respondents had visited the lake of Shkodra at least once during the last four weeks doing activities such as walking, cycling, or relaxing by consuming something in the surroundings of the lake. Most of the visitors frequented the BGS spaces accompanied by their wife/husband or boyfriend/girlfriend. According to 
statistical analysis, there is a significant link $(p<0.05)$ between the two variables, a) frequency of visits to the BGS and b) feelings of positive mood stating that people who visit Shkodra' Lake several times a week feel safe, more satisfied and really calm. Referring to the methodology, one of the limitations of this study is conducting the survey using an on-line platform which created biases in the obtained sample, in order to better identify gaps in research on the benefits of blue and green spaces on the population health and well-being.

The results of this study show that $85.3 \%$ of the respondents had visited the lake of Shkodra at least once during the last four weeks doing activities such as walking, cycling, or relaxing by consuming something in the surroundings of the lake. Most of the visitors frequented the BGS spaces accompanied by their wife/ husband or boyfriend/girlfriend.

From the methodological aspect, another limitation of this study is conducting the survey using an online platform which created biases in the obtained sample, mostly expressing the opinion of relatively young people, with an average age of 30.32 years, leaving apart the opinion of older people who use fewer social media and have difficulties in using electronic devices such as computers, tablets, and mobile phones (Vaportzis et al., 2017).

However, one of the study's strengths was the significant number of respondents, which ensured that the survey was representative at the population level. In addition, it is an original survey, designed specifically for this study.

Considering the positive effects that visits to BGS evoke in people's mood, it would be important to promote their visit by organizing activities, as well as the creation of green spaces with water surfaces in urban areas that do not dispose of them.

The results of this study reinforce the importance of BGS as a community resource to promote good health. Therefore, local governments who are often in charge of the design and maintenance of BGS could address community health problems by improving and creating BGS.

However, studies have shown that BGSs, in general, are underutilized. Although the health benefits of BGS have been shown, it is likely that such findings have not been adequate to persuade decision-makers to act. It is critical to emphasize that strengthening BGS is probably a practical health promotion effort that local governments can undertake.

Although the findings are not conclusive, there is evidence that access to safe, clean, and appealing blue spaces has several health and wellness advantages, due to different processes such as reducing temperatures, increasing physical activity, reducing stress, and promoting quality time with relatives and friends.

As the study was a cross-sectional one, the results should be interpreted with attention. Although the findings show that visits to the BGS positively influence people's mood, to establish a true cause-effect relationship we would need longitudinal data to state this finding with certainty.

The current study's goal was to decrease the gaps that exist in research, trying to provide the potential advantages that BGS bring in the population health and well-being (Grellier et al., 2017), contributing to improve some of the most significant public health issues of the twenty-first century such as depression and anxiety (WHO, 2013), lack of physical activity that may increase the risk of cardiovascular diseases (Guthold et al., 2018), dementia and several malignant tumours in the long term (WHO, 2018). In addition, BGS can be used for more than just disease prevention, such as the promotion of excellent psychological health and the rehabilitation of persons with chronic diseases, recovering conditions or health problems in progress.

\section{Responsible reporting and conflict of interest}

The authors declare no conflict of interest. S.K. processed the visitor's data. S.K. and O.B. developed the methodology. S.K. wrote the manuscript and prepared the visualization. O.B. wrote the discussion and revised the manuscript. 


\section{REFERENCES}

American Psychological Association. (2005). Toward an urban psychology: Research, action, and policy. Washington, DC: Author.

Astell-Burt, T., Feng, X. \& Kolt, G. S. (2013). Mental health benefits of neighbourhood green space are stronger among physically active adults in middle-to-older age: evidence from 260,061 Australians. Preventive medicine, 57(5), 601606. https://doi.org/10.1016/j.ypmed.2013.08.017

Astell-Burt, T., Feng, X. \& Kolt, G. S. (2014). Is neighborhood green space associated with a lower risk of type 2 diabetes? Evidence from 267,072 Australians. Diabetes care, 37(1), 197-201. https://doi.org/10.2337/dc13-1325

Bailey, A. W., Anderson, M. \& Cox, G. (2021). The Cortex in Context: Investigating the Influence of Activity and Space on Psychological Well-Being. Leisure Sciences, 1-18. https://doi.org/10.1080/01490400.2021.1889421

Barton, J. \& Pretty, J. (2010). What is the best dose of nature and green exercise for improving mental health? A multi-study analysis. Environmental science \& technology, 44(10), 3947-3955. https://doi.org/10.1021/es903183r

Bauer, U. E., Briss, P. A., Goodman, R. A. \& Bowman, B. A. (2014). Prevention of chronic disease in the 21st century: elimination of the leading preventable causes of premature death and disability in the USA. The Lancet, 384(9937), 45-52. https://doi.org/10.1016/S0140-6736(14)60648-6

Berman, M. G., Kross, E., Krpan, K. M., Askren, M. K., Burson, A., Deldin, P. J., Kaplan, S., Sherdell, L., Gotlib, I. H. \& Jonides, J. (2012). Interacting with nature improves cognition and affect for individuals with depression. Journal of affective disorders, 140(3), 300-305. https://doi.org/10.1016/j.jad.2012.03.012

Braçe, O., Garrido-Cumbrera, M., Foley, R., Correa-Fernández, J., Suárez-Cáceres, G. \& Lafortezza, R. (2020). Is a View of Green Spaces from Home Associated with a Lower Risk of Anxiety and Depression? International Journal of Environmental Research and Public Health, 17(19), 7014. https://doi.org/10.3390/ijerph17197014

Bratman, G. N., Hamilton, J. P. \& Daily, G. C. (2012). The impacts of nature experience on human cognitive function and mental health. Annals of the New York academy of sciences, 1249(1), 118-136. https://doi.org/10.1111/j.17496632.2011.06400.x

Brunekreef, B. \& Holgate, S. T. (2002). Air pollution and health. The lancet, 360(9341), 1233-1242. https://doi.org/10.1016/ S0140-6736(02)11274-8

Chen, Y. \& Yuan, Y. (2020). The neighborhood effect of exposure to blue space on elderly individuals' mental health: A case study in Guangzhou, China. Health \& Place, 63, 102348. https://doi.org/10.1016/j.healthplace.2020.102348

Cohen, S., Janicki-Deverts, D. \& Miller, G. E. (2007). Psychological stress and disease. Jama, 298(14), 1685-1687. https:// doi.org/10.1001/jama.298.14.1685

Costanza, R., De Groot, R., Braat, L., Kubiszewski, I., Fioramonti, L., Sutton, P.,... \& Grasso, M. (2017). Twenty years of ecosystem services: how far have we come and how far do we still need to go?. Ecosystem services, 28, 1-16. https:// doi.org/10.1016/j.ecoser.2017.09.008

Dadvand, P., Sunyer, J., Basagana, X., Ballester, F., Lertxundi, A., Fernandez-Somoano, A.,... \& Nieuwenhuijsen, M. J. (2012). Surrounding greenness and pregnancy outcomes in four Spanish birth cohorts. Environmental health perspectives, 120(10), 1481-1487. https://doi.org/10.1289/ehp.1205244

Darwall, W., Carrizo, S., Numa, C., Barrios, V., Freyhof, J. \& Smith, K. (2014). Freshwater Key Biodiversity Areas in the Mediterranean Basin Hotspot: Informing species conservation and development planning in freshwater ecosystems. IUCN, Cambridge. https://doi.org/10.2305/IUCN.CH.2014.SSC-OP.52.en

Daykin, N., Mansfield, L., Meads, C., Julier, G., Tomlinson, A., Payne, A.,... \& Victor, C. (2018). What works for wellbeing? A systematic review of wellbeing outcomes for music and singing in adults. Perspectives in public health, 138(1), 39-46. https://doi.org/10.1177/1757913917740391

De Bell, S., Graham, H., Jarvis, S., \& White, P. (2017). The importance of nature in mediating social and psychological benefits associated with visits to freshwater blue space. Landscape and Urban Planning, 167, 118-127. https://doi. org/10.1016/j.landurbplan.2017.06.003

De Vries, S., Verheij, R. A., Groenewegen, P. P. \& Spreeuwenberg, P. (2003). Natural environments-healthy environments? An exploratory analysis of the relationship between greenspace and health. Environment and planning $A$, 35(10), 1717-1731. https://doi.org/10.1068/a35111 
Demoury, C., Thierry, B., Richard, H., Sigler, B., Kestens, Y. \& Parent, M. E. (2017). Residential greenness and risk of prostate cancer: A case-control study in Montreal, Canada. Environment international, 98, 129-136. https://doi.org/10.1016/j.envint.2016.10.024

Dhora, D. (2005). Liqeni i Shkodres. Univ. Shkodra 'Luigj Gurakuqi', Shkodra, 1-252.

Dye, C. (2008). Health and urban living. Science, 319(5864), 766-769. https://doi.org/10.1126/science.1150198

Edwards, P. \& Tsouros, A. D. (2006). Promoting physical activity and active living in urban environments: the role of local governments. WHO Regional Office Europe.

Ewing, R. (2005). Can the physical environment determine physical activity levels? Exercise and sport sciences reviews, 33(2), 69-75. https://doi.org/10.1097/00003677-200504000-00003

Finger, M. (1994). From knowledge to action? Exploring the relationships between environmental experiences, learning, and behavior. Journal of social issues, 50(3), 141-160. https://doi.org/10.1111/j.1540-4560.1994.tb02424.x

Finlay, J., Franke, T., McKay, H. \& Sims-Gould, J. (2015). Therapeutic landscapes and wellbeing in later life: Impacts of blue and green spaces for older adults. Health \& place, 34, 97-106. https://doi.org/10.1016/j.healthplace.2015.05.001

Foley, R. (2017). Swimming as an accretive practice in healthy blue space. Emotion, Space and Society, 22, 43-51. https:// doi.org/10.1016/j.emospa.2016.12.001

Galea, S. \& Vlahov, D. (2005). Urban health: evidence, challenges, and directions. Annu. Rev. Public Health, 26, $341-365$. https://doi.org/10.1146/annurev.publhealth.26.021304.144708

Gascon, M., Triguero-Mas, M., Martínez, D., Dadvand, P., Forns, J., Plasència, A. \& Nieuwenhuijsen, M. J. (2015). Mental health benefits of long-term exposure to residential green and blue spaces: a systematic review. International journal of environmental research and public health, 12(4), 4354-4379. https://doi.org/10.3390/ijerph120404354

Gascon, M., Triguero-Mas, M., Martínez, D., Dadvand, P., Rojas-Rueda, D., Plasència, A. \& Nieuwenhuijsen, M. J. (2016). Residential green spaces and mortality: a systematic review. Environment international, 86, 60-67. https://doi.org/10.1016/j.envint.2015.10.013

Gascon, M., Zijlema, W., Vert, C., White, M. P. \& Nieuwenhuijsen, M. J. (2017). Outdoor blue spaces, human health and well-being: A systematic review of quantitative studies. International journal of hygiene and environmental health, 220(8), 1207-1221. https://doi.org/10.1016/j.ijheh.2017.08.004

Godfrey, R. \& Julien, M. (2005). Urbanisation and health. Clinical Medicine, 5(2), 137. https://doi.org/10.7861/clinmedicine.5-2-137

Grahn, P. \& Stigsdotter, U. A. (2003). Landscape planning and stress. Urban forestry \& urban greening, 2(1), 1-18. https:// doi.org/10.1078/1618-8667-00019

Grellier, J., White, M. P., Albin, M., Bell, S., Elliott, L. R., Gascón, M.,... \& Fleming, L. E. (2017). BlueHealth: a study programme protocol for mapping and quantifying the potential benefits to public health and well-being from Europe's blue spaces. BMJ open, 7(6), e016188. https://doi.org/10.1136/bmjopen-2017-016188

Guthold, R., Stevens, G. A., Riley, L. M. \& Bull, F. C. (2018). Worldwide trends in insufficient physical activity from 2001 to 2016: a pooled analysis of 358 population-based surveys with 1.9 million participants. The lancet global health, 6(10), e1077-e1086. https://doi.org/10.1016/S2214-109X(18)30357-7

Hanley, N. \& Czajkowski, M. (2019). The role of stated preference valuation methods in understanding choices and informing policy. Review of Environmental Economics and Policy, 13(2), 248-266. https://doi.org/10.1093/reep/rez005

Hartig, T. \& Kahn, P. H. (2016). Living in cities, naturally. Science, 352(6288), 938-940. https://doi.org/10.1126/science. aaf3759

Hartig, T., Evans, G. W., Jamner, L. D., Davis, D. S. \& Gärling, T. (2003). Tracking restoration in natural and urban field settings. Journal of environmental psychology, 23(2), 109-123. https://doi.org/10.1016/S0272-4944(02)00109-3

Hartig, T., Mitchell, R., De Vries, S., \& Frumkin, H. (2014). Nature and health. Annual review of public health, 35, $207-228$. https://doi.org/10.1146/annurev-publhealth-032013-182443

Hazer, M., Formica, M. K., Dieterlen, S. \& Morley, C. P. (2018). The relationship between self-reported exposure to greenspace and human stress in Baltimore, MD. Landscape and urban planning, 169, 47-56. https://doi.org/10.1016/j.landurbplan.2017.08.006

Honold, J., Lakes, T., Beyer, R. \& van der Meer, E. (2016). Restoration in urban spaces: Nature views from home, greenways, and public parks. Environment and behavior, 48(6), 796-825. https://doi.org/10.1177/0013916514568556 
Hystad, P., Davies, H. W., Frank, L., Van Loon, J., Gehring, U., Tamburic, L. \& Brauer, M. (2014). Residential greenness and birth outcomes: evaluating the influence of spatially correlated built-environment factors. Environmental health perspectives, 122(10), 1095-1102. https://doi.org/10.1289/ehp.1308049

Jeon, J. Y., Lee, P. J., You, J. \& Kang, J. (2010). Perceptual assessment of quality of urban soundscapes with combined noise sources and water sounds. The Journal of the Acoustical Society of America, 127(3), 1357-1366. https://doi. org/10.1121/1.3298437

Jiang, B., Chang, C. Y. \& Sullivan, W. C. (2014). A dose of nature: Tree cover, stress reduction, and gender differences. Landscape and Urban Planning, 132, 26-36. https://doi.org/10.1016/j.landurbplan.2014.08.005

Kaplan, S. (1995). The restorative benefits of nature: Toward an integrative framework. Journal of environmental psychology, 15(3), 169-182. https://doi.org/10.1016/0272-4944(95)90001-2

Kardan, O., Gozdyra, P., Misic, B., Moola, F., Palmer, L. J., Paus, T. \& Berman, M. G. (2015). Neighborhood greenspace and health in a large urban center. Scientific reports, 5(1), 1-14. https://doi.org/10.1038/srep11610

Kellert, S. R. (2002). Experiencing nature: Affective, cognitive, and evaluative development in children. Children and nature: Psychological, sociocultural, and evolutionary investigations, 117151.

Keniger, L. E., Gaston, K. J., Irvine, K. N. \& Fuller, R. A. (2013). What are the benefits of interacting with nature?International journal of environmental research and public health, 10(3), 913-935. https://doi.org/10.3390/ijerph10030913

Kinderman, P., Tai, S., Pontin, E., Schwannauer, M., Jarman, I. \& Lisboa, P. (2015). Causal and mediating factors for anxiety, depression and well-being. The British Journal of Psychiatry, 206(6), 456-460. https://doi.org/10.1192/bjp. bp.114.147553

Kingsley, M. \& Ontario, E. (2019). Commentary Climate change, health and green space co-benefits. Health promotion and chronic disease prevention in Canada: research, policy and practice, 39(4), 131. https://doi.org/10.24095/hpcd p.39.4.04

Lachowycz, K. \& Jones, A. P. (2013). Towards a better understanding of the relationship between greenspace and health: Development of a theoretical framework. Landscape and urban planning, 118, 62-69. https://doi.org/10.1016/j.landurbplan.2012.10.012

Leaf, P. J., Alegria, M., Cohen, P., Goodman, S. H., Horwitz, S. M., Hoven, C. W., Narrow,W.E., Vaden-Kiernan, M., Regier, D. A. (1996). Mental health service use in the community and schools: Results from the four-community MECA study. Journal of the American Academy of Child \& Adolescent Psychiatry, 35(7), 889-897. https://doi.org/10.1097/00004583199607000-00014

Liamputtong, P., Fanany, R. \& Verrinder, G. (2012). Health, illness and well-being: perspectives and social determinants.

Llopis-Albert, C., Merigó, J. M., Liao, H., Xu, Y., Grima-Olmedo, J. \& Grima-Olmedo, C. (2018). Water policies and conflict resolution of public participation decision-making processes using prioritized ordered weighted averaging (OWA) operators. Water resources management, 32(2), 497-510. https://doi.org/10.1007/s11269-017-1823-2

Loera-González, J. (2016). Authorized voices in the construction of wellbeing discourses: A reflective ethnographic experience in Northern Mexico. In Cultures of Wellbeing (pp. 240-259). Palgrave Macmillan. https://doi. org/10.1057/9781137536457_10

Maas, J., Van Dillen, S. M., Verheij, R. A. \& Groenewegen, P. P. (2009). Social contacts as a possible mechanism behind the relation between green space and health. Health \& place, 15(2), 586-595. https://doi.org/10.1016/j.healthplace.2008.09.006

Maas, J., Verheij, R. A., Groenewegen, P. P., De Vries, S. \& Spreeuwenberg, P. (2006). Green space, urbanity, and health: how strong is the relation? Journal of epidemiology \& community health, 60(7), 587-592. https://doi.org/10.1136/ jech.2005.043125

Marmot, M. \& World Health Organization. (2013). Review of social determinants and the health divide in the WHO European Region (No. EUR/RC63/TD/2). World Health Organization. Regional Office for Europe.

Martin, L., White, M. P., Hunt, A., Richardson, M., Pahl, S. \& Burt, J. (2020). Nature contact, nature connectedness and associations with health, wellbeing and pro-environmental behaviours. Journal of Environmental Psychology, 68, 101389. https://doi.org/10.1016/j.jenvp.2020.101389

McDougall, C. W., Hanley, N., Quilliam, R. S., Needham, K. \& Oliver, D. M. (2020). Valuing inland blue space: A contingent valuation study of two large freshwater lakes. Science of the Total Environment, 715, 136921. https://doi.org/10.1016/j.scitotenv.2020.136921 
McKeigue, P. M. (1997). Cardiovascular disease and diabetes in migrants-interactions between nutritional changes and genetic background.

Mercuri, A. M. \& Sadori, L. (2014). Mediterranean culture and climatic change: past patterns and future trends. In The Mediterranean Sea (pp. 507-527). Springer, Dordrecht. https://doi.org/10.1007/978-94-007-6704-1_30

Miho, A. \& Witkowski, A. (2005). Diatom (Bacillariophyta) flora of Albanian coastal wetlands taxonomy and ecology: A review. Proceedings-California Academy of Sciences, 56(1/17), 129.

Mitchell, R. \& Popham, F. (2007). Greenspace, urbanity, and health: relationships in England. Journal of Epidemiology \& Community Health, 61(8), 681-683. https://doi.org/10.1136/jech.2006.053553

Mitchell, R. \& Popham, F. (2008). Effect of exposure to natural environment on health inequalities: an observational population study. The lancet, 372(9650), 1655-1660. https://doi.org/10.1016/S0140-6736(08)61689-X

Morris, N. (2003). Health, well-being and open space. Edinburgh: Edinburgh College of Art and Heriot-Watt University.

Mustafić, H., Jabre, P., Caussin, C., Murad, M. H., Escolano, S., Tafflet, M.,... \& Jouven, X. (2012). Main air pollutants and myocardial infarction: a systematic review and meta-analysis. Jama, 307(7), 713-721. https://doi.org/10.1001/jama.2012.126

Nord, M., Luloff, A. E. \& Bridger, J. C. (1998). The association of forest recreation with environmentalism. Environment and behavior, 30(2), 235-246. https://doi.org/10.1177/0013916598302006

Nutsford, D., Pearson, A. L., Kingham, S. \& Reitsma, F. (2016). Residential exposure to visible blue space (but not green space) associated with lower psychological distress in a capital city. Health \& place, 39, 70-78. https://doi.org/10.1016/j. healthplace.2016.03.002

Olesen, J., Gustavsson, A., Svensson, M., Wittchen, H. U., Jönsson, B., CDBE2010 Study Group \& European Brain Council. (2012). The economic cost of brain disorders in Europe. European journal of neurology, 19(1), 155-162. https://doi. org/10.1111/j.1468-1331.2011.03590.x

Popkin, B. M., Duffey, K. \& Gordon-Larsen, P. (2005). Environmental influences on food choice, physical activity and energy balance. Physiology \& behavior, 86(5), 603-613. https://doi.org/10.1016/j.physbeh.2005.08.051

Pouso, S., Borja, Á., Fleming, L. E., Gómez-Baggethun, E., White, M. P. \& Uyarra, M. C. (2021). Contact with blue-green spaces during the COVID-19 pandemic lockdown beneficial for mental health. Science of The Total Environment, 756, 143984. https://doi.org/10.1016/j.scitotenv.2020.143984

Pretty, J., Peacock, J., Sellens, M. \& Griffin, M. (2005). The mental and physical health outcomes of green exercise. International journal of environmental health research, 15(5), 319-337. https://doi.org/10.1080/09603120500155963

Report by Government. (2020). Development of a commercial project in Skadar Lake National Park and candidate Emerald site (Montenegro). https://rm.coe.int/files20e-2020-montenegro-skadar-lake-govt-rep/16809ce01f.

Roe, J. \& Aspinall, P. (2011). The restorative benefits of walking in urban and rural settings in adults with good and poor mental health. Health \& place, 17(1), 103-113. https://doi.org/10.1016/j.healthplace.2010.09.003

Samet, J. M., Dominici, F., Curriero, F. C., Coursac, I. \& Zeger, S. L. (2000). Fine particulate air pollution and mortality in 20 US cities, 1987-1994. New England journal of medicine, 343(24), 1742-1749. https://doi.org/10.1056/ NEJM200012143432401

Seresinhe, C. I., Preis, T. \& Moat, H. S. (2015). Quantifying the impact of scenic environments on health. Scientific reports, 5(1), 1-9. https://doi.org/10.1038/srep16899

Shanahan, D. F., Fuller, R. A., Bush, R., Lin, B. B. \& Gaston, K. J. (2015). The health benefits of urban nature: how much do we need? BioScience, 65(5), 476-485. https://doi.org/10.1093/biosci/biv032

Shanahan, D. F., Lin, B. B., Bush, R., Gaston, K. J., Dean, J. H., Barber, E. \& Fuller, R. A. (2015). Toward improved public health outcomes from urban nature. American journal of public health, 105(3), 470-477. https://doi.org/10.2105/ AJPH.2014.302324

Sturm, R. \& Cohen, D. (2014). Proximity to urban parks and mental health. The journal of mental health policy and economics, 17(1), 19.

Sugiyama, T., Leslie, E., Giles-Corti, B. \& Owen, N. (2008). Associations of neighbourhood greenness with physical and mental health: do walking, social coherence and local social interaction explain the relationships? Journal of Epidemiology \& Community Health, 62(5), e9-e9. https://doi.org/10.1136/jech.2007.064287

Takano, T., Nakamura, K. \& Watanabe, M. (2002). Urban residential environments and senior citizens' longevity in megacity areas: the importance of walkable green spaces. Journal of Epidemiology \& Community Health, 56(12), 913-918. https://doi.org/10.1136/jech.56.12.913 
Taylor-Gooby, P. (2004). New risks, new welfare: the transformation of the European welfare state. Oxford University Press. https://doi.org/10.1093/019926726X.001.0001

Teisl, M. F. \& O'Brien, K. (2003). Who cares and who acts? Outdoor recreationists exhibit different levels of environmental concern and behavior. Environment and behavior, 35(4), 506-522. https://doi.org/10.1177/0013916503035004004

Thompson, C. W., Roe, J., Aspinall, P., Mitchell, R., Clow, A. \& Miller, D. (2012). More green space is linked to less stress in deprived communities: Evidence from salivary cortisol patterns. Landscape and urban planning, 105(3), $221-229$. https://doi.org/10.1016/j.landurbplan.2011.12.015

Tong, S. T. \& Chen, W. (2002). Modeling the relationship between land use and surface water quality. Journal of environmental management, 66(4), 377-393. https://doi.org/10.1006/jema.2002.0593

Trougakos, J. P., Chawla, N. \& McCarthy, J. M. (2020). Working in a pandemic: Exploring the impact of COVID-19 health anxiety on work, family, and health outcomes. Journal of Applied Psychology. https://doi.org/10.1037/apl0000739

Tyrväinen, L., Ojala, A., Korpela, K., Lanki, T., Tsunetsugu, Y. \& Kagawa, T. (2014). The influence of urban green environments on stress relief measures: A field experiment. Journal of environmental psychology, 38, 1-9. https://doi. org/10.1016/j.jenvp.2013.12.005

Ulrich, R. S., Simons, R. F., Losito, B. D., Fiorito, E., Miles, M. A. \& Zelson, M. (1991). Stress recovery during exposure to natural and urban environments. Journal of environmental psychology, 11(3), 201-230. https://doi.org/10.1016/ S0272-4944(05)80184-7

Vaportzis, E., Giatsi Clausen, M. \& Gow, A. J. (2017). Older adult's perceptions of technology and barriers to interacting with tablet computers: a focus group study. Frontiers in psychology, 8, 1687. https://doi.org/10.3389/fpsyg.2017.01687

Vert, C., Nieuwenhuijsen, M., Gascon, M., Grellier, J., Fleming, L. E., White, M. P. \& Rojas-Rueda, D. (2019). Health benefits of physical activity related to an urban riverside regeneration. International journal of environmental research and public health, 16(3), 462. https://doi.org/10.3390/ijerph16030462

Villeneuve, P. J., Jerrett, M., Su, J. G., Burnett, R. T., Chen, H., Wheeler, A. J. \& Goldberg, M. S. (2012). A cohort study relating urban green space with mortality in Ontario, Canada. Environmental research, 115, 51-58. https://doi.org/10.1016/j. envres.2012.03.003

Vitorio, R., Stuart, S., Rochester, L., Alcock, L. \& Pantall, A. (2017). fNIRS response during walking-Artefact or cortical activity? A systematic review. Neuroscience \& Biobehavioral Reviews, 83, 160-172. https://doi.org/10.1016/j.neubiorev.2017.10.002

Völker, S. \& Kistemann, T. (2011). The impact of blue space on human health and well-being-Salutogenetic health effects of inland surface waters: A review. International journal of hygiene and environmental health, 214(6), 449-460. https:// doi.org/10.1016/j.ijheh.2011.05.001

Völker, S., Heiler, A., Pollmann, T., Claßen, T., Hornberg, C. \& Kistemann, T. (2018). Do perceived walking distance to and use of urban blue spaces affect self-reported physical and mental health? Urban forestry \& urban greening, 29, 1-9. https://doi.org/10.1016/j.ufug.2017.10.014

Von der Lippe, M., Saumel, I. \& Kowarik, I. (2005). Cities as drivers for biological invasions-the role of urban climate and traffic. ERDE-Berlin, 136(2), 123.

White, M. P., Alcock, I., Wheeler, B. W. \& Depledge, M. H. (2013). Coastal proximity, health and well-being: results from a longitudinal panel survey. Health \& place, 23, 97-103. https://doi.org/10.1016/j.healthplace.2013.05.006

White, M. P., Elliott, L. R., Taylor, T., Wheeler, B. W., Spencer, A., Bone, A., Depledge M. H. \& Fleming, L. E. (2016). Recreational physical activity in natural environments and implications for health: A population based cross-sectional study in England. Preventive Medicine, 91, 383-388. https://doi.org/10.1016/j.ypmed.2016.08.023

White, M. P., Wheeler, B. W., Herbert, S., Alcock, I. \& Depledge, M. H. (2014). Coastal proximity and physical activity: is the coast an under-appreciated public health resource? Preventive Medicine, 69, 135-140. https://doi.org/10.1016/j. ypmed.2014.09.016

Wood, L., Hooper, P., Foster, S. \& Bull, F. (2017). Public green spaces and positive mental health-investigating the relationship between access, quantity and types of parks and mental wellbeing. Health \& place, 48, 63-71. https://doi. org/10.1016/j.healthplace.2017.09.002

World Health Organisation. (2000). Obesity: preventing and managing the global epidemic. Report of a WHO consultation 


\title{
Políticas públicas ambientales y desarrollo turístico sostenible en las áreas protegidas de Ecuador
}

\author{
Environmental public policies and sustainable tourism development in \\ Ecuador's protected areas
}

Iván Mendoza-Montesdeoca

imendozam@espam.edu.ec@0000-0001-7632-144X

Escuela Superior Politécnica Agropecuaria de Manabí (ESPAM MFL).

Matriz de Calceta. Avda. 10 de agosto, $n^{\circ} 82$ y Granda Centeno. Ecuador

Manuel Rivera-Mateos

manuel.rivera@uco.es@0000-0003-2780-380X

Universidad de Córdoba. Plaza del Cardenal Salazar, 1. 14071 Córdoba, España

Yamil Doumet-Chilán

ndoumet@espam.edu.ec @ 0000-0003-4295-5270

Escuela Superior Politécnica Agropecuaria de Manabí (ESPAM MFL).

Matriz de Calceta. Avda. 10 de agosto, $n^{\circ} 82$ y Granda Centeno, Ecuador

\section{INFO ARTÍCULO}

Recibido: 02/09/2021

Revisado: 01/01/2022

Aceptado: 12/01/2022

\section{PALABRAS CLAVE}

\section{Turismo}

Políticas ambientales

Áreas protegidas

Espacios naturales

Desarrollo turístico sostenible

Ecuador

\section{KEYWORDS}

Tourism

Environmental policies

Protected Areas

Natural spaces

Sustainable tourism development

Ecuador

\begin{abstract}
RESUMEN
Análisis crítico de las políticas públicas de conservación, gestión ambiental y desarrollo turístico en los espacios naturales protegidos de Ecuador para detectar sus disfunciones, contradicciones y problemas de aplicabilidad. Se utiliza una metodología de investigación predominantemente exploratoria y con enfoque descriptivo-analítico a la hora de estudiar y sistematizar las distintas normativas, acciones y directrices existentes e implementadas por parte de organismos internacionales y nacionales con competencias en conservación ambiental y desarroIlo sostenible, las cuales se sistematizan y analizan a través de los principales documentos de interés que recogen principios, lineamientos estratégicos y normas específicas de aplicación. Se han identificado a través de fuentes primarias y secundarias y documentación interna de diversas Administraciones los efectos e impactos más visibles que han generado estas políticas en la protección y/o valorización del patrimonio natural, así como en el desarrollo turístico compatible con la conservación de estos espacios, la generación de ingresos complementarios y la diversificación económica para las comunidades locales. Se concluye que la normativa ecuatoriana sobre conservación de áreas protegidas presenta notables puntos de colisión y falta de coherencia o coordinación con las políticas sectoriales de turismo. Esto es consecuencia de la falta de una visión estratégica y de planificación territorial como destinos turísticos sostenibles y la inexistencia de un marco de gestión, ordenación y planificación compartida y colaborativa entre los distintos agentes locales.
\end{abstract}

\begin{abstract}
Critical analysis of public policies on environmental conservation, management, and tourism development in the protected natural areas of Ecuador to detect their dysfunctions, contradictions, and problems of applicability. A predominantly exploratory research methodology with a descriptive-analytical approach is used when studying and systematizing the different regulations, actions and guidelines existing and implemented by international and national organizations with competencies in environmental conservation and sustainable development. These are systematized and analyzed through the main documents of interest that include principles, strategic guidelines, and specific rules of application.
\end{abstract}




\begin{abstract}
Through primary and secondary sources, and internal documentation of various Administrations we have identified the most visible effects and impacts that these policies have generated in the protection and/or valorization of the natural heritage, as well as in the tourist development compatible with the conservation of these spaces, the generation of complementary income and economic diversification for local communities. We concluded that Ecuadorian regulations on the conservation of protected areas present notable points of collision and lack of coherence or coordination with tourism policies. This is the consequence of two main factors: the lack of a broad strategic vision and comprehensive territorial planning of these territories as sustainable tourist destinations and the lack of a framework for management, planning and collaborative planning between the different local agencies and agents that affect these spaces.
\end{abstract}

\title{
1. INTRODUCCIÓN
}

La Unión Internacional para la Conservación de la Naturaleza (UICN, 2011) sostiene que en los espacios naturales protegidos la ausencia de políticas públicas o normativas específicas no es muchas veces el problema principal, sino más bien la falta de integración y coherencia de las estrategias y planes sobre biodiversidad derivados de las distintas acciones sectoriales que inciden en un mismo espacio protegido y, en definitiva, la falta de un sistema de gobernanza que determine de manera racional y eficiente las normas, el reparto competencial, las funciones institucionales y los procesos e instrumentos de gestión y evaluación. En esta misma línea, Coreau, Guillet y Rabaud (2018) señalan que los investigadores y profesionales vinculados a la ecología y el desarrollo sostenible han de trabajar conjuntamente en la definición de nuevas estrategias de gobernanza y políticas públicas para las áreas protegidas y la preservación de sus servicios ecosistémicos y biodiversidad. Según Forleo y Palmeri (2018), estos constituyen, a su vez, un instrumento de soporte y cualificación, por ejemplo, de numerosas actividades recreativas y de ocio demandadas por numerosas personas. Por lo tanto, es muy necesario analizar -como pretendemos aquí- si la normativa nacional que persigue alcanzar objetivos de conservación y un uso turístico sustentable, así como las políticas públicas sobre las áreas protegidas de Ecuador, realmente responden a las necesidades demandadas por los visitantes, los agentes turísticos y las comunidades locales.

La Organización Mundial del Turismo (OMT, 2016) ha señalado el año 2015 como decisivo para el desarrollo mundial al haber aprobado los Gobiernos la Agenda 2030 para el Desarrollo Sostenible, junto con los Objetivos de Desarrollo Sostenible (ODS), un conjunto de 17 Objetivos con 169 metas asociadas que se centran en las personas de manera transformadora y universal. Y precisamente en este ámbito el turismo se ha considerado como un instrumento útil que puede contribuir, directa o indirectamente, a la consecución de dichos ODS y particularmente respecto a su vinculación más directa con los objetivos 8,12 y 14 relacionados con el crecimiento económico sostenible, así como con los procesos de consumo y de producción sostenibles. De acuerdo con lo que establece la Agenda 2030, el turismo sostenible está llamado a ser uno de los principales medios para prevenir y evitar los impactos negativos derivados de las presiones antrópicas e intereses comerciales cortoplacistas comerciales y el uso masivo e irracional de los recursos patrimoniales desde un enfoque desarrollista, economicista y no sustentable a largo plazo.

La Unión Internacional para la Conservación de la Naturaleza (UICN, 2014) también ha reconocido que en las últimas décadas no solo se ha dado un aumento significativo en el número de áreas protegidas a nivel mundial, sino que también se ha producido un significativo cambio en la comprensión acerca de cómo pueden y deben ser gobernados y gestionados estos espacios. De esta manera, la creación de áreas protegidas se ha convertido en una herramienta indispensable para la conservación, haciendo que las políticas públicas implementen la creación de normativas cuyo objetivo principal sea buscar una coexistencia sostenible entre el medio ambiente, la población local y las expectativas de desarrollo socioeconómico.

Pero como señalan Rodríguez y Ávila (2014), las políticas de protección ambiental presentan una gran complejidad en su aplicación por cuanto se entrelazan en ellas diferentes políticas sectoriales, variables y enfoques territoriales que en la práctica requieren de políticas más integrales que superen el mero enfoque sectorial. Si a ello unimos la existencia en muchos países de un inadecuado marco institucional y 
competencial, la falta de unas estrategias de gobernanza específicas para estos espacios protegidos, la escasa participación y sensibilización del tejido social y ciudadano o la escasa estructuración y vertebración del mapa de actores implicados, el compendio de normas legales se hace obviamente inaplicable desde el punto de vista operativo. Por esto, autores como Meinard (2017) y Ward, Stringer y Holmes (2018), insisten en la necesidad de articular políticas públicas integrales e intersectoriales en estas áreas protegidas con voluntad política de coordinación y cooperación interinstitucional y público-privada y con financiación suficiente en el ámbito de estas áreas protegidas y sus áreas de influencia. Además, estas políticas deben someterse a un proceso de medición y evaluación de resultados y de impactos (Gibson et al., 2017), más aún cuando las políticas ambientales pretenden paralelamente promover otros fines que van más allá de la conservación ambiental como las actividades económicas sostenibles y el desarrollo local.

Los nuevos modelos de gestión de las áreas protegidas deben considerar a éstas como territorios que mantienen en mayor o menor grado semejanzas entre sí: biológicas, geográficas, paisajísticas, de ciertos niveles de éxito (y a veces hasta de fracaso) de sus actividades de gestión y manejo de sus ecosistemas y recursos, parecidos niveles de incidencia de las actividades humanas, etc. (Yánez et al., 2013). Por tanto, es necesario conocer de qué forma se están ejecutando acciones y estrategias planificadas en los modelos de desarrollo planteados en estos espacios, de manera que se puedan establecer análisis comparativos y extraer lecciones aprendidas y casos de referencia de buenas prácticas extrapolables, en mayor o menor medida, a otros territorios. Asimismo, también resulta imprescindible precisar si dichos modelos se enmarcan realmente en los principios y objetivos de una política de sostenibilidad, sobre todo con la obligación de brindar garantías de conservación del patrimonio natural y al mismo tiempo permitir mayores oportunidades de participación a las comunidades locales, cuya economía y supervivencia dependen, en definitiva, de los recursos y sistemas ecosistémicos de las áreas protegidas como las que aquí referimos de Ecuador.

No es casualidad que al menos a nivel de discurso teórico y político en los últimos años, las organizaciones públicas y privadas de todo tipo hayan comenzado a reconocer las conexiones e interdependencias entre las dimensiones económicas, ambientales y sociales de la sostenibilidad y, de hecho, es comúnmente aceptado que las políticas nacionales para el desarrollo de las áreas protegidas han de definir y comprender el conjunto de principios, objetivos, marco legal e institucional, líneas estratégicas, instrumentos de gestión y resultados esperados para garantizar la provisión de bienes y servicios ambientales y la conservación de la diversidad biológica para el bienestar social y económico de sus poblaciones (CONAP, 1999 y Forleo, 2018).

Como señala Paz (2018) existen aproximadamente 202.000 áreas protegidas en el mundo, las cuales cubren el $17,7 \%$ del área total terrestre del planeta, suponiendo que "la puntuación promedio de la huella humana dentro de estos espacios es de 3,3, esto es, casi un $50 \%$ más bajo que la media global que se cifra en 6,16 puntos. No obstante, a pesar de estos datos relativamente favorables, las actividades humanas son frecuentes en muchas áreas protegidas y solo el $42 \%$ de estos territorios están libres de cualquier presión antrópica". Las áreas protegidas con objetivos estrictos de conservación de la biodiversidad (categorías 1 y 2 de la Unión Internacional para la Conservación de la Naturaleza, UICN) tienen menor presión humana que las categorías 3 a 6 . Esto en parte se debe a que estas últimas categorías permiten algunas actividades y la explotación sostenible de los recursos territoriales.

Las amenazas directas e indirectas que afectan a la conservación de estos espacios que prestan importantes servicios ecosistémicos y cuentan con un patrimonio natural que sirve de soporte básico para el turismo sostenible, pueden encontrar su punto de inflexión si se adopta una eficiente toma de decisiones en materia de planificación y gestión del territorio y un sistema de gobernanza colaborativa con los agentes del sector privado, el tejido productivo y la propia comunidad local, promoviendo un compromiso entre las partes en materia de sostenibilidad. Pero resulta evidente, en cualquier caso, que el concepto tradicional de "área protegida" ha sido ampliamente superado, y en las últimas décadas, los espacios protegidos están asumiendo fines muy diversos y alejados de sus objetivos primigenios (conservación de la naturaleza, investigación científica, educación ambiental, turismo y recreación...), y de ahí la tendencia a declarar piezas cada vez más extensas que abarcan comarcas enteras con un predominio absoluto de tierras de propiedad privada y una clara situación de marginalidad y declive demográfico y socioeconómico. Además, a éstas se les exige, entre otras cosas, que doten de un distintivo de calidad a las actividades o productos que se 
generen en su seno, que contribuyan a la salvaguarda de los bienes del patrimonio cultural radicados en su interior, o que sean referentes de iniciativas de desarrollo socioeconómico endógenos en diferentes ámbitos, sobre todo turísticos, entre otros muchos cometidos (Mulero \& Rivera, 2019). Por ello mismo, la adopción de nuevos sistemas de gobernanza y planificación integral y no meramente sectorial se hace aún más necesaria.

Sólo desde la confluencia de los vectores antedichos pueden explicarse precisamente las cifras tan amplias de territorios a nivel mundial que se encuentran sujetos a protección bajo alguna figura de corte internacional, estatal o autonómica y todo parece apuntar, además, a que los nuevos espacios protegidos se han concebido, en buena medida, como una herramienta para un nuevo modelo de desarrollo integral más allá de la mera conservación del medio natural. De esta manera, hoy se espera que las masivas declaraciones recientes de espacios protegidos contribuyan a la dinamización socioeconómica de extensas áreas rurales a través de inversiones públicas, planes de desarrollo sostenible $u$ otras estrategias. Y, en este sentido, Herrera (2020), en un estudio realizado sobre la política turística en Ecuador en el periodo 2009-2013, determinó que las acciones ejecutadas evidenciaron una lógica de actuación muy sesgada y orientada meramente a la consecución de objetivos rectores de política económica cortoplacista en los que la política pública turística a nivel nacional no obtuvo, desde luego, resultados tangibles exitosos y sustantivos, a lo que se sumó el divorcio o escasas sinergias positivas entre la política de turismo y la gestión ambiental de las áreas protegidas. De hecho, los objetivos y enfoques de ambas políticas públicas son desafortunadamente en muchos casos muy diferentes y se aplican por administraciones distintas a modo de compartimentos estancos, sobre todo en sus etapas iniciales (Ngo et al., 2018), pese a que los gestores de destinos suelen reconocer a nivel de discurso teórico que la mejor vía de desarrollo turístico es la planificación integral y no meramente sectorial de los recursos territoriales de los espacios protegidos (Lundberg, 2015).

Pero pese a estas evidencias, consideraciones y realidades sobre la gobernanza de los espacios naturales protegidos, lo cierto es que aún son relativamente escasos los estudios de caso que analicen con detalle y de manera demostrativa las consecuencias y resultados de las políticas públicas en la dinamización socioeconómica en general y turístico-recreativa en particular de las áreas protegidas y las comunidades locales de sus áreas de influencia. Esto si cabe es aún más evidente en países como Ecuador, donde estas políticas son relativamente recientes y apenas han trascendido del discurso teórico recurrente con pocas acciones sustantivas, contrastadas y evaluadas que puedan servir de ejemplos de buenas prácticas, a lo que se suma la inexistencia de sistemas de información territorial bien desarrollados y capaces de servir de soporte a la todavía débil planificación y gobernanza de estos espacios protegidos.

Debido a esto resultan fundamentales los análisis actualizados y las evaluaciones continuas de la aplicabilidad y efectividad de las políticas públicas propuestas y la ejecución práctica de las estrategias y metas planteadas, por lo que en este trabajo se ha pretendido abordar estas cuestiones con el propósito de realizar un análisis crítico sobre las políticas públicas ambientales puestas en marcha en las áreas protegidas de Ecuador desde la perspectiva de su funcionalidad y orientación para propiciar el desarrollo turístico sostenible, todo esto de manera compatible con la conservación de sus servicios ecosistémicos básicos y su propia biodiversidad.

\section{METODOLOGÍA}

El presente trabajo hace uso de un método de investigación con un enfoque descriptivo y analítico-sintético a través del cual se han sistematizado y analizado las distintas normativas, directrices y estrategias implementadas por organismos internacionales y nacionales con competencias en conservación ambiental y desarrollo turístico sostenible. En concreto, se han tenido en cuenta los principales documentos de interés que recogen principios, lineamientos estratégicos y normas específicas de aplicación, delimitando las dos variables acerca del marco legal establecido y las políticas públicas (la ambiental y la turística), en el marco de la sostenibilidad y el desarrollo integral de los espacios naturales protegidos (tabla 1). 
Tabla 1. Fases metodológicas, fuentes documentales e indicadores utilizados.

\begin{tabular}{|c|c|c|}
\hline $\begin{array}{l}\text { Fase 1. Análisis descriptivo-sintético y } \\
\text { sistematización }\end{array}$ & $\begin{array}{l}\text { Fase } 2 \text {. Establecimiento de } \\
\text { indicadores de referencia }\end{array}$ & $\begin{array}{l}\text { Fase 3. Conclusiones sobre resultados } \\
\text { y deficiencias de las políticas públicas } \\
\text { (ambientales, turísticas) }\end{array}$ \\
\hline $\begin{array}{l}\text { Análisis bibliográfico y documental. } \\
\text { Estado de la cuestión }\end{array}$ & $\begin{array}{l}\text { Indicadores de competitividad y } \\
\text { sostenibilidad turística del Foro } \\
\text { Económico Mundial referidos a } \\
\text { Ecuador (2015-2020). }\end{array}$ & $\begin{array}{l}\text { Análisis crítico de las políticas públicas } \\
\text { puestas en marcha y sus disfunciones, } \\
\text { contradicciones y problemas de } \\
\text { aplicabilidad. Valoración en términos } \\
\text { de sostenibilidad turística integral. }\end{array}$ \\
\hline $\begin{array}{l}\text { Marco legal e institucional con } \\
\text { incidencia en el manejo y gestión } \\
\text { de las áreas protegidas desde la } \\
\text { perspectiva ambiental y de desarrollo } \\
\text { turístico sostenible. }\end{array}$ & $\begin{array}{l}\text { Indicadores de monitoreo para el } \\
\text { manejo turístico y ambiental de los } \\
\text { Planes de Gestión Operativa Anual } \\
\text { (PGOA) de las áreas protegidas de } \\
\text { Ecuador. }\end{array}$ & $\begin{array}{l}\text { Conclusiones a partir de estudio de } \\
\text { indicadores de referencia de la Fase } \\
2 \text { y resultados obtenidos de análisis } \\
\text { bibliográfico y documental (Fase } 1 \text { ). }\end{array}$ \\
\hline $\begin{array}{l}\text { Sistematización de normativas, } \\
\text { estrategias y directrices } \\
\text { implementadas por organismos } \\
\text { internacionales y nacionales con } \\
\text { competencias en conservación } \\
\text { ambiental y desarrollo sostenible. }\end{array}$ & $\begin{array}{l}\text { Objetivos de Desarrollo Sostenible } \\
\text { (ODS) }\end{array}$ & \\
\hline $\begin{array}{l}\text { Explotación de datos estadísticos } \\
\text { sobre turismo y medio ambiente } \\
\text { en espacios protegidos de Ecuador. } \\
\text { Caracterización territorial, ambiental y } \\
\text { socioeconómica del SNAP de Ecuador. }\end{array}$ & & \\
\hline
\end{tabular}

Fuente: Elaboración propia.

Además del análisis crítico de las principales normas legales, estrategias y reglamentos relacionados con la conservación y el desarrollo turístico sostenible de los espacios naturales protegidos de Ecuador, y que se indican en el apartado 4 de resultados, hemos considerado aquellas fuentes de referencia en materia de indicadores de seguimiento de políticas públicas, particularmente el sistema de indicadores de competitividad y sostenibilidad turística del Foro Económico Mundial (Schwab et al., 2017) y los de monitoreo de manejo turístico y ambiental del Manual para la Gestión Operativa de las Áreas Protegidas de Ecuador (Columba, 2013). Con esto se ha pretendido obtener en una fase final una serie de conclusiones y reflexiones, mediante un análisis crítico, sobre la eficacia y eficiencia de la gestión y planificación realizadas en estos espacios protegidos y sobre el comportamiento y dinámica turística detectadas en el Sistema Nacional de Áreas Protegidas de Ecuador respecto a las variables macroeconómicas del turismo a nivel nacional.

\section{SIGNIFICACIÓN AMBIENTAL Y SOSTENIBILIDAD TURÍSTICA DE LOS ESPACIOS NATURALES PROTEGIDOS DE ECUADOR}

Ecuador en 2019, antes de la crisis sanitaria, registró un volumen de turistas superior a los 2,4 millones, principalmente concentrados en los espacios naturales protegidos de Islas Galápagos y la Amazonía. Este flujo turístico generó un total de 1.871 millones de dólares USD en ingresos directos por la actividad turística y más de 2.287 millones en ingresos por divisas por turismo, alcanzándose la mejor cifra de aportación de la actividad turística al PIB Nacional (un 2,2\%) tras un crecimiento continuo en la última década sólo truncado por la crisis de la pandemia del Covid-19 en 2020 (Instituto Geográfico Militar, 2020). Por su parte, la participación del sector turístico en el empleo total del país en 2019 alcanzó un 6,1\%, si bien muy por detrás de sectores económicos como el agrario y el comercial y con cierta tendencia al estancamiento desde 2015, coincidiendo con una situación inestable y de evolución de "dientes de sierra" que se ha venido percibiendo 
en el último sexenio en el comportamiento de la demanda, particularmente en los espacios naturales protegidos, donde se concentra buena parte de la actividad turística (figura 1).

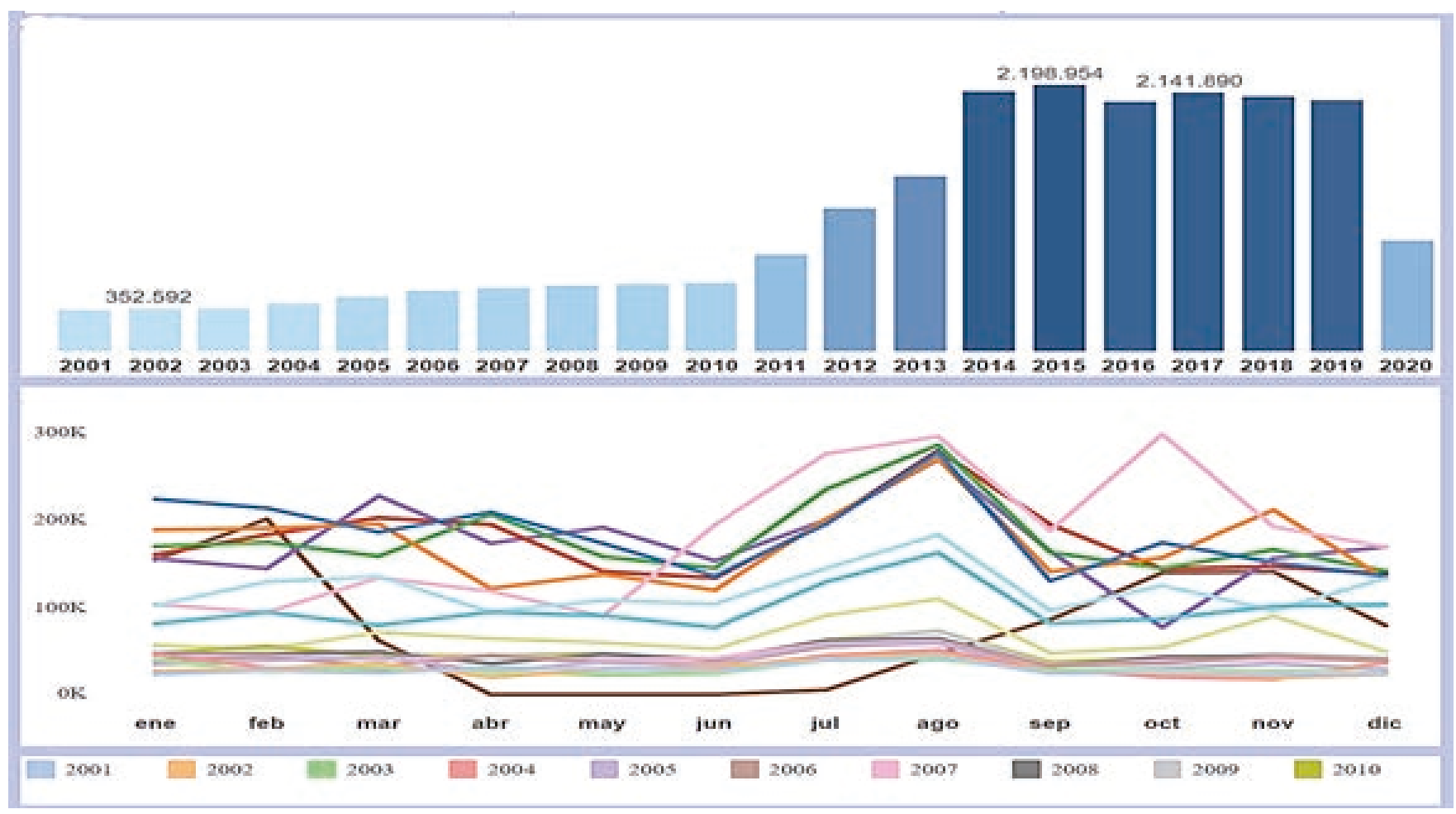

Figura 1. Evolución del número de visitantes en Áreas Protegidas de Ecuador (2001-2020). Fuente: Ministerio del Medio Ambiente (2021). Elaboración propia.

En este sentido, hay que aclarar que en 2019 del total de turistas registrados en Ecuador (2.430.000), unos 2.057.847 (un 84,6\%) visitaron algún espacio natural protegido, siendo el Parque Nacional de MachaliIla, las Islas Galápagos y la Reserva Marino-Costera de Puntilla de Santa Elena los que acapararon una parte muy importante de dichas visitas (figura 2). En consecuencia, la actividad turística en Ecuador se encuentra muy concentrada de manera abrumadora en las áreas naturales de mayor fragilidad ambiental, sobre todo en espacios costero-marítimos e insulares, por lo que los problemas de sostenibilidad tanto ambientales como turísticos están al orden del día, más aún si consideramos la fuerte estacionalidad de los flujos turísticos, muy concentrados en los meses de verano (figura 1).

La importancia de las áreas protegidas de Ecuador como soporte fundamental de su oferta turística se explica por ser uno de los 17 países de mayor biodiversidad del mundo y por ocupar el segundo lugar en número de especies endémicas, además de contar con 17 diferentes ecosistemas y con un 35\% de su extensión territorial cubierta por biomas no perturbados, sobre todo en la región del Amazonas. Su Sistema Nacional de Áreas Protegidas (SNAP) abarca, de hecho, el 13,64\% del territorio nacional, con un total de 64 espacios protegidos y una extensión de 18.401 .927 has. (figura 3). La diversidad biológica es fundamental, en consecuencia, para el desarrollo económico nacional y es un elemento fundamental de sus estrategias nacionales y regionales de desarrollo turístico sostenible, al menos a nivel de discurso teórico, habida cuenta del gran potencial, insuficientemente explorado aún, y de los beneficios derivados de la conservación del medio natural y el mantenimiento de sus señas de identidad eco-culturales e indígenas para convertirse en un destino turístico de primer orden. 


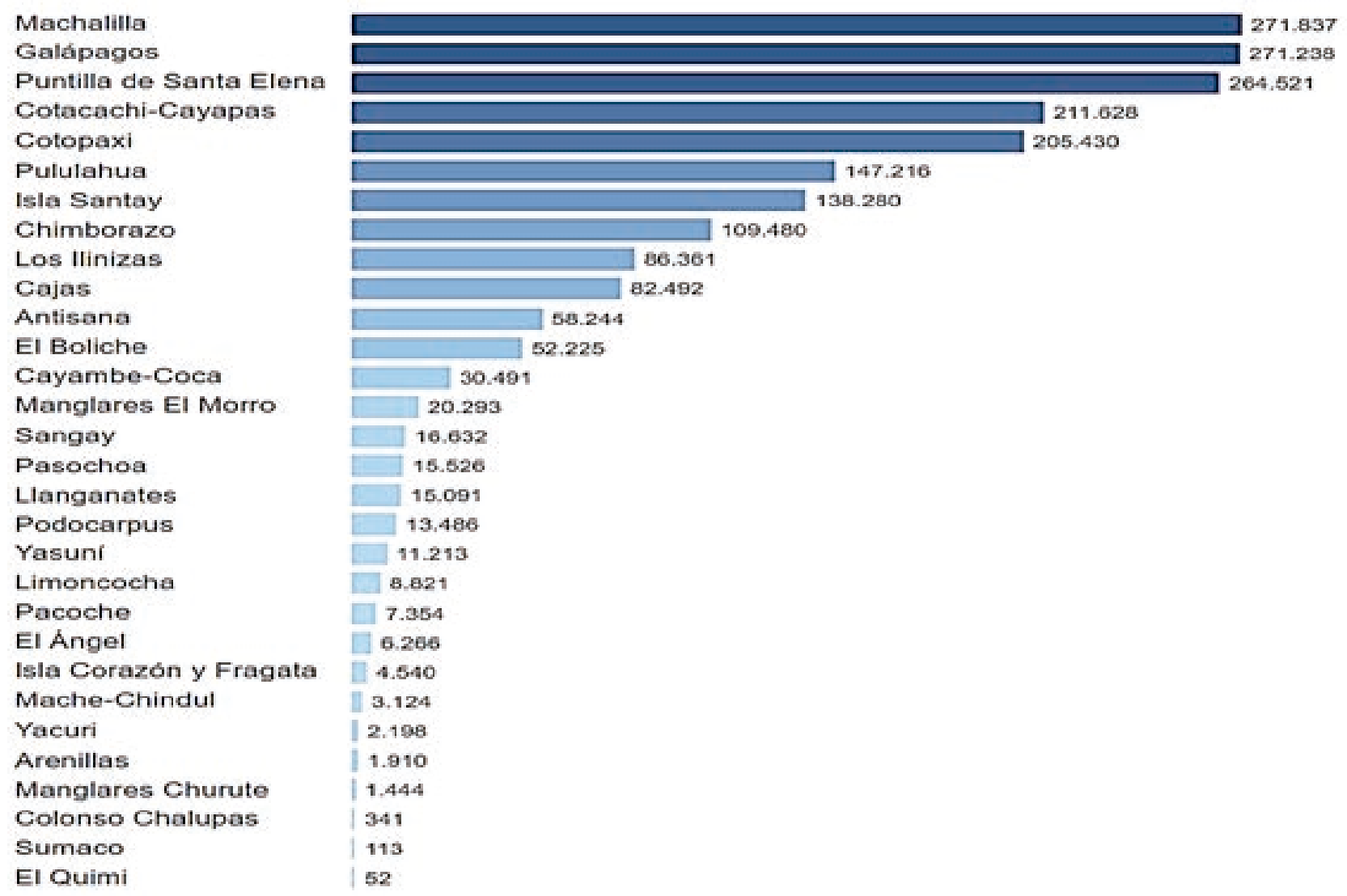

Figura 2. Visitantes en Áreas Protegidas de Ecuador (2019). Fuente: Ministerio del Medio Ambiente (2020). Elaboración propia.

Como ya fue diagnosticado por el Ministerio de Turismo de Ecuador (MINTUR, 2017) este país forma parte del $30 \%$ de los países con un mayor potencial a nivel mundial de desarrollo turístico atendiendo a la calidad y diversidad de sus recursos naturales y culturales. Actualmente, hay registrados unos 3.366 atractivos turísticos a nivel nacional, de los cuales el 3\% se ubican en la región insular de las Galápagos, el 28\% en la región Costa, el 53\% en los Andes y el 17\% en la Amazonia, mientras que el 51\% de dichos atractivos corresponden a manifestaciones culturales y el $49 \%$ a sitios naturales. Para el Ministerio del Ambiente (2020) los espacios naturales que forman parte del Sistema Nacional de Áreas Protegidas (SNAP) vienen experimentando en los últimos años un nivel de afluencia de visitantes aceptable y a buen ritmo gracias a la presencia de los visitantes nacionales, que suponen un $95 \%$ del total, mientras que la demanda internacional es de solo un 5\%. La cifra total de visitantes más actualizada es de 368.309 personas en el conjunto de las áreas de conservación del país (MAE, 2020).

Los turistas que visitan Ecuador realizan principalmente, por este orden, actividades de turismo cultural (un $73,8 \%$ ), ecoturismo (21\%), sol y playa (10,2\%), turismo deportivo de naturaleza y de aventura (3,9\%), turismo de salud $(2,7 \%)$, turismo rural comunitario $(1,3 \%)$ y parques temáticos $(1,3 \%)$, pero en cualquier caso una buena parte de los mismos valora especialmente el nivel de conservación, autenticidad y diferenciación de los recursos naturales y culturales. El Ministerio de Turismo (MINTUR, 2017) señale que las nuevas formas de turismo responsable y sostenible son precisamente las que presentan mayores potencialidades de futuro a medio y largo plazo. Pero para la activación y desarrollo de estas potencialidades, las instituciones gubernamentales y las organizaciones no gubernamentales han de ejercer un papel proactivo y decisivo a la hora de dinamizar turísticamente territorios aún embrionarios en oferta turística y con un tejido empresarial y emprendedor débil y escaso, además de poco vertebrado, y con unas comunidades locales poco sensibilizadas y concienciadas sobre las posibilidades de desarrollo socioeconómico a través de la actividad turística y sus efectos de arrastre en otros sectores de actividad (Idelhadj et al., 2012; Siri \& Sanchai, 2017). Y 
por ello mismo, las políticas públicas han de conseguir que los beneficios e ingresos procedentes de la actividad turística redunden sustantivamente en inversiones y beneficios para dichas comunidades anfitrionas en aspectos diversos como las condiciones de accesibilidad, las infraestructuras y equipamientos públicos, el empleo, la diversificación productiva local, la ordenación sostenible del territorio, etc.

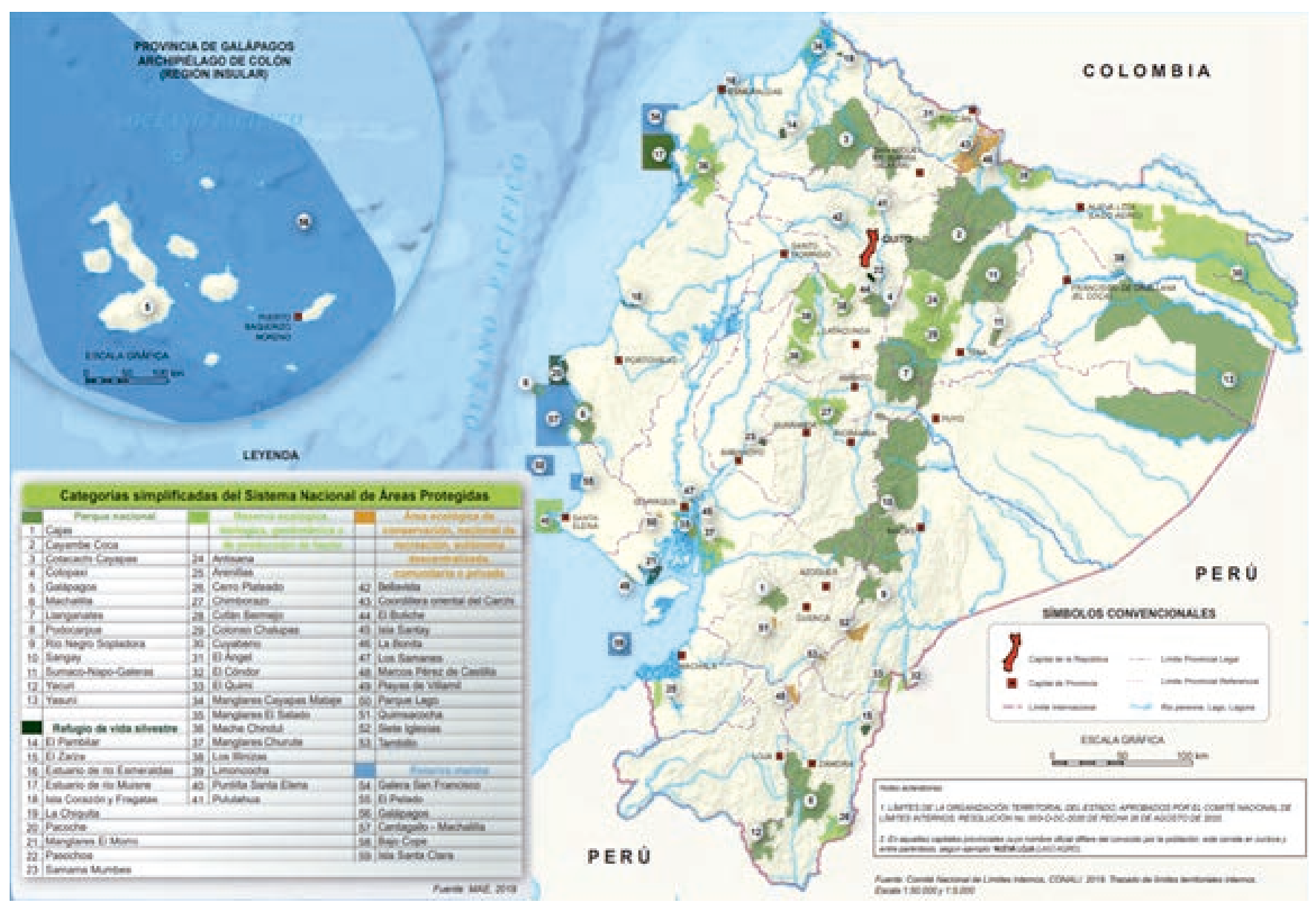

Figura 3. Sistema Nacional de Áreas Protegidas de Ecuador. Fuente: Ministerio del Ambiente de Ecuador, 2019.

En lo que respecta al territorio protegido de Ecuador el Ministerio del Ambiente de Ecuador (2017) especifica que hay sectores muy importantes que aún están fuera de los esquemas de protección y particularmente el $24 \%$ del territorio de vegetación remanente del país corresponde a las zonas necesarias para la conservación de la biodiversidad. De este porcentaje, que equivale a 3,6 millones de hectáreas, el 35\% está dentro del SNAP y el 13\% está incluido en el programa "Socio Bosque" a través de acuerdos de conservación con la comunidad. Un problema que también tiene el país es la exclusión de las zonas planteadas en este estudio para la conservación de las especies.

El artículo 405 de la Constitución de la República de Ecuador 2008 dispone que el Sistema Nacional de Áreas Protegidas (SNAP) garantizará la conservación de la biodiversidad y el mantenimiento de las funciones ecológicas, añadiendo que dicho sistema se integrará por los subsistemas estatal, autónomo descentralizado, comunitario y privado, y su rectoría y regulación estará ejercida por el Estado. Dentro de la normativa derivada se contemplan procesos de protección y cuidado del patrimonio natural de forma participativa mediante distintos subsistemas del SNAP, pero es necesario abordar la realidad de las distintas áreas protegidas de Ecuador y sus diversas variables de presión a las que son sometidas. Hay que reconocer las problemáticas que tienen las entidades encargadas de la gestión, administración y control para validar el cumplimiento de todas sus funciones y competencias considerando que cuentan con presupuestos limitados y 
modelos de desarrollo muy apegados a modelos tradicionales que dificultan la implementación de modelos de desarrollos mixtos (público/privados) que involucren la cooperación y corresponsabilidad de los actores participantes en todo el proceso de la cadena de valor de los destinos y productos turísticos. En efecto, la incapacidad de lograr una interacción satisfactoria entre estas lógicas y modos de gobernanza ha conducido al final a un diseño inconsistente e incoherente (Unkuch \& Rodrigues, 2017).

El Ministerio del Ambiente (2016) reconoce que en las áreas de protección pública, a pesar del respaldo legal, la aplicación de leyes de gestión ambiental es deficiente. El apoyo institucional podría ser fortalecido pero lo cierto es que existe un muy limitado presupuesto, si bien dependiendo de la región, evidenciando un centralismo extremo y una distribución territorial nada equitativa. Esto se refleja en un personal reducido, falta de capacitación, escasa planificación práctica y sustantiva y poco compromiso de las comunidades y gestores locales. Como resultado los propietarios privados y habitantes de las comunidades de las zonas de influencia y amortiguación ambiental dedican la mayor parte de su tiempo a desarrollar actividades no sostenibles.

Las amenazas directas e indirectas que sufren los espacios naturales protegidos en Ecuador han ido incrementándose desde la primera década de este siglo, pese a los distintos convenios mundiales directamente aplicables a las áreas protegidas nacionales que entraron en vigor y la transposición a la legislación ecuatoriana y su insistencia precisamente en la necesidad de una concertación público-privada y una cooperación comunitaria para afrontar los retos de la sostenibilidad ambiental y turística en estos espacios. Hemos de destacar, en este sentido, la Convención relativa a los Humedales de Importancia Internacional (Convenio Ramsar) de 1971, dedicada especialmente a la protección de los Hábitats de las Aves Acuáticas, la Convención sobre la Protección del Patrimonio Mundial Cultural y Natural (1972), la Convención sobre la Conservación de Especies Migratorias de Animales Silvestres (1979), la Convención de las Naciones Unidas sobre el Derecho del Mar (1982), la Convención Marco de las Naciones Unidas sobre el Cambio Climático (1992) y la Convención de las Naciones Unidas de Lucha contra la Desertificación en los países afectados por sequía grave o desertificación (1994); ésta última adaptada, revisada y aplicada en 2003 en Ecuador.

Para la Secretaría Nacional de Planificación y Desarrollo (SENPLADES, 2017), aun cuando Ecuador ha asignado casi un $20 \%$ de su territorio nacional al SNAP, el sector ambiental recibe limitada atención y recursos presupuestarios. El Fondo de Áreas Protegidas (FAP) genera aproximadamente 600.000 USD por año, lo que, en términos relativos, representa $0,0025 \%$ del PIB o 0,77\% del presupuesto de 2008 del MAE. El gobierno no considera, de hecho, una prioridad estratégica la provisión de financiación para la conservación del SNAP, pese a que en el art. 14 de la Ley Orgánica de la Biodiversidad de Ecuador se expresa que el Ministerio de Turismo junto al Ministerio del Ambiente son los competentes de un efectivo manejo y control de las actividades turísticas en áreas naturales a nivel nacional, regional y local, promoviendo actuar en el manejo correcto de los recursos naturales y culturales dentro y fuera de las áreas protegidas.

Algunos estudios realizados en diversas zonas protegidas de Ecuador (Yanez, 2016) coinciden en considerar que en áreas protegidas como la Reserva Ecológica Manglares Churute (REMCh ), elParque Nacional Yasuní (PNY), la Reserva Biológica Limoncocha (RBL), la Reserva Ecológica Cotacachi Cayapas (RECC), la Reserva Ecológica Mache Chindul (REMACH), el Parque Nacional Podocarpus (PNP) o el Parque Nacional Sumaco Napo-Galeras (PNSNG), entre otras, la problemática principal gira en torno a la pérdida de cobertura de vegetación autóctona, la extracción de madera, el desarrollo de actividades Mineras y/o petroleras, y la caza, pesca y recolección de fauna silvestre de manera furtiva. Pero a estos impactos han de sumarse los problemas vinculados a incendios, crecimiento demográfico, conflictos de tenencia de la tierra, desarrollo de ganadería y pastoreo, erosión, vulcanismo, avances de la frontera agrícola, introducción de especies invasivas en los parques nacionales y reservas ecológicas como de producción faunística. Por otro lado, aparecen problemas dentro de los refugios de vida silvestre y las reservas ecológicas vinculados a la contaminación por aguas residuales, residuos sólidos, la producción camaronera y/o la pérdida de cobertura vegetal. Todo ello demuestra las vulnerabilidades que posee el sistema y la necesidad innegable de poder aplicar modelos de planificación y desarrollo más ajustados a sus realidades y dinámicas socioculturales, socioeconómicas, socioambientales y de gobernabilidad, introduciendo propuestas como el turismo alternativo sostenible como estrategias para la conservación del patrimonio, así como la puesta en valor de este. 
Al hablar del manejo sostenible en las áreas protegidas de Ecuador hay que considerar plantear alternativas que vinculen la diversidad económica con la conservación del medio natural. En términos generales, señala Bonilla (2019), el desarrollo del turismo en las áreas protegidas de Ecuador se enmarca, al menos a nivel de discurso y enfoque teóricos, de acuerdo con las directrices del MAE, por lo que el SNAP brinda facilidades y fiscalización para el desarrollo de la actividad turística. De igual forma, el MAE (2017) declara que, según un estudio del perfil del turista realizado en la Reserva Geobotánica Pululahua, el visitante además de hacer uso del espacio público desea obtener servicios complementarios que aumenten su satisfacción, tales como alimentos y bebidas, hospedaje y recreación. Y en este ámbito, es necesario reconocer las limitaciones de gestión, planificación, inversión, ejecución y control en materia de turismo sostenible que posee el patrimonio natural de Ecuador, sobre todo cuando la dinámica entre oferta y territorio representan a estas como principales motivaciones para llevar a cabo una experiencia turística. Por otro lado, se promueve el turismo como un instrumento estratégico para la generación de impactos positivos dentro de las dimensiones y variables estudiadas en la sostenibilidad como el cambio climático y la actual crisis sanitaria.

\section{RESULTADOS. LAS POLÍTICAS AMBIENTALES Y SU ORIENTACIÓN HACIA EL DESARROLLO TURÍSTICO SOSTENIBLE}

Las políticas ambientales de Ecuador entroncan con un antecedente pionero en América como fue la Convención para la Protección de la Flora, de la Fauna y de las Bellezas Escénicas Naturales de los Países de América, que dio lugar a algunas normas y estrategias a partir de 1942 finalmente asumidas por el Estado de Ecuador, que, si bien tardíamente, avanzaron en una visión más comercial de la naturaleza a un enfoque de protección y conservación de la biodiversidad: en particular, la Estrategia Preliminar para la Conservación de Áreas Silvestres y Sobresalientes de Ecuador (1976), la Ley Forestal y de Conservación de Áreas Naturales y Vida Silvestre (1981), aún vigente, la Estrategia para la incorporación del SNAP en los procesos de planificación y ordenamiento territorial y la participación comunitaria en el manejo y la gestión de estas áreas (1989), la plena institucionalización del SNAP en el marco de las políticas estatales ambientales en 1998 (Columba, 2013) y la Ley de Gestión Ambiental de 2004. El objetivo principal de estas fue "proteger y conservar en su medio ambiente natural, ejemplares de todas las especies y géneros de su flora y su fauna indígenas, incluyendo las aves migratorias" y planteó también la declaración y establecimiento de áreas protegidas específicas. Pese a su fecha ya lejana, lo cierto es que esta Convención es la única de amplio alcance en el ámbito de la conservación en el hemisferio occidental y, de hecho, sigue siendo una referencia inexcusable para la legislación nacional de áreas protegidas y, en algunos casos, como una referencia de calado para la toma de decisiones jurídicas que favorezcan la protección de la naturaleza en aquéllas.

La declaración final contiene disposiciones sobre los derechos y responsabilidades de las Partes Contratantes en sentido amplio, que siguen siendo relevantes y algunas de ellas incluyen obligaciones generales y otras más detalladas. Las principales disposiciones que se aplican son las que instan al establecimiento de áreas protegidas, de manera que el artículo II estipula que los Gobiernos Contratantes establecerán parques o reservas nacionales, monumentos naturales o reservas de regiones vírgenes tan pronto como a juicio de las autoridades del país sea necesario, lo permitan las circunstancias y se notifique previamente a la Unión Panamericana la creación de dichas áreas y de los sistemas administrativos adoptados para su gestión y planificación. Esta convención define cuatro categorías de áreas protegidas (Art. I) que siguen teniendo vigencia y sentido en las distintas regiones de Ecuador:

1. Los parques nacionales, establecidos para la protección y conservación de las bellezas escénicas naturales y de la flora y fauna de importancia nacional, así como para su disfrute por parte de la ciudadanía.

2. Las reservas nacionales, establecidas para la conservación y utilización, bajo vigilancia oficial, de las riquezas naturales, en las cuales se dará a la flora y la fauna la máxima protección que sea compatible con los diversos fines para los que son creadas, entre ellos -al menos en teoría- el desarrollo sostenible de las poblaciones aledañas. 
3. Los monumentos naturales, cuyo fin es conservar algún elemento natural específico tales como especies vivas tanto animales como vegetales y de interés biológico, estético o valor histórico o científico. A estos monumentos se les da una protección absoluta y en ellos sólo permiten los usos de carácter investigador y científico debidamente autorizados, así como las inspecciones de control ambiental pertinentes de las autoridades gubernamentales.

4. Las regiones vírgenes, que son administradas por los poderes públicos en aquellos lugares en los que existen condiciones primitivas de muy alto nivel de conservación en materia de flora y fauna, paisaje, culturas y formas de vida tradicionales, etc., con ausencia de caminos y vías de comunicación para el tráfico rodado de motor y sin explotación comercial apreciable.

La utilización de esta gama de categorías de áreas protegidas en función de una serie de objetivos de conservación y manejo sostenible de estos espacios, tiene en Ecuador su plasmación en una gama aún más amplia de áreas protegidas (tabla 2) que van desde una protección integral y absoluta de determinados espacios hasta la compatibilización con la autorización en otras áreas de determinados usos del suelo y actividades económicas y sociales sometidas a determinadas regulaciones, si bien estas pueden ir más allá de los instrumentos jurídicos ambientales, con lo que ello supone de cierto confusionismo y dispersión legal en la práctica, por ejemplo en lo que se refiere a la prevalencia de determinadas normas sectoriales sobre otras que concurren en un mismo espacio.

En la legislación ambiental de Ecuador también se definen objetivos y estrategias generales para la preservación a largo plazo de los servicios ecosistémicos y todos los componentes bióticos y abióticos de estos espacios naturales, como también de los socioculturales de las poblaciones rurales e indígenas que los habitan. Entre estos objetivos se pueden destacar los siguientes: 1) crear y mantener un sistema o red nacional de áreas protegidas integral, adecuado y representativo de las especies y los ecosistemas importantes, terrestres, marinos y de agua dulce; 2 ) crear y mantener un sistema o red nacional de áreas protegidas para concretar en la realidad toda la variedad de objetivos de conservación de la naturaleza, desde la protección estricta hasta los múltiples usos posibles; 3) crear y manejar áreas protegidas para aprovechar al máximo su relevancia científica, educativa, recreativa, cultural, social, histórica o arqueológica, en consonancia con sus objetivos primarios de conservación y con las metas estratégicas del sistema de áreas protegidas; 4) promover una política nacional de prevención, control y contención de aquellas especies exóticas invasoras que puedan tener un efecto perjudicial sobre la biodiversidad y las áreas protegidas.

Por otro lado, en dicha legislación nacional también se consideran objetivos específicos relacionados con la conservación de la naturaleza, tales como: 1) hacer efectivas las obligaciones internacionales del país incorporándolas al ordenamiento nacional; 2) proteger y restaurar los hábitats y ecosistemas irreemplazables cuyas características únicas no pueden reproducirse mediante la conservación de otras áreas; 3) proteger las especies en peligro de extinción, amenazadas y endémicas, otorgando la máxima prioridad a las especies que están en peligro de extinción, tanto a nivel local como a escala planetaria, y también a sus hábitats; 4) conservar los hábitats necesarios para el mantenimiento de poblaciones viables de especies migratorias; 5) preservar y mantener pequeñas áreas específicas que merecen especial protección debido a su elevada importancia natural y cultural, o por ser poseedoras de otros valores relevantes para las generaciones presentes y futuras; 6) proteger paisajes terrestres y marinos especiales así como sus ecosistemas, con objeto de proporcionar servicios ecológicos esenciales y sustento económico; 7) proteger y preservar grandes áreas naturales intactas y relativamente exentas de fragmentación, así como ecosistemas naturales gravemente amenazados; 8) promover un enfoque eco sistémico de la conservación de la naturaleza, interconectando las áreas protegidas para formar redes ecológicas e integrando dichas áreas protegidas en el paisaje terrestre y marino circundante; 9) utilizar zonas de amortiguamiento y corredores biológicos para facilitar la conectividad ecológica como parte integrante del sistema de áreas protegidas; 10) proporcionar refugios y espacios para ampliar el área de repartición de determinadas especies, a fin de combatir el impacto del cambio climático; 11) concebir y manejar el sistema de áreas protegidas y los espacios que lo conforman de manera que se refuerce la resiliencia de los ecosistemas y las especies ante el cambio climático y otros factores de cambio global, además de brindar la flexibilidad necesaria para posibilitar un manejo adaptativo y responder así al cambio. 
Tabla 2. Categorías de áreas protegidas reconocidas en la legislación ambiental de Ecuador.

\begin{tabular}{|l|l|}
\hline \multicolumn{1}{|c|}{ Categoría } & \multicolumn{1}{c}{ Definición en función de los objetivos de manejo } \\
\hline $\begin{array}{l}\text { Categoría IA: } \\
\text { Reserva natural } \\
\text { estricta }\end{array}$ & $\begin{array}{l}\text { Áreas estrictamente protegidas, reservadas para proteger la biodiversidad, así } \\
\text { como sus principales rasgos geológicos o geomorfológicos: Las visitas, el uso } \\
\text { y los impactos están estrictamente controlados y limitados para garantizar la } \\
\text { salvaguarda de los valores de conservación. Estas áreas protegidas pueden } \\
\text { servir como áreas de referencia indispensables para la investigación científica y } \\
\text { la gestión pública del espacio natural. }\end{array}$ \\
\hline $\begin{array}{l}\text { Categoría IB: } \\
\text { Área silvestre }\end{array}$ & $\begin{array}{l}\text { Generalmente son áreas no modificadas o ligeramente modificadas de gran } \\
\text { tamaño, que mantienen su carácter e influencia natural, sin asentamientos } \\
\text { humanos significativos ni permanentes, protegidas y manejadas a efectos de } \\
\text { preservar su estado natural. }\end{array}$ \\
\hline
\end{tabular}

Categoría II:

Parque nacional

Categoría III:

Monumento o

característica

natural

Categoría IV:

Área de gestión

de hábitats o

especies
Grandes áreas naturales o casi naturales establecidas para proteger procesos ecológicos a gran escala, junto con el complemento de especies y ecosistemas característicos del área, que también revisten un interés de tipo espiritual, científico, educativo, recreativo y de visita, cuando ello resulta ambiental y culturalmente compatible.

Estas áreas se establecen para proteger un monumento natural en particular, que puede ser una formación terrestre, una montaña submarina, una caverna submarina, un rasgo geológico o incluso un elemento biológico, como una arboleda antigua. Normalmente son áreas protegidas bastante pequeñas y a menudo tienen gran atractivo para los visitantes.

El objetivo de estas áreas protegidas es la protección de especies o hábitats específicos y su manejo refleja dicha prioridad. Muchas áreas protegidas de categoría IV requieren intervenciones activas y periódicas para responder a las necesidades de determinadas especies o para mantener los hábitats, pero ello no es obligatorio para la categoría.

Un área protegida donde la interacción entre los seres humanos y la naturaleza ha producido a lo largo del tiempo un área de carácter distintivo, con valores ecológicos, biológicos, culturales y estéticos significativos. En dichas áreas es vital salvaguardar la integridad de dicha interacción para proteger y mantener el área, y conservar sus valores naturales y de otro tipo.

Estas áreas protegidas conservan ecosistemas y hábitats junto con valores culturales y sistemas tradicionales de manejo de los recursos naturales asociados a ellos. Normalmente son extensas, con una mayoría del área en condiciones naturales y con cierta importancia de las comunidades rurales que viven dentro del área o en sus zonas de influencia. Una parte incluye el manejo sostenible de los recursos naturales y se considera que uno de los objetivos principales del área es el uso no industrial y de bajo nivel de los recursos naturales, compatible con la conservación de la naturaleza. Se trata del área protegida más claramente orientada -por no decir la única- hacia la promoción del desarrollo sostenible y no meramente hacia la conservación de la naturaleza.
Categoría VI: Área

protegida con uso sostenible de recursos naturales 
las funciones de los principales actores implicados en las mismas y sus conexiones y sinergias como paso previo para implementar líneas de apoyo y colaboración público-privada para garantizar la conservación y la sostenibilidad de estos espacios; 5) garantizar la conectividad de los ecosistemas y evitar su fragmentación mediante mejoras de la gestión de su biodiversidad; 6) identificar los impactos actuales y potenciales de las actividades humanas, tanto las que se originan en zonas circundantes como las que se producen en el interior de las áreas protegidas y afectan a las zonas aledañas, ya sean terrestres o marinas.

Tabla 3. Tipos de gobernanza de las áreas protegidas de Ecuador.

Tipo de Gobernanza

\section{Gobierno}

Comunidades Locales e Indígenas

Propietarios Privados
Descripción como integrante del sistema oficial de áreas protegidas

Modelo Clásico: Áreas de propiedad o de control estatal

Nuevo: Conservación voluntaria por parte comunidades locales e indígenas

Nuevo: Conservación voluntaria por parte de propietarios voluntarios (personas físicas o jurídicas)

Algunos elementos nuevos: ONG, comunidades, empresas.

Cogestión

Fuente: Dudley \& Stolton, 2008.

En el caso de Ecuador se establece en los números 5 y 7 del artículo 3 de la Constitución de la República que son "deberes primordiales del Estado promover el desarrollo sustentable y la redistribución equitativa de los recursos y la riqueza, así como proteger el patrimonio natural y cultural del país". Asimismo, en el artículo 15 de la Constitución se establece que el Estado promoverá, en el sector público y privado, "el uso de tecnologías ambientalmente limpias y de energías alternativas, no contaminantes y de bajo impacto", mientras que, a su vez, el artículo 57 (número 8) reconoce expresamente "como derecho de las comunas, comunidades, pueblos y nacionalidades del país el conservar y promover sus prácticas de manejo de la biodiversidad y de su entorno natural, sin perjuicio de que el propio Estado establezca y ejecute programas específicos, con la participación de estas poblaciones, para asegurar la conservación y utilización sustentable de la biodiversidad". El apartado 15 del artículo 66 de la misma Constitución es también importante en la medida en que reconoce y garantiza a las personas el derecho a desarrollar actividades económicas, entre ellas el turismo, en forma individual o colectiva, conforme a los principios de solidaridad, responsabilidad social y ambiental.

Volvemos a identificar también no pocas referencias a nivel teórico a la inclusión de objetivos genéricos sociales y económicos, así como de gobernanza, en la legislación sobre áreas protegidas de Ecuador, en concreto las que a continuación enumeramos: 1) velar por que se dé un uso sostenible a las áreas protegidas, en consonancia con los objetivos primarios de conservación de las mismas; 2) el mantenimiento de los servicios de los ecosistemas y de los recursos naturales, en línea con los objetivos de conservación establecidos, pero también para asegurar medios de subsistencia y promover el desarrollo sostenible de las poblaciones rurales y ayudar a la sociedad a adaptarse al cambio climático; 3) proporcionar a los valores culturales (históricos, arqueológicos, paisajísticos tanto en el ámbito terrestre como en el marino, sagrados y estéticos) una protección acorde con los mismos objetivos de preservación de la naturaleza; 4) promover oportunidades recreativas para los visitantes locales y los procedentes de lugares más lejanos (turismo); 5) garantizar una participación plena de todos los sectores de la sociedad en la creación y el manejo de áreas protegidas; 6) garantizar un reparto equitativo de los beneficios procedentes de los usos autorizados en las áreas protegidas; 7) reconocer distintos modelos de gobernanza de áreas protegidas, incluidas las conservadas de forma voluntaria por comunidades locales, pueblos indígenas y particulares o grupos de personas, siempre y cuando se ajusten a la definición de área protegida y satisfagan los requisitos establecidos en la legislación; 8) promover la cooperación intergubernamental y la cogestión por parte de múltiples organismos y entidades; 9) proteger las especies, los genes y los genomas de interés económico para la obtención de alimento y fibras, para la medicina y para la investigación científica; 10) proteger los valores inmateriales 
que estas áreas protegidas pueden aportar a las comunidades locales y a los individuos a través de la cultura, el conocimiento, la memoria, el significado espiritual, el bienestar social, la salud mental y física y los valores existenciales.

Pasando de una perspectiva global a un análisis más específico de las directrices para la gestión eficiente de las áreas protegidas en la normativa ecuatoriana de carácter ambiental, particularmente la Ley Forestal y de Conservación de Áreas Naturales y Vida Silvestre de 2004, hemos de hacer referencia a su art. 66, que define y caracteriza el patrimonio de las áreas naturales del Estado como aquel constituido por el conjunto de áreas silvestres que se destacan por su valor protector, científico, escénico, educacional, turístico y recreacional, por su flora y fauna, o porque constituyen ecosistemas que contribuyen a mantener el equilibrio del medio ambiente, correspondiendo al Ministerio del Ambiente la determinación y delimitación de las áreas que forman este patrimonio, sin perjuicio de las áreas ya establecidas por leyes especiales. El Capítulo 3 , art. 72, determina también que en las unidades territoriales y patrimoniales que el Ministerio del Ambiente establezca, se controlará el ingreso de público y sus actividades, incluyendo incluso la propia investigación científica, de manera que se otorgan importantes competencias ejecutivas a este Ministerio, que, además, según el artículo 70, puede incluso expropiar tierras y recursos naturales de propiedad privada enclavadas en las áreas protegidas o instrumentar expedientes de reversión de otras propiedades al Estado, según los casos, cuando existan objetivos de conservación de la naturaleza debidamente justificados. Por su parte, el art. 67 menciona que las áreas naturales del patrimonio del Estado se clasifican a efectos de su administración y gestión en las siguientes categorías: a) Parques nacionales; b) Reservas ecológicas; c) Refugios de vida silvestre; d) Reservas biológicas; e) Áreas nacionales de recreación; f) Reservas de producción de fauna; y g) Áreas de caza y pesca. Y es aquí precisamente donde se refiere la posibilidad y necesidad de desarrollar algunas actividades de turismo sostenible dentro de estos espacios declarados como protegidos, mientras que el art. 68 posterior concreta aún más con la previsión de la formulación de planes de ordenación de cada una de dichas áreas. Por último, el art. 69. establece que la planificación, manejo, desarrollo, administración, protección y control del patrimonio de las áreas naturales del Estado, estará a cargo del Ministerio del Ambiente, pero sin prever lamentablemente ningún instrumento de coparticipación y coordinación en dicha gestión con el Ministerio de Turismo para el caso de la ordenación de los usos turístico-recreativos.

En la ley mencionada se hacen sólo menciones muy genéricas a la planificación y ordenación de los espacios protegidos, sin considerar expresamente que el Sistema Nacional de Áreas Protegidas de Ecuador conforma un conjunto territorial no homogéneo y con características físicas, geológicas o ambientales ciertamente diversas según zonas. Por otro lado, los niveles de desarrollo socioeconómico de sus áreas de influencia también son muy diferentes según territorios; por ejemplo, entre las áreas naturales de la sierra ecuatoriana y las zonas litorales. Igualmente, es importante señalar que a no todas las áreas protegidas y declaradas legalmente como tal en el país se les han asignado funciones de estímulo a las estrategias de desarrollo sostenible de actividades como la turística, ya que en Ecuador existen territorios cuya declaración responde exclusivamente a la preservación ambiental de zonas de especial fragilidad, como es el caso de las áreas de Yasuní, Sumaco, Llanganates y Mazán, entre otras, a lo que hemos de añadir la problemática creciente de los conflictos de usos del suelo y control de las tierras que alcanza en ciertos casos una dimensión preocupante que dificulta la implementación de las estrategias de planificación y sostenibilidad. El hecho, por último, de que en los espacios protegidos en los que se pueden, en principio, desarrollar actividades de educación ambiental y turístico-recreativas y de turismo científico no esté participando activamente el Ministerio de Turismo de Ecuador, ni tan siguiera en la planificación y gestión de proyectos turísticos sostenibles, está limitando la capacidad del Estado a la hora de fomentar activamente las iniciativas de las comunidades rurales de las zonas de influencia de estos espacios y para orientarlas debidamente según criterios de sostenibilidad.

La Visión y Estrategia del año 2017 del Ministerio de Turismo de Ecuador tiene como objetivo convertir al país en un referente turístico y un instrumento clave para el desarrollo sustentable, social y económico del país (MINTUR, 2017). Para la consecución de este objetivo tiene establecidas diversas políticas transversales denominadas "de entorno" que persiguen concretamente: 
- Fortalecer y potenciar la industria turística en el marco de los principios de desarrollo sostenible, respetando las riquezas culturales y naturales del país.

- Incentivar la generación y mantenimiento de las cadenas de valor del turismo, promoviendo la inclusión de la microempresa y de los actores de la economía popular y solidaria, así como garantizar la seguridad y la calidad de los destinos.

- Promover la innovación y el conocimiento en los proveedores de servicios turísticos.

- Potenciar los destinos turísticos del país, a través de la inversión en infraestructura, conectividad y promoción.

\section{DISCUSIÓN}

Pese a los principios constitucionales, ciertamente claros y rotundos, que afectan a la conservación y uso sostenible de las áreas protegidas de Ecuador, el análisis de las escasas figuras legales que los han desarrollado y de las acciones -también contadas de carácter aplicado y sustantivo- que han tenido alguna trascendencia, hemos de coincidir con algunos autores como Guambuguete (2016) en que en la práctica se inculcan con frecuencia las determinaciones de este marco constitucional y legal bien por inobservancia manifiesta de las mismas en las actuaciones públicas y privadas o bien simplemente por inacción y falta de aplicación de medidas sustantivas y coherentes, a lo que se suma no pocas veces la indefinición y confusión jurídicas existentes por la falta de una normativa de desarrollo eficaz. Y, por ende, también es manifiesta la falta de confianza de la ciudadanía y los agentes privados con incidencia en las áreas protegidas respecto a la capacidad de acción de las instituciones y de coordinación y cooperación entre las mismas. Esto es particularmente apreciable en el caso de la praxis gubernamental centrada en favorecer a toda costa el aprovechamiento y extracción de los recursos naturales no renovables con criterios cortoplacistas y economicistas y no el uso sostenible de dichos recursos mediante estrategias de planificación y prevención de impactos que, paralelamente, mantengan el control de dichos recursos y los usos del suelo por parte de las comunidades rurales mediante proyectos de desarrollo endógeno y comunitario que mejoren su calidad de vida de manera compatible con la conservación de sus espacios protegidos.

No obstante, en la legislación ambiental ecuatoriana apenas se incluyen principios y objetivos concretos de desarrollo sostenible en general y turístico en particular. Lo cierto es que estos son en la práctica muy limitados y tangenciales. En realidad, sólo la categoría VI de la clasificación de áreas protegidas indicada en el cuadro 1 permite de manera clara usos del suelo y actividades económicas productivas que sean compatibles con la preservación del medio natural, de manera que la legislación sectorial de carácter ambiental no es consecuente, en la práctica, con los principios constitucionales ya mencionados.

El análisis efectuado de las políticas turísticas en Ecuador revela, por su parte, en lo que se refiere a la "seguridad", que este concepto integra en sentido amplio no sólo la seguridad policial y de orden público y la lucha contra la criminalidad, sino también otras vertientes como los sistemas de prevención y atención de accidentes, los servicios sanitarios, la seguridad alimentaria, las buenas prácticas sociales, la seguridad ambiental, etc. En definitiva, se pretende abordar una seguridad de carácter integral de cara al turista, a la vez que cuidando particularmente la propia percepción que pueden tener los visitantes, intermediarios y prestadores de servicios turísticos. Pero este pilar básico no prevé, sin embargo, acciones planificadas de carácter regional o subregional adaptadas a las diferentes realidades y casuísticas de los distintos destinos turísticos ecuatorianos en materia, por ejemplo, de accesibilidad, información turística, sensibilización turística ambiental, etc., por lo que se fijan únicamente una serie de medidas muy generalistas y excesivamente "planas", cuya aplicabilidad y resultados tangibles se están poniendo en entredicho por la inexistencia de planes regionalizados más sustantivos y realistas que, por ejemplo, se adapten a las realidades territoriales más singulares de los espacios naturales protegidos.

En lo que respecta a la promoción de los destinos y productos turísticos el Ministerio de Turismo plantea un pilar básico que busca mejorar la competitividad de Ecuador como destino turístico para su desarrollo económico integral. En particular, se manifiesta el objetivo estratégico de generar destinos turísticos 
sostenibles y competitivos en los que se desarrollen productos turísticos innovadores a través de una adecuada planificación territorial. Pero, de la misma manera que hemos comentado anteriormente, el enfoque adoptado para alcanzar este pilar básico es excesivamente general, ya que se obvia, por ejemplo, la realidad singular de las áreas protegidas, pese a ser éstas las que conforman los principales destinos turísticos ecuatorianos por volumen de visitantes a nivel regional, según el Sistema de Información de la Biodiversidad (MAE, 2016).

La importante concentración de los flujos turísticos en los espacios naturales protegidos a la que nos hemos referido en el apartado 3 de este estudio, exige prioritariamente establecer medidas sustantivas que mejoren la gestión ambiental y turística, además de sus infraestructuras y equipamientos de uso público. Asimismo, la necesidad de planes rectores de ordenación y de uso y gestión de estas áreas protegidas se hace si cabe más necesaria si consideramos el beneficio que pueden generar para comunidades y pueblos ancestrales ubicados en su interior o áreas de influencia socioeconómica. No es una casualidad, en este sentido, que el SNAP (Sistema Nacional de Áreas Protegidas) haya generado unos ingresos anuales que bordearon los 527 millones USD en el año 2014 y que representaron en torno al 35\% de los ingresos totales turísticos del Ecuador. Y, por añadidura, los visitantes extranjeros que visitan la red de espacios protegidos del SNAP gastan en promedio unos 2797 USD de media en sus visitas, aproximadamente 1200 USD más que el turista extranjero que visita otros destinos de Ecuador especializados en otros segmentos de demanda como el sol y playa, el cultural, el rural generalista, etc. (Ministerio de Ambiente, 2020).

El Ministerio del Ambiente de Ecuador (MAE, 2019) afirma que cerca del $70 \%$ de los turistas extranjeros que se acercan a estas áreas protegidas está motivado por la observación y contacto directo con la naturaleza con fines también de conocimiento y aprecio de la misma, pero también gusta de realizar complementariamente algunas actividades dentro de las Áreas Protegidas como la práctica de actividades blandas de carácter físico-deportivo como el senderismo y en menor medida las relacionadas con los deportes de aventura y de mayor riesgo, si bien con el inconveniente de que este tipo de prácticas apenas cuentan con una regulación y ordenación turística y tan sólo están afectadas por alguna regulación ambiental un tanto laxa. Este es un caso más que hace más necesaria la adopción de políticas públicas más orientadas hacia la planificación y gestión estratégica de los recursos territoriales de las áreas protegidas si realmente se pretende convertir estas en un verdadero instrumento de desarrollo turístico sostenible. Pero lo cierto es que, aunque las políticas y programas de turismo en Ecuador se refieren a nivel de discurso teórico a la importancia de desarrollar modelos turísticos sostenibles adaptados a estos espacios protegidos como el turismo rural comunitario, este no es en la práctica una prioridad en la aplicación de programas y experiencias concretas que aborden la problemática integral del turismo de estas áreas protegidas y sus necesidades de desarrollo (Mendoza, 2016).

La Visión estratégica del Ministerio de Turismo referida al pilar básico de la calidad turística en Ecuador tiene, asimismo, que adaptarse a las características territoriales específicas de los espacios naturales protegidos y ha de acompañarse paralelamente de una planificación ambiental y de regulación de usos y sistemas de gestión y gobernanza como también de implantación de estándares de calidad y sostenibilidad ya reconocidos y contrastados en otros territorios similares (Sayda et al., 2020; Ward, Stringer \& Holmes, 2018). $Y$, en relación con los objetivos se sostenibilidad, la conectividad en materia de transporte público, accesos, multimodalidad de medios no motores, etc. con los mercados nacionales e internacionales, es otra de las prioridades, pero en la práctica las infraestructuras de soporte de la accesibilidad en diferentes regiones del país, sobre todo en las zonas litorales, presentan fuertes deficiencias como resultado, una vez más, de una política excesivamente centralizada en la atención de las necesidades de las grandes ciudades, una escasa capacidad de gestión y aplicabilidad de proyectos de desarrollo integral a nivel local y provincial y fuertes limitaciones para la inversión nacional y extranjera en el sector turístico, lo que ha venido apuntándose ya en algunos estudios recientes (Herrera \& Maria, 2020). En este sentido, pese a que Ecuador ha ascendido en el ranking de desempeño de competitividad turística desde 2009, cuando ocupaba el puesto 96 según el Foro Económico Mundial, en 2019 aún sigue ocupando un puesto bajo en dicho ranking (70/140) y en el último quinquenio ha ido perdiendo competitividad, así como niveles de empleo, llegadas en turismo y otras variables como la sostenibilidad turística y ambiental (Schwab \& Zahidi, 2020). 


\section{CONCLUSIONES}

En este trabajo se han analizado las principales declaraciones y normas internacionales que más han incidido en la articulación e inspiración de las políticas ambientales y en materia de sostenibilidad que afectan a las áreas protegidas de Ecuador y al conjunto del país y que, al mismo tiempo, inciden en las políticas sectoriales de turismo. Estas áreas protegidas conforman los principales destinos turísticos de Ecuador tanto para turistas nacionales como extranjeros, que tienen además un gasto turístico medio superior al de los visitantes de los destinos de sol y playa y otros de carácter cultural y rural. En lo que respecta a la normativa nacional, se ha profundizado particularmente en el análisis de la Ley Forestal, de Biodiversidad y Vida Silvestre, que establece la posibilidad de realizar actividades de desarrollo sostenible dentro y fuera de zonas protegidas siempre y cuando sean compatibles con la conservación del medio natural y la preservación de sus servicios ecosistémicos, si bien las determinaciones de esta normativa son de carácter muy teórico y genérico y no han sido objeto de un necesario desarrollo reglamentario más sustantivo.

En cuanto a las políticas públicas de turismo desafortunadamente no se proyectan en la misma acciones y ordenaciones específicas para el turismo rural y de naturaleza y la sostenibilidad turística de las áreas protegidas, pese a ser estas las que conforman una parte importante de los principales destinos turísticos del país y presentar unos altos índices de biodiversidad y calidad paisajística. Sus planteamientos, en fin, son también excesivamente generalistas y a nivel de discurso teórico, sin existencia de una planificación turística territorializada por regiones, subregiones, tipologías de destinos turísticos y de segmentos de demanda. A la falta de una hoja de ruta bien definida y sustantiva tanto para las políticas ambientales como turísticas en el ámbito de los espacios naturales protegidos de Ecuador, se une la existencia de numerosos puntos de colisión, falta de coherencia y descoordinación entre las políticas ambientales y las de carácter sectorial y territorial como las de turismo y ordenación del territorio, como consecuencia de la falta de una visión estratégica y de planificación territorial integral de los espacios naturales protegidos como destinos turísticos sostenibles y la inexistencia de un marco de gestión, ordenación y planificación compartida y colaborativa entre los distintos organismos que inciden en dichos espacios con sus diversas políticas sectoriales.

La realidad y la problemática que actualmente presenta buena parte de las áreas protegidas en el país, denotan la falta de una política proactiva que promueva la gestión sostenible del turismo en estos espacios, de manera que no sólo se está poniendo en cuestión el desarrollo sostenible, sino que peligra la propia conservación de sus recursos territoriales, ciertamente muy frágiles, frente a un crecimiento espontáneo, desordenado y a veces exponencial de la demanda turístico-recreativa. Los resultados obtenidos del análisis crítico de las normativas y políticas indicadas apuntan a la necesidad perentoria de acciones específicas y adaptadas a la realidad territorial de estos espacios naturales protegidos, pero para ello se requieren cambios profundos en las formas de actuar de la propia Administración Pública a la que compete su gestión, así como una nueva dinámica de gobernanza en la que primen los principios de cooperación, corresponsabilidad y participación.

Por otro lado, el diagnóstico realizado sobre la ordenación y planificación de estas áreas protegidas nos ha revelado, asimismo, la existencia de importantes déficits de información respecto a la mayoría de los aspectos relacionados con el desarrollo turístico de estos territorios, la incidencia de esta actividad en la estructura socioeconómica y empresarial de su área de influencia, los impactos territoriales de carácter ambiental y sociocultural o incluso sobre el mismo perfil de la demanda actual y/o potencial que busca actividades de carácter turístico-recreativo en contacto directo con el medio natural. Y no es menos cierto también que existen carencias importantes de comunicación entre los gestores de estos territorios y el resto de los agentes implicados, especialmente con la propia población local, los emprendedores y hasta los propios visitantes; lo que se agrava, aún más, con la existencia de una oferta turística dispersa y muy desestructurada, que sufre los problemas propios de un desarrollo emergente, espontáneo y desordenado y que no responde a los criterios de calidad que satisfagan realmente las expectativas de los visitantes, al menos de aquéllas que se promocionan a través de los intermediarios y operadores turísticos privados y la propias campañas de marketing de las Administraciones Públicas. 


\section{Declaración responsable y conflicto de intereses}

Los autores declaran que no existe ningún conflicto de interés con relación a la publicación de este artículo. Las tareas se han distribuido entre los autores de la siguiente manera: Los tres autores han participado en la revisión bibliográfica y estado de la cuestión, el diseño de la metodología y la redacción del artículo. La aportación del análisis cuantitativo y actualizado de datos estadísticos de turismo y medio ambiente ha estado a cargo de Manuel Rivera.

\section{REFERENCIAS}

Bonilla Maldonado, D. (2019). El constitucionalismo radical ambiental y la diversidad cultural en América Latina. Los derechos de la naturaleza y el buen vivir en Ecuador y Bolivia. Revista de Derecho del Estado, 42, 3-23. https://doi. org/10.18601/01229893.n42.01

Columba Zárate, K. (2013). Manual para la Gestión Operativa de las Áreas Protegidas de Ecuador. Ministerio del Ambiente.

Comisión Mundial de Áreas Protegidas de la UICN (2007). Establecimiento de redes de áreas protegidas marinas. Guía para el Desarrollo de capacidades nacionales y regionales para la creación de redes AMPs. https://www.iucn.org/sites/dev/ files/import/downloads/mpa_networkes.pdf.

Conap (1999). Política nacional y estrategias para el desarrollo del sistema guatemalteco de áreas protegidas. N.A.P.

Convention on Biological Diversity (CBD) (2010). The Strategic Plan for Biodiversity 2011-2020 and the Aichi Biodiversity Targets. https://www.cbd.int/doc/decisions/cop-10/cop-10-dec-02-en.pdf.

Coreau, A., Guillet, F. \& Rabaud, S. (2018). The influence of ecological knowledge on biodiversity conservation policies: A strategic challenge for knowledge producers. Journal for Nature Conservation, 46, 97-10. https://doi.org/10.1016/j. jnc.2017.10.008

Forleo, M. \& Palmieri, N. (2018). A framework for assessing the relational accessibility of protected areas. Journal of Cleaner Production, 194, 594-606. https://doi.org/10.1016/j.jclepro.2018.05.149

Gibson, F., Rogers, A.S., Roberts, A., Possingham, H., Mccarthy, M. \& Pannell, D. (2017). Factors influencing the use of decision support tools in the development and design of conservation policy. Environmental Science \& Policy, 70, 1-8. https://doi.org/10.1016/j.envsci.2017.01.002.

Guambuguete, J.P. (2016). Análisis del Art. 407 de la Constitución de la República del Ecuador sobre el Principio de Intangibilidad de las Áreas Protegidas. http://www.dspace.uce.edu.ec/bitstream/25000/7908/1/T-UCE-0013-Ab-378.pdf

Herrera C. \& Maria, Jh. (2020). Análisis de las políticas públicas de turismo en Ecuador Periodo 2009-2013. Universidad Andina Simón Bolívar, Sede Ecuador, Área de Estudios Sociales y Globales. T3359-MRI-Herrera-Analisis.pdf (uasb.edu.ec)

Idelhadj, A., Rivera, M. \& Rodríguez, L. (2012). Turismo responsable, espacios rurales y naturales y cooperación para el desarrollo: a propósito de la "Declaración de Tetuán" (Marruecos). Pasos. Revista de Turismo y Patrimonio Cultural, 10(5), 651-664. https://doi.org/10.25145/j.pasos.2012.10.079

Instituto Geográfico Militar de Ecuador (2020). Atlas Turístico del Ecuador: cuatro municipios por descubrir. Ministerio de Turismo. https://servicios.turismo.gob.ec/atlas-turistico

Lausche, B. (2011a). Guidelines for Protected Areas Legis/ation. IUCN (Unión Internacional para la Conservación de la Naturaleza).

Lausche, B. (2011b). Directrices para la legislación relativa a áreas protegidas. UICN (Unión Internacional para la Conservación de la Naturaleza).

Lundberg, E. (2015). The level of tourism development and resident attitudes: A comparative case study of coastal destinations. Scandinavian Journal of Hospitality and Tourism, 15(3), 266-294. https://doi.org/10.1080/15022250.2015.1 005335

Meinard (2017). What is a legitimate conservation policy. Biological Conservation, 213, 115-123. https://doi.org/10.1016/j. biocon.2017.06.042

Mendoza Ramos, F.M. (2016). Análisis de las políticas para el turismo en Ecuador con énfasis en el turismo rural comunitario. Revista San Gregorio, 15, 122-127.

Ministerio del Ambiente de Ecuador (2016). Áreas protegidas de Ecuador, Socio estratégico para el desarrollo. MAE. 
Ministerio del Ambiente Ecuador, MAE (2017). Lineamientos para la creación y gestión de Áreas de Conservación y Uso Sustentable Autónomas Descentralizadas, Comunitarias y Privadas. Ministerio del Ambiente, 5-70. https://info.undp.org/ docs/pdc/Documents/ECU/Lineamientos\%20creacion\%20areas\%20conservacion2017.pdf

Ministerio de Turismo de Ecuador, MINTUR (2019, 14 de julio). Inventario de Atractivos Turísticos de Ecuador. https://www. turismo.gob.ec/ministerio-de-turismo-actualiza-el-levantamiento-de-atractivos-turisticos-a-nivel-nacional/.

Ministerio de Turismo de Ecuador, MINTUR (2017). Políticas Públicas sobre Turismo en Ecuador. Gobierno de Ecuador.

Ministerio del Ambiente (2016). La gestión integral de las áreas protegidas es una prioridad para el Ministerio del Ambiente. https://www.ambiente.gob.ec/la-gestion-integral-de-las-areas-protegidas-es-una-prioridad-para-el-ministerio-del-ambiente/

Ministerio del Ambiente (2020, 22 de abril). https://www.ambiente.gob.ec/covid-19-un-respiro-para-la-naturaleza/

Mulero, A. \& Rivera, M. (2019). Turismo de naturaleza y espacios naturales protegidos en España. Abaco: Revista de cultura y ciencias sociales, 98, 84-96

Naciones Unidas (2018). La Agenda 2030 y los Objetivos de Desarrollo Sostenible: una oportunidad para América Latina y el Caribe (LC/G. 2681-P/Rev. 3), Santiago.

Ngo, T., Lohmann, G. \& Hales, R. (2018). Collaborative marketing for the sustainable development of community-based tourism enterprises: Voices from the field. Journal of Sustainable Tourism, 26(1), 1-19. https://doi.org/10.1080/0966 9582.2018.1443114.

Organización Mundial de Turismo \& Secretaría de RAMSAR (2019, 14 de junio). Destinos de humedales apoyando el turismo sostenible. https://www.e-unwto.org/doi/pdf/10.18111/9789284414703

Paz Carmona, A.J. (2018). Un tercio de las áreas protegidas en el mundo bajo amenaza humana. MONGABAY LATAM. https:// es.mongabay.com/2018/05/areas-protegidas-amenazadas-por-el-hombre/

Sayda, Marlene, Unkuch, Saant \& Rodrigues, C.M. (2017). Gobernanza e instrumentos de política: un análisis de la política de turismo comunitario del Ecuador. Revista Latinoamericana de Políticas y Acción Pública, 4 (2), 59-83. https://doi. org/10.17141/mundosplurales.2.2017.3073

Schwab, K., Martin, C., Samans, R., Moavenzadeh, J. \& DrzeniekHanouz, M. (2017). The Travel \& Tourism Competitiveness Report 2017. World Economic Forum and R. Crotti \& T. Misrahi (Eds.).

Secretaría del Convenio sobre la Diversidad Biológica (2010). Perspectiva Mundial sobre la Diversidad Biológica. https:// www.cbd.int/doc/publications/gbo/gbo3-final-es.pdf.

Secretaría Nacional de Planificación y Desarrollo, SENPLADES. (2017). Plan Nacional de Desarrollo. Todo una Vida 20172021. http://www.buenvivir.gob.ec/versionesplannacional;jsessionid=DD521DB879E2E0EFA2A620A44FBC8DD

Siri, R. \& Sanchai, O. (2017). Local community participatory learning with a nature interpretation system: A case study in Ban Pong, Chiang Mai, Thailand. Kasetsart Journal of Social Sciences, 38(2), 181-185. https://doi.org/10.1016/j. kjss.2016.04.003

Schwab, K. \& Zahidi, S. (Ed.) (2020). The Global Competitiveness Report, Edition 2020. WEF.

Unión Internacional para la Conservación de la Naturaleza, UICN (2011). Orientaciones futuras de la acción sobre biodiversidad en el ultramar de Europa. https://portals.iucn.org/library/sites/library/files/documents/2011-024-Es.pdf.

Unión Internacional para la Conservación de la Naturaleza, UICN (2013). Conservación Ahora. https://cmsdata.iucn.org/ downloads/revista_web_sur.pdf.

Unión Internacional para la Conservación de la Naturaleza, UICN (2019). Gobernanza de áreas protegidas: de la compresión a la acción. http://cmsdata.iucn.org/downloads/iucn_spanish_governance_book.pdf.

Ward, C., Stringer, L. \& Holmes, G. (2018). Changing governance, changing inequalities: Protected area co-management and access to forest ecosystem services: a Madagascar case study. Ecosystem Services, 30, 137-148. https://doi. org/10.1016/j.ecoser.2018.01.014

Wyborn, C. \& Bixler, R.P. (2013). Collaboration and nested environmental governance: scale dependency, scale framing, and cross-scale interactions in collaborative conservation. Journal of Environmental Management, 123, 58-67. https://doi.org/10.1016/j.jenvman.2013.03.014.

Yánez, M., P., Benavides, J. \& Quishpe, C. (2013). Multivariate characterization of the entities that make up the patrimony of natural areas of the Ecuadorian State: Phase I. La Granja, 18(2), 5-32.

Yánez, M. (2016). Las Áreas Naturales Protegidas del Ecuador: características y problemática general. UNIBE. 


\title{
La importancia de las capacidades dinámicas en el replanteamiento de una ventaja competitiva innovadora. Estudio de caso en empresas tecnológicas cordobesas
}

\section{The importance of dynamic capabilities in the reformulation of an innovative competitive advantage. Case study of Cordoba technology companies}

\author{
María Amalia Trillo-Holgado \\ maru.trillo@uco.es@0000-0002-1626-8066 \\ Carolina León-Urban \\ d22leurc@uco.es@0000-0002-3862-6784 \\ Rocío López-Caballero \\ d22locar@uco.es@0000-0003-2701-9951
}

Universidad de Córdoba (Área de Organización de Empresas). Edificio Gregor Mendel (C5), $3^{a}$ planta. Campus de Rabanales. Ctra. Madrid-Cádiz, Km. 369. 14071 Córdoba, España

\section{INFO ARTÍCULO}

Recibido: 08/10/2021

Revisado: 05/01/2022

Aceptado: 13/01/2022

\section{PALABRAS CLAVE}

Ventaja competitiva Capacidades dinámicas Innovación

Estudio de caso

\section{KEYWORDS}

Competitive advantage

Dynamic capabilities

Innovation

Case study

\begin{abstract}
RESUMEN
La capacidad de innovación de las empresas se relaciona con la reconfiguración o modificación de sus ventajas competitivas. Su mejor explicación atiende a la perspectiva de las capacidades dinámicas (habilidades organizativas para gestionar sus recursos en entornos cambiantes), campo que requiere de profundización práctica. Metodológicamente se construye un modelo a través del cual se identifican determinadas variables e indicadores para facilitar a los directivos explicar cómo aquellos recursos y capacidades que intervienen en mayor medida en el desarrollo de nuevos procesos, productos o servicios se relacionan la reconfiguración de la ventaja competitiva de la empresa. Para corroborar la utilidad del modelo se lleva a cabo un estudio de caso ejemplar dentro del sector tecnológico basado en una empresa pública y otra privada. Como conclusiones y resultados, se puede afirmar que se apoya la literatura reciente verificando cómo las actividades específicas de innovación respaldan las capacidades dinámicas a partir de las que se determina la ventaja competitiva sostenible de la empresa. La cultura y el comportamiento colaborativo juegan un papel fundamental que, junto a la tecnología resulta especialmente evidente en el caso del sector privado en comparación con el público.
\end{abstract}

\begin{abstract}
The innovation capacity of companies is related to the reconfiguration or modification of their competitive advantages. It is best explained from the perspective of dynamic capabilities (organisational abilities to manage their resources in changing environments), a field that requires further practical study. Methodologically, a model is provided. The model identifies the most important variables and indicators in order to facilitate managers strategy. That model allows them to explain how those resources and capacities taking part in the development of new processes, products or services influence the reconfiguration of competitive advantage. To support the utility of the model, an exemplary case carried out within the technology sector based on a public and a private company. As conclusions and results, it can be stated that this empirical study supports the scientific literature, verifying how specific innovation activities have to do with the dynamic capabilities from which the company's sustainable competitive advantage is determined. Regarding that, culture and collaborative behavior play a fundamental role, which along with technology, are evident in the case of the private sector compared to the public one.
\end{abstract}




\section{INTRODUCCIÓN}

En los últimos años, se ha considerado que la capacidad de innovación de las empresas influye en el logro y mantenimiento de sus ventajas competitivas, las cuales les van a permitir tener un mejor desempeño que el de sus competidores y situarlas en una posición superior para competir. En este sentido, Piening y Salge (2015) señalan la necesidad investigadora de profundizar en los antecedentes, contingencias y consecuencias del proceso de innovación empresarial, tanto desde el punto de vista teórico como práctico.

Por el motivo referido más arriba, este trabajo pretende explicar cómo se reconfigura la ventaja competitiva a través de la capacidad de innovación de las empresas mediante la perspectiva de las capacidades dinámicas, la cual se basa en la habilidad de las organizaciones para renovar sus competencias y dar una respuesta rápida a los cambios del entorno (Miranda, 2015) a través de la búsqueda de oportunidades, con el fin de crear nuevos productos, servicios o procesos. No en vano, Teece (2014) señaló el impacto significativo de la teoría de las capacidades dinámicas sobre sobre la gestión estratégica, habida cuenta de que, a este respecto, la literatura no está claramente unificada. Así mismo, Mamédio et al. (2019) resaltan el interés de ahondar en el tiempo que necesitan las diferentes capacidades a la hora de materializarse en resultados medibles según las distintas industrias a las que se refieran.

Intentando dar respuesta a la problemática expuesta, el trabajo consta de una parte teórica en la que se analizan los principales factores causantes del dinamismo del entorno y cómo las capacidades dinámicas y los recursos estratégicos influyen en el proceso de innovación empresarial con el ánimo de contribuir a la sistematización del conocimiento al respecto. En segundo lugar, se construye un modelo conceptual en el que se muestra la innovación como resultado de las capacidades dinámicas y fuente de la ventaja competitiva de las organizaciones y, por último, a partir de dicho modelo, se verifican empíricamente los conocimientos previamente ordenados llevando a cabo un estudio de casos de dos empresas representativas en su ámbito geográfico, una del sector público y otra del privado, que actúan en el ámbito tecnológico. La elaboración de una entrevista semi-estructurada permite recabar la información objeto de análisis y explicar cómo se produce la reconfiguración de la ventaja competitiva a partir de la innovación desde la perspectiva de las capacidades dinámicas.

\section{MARCO TEÓRICO}

\subsection{El dinamismo del entorno}

Las empresas operan en entornos dinámicos, por lo que es importante prever los cambios que se puedan producir a fin de aprovechar las oportunidades brindadas por el mercado.

Suárez y Oliva (2005) definen el entorno de una organización como "el patrón de todas las condiciones e influencias externas que afectan a su vida y desarrollo", y el dinamismo como "la incertidumbre o inestabilidad (volatilidad) de un entorno". De forma similar, otros autores se refieren al dinamismo del entorno como la ratio de cambio e inestabilidad, así como al grado en el que el estado futuro del entorno resulta imprevisible.

Sin embargo, cabe considerar que el hecho de que se produzcan variaciones en un entorno competitivo no es condición suficiente para considerarlo de carácter dinámico. “En entornos estables también se producen cambios externos, pero estos cambios son, en gran medida, predecibles e incrementales" (Ambrosini et al., 2009), por lo que el concepto de dinamismo se centra en los cambios que resultan difíciles de predecir y que aumentan la incertidumbre. Así, el nivel de dinamismo depende de la regularidad, profundidad e incertidumbre asociadas a los cambios que surgen en el entorno competitivo de la empresa (Sidhu et al., 2007) que se ve obligada a establecer relaciones con otras empresas (Peng \& Beamish, 2014).

Se han clasificado los factores causantes del dinamismo en el entorno, dispersos en la literatura que habla de ellos, en tres grandes bloques: factores de oferta, factores de demanda y factores relativos al entorno macroeconómico (tabla 1). 
Tabla 1. Principales factores causantes del dinamismo en el entorno empresarial.

\begin{tabular}{|c|c|}
\hline Factores de Oferta & Posibles Causas de Dinamismo \\
\hline Materias primas & $\begin{array}{l}\text { Cambios bruscos en la disponibilidad y el precio de las } \\
\text { materias primas }\end{array}$ \\
\hline Tecnología & $\begin{array}{l}\text { Rápido progreso de nuevas tecnologías y procesos } \\
\text { productivos } \\
\text { Rápido avance en el desarrollo de nuevos productos }\end{array}$ \\
\hline Nuevos competidores & $\begin{array}{l}\text { Nacimiento de nuevas empresas } \\
\text { Entrada de nuevos competidores procedentes de otra } \\
\text { industria o área geográficas }\end{array}$ \\
\hline Factores de Demanda & Posibles Causas de Dinamismo \\
\hline Consumidores & $\begin{array}{l}\text { Cambios en los patrones de demanda, necesidades y } \\
\text { preferencias de los consumidores } \\
\text { Aparición de nuevos segmentos de mercado }\end{array}$ \\
\hline Otros factores macroeconómicos & Posibles Causas de Dinamismo \\
\hline Política gubernamental & $\begin{array}{l}\text { Cambios en la política económica, fiscal y financiera } \\
\text { Cambios en la regulación específica del sector }\end{array}$ \\
\hline Turbulencias económicas & $\begin{array}{l}\text { Cambios de ciclo económico } \\
\text { Sacudidas económicas }\end{array}$ \\
\hline
\end{tabular}

Fuente: Elaboración propia.

Desde el lado de la oferta, las fluctuaciones inesperadas en los precios de las materias primas desestabilizan la estructura de costes de las empresas que se ven obligadas a incrementar sus precios, lo que, dependiendo de la elasticidad-precio de la demanda, puede repercutir negativamente en el consumo de los productos. Además, el incremento en el precio de las materias primas puede hacer viable la utilización de otros insumos o métodos de producción que no resultaban rentables hasta el momento.

Otro de los factores de la oferta es el rápido avance de la tecnología. En los últimos años, el sector tecnológico ha experimentado profundos cambios dando lugar a múltiples innovaciones radicales, es decir, nuevos productos o procesos completamente diferentes a los ya existentes. Cuando estas innovaciones se producen con relativa frecuencia, el entorno se define como tecnológicamente dinámico. El dinamismo tecnológico puede darse en procesos productivos mediante el desarrollo o aplicación de nuevas tecnologías que permitan producir incurriendo en menores costes o aumentando el nivel de calidad de los productos, así como ofreciendo productos novedosos que satisfagan mejor las necesidades de los consumidores. Además, las capacidades analíticas relacionadas con el big data tienen un impacto muy positivo sobre las capacidades dinámicas potenciando la innovación incremental (Mikalef et al., 2019).

Por último, dentro de los factores de la oferta, se observa la amenaza de nuevos competidores, ya sea por el nacimiento de nuevas empresas o por la entrada de empresas procedentes de otras industrias o áreas geográficas. Una de las consecuencias del proceso de globalización es la intensificación de la competencia debido a la eliminación de barreras para la libre circulación de bienes y servicios, lo que ha favorecido el auge de empresas multinacionales que pasan a competir en un número creciente de países. Además, las economías nacionales están más interrelacionadas, produciéndose un mayor movimiento de capitales, de financiación y de tecnología entre ellas.

El segundo bloque, factores de la demanda, atiende a los consumidores. En la medida en que se produzcan cambios más o menos continuos e impredecibles en sus necesidades, aumentará el nivel de dinamismo en el entorno competitivo. Dentro de este dinamismo que afecta a los clientes, se encuentran los cambios en las preferencias y pautas de demanda de los consumidores actuales, así como la posibilidad de que aparezcan nuevos segmentos de clientes con nuevas necesidades. Las alteraciones de los patrones de compra de 
los clientes no sólo responden a los cambios en su nivel de ingresos o en los precios de los bienes y servicios, sino que también vienen motivadas por sus deseos.

El tercer y último conjunto de factores se refiere al entorno macroeconómico, cuya variación, dependiendo del grado y la frecuencia, puede generar incertidumbre e inestabilidad en el entorno competitivo de la empresa. Dichos factores hacen referencia a elementos de la política gubernamental y a variaciones que afectan a la economía en general. La política económica, fiscal y financiera varía en función del partido político que gobierne en cada momento, por lo que no se mantienen estables dado los continuos cambios de gobierno que se producen, lo cual genera una situación de incertidumbre para los agentes económicos y alteran las reglas del juego competitivo (Kale, 2010). Por otra parte, los cambios de ciclo económico (de expansión a recesión, y viceversa) y las sacudidas económicas (subida repentina de tipos de interés) alteran el marco general en el que se desarrolla la competencia (Suárez \& Oliva, 2005). También podríamos incluir las políticas supranacionales.

En este contexto, las empresas necesitan lograr ventajas competitivas, es decir, características que las diferencien de sus competidores y les permitan colocarse en una posición relativa superior para competir. La forma de generar verdaderas ventajas competitivas sostenibles viene dada por las habilidades de las organizaciones para gestionar sus recursos en entornos cambiantes, es decir, por sus capacidades dinámicas. El dinamismo del entorno es la condición necesaria para el impulso de este tipo de capacidades puesto que, si el entorno en el que opera la empresa no está caracterizado por el acontecimiento de cambios, o si los cambios resultan fácilmente predecibles, no tiene sentido hablar de adaptación alguna a los mismos.

La dinámica de los mercados exige que las organizaciones desarrollen nuevas capacidades y las utilicen para el desarrollo de productos, servicios y procesos innovadores que les permitan obtener ventajas competitivas. Si la innovación es de proceso (introducción de un cambio significativo en la tecnología de producción de un bien o servicio) se logrará obtener una ventaja competitiva de liderazgo en costes y si es de producto o servicio (introducción en el mercado de nuevos o significativamente mejorados productos o servicios) se conseguirá una ventaja competitiva de diferenciación de producto o servicio.

\subsection{El enfoque de las capacidades dinámicas}

El enfoque de capacidades dinámicas surge del intento de Pisano (1994), Collins (1994) y Teece et al. (1997) por superar las limitaciones de la Teoría de Recursos y Capacidades. Dicha teoría define los beneficios de la empresa a partir únicamente de sus fortalezas y debilidades, entendiendo éstas como la existencia o la ausencia de recursos y capacidades que permitan lograr ventajas competitivas. Por tanto, esta teoría tiene un carácter estático y no considera el dinamismo del entorno causado por el avance tecnológico, los cambios regulatorios y de ciclo económico, el cambio competitivo y los cambios en las pautas de demanda.

Si el entorno en el que opera la empresa es de carácter relativamente estático, estable y cuyos cambios son predecibles, el valor estratégico de los recursos que configuran las capacidades competitivas de la empresa también se mantendrá estable, no erosionándose, por tanto, la ventaja competitiva con la que cuenta la misma. En este tipo de entornos no tendrá sentido hablar de capacidades dinámicas. Por el contrario, cuando los mercados son dinámicos o de "alta velocidad", el valor de los recursos y capacidades que sustentan la ventaja competitiva también varía, como se muestra en Garzón (2015) y debe tender a su mejora y ampliación, tal como se observa en el caso concreto que propone Collins (2021)

Dado que la Teoría de Recursos y Capacidades no es capaz de explicar cómo las empresas renuevan sus competencias para adaptarse al entorno cambiante y mantener sus ventajas competitivas, en las últimas décadas, se ha venido desarrollando por parte de la literatura especializada en dirección estratégica una nueva perspectiva que ha recibido el nombre de Capacidades Dinámicas (Teece, 2007). Por tanto, esta perspectiva surge para mejorar la capacidad explicativa de la Teoría de Recursos y Capacidades respecto al carácter sostenible de la ventaja competitiva en entornos de rápido cambio, al considerar la naturaleza evolutiva de los recursos y capacidades de la empresa con relación a los cambios en el entorno en el que opera la misma (Wang \& Ahmed, 2007). Las empresas que han logrado el éxito en tales ambientes competitivos son 
las que han demostrado capacidad de respuesta en el momento, y rápida y flexible innovación de producto (Teece et al., 1997).

\subsubsection{Capacidades dinámicas y reconfiguración de la ventaja competitiva}

El hecho de que el estudio del fenómeno de las capacidades dinámicas se haya abordado desde varias perspectivas teóricas o enfoques implica que, al modificarse la perspectiva desde la que se analiza el fenómeno de estudio, las conclusiones a las que se llega en cada análisis son diferentes, pero, como se observa a lo largo de este epígrafe, todas las perspectivas tienen en común la relación con la necesidad de replanteamiento con la ventaja competitiva para abordar el mercado.

Desde un enfoque contingente, las capacidades dinámicas se definen como capacidades que permiten responder a los cambios producidos en el entorno (Zajac et al. 2000); desde un enfoque de innovación, se refieren a la habilidad de la empresa para desarrollar nuevas soluciones (Teece \& Pisano, 1994); y desde la teoría de construcción de capacidades se conciben como capacidades que permiten modificar las capacidades o rutinas organizativas actuales de la empresa (Oliver \& Holzinger, 2008).

\subsubsection{Enfoque de innovación}

Abordando en primer lugar la corriente de innovación, ésta concibe las capacidades dinámicas en función de la capacidad que tiene la empresa para innovar, en sentido amplio, esto es, mediante el lanzamiento de nuevos productos o servicios, innovaciones de proceso o descubrimiento de nuevos mercados y modelos de negocio. Dentro de la evolución del concepto, se reconoce la necesidad de adaptación y generación de capacidades difíciles de imitar. Así, bajo esta corriente, las capacidades dinámicas parecen quedar definidas en función de su output (innovación). Este enfoque considera que la aplicación de las capacidades dinámicas tiene como resultado la innovación.

En cuanto a la evolución experimentada por este enfoque, la primera definición fue aportada en 1934 por Schumpeter, quien consideró la capacidad de innovación como la causante de la "destrucción creativa" que se refiere al proceso por el que la aparición de nuevos productos o servicios destruye otros ya existentes en el mercado, haciendo incluso desaparecer a empresas y modelos de negocios. Pero, según Schumpeter, este proceso depende de las características de la figura del emprendedor, quien será el responsable del cambio continuo y de la innovación. Sin embargo, hasta la aportación realizada por Teece y Pisano (1994) no se considera la existencia de una definición formal del concepto de capacidades dinámicas. Estos autores consideraron el dinamismo del entorno haciendo referencia a la innovación como herramienta para responder a las "circunstancias cambiantes del mercado" $y$, más adelante, describieron las capacidades dinámicas como aquéllas difíciles de imitar y que permiten a la empresa adaptarse a las necesidades cambiantes de los clientes y a los cambios tecnológicos que se producen en el mercado.

\subsubsection{Enfoque de construcción de las capacidades}

La corriente con mayor número de aportaciones es el enfoque de construcción de capacidades que entiende las capacidades dinámicas como las habilidades para integrar, construir y reconfigurar competencias o rutinas, a partir de la alteración y recombinación de los recursos con los que cuenta la empresa y la adquisición de nuevos recursos, lo cual tiene como resultado la generación de nuevas capacidades organizativas y la propia ventaja competitiva en respuesta al entorno cambiante. En este escenario, se desarrolla la búsqueda y administración de oportunidades y amenazas como elementos clave en las capacidades dinámicas, que permitan involucrar la generación de valor superior para los consumidores a partir del enfoque en la orientación y los intereses del mercado.

El primer autor de esta corriente fue Nelson, quien en 1991 definió el concepto de capacidades dinámicas introduciendo la evolución de las capacidades esenciales de la empresa dado que se encuentran en un contexto Schumpeteriano (evolutivo, de rápido cambio o de alta velocidad), por lo que las capacidades de la 
empresa también deben evolucionar y actualizarse al igual que su entorno. En 1997, Teece, Pisano y Shuen definieron las capacidades dinámicas como las habilidades de la empresa para reconfigurar sus competencias internas y externas en función de los cambios del entorno para lograr nuevas formas de obtener ventajas competitivas. Los autores cuyas aportaciones fueron posteriores a las de Teece, Pisano y Shuen también tuvieron en cuenta, a la hora de definir las capacidades dinámicas, la reconfiguración de los recursos para adaptarlos a las condiciones cambiantes del mercado y conseguir mantener la ventaja competitiva.

En 2007, Augier y Teece incorporaron a las anteriores definiciones el adjetivo de "inimitable" a la capacidad de la empresa para reconfigurar su base de activos. Por su parte, Oliver y Holzinger (2008) consideraron las capacidades dinámicas como las habilidades para desarrollar competencias internas que permitan satisfacer las necesidades del mercado.

\subsubsection{Enfoque contingente}

Existe una tercera corriente denominada enfoque contingente, en función de la cual las capacidades dinámicas se definen en términos de ajuste con las características del entorno. Según este enfoque, el ajuste respecto a las características de un entorno cambiante dependerá de la respuesta estratégica para adaptarse. Por lo tanto, los trabajos clasificados en esta corriente consideran que las capacidades dinámicas de la empresa responden a un esquema del tipo señales externas-interpretación-respuesta-evaluación. Las organizaciones deben mostrar una actitud proactiva a las señales que reciben de su entorno, interpretándolas y dándoles respuesta a las contingencias que puedan producirse y, por último, evaluar el grado de adaptación.

Eisenhardt y Martin (2000) definieron las capacidades dinámicas como los procesos estratégicos llevados a cabo por la empresa para obtener nuevas configuraciones de recursos cuando los mercados experimentan cambios. Se considera que las oportunidades del entorno que se aprovechen por las empresas pueden generar ventajas competitivas. Zajac et al. (2000) determinaron las capacidades dinámicas como las capacidades de la empresa para llevar a cabo el cambio necesario ante contingencias ambientales (externas) y organizativas (internas), lo que da lugar a un incremento del beneficio.

En 2001, Rindova y Kotha introdujeron el término "Continua Metamorfosis" para describir las transformaciones que experimentan las empresas para ajustar sus recursos a los cambios asociados a su entorno dinámico. Se concibieron las capacidades dinámicas como el origen de las ventajas competitivas sostenibles en entornos de continuo cambio. Para finalizar esta corriente, cabe mencionar la aportación realizada por Aragón-Correa y Sharma (2003), quienes consideraron que las capacidades dinámicas surgen como consecuencia de la aplicación de estrategias proactivas que tratan de anticiparse a los cambios y reducir la incertidumbre del entorno.

\subsubsection{Conclusiones de los tres enfoques}

Aunque las tres corrientes responden a esquemas distintos, no se puede considerar que las mismas sean excluyentes entre sí. En este sentido, tanto la corriente o enfoque de innovación, como la perspectiva contingente, parecen definir a las capacidades dinámicas en función de sus resultados o efectos, innovación y estado de adaptación, respectivamente. Sin embargo, aunque las definiciones que conforman cada enfoque difieren en cuanto a la forma en la que son enunciadas, pueden identificarse dos aspectos comunes en las mismas: capacidad de la empresa para mantenerse adaptada a entornos de rápido cambio. Ambos aspectos ponen de manifiesto la necesidad de tener en cuenta no sólo los factores externos (entorno) e internos (recursos y capacidades) de la organización, sino que también debe considerarse la evolución de ambos factores a lo largo del tiempo y la forma en la que las empresas logran el ajuste entre ellos mediante el "ajuste o encaje dinámico" entre los factores internos y los factores del contexto (Zajac et al., 2000; Rindova \& Kotha, 2001) para tratar de explicar la consecución de ventaja competitiva sostenible por parte de las empresas que operan en entornos de carácter dinámico en los que se producen cambios de carácter impredecible. 
Teece et al. (1997) afirmó que "las capacidades dinámicas reflejan la habilidad organizativa de lograr nuevas e innovadoras formas de ventaja competitiva". El desarrollo y la utilización de las capacidades dinámicas influyen en el nivel y alcance de la innovación de la empresa, lo que le permite mantenerse adaptada a un entorno cambiante. Las empresas con éxito en el mercado son aquellas que pueden demostrar la capacidad de respuesta oportuna y la innovación de productos de manera rápida y flexible, junto con la capacidad de gestión para coordinar eficazmente y redistribuir las competencias internas y externas. Por ello, este trabajo se centrará en el enfoque de innovación para articular la relación existente entre el desarrollo y el uso de las capacidades dinámicas de las organizaciones y sus esfuerzos para innovar, lo que supone un gran impacto sobre la gestión estratégica de la empresa, tal como señala Teece (2014), habida cuenta de que la empresa que no innova se ve avocada a tener que salir del mercado.

Para concluir, la definición de capacidades dinámicas propuesta en este trabajo es la siguiente: habilidades de la empresa para renovar y actualizar sus competencias en función de los cambios que vayan surgiendo en el entorno en el que operan, de forma que le permitan desarrollar nuevos procesos, productos o servicios con el fin de conseguir mantener o ampliar sus ventajas competitivas.

\subsubsection{Recursos y capacidades estratégicos relacionados con la capacidad de innovación}

Los recursos estratégicos más comúnmente relacionados con la capacidad de innovación son (Leonard \& Sensiper 1998; Oke et al. 2009): el capital humano, el liderazgo, la cultura y las estructuras y sistemas.

Respecto a las capacidades dinámicas necesarias para la innovación, según la literatura que analiza la gestión del conocimiento, las capacidades dinámicas asociadas a la innovación (Grant, 1996; Zahra \& George, 2002; Lavie, 2006) son: la creación de conocimiento, la absorción de conocimiento, la integración de conocimiento y la reconfiguración de conocimiento. Esto se relaciona con las capacidades generales de aprendizaje de la organización en las que la literatura al respecto está menos enfocada, tal como afirma Ipek (2019).

Además, tal como señala Zahra (2021), los investigadores apenas han estudiado la cuestión fundamental sobre cómo las empresas emprendedoras gestionan sus recursos para obtener una ventaja competitiva.

\section{METODOLOGÍA. MODELO PROPUESTO SOBRE LA RELACIÓN ENTRE LAS CAPACIDADES DINÁMICAS, LA INNOVACIÓN Y LA VENTAJA COMPETITIVA}

Metodológicamente se ha seguido el siguiente proceso. En primer lugar, a la luz de la literatura expuesta se ha elaborado un modelo de análisis para visualizar y, por tanto, poder gestionar, las capacidades dinámicas de la empresa en relación con innovación y la ventaja competitiva de la misma. De acuerdo con las variables que conforman cada uno de los constructos del modelo se han desarrollado las preguntas de una entrevista semi-estructurada (véase figura, Anexo), que se ha pasado a un miembro del equipo de altos directivos de cada empresa y, por último, teniendo en cuenta, no solo los resultados de la entrevista, sino también la información recabada de la observación directa (trabajo de alguno de los autores en las empresas observadas) y de los principales medios publicados por las empresas (páginas webs y memorias anuales), se ha procedido a un análisis de casos ejemplares en la provincia de Córdoba. Esto ha permitido proporcionar una herramienta útil desde el punto de vista estratégico.

El modelo construido (figura 1) requiere la siguiente interpretación: la movilización de los recursos que da lugar al desarrollo de capacidades y que forman parte del proceso de investigación y desarrollo empresarial culmina en resultados de innovación que llevan a la reconfiguración de la ventaja competitiva de la empresa. Este ciclo se retroalimenta ya que la nueva ventaja competitiva permite la adquisición de nuevos recursos y, por tanto, el desarrollo de nuevas capacidades que posibilitan nuevos procesos de innovación y, por consiguiente, nuevas maneras de competir. Dicho modelo se expresa a través de las variables e indicadores que se muestran en las tablas 2 a 4 a continuación, ya que en la literatura no se ha observado la existencia de una métrica o sistema de indicadores que evalúen la capacidad dinámica de innovación en las organizaciones, 
tal como indica Sánchez (2017). Pero, sí hay que poner de manifiesto la existencia de estudios específicos donde se observa que determinados recursos y capacidades desarrolladas en conjunto permiten a las empresas obtener competitividad, tal como se muestra en Acosta-Medina et al. (2018), otros modelos donde las capacidades dinámicas atienden a clasificaciones distintas de la planteada, como el de Garzón (2015) o casos muy concretos donde se analiza la influencia del entorno y de determinados recursos y capacidades empresariales sobre el resultado exportador, como en González-Ferriz (2021).

El entorno dinámico de las empresas les obliga a desarrollar capacidades dinámicas para adaptarse y responder a los requerimientos del contexto cambiante en el que se encuentran. Las capacidades dinámicas de la empresa están soportadas por la combinación de sus recursos estratégicos (capital humano, liderazgo, recursos físicos e infraestructuras, cultura organizativa, estructura y sistemas).

Por su parte, a partir de la creación, absorción, integración y reconfiguración del conocimiento, tanto interno como externo, las capacidades de las empresas pueden evolucionar rápidamente (capacidades dinámicas), lo cual les permiten desarrollar nuevos productos, servicios o métodos de producción para conseguir o mantener las ventajas competitivas. Por tanto, la innovación es el resultado de la aplicación de las capacidades dinámicas. En sentido similar se pronuncian Torres-Barreto y Antolinez (2017) que analizan cómo los intangibles de una empresa orientada hacia el emprendimiento influyen en su ventaja competitiva. Dicha innovación puede ser incremental si se introducen ciertos cambios en un producto existente para mejorarlo en algún aspecto, o radical cuando se incorpora al mercado un producto o servicio totalmente nuevo. Por otro lado, cuando la innovación es de proceso, es decir, hay un cambio significativo en el método de producción de un bien o servicio, dará lugar a una ventaja competitiva de liderazgo en costes debido a que se puede producir a menor coste como consecuencia de la nueva tecnología incorporada. Si la innovación es de producto o servicio, la ventaja competitiva que se puede lograr a partir de dicha innovación es la diferenciación del producto o servicio con respecto a los de la competencia, ya que la empresa proporciona algo único que valoran los clientes.

DINAMISMO DEL ENTORNO

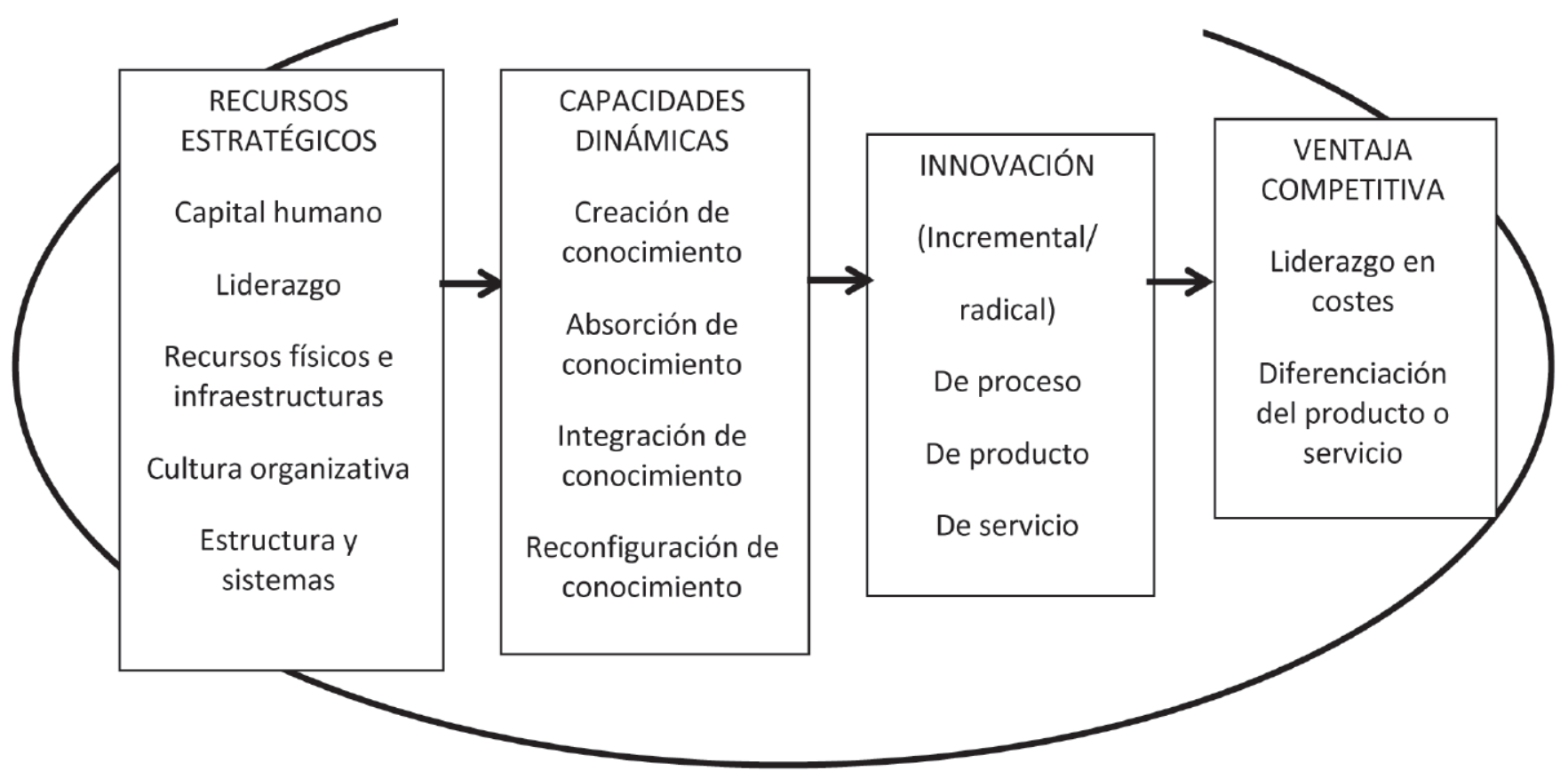

Figura 1. Modelo de reconfiguración de la ventaja competitiva. Fuente: Elaboración propia. 
Tabla 2. Variables e indicadores de los elementos del modelo relacionados con los recursos estratégicos.

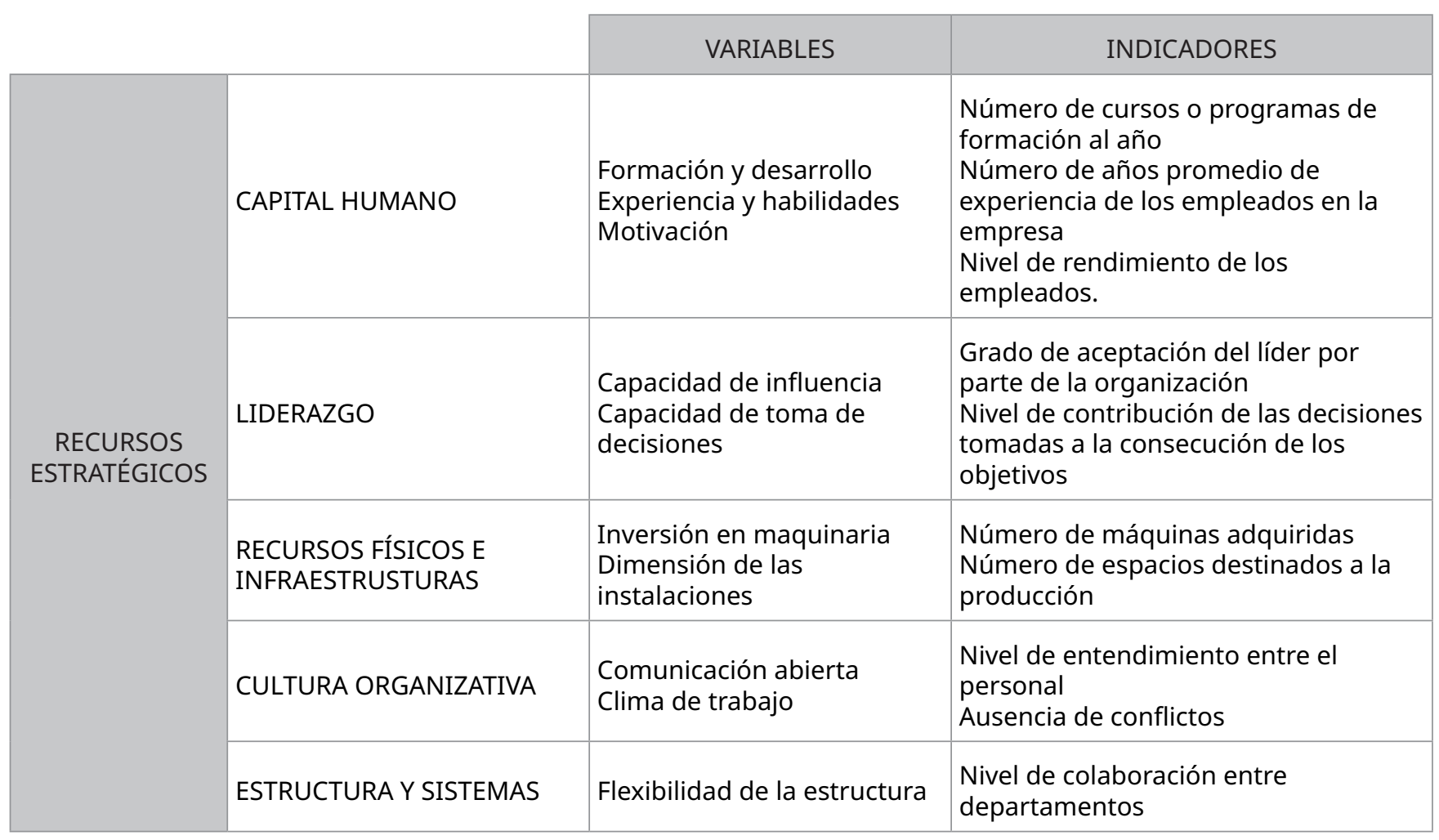

Fuente: Elaboración propia.

Tabla 3. Variables e indicadores de los elementos del modelo relacionados con las capacidades dinámicas.

\begin{tabular}{|c|c|c|c|}
\hline & & VARIABLES & INDICADORES \\
\hline \multirow{4}{*}{$\begin{array}{l}\text { CAPACIDADES } \\
\text { DINÁMICAS }\end{array}$} & $\begin{array}{l}\text { CREACIÓN DE } \\
\text { CONOCIMIENTO }\end{array}$ & $\begin{array}{l}\text { Solicitud de ofertas a } \\
\text { diferentes proveedores } \\
\text { Alianzas estratégicas } \\
\text { Recepción de información } \\
\text { de los clientes }\end{array}$ & $\begin{array}{l}\text { Número de ofertas solicitadas a } \\
\text { proveedores } \\
\text { Acuerdos de colaboración con otras } \\
\text { empresas del sector } \\
\text { Encuestas realizadas a los clientes }\end{array}$ \\
\hline & $\begin{array}{l}\text { ABSORCIÓN DE } \\
\text { CONOCIMIENTO }\end{array}$ & Inversión en I+D & $\begin{array}{l}\text { Porcentaje de beneficios destinado a } \\
\text { I+D }\end{array}$ \\
\hline & $\begin{array}{l}\text { INTEGRACIÓN DE } \\
\text { CONOCIMIENTO }\end{array}$ & $\begin{array}{l}\text { Intercambio de información } \\
\text { entre departamentos } \\
\text { Rutinas organizativas }\end{array}$ & $\begin{array}{l}\text { Reuniones periódicas entre los } \\
\text { miembros de los departamentos. } \\
\text { Número de tareas o actividades } \\
\text { determinadas por pautas de actuación } \\
\text { establecidas }\end{array}$ \\
\hline & $\begin{array}{l}\text { RECONFIGURACIÓN DE } \\
\text { CONOCIMIENTO }\end{array}$ & $\begin{array}{l}\text { Análisis del entorno } \\
\text { Búsqueda de oportunidades }\end{array}$ & $\begin{array}{l}\text { Estudios de mercado realizados } \\
\text { Número de oportunidades detectadas }\end{array}$ \\
\hline
\end{tabular}

Fuente: Elaboración propia. 
Tabla 4. Variables e indicadores de los elementos del modelo relacionados con la innovación y la ventaja competitiva.

\begin{tabular}{|c|c|c|c|}
\hline & & \\
\hline & & VARIABLES & INDICADORES \\
\hline \multirow[b]{2}{*}{ INNOVACIÓN } & DE PROCESO & $\begin{array}{l}\text { Introducción de nuevos } \\
\text { métodos de producción }\end{array}$ & Incorporación de nuevas tecnologías \\
\hline & DE PRODUCTO O SERVICIO & $\begin{array}{l}\text { Introducción en el mercado } \\
\text { de nuevos productos o } \\
\text { servicios } \\
\text { Modificaciones en los } \\
\text { productos o servicios } \\
\text { existentes }\end{array}$ & $\begin{array}{l}\text { Número de productos o servicios } \\
\text { introducidos en el mercado } \\
\text { Número de cambios realizados en los } \\
\text { productos o servicios }\end{array}$ \\
\hline \multirow{2}{*}{$\begin{array}{l}\text { VENTAJA } \\
\text { COMPETITIVA }\end{array}$} & LIDERAZGO EN COSTES & Reducción de costes & $\begin{array}{l}\text { Porcentaje de disminución de los } \\
\text { costes }\end{array}$ \\
\hline & $\begin{array}{l}\text { DIFERENCIACIÓN DEL } \\
\text { PRODUCTO O SERVICIO }\end{array}$ & $\begin{array}{l}\text { Mejora de la calidad del } \\
\text { producto o servicio }\end{array}$ & Grado de satisfacción del cliente \\
\hline
\end{tabular}

Fuente: Elaboración propia.

\section{RESULTADOS. ESTUDIO DE CASO}

\subsection{Selección y descripción de las empresas}

Para el estudio de casos se han seleccionado dos empresas representativas, una del ámbito público y otra del privado, cuyo sector de actividad es el de las Tecnologías de la Información y las Comunicaciones (TIC), que ha experimentado un importante progreso en los últimos años como consecuencia de los continuos cambios tecnológicos que se han producido y, por tanto, es un sector caracterizado por altas tasas de innovación.

Las razones anteriores, es decir, el ámbito y el sector al que pertenecen las empresas objeto de estudio, además de por su carácter representativo en la provincia de Córdoba y la facilidad de acceso a la información, justifican la elección de las empresas Eprinsa y ABBAS, que se describen a continuación.

De acuerdo a la página web de la primera empresa, Empresa Provincial de Informática S.A. (Eprinsa), ésta es una empresa pública creada por la Diputación de Córdoba en agosto de 1990 con objeto de dar asistencia informática integral, formación de personal y producción cartográfica a las Administraciones Locales de la provincia: los Ayuntamientos, Diputación, sus Organismos Autónomos, Empresas Públicas, Mancomunidades, Consorcios y otras Entidades Públicas Locales. Constituye un instrumento de coordinación y dinamización que coopera en la modernización de la gestión local de Córdoba nuestra provincia, mediante el diseño e implantación de proyectos I+D. Para ello, cuenta con los medios técnicos y humanos más avanzados en el tratamiento de la información y las telecomunicaciones.

Desde Eprinsa se impulsa el Plan Informático Provincial, que comprende un programa de ayuda a la inversión municipal en infraestructura, mediante la cesión de software de base, licencias de uso de aplicaciones, dotaciones de equipamientos de hardware, gasto de comunicaciones, etc.

Las actuaciones dentro de este marco de cooperación se realizan en las siguientes áreas:

- Administración, instalaciones y consultoría de sistemas operativos, bases de datos y comunicaciones.

- Soporte a usuarios, hot-line (línea telefónica de servicio ininterrumpido que se ofrece a los usuarios para llamadas de urgencia y problemas técnicos) y gestión de incidencias informáticas.

- Desarrollo, mantenimiento, soporte y formación de aplicaciones de gestión local y otras licencias de software.

Además, se disponen de otros servicios comerciales:

- Soporte de hardware y software aparte de los servicios de cooperación: averías, microinformática, redes locales, etc. 
- Todo lo relacionado con el acceso, diseño, mantenimiento, soporte y publicación en internet, correo electrónico.

- Trabajos de impresión corporativa, subproductos cartográficos y desarrollo de aplicaciones multimedia a medida.

Aparte, afirman seguir creando nuevos servicios: gestión de contenidos, intercambios de información, unificación de comunicaciones, soporte remoto, outsourcing, imagen corporativa, etc.

Debido a lo anterior, Eprinsa ha tenido varios reconocimientos públicos al trabajo y avances tecnológicos logrados, que van más allá de la provincia, recibiendo por ello varios galardones de prestigio, tal como figura en su propia web.

La otra empresa que se va a analizar es Abbas Servicios de Informática y Telecomunicaciones, S.L., una empresa privada constituida en octubre de 2014 con objeto de prestar servicios avanzados de informática y telecomunicaciones para empresas y operadores: servicios de ingeniería de sistemas, sistemas de almacenamiento, copias de seguridad y de aplicaciones de gestión empresarial, servicios de housing de servidores y hosting (alojamiento de portales web),transmisión de datos (red corporativa) y acceso a internet, y desarrollo de aplicaciones verticales (softwares diseñados para fines específicos) para el sector de las telecomunicaciones $u$ otros sectores donde la demanda no esté cubierta. Sus clientes objetivos son las empresas de 50 o más empleados, o aquellas empresas que cuenten con una plataforma informática de complejidad equivalente.

\subsection{Análisis de los casos}

En cuanto a las innovaciones de servicio, Eprinsa implantó en 2012 el acceso electrónico de los ciudadanos a los servicios públicos de la provincia de Córdoba para que pudieran realizar diferentes trámites municipales a través de la sede electrónica de los Ayuntamientos. Este proyecto fue cofinanciado por la Diputación de Córdoba y el Fondo Europeo de Desarrollo Regional. Además de facilitar las relaciones entre las Administraciones y los ciudadanos, está innovación fue llevada a cabo para acelerar a la puesta en marcha de una Administración electrónica en Córdoba, según obligaba la Ley 11/2007, de 22 de junio, de acceso electrónico de los ciudadanos a los servicios públicos, que reconocía el derecho de los ciudadanos a relacionarse con las Administraciones Públicas por medios electrónicos.

Por el contrario, la innovación de servicio de ABBAS estaba destinada a sus clientes empresas, a fin de permitirles seguir disponiendo del servicio de transmisión de datos gracias a una línea de respaldo que cubriera la avería de la línea principal. Esta innovación fue íntegramente financiada por la propia empresa, por lo que, a diferencia de Eprinsa, no contó con la ayuda de otras instituciones u organismos públicos para la financiación del proyecto.

Ambas empresas también han realizado innovaciones de proceso. La de Eprinsa ha consistido en la sustitución de la infraestructura de sus sistemas centrales mediante la adquisición de servidores de almacenamiento en red para ampliar la capacidad de almacenamiento de información de sus clientes. Antes de la puesta en marcha de la innovación, se realizaron estudios de las necesidades y capacidades de la empresa, así como de las necesidades de sus clientes. En cambio, la innovación de proceso de ABBAS se basó en la atención técnica a clientes empresariales prestada directamente por ingenieros de red o de sistemas, dado que se detectó que los problemas técnicos que presentaban los clientes se resolvían de forma más eficaz si eran atendidos por ingenieros en lugar de por teleoperadores.

Las innovaciones de ambas empresas (tabla 5), tanto las de servicios como las de proceso, tienen un carácter incremental porque han supuesto mejoras en sus prestaciones. No han sido radicales porque, en el caso de Eprinsa, la innovación de servicio ha consistido en la introducción del acceso electrónico de los ciudadanos a las sedes electrónicas de los Ayuntamientos, y la de proceso en ampliar la capacidad de almacenamiento de la empresa para prestar un mejor servicio. ABBAS únicamente ha incorporado a la línea principal de transmisión de datos otra línea de respaldo por lo que, no se ha introducido un servicio totalmente nuevo. Y su innovación de proceso ha permitido una mejora en la prestación de los servicios porque los 
problemas técnicos de los clientes son atendidos por personal cualificado que cuenta con los conocimientos necesarios para comprenderlos y resolverlos.

Tabla 5. Resumen y comparación de las innovaciones de ambas empresas.

\begin{tabular}{|c|c|c|}
\hline & EPRINSA & ABBAS \\
\hline INNOVACIÓN DE SERVICIO & $\begin{array}{l}\text { Implantación del Acceso Electrónico de } \\
\text { los Ciudadanos a los Servicios Públicos } \\
\text { de la provincia de Córdoba }\end{array}$ & $\begin{array}{l}\text { Líneas de respaldo para que no se } \\
\text { pierda el servicio cuando las líneas } \\
\text { principales sufran alguna avería. }\end{array}$ \\
\hline INNOVACIÓN DE PROCESO & $\begin{array}{l}\text { Adquisición de servidores de } \\
\text { almacenamiento en red para ampliar } \\
\text { la capacidad de almacenamiento de } \\
\text { información de sus clientes. }\end{array}$ & $\begin{array}{l}\text { Atención técnica a clientes } \\
\text { empresariales prestada directamente } \\
\text { por ingenieros de red o de sistemas. }\end{array}$ \\
\hline $\begin{array}{l}\text { TIPO DE INNOVACIÓN SEGÚN SU } \\
\text { GRADO DE NOVEDAD }\end{array}$ & Incrementales & Incrementales \\
\hline
\end{tabular}

Fuente: Elaboración propia.

Analizando los recursos estratégicos de ambas empresas (tabla 6) podemos observar que Eprinsa ha llevado a cabo acciones formativas anuales para que su capital humano se actualice y profundice respecto a nuevas técnicas y conocimientos útiles para el desarrollo de las innovaciones efectuadas. Por el contrario, ABBAS ha considerado que no son necesarios los cursos de formación para sus empleados, ya que éstos ya cuentan con los conocimientos necesarios para aplicarlos a las innovaciones.

Con relación a las decisiones tomada por el líder, ha sido muy importante la decisión de la Diputación de Córdoba de financiar el servicio innovador y, la del gerente de Eprinsa para la puesta en marcha de las innovaciones, por lo que podemos identificar la existencia de un liderazgo de tipo transformacional, ya que Eprinsa depende de las decisiones que tome la Diputación y su gerente. Sin embargo, en ABBAS existe un liderazgo transaccional dado que las decisiones son tomadas de forma conjunta, contando además con consultores externos.

Para el desarrollo de las innovaciones, en Eprinsa se ha producido una transformación de las infraestructuras para responder a las necesidades de almacenamiento de datos de los clientes. En cambio, ABBAS ya disponía de unas infraestructuras adaptadas a sus servicios tecnológicos, por lo que no ha sido necesario transformar sus recursos físicos.

Comparando la cultura organizativa de ambas empresas, tal y como se puede observar en la tabla 6 , los valores que comparten los miembros de cada organización son diferentes. Pero tanto en la empresa pública como en la privada, se han visto reforzados tras las innovaciones.

El último recurso analizado es la estructura y sistemas, que en el caso de Eprinsa, para la introducción de las innovaciones, se ha creado una comisión compuesta por miembros de todos los departamentos. Por el contrario, en ABBAS no se ha producido una variación en su estructura pero, se ha fortalecido el nivel de colaboración entre los departamentos como consecuencia de la innovación.

Tanto en la empresa pública como en la privada se han llevado a cabo prácticas que se pueden asociar con sus capacidades dinámicas (tabla 7).

Para la creación de conocimiento, Eprinsa elabora, por orden de la Diputación, un expediente de contratación, antes de la adquisición de los sistemas de almacenamiento, en el que se analizan de forma exhaustiva las distintas ofertas de los proveedores. Sin embargo, en ABBAS únicamente se solicita ofertas a distintos proveedores para compras de importe elevado. Dado que Eprinsa es una empresa pública, mantiene una encomienda de gestión con la Diputación de Córdoba, es decir, un acuerdo por el cual la Diputación encomienda a Eprinsa la ejecución del proyecto de Implantación del Acceso Electrónico. En cambio, ABBAS mantiene acuerdos de colaboración con otras empresas del sector y se han creado equipos técnicos conjuntos formados por ingenieros de ambas empresas, para dar solución a problemas concretos. Otra forma de creación de conocimiento de Eprinsa es la realización de encuestas anuales a los clientes para medir su nivel de 
satisfacción con los servicios prestados. ABBAS no realiza este tipo de encuestas pero, mide la satisfacción de sus clientes a través de hechos como que el cliente no se dé de baja en sus servicios y que los recomiende a otras empresas.

Tabla 6. Resumen y comparación de los recursos de ambas empresas.

\begin{tabular}{|c|c|c|}
\hline & EPRINSA & ABBAS \\
\hline $\begin{array}{l}\text { CONOCIMIENTOS Y FORMACIÓN DEL } \\
\text { CAPITAL HUMANO }\end{array}$ & $\begin{array}{l}\text { Acciones formativas anuales para } \\
\text { la actualización y profundización de } \\
\text { nuevas técnicas y conocimientos. }\end{array}$ & $\begin{array}{l}\text { Aplicación de los conocimientos de la } \\
\text { plantilla, la cual cuenta con titulación } \\
\text { superior en ingeniería. }\end{array}$ \\
\hline DECISIONES TOMADAS POR EL LÍDER & $\begin{array}{l}\text { Decisión de la Diputación para } \\
\text { financiar la innovación de servicio y } \\
\text { del gerente de Eprinsa para la puesta } \\
\text { en marcha de las innovaciones. }\end{array}$ & $\begin{array}{l}\text { Dado el carácter técnico y experto de } \\
\text { la plantilla, las decisiones se toman } \\
\text { de forma conjunta, contando además } \\
\text { con consultores externos. }\end{array}$ \\
\hline $\begin{array}{l}\text { RECURSOS FÍSCOS E } \\
\text { INFRAESTRUCTURAS }\end{array}$ & $\begin{array}{l}\text { Transformación de infraestructuras } \\
\text { para responder a necesidades de } \\
\text { capacidad. }\end{array}$ & $\begin{array}{l}\text { Disponibilidad de infraestructuras } \\
\text { adaptadas a los servicios } \\
\text { tecnológicos. }\end{array}$ \\
\hline $\begin{array}{l}\text { CULTURA ORGANIZATIVA (valores } \\
\text { aceptados por la organización) }\end{array}$ & $\begin{array}{l}\text { Transparencia, trabajo en equipo } \\
\text { y comunicación abierta entre el } \\
\text { personal. }\end{array}$ & $\begin{array}{l}\text { Orientación al cliente, integración y } \\
\text { excelencia profesional. }\end{array}$ \\
\hline $\begin{array}{l}\text { ESTRUCTURA Y SISTEMAS (nivel de } \\
\text { colaboración entre departamentos) }\end{array}$ & $\begin{array}{l}\text { Creación de una Comisión } \\
\text { compuesta por miembros de todos } \\
\text { los departamentos y de grupos de } \\
\text { trabajo multidepartamentales. }\end{array}$ & $\begin{array}{l}\text { Fortalecimiento del nivel de } \\
\text { colaboración entre departamentos. }\end{array}$ \\
\hline
\end{tabular}

Fuente: Elaboración propia.

La práctica asociada a la absorción de conocimiento llevada a cabo por ambas empresas es la inversión en I+D, sin embargo, es diferente en cada empresa, ya que en Eprinsa varía en función de su beneficio; y en ABBAS se destina un porcentaje fijo que representa el $10 \%$ del beneficio.

Para integrar el conocimiento, en las dos empresas analizadas se realizan reuniones entre los miembros de los distintos departamentos, pero la frecuencia es distinta en cada una de ellas, dado que en Eprinsa se organizan semanalmente y en ABBAS de forma continuada para tratar temas de importancia, como pueden ser los problemas técnicos de los clientes.

Por último, la capacidad dinámica de reconfiguración de conocimiento hace referencia a la generación de nuevas formas de creación de valor. Para ello, ambas empresas realizaron una búsqueda de oportunidades que permitieron el desarrollo de las innovaciones. En el caso de Eprinsa se descubrió la necesidad de simplificar los trámites con las Administraciones públicas y dar respuesta a la ley que reconoce el derecho de acceso electrónico de los ciudadanos a los servicios públicos. En cambio, ABBAS identificó la oportunidad de crear una línea de respaldo a la línea principal de transmisión de datos, observando las carencias de los servicios prestados por la competencia.

Por último, comentar (tabla 8) que, tanto Eprinsa como ABBAS coinciden en que uno de sus recursos que más ha evolucionado tras el desarrollo de sus innovaciones, ha sido el capital humano debido al incremento de sus capacidades, que en la empresa pública se ha producido mediante las acciones formativas, y en la empresa privada como consecuencia de la aplicación de los conocimientos de su plantilla. En cambio, en Eprinsa se han desarrollado más los recursos físicos por la modernización de sus infraestructuras, y en ABBAS ha evolucionado más la cultura organizativa debido a sus valores de orientación al cliente y excelencia profesional, los cuales han sido esenciales para identificar las necesidades de los clientes y ofrecer un servicio de respaldo a las líneas principales de transmisión de datos.

En cuanto a las capacidades dinámicas, ambas empresas han desarrollado la creación de conocimiento como consecuencia de las tres prácticas llevadas a cabo, pero en el caso de Eprinsa ha evolucionado más la reconfiguración de conocimiento por los estudios de las necesidades y capacidades de la empresa, así 
como de las necesidades de sus clientes para la introducción de sus innovaciones. Sin embargo, en ABBAS, la absorción de conocimiento ha progresado de manera más acusada, ya que todos los años se destina un porcentaje fijo de sus beneficios a la inversión en I+D, y en Eprinsa este porcentaje es variable dependiendo de sus beneficios.

Tabla 7. Resumen y comparación de las capacidades dinámicas de ambas empresas.

\begin{tabular}{|c|l|l|}
\cline { 2 - 3 } \multicolumn{1}{c|}{} & \multicolumn{1}{|c|}{ EPRINSA } & \multicolumn{1}{c|}{ ABBAS } \\
\hline CREACIÓN DE CONOCIMIENTO & $\begin{array}{l}\text { Elaboración de expedientes de } \\
\text { contratación. } \\
\text { Acuerdo de colaboración con la } \\
\text { Diputación de Córdoba. } \\
\text { Encuestas anuales a clientes. }\end{array}$ & $\begin{array}{l}\text { Solicitud de ofertas a proveedores } \\
\text { para compras sustanciales. } \\
\text { Acuerdos de colaboración con otras } \\
\text { empresas del sector. } \\
\text { Utilización de factores para medir la } \\
\text { satisfacción del cliente. }\end{array}$ \\
\hline ABSORCIÓN DE CONOCIMIENTO & $\begin{array}{l}\text { Inversión en I+D varía en función del } \\
\text { beneficio. }\end{array}$ & $\begin{array}{l}\text { Inversión en I+D de un porcentaje } \\
\text { superior al 10\% del beneficio. }\end{array}$ \\
\hline INTEGRACIÓN DE CONOCIMIENTO & $\begin{array}{l}\text { Reuniones semanales para revisar } \\
\text { el avance de los objetivos de la } \\
\text { empresa y tratar temas generales } \\
\text { yécnicos que afecten a más de un } \\
\text { departamento. }\end{array}$ & $\begin{array}{l}\text { Reuniones de forma continuada para } \\
\text { temas de importancia. }\end{array}$ \\
\hline CONOCIMIENTO & $\begin{array}{l}\text { Oportunidad detectada en la } \\
\text { innovación de servicio fue la } \\
\text { necesidad de crear una administración } \\
\text { electrónica que redujera la duración } \\
\text { de las gestiones y trámites. }\end{array}$ & $\begin{array}{l}\text { Identificación de oportunidades } \\
\text { analizando las carencias de los } \\
\text { servicios prestados tradicionalmente } \\
\text { por la competencia. }\end{array}$ \\
\hline
\end{tabular}

Fuente: Elaboración propia.

Las innovaciones desarrolladas por ambas empresas han contribuido a la reconfiguración de sus ventajas competitivas. La innovación de servicio de Eprinsa ha afianzado el carácter integral, innovador y exclusivo de sus servicios prestados a organismos públicos, y la innovación de proceso ha permitido incrementar la calidad de estos servicios debido a la adquisición de servidores que han ampliado la capacidad de almacenamiento de los datos de sus clientes. En cambio, en la empresa privada ABBAS, tanto su innovación de servicio como la de proceso han mejorado la calidad de sus servicios, tanto en fiabilidad porque los clientes cuentan con la garantía de una línea de respaldo para la transmisión de datos, como en funcionalidades por las características de sus servicios adaptados a las necesidades de sus clientes.

Tabla 8. Resumen y comparación de la evolución de los recursos y capacidades dinámicas como elementos que de reconfiguración de la ventaja competitiva de ambas empresas.

\begin{tabular}{|c|l|l|}
\cline { 2 - 3 } & \multicolumn{1}{c|}{ EPRINSA } & \multicolumn{1}{c|}{ ABBAS } \\
\hline EVOLUCIÓN DE LOS RECURSOS & $\begin{array}{l}\text { Incremento de las capacidades del } \\
\text { capital humano. } \\
\text { Modernización de las infraestructuras. }\end{array}$ & $\begin{array}{l}\text { Incremento de las capacidades del } \\
\text { capital humano. } \\
\text { Refuerzo de la cultura organizativa. }\end{array}$ \\
\hline $\begin{array}{c}\text { EVOLUCIÓN DE LAS CAPACIDADES } \\
\text { DINÁMICAS }\end{array}$ & $\begin{array}{l}\text { Creación de conocimiento. } \\
\text { Reconfiguración de conocimiento. }\end{array}$ & $\begin{array}{l}\text { Creación de conocimiento. } \\
\text { Absorción de conocimiento. }\end{array}$ \\
\hline VENTAJA COMPETITIVA & $\begin{array}{l}\text { Prestación de un servicio de carácter } \\
\text { integral, innovador y exclusivo a } \\
\text { organismos públicos. }\end{array}$ & $\begin{array}{l}\text { Calidad de los servicios prestados, } \\
\text { tanto en fiabilidad como en } \\
\text { funcionalidades. }\end{array}$ \\
\hline
\end{tabular}

Fuente: Elaboración propia. 


\section{DISCUSIÓN Y CONCLUSIONES}

En conclusión, en ambas empresas (una pública y otra privada), se ha puesto de manifiesto como su ventaja competitiva se reconfigura de acuerdo a sus capacidades dinámicas, atendiendo a las directrices que se exponen a continuación, la cuales son susceptibles de extrapolación, con carácter general, a otras empresas de diferentes sectores o países.

En lo que respecta a la gestión de su conocimiento, especialmente en su etapa de captación, hay que tener en cuenta que el comportamiento colaborativo, las interacciones sociales y las distintas formas de relación vertical, como modos de captación del conocimiento, incrementan el desarrollo de capacidades (Vanpoucke et al., 2014; He et al., 2018 y Mamédio, 2019)

Si se atiende a la formación de los empleados, que resulta un pilar fundamental, esta formación se completa con reuniones de forma periódica que favorecen la integración del conocimiento, lo que resulta esencial ya que, tal como señala Sanluke et al. (2019), para dar soluciones al mercado, además del conocimiento externo e interno, se necesita la capacidad de integración del mismo.

Respecto al refuerzo de la cultura organizativa de la empresa, donde destaca la potenciación del espíritu colaborativo necesario para el desarrollo de innovaciones, hay que apuntar que constituye un soporte básico de la estrategia de la empresa (Bueno \& Morcillo, 2019), lo que se relaciona con la idea puesta de manifiesto en Teece (2019) que explica cómo la estrategia empresarial junto a las capacidades dinámicas determina una ventaja competitiva sostenible en un entorno global.

Si se atiende al proceso progresivo que supone la innovación (incremental), este análisis ha permitido reafirmar la idea de Piening y Salge (2015) que propugnan que las actividades específicas de innovación respaldan las capacidades dinámicas y sus interrelaciones en términos de efectos complementarios o sustitutivos.

Sin embargo, se observa en la empresa privada en comparación con la pública una orientación más estrecha hacia el cliente, que lleva a centrar la ventaja competitiva en la calidad alimentada por estructuras poco jerarquizadas donde priman las ideas del grupo y/o asesoramiento de empresas especializadas, partiendo de estructuras tecnológicas muy punteras. En el caso de la empresa pública, las decisiones orientadas las clientes pueden verse dotadas de un cierto cariz político. Por otro lado, las inversiones realizadas para el desarrollo de las mismas dependen de presupuestos públicos y los procesos suelen ser más lentos al tener que cumplir toda la serie de trámites burocráticos marcados por las Administraciones.

En el caso de la empresa pública, sobre todo si es de baja tecnología, tiene especial importancia el hecho de que la innovación organizativa produce un efecto directo y positivo en el rendimiento de la empresa (Ryeowon et al., 2019).

La integración de conocimientos se canaliza a través del entramado de comunicaciones que se producen en la empresa, tanto de tipo formal como informal, especialmente en los grupos y reuniones de trabajo. Se vislumbra como estas comunicaciones suelen fluir más ágilmente en el ámbito privado que en el público.

La contribución principal de este trabajo se relaciona con el aporte de una herramienta estratégica relacionada con la gestión de las capacidades dinámicas que forman parte del proceso de desarrollo de una ventaja competitiva innovadora en la empresa. Ambos constructos se retroalimentan y permiten la evolución de la entidad. Además, se ponen de manifiesto diferentes maneras de actuar en la práctica, tanto del sector público como privado.

Para investigaciones futuras se propone hacer extensible el estudio a una muestra amplia de empresas, además de, tal como se apuntó en la introducción de este trabajo, cuantificar el tiempo de reacción de un tipo y otro de empresas. Sería también interesante determinar el porcentaje de $I+D+i$ dedicado en cada proceso y tipo de empresa.

\section{Agradecimientos}

Sean nuestros agradecimientos para las empresas colaboradoras en este trabajo, que han hecho posible su desarrollo. 


\section{Declaración responsable y conflicto de intereses}

Las autoras declaran que no existe ningún conflicto de interés con relación a la publicación de este artículo, que ha sido fruto del trabajo colaborativo y equilibrado entre todas ellas.

\section{REFERENCIAS}

Acosta-Medina, J., Plata-Gómez, K.R., Puentes-Garzón D.E. \& Torres-Barreto, M. L. (2018). Influence of resources and capabilities in finance performance and business competitiveness: a literature review. I+D Revista de Investigaciones, 13(1), 125-134. https://doi.org/10.33304/revinv.v13n1-2019013

Ambrosini, V., Bowman, C. \& Collier, N. (2009). Dynamic Capabilities: An Exploration of How Firms Renew their Resource Base. British Journal of Management, 20, Special Issue, S9-S24. https://doi.org/10.1111/j.1467-8551.2008.00610.x

Aragón-Correa, J.A. \& Sharma, S. (2003). A Contingent Resource-Based View of Proactive Corporate Environmental Strategy. Academy of Management Review, 28(1), 71-88. https://doi.org/10.5465/amr.2003.8925233

Augier, M. \& Teece, D.J. (2007). Dynamic Capabilities and Multinational Enterprise: Penrosean Insights and Omissions. Management International Review, 47(2), 175-192. https://doi.org/10.1007/s11575-007-0010-8

Bueno E. \& Morcillo P. (2019, 25-27 septiembre). Un proceso estratégico para la empresa sostenible. Cultura, Ventaja Adaptativa y Estrategia [Comunicación]. XX Congreso Internacional AECA. Asociación Española de Contabilidad y Administración de Empresas, Málaga.

Collins, D.J. (1994). Research Note: How Valuable are Organizational Capabilities? Strategic Management Journal, 15, Winter Special Issue, 143-152. https://doi.org/10.1002/smj.4250150910

Collins, C. J. (2021). Expanding the resource based view model of strategic human resource management. The International Journal of Human Resource Management, 32(2), 331-358. https://doi.org/10.1080/09585192.2019.1711442

Eisenhardt, K.M. \& Martin, J.A. (2000). Dynamic capabilities. What are they? Strategic Management Journal, 21(10/11), 1105-1121. https://doi.org/10.1002/1097-0266(200010/11)21:10/11<1105::AID-SMJ133>3.0.CO;2-E

Garzón, M. A. (2015). Modelo de Capacidades Dinámicas. Dimensión Empresarial, 13 (1), 111-131. https://doi.org/10.15665/ rde.v13i1.341

González-Ferriz, F. (2021). Análisis de los factores determinantes del resultado exportador en las empresas españolas del sector calzado. Revista de Estudios Andaluces, 42, 138-157. https://doi.org/10.12795/rea.2021.i42.07

Grant, R.M. (1996). Prospering in dynamically-competitive environments: Organizational capability as knowledge integration. Organization Science, 7(4), 375-387. https://doi.org/10.1287/orsc.7.4.375

He, X., Yi, Y. \& Wei, Z. (2018). New product development capabilities in China: the moderating role of TMT cooperative behavior. Asian Business Management, 18(2), 73-97. https://doi.org/10.1057/s41291-018-00055-X

Ipek, I. (2019). Organizational learning in exporting: a biblimetric analysis and critical review of the empirical research. International Business Review, 28(3), 544-559. https://doi.org/10.1016/j.ibusrev.2018.11.010

Kale, D. (2010). The Distinctive Patterns of Dynamic Learning and Inter-firm Differences in the Indian Pharmaceutical Industry. British Journal of Management, 21(1), 223-238. https://doi.org/10.1111/j.1467-8551.2009.00651.x

Lavie, D. (2006). Capability Reconfiguration: An Analysis of Incumbent Responses to Technological Change. Academy of Management Review, 31(1), 153-174. https://doi.org/10.5465/amr.2006.19379629

Leonard, D. \& Sensiper, S. (1998). The role of tacit knowledge in group innovation. California Management Review, 40(3), 112-125. https://doi.org/10.2307/41165946

Mamédio, D., Rocha,C., Szczepanik, D. \& Kato, H. (2019). Strategic alliances and dynamic capabilities: a systemic review. Journal of Strategy Management, 12(1), 83-102. https://doi.org/10.1108/JSMA-08-2018-0089

Mikalef, P., Boura, M. \& Lekakos, G. (2019). Big Data Analytics Capabilities and Innovation: The Mediating Role of Dynamic Capabilities and Moderating Effect of the Environment. British Journal of Management, 30(2), 272-298. https://doi. org/10.1111/1467-8551.12343

Miranda, J. (2015). El Modelo de las Capacidades Dinamicas en las Organizaciones. Investigación Administrativa, $44,116$. https://doi.org/10.35426/IAv44n116.05

Nelson, R.R. (1991). Why Do Firms Differ, and How Does it Matter? Strategic Management Journal, 12, 61-74. https://doi. org/10.1002/smj.4250121006 
Oke, A., Munshi, N. \& Walumbwa, F. (2009). The Influence of Leadership on Innovation Processes and Activities. Organizational Dynamics, 38(1), 64-72. https://doi.org/10.1016/j.orgdyn.2008.10.005

Oliver, C. \& Holzinger, I. (2008). The Effectiveness of Strategic Political Management: A Dynamic Capabilities Framework. Academy of Management Review, 33(2), 496-520. https://doi.org/10.5465/amr.2008.31193538

Peng, G. \& Beamish, P. (2014). MNC Subsidiary Size and Expatriate Control: Resource-Dependence and Learning Perspectives. Journal of World Business, 49(1), 51-62. https://doi.org/10.1016/j.jwb.2012.11.001

Piening, E. P. \& Salge, T. O. (2015). Understanding the antecedent, contingencies, and performances implications of process innovation: a dynamic capabilities perspective. The Journal of Product Innovation Management, 32(1), 80-97. https://doi.org/10.1111/jpim.12225

Pisano, G. (1994). Knowledge, Integration, and the Locus of Learning: An Empirical Analysis of Process Development. Strategic Management Journal, 15, winter special issue, 85-100. https://doi.org/10.1002/smj.4250150907

Ryeowon, L., Jong-Ho, L. \& Garret T. C. (2019). Synergy effects of innovation on performance. Journal of Business Research, 99, 507-515. https://doi.org/10.1016/j.jbusres.2017.08.032

Rindova, V.P. \& Kotha, S. (2001). Continuous 'Morphing': Competing Through Dynamic Capabilities, Form and Function. Academy of Management Journal, 44(6), 1263-1280. https://doi.org/10.2307/3069400

Saluke, S., Weerawardena, J. \& McColl-Kennedy, J.R. (2019). The central role of knowledge integration capability in service innovation-based competitive strategy. Industrial Marketing Management, 76, 144-156. https://doi.org/10.1016/j. indmarman.2018.07.004

Sánchez, D. (2017). Cómo medir la capacidad dinámica de innovación en las organizaciones. Universidad Simón Bolívar, Venezuela. https://doi.org/10.17081/bonga/2089.c4

Sidhu, J.S., Commandeur H.R. \& Volberda, H.W. (2007). The Multifaceted Nature of Exploration and Exploitation: Value of Supply, Demand, and Spatial Search for Innovation. Organization Science, 18(1), 20-38. https://doi.org/10.1287/ orsc. 1060.0212

Suárez, F. \& Oliva, R. (2005). Environmental Change and Organizational Transformation. Industrial and Corporate Change, 14(6), 1017-1041. https://doi.org/10.1093/icc/dth078

Teece, D. J. (2019). A dynamic capabilities-based entrepreneurial theory of the multinational enterprise. Journal of International Business Studies, 45. 8-37. https://doi.org/10.1057/jibs.2013.54

Teece, D. J. (2014). The foundations of enterprise performance: dynamic and ordinary capabilities in an (economic) theory of firms. Academy of Management Perspective, 28 (4), 328-352. https://doi.org/10.5465/amp.2013.0116

Teece, D.J. (2007). Explicating dynamic capabilities. The nature and microfoundations of (sustainable) enterprise performance. Strategic Management Journal, 28 (13), 1319-1350. https://doi.org/10.1002/smj.640

Teece, D.J. \& Pisano, G. (1994). The Dynamic capabilities of firms: an Introduction, Industrial and Corporate Change, 3(3), 537-556. https://doi.org/10.1093/icc/3.3.537-a

Teece,D.J., Pisano, G. \& Shuen, A. (1997). Dynamic capabilities and strategic management. Strategic Management Journal, 18(7), 509-533. https://doi.org/10.1002/(SICI)1097-0266(199708)18:7<509::AID-SMJ882>3.0.CO;2-Z

Torres-Barreto, M. L. \& Antolinez, D. F. (2017). Exploring the boosting potential of intellectual resources and capabilities on firm's competitiveness. Espacios, 38(31). Retrieved from http://www.revistaespacios.com/a17v38n31/ a17v38n31p35.pdf.

Vanpoucke. E, Vereecke, A. \& Wetzels, M. (2014). Developing supplier integration capabilities for sustainable competitive advantage: a dynamic capabilities approach. Journal of Operations Management, 32(7-8), 446-461. https://doi. org/10.1016/j.jom.2014.09.004

Wang, C.L. \& Ahmed, P.K. (2007). Dynamic capabilities: a review and research Agenda. International Journal of Management Reviews, 9(1), 31-51. https://doi.org/10.1111/j.1468-2370.2007.00201.x

Zahra, S. A. \& George, G. (2002). Absorptive capacity: a review, reconceptualization, and extension. Academy of Management Review, 27(2), 185-203. https://doi.org/10.5465/amr.2002.6587995

Zahra, S. A. (2021). The Resource-Based View, Resourcefulness, and Resource Management in Startup Firms: A Proposed Research Agenda. Journal of Management, 01492063211018505. https://doi.org/10.1177/01492063211018505

Zajac, E.J., Kraats, M.S. \& Bresser, R.F.K. (2000). Modeling the dynamics of strategic fit: a normative approach to strategic change. Strategic Management Journal, 21(4), 429-453. https://doi.org/10.1002/(SICI)1097-0266(200004)21:4<429::A ID-SMJ81>3.0.CO;2-\# 
ANEXO

\section{Entrevista semi-estructurada}

1. ¿Cuáles han sido las dos innovaciones más importantes llevadas a cabo en los últimos años por su empresa? Por favor, señale una innovación de producto o servicio ${ }^{1}$, y otra de proceso ${ }^{2}$.

2. ¿Cómo se detectaron las oportunidades en el mercado que llevaron a introducir las innovaciones anteriores? ¿Qué métodos o técnicas se han utilizado para identificarlas?

3. ¿Las innovaciones realizadas han sido incrementales ${ }^{3}$ o radicales ${ }^{4}$ ?

4. Describa cómo han contribuido al desarrollo de estas innovaciones los siguientes recursos estratégicos:

- Los conocimientos y la formación del capital humano.

- Las decisiones tomadas por el líder de la organización.

- Los recursos físicos e infraestructuras (maquinaria, instalaciones, tecnología).

- La cultura organizativa (los valores generalmente aceptados por los miembros de la organización, la comunicación y el clima de trabajo existente).

- La estructura y sistemas (el nivel de colaboración entre los diferentes departamentos).

5. ¿Antes de adquirir la maquinaria o las materias primas, servicios, etc. correspondientes a las innovaciones indicadas en la pregunta 1, la empresa solicitó ofertas a los diferentes proveedores?

6. ¿La empresa mantiene acuerdos de colaboración con otras empresas o instituciones que favorecieron la introducción de estas innovaciones (las de la pregunta 1)? En caso afirmativo, explique de qué manera.

7. ¿Se realizan encuestas a los clientes para recoger información sobre sus necesidades y medir su grado de satisfacción con el producto o servicio ofrecido? En caso afirmativo, indique cómo esta información favoreció la introducción y consolidación de las innovaciones especificadas en la pregunta 1.

8. ¿La empresa destina un porcentaje de sus beneficios anuales a la inversión en I+D+i?

9. ¿Se organizan reuniones periódicas para intercambiar información entre los miembros de los diferentes departamentos?, ¿cuáles son los temas tratados en dichas reuniones?, ¿cómo favoreció la información recogida en estas reuniones a la introducción de las innovaciones especificadas (en la pregunta 1)?

10. ¿Cuál es su ventaja competitiva5? ¿Cree que ha cambiado/evolucionado a raíz de la introducción de las innovaciones (de la pregunta 1)?

11. Del mismo modo, después de la introducción de estas innovaciones, ¿considera que han evolucionado los siguientes recursos y capacidades de la organización? (señale con una X lo que considere oportuno).

1 Introducción en el mercado de nuevos (o significativamente mejorados) productos o servicios. Incluye alteraciones significativas en las especificaciones técnicas, en los componentes, en los materiales, la incorporación de software o en otras características funcionales.

2 Implementación de nuevos (o significativamente mejorados) procesos de fabricación, logística o distribución. Por ejemplo, redefinir los procesos productivos puede servir para aumentar el valor del producto final gracias a un menor coste de fabricación, un menor tiempo de respuesta o una mayor calidad.

3 La innovación incremental tiene lugar cuando se introducen ciertos cambios en algún proceso, producto o servicio existente para mejorarlo en algún aspecto.

4 La innovación radical se refiere a la introducción en el mercado de un producto o servicio totalmente nuevo o a la incorporación de un nuevo proceso.

5 La ventaja competitiva hace referencia a cualquier característica de la empresa que la diferencia de otras, colocándola en una posición relativa superior para competir y permitiéndole obtener un rendimiento superior a las otras en su actuación competitiva. El origen de la ventaja competitiva puede estar en numerosas características de la actividad de la empresa, pero cualquiera de ellas conduce a una de las dos ventajas competitivas básicas: liderazgo en costes o diferenciación del producto o servicio. 


\begin{tabular}{|l|l|l|l|l|l|}
\hline \multicolumn{1}{|c|}{ Recursos y Capacidades } & Mucho & Bastante & Un poco & $\begin{array}{c}\text { Muy } \\
\text { ligeramente }\end{array}$ & $\begin{array}{c}\text { No han } \\
\text { evolucionado }\end{array}$ \\
\hline $\begin{array}{l}\text { Incremento de las capacida- } \\
\text { des del capital humano }\end{array}$ & & & & \\
\hline $\begin{array}{l}\text { Impulso del Liderazgo } \\
\text { Incremento de recursos } \\
\text { físicos y modernización de las } \\
\text { infraestructuras }\end{array}$ & & & & \\
\hline $\begin{array}{l}\text { Refuerzo de la cultura orga- } \\
\text { nizativa (creencias, valores } \\
\text { compartidos) }\end{array}$ & & & & \\
\hline $\begin{array}{l}\text { Flexibilidad de laestructura y } \\
\text { sistemas (nivel de colabora- } \\
\text { ción entre los departamentos) }\end{array}$ & & & & \\
\hline Creación de conocimiento & & & & \\
\hline Absorción de conocimiento & & & & \\
\hline Integración de conocimiento & & & & \\
\hline $\begin{array}{l}\text { Reconfiguración de conoci- } \\
\text { miento9 }\end{array}$ & & & & \\
\hline
\end{tabular}

6 La creación de conocimiento se refiere al proceso que incrementa y hace disponible el conocimiento creado por los individuos por medio de la creación de alianzas estratégicas, relaciones cercanas con el cliente, etc.

7 La capacidad de absorción se define como la habilidad y motivación de los empleados para obtener conocimiento externo y utilizarlo para el desarrollo de la capacidad de innovación. En definitiva, se trata de la habilidad para reconocer el valor de la nueva información, asimilarla y aplicarla a fines comerciales.

8 El concepto de integración ha sido definido como el conjunto de procedimientos inter-organizacionales y entre unidades funcionales orientados a la interacción y la colaboración, es decir, aquellos procedimientos que buscan el intercambio de información y la colaboración entre departamentos o entre organizaciones.

9 La reconfiguración de conocimiento se define como el proceso de generación de nuevas alternativas de configuración de capacidades, actividades organizativas y formas de creación de valor ante los cambios que se produzcan en el mercado. Para ello, es necesaria la búsqueda de oportunidades y la identificación dichos cambios. 


\title{
Cambios observados y proyectados en los tipos de regímenes bioclimáticos de Argentina
}

\section{Observed and projected changes in the types of bioclimatic regimes in Argentina}

\author{
Valeria Soledad Duval \\ valeria.duval@uns.edu.ar @ 0000-0001-9048-3058 \\ Universidad Nacional del Sur-CONICET \\ 12 de Octubre.1098. CP 8000 Bahía Blanca, Argentina \\ Rafael Cámara-Artigas \\ rcamara@us.es @ 0000-0003-1046-3749
}

Departamento de Geografía Física y Análisis Geográfico Regional, Facultad de Geografía e Historia, Universidad de Sevilla. C/ Doña María de Padilla s/n. 41004 Sevilla, España

\section{INFO ARTÍCULO}

Recibido: 23/10/2021

Revisado: 03/12/2021

Aceptado: 12/01/2022

\section{PALABRAS CLAVE}

Cartografía bioclimática

Cambio climático

Ecorregiones

Geografía física

\section{KEYWORDS}

Bioclimatic mapping

Climate change

Ecoregions

Physical geography

\begin{abstract}
RESUMEN
El estudio de los límites bioclimáticos es esencial en cada región para conocer la distribución de las formaciones vegetales. El objetivo del trabajo fue elaborar mapas bioclimáticos de Argentina en tres períodos de tiempo (Ultimo Máximo Glaciar, actualidad y escenario de cambio climático RCP8.5 del 2070) y analizar sus cambios. Para ello, se aplicó la metodología de los tipos de regímenes bioclimáticos a partir de bases de datos continuas climáticas de WordClim. Como resultado se observó una reducción en la superficie de los tipos térmicos mesocriófilo, hipercriófilo y criófilo, entre el Último Máximo Glaciar y la actualidad y aparece el termófilo en el escenario futuro. Esta investigación es una aportación para la comprensión de la distribución de la vegetación a escala nacional y su dinámica.
\end{abstract}




\section{INTRODUCCIÓN}

El clima es el principal elemento que determina la distribución de la vegetación en el mundo (Cain, 1944; Tuhkanen, 1980). El bioclima, por su parte, tiene en consideración las necesidades térmicas e hídricas de las plantas integrantes en una formación vegetal. La limitación en algunos de estos aspectos es clave para explicar la distribución de dichas formaciones. Es por ello que es necesaria la caracterización y la cartografía de las condiciones bioclimáticas para comprender la distribución actual de las formaciones vegetales del planeta. Dicha distribución se verá matizada localmente por las condiciones geobotánicas que rijan: así sobre el karst o sobre formaciones de costras calcáreas o férricas, o los procesos de saturación de agua por inundación, marcarán cambios por defecto o exceso de las condiciones hídricas, dando lugar a formaciones intrazonales, como las marismas, los manglares, sabanas inundables, los esteros por exceso de agua, o las sabanas o estepas por la presencia de formaciones superficiales específicas.

El conocimiento preciso y detallado de la composición y distribución vegetal en conjunto con la disponibilidad de datos climáticos y de Sistemas de Información Geográfica, para su análisis, contribuyen a delimitar las fronteras/ecotonos bioclimáticos y a elaborar modelos que permitan definir programas para la conservación de las especies y de sus hábitats. Además, posibilita la determinación de escenarios futuros de cambio climático y por ende de los límites fitogeográficos de una región (Fernández, 2004).

Un importante avance en la bioclimatología se generó a partir de la creación de índices que contribuyeron a definir las clasificaciones bioclimáticas, entre ellas la propuesta por Holdridge (1947) sobre la base de las zonas de vida, la de Walter (1977) en los diagramas ombrotérmicos del atlas climatológico y el más actual de Bailey (2009), que considera las ecorregiones con un propósito de conservación estableciendo distintas escalas de análisis. Por otra parte, en Argentina, Bruniard (2000) también realizó una aproximación al modelo fitoclimático mundial. Este se basó en el establecimiento de valores-límite críticos para el desarrollo de las diversas comunidades vegetales sobre la base de los regímenes térmicos e hídricos. El autor definió 7 valores críticos de temperatura que le permitieron determinar 9 zonas caracterizadas por su régimen térmico anual y 2 índices de humedad (anual y estival). De la combinación de ambos, se identificaron 20 tipos de vegetación de acuerdo a su fisonomía y ritmo estacional. Los resultados se mostraron en mapas a escala continental, aunque dicho modelo se ajusta más precisamente en el continente americano y no así a los restantes (Fidalgo \& Muñoz, 2003).

En Argentina, no existe una profundización y/o avances actuales sobre una clasificación bioclimática del territorio. Tampoco hay estudios realizados sobre la temática a escala nacional, en el pasado y en un futuro. Si existe, sin embargo, un trabajo detallado de las ecorregiones y complejos ecosistémicos del país, realizado por Morello et al. (2012) en el cual se trata cada ecorregión a escalas entre 1:1.000.000 y 1:300.000 (incluso más pequeñas) desde esta categoría desciende a la subregión, complejo, sistemas ecológicos, tipo de tierra (formaciones vegetales) y fases (vegetación y suelos). En cada ecorregión se trata la geomorfología, clima, ambiente natural y ambiente humano, descendiendo luego a las subregiones, complejos, etc., desglosando apartados en cada uno de ellos. En este trabajo se utiliza el nivel de ecorregión para relacionarla con los tipos de bioclimas, contando con la base cartográfica vectorial del Instituto Geográfico Nacional de Argentina (https://www.ign.gob.ar/NuestrasActividades/InformacionGeoespacial/CapasSIG).

El objetivo del presente trabajo es elaborar una cartografía bioclimática de Argentina en tres períodos de tiempo (Ultimo Máximo Glaciar-20.000 B.P.-, actualidad y escenario de cambio climático RCP-Trayectorias de concentración representativas- 8.5 para el año 2070). Se han elegido estos tres momentos por, en el caso del último Máximo Glaciar, disponer de base de datos de este momento y ser el pulso más frío antes del Holoceno (http://www.worldclim.com/version1). En el escenario del cambio climático se ha optado por una situación extrema (RCP 8.5) en un periodo de tiempo de medio plazo (entre los años 1970-2000). Se seleccionó el modelo CCSM4 (Sistema Climático Comunitario) patrocinado por la National Science Foundation (NSF) y el Departamento de Energía de los Estados Unidos (DOE) porque es un modelo de clima para simular el sistema climático de la Tierra, compuesto por cinco modelos separados de la atmósfera, el océano, la tierra, el hielo terrestre y el hielo marino de la Tierra. Se suma un componente acoplador central que coordina los modelos y pasa la información entre ellos y permite realizar investigaciones fundamentales sobre los esta- 
dos climáticos pasados, presentes y futuros de la Tierra. Se ha utilizado tanto para el Ultimo Máximo Glaciar como para el escenario de cambio climático futuro, y así de esta forma, la comparación de resultados es coherente respecto al modelo. La implementación estándar para las cuadrículas en CCSM ha sido que los modelos de la atmósfera y la tierra se ejecutan en cuadrículas idénticas y el del océano y el hielo marino se ejecutan a su vez también en cuadrículas idénticas.

Esta elección de un escenario extremo de RCP está justificada por lo que se expone a continuación. Hausfather \& Peters (2020) indicaron que el escenario de cambio climático con RCP 8.5 se trata de un futuro improbable ya que se basó en la proyección de una sobreestimación de la producción de carbón. Consideran que para 2070 este tipo de recursos estará en vías de agotamiento y no podrá producirse más emisión de gases invernadero, porque se habrá sustituido por energías limpias alternativas como la solar o la eólica. Según estos autores, esto hacía que el escenario RCP 8.5 sea cada vez más inverosímil con cada año que pasa. Desde el Quinto Reporte del IPCC -Grupo Intergubernamental de Expertos sobre el Cambio Climáticose ha pensado que esta situación es muy poco probable, pero aún posible, ya que las retroalimentaciones no se comprenden bien (Ward et al., 2012). Pero la actual crisis energética ha hecho que muchos países desarrollados vuelvan a explotar sus recursos de minas de carbón, para sustituir al gas y el petróleo como fuentes de energía. Incluso China que como gran potencial industrial ha agotado sus recursos de carbón desde principios del siglo XXI (Zhang et al., 2016) y está demandando carbón actualmente a otros países.

Tal como se observa en la tabla 1, la proyección para 2070 de RCP 8.5 es de $2{ }^{\circ} \mathrm{C}$ de media. El objetivo central del Acuerdo de París fue mantener el aumento de la temperatura mundial en este siglo por debajo de los $2^{\circ} \mathrm{C}$ por encima de los niveles antes de la Revolución Industrial (IPCC, 2013).

Tabla 1. Proyecciones de aumento del calentamiento global $\left({ }^{\circ} \mathrm{C}\right)$.

\begin{tabular}{|c|c|c|}
\hline & $2046-2065$ & $2081-2100$ \\
\hline Escenario & Media y rango probable & Media y rango probable \\
\hline RCP 2.6 & $1.0(0.4$ a 1.6$)$ & $1.0(0.3$ a 1.7$)$ \\
\hline RCP 4.5 & $1.4(0.9$ a 2.0$)$ & 1.8 (1.1 a 2.6$)$ \\
\hline RCP 6 & $1.3(0.8$ a 1.8$)$ & $2.2(1.4$ a 3.1$)$ \\
\hline RCP 8.5 & $2.0(1.4$ a 2.6$)$ & 3.7 (2.6 a 4.8$)$ \\
\hline
\end{tabular}

Fuente: IPCC, 2013.

El trabajo de Steffena et al. (2018) detecta, sin embargo, un umbral en el cual las temperaturas pueden aumentar entre 4 y $5^{\circ} \mathrm{C}$ comparadas con niveles pre-industriales, tomando en cuenta los mecanismos de retroalimentación del sistema climático. Esto avalaría la situación de $2{ }^{\circ} \mathrm{C}$ para un RCP 8.5 en 2070, a la que acompañaría un incremento medio del nivel del mar de 0,30 m para 2070 y de 0,63 m para 2100 (Cámara et al., 2022).

Este trabajo es un aporte esencial debido a la relación existente entre los regímenes bioclimáticos y la distribución de las formaciones vegetales. De esta manera se puede conocer la correlación entre ambas variables. Por otra parte, el análisis multitemporal permite realizar proyecciones sobre el impacto que el incremento de los gases del efecto invernadero (GEI) tiene sobre la distribución de los regímenes bioclimáticos. La base cartográfica contribuye a visualizar los cambios espaciales de estos regímenes en los distintos escenarios temporales.

\section{ANTECEDENTES TEÓRICOS}

Recientemente, Cámara et al. (2020) propusieron una cartografía sobre la base a los tipos de regímenes bioclimático (TRB) representados en tres escalas: mundial, regional y local. Se identificaron en la escala 
local 162 subtipos de regímenes (TRBs) que surgen de la combinación de los 27 tipos de regímenes bioclimáticos, según las limitaciones térmicas e hídricas de la vegetación en cada espacio, con los 9 tipos ombrotérmicos de Thornthwaite. También realizaron cartografías considerando la variable temporal, y es por ello que también es una metodología multitemporal, ya que ha sido aplicada para el período del último Máximo Glaciar y para escenarios futuros de cambio climático. A escala nacional, hay ejemplos de la aplicación de esta metodología en España, tanto para el escenario actual como para el del último Máximo Glaciar. También se han utilizado para estudios de investigación o asesorías internacionales en Mozambique, Guinea Ecuatorial, Brasil, Chile y Estados Unidos (Cámara et al., 2020). A escala regional se empleó en el caso de Paraiba, Brasil (Cámara et al., 2022).

En América Latina, existen algunos países que cuentan con el mapa bioclimático nacional. Entre ellos se destacan México, Chile y Ecuador. En el primer caso, Hernández Cerda et al. (2018) identificaron 7 bioclimas en México comparando dos sistemas de clasificación de distinta escala de aplicación: la climática de Köppen modificado por García (1964) y el Worldwide Bioclimatic Classification System de Rivas Martínez et al. (2011). En Chile, Uribe et al. (2012) realizaron un atlas bioclimático en el cual integraron variables topoclimáticas, de vegetación y de topografía local enfocado al uso agrícola. El Ministerio de Ambiente del Ecuador (2013) actualizó el mapa bioclimático continental del país donde se reconocen 4 grandes bioclimas tropicales, con limitaciones del modelo vinculadas a las zonas de "cordillera costanera". En Perú, Ninahuaman (2016) estableció 12 regiones bioclimáticas para el país sobre la base de la clasificación de Bagnouls \& Gaussen (1963), aporte que se convirtió en un antecedente fundamental a escala nacional. En la mayoría de los casos antes mencionados, existe una base cartográfica de las clasificaciones de los regímenes bioclimáticos.

En Argentina, hay una clasificación bioclimática de todo el territorio publicada por Czajkowski et al. (2009), quienes lo aplicaron en el campo de la conservación energética. Utilizaron como base, los datos de 154 estaciones meteorológicas otorgados por el Servicio Meteorológico Nacional (SMN) del país. De la aplicación y combinación de diferentes variables se obtuvo el mapa final con 5 categorías, las cuales no se nombran y analizan en profundidad. También hay publicaciones con mapas de algunas regiones como el noroeste argentino (Peroné \& Cannelli, 1987) o de algunas provincias como Buenos Aires (Czajkowski \& Rosenfeld, 1992), Mendoza (González et al., 2009) y Jujuy (Entrocassi et al., 2014).

Por otra parte, las grandes transformaciones que se están generando como producto del cambio climático hacen necesario que se elaboren modelos de regímenes bioclimáticos que contemplen escenarios futuros con niveles de concentración de GEI. De esta forma, se puede analizar las tendencias y los cambios que se sucederán en estos regímenes en respuesta a la concentración de estos gases en la atmósfera. En los países latinoamericanos no se han realizado estudios de este tipo a escala nacional. Sin embargo, se registra, a nivel regional, la aplicación en Paraiba (Brasil) donde se elaboró un mapa de los regímenes bioclimáticos para el escenario de cambio climático de 2070, con RCP 8.5 (Cámara Artigas et al., 2022). En Argentina no se ha realizado ningún mapa que muestre ese cambio a futuro, aunque si se registra la aplicación de gráficos y modelados de temperatura y precipitaciones para esos escenarios (Zazulie et al., 2017; Rolla et al., 2018; Doyle, 2019).

\section{METODOLOGÍA}

Para lograr la representación de los TRB se aplicó la metodología de Cámara Artigas et al. (2020), que es un método analítico y cartográfico, que tiene un enfoque multiescalar y multitemporal sobre las formaciones vegetales a partir de los regímenes bioclimáticos. La base de datos climática continua a escala mundial utilizada fue Worldclim (https://www.worldclim.org/data/index.html) para el período glaciar, el escenario actual y el futuro de cambio climático. Los datos son producto de la interpolación de 9.000 a 60.000 estaciones meteorológicas y su resolución espacial es de 1 km² (Hijmans et al., 2005). Los valores mensuales de temperatura y de precipitación fueron descargados seleccionando el modelo climático CCSM 4.0 para el área de análisis. A esta capa de escala planetaria se le realizó un recorte o máscara con los límites del territorio 
argentino en el software ArcGis $10.4{ }^{\circledR}$. Este procedimiento se realizó para las condiciones históricas, las actuales y las futuras, con proyecciones de cambio climático RCP 8.5 para el escenario 2070.

Partiendo de la metodología de balances bioclimáticos de Montero de Burgos \& González (1974) se opera con los rasters de temperatura y precipitación mensual, para obtener las variables necesarias para la identificación de los regímenes bioclimáticos. A partir de ellos, se obtuvieron los rasters mensuales y anuales de paralización vegetativa hídrica y térmica. La temperatura es un factor fundamental en el desarrollo de las plantas, siendo limitante o potenciador de su distribución considerando los límites óptimos de cada especie. Sobre la base de ello, la clasificación utilizada en este trabajo considera la cantidad de meses en el año con presencia o no de paralización vegetativa térmica (PVT). En la tabla 2 se muestra cada categoría (termofilia, euritermofilia, criofilia, mesocriofila e hipercriofilia). De la misma forma, existe una paralización vegetativa hídrica (PVH) que se basa en la presencia y/o ausencia de agua. La PVH se clasifica en ombrofilia, mesofilia, tropofilia, xerofilia e hiperxerofilia, según la cantidad de meses en la cual la planta presenta déficit de agua (tabla 2).

Tabla 2. Clasificación de los tipos de regímenes bioclimáticos (TRB) en función de los meses de la paralización vegetativa térmica (PVT) e hídrica (PVH).

\begin{tabular}{|c|c|c|c|c|}
\hline Meses de PVT & $\mathbf{0}$ & $\mathbf{1}$ a $\mathbf{5}$ meses & $\mathbf{6}$ a $\mathbf{1 0}$ meses & $\mathbf{1 1}$ a $\mathbf{1 2}$ meses \\
\hline TRB & $\begin{array}{c}\text { Termófilia } \\
\text { Euritermofilia }\end{array}$ & Criofilia & Mesocriófilia & Hipercriófilia \\
\hline Meses de PVH & $\mathbf{0}$ & $\mathbf{1}$ a $\mathbf{4}$ meses & $\mathbf{5}$ a $\mathbf{8}$ meses & $\mathbf{9}$ a 12 meses \\
\hline TRB & $\begin{array}{c}\text { Ombrofilia } \\
\text { Mesofilia }\end{array}$ & Tropofilia & Xerofilia & Hiperxerofilia \\
\hline
\end{tabular}

Fuente: Elaboración propia.

Según lo expuesto, los regímenes bioclimáticos tropicales son aquellos cuya media mensual es superior a los $18{ }^{\circ} \mathrm{C}$, mientras que los hipercriófilos son los que poseen al menos 10 meses con temperaturas medias mensuales por debajo de $7,5^{\circ} \mathrm{C}$. En el caso de la humedad, los ombrófilos son los más húmedos y los hiperxerófilos, los de mayor aridez.

Luego de obtener los rasters del Índice Ombrotérmico de Thornthwaite y Mather (1955) y los de PVT y $\mathrm{PVH}$, se generaron los rasters condicionales de tropicalidad, subtropicalidad y zonas templadas y frías de Argentina. La explicación y desarrollo de las fórmulas usando el software ArcGis ${ }^{\circledR}$ se encuentran desarrollados en el anexo de Cámara Artigas et al. (2020). Como resultado se obtuvieron los rasters de los subtipos de regímenes bioclimáticos, donde su nomenclatura se conforma con la denominación térmica seguida de la denominación hídrica y su tipo ombrotérmico (por ejemplo: euritermo mesófilo húmedo medio). En la elaboración de cada mapa se desestimaron aquellos subtipos de regímenes bioclimáticos cuya cantidad de píxeles fuera inferior a 500 (equivalente a $350 \mathrm{Km}^{2}$ o un área equivalente de $18 \times 18 \mathrm{Km}$ ) por ser poco representativo de la superficie del territorio argentino a esta escala. Se les aplicó los colores definidos para cada subtipo (https://www.geografiafisica.org/wp-content/uploads/2020/11/Figura5.jpg), según lo establecido por Cámara et al. (2020) y posteriormente se calculó la superficie (en $\mathrm{km}^{2}$ ) de cada uno de ellos para realizar una comparación más ajustada entre los mapas de cada período (pasado, escenario actual y futuro).

\section{RESULTADOS}

Se realizaron tres mapas de regímenes bioclimáticos a escala nacional para cada periodo seleccionado (Último Máximo Glaciar, escenario actual y futuro con RCP 8.5 para el año 2070), usando la metodología mencionada anteriormente. A continuación, se desarrolla la explicación de la distribución de los regímenes bioclimáticos en escenario temporal y se visualiza su cartografía. 


\subsection{Los Tipos de Regímenes Bioclimáticos durante el Último Máximo Glaciar}

El Último Máximo Glaciar fue la época de máxima extensión de la superficie de hielo durante la Última Glaciación Pleistocena, que tuvo una duración de alrededor de 100.000 años y finalizó hace 11.000 B.P. El nivel de los océanos descendió hasta 100 m en relación con la actualidad y el clima frío de este período dio lugar a la existencia del permafrost en las latitudes medias de casi toda la superficie terrestre. En el actual territorio argentino, el Último Máximo Glaciar tuvo su mayor desarrollo entre los 24.000 y 22.000 B.P., donde el volumen de hielo acumulado fue superior al resto del período, según Ponce \& Rabassa (2012). Durante este período, se incrementó la superficie de la Patagonia continental como resultado de la disminución del nivel del mar, que se encontraba a los $140 \mathrm{~m}$ por debajo del actual, y la exposición de la plataforma. Esto contribuyó a que el efecto moderador marino sea menor dando lugar al aumento de las temperaturas extremas y a la disminución de las precipitaciones (Ponce \& Rabassa, 2012). Se incrementó el volumen de hielo acumulado y se intensificaron los vientos provenientes del oeste, siendo más fríos y secos (Compagnucci, 2011).

La finalización de este período se marcó por el rápido decrecimiento en el volumen del hielo. Su causa se debe a cambios en la radiación solar recibida en el hemisferio Norte hace 22.000 B.P., asociado a los ciclos de Milankovich. Como resultado se desencadenaron transformaciones en el clima planetario, las cuales incidieron directamente en la deglaciación y en el incremento del nivel del mar. De acuerdo a la descripción antes realizada, existía una variedad de paleoambientes. En el mapa de los TRB del Último Máximo Glaciar (mapa 1), se observa una superficie mayor que la actual ya que la plataforma continental, tal como se explicó, fue sobre expuesta en este período, debido al descenso del nivel del mar. Se reconocieron una totalidad de 16 TRB y 64 subtipos.

Durante este período se puede observar que el tipo térmico con mayor superficie era el criófilo, seguido del mesocriófilo y del hipercriófilo. El euritermófilo se desarrollaba en el sector norte, principalmente centro y Este y era el de menor extensión. No hay registro del termófilo para ese período. El TRB crío mesófilo fue el de mayor extensión, el cual se caracteriza por presentar paralización térmica de 1 a 5 meses, aunque no hídrica. Se distribuía principalmente en el centro del actual país y en parte del Mar Argentino. El subtipo que tenía una superficie mayor era el crío mesófilo seco-subhúmedo, también en parte de la actual región noroeste donde se encentraban los regímenes más secos. El crío xerófilo es otro régimen bioclimático de gran expansión al Sur del continente durante este período, principalmente del subtipo crío xerófilo árido. A diferencia del anterior, hay una paralización hídrica de 5 a 8 meses y térmica de 1 a 5 meses.

Otro subtipo con mayor superficie fue el mesocrío xerófilo árido que ocupaba el centro-sur de la Patagonia y noroeste del país, vinculado con las áreas de mayor altura. En relación con los TRB asociados a las zonas polares, el hipercrío mesófilo era el de mayor área y se desarrollaba en el sector oeste, vinculado a la Cordillera de los Andes y en la zona sur, en la actual Tierra del Fuego e Islas Malvinas. El subtipo más representativo fue el hipercrío mesófilo seco-subhúmedo, que se caracteriza por una paralización térmica anual mayor de 9 meses. Además, en este período existía una mayor superficie de regímenes bioclimáticos vinculados con los de tipo mesófilos y xerófilos, en cuestión de humedad. En relación con la temperatura, predominaban los crio y mesocrío.

\subsection{Tipos de Regímenes Bioclimáticos en la actualidad}

En el actual mapa de TRB (mapa 2) se observan cambios en relación con el mapa del Último Máximo Glaciar (mapa 1), tanto en la superficie terrestre como en los regímenes bioclimáticos, como producto del período postglacial. El ascenso del mar, luego de la última glaciación generó que la superficie terrestre se viera reducida. Como primer análisis se observa la existencia de 17 TRB y 75 subtipos. La comparación con el mapa de TRB del Último Máximo Glaciar muestra que algunos de esos TRBs tienen una mayor extensión y, por el contrario, otros se ven reducidos en su área.

En la actualidad, son los eurotermófilos (bioclimas subtropicales) aquellos que ocupan más superficie del país. En el Último Máximo Glaciar, este estaba reducido a la zona centro-Este y actualmente dicho límite 
se extendió hacia el Sur. Se reconoce el euritermo mesófilo como aquel TRB que predomina en centro Este del país. Los subtipos que dominan son el euritermo mesófilo subhúmedo-húmedo y el euritermo mesófilo seco-subhúmedo. Por otra parte, dentro de los criófilos (bioclimas templados-fríos), el crio tropófilo es el que adquiere mayor relevancia siendo el crio tropófilo árido, dentro de los subtipos, el más representativo.

En comparación con el mapa anterior, los TRB críofilos se desarrollan principalmente en la Patagonia. En los mesocriofilos e hipercriofilos (bioclimas subpolares y polares) se observa una reducción de su superficie quedando relegados al Sur del país en la zona de Tierra del Fuego e Islas Malvinas y en la Cordillera de los Andes. Entonces, en síntesis, predominan los euritermofilos y criofilos, en relación con los tipos termófilos (tropicales) que están ausentes, y en cuanto a la clasificación según la paralización hídrica, son más representativos los mesófilos (sin PVH) y tropófilos (con PVH de 1 a 4 meses).

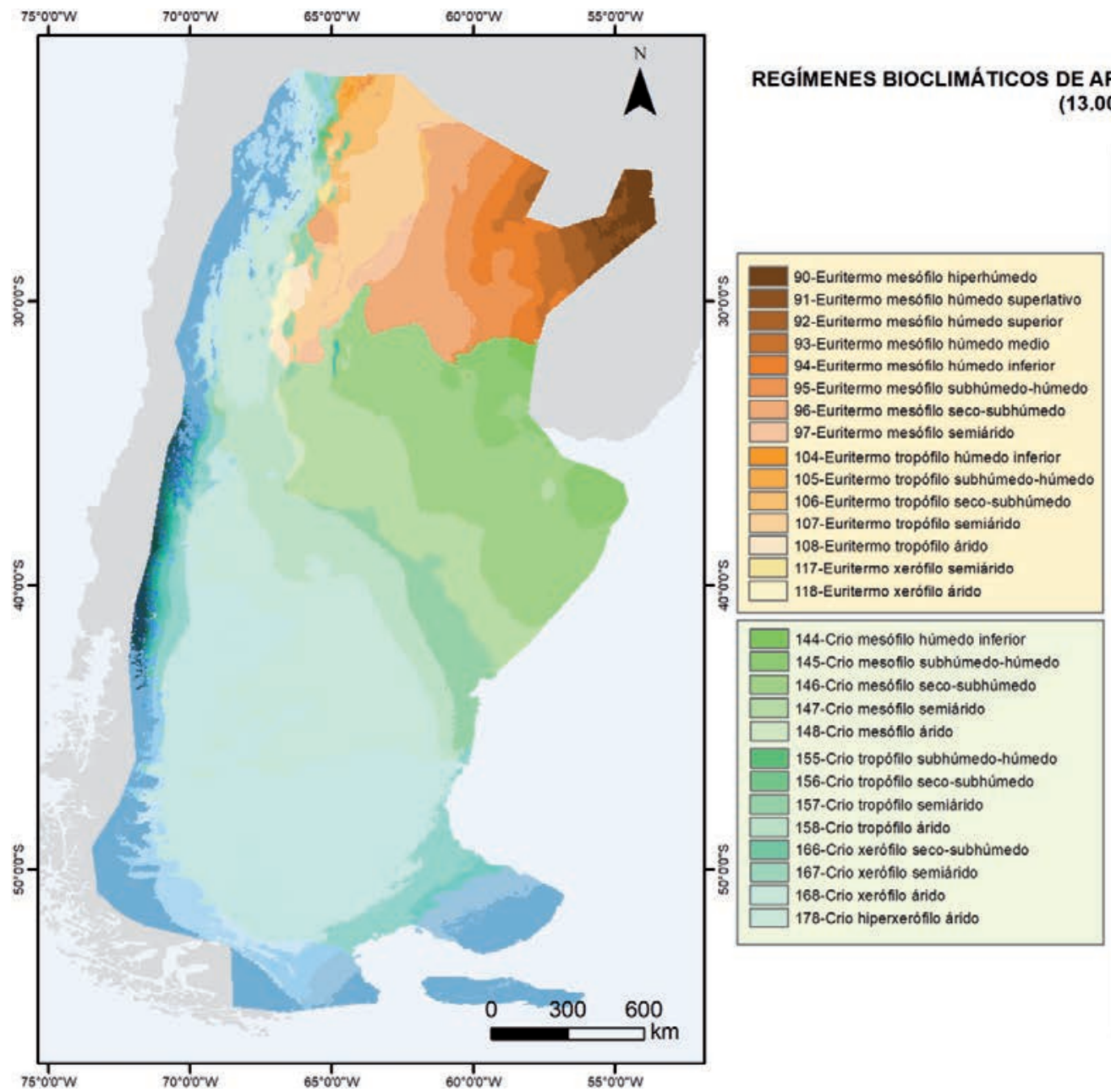

(13.000 BP)

Mapa 1. Tipos de Regímenes Bioclimáticos de Argentina durante el Último Máximo Glaciar. Fuente: Elaboración propia.

En base a esta relación bioclimática, se ha realizado una combinación de las ecorregiones de Argentina. Se utilizó 16 de las 18 ecorregiones identificadas en la obra de Morello et al. (2012) (se ha desestimado el mar Argentino y la Antártida). Hay ecorregiones que responden a situaciones intrazonales como áreas inundadas, como es el caso del Chaco Húmedo, Deltas e Islas y Esteros del Iberá u otras que hacen referencia a situaciones con relieve como Altos Andes, Puna, Yungas, Monte de llanura y mesetas y Monte de sierras y Bolsones. 


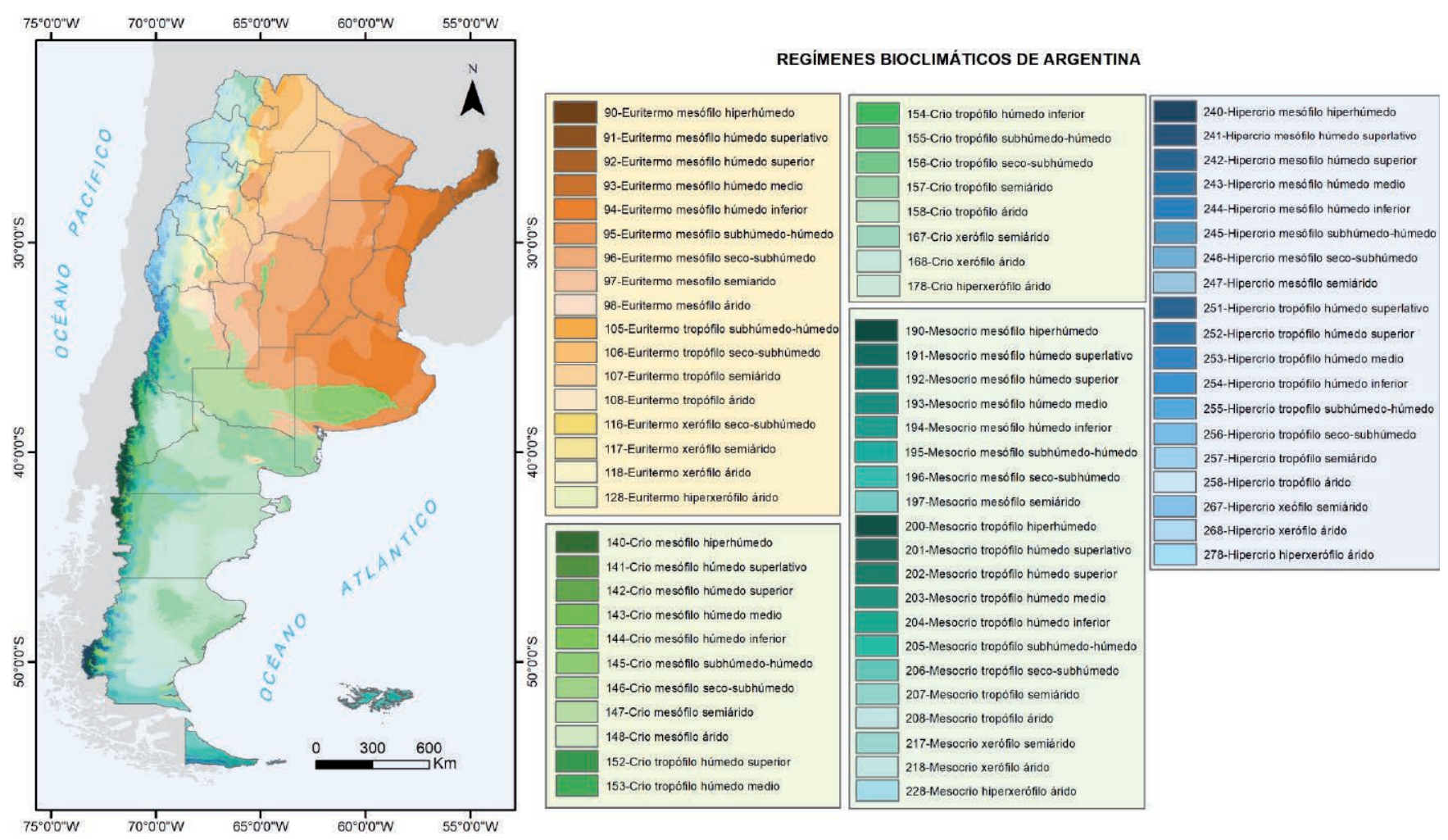

Mapa 2. Tipos de Regímenes Bioclimáticos de Argentina en la actualidad. Fuente: Elaboración propia.

En el dominio subtropical, el TRB que más veces está presente en las ecorregiones es el euritermo mesófilo en sus diferentes situaciones de ombroclimas:

- superlativo a medio en la Selva Paraenense,

- húmedo medio en Campos y Malezales,

- húmedo inferior a húmedo-subhúmedo en los Esteros de Iberá, al norte de La Pampa y el Espinal,

- húmedo inferior a subhúmedo seco en la Pampa,

- húmedo-subhúmedo a subhúmedo-seco en el Chaco húmedo,

- subhúmedo-seco a semiárido en el Chaco Seco y en el Espinal.

EI TRB euritermo tropófilo, con una estacionalidad pluviométrica contrastada, está representado en las Yungas y parcialmente en el Chaco Seco. El euritermo xerófilo e hiperxerófilo, con una PVH superior a 5 meses, está presente en la ecorregión de Montes de Sierras y Bolsones.

Respecto a los bioclimas fríos -templados tipo criófilos, se encuentran distribuidos en condiciones de PVH en la Puna (crio xerófilo y crio hiperxerófilo) y en la Estepa Patagónica (crio tropófilo y crio xerófilo). Estas ecorregiones se desarrollan en condiciones bioclimáticas similares pero una en un altiplano, la Puna, y la otra en llanura, con respuestas fisionómicas similares con dominio de herbáceas amacolladas y plantas adaptadas a condiciones de permanencia de manto de nieve. El TRB crio xerófilo también se observa en la ecorregión de Montes de Sierras y Bolsones.

Hay dos situaciones con bioclimas crio mesófilos, con sólo PVT de 1 a 5 meses, en Monte de Llanura y Mesetas y en Pampa y Espinal más meridional en condiciones ombroclimaticas húmedo a subhúmedo en la ecorregión Pampa y semiárido en el Espinal.

En condiciones de medios subpolares con bioclimas micro mesófilas sólo se encuentran las Islas del Atlántico Sur en condiciones de ombroclima subhúmedo seco y en los bosques patagónicos en ombroclima hiperhúmedo a subhúmedo-seco. En este mismo medio pero con PVH, se sitúan los Altos Andes (mesocrio xerófilo e hiperxerófilo en condiciones ombroclimáticas áridas), y en la Estepa Patagónica más meridional con bioclima mesocrio tropófilo semiárido. 
En esta síntesis no están representados actualmente en Argentina los bioclimas del dominio tropical, que aparecen ya en Brasil o Paraguay. En la tabla 3 se muestra la relación entre las ecorregiones de Argentina y los tipos de regímenes bioclimáticos.

Tabla 3. Relación entre las ecorregiones de Argentina y los tipos de regímenes bioclimáticos en los que se distribuyen.

\begin{tabular}{|c|c|}
\hline ECORREGIONES & TRBs \\
\hline 2-Islas del Atlántico sur & Mesocrio mesófilo subhúmedo-seco \\
\hline 3-Altos Andes & $\begin{array}{l}\text { Mesocrio xerófilo árido/ mesocrio hiperxerófilo árido/ hipercrio tropófilo } \\
\text { semiárido/ hipercrio xerófilo árido }\end{array}$ \\
\hline 4-Puna & Crio xerófillo semiárido-árido/ crio hiperxerófilo árido /mesocrio xerófilo árido \\
\hline 5-Seva Paranaense & Euritermo mesófilo húmedo superlativo a medio \\
\hline 6 -Yungas & Euritermo tropófilo subhúmedo-seco \\
\hline 7-Bosques Patagónicos & Mesocrio mesófilo hiperhúmedo-subhúmedo seco \\
\hline 9-Campos y Malezas & Euritermo mesófilo húmedo medio \\
\hline 10-Chaco Húmedo & Euritermo mesófilo húmedo-subhúmedo a subhúmedo-seco \\
\hline 11-Chaco Seco & $\begin{array}{l}\text { Euritermo mesófilo subhúmedo-seco a semiárido/ euritermo tropófilo } \\
\text { semiárido }\end{array}$ \\
\hline 12-Delta e Islas & Euritermo mesófilo húmedo-subhúmedo \\
\hline 13-Espinal & $\begin{array}{l}\text { Euritermo mesófilo húmedo-subhúmedo a subhúmedo seco/ crio mesophyllo } \\
\text { semiárido }\end{array}$ \\
\hline 14-Estepa Patagónica & $\begin{array}{l}\text { Crio tropófilo semiárido a árido/ crio xerófilo árido/ mesocrio tropófilo } \\
\text { semiárido }\end{array}$ \\
\hline 15-Esteros del Iberá & Euritermo mesófilo húmedo inferior a húmedo-subhúmedo \\
\hline 16-Monte de Llanura y Mesetas & Crio mesófilo semiárido/ crio tropófilo semiárido a árido \\
\hline 17-Monte de Sierras y Bolsones & Euritermo xerófilo árido/ euritermo hiperxerófilo árido/ crio xerófilo árido \\
\hline 18- Pampa & $\begin{array}{l}\text { Euritermo mesófilo húmedo inferior a subhúmedo-seco/ crio mesófilo húmedo- } \\
\text { subhúmedo }\end{array}$ \\
\hline
\end{tabular}

Fuente: Elaboración propia.

\subsection{Tipos de Regímenes Bioclimáticos con RCP 8.5 para el escenario 2070}

En el mapa del TRB de escenario futuro de cambio climático se seleccionó el año 2070. En el Quinto Informe del IPCC se han definido 4 nuevos escenarios de emisión denominadas RCP. En cada una de ellas, hay una situación asociada según las emisiones de los gases de efecto invernadero (GEI): un nivel muy bajo (RCP 2.6), dos de estabilización (RCP 4.5 y RCP 6.0) y un escenario con un nivel muy alto de concentración (RCP 8.5). La finalidad de la elaboración de esta cartografía es analizar cómo se verían modificados los actuales TRB con la influencia de estos gases en la atmósfera, en un escenario donde su concentración sea elevada (RCP 8.5). De esta forma, poder planificar estrategias que permitan reducir los gases contaminantes y evitar que este modelo futuro, se convierta en una realidad. 


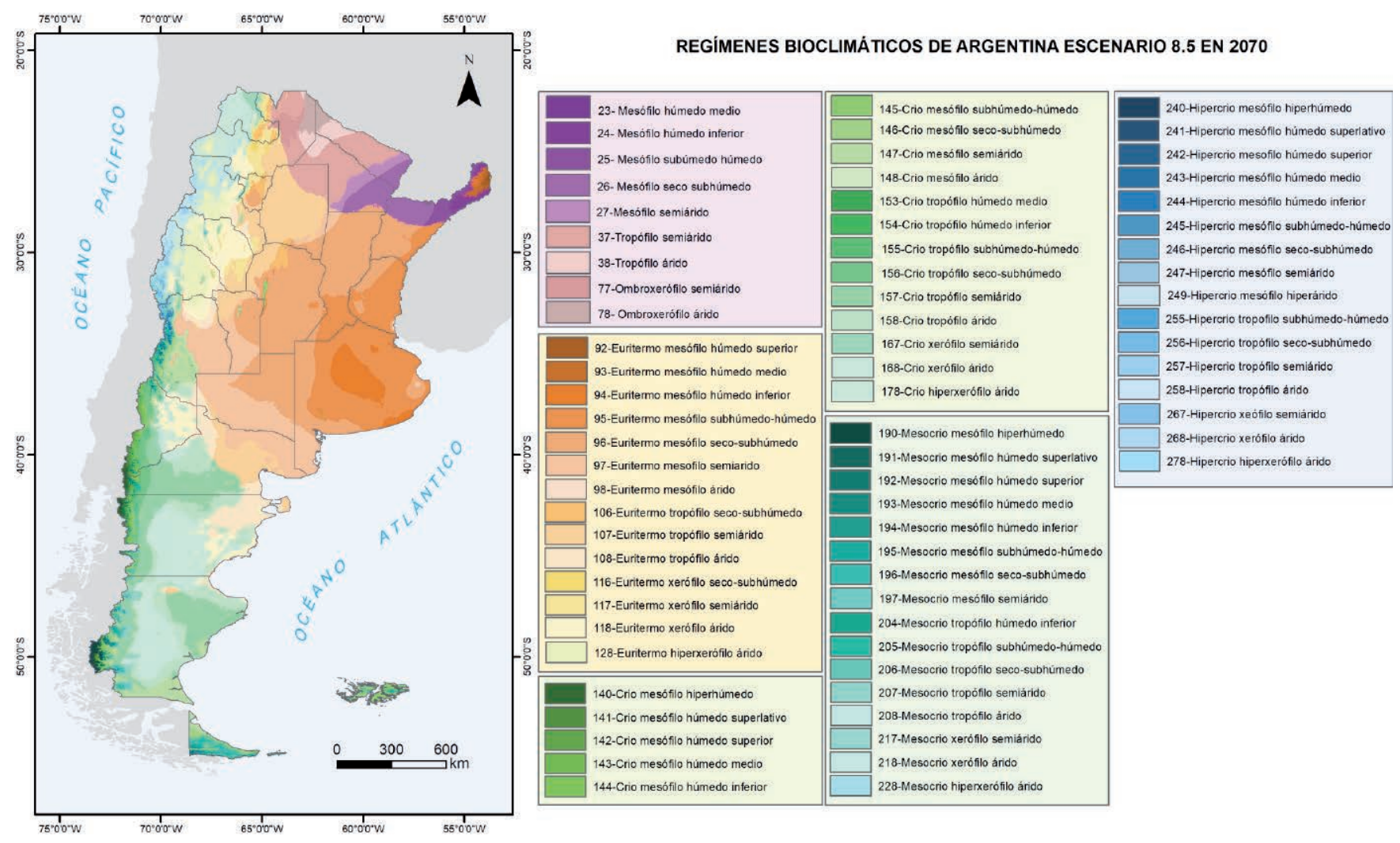

Mapa 3. Tipos de Regímenes Bioclimáticos de Argentina para el escenario de cambio climático con RCP 8.5 - año 2070. Fuente: Elaboración propia.

En el mapa 3 se muestra una totalidad de 19 TRB y 73 TRBs. Los TRB mesófilo, tropófilo y xerófilo (bioclimas tropicales) aparecen en esta cartografía, estando ausentes en las anteriores. Se distribuyen en el Noreste y centro-Norte del país. En el mapa actual (mapa 2), no se visualizan dichos tipos por lo cual se puede inferir que el incremento de los GEI considerando un RCP elevado, daría lugar a un incremento en las temperaturas en dicho sector del país. Según la Secretaría de Ambiente y Desarrollo Sustentable de la Nación (2015) y Camilloni (2018), los cambios en temperatura proyectados para fines del presente siglo indican incrementos en todo el país con valor promedio de $1^{\circ} \mathrm{C}$, aunque en el Noroeste y Patagonia se observarían los máximos cambios con temperaturas que ascienden de $3,5^{\circ} \mathrm{C}$ a $5^{\circ} \mathrm{C}$.

Como producto de la aparición de nuevos TRB al norte del país, los tipos asociados a los TRB euritermófilos se ven desplazados más hacia el Sur, abarcando parte de la Patagonia Norte, en las provincias de Río Negro, Chubut y Mendoza. Sigue predominando como en el Mapa 2 el tipo euritermo mesófilo, debido a su mayor extensión en todo el territorio argentino. Los tipos vinculados a los bioclimas criófilos se extienden principalmente en la Patagonia, cuyo límite norte fue modificado y se limita al sector central y Sur. También en la zona vinculada a la Cordillera de los Andes, en el noroeste del país. En el resto de las provincias de la Patagonia predominan los TRB criófilos y los mesocriófilos e hipercriófilos se encontrarían en el sector de las montañas. Los tipos vinculados a los bioclimas mesocriófilos e hipercriofilos se ven reducidos en su superficie. En el primer caso a sitios específicos de la Cordillera de los Andes, en Tierra del Fuego y en sectores de las Islas Malvinas. Los tipos del bioclima hipercriófilo, solamente se distribuyen en el Oeste del país, relacionados con el sistema montañoso de los Andes, desde Jujuy hasta Mendoza.

Según la Secretaría de Ambiente y Desarrollo Sustentable de la Nación (2015), para el futuro lejano se proyecta un descenso de 10 a $20 \%$ en el oeste de la Patagonia norte y central y un aumento en el centro y Este del país. Se ha observado un incremento en superficie de la xerofilia, que determina la paralización vegetativa de 5 a 8 meses. 


\section{DISCUSIÓN}

Si bien existe un antecedente de regionalización bioclimática en Argentina, este está más enfocado en los aspectos energéticos vinculados con el hábitat (Czajkowski et al., 2009). Entonces, en comparación con lo presentado en este trabajo de investigación se puede mencionar que existen diferencias en cuanto a los métodos utilizados para la obtención de los mapas bioclimáticos, también en las variables climáticas usadas y en la base de datos y finalmente en el nivel de detalle de las categorías detectadas en cada clasificación. Además, el análisis de este artículo, se realizó considerando otros períodos de tiempo, pasado y futuro.

Si se comparan los TRB del Último Máximo Glaciar con la situación actual y el escenario de cambio climático con RCP 8.5 para el 2070, se observan algunas modificaciones significativas. Entre ellos la superficie de los tipos térmicos que fue cambiando en cuanto a su preponderancia en cada período analizado. Mientras que el criófilo fue el de mayor extensión durante el último Máximo Glaciar con 1.526 .738 km², en el mapa actual y en el escenario 2070, es el euritermófilo, el que obtiene mayor predominio, con $1.365 .641 \mathrm{Km}^{2} \mathrm{y}$ 1.598.736 Km² respectivamente. Se observa además una reducción notable del mesocriófilo e hipercriófilo y en menor medida del criófilo entre el primer período y el segundo (Mapa 1 a Mapa 2), tendencia que se mantiene para el escenario del 2070. Por el contrario, aparece el tropófilo como un nuevo tipo térmico que se visualiza con una gran superficie en el año 2070 con una superficie de 147.151,9 km². El euritermófilo, durante este período, incrementa su superficie, aunque no de forma tan significativa como del primero al segundo mapa.

Si se considera el periodo actual con el escenario de cambio climático del año 2070, se observan incrementos y decrecimientos de los TRBs entre ambos períodos. La variación de su superficie se observa en la tabla 4.

El bioclima tropófilo en el dominio tropical para 2070, alcanzaría una superficie de 147.152 km² y el mesófilo $111.146 \mathrm{~km}^{2}$, ubicados ambos al Norte de Argentina, frontera con Brasil y Paraguay. Otros TRBs que se verán ampliados en su área de distribución de forma significativa para el 2070, serían: euritermo mesófilo, tropófilo, xerófilo e hiperxerófilo. Es decir, se incrementan los TRB de categoría tropical y subtropical. Por el contrario, todos los TRBs de las categorías templados-fríos, subpolares y polares sufrirían pérdidas en su superficie. Los que tienen un decrecimiento más elevado en el futuro serían: euritermo ombrófilo, crio ombrófilo, crio mesófilo, crio mesófilo, y crio tropófilo. Los bioclimas crio xerófilo y crio hiperxerófilo aumentan en superficie, siendo esto una anomalía que se explica por la presencia de la Cordillera de los Andes, por aumento de la nivación.

Se destaca en este trabajo las transformaciones espaciales de los regímenes bioclimáticos en los períodos seleccionados, que se pueden explicar como producto del cambio climático. En Argentina, este fenómeno se caracteriza por un incremento en las temperaturas medias anuales, principalmente en la Patagonia, y por la variación en las precipitaciones por regiones, incrementándose en la zona centro-este del país y disminuyendo en la región de Cuyo (Camilloni, 2018). El aumento de los GEI se observa principalmente en la época del Antropoceno, término acuñado por Crutzen \& Stoermer (2000). Estas trasformaciones se han intensificado en los últimos siglos repercutiendo también en los regímenes bioclimáticos. Tonni (2006) afirma que los cambios climáticos durante el Holoceno afectaron la composición y distribución de la biota generando incluso el proceso de extinción de algunos seres vivos. Se puede inferir que desde el Holoceno y hasta el escenario 2070, estos procesos se irán acelerando y generando la necesidad de procesos adaptativos en las plantas y animales, afectando la cantidad de su población y su distribución en el territorio argentino y en algunos casos, determinando su peligro de extinción (Teta et al., 2014). Algunos ejemplos ya analizados con miras al futuro se visualizan en Rodríguez Cravero et al. (2017), en el cual estudiaron la aptitud de hábitat del género Stevia en el noroeste del país comparando su distribución actual con la del escenario 2050 con RCP 2.5 y RCP 8.5. 
Tabla 4. Variación de la superficie absoluta en $\mathrm{Km}^{2}$ de los TRB en los Mapas 1, 2 y 3 de los períodos analizados. El color rosado indica regresión de superficie y el azul progresión.

\begin{tabular}{|c|c|c|c|c|}
\hline \multicolumn{2}{|c|}{ Tipos de Regímenes Bioclimáticos } & Último Máximo Glaciar & Actual & Escenario RCP 8.52070 \\
\hline \multirow{3}{*}{ TROPICALES } & Mesófilo & 0 & 0 & 111146 \\
\hline & Tropófilo & 0 & 44.8 & 147151.9 \\
\hline & Ombroxerófilo & 0 & 0 & 31994.9 \\
\hline \multirow{5}{*}{ SUBTROPICALES } & Euritermo ombrófilo & 305.0 & 1.4 & 0 \\
\hline & Euritermo mesófilo & 400663.2 & 997182.0 & 1024800.0 \\
\hline & Euritermo tropofilo & 220560.7 & 295782.2 & 332234.0 \\
\hline & Euritermo xerófilo & 12062.7 & 60040.4 & 182215.6 \\
\hline & Euritermo hiperxerófilo & 335.5 & 12635.7 & 59486.7 \\
\hline \multirow{5}{*}{ TEMPLADOS-FRÍOS } & Crio ombrófilo & 0 & 5.6 & 0 \\
\hline & Crio mesófilo & 737764.5 & 270614.4 & 139795.6 \\
\hline & Crio tropófilo & 317566.0 & 531931.4 & 350157.5 \\
\hline & Crio xerófilo & 421372.7 & 259765.1 & 266020.3 \\
\hline & Crio hiperxerófilo & 50035.2 & 19859.7 & 33978.7 \\
\hline \multirow{4}{*}{ SUBPOLARES } & Mesocrio mesófilo & 23149.5 & 101529.4 & 54468.4 \\
\hline & Mesocrio tropófilo & 183396.5 & 119784.0 & 28469.7 \\
\hline & Mesocrio xerófilo & 664457.7 & 67412.1 & 23440.2 \\
\hline & Mesocrio hiperxerófilo & 1769.0 & 11368.0 & 4654.3 \\
\hline \multirow{4}{*}{ POLARES } & Hipercrio mesófilo & 401746.0 & 26100.9 & 14044.8 \\
\hline & Hipercrio tropófilo & 103334.0 & 40289.9 & 12459.3 \\
\hline & Hipercrio xerófilo & 82273.7 & 18431.0 & 6103.3 \\
\hline & Hipercrio hiperxerófilo & 1189.5 & 1091.3 & 3286.5 \\
\hline
\end{tabular}

Fuente: Elaboración propia.

Como se mencionó anteriormente no existen antecedentes en el país sobre este tipo de estudios y por lo tanto no se puede realizar ninguna comparación. Sin embargo, en relación con el caso de Paraiba se pueden visualizar algunas similitudes, más allá de las diferencias en la distribución de los regímenes bioclimáticos y en la escala de análisis de esta región de Brasil con la Argentina. Según Cámara et al. (2022), en Paraiba se observaron cambios en los TRB durante los tres periodos analizados. Si se hace hincapié en el mapa actual en relación con el del año 2070, en el primero se registra la presencia de 9 TRB, mientras que en el segundo el número se reduce a 4 . En el escenario futuro se observan subtipos más áridos, desapareciendo los húmedos y subhúmedos. Esta situación modificaría completamente el área de distribución de las plantas. En el caso de Argentina, los cambios más significativos se muestran sobre la base de la condición térmica, incrementándose los tipos los medios tropicales y subtropicales y disminuyendo la superficie de los medios templados-fríos y subpolares. Este nuevo patrón de los regímenes bioclimáticos en el escenario futuro de cambio climático también afectaría el área de distribución de las plantas y consiguientemente de las formaciones vegetales de Argentina. 


\section{CONCLUSIONES}

La generación de mapas bioclimáticos es esencial para definir la distribución de los seres vivos en un territorio. En especial, la metodología de TRB (Cámara Artigas et al., 2020) es un gran aporte en la investigación sobre esta temática ya que tiene como ventajas su utilización y aplicación en distintas escalas de análisis (nacional, regional, provincial, etc.) y en diferentes temporalidades, abarcando desde Último Máximo Glaciar hasta escenarios futuros de cambio climático. Su representación cartográfica permite ver rápidamente la información sobre los regímenes bioclimáticos de un territorio y establece modelos para poder definir posibles escenarios para el futuro bajo elevadas concentraciones de GEI.

El estudio realizado muestra los cambios y dinámica de los tipos bioclimáticos desde el Último Máximo Glaciar hasta la actualidad, y desde la situación de esta hasta un escenario de cambio climático con RCP 8.5 en 2070. El resultado es una fase de calentamiento holocena hasta la actualidad en la que retroceden los bioclimas de medios subpolares (mesocriófilos) y templados fríos (criófilos) y aumentan la superficie de los subtropicales (euritermófilos) y en 2070 aparecen los tropicales (mesófilos y tropófilos) debido al calentamiento general por la subida de hasta $3^{\circ} \mathrm{C}$ para dentro de 50 años (hasta 2017) según RCP 8.5, que es el escenario utilizado.

Esta metodología permite constatar los cambios cuaternarios en los bioclimas, y por lo tanto en las formaciones vegetales y ecorregiones, a partir del conocimiento actual de la distribución de estas conforme a los tipos de regímenes bioclimáticos. De la misma manera se pueden inferir los cambios futuros a partir de la información disponible de temperaturas y precipitaciones mensuales en la base de datos continua climática de Wordclim y las relaciones de los TRB actuales con la vegetación actual tal como se refleja en la Tabla 3. La validez de este método ha sido contratada con la realización del mapa mundial de la situación actual (Cámara, 2004; Cámara et al., 2020, Cámara et al. 2022), o su aplicación a lugares concretos a nivel nacional o regional.

En Argentina, no existe una clasificación actualizada de los regímenes bioclimáticos así como tampoco una cartografía que sea temporal, con lo cual este trabajo constituye un avance fundamental en esta temática. Puede ser utilizado para la explicación de las áreas de distribución de las especies pasadas, presentes y futuras. Se pueden derivar estudios sobre diferentes problemáticas a partir de la aplicación de esta metodología en regiones y provincias del país. Por ejemplo, se pueden combinar los regímenes bioclimáticos con las ecorregiones del territorio para conocer su correspondencia y de esta forma explicar las variaciones en la fisonomía de la vegetación entre distintas ecorregiones e inclusive en el interior de cada una de ellas. Por otra parte, conocer mediante el modelado las condiciones bioclimáticas futuras de cambio climático permite activar líneas de trabajo de planificación en pos de mitigar los efectos adversos generados por los elevados niveles de concentración de GEI en la atmósfera.

\section{Agradecimientos y financiación}

Este trabajo se realizó en el marco del proyecto de investigación Geografía física aplicada al estudio de la interacción sociedad-naturaleza. Problemáticas a diversas escalas témporo-espaciales (24/G078). Este es dirigido por la Dra. Alicia M. Campo y se encuentra subsidiado por la Secretaría de Ciencia y Tecnología de la Universidad Nacional del Sur. También al apoyo del Consejo Nacional de Investigaciones Científicas y Técnicas (CONICET).

\section{Declaración responsable y conflicto de intereses}

Los autores declaran que no existe ningún conflicto de interés con relación a la publicación de este artículo. Los dos autores han participado en la revisión bibliográfica, la aplicación de la metodología, la elaboración de la cartografía y la redacción del artículo. 


\section{REFERENCIAS}

Bagnouls, F. \& Gaussen, H. (1963). Los Climas Biológicos e Sua Classificacao. Boletim Geográfico, 76, 545-566. Bailey, R.G. (2009). Ecosystem Geography. From Ecoregions to Sites. Springer. https://doi.org/10.1007/978-0-387-89516-1

Bruniard, E.D. (2000). Los Regímenes Climáticos y la Vegetación Natural. Aportes para un modelo fitoclimático mundial, Academia Nacional de Geografía. Academia Nacional de Geografía.

Cain, S.A. (1944). Foundations of plant geography. Harper and Brothers.

Cámara Artigas, R., Díaz del Olmo, F. \& Martínez-Batlle, J. R. (2020). TBRs, a methodology for the multi-scalar cartographic analysis of the distribution of plant formations. Boletín de la Asociación de Geógrafos Españoles, 85(2915), 1-38. https://doi.org/10.21138/bage.2915

Cámara R. (2004). Escalonamiento Bioclimático, Regímenes Ecodinámicos y Formaciones Vegetales de la Isla de la Española en República Dominicana. En: Panareda (Ed.) Estudios en Biogeografía 2004: Libro Homenaje a José Manuel Rubio Recio y Jesús García Fernández (p. 39-55). Terrassa, Aster.

Cámara Artigas, R., De Souza, B.I. \& Porto De Lima, R. (2022). Climatic changes and distribution of plant formations in the state of Paraiba, Brazil. Cuadernos de Investigación Geográfica, 48. En prensa. https://doi.org/10.18172/cig.5044

Camilloni, I. (2018). Argentina y el cambio climático. Ciencia e Investigación, 5, 5-10. http://aargentinapciencias.org/ wp-content/uploads/2018/11/1-Camilloni-cei68-5-2.pdf

Compagnucci, R.H. (2011). Atmospheric circulation over Patagonia since the Jurassic to present: a review through proxy data and climatic modeling scenarios. Biological Journal of the Linnean Society, 103(2), 229- 249. https://doi.org/10.1111/j.1095-8312.2011.01655.x

Crutzen, P.J. \& Stoermer, E.F. (2000). The 'Anthropocene". Global Change Newsletter, 41, 17-18. https://doi.org/10.17159/ sajs.2019/6428

Czajkowski, J.D., Gómez, A., Martini, I. \& Rosenfeld, Y. (2009). Regionalización bioclimática de Argentina mediante el uso de técnicas multivariadas y SIG. [Comunicación en congreso], VI Encuentro de Geógrafos de América Latina (EGAL). Buenos Aires, Argentina.

Czajkowski, J.D. \& Rosenfeld, E. (1992). Regionalización bioclimática de la provincia de Buenos Aires. [Comunicación en congreso]. XV Reunión de Trabajo de la Asociación Argentina de Energía Solar (ASADES). Catamarca, Argentina.

Doyle, M. (2019). El clima en Argentina, su variabilidad, cambio y posibles escenarios futuros. Revista Argentina de producción animal, 39, 31-41. https://ppct.caicyt.gov.ar/index.php/rapa/article/view/16608/pdf

Entrocassi, G.S., Hormigo, D.F., Gavilán, R.G. \& Sánchez-Mata, D. (2014). Bioclimatic typology of Jujuy Province (Argentina). Lazaroa, 35, 07-18. https://doi.org/10.5209/rev_LAZA.2014.v35.42366

Fernández González, F. (2004). Bioclimatología. En J. Izco (Coord.) Botánica (p. 715-794). Mc Graw-Hill Interamericana.

Fick, S.E. \& Hijmans, R.J. (2017). WorldClim 2: new 1 km spatial resolution climate surfaces for global land areas. International Journal of Climatology, 12, 4302-4315. https://doi.org/10.1002/joc.5086

Fidalgo Hijano, C. \& Muñoz Jiménez, J. (2003). Nuevas aportaciones para un modelo fitoclimático mundial. Ería. Revista Cuatrimestral De Geografía, 60, 133-137. https://doi.org/10.17811/er.0.2003.133-137

García, E. (1964). Modificaciones al Sistema de Clasificación Climática de Köppen (para adaptarlo a las condiciones de la República Mexicana (5 $5^{a}$ ed.). Instituto de Geografía, UNAM.

González Loyarte, M.M., Menenti, M. \& Diblasi, A. (2009). Mapa bioclimático para las Travesías de Mendoza (Argentina) basado en la fenología foliar. Revista de la Facultad de Ciencias Agrarias, 41(1), 105-122. http://revista.fca.uncu.edu. ar/images/stories/pdfs/2009-01/T41_1_10.pdf

Hausfather, Z. \& Peters, G. (2020). Emissions the 'business as usual' story is misleading. Nature, 577(7792), 618-20. https://doi.org/10.1038/d41586-020-00177-3

Hernández Cerda, M.E., Ordoñez Díaz, M. \& Giménez de Azcárate, J. (2018). Análisis comparativo de dos sistemas de clasificación bioclimática aplicados en México. Investigaciones Geográficas, 95, 1-14. https://doi.org/10.14350/rig.57451

Hijmans, R.J., S.E. Cameron, J.L. Parra, P.G. Jones \& A. Jarvis, (2005). Very high resolution interpolated climate surfaces for global land areas. International Journal of Climatology, 25, 1965-1978 https://doi.org/10.1002/joc.1276

Holdridge, L. R. (1947). Determination of world plant formation from simple climatic data. Science, 105, 267-268. http:// dx.doi.org/10.1126/science.105.2727.367 
IPCC. (2013). Climate Change 2013: The Physical Science Basis. Contribution of Working Group I to the Fifth Assessment Report of the Intergovernmental Panel on Climate Change. Stocker, T.F., D. Qin, G.-K. Plattner, M. Tignor, S.K. Allen, J. Boschung, A. Nauels, Y. Xia, V. Bex and P.M. Midgley (eds.). Cambridge University Press, Cambridge, United Kingdom and New York, USA.

Ministerio de Ambiente del Ecuador. (2013). Modelo bioclimático del Ecuador continental. Para la representación cartográfica de ecosistemas del Ecuador continental. Ministerio de Ambiente del Ecuador.

Montero de Burgos, J.L. \& González, J.L. (1974). Diagramas bioclimáticos. ICONA.

Morello, J., Metteucci S.D., Rodríguez, A.F. \& Silva, M.E. (2012). Ecorregiones y complejos ecosistémicos argentinos. FADU y GEPAMA. Buenos Aires. Orientación Gráfica Editora.

Ninahuaman Mucha, N. (2016). Investigación bioclimática del Perú, un aporte a la educación para mitigar los efectos del cambio climático. [Tesis de Magister, Universidad Autónoma de ICA]. Repositorio Institucional Universidad Autónoma de ICA. http://repositorio.autonomadeica.edu.pe/handle/autonomadeica/66

Peroné, D. \& Cannelli, N. (1987). Clasificación bioclimática de la región NEA. [Comunicación en congreso]. Actas de la 12a. reunión de trabajo de ASADES. Mendoza, Argentina.

Ponce, F. \& Rabassa, J. (2012). La plataforma submarina y la costa atlántica argentina durante los últimos 22.000 años. Ciencia Hoy, 127, 11-17. https://www.cienciahoy.org.ar/ch/In/hoy127/Plataformasubmarina.pdf

Rivas Martínez, S., Rivas Sáenz, S. \& Penas, A. (2011). Worldwide bioclimatic classification system. Global Geobotany, 1, 1-634.

Rodríguez Cravero, J., Grosi, M., Fuentes-Castillo, T. \& Gutiérrez, D.G. (2017). Cambio climático y modelado de distribución de especies de Stevia (Asteraceae) en el noroeste de la Argentina. Ecología Austral, 27, 462-473. https://doi. org/10.25260/EA.17.27.3.0.588

Rolla, A.L., Nuñeza, M., Guevarad, E., Meirad, S., Rodríguez, G. \& Ortiz de Zárate, M.I. (2018). Climate impacts on crop yields in Central Argentina. Adaptation strategies. Agricultural Systems, 160, 44-59. https://doi.org/10.1016/j. agsy.2017.08.007

Secretaría de Ambiente y Desarrollo Sustentable de la Nación. (2015). Tercera Comunicación Nacional el Gobierno de la República Argentina a las Partes de la Convención Marco de las Naciones Unidas sobre Cambio Climático. Secretaría de Ambiente y Desarrollo Sustentable de la Nación. https://unfccc.int/resource/docs/natc/argnc3s.pdf

Steffena, W., Rockströma J., Richardson K., Lentond T.M., Folkea, C. Diana Livermanf D., Summerhayesg C.P., Barnoskyh, A.D., Cornella S.E., Crucifixi, M. Dongesa, J.F., Fetzera, I., Ladea, S.J., Scheffer M., Winkelmannk, R. Schellnhubera, H.J. (2018). Trajectories of the Earth System in the Anthropocene. PNAS, 115(33), 8252-8259. https://doi.org/10.1073/ pnas. 1810141115

Teta P., Formoso A., Tammone M., Tommaso D. C. de, Fernández F. J., Torres J. \& Pardiñas U.F.J. (2014). Micromamíferos, cambio climático e impacto antrópico: ¿Cuánto han cambiado las comunidades del sur de América del Sur en los últimos 500 años?. Therya, 5 1, https://doi.org/10.12933/therya-14-183

Thornthwaite, C.W. \& Mather, J.R. (1955). The Water Balance. Climatology, 8, 1-104. https://doi.org/10.1017/ CB09781107339200.011

Tonni, E. (2006). Cambio climático en el holoceno tardío de la Argentina. Una síntesis con énfasis en los últimos 1000 años. Folia Histórica del Nordeste, 16, 187-195. https://doi.org/10.30972/fhn.0163429

Tuhkanen, S. (1980). Climatic parameters and indices in plant geography. Acta Phytogeographica Suecica, 67, 1-108. http://dx.doi.org/10.30972/fhn.0163429

Uribe, J.M., Cabrera, R., De la Fuente, A. \& Paneque, M. (2012). Atlas bioclimático de Chile. Santiago de Chile: Facultad de Ciencias Agronómicas. http://repositorio.uchile.cl/handle/2250/178567

Walter, H. (1997). Zonas de Vegetación y clima. Omega.

Ward, J.D., Mohr, S.H., Myers, B.R., Nel, W.P. (2012). High estimates of supply constrained emissions scenarios for longterm climate risk assessment. Energy Policy, 51, 598-604. https://doi.org/10.1016/j.enpol.2012.09.003

Zazulie, N., Rusticucci, M. \& Raga, G. (2017). Regional climate of the Subtropical Central Andes using high-resolution CMIP5 model. Climate Dynamics, 51, 2913-2925. https://doi.org/10.1007/s00382-017-3560-X

Zhang Y., Feng F., Zhang M., Ren H., Bai J., Guo Y., Jiang H., Kang L. (2016). Residual coal exploitation and its impact on sustainable development of the coal industry in China, Energy Policy, 96, 534-541. https://doi.org/10.1016/j. enpol.2016.06.033 


\title{
Transporte aéreo y pandemia de la COVID-19: ¿Hacia un cambio de trayectoria en la red aeroportuaria española?
}

\author{
Air transportation and the COVID-19 pandemic: Towards a change \\ of the path in the spanish airport network? \\ Roberto Díez-Pisonero \\ rdpisonero@ghis.ucm.es @ 0000-0002-7817-628X
}

Cándida Gago-García

cgago@ucm.es@0000-0003-2315-7943

Departamento de Geografía, Facultad de Geografía e Historia. Universidad Complutense de Madrid. C/ Profesor Aranguren s/n. Ciudad Universitaria. 28040 Madrid, España

\section{INFO ARTÍCULO}

\section{Recibido: $13 / 12 / 2021$}

Revisado: 13/01/2022

Aceptado: 19/01/2022

\section{PALABRAS CLAVE}

Transporte aéreo

COVID-19

Red aeroportuaria

Conectividad

España

\section{KEYWORDS}

Air transportation

COVID-19

Airports

Air connectivity

Spain

\begin{abstract}
RESUMEN
La COVID-19 ha supuesto un profundo shock en la economía global y en particular en la industria de la aviación, al ser esta damnificada de medidas restrictivas para frenar la propagación del virus. En este trabajo además de presentar, como contexto, el impacto de la COVID-19 a escala global en el sector comercial de la aviación, se realiza un análisis de la conectividad aérea de los aeropuertos españoles para comprender los cambios acaecidos. Para el estudio, de carácter diacrónico (1970-2020), se emplea un coeficiente de conectividad topológica, cartografía y otras medidas (análisis de frecuencias y volumen de viajeros). La pandemia está suponiendo un punto de inflexión en la historia aeronáutica que obliga a una adaptación constante en España y en el resto del mundo, tanto en términos comerciales como en materia de seguridad sanitaria.
\end{abstract}




\section{INTRODUCCIÓN}

El trabajo presenta un estudio de la evolución de la movilidad y la conectividad del transporte aéreo en España (doméstico e internacional) después de la primera ola de la pandemia por COVID-19 (primavera de 2020), momento en que, a partir de su declaración por parte de la OMS (Organización Mundial de la Salud), el Gobierno de España declaró el estado de alarma y con ello el confinamiento de la población. Este hecho no fue único, sino que se produjo generalizadamente en casi todos los países del mundo (salvo escasas excepciones), para evitar la propagación de la enfermedad. Pese a todas las restricciones la contención del virus no ha sido posible, siendo el transporte aéreo uno de los vectores fundamentales de su propagación (Sun et al., 2021a), aun cuando se dispuso de numerosas advertencias sobre la importancia de las restricciones en la movilidad en este medio de transporte (Ribeiro et al., 2020).

Todo lo ocurrido debe remitirse al hecho de que la movilidad es una de las características más relevantes de las sociedades contemporáneas. Esta desempeña un rol protagonista en el proceso de globalización, ya que las conexiones se acometen con tal velocidad que permiten la reducción de las distancias y el acercamiento de los territorios (Córdoba et al., 2007). En ello han contribuido ostensiblemente los modernos sistemas de transporte y, muy especialmente la aviación, sector estratégico que tiene un protagonismo decisivo en la actual sociedad globalizada (Graham, 2005).

El avión, elemento y vehículo de la actual civilización técnica, ha posibilitado la percepción de un espacio diferente al que otros medios de transporte superficial pueden ofrecer al permitir comparecer físicamente en un lugar en tiempos reducidos y a escalas muy diferentes (Córdoba et al., 2007). Los estudios sobre los impactos territoriales del transporte aéreo insisten en que a diferencia de las infraestructuras marítima o terrestre, el avión no necesita un contacto físico con la superficie de forma continuada por lo que los flujos y relaciones se desarrollan de manera más flexible y, por consiguiente, menos restrictiva (Cano, 1980), potenciando notoriamente la movilidad, la accesibilidad a lugares enclavados o aislados, los flujos y el intercambio, al superar las restricciones ocasionadas por las condiciones orográficas. Por tanto, puede adquirir un papel decisivo como instrumento de cohesión territorial (Hernández Luis, 2010).

Ello ha contribuido a una nueva percepción en que el ser humano se relaciona con el espacio, expresada en términos de "convergencia espacio-temporal" (Janelle, 1969), "plasticidad" (Relp, 1976; Forer, 1978) o "compresión espacio-temporal" (Harvey, 1983), entre otras denominaciones. Las distancias euclidianas son sustituidas por otras de carácter funcional, cuya percepción viene definida en términos de frecuencias, tiempos de desplazamiento y cantidad de pasajeros y mercancías (Gago, 2003; Díez-Pisonero, 2015). No obstante, ello no constituye un fenómeno generalizado. El paradigma de la movilidad, desarrollado desde las Ciencias Sociales, enfatiza el carácter asimétrico y la espacialidad diferencial que genera la movilidad en general (Larsen et al., 2006) y en particular, el transporte aéreo entre aquellos espacios e individuos intensamente comunicados y los que no lo están. Este paradigma, conocido con el anglicismo "mobility turn", fue propuesto en la década de 1990 por el sociólogo británico John Urry para enfatizar el papel y la importancia histórica y contemporánea de todos los tipos de movilidad (ideas, capitales, turistas, trabajadores, mercancías, servicios, etc.) sobre los individuos y la sociedad. Esta movilidad también puede entenderse en relación con las clases sociales, los ingresos o los flujos diferenciales entre territorios (Urry, 2020).

Según estos planteamientos, las disimilitudes entre lugares tienden a intensificarse, ya que un mundo de flujos hace que se incremente la competitividad, al tiempo que se produce simultáneamente una importante convergencia de los países ricos y nuevas polarizaciones (Cumings, 1999). Estas opiniones sostienen que los procesos de compresión espacio-temporal y de re-escalamiento ligados al transporte aéreo son básicamente elitistas (Stein, 2001), siendo manifestaciones de un desarrollo desigual y de relaciones de poder, dominación y subordinación en un mundo que se encoge, pero no de manera equitativa ni social ni territorialmente (Agnew, 2001; Knowles 2006). Fruto también del capitalismo, estos avances de la conectividad responden a las demandas de los procesos de producción (Cresswell, 2006), reflejando, así, cómo se construyen las cambiantes geografías de la accesibilidad en el tiempo, por ejemplo, en la formación y destrucción de los diferentes patrones de centralidad y perificidad que, inevitablemente, favorecen a algunos grupos y lugares más que a otros. Se trata de un debate abierto, pues incluso en la gestión de la epidemia 
global se observan los efectos diferenciales que imprimen las redes de transporte a los territorios (acceso a recursos, abastecimiento, movilidad, centralidad, accesibilidad, entre otros).

A pesar de que el transporte aéreo ha facilitado visiblemente la compresión del mundo, últimamente se ha puesto de relieve que también, como vector de la globalización, ha contribuido a la propagación de enfermedades, virus y pandemias, como la de la COVID-19. Esta ha supuesto un profundo varapalo en la economía global. Por ejemplo, en 2020 el PIB mundial decreció como media un -3,4\%, e incluso un punto porcentual más en los países de la $\operatorname{OECD}(-4,7 \%)$, con un aumento de la tasa de desempleo hasta el $7,1 \%$ del total de la fuerza laboral del planeta, frente al 6,5\% de media en el periodo de 2013 a 2019 (OECD, 2021).

La propagación de la enfermedad infecciosa provocada por el virus SRAS-CoV-2 no es un caso aislado, pues se dispone de ejemplos anteriores a la actual pandemia, que advertían de esa posibilidad, por ejemplo con el caso de la pandemia de gripe originada en México (gripe A- H1N1) entre 2009-2010 (Omic \& Van Mieghem, 2010). No obstante, la gravedad de la enfermedad (defunciones y secuelas en los pacientes) ${ }^{1}$ ha desencadenado una reflexión rápida, intensa y prolífica, en los organismos multilaterales (ej. OMS), en los gobiernos, en el mundo académico y de la investigación y también en la opinión pública, sobre los mecanismos por los cuales se ha transmitido tan raudamente por el planeta. Sirva como ejemplo de este interés que un rastreo en el buscador de trabajos académicos Google Scholar realizada con la palabra "COVID-19" ha devuelto a los autores que firman este artículo más de 4.400 .000 resultados (búsqueda realizada el 15 de noviembre de 2021).

En este trabajo se utilizarán indicadores de conectividad de la red de transporte aéreo, lo que permitirá, en primer lugar, conocer el impacto de la pandemia en el sector de la aviación comercial a escala global, a raíz de datos y estadísticas oficiales de los principales organismos de la industria aeronáutica y, en segundo lugar, realizar un análisis de la conectividad aérea de los aeropuertos españoles. Esto último posibilitará comprender y visualizar los cambios acaecidos en la red aeroportuaria española, mostrando y evaluando el impacto de la pandemia (2019-2020). La lógica que hay detrás de este análisis es detectar qué trayectorias, en un periodo amplio (1970-2015), han sido truncadas por la pandemia y también qué conexiones aéreas han resistido la crisis, indicador de la robustez de los vínculos territoriales entre pares de ciudades conectadas.

Para ello, se analizará diacrónicamente el grado de vertebración nacional entre los sistemas urbanos (conectividad nacional) y la evolución de la participación de los aeropuertos españoles en el escenario internacional (conectividad externa) en los dos tramos temporales identificados, a través del estudio de la conectividad, fundamentalmente por medio de un coeficiente de conectividad topológica. El trabajo se cierra con las conclusiones de la investigación.

\section{LA COVID-19 Y EL TRANSPORTE AÉREO. ESTADO DE LA CUESTIÓN}

La magnitud del crecimiento del sistema de transporte aéreo ( $n^{\circ}$ de operaciones y volumen de pasajeros transportados) desde la década de 1970 es visible a cualquier escala de análisis. Deteniéndose en la escala mundo (figura 1), se observa una evolución positiva y constante durante las últimas décadas en el tráfico de pasajeros, salvo momentos de retroceso coyuntural, ligado a crisis económicas o bélicas que ocasionaban un encarecimiento del combustible y/o el temor a los desplazamientos (Oprea, 2010; Dobruszkes \& Van Hamme, 2011; Chi \& Baek, 2013). Esto es ejemplo de las indiscutibles relaciones entre transporte aéreo y actividad económica (Ishutkina \& Hansman, 2008) y también, de forma muy acusada, con la actividad turística (Sorupia, 2005).

Hasta 2020 el principal evento que hizo tambalear el sector aéreo en la escala global fueron los atentados terroristas del 11S en Nueva York (figura 1). Ello impactó sobre las frecuencias y el volumen de pasajeros de forma muy rápida (Inglada \& Rey, 2004; Ito \& Lee, 2005). No obstante, la magnitud del shock en el sector de

1 En la fecha de revisión de este artículo, 11-12-2021, en el mundo se habían contagiado 270 millones de personas con el virus de la COVID-19. Esta infección había causado hasta ese momento 5.300.000 defunciones. Fuente: COVID-19 Dashboard by the Center for Systems Science and Engineering (CSSE) at Johns Hopkins University (JHU). Obtenido de: https://coronavirus.jhu.edu/map.html 
la actual crisis sanitaria, motivada por la pandemia de la COVID-19, ha llevado a muchos expertos a calificarla como la peor de toda la historia de la aviación comercial: si la predicción del tráfico mundial para 2020, antes de la declaración de la pandemia por la OMS en marzo de ese mismo año, era de 9.400 millones de pasajeros, la cifra se ha visto mermada hasta los 3.800 millones $\left(\mathrm{OACI}^{2}, 2020\right)$. Esta crisis es incluso peor que el escenario generado tras los citados ataques terroristas del 11-S, cuando el sector aéreo tardó cerca de una década en recuperarse por completo (Wyman, 2020).

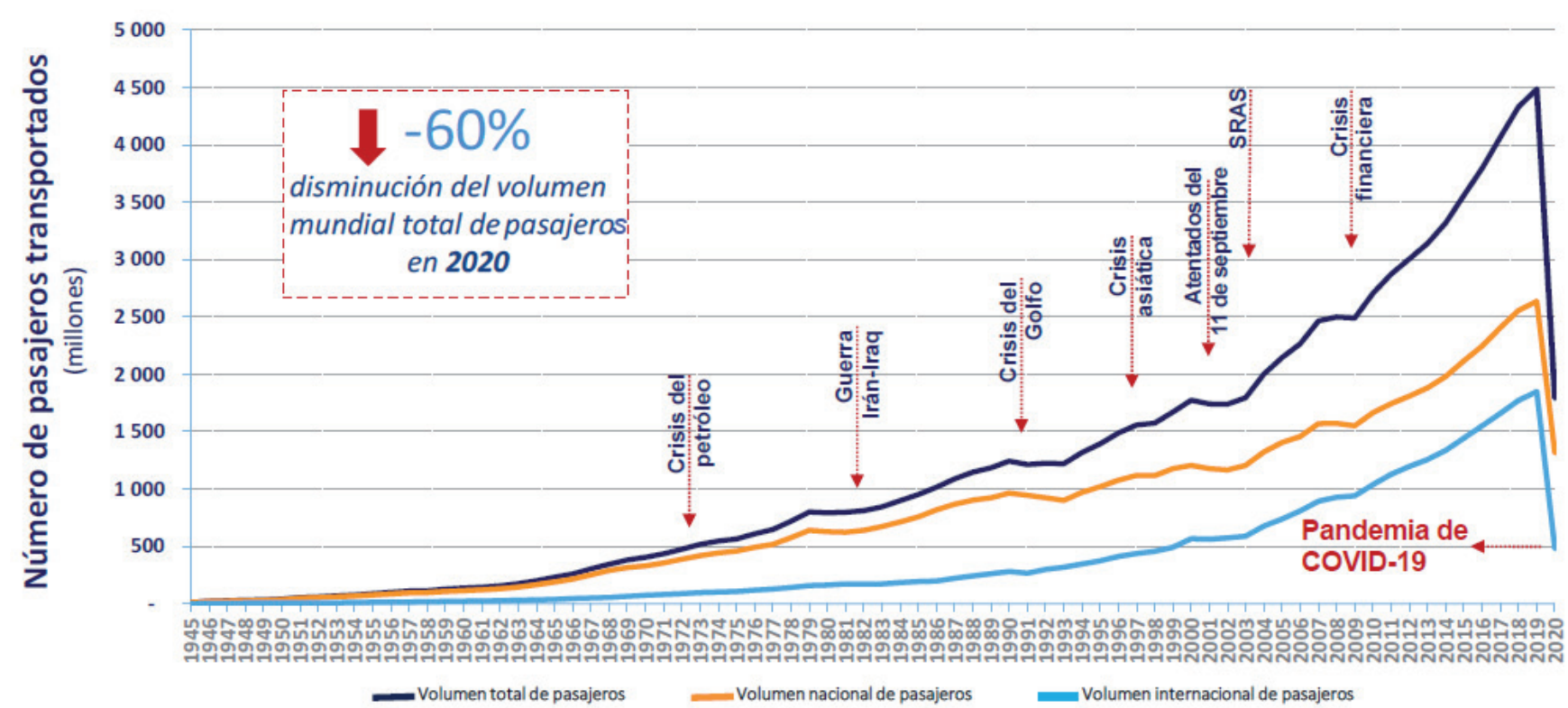

Figura 1. Impacto de la pandemia de la COVID-19 en la evolución del número de pasajeros aéreos. Fuente: OACI (2021c).

El brote del coronavirus en Wuhan (China) y su rápida expansión al resto del mundo obligó a muchos países a poner en marcha medidas restrictivas y de contención para frenar la propagación del virus, lo que ha asestado un golpe muy violento a toda la industria aérea. En pocos días, casi todos los vuelos fueron cancelados, los aeropuertos cerrados, la flota mundial en tierra y miles de empleados despedidos, tal como se demuestra en las siguientes líneas y en la figura 1. El confinamiento y el cierre de las fronteras decretados casi simultáneamente por los gobiernos de todo el mundo derivó en una reducción de más del 85\% del transporte aéreo mundial (IATA, 2020), con repercusiones en todos los sectores vinculados a la actividad. Según la OACI (2020), este impacto se constata así:

- En el tráfico aéreo de pasajeros: reducción general de pasajeros (tanto internacionales como nacionales) que oscila entre el 59\% y el 60\% en 2020, en comparación con 2019 (OACI, 2020).

- En la actividad de los aeropuertos: pérdida estimada de aproximadamente el 64,2\% del tráfico de pasajeros y el $65 \%$ (más de 111,8 mil millones de USD) en ingresos aeroportuarios en 2020, en comparación con los negocios habituales (según la ACI). En ello se incluyen las pérdidas económicas en las infraestructuras, por la ausencia de facturación en los slots, en las actividades de despegue y aterrizaje y también por la caída en la demanda de los servicios auxiliares en las zonas comerciales (restaurantes, cafeterías y tiendas de duty free). Por ejemplo, AENA ${ }^{3}$ registró pérdidas de alrededor

2 OACI: acrónimo de Organización de Aviación Civil Internacional. Organismo dependiente de Naciones Unidas, creado en 1944. Constituye un foro para los Estados en relación con el funcionamiento de la aviación civil, desarrollando políticas y normas, realizando auditorías de cumplimiento, estudios y análisis. También brinda asistencia técnica y coordina la capacidad técnica y operativa de la aviación comercial en la escala mundo. Sus siglas en inglés son ICAO (International Civil Aviation Organization).

3 AENA: Aeropuertos Españoles y Navegación Aérea. Empresa pública encargada de la gestión de la red de aeropuertos y helipuertos de interés general del Estado de España. 
de 346,4 millones de euros durante el primer semestre del año 2021 (el doble de los 170,7 millones en "números rojos" que reportó durante el mismo periodo del año anterior) por el desplome de sus ingresos, provocado con las restricciones a la movilidad por la pandemia (Muñoz, 2021).

- En la economía de las aerolíneas: disminución del 66,3\% en los ingresos por pasajeros por kilómetros (RPK, tanto internacionales como nacionales) en 2020, en comparación con 2019 (según la IATA).

- En la actividad turística en general: disminución en los ingresos por turismo internacional de entre 910 y 1.170 mil millones de USD en 2020, en comparación con los 1,5 miles de millones de USD generados en 2019, con el 100\% de los destinos en todo el mundo con restricciones de viaje (según la UNWTO).

- En el comercio mundial: caída del volumen del comercio mundial de mercancías en un 9,2\% en 2020, en comparación con 2019 (según la WTO-OMC). Ello se ve también reflejado en el tráfico aéreo de mercancías, principalmente debido a la reducción de los vuelos comerciales, que las transportaban en las bodegas de las aeronaves. Consecuentemente, la capacidad de carga aérea en la "primera pulsión" de la pandemia cayó aproximadamente en un $80 \%$, precisamente cuando a escala global era más necesaria la ayuda de emergencia y las dotaciones de material sanitario. No obstante, el segmento de carga se ha recuperado rápidamente y a finales de 2020 el número de vuelos de carga operados a nivel mundial se había expandido en un 2,74\%, con respecto a 2019 (OACI, 2021 b).

La caída del tráfico aéreo empezó a hacerse evidente a mediados del mes de marzo de 2020, cuando los cierres de fronteras y confinamientos comenzaron a generalizarse en Europa y América. Este impacto se materializó en todos los aeropuertos del mundo, con especial hincapié en algunos de los principales hubs, que experimentaron una paralización en la evolución de los pasajeros aéreos durante los meses más duros del confinamiento (figura 2).

Con el objetivo de minimizar los impactos en el número de pasajeros aéreos, en el empleo y en las economías de todo el mundo, la IATA 4 instó a los gobiernos a coordinarse para levantar las restricciones fronterizas y encontrar alternativas a las medidas de cuarentena. Será a partir de julio de 2020 cuando, paulatinamente, el sector del transporte aéreo empezaría a reanudar su actividad con la reapertura de las fronteras, con un incremento muy rápido sobre todo en los subsistemas domésticos (Sun et al., 2021b); no obstante, todavía a finales del año 2021, el tráfico aéreo seguía siendo relativamente bajo, por debajo de los niveles previos (OACI, 2021a). También es posible encontrar impactos y trayectorias de recuperación del sector diversas debido a estrategias muy heterogéneas en la gestión de las restricciones de la movilidad. Por ejemplo, desde una "perspectiva epidemiológica la estrategia desarrollada en China, basada en prohibiciones extremas de viaje y requisitos de cuarentena, podría considerarse la mejor. Desde la perspectiva económica, de garantía de la movilidad y de viabilidad del sector, el enfoque desarrollado en Estados Unidos, basado en permitir un alto grado de tráfico aéreo nacional a pesar de la creciente presión de la pandemia, es el óptimo; mientras que en Europa se optó por una estrategia intermedia" (Sun et al., 2021b, p. 10). Ello generó también impactos diferenciales en estas tres grandes regiones de conectividad, con un profundo pero muy corto impacto en China y mucho más prolongado y heterogéneo en el caso de los países europeos.

Descendiendo escalarmente, se evidencia que todas las regiones del mundo han experimentado una caída generalizada de los asientos ofrecidos por las compañías, de los pasajeros y de los ingresos operativos brutos de las aerolíneas (figura 3). Como ya se ha señalado, en términos generales, el impacto ha sido mayor en los mercados internacionales que en los domésticos, que fueron el refugio de muchas empresas para mantener un cierto nivel de actividad. Es importante destacar que, en muchos casos, las aerolíneas de bajo coste fueron más resilientes y no empezaron a reducir su oferta de vuelos hasta la primera mitad de marzo, al estar menos expuestas al tráfico internacional y al transcontinental que las aerolíneas de red (que operan una flota amplia y diversa) (Atlas Magazine, 2020).

4 IATA: International Air Transport Association. Asociación comercial de las aerolíneas en el mundo, representando a unas 290 aerolíneas o el $83 \%$ del tráfico aéreo total. Apoya a distintas áreas de la actividad de la aviación y propone políticas para la industria del sector. Fuente IATA, obtenido de: https://www.iata.org/en/about/ 
Roberto Díez-Pisonero \& Cándida Gago-García / REA N. 43 (2022) 159-187
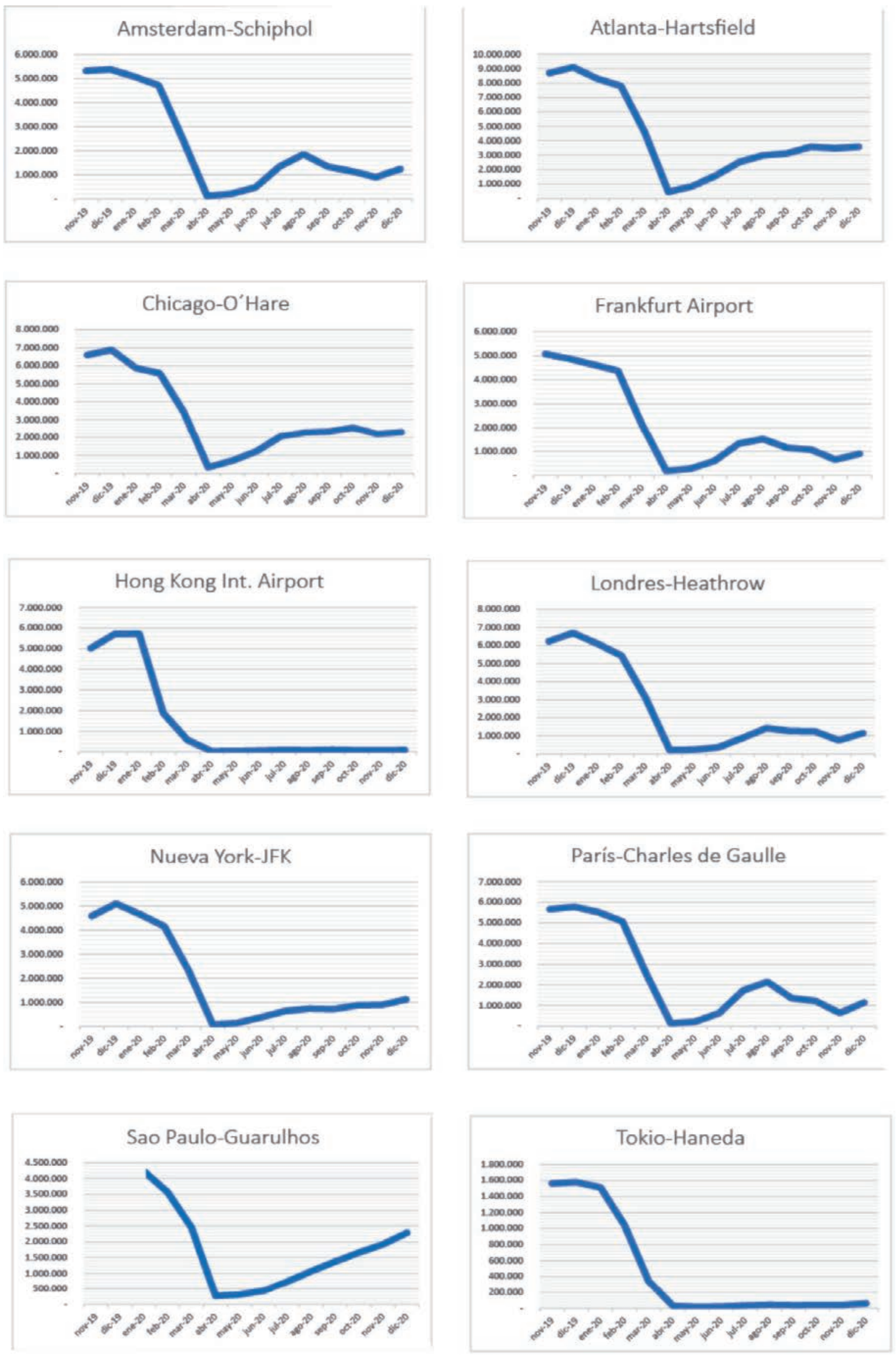

Figura 2. Impacto de la pandemia de la COVID-19 en la evolución del número de pasajeros aéreos (selección de hubs aéreos mundiales; nov/2019-dic/2020). Fuente: Elaboración propia a partir de las páginas web de los respectivos aeropuertos.

(C) Editorial Universidad de Sevilla 2022 | Sevilla, España| CC BY-NC-ND 4.0 | e-ISSN: 2340-2776 | doi: https://dx.doi.org/10.12795/rea.2022.i43.09 


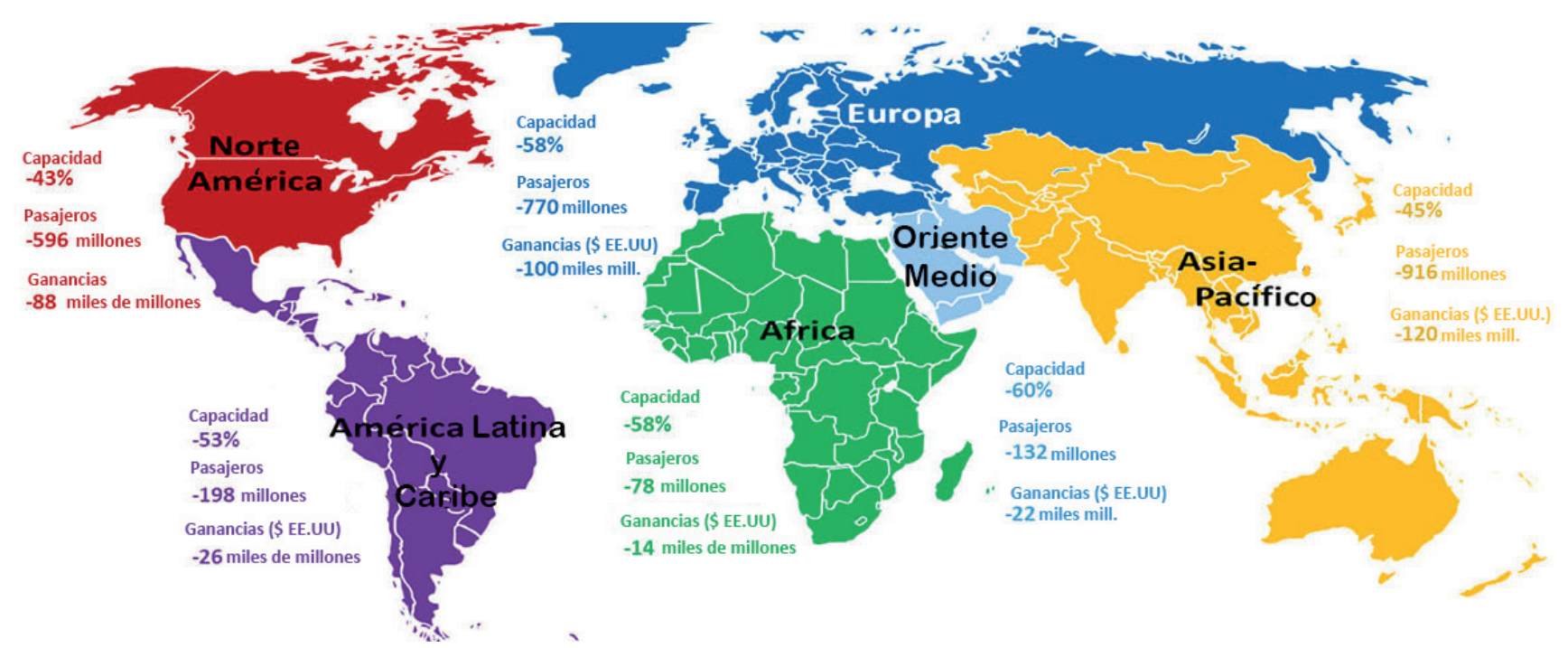

Figura 3. Impacto estimado en el tráfico de pasajeros internacionales e ingresos por grandes regiones mundiales para 2020. Fuente: OACI (2020). Traducción al castellano.

Resulta evidente que la pandemia ha ocasionado una paralización de gran parte de la flota de los operadores a nivel mundial, con el consiguiente cierre de rutas y mercados, que ha supuesto un impacto negativo para los resultados económicos y financieros de todas las compañías aéreas. Aunque algunas de ellas ya se encontraban en una situación desesperada antes del brote de la COVID-19, estas se han visto gravemente afectadas por la crisis sanitaria. Especialmente, durante los meses más duros del confinamiento, se vieron obligadas a tomar medidas drásticas y cancelar numerosas operaciones, reducir las frecuencias de muchas rutas o limitar los aeropuertos de llegada de sus vuelos procedentes del extranjero, todo ello de acuerdo con las restricciones adoptadas. Como resultado, muchas compañías aéreas se declararon en quiebra, como Virgin Australia, Latam, Aeroméxico o Flybe, entre otras. Otras deben su supervivencia únicamente a la intervención de sus respectivos gobiernos estatales a través de rescates económicos, como Alitalia, Air France, KLM-Royal Dutch Airlines o Lufthansa (Atlas Magazine, 2020).

Como se puede observar, la pandemia ha supuesto un profundo varapalo en la economía global, en general, y en la industria de la aviación, en particular. Según los diferentes estudios mensuales que la IATA ha estado publicando en su web durante el transcurso de la pandemia y de acuerdo a las estimaciones, se confirma que el posible impacto de la COVID-19 en la industria aérea será muy elevado, aunque las repercusiones reales dependerán de la duración y la magnitud del brote, de las medidas de contención, del grado de confianza del consumidor en los viajes aéreos, de las condiciones económicas y de la marcha del proceso de vacunación, entre otros factores. Es, por ello, que las autoridades advierten que el regreso a la normalidad no está en la agenda para el futuro inmediato, pues se prevé que la industria no vuelva a los niveles de actividad de 2019 hasta el año 2024 (IATA, 2020).

\section{METODOLOGÍA}

Para evaluar la conectividad aeroportuaria española (doméstica e internacional) y, por consiguiente, analizar el grado de vertebración nacional entre los sistemas urbanos (conectividad doméstica) y la evolución de la participación de muchos de los aeropuertos españoles en el escenario global durante la pandemia (conectividad internacional), se ha realizado un análisis diacrónico, con una "fotografía" de los años 1970, 2015, 2019 y 2020. La lógica es identificar los patrones de evolución de la red (antes de la pandemia, en una trayectoria amplia, 1970-2015) y ver qué dinámicas han sido las más afectadas comparando la situación entre las diferentes fechas. 
Es necesario señalar que la investigación debe ajustarse a la disponibilidad de datos del equipo. El tratamiento estadístico de las diferentes variables (conexiones y frecuencias) se ha llevado a cabo para los años 1970, 2015, 2019 y 2020. Las dos primeras fechas (1970-2015), con 45 años de diferencia, ofrecen un margen de tiempo adecuado para comprender y visualizar las trayectorias acaecidas en la red aeroportuaria española. Estas deben ponerse esencialmente en relación con la restructuración del sector, con especial énfasis en las consecuencias derivadas del proceso de liberalización y en el incremento del turismo internacional (Díez-Pisonero, 2016). La consideración en el análisis del último periodo, años de 2019 a 2020, tiene por objetivo mostrar y evaluar la situación inmediatamente prepandémica y el impacto de la pandemia.

Se han empleado para el análisis datos de conexiones y frecuencias entre pares de ciudades, tanto de tráfico doméstico como internacional, extraídas a partir de las conocidas en el sector como Guías ABC. En 1970, en formato papel "ABC World Airways Guide, October 1970" y, en 2015, 2019 y 2020, en formato digital "Base de datos de Comber International Guides -OAG". Los datos están referidos en todo caso a los meses del final de verano (agosto y septiembre).

Estos se han sometido a un tratamiento estadístico, utilizando para el análisis el cálculo de un coeficiente de conectividad topológica (Córdoba \& Gago, 2010). Para la interpretación también se han utilizado, cuando así la lógica lo recomienda, datos sobre frecuencias aéreas entre pares de ciudades, procedentes de las fuentes anteriormente citadas.

El coeficiente de Conectividad (CC) es una medida topológica que evalúa la conectividad real de un nodo (los arcos que unen ese nodo con otros) en relación con su conectividad potencial (el número total de arcos susceptibles de relacionar el nodo con los demás del sistema, es decir, todos menos él mismo). El significado de esta medida de conectividad, debe ponerse en relación con el vínculo que se establece entre dos ciudades más allá de una frecuencia de vuelo muy alta. Así, para una ciudad escasamente conectada y su hinterland o área de influencia aeroportuaria (el territorio al que sirve), el aumento de las conexiones con otros nodos incrementa la centralidad topológica, favoreciendo el desenclave. Ocurre así, en el transporte aéreo, especialmente en el de carácter doméstico, que muchas veces una línea no resulta especialmente rentable para las compañías comerciales, pero aun así se conserva en relación con criterios de servicio público. En ello juegan un papel fundamental las subvenciones públicas (de carácter estatal o regional, aunque muy limitadas en Europa debido a la desregulación del sector), pero también la limitación de la frecuencia (que puede ser no muy alta, con ello concentrando la demanda en uno o dos días, semanalmente) o la organización operativa interna de los diferentes planes de vuelo de las aeronaves a lo largo de la semana.

La expresión matemática del coeficiente de conectividad se muestra en la figura 4:

$$
\mathrm{CC}_{\mathrm{V}_{\mathrm{i}}}=\frac{\sum_{\mathrm{i}=1}^{\mathrm{N}_{\mathrm{j}}-1} \mathrm{a}_{\mathrm{i}}}{\mathrm{N}_{\mathrm{j}}} \cdot 100 \quad \text { para } \quad \mathbf{a}_{\mathrm{i}}=\left[\begin{array}{l}
1 \text { if } \operatorname{gbranch}\left(\mathrm{V}_{\mathrm{i}}, \mathrm{V}_{\mathrm{j}}\right) \\
0 \text { if } \not \text { bbranch }\left(\mathrm{V}_{\mathrm{i}}, \mathrm{V}_{\mathrm{j}}\right)
\end{array}\right.
$$

donde:

$\mathrm{CC}=$ Coeficiente de Conectividad

$\mathrm{v}_{\mathrm{i}}=$ nodo $i$

$a_{\mathrm{i}}=$ relaciones (arcos) del nodo $i$

$\mathrm{N}_{\mathrm{j}}=$ todos los nodos del sistema

$100=$ multiplicador para obtener datos en tantos por cien

Figura 4. Fórmula del coeficiente de conectividad. Fuente: Córdoba \& Gago (2010).

Para analizar la evolución de la red de transporte aéreo doméstica y siguiendo estas indicaciones, se obtiene el coeficiente de conectividad teórico de cada aeropuerto (considerando todos los aeropuertos de 
la red española). Sin embargo, para obtener unos resultados más exhaustivos conviene establecer unas restricciones para cada una de las infraestructuras aeroportuarias. En concreto, estas limitaciones consisten en:

Por un lado, para la obtención de los resultados se ha decidido descartar una serie de infraestructuras por las siguientes razones:

- En 1970 no se han considerado un total de diez aeropuertos de la red general: Jerez, Vitoria, Badajoz, Murcia (Alcantarilla), Madrid-Cuatro Vientos, Granada, León y Sabadell. Se trata de infraestructuras que registraron un volumen de pasajeros muy reducido y, además, únicamente de tráfico no regular-nacional. Los aeropuertos de Castellón y Lleida no estaban todavía construidos.

- Para el año 2015 se han descartado nueve infraestructuras por diferentes razones: en primer lugar, Huesca-Pirineos, Madrid-Torrejón, Madrid-Cuatro Vientos, Sabadell y Son Bonet (tráfico no comercial), Ciudad Real y Castellón (iniciativa privada), Córdoba y Ceuta (por ausencia o escasez de datos homologables para el análisis, aparte de presentar un escaso volumen de pasajeros).

- Para los años de 2019 y 2020 se han obviado en el análisis: Huesca-Pirineos, Madrid-Torrejón, Madrid-Cuatro Vientos, Sabadell, Son-Bonet, (por escaso volumen de pasajeros), Burgos, Córdoba, León, Lleida, Logroño, Salamanca, Ceuta (por ausencia de datos homologables para el análisis); Ciudad Real y Castellón (iniciativa privada).

Por otro lado, las restricciones en la inclusión de nodos para el caso del análisis de la conectividad doméstica derivan, también, de la distancia o cercanía entre aeropuertos. Como sabemos, el transporte aéreo requiere una distancia mínima para garantizar su efectividad, ya que los aeropuertos también compiten en la atracción de la demanda en un área amplia. Se considera que la distancia de 250 kilómetros es idónea para determinar una baja competencia en la atracción de la demanda entre aeropuertos cercanos (Díez-Pisonero, 2016). De esta manera, además de restar el propio aeropuerto estudiado del número total de nodos, se procederá a excluir a todos aquellos que se encuentren en un radio de acción inferior a esa distancia. Así, se obtiene el coeficiente de conectividad ajustado (CCA), más certero, que permitirá aproximar en mayor medida a la realidad aérea española y, por consiguiente, el valor real del grado de cohesión de la red en su conjunto.

La metodología también incluye el cálculo de coeficientes de conectividad internacional de los aeropuertos españoles (total de conexiones del aeropuerto respecto al total de conexiones internacionales desde España). Se ha recurrido también a las estadísticas sobre el volumen de viajeros domésticos e internacionales. Las fuentes han sido las estadísticas de AENA y del Ministerio de Transportes, Movilidad y Agenda urbana. Por último, el análisis se apoya en cartografía temática sobre conexiones aéreas nacionales y volumen de pasajeros (nacionales e internacionales), para la mejor interpretación de los resultados. También es necesario señalar algunas especificidades temáticas del análisis. Este se refiere al estudio de la aviación comercial de pasajeros. No aborda el tráfico de mercancías y el sector logístico que ya se ha indicado que no sufrió los impactos de manera tan descarnada 5 .

\section{TRAYECTORIA DE LA RED AEROPORTUARIA ESPAÑOLA (1970-2015)}

La primera fase del estudio pretende valorar las dinámicas de largo plazo de la red de transporte aéreo en España. En primer lugar, se puede corroborar cómo en estos 45 años el grado de cohesión del sistema ha evolucionado favorablemente, tanto en el ámbito nacional como internacional. En el primer caso, el grado de cohesión ha pasado del $18,17 \%$ al 24,09\%, mientras que para la conexión del sistema internacionalmente los registros han incrementado del 4,98\% al 11,23\% (tabla 1; figuras 5 y 6 ). Es decir, en ambos casos, el número de enlaces aéreos ha aumentado de manera considerable.

5 Durante la pandemia, el papel de la industria de carga aérea ha sido crítico, manteniendo abiertas las cadenas internacionales de suministro. Para muchas aerolíneas, la carga se convirtió en una fuente vital de ingresos cuando los vuelos de pasajeros estaban en tierra. En 2020, la industria de carga aérea generó 129 mil millones de USD, lo que representó aproximadamente un tercio de los ingresos totales de las aerolíneas y un aumento del 10-15\% en comparación con los niveles anteriores a la crisis (IATA, 2021). 
Tabla 1. Grado de cohesión de la red aeroportuaria española (1970-2015).

\begin{tabular}{|c|c|c|c|}
\hline \multicolumn{2}{|c|}{1970} & & 2015 \\
\hline $\begin{array}{c}\text { CC nacional } \\
(\mathrm{N}=31)\end{array}$ & CC internacional $(\mathrm{N}=44)$ & $\begin{array}{c}\text { CC nacional } \\
(\mathrm{N}=39)\end{array}$ & CC internacional $(\mathrm{N}=266)$ \\
\hline $18,17 \%$ & $4,98 \%$ & $24,09 \%$ & $11,23 \%$ \\
\hline
\end{tabular}

Fuente: Resultados de la investigación a partir de las Guías ABC-Comber International Guides -OAG.

Aunque son varios los factores que intervienen en esta evolución positiva, uno de los determinantes ha sido el proceso de liberalización experimentado por el sector de la aviación a finales del siglo pasado. El sector aeronáutico español, previo a dicho proceso, estaba muy regulado y protegido (Antón \& Córdoba, 1999) y el Grupo Iberia ejercía prácticamente de monopolio. Pero, tras los paquetes de medidas liberalizadoras de 1989, 1990 y 1992, inducidos en buena medida por la política de cielos abiertos de la Unión Europea (Gago, 2003), el transporte de pasajeros en España experimentó una gran revolución, con la creación de un verdadero mercado regional en el espacio de la Unión Europea. Ello ha supuesto libertad de entrada y salida y libre establecimiento de rutas, frecuencias, capacidades y precios por parte de las compañías aéreas, registradas y certificadas en cualquier estado miembro (Serrano, 1999).

Asimismo, cabe mencionar otros factores para el caso de España que justifican esta evolución favorable como la entrada en la todavía entonces Comunidad Económica Europea, la internacionalización de la economía en el contexto europeo y mundial, la creciente atracción turística, el afianzamiento como puente de conexión con los países iberoamericanos y el crecimiento del nivel de vida de la población, entre otras razones.

Respecto al tráfico nacional, en 1970 diez aeropuertos registraban un CCA superior a la media nacional $(18,4 \%)$. Se trataba de aquellas infraestructuras pertenecientes a las grandes ciudades del país (Madrid, Barcelona, Sevilla, Valencia), destinos turísticos de primera magnitud (Las Palmas de Gran Canaria, Tenerife, Palma de Mallorca, Málaga, Lanzarote) y ciudades como Santiago que servía a su área urbana-regional, en el noroeste del país (tabla 2). La conjunción de estos tres hechos, deben interpretarse como factores suficientes para la consecución de una densa red de enlaces aéreos, lo que justificaría su destacada conectividad, sobre todo, de Madrid y Barcelona al conectarse estas dos con la mayor parte de los aeropuertos españoles (figura 5).

Por debajo del citado umbral, pero no muy alejado de él (entre el $10 \%$ y 18\%; tabla 3), se encuentran ciudades importantes en sus contextos regionales (Oviedo, Santander, Bilbao, A Coruña); destinos turísticos de gran predominio de la modalidad chárter (Alicante, Ibiza, Murcia-San Javier) y centros regionales como San Sebastián y Almería, en el norte y sur, respectivamente. Destaca también el caso singular de El Aaiún, todavía formando parte de la red nacional, hasta la Marcha Verde de 1975. Lejos de estos, el resto de nodos están bastante distanciados de la media nacional, al registrar tan sólo uno o dos enlaces aéreos nacionales (casi siempre con Madrid y/o Barcelona).

En 2015 la situación ha cambiado de manera notoria. Aparte de superar los 175 millones de pasajeros anuales (domésticos e internacionales; AENA, 2015), la organización de la red mostraba altos signos de madurez, pues tanto el grado de cohesión del sistema como el número de aeropuertos que se encontraban por encima de la conectividad media del sistema aumentan (tabla 4; figura 6). El proceso de liberalización del sector, la aparición de nuevas compañías, entre ellas las aerolíneas low cost, y la mayor competitividad aérea, bien pueden justificar este profundo cambio. En 2015, son quince los aeropuertos que gozan de un CCA por encima de la media (24,09\%). Además de los que ya figuraban en 1970, aparecen Bilbao, Asturias y Santander, que escalan posiciones al incrementar su número de enlaces con el resto de ciudades españolas. Junto a estos, Alicante, Ibiza y Menorca como importantes destinos turísticos ${ }^{6}$.

6 En 1970 tan sólo existía en Tenerife el aeropuerto de Los Rodeos (hoy conocido como Tenerife Norte). Sin embargo, las demandas del sector turístico y la saturación del anterior provocaron que en 1978 se inaugurara el aeropuerto Reina Sofía (hoy Tenerife Sur), consolidándose como el aeropuerto tinerfeño de mayor importancia internacional. 


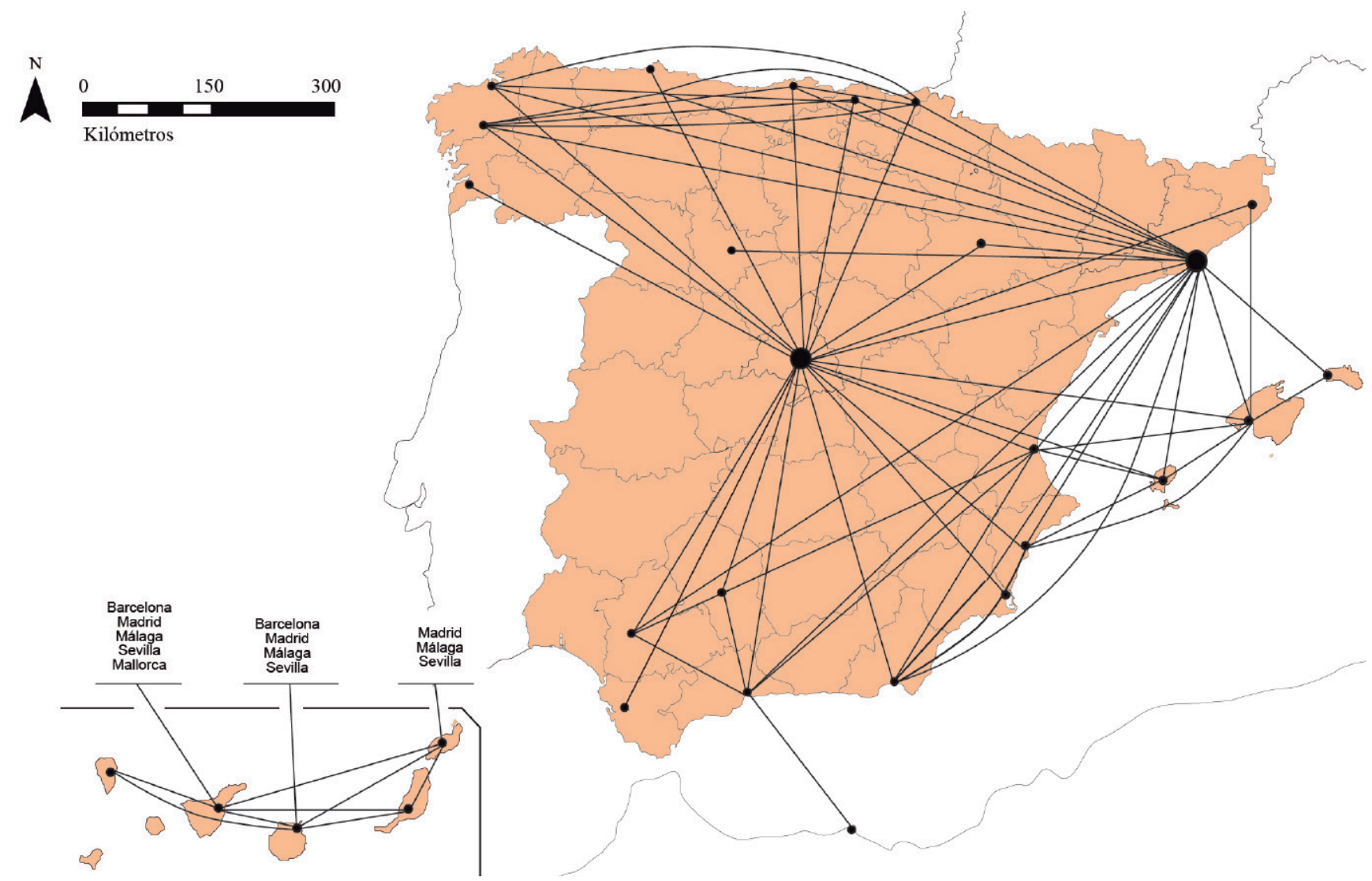

Figura 5. Red de conexiones aéreas domésticas en España, 1970. Fuente: Elaboración propia a partir de las Guías ABC-Comber International Guides -OAG.

Tabla 2. Aeropuertos con CCA nacional superior a la media del país (1970).

\begin{tabular}{|c|c|c|c|c|}
\hline \multirow{2}{*}{ Aeropuerto } & \multirow{2}{*}{$\mathrm{N}^{\circ}$ conexiones } & \multicolumn{3}{|c|}{ Coeficiente de Conectividad Ajustado (CCA) } \\
\hline & & $\mathrm{N}$ & $\mathrm{N}-1$ & CCA \\
\hline Madrid & 23 & 30 & 29 & 79,31 \\
\hline Barcelona & 20 & 29 & 28 & 71,43 \\
\hline Málaga & 10 & 28 & 27 & 37,04 \\
\hline Gran Canaria & 11 & 31 & 30 & 36,67 \\
\hline Sevilla & 8 & 29 & 28 & 28,57 \\
\hline Palma de Mallorca & 8 & 31 & 30 & 26,67 \\
\hline Tenerife & 8 & 31 & 30 & 26,67 \\
\hline Valencia & 7 & 29 & 28 & 25,00 \\
\hline Santiago & 6 & 29 & 28 & 21,43 \\
\hline Lanzarote & 6 & 31 & 30 & 20,00 \\
\hline
\end{tabular}

Fuente: Resultados de la investigación a partir de las Guías ABC-Comber International Guides -OAG. 
Tabla 3. Aeropuertos con CCA nacional entre 10 y 18\% (1970).

\begin{tabular}{|c|c|c|c|c|}
\hline \multirow{2}{*}{ Aeropuerto } & \multirow{2}{*}{$\mathrm{N}^{\circ}$ conexiones } & \multicolumn{3}{|c|}{ Coeficiente de Conectividad Ajustado (CCA) } \\
\hline & & $\mathrm{N}$ & $\mathrm{N}-1$ & CCA \\
\hline Alicante & 5 & 29 & 28 & 17,86 \\
\hline Almería & 5 & 29 & 28 & 17,86 \\
\hline San Sebastián & 5 & 29 & 28 & 17,86 \\
\hline Asturias & 5 & 30 & 29 & 17,24 \\
\hline Ibiza & 5 & 31 & 30 & 16,67 \\
\hline El Aaiún & 5 & 32 & 31 & 16,13 \\
\hline Santander & 4 & 28 & 27 & 14,81 \\
\hline A Coruña & 4 & 29 & 28 & 14,29 \\
\hline Bilbao & 4 & 30 & 29 & 13,79 \\
\hline Murcia & 3 & 28 & 27 & 11,11 \\
\hline
\end{tabular}

Fuente: Resultados de la investigación a partir de las Guías ABC-Comber International Guides -OAG.

Tabla 4. Aeropuertos con CCA nacional superior a la media del país (2015).

\begin{tabular}{|c|c|c|c|c|}
\hline \multirow{2}{*}{ Aeropuerto } & \multirow{2}{*}{$\mathrm{N}^{\circ}$ conexiones } & \multicolumn{3}{|c|}{ Coeficiente de Conectividad Ajustado (CCA) } \\
\hline & & $\mathrm{N}$ & $\mathrm{N}-1$ & CCA \\
\hline Madrid & 28 & 38 & 37 & 75,68 \\
\hline Barcelona & 27 & 37 & 36 & 75,00 \\
\hline Palma de Mallorca & 23 & 39 & 38 & 60,53 \\
\hline $\begin{array}{l}\text { Tenerife ( } 2 \\
\text { aeropuertos) }\end{array}$ & 20 & 39 & 38 & 52,63 \\
\hline Málaga & 17 & 36 & 35 & 48,57 \\
\hline Bilbao & 17 & 38 & 37 & 45,95 \\
\hline Gran Canaria & 16 & 39 & 38 & 42,11 \\
\hline Alicante & 15 & 37 & 36 & 41,67 \\
\hline Sevilla & 15 & 37 & 36 & 41,67 \\
\hline Ibiza & 15 & 39 & 38 & 39,47 \\
\hline Santiago & 14 & 37 & 36 & 38,89 \\
\hline Valencia & 14 & 37 & 36 & 38,89 \\
\hline Menorca & 14 & 39 & 38 & 36,84 \\
\hline Asturias & 13 & 38 & 37 & 35,14 \\
\hline Lanzarote & 13 & 39 & 38 & 34,21 \\
\hline Santander & 11 & 36 & 35 & 31,43 \\
\hline
\end{tabular}

Fuente: Resultados de la investigación a partir de las Guías ABC-Comber International Guides -OAG. 


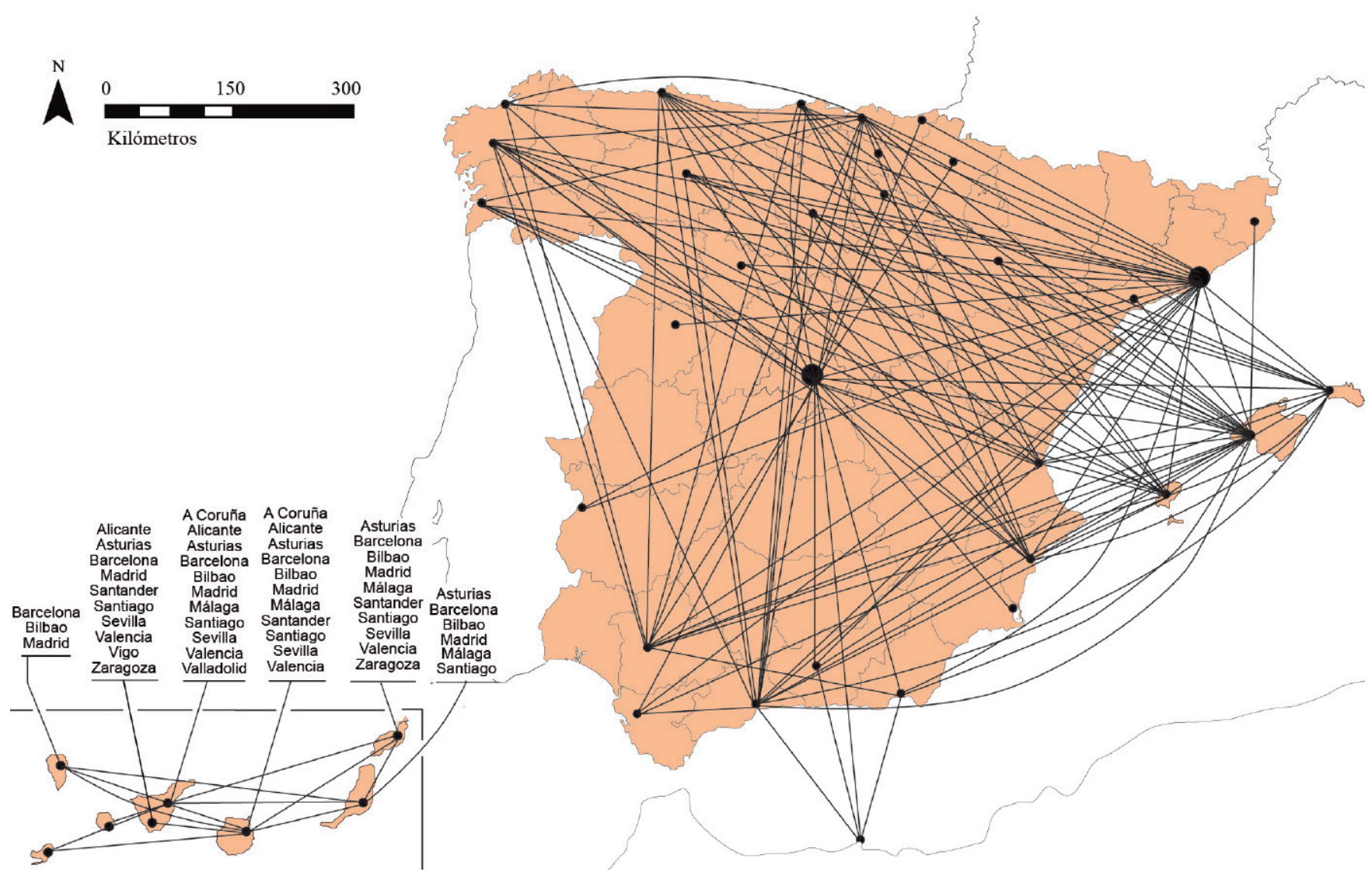

Figura 6. Red de conexiones aéreas domésticas en España, 2015. Fuente: Elaboración propia a partir de las Guías ABC-Comber International Guides -OAG.

Por debajo de ellos, otros tantos (entre el 10 y $24 \%$ de CCA). Aunque todavía no alcanzan la media, algunos han experimentado un gran avance respecto al año 1970 como Zaragoza, Valladolid, Reus y Jerez. Su número de enlaces aéreos nacionales se ha incrementado de manera constatable, bien por la consolidación de centros rectores de sus respectivas comunidades autónomas (Zaragoza y Valladolid), bien por el crecimiento de pequeñas ciudades que auspician la descongestión del tráfico aéreo de sus respectivos centros nodales (Reus para Barcelona y Jerez para Sevilla). Sin embargo, otros retroceden posiciones: en primer lugar, Fuerteventura ante la competencia de las capitales de las provincias canarias; pero, el caso más destacado es el fuerte retroceso de San Sebastián por la gran competencia aeroportuaria que ejerce Bilbao. En escalones inferiores, muchos de los pequeños aeropuertos regionales de segundo y tercer nivel cuyo tráfico de pasajeros es mayoritariamente nacional (Gámir \& Ramos, 2011). Es decir, aeropuertos cuya conectividad aérea se reduce casi exclusivamente con las tres principales instalaciones españolas (Madrid y/o Barcelona y/o Palma de Mallorca).

Sin embargo, es en el tráfico internacional donde se ha observado una profunda metamorfosis. En 1970, cuando en España existía todavía una gran regulación del tráfico aéreo e Iberia ejercía el rol de compañía de bandera con hub principal en Madrid, el tráfico internacional español estaba totalmente dirigido por la capital. De los 44 enlaces internacionales con los que España estaba comunicada en 1970, Madrid polarizaba 43 de los mismos. Por consiguiente, su CC era casi del 100\%. Solo nueve ciudades más contaban con algún enlace aéreo internacional-regular: Barcelona (6), Las Palmas de G.C. (6), Palma de Mallorca (5), Málaga (2), Valencia (2), Tenerife (1), Alicante (1), Sevilla (1) y Girona (1) (tabla 5). El resto de ciudades no registraban ninguna conexión fuera de nuestras fronteras, salvo los destinos turísticos (archipiélagos y costa mediterránea) pero tan sólo mediante vuelos chárter. De esta manera, si un pasajero quería ir al extranjero en avión en aquel entonces, debía pasar previamente por Madrid en la mayoría de los casos. Es, por esto, por lo que se considera que la red española estaba fuertemente polarizada. 
Tabla 5. Aeropuertos con mayor CC internacional (1970). Selección de casos.

\begin{tabular}{|l|c|c|c|}
\hline \multicolumn{1}{|c|}{ Aeropuerto } & $\begin{array}{c}N^{\circ} \text { conexiones aéreas } \\
\text { internacionales }\end{array}$ & $\begin{array}{c}N^{\circ} \text { aeropuertos } \\
\text { internacionales con } \\
\text { conexión desde España }\end{array}$ \\
\hline Madrid & 43 & 44 & 97,72 \\
\hline Barcelona & 6 & 44 & 13,63 \\
\hline Gran Canaria & 6 & 44 & 13,63 \\
\hline Palma de Mallorca & 5 & 44 & 4,36 \\
\hline Málaga & 2 & 44 & 4,54 \\
\hline Valencia & 2 & 44 & 2,27 \\
\hline Alicante & 1 & 44 & 2,27 \\
\hline Girona & 1 & 44 & 2,27 \\
\hline Sevilla & 1 & 44 & 2,27 \\
\hline Tenerife & 1 & 44 & 27 \\
\hline
\end{tabular}

Fuente: Resultados de la investigación a partir de las Guías ABC-Comber International Guides -OAG.

En 2015, puede decirse que la situación es muy diferente, con 222 destinos internacionales más que en 1970. Algunos rasgos explicativos se encuentran en el importante proceso de internacionalización económica y la liberalización comercial (Villarrolla et al., 2006) y también en relación con el desarrollo del sector turístico (Vizcaíno, 2015). El transporte aéreo es, así, un indicador de la creciente presencia internacional de España.

La transformación del sector aéreo también se ha visto favorecida por una adaptación importante de las demandas de movilidad y de la creciente competencia entre las aerolíneas. Se asiste al proceso de privatización de la compañía de bandera (Iberia) en 1999, la liberalización de la actividad y el nacimiento de las compañías de bajo coste (CBC) que, con su modelo de actuación muy flexible basado en el "punto a punto", han multiplicado el número de aeropuertos emisores y receptores (Wensveen \& Leick, 2009).

En 2015 España está conectada con un total de 266 aeropuertos internacionales y, aunque Madrid y Barcelona siguen teniendo los CC más elevados, ahora la conectividad topológica está más repartida (tabla 6). Es decir, hay muchos otros aeropuertos que tienen conexión fuera de nuestras fronteras, de tal manera que su inserción en las corrientes globalizadoras se ha materializado e intensificado, aunque conviene matizar que esta apertura está intensamente focalizada en el viejo continente. Tan solo Madrid, como principal hub de conexión de España con el resto del mundo, está conectada con otras grandes regiones mundiales, especialmente con Latinoamérica, África y Asia. Por otra parte, Barcelona aunque goza de un CC superior a Madrid, no ejerce de gran hub intercontinental, aunque que ha visto incrementar sus conexiones internacionales de manera sobresaliente, especialmente con América y con el margen africano de la cuenca mediterránea (Díez-Pisonero, 2016).

Por debajo de ellas, otras tantas ciudades cuentan con un CC superior a la media nacional por tratarse de destacados destinos turísticos, bien de los archipiélagos (Palma de Mallorca, Tenerife, Gran Canaria y Fuerteventura), bien de la costa mediterránea (Málaga, Alicante, Valencia). Junto a ellos Girona cuya participación en el mercado internacional, tras el "efecto Ryanair", creció exponencialmente. En rangos inferiores otros aeropuertos que, a pesar de contabilizar unos CC por debajo de la media nacional, han experimentado una apertura internacional considerable gracias a las CBC (Serrano \& García, 2015). El número de conexiones internacionales de estas infraestructuras no alcanza los niveles de los principales aeropuertos españoles pero, si comparamos su situación respecto a 1970, supone un cambio considerable.

7 El aeropuerto de Girona ha desempeñado una función de hub para la aerolínea de bajo coste Ryanair que fijó esta localización como base de operaciones en 2004. 
Tabla 6. Aeropuertos con mayor CC internacional (2015). Selección de los 10 primeros.

\begin{tabular}{|l|c|c|c|}
\hline \multicolumn{1}{|c|}{ Aeropuerto } & $\begin{array}{c}N^{\circ} \text { conexiones aéreas } \\
\text { internacionales }\end{array}$ & $\begin{array}{c}N^{\circ} \text { aeropuertos } \\
\text { internacionales con } \\
\text { conexión desde España }\end{array}$ & CC \\
\hline Barcelona & 159 & 266 & 53,77 \\
\hline Madrid & 142 & 266 & 44,73 \\
\hline Palma de Mallorca & 119 & 266 & 32,70 \\
\hline Málaga & 87 & 266 & 32,33 \\
\hline Alicante & 86 & 266 & 28,19 \\
\hline Gran Canaria & 75 & 266 & 26,69 \\
\hline Tenerife (2 aeropuertos) & 71 & 266 & 23,30 \\
\hline Ibiza & 62 & 266 & 17,66 \\
\hline Fuerteventura & 47 & 266 & 16,54 \\
\hline Menorca & 44 & 266 & 2 \\
\hline
\end{tabular}

Fuente: Resultados de la investigación a partir de las Guías ABC-Comber International Guides -OAG.

\section{IMPACTO DE LA COVID-19 EN LA RED AEROPORTUARIA ESPAÑOLA: ¿UNA TRAYECTORIA TRUNCADA?}

La actual crisis sanitaria motivada por la pandemia de la COVID-19 está teniendo un profundo impacto en toda la industria aeronáutica. Como se ha presentado en el apartado 2 , sus consecuencias han supuesto un duro golpe a nivel global y regional y, por supuesto, estas también se han sentido y se siguen apreciando a escala nacional. Como dato ilustrativo, cabe mencionar la tónica ascendente generalizada tanto en número de pasajeros como número de operaciones en los aeropuertos españoles entre 2015-2019, salvo Salamanca y Murcia, y la profunda caída de las métricas entre 2019-2020, extendida a todas las infraestructuras, a excepción de casos puntuales de relevancia menor (figura 7). En términos globales, y según datos de AENA (2021), en 2020 los pasajeros en vuelos domésticos supusieron un total de 76.065.000, con una reducción del $(-72,4 \%)$ con respecto a 2019. Las operaciones comerciales nacionales se redujeron en proporción menor $(-48,5 \%)$, lo que indica, desde nuestro punto de vista, cómo el servicio se garantizó proporcionando una conectividad mínima a pesar de la reducción drástica de la demanda.

El impacto para el caso concreto del movimiento de viajeros en los aeropuertos españoles (figura 8; tabla 7) es evidente en cuanto a la ruptura de la trayectoria ascendente que se venía produciendo desde 2019. Así, el volumen de pasajeros para el verano de 2020 es considerablemente menor al del año anterior, no habiéndose alcanzado tampoco la "esperada recuperación en el verano de 2021", aunque sí se observa un crecimiento evidente con respecto al primer año de la pandemia. Esta trayectoria nos habla ya de un impacto de largo alcance y, por lo menos para el caso de España, de un proceso de recuperación lento.

Para valorar el peso del turismo en la evolución de la demanda aeroportuaria se ha elaborado la ya citada tabla 7, referida a los meses de julio y agosto. En este sentido, sí se observan algunos patrones diferenciados dependiendo de los aeropuertos. Por ejemplo, caídas algo menos pronunciadas en algunos de los insulares entre el verano de 2019 y el de 2020, fundamentalmente en las Islas Canarias (Tenerife Norte y La Palma), que debe ponerse en relación con la activación del turismo nacional en el verano de 2020. También, unas tasas de variación menos negativas que en el conjunto del sistema en un periodo más amplio (entre 2019 y 2021), en algunos destinos de sol y playa ligados tanto a una demanda nacional como internacional: Palma de Mallorca, Málaga, Gran Canaria, Ibiza, Valencia, Tenerife Norte, Menorca, La Palma, Fuerteventura. A ello, se unen aeropuertos de interior, que muestran una tendencia clara de recuperación (aunque todavía 
con niveles inferiores a la situación prepandémica). Es especialmente notorio el caso de los aeropuertos de Santiago y Asturias, aunque en el grupo de aeropuertos con tasas de recuperación superiores a la media también se encuentran Valencia, Sevilla, Bilbao y A Coruña.

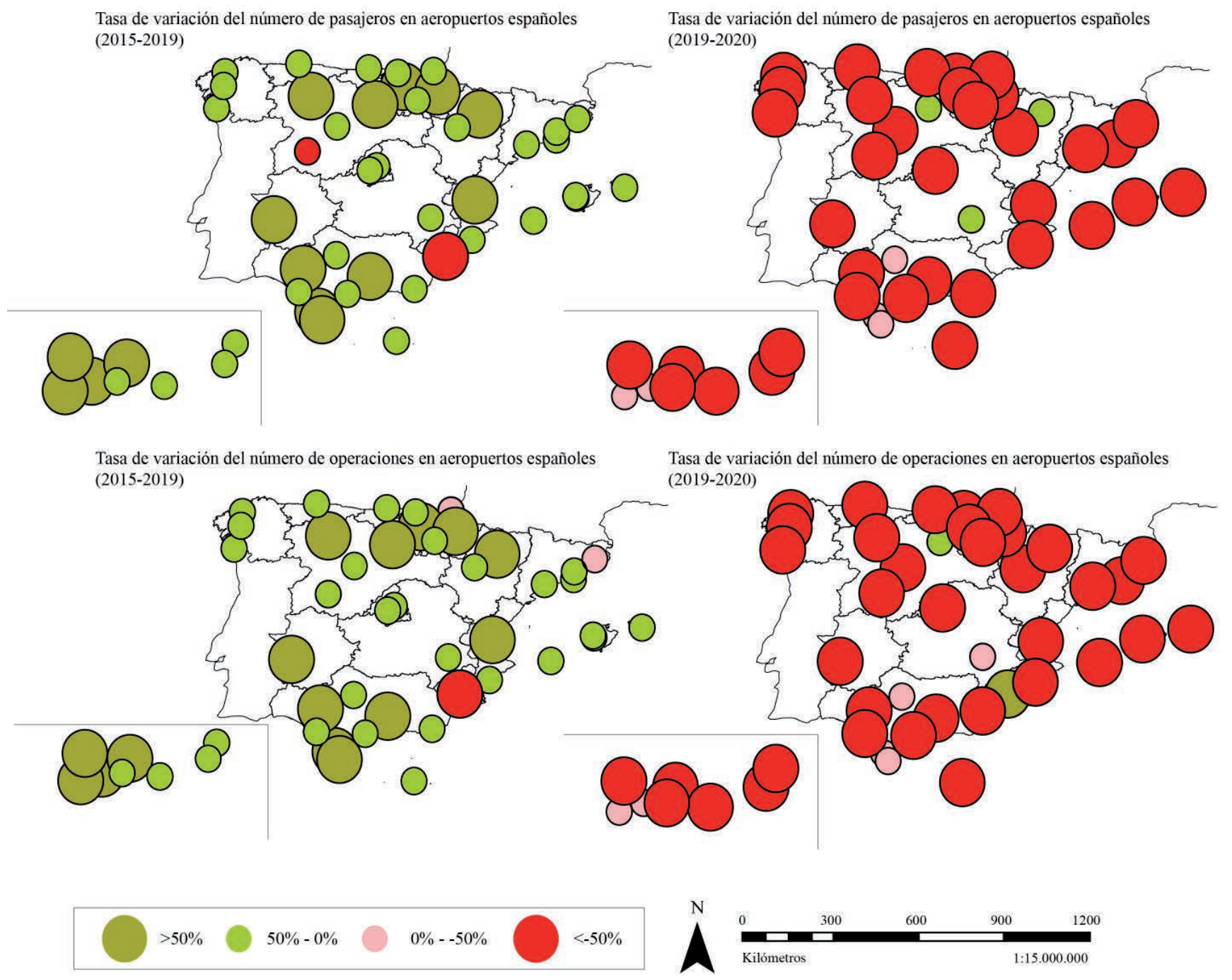

Figura 7. Tasa de variación de pasajeros y operaciones aéreas en aeropuertos españoles (2015-2019 y 2019-2020). Fuente: Elaboración propia a partir de datos de AENA (2015, 2019, 2020).

Los grandes aeropuertos nacionales (Madrid y Barcelona), con una demanda más diversificada en cuanto al perfil del usuario (sector MICE, recepción de trabajadores, inmigrantes) y su función de hub, muestran un proceso de recuperación más débil, coherente con la coyuntura internacional. Es patente la escasa recuperación del aeropuerto de Girona, debido a la casi absoluta supresión de la actividad de la compañía Ryanair en este último, que cumplía funciones logísticas y de hub. Por último, es destacable también la escasa y lenta recuperación de la actividad en Tenerife-Sur, en relación con una dependencia muy alta de la demanda internacional, aunque debe tenerse en cuenta que la temporada alta de turismo en el sur de la Isla de Tenerife no coincide con los meses estivales.

Los datos con respecto a los indicadores de movilidad en los veranos de 2020 y 2021 son, así, coherentes con la dinámica de movilidad ligada a la crisis de la pandemia. En la primera ola y no solo para España, el cierre de las fronteras decretados progresivamente por los gobiernos de todo el mundo para contener el brote de la COVID-19 derivó en una promoción del turismo doméstico y de la movilidad nacional. 
En este sentido, en junio de 2020 y para el turismo nacional se "anticipaba una primera recuperación de la demanda doméstica de proximidad, aunque condicionada por una mayor preferencia hacia instalaciones turísticas de menor tamaño (casas rurales, pequeños establecimientos) y/o gratuito (segundas residencias, familiares y amigos) y el vehículo privado como medio de desplazamiento" (...). Las caídas más intensas del sector turístico se observaron en aquellos destinos "más expuestos a mercados internacionales, muy condicionados por las restricciones de movilidad, las garantías sanitarias entre países y el fenómeno de la staycation" (Exceltur, 2020, pp. 6 y 7). Es decir, la paulatina recuperación de la actividad aérea tras el confinamiento estricto de marzo se focalizó especialmente en el mercado doméstico, que vio como las conexiones o rutas se restablecía en verano al configurarse una red en estructura similar a la prepandémica (tablas 7, 8 y 9. figura 9). No obstante, las pérdidas han sido importantes tanto en relación con la pérdida global de pasajeros como de frecuencias, aunque con una cierta recuperación de la caída en 2021 (tabla 7).

Tabla 7. Tasa de variación del total de pasajeros en los aeropuertos españoles en los veranos. 2019-2020 y 2019-2021. (Datos referidos únicamente a los meses de julio y agosto).

\begin{tabular}{|c|c|c|}
\hline Aeropuerto & $2019-2020$ & 2019-2021 \\
\hline Total & $-72,93$ & $-43,71$ \\
\hline A.S. Madrid-Barajas & $-80,00$ & $-52,90$ \\
\hline Barcelona-Prat & $-81,59$ & $-52,42$ \\
\hline Palma-Mallorca & $-72,40$ & $-40,11$ \\
\hline Málaga & $-71,73$ & $-42,74$ \\
\hline Alicante-Elche & $-73,53$ & $-50,59$ \\
\hline Gran Canaria & $-60,43$ & $-32,98$ \\
\hline Tenerife-Sur & $-77,16$ & $-51,01$ \\
\hline Ibiza & $-63,04$ & $-28,32$ \\
\hline Valencia & $-65,53$ & $-31,00$ \\
\hline Sevilla & $-65,32$ & $-31,02$ \\
\hline Lanzarote & $-64,68$ & $-39,46$ \\
\hline Tenerife Norte & $-39,70$ & $-15,31$ \\
\hline Fuerteventura & $-57,25$ & $-30,55$ \\
\hline Bilbao & $-68,34$ & $-34,76$ \\
\hline Menorca & $-60,16$ & $-19,65$ \\
\hline Santiago & $-60,89$ & $-15,68$ \\
\hline La Palma & $-39,67$ & $-18,61$ \\
\hline Asturias & $-55,33$ & $-13,74$ \\
\hline Girona & $-87,80$ & $-77,86$ \\
\hline A Coruña & $-73,07$ & $-39,20$ \\
\hline Resto aeropuertos red comercial & $-72,57$ & $-46,16$ \\
\hline
\end{tabular}

Fuente: Resultados de la investigación a partir de las estadísticas de AENA, 2019-2021. 
--A.S. Madrid-Barajas

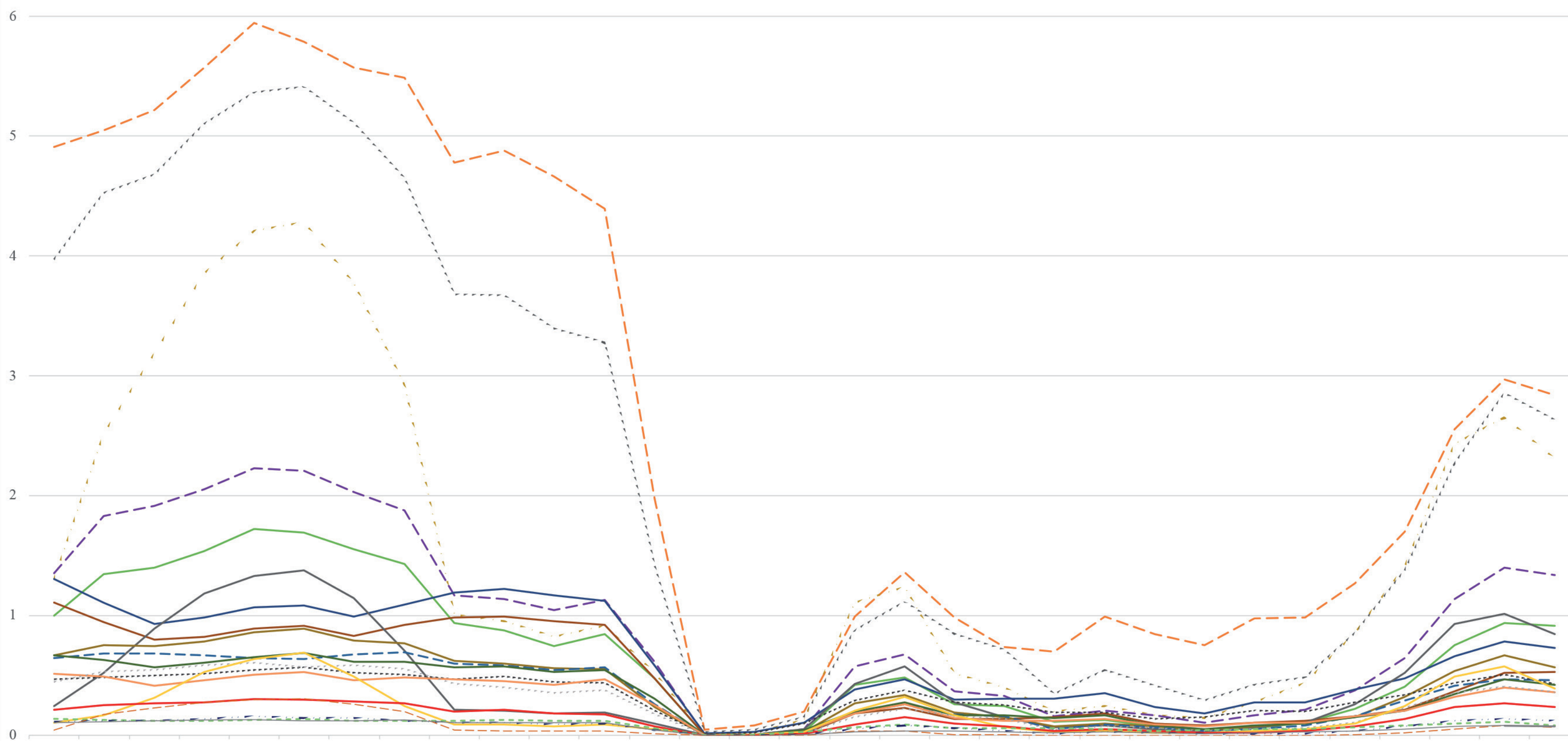

Barcelona-Pra

- -Palma-Mallorca

--Málaga

—Alicante-Elche

- Gran Canaria

— Tenerife-Sur

—Ibiza

—Valencia

- -Sevilla

- Lanzarote

-.-.-Tenerife Norte

-Fuerteventura

---Bilbao

-Menorca

-Santiago

- -La Palma

$-\cdot \cdot$ Asturias

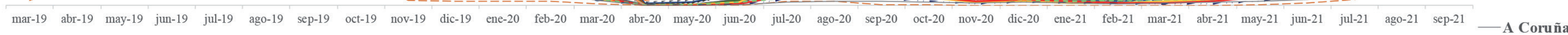

Figura 8. Evolución del volumen de pasajeros en aeropuertos españoles. Marzo 2019 a septiembre 2021. Fuente: Resultados de la investigación a partir de las estadísticas de AENA, 2019- 2020. 


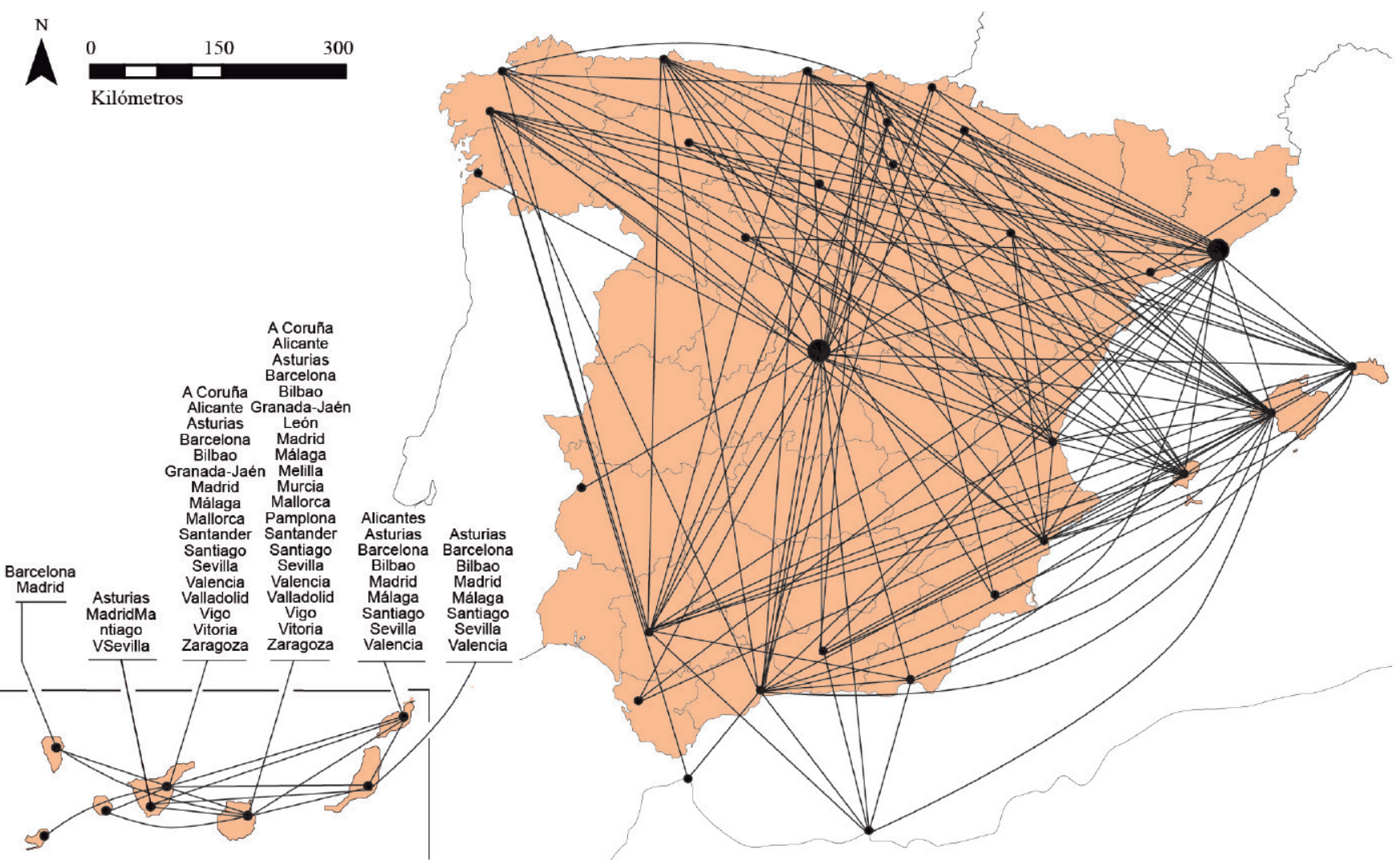

Figura 9. Red de conexiones aéreas domésticas en España, 2020, agosto. Fuente: Resultados de la investigación a partir de las Guías ABC-Comber International Guides-OAG.

El descenso de frecuencias también ha sido muy acusado. La tabla 8 recoge las principales rutas domésticas en los años estudiados. En esta tabla se aprecia un doble aspecto: i) una treintena de rutas en relación con la conectividad de los dos hub principales (Madrid y Barcelona, en colores amarillo y azulado) y los destinos insulares (en verde) polarizan una proporción considerable de las frecuencias totales anuales (por encima del $60 \%$ en ambas fechas), cuestión que es interesante pero no está relacionada con la pandemia, más bien con la funcionalidad del sistema; ii) todas estas rutas experimentaron durante el 2020 pérdidas importantes con respecto al año anterior (-48,5\%, como promedio), siendo los destinos insulares (entre las Islas de Canarias y la ruta Ibiza- Palma de Mallorca) aquellos que mostraron decrecimientos, aunque significativos, por debajo de la media.

Así, el restablecimiento del tráfico doméstico en 2020, tras el severo confinamiento de primavera, adquiere gran interés. Es decir, se reestablecieron las rutas, aun con una demanda considerablemente menor, y no solo en aquellas localizaciones donde el concurso del transporte aéreo es más necesario y efectivo para el desenclave (destinos insulares). Esto se observa en gran parte de la red aeroportuaria, en aquellos aeropuertos con un CCA superior a la media nacional (33,2\%; tabla 9): (i) Madrid y Barcelona, con CCA superiores al $80 \%$, al tratarse de los dos grandes aeropuertos de la jerarquía aeroportuaria española; (ii) los aeropuertos con funcionalidad turística destacada en ambos archipiélagos y en la costa mediterránea, como Gran Canaria (82,35\%), Palma de Mallorca (76,47\%), Tenerife (67,65\%), Valencia (67,65\%), Málaga (58,06\%), Ibiza (50\%), Menorca (44\%), Lanzarote (38,24\%); y (iii) ciudades importantes de la jerarquía urbana que sirven a sus áreas urbano-regionales como Sevilla (59,38\%), Bilbao $(54,55 \%)$, Santiago $(46,48 \%)$, Asturias $(45,45 \%)$ y Zaragoza (39,39\%). Otros aeropuertos de carácter regional, aunque con CCA inferiores a la media, también presentan coeficientes de conexión adecuados, como Pamplona, Valladolid, San Sebastián y A Coruña, entre otros. 
Tabla 8. Evolución de las principales rutas domésticas en España (frecuencias 2019 y 2020).

\begin{tabular}{|c|c|c|c|c|c|}
\hline \multirow[b]{2}{*}{ RUTA (Ida y vuelta) } & \multicolumn{2}{|c|}{2019} & \multicolumn{2}{|c|}{2020} & \multirow{2}{*}{$\begin{array}{c}\% \text { variación } \\
\text { frecuencias } \\
\text { totales. } \\
2019-2020\end{array}$} \\
\hline & $\begin{array}{c}\text { Total } \\
\text { frecuencias } \\
\text { anuales }\end{array}$ & $\begin{array}{l}\% \text { respecto } \\
\text { al total de las } \\
\text { frecuencias }\end{array}$ & $\begin{array}{c}\text { Total } \\
\text { frecuencias } \\
\text { anuales }\end{array}$ & $\begin{array}{l}\% \text { respecto } \\
\text { al total de las } \\
\text { frecuencias }\end{array}$ & \\
\hline A Coruña- Madrid & 5762 & 1,40 & 2360 & 1,11 & $-59,04$ \\
\hline Alicante- Madrid & 4161 & 1,01 & 1674 & 0,79 & $-59,77$ \\
\hline Asturias- Madrid & 5461 & 1,33 & 1961 & 0,93 & $-64,09$ \\
\hline Barcelona- Bilbao & 4405 & 1,07 & 1827 & 0,86 & $-58,52$ \\
\hline Barcelona- Ibiza & 8700 & 2,11 & 4241 & 2,00 & $-51,25$ \\
\hline Barcelona- Madrid & 16878 & 4,10 & 6511 & 3,07 & $-61,42$ \\
\hline Barcelona- Málaga & 5088 & 1,24 & 2512 & 1,19 & $-50,63$ \\
\hline Barcelona- Menorca & 6284 & 1,53 & 3720 & 1,76 & $-40,80$ \\
\hline Barcelona- Sevilla & 6532 & 1,59 & 2790 & 1,32 & $-57,29$ \\
\hline Barcelona-Palma de Mallorca & 15906 & 3,86 & 7781 & 3,67 & $-51,08$ \\
\hline Bilbao- Madrid & 7074 & 1,72 & 2696 & 1,27 & $-61,89$ \\
\hline El Hierro- Tenerife & 3645 & 0,89 & 2988 & 1,41 & $-18,02$ \\
\hline Fuerteventura- Gran Canaria & 12993 & 3,16 & 7831 & 3,70 & $-39,73$ \\
\hline Fuerteventura- Tenerife & 5181 & 1,26 & 3443 & 1,62 & $-33,55$ \\
\hline Gran Canaria-Lanzarote & 15248 & 3,70 & 8907 & 4,20 & $-41,59$ \\
\hline Gran Canaria-Madrid & 9704 & 2,36 & 5156 & 2,43 & $-46,87$ \\
\hline Gran Canaria-Tenerife & 22898 & 5,56 & 12446 & 5,87 & $-45,65$ \\
\hline Ibiza- Madrid & 7268 & 1,77 & 3710 & 1,75 & $-48,95$ \\
\hline Ibiza- Palma de Mallorca & 9758 & 2,37 & 5330 & 2,52 & $-45,38$ \\
\hline La Palma- Tenerife & 15172 & 3,69 & 8931 & 4,21 & $-41,13$ \\
\hline Lanzarote- Madrid & 3161 & 0,77 & 1590 & 0,75 & $-49,70$ \\
\hline Lanzarote- Tenerife & 7035 & 1,71 & 4486 & 2,12 & $-36,23$ \\
\hline Madrid- Málaga & 4668 & 1,13 & 2209 & 1,04 & $-52,68$ \\
\hline Madrid- Menorca & 2881 & 0,70 & 1626 & 0,77 & $-43,56$ \\
\hline Madrid- Palma de Mallorca & 14095 & 3,42 & 6986 & 3,30 & $-50,44$ \\
\hline Madrid- Sevilla & 5319 & 1,29 & 2003 & 0,95 & $-62,34$ \\
\hline Madrid- Tenerife & 11230 & 2,73 & 5030 & 2,37 & $-55,21$ \\
\hline Madrid- Valencia & 5602 & 1,36 & 2540 & 1,20 & $-54,66$ \\
\hline Madrid- Vigo & 5839 & 1,42 & 2003 & 0,95 & $-65,70$ \\
\hline Menorca- Palma de Mallorca & 7843 & 1,91 & 3997 & 1,89 & $-49,04$ \\
\hline Palma de Mallorca- Valencia & 5979 & 1,45 & 2916 & 1,38 & $-51,23$ \\
\hline CONEXIONES ACUMULADAS & 261770 & 63,60 & 132201 & 62,38 & \\
\hline TOTAL CONEXIONES ANUALES* & 411587 & & 211928 & & $-48,51$ \\
\hline
\end{tabular}

Fuente: Resultados de la investigación a partir de estadísticas de AENA, 2019 y 2020. 
Tabla 9. Aeropuertos con CCA nacional superior a la media del país (2020).

\begin{tabular}{|c|c|c|c|c|}
\hline \multirow{2}{*}{ Aeropuerto } & \multirow{2}{*}{$\mathrm{N}^{\circ}$ conexiones } & \multicolumn{3}{|c|}{ Coeficiente de Conectividad Ajustado (CCA) } \\
\hline & & $\mathrm{N}$ & $\mathrm{N}-1$ & CCA \\
\hline Madrid & 30 & 34 & 33 & 90,91 \\
\hline Barcelona & 27 & 33 & 32 & 84,38 \\
\hline Gran Canaria & 28 & 35 & 34 & 82,35 \\
\hline Palma de Mallorca & 26 & 35 & 34 & 76,47 \\
\hline Tenerife & 23 & 35 & 34 & 67,65 \\
\hline Sevilla & 19 & 33 & 32 & 59,38 \\
\hline Málaga & 18 & 32 & 31 & 58,06 \\
\hline Bilbao & 18 & 34 & 33 & 54,55 \\
\hline Valencia & 17 & 33 & 32 & 53,13 \\
\hline Ibiza & 17 & 35 & 34 & 50,00 \\
\hline $\begin{array}{l}\text { Santiago de } \\
\text { Compostela }\end{array}$ & 15 & 33 & 32 & 46,88 \\
\hline Asturias & 15 & 34 & 33 & 45,45 \\
\hline Menorca & 15 & 35 & 34 & 44,12 \\
\hline Alicante & 14 & 33 & 32 & 43,75 \\
\hline Zaragoza & 13 & 34 & 33 & 39,39 \\
\hline Lanzarote & 13 & 35 & 34 & 38,24 \\
\hline
\end{tabular}

Fuente: Resultados de la investigación.

Aunque el shock en la movilidad del sistema de transporte aéreo español durante la primera ola de la pandemia fue generalizado, tanto a escalas nacional como internacional, pretendemos en las siguientes líneas ahondar en el comportamiento específico de la movilidad aérea internacional. En relación con las cifras de 2019, España perdió en 2020 alrededor de 147,3 millones de pasajeros internacionales, lo que supuso un decrecimiento de aproximadamente el 77,76 \% del volumen del año anterior (tabla 10). Se trata de una cifra muy alta, y casi todos los aeropuertos importantes experimentaron pérdidas superiores al $70 \%$. En líneas generales, la proporción de pérdidas de pasajeros fue menor en el tráfico doméstico, aunque debe señalarse que este solo suponía el 30\% aproximadamente del total.

Destacan localizaciones con pérdidas significativamente superiores a la media, como Girona (instalación que respondía mayoritariamente a la demanda extranjera), Ibiza, Málaga, Menorca y Palma de Mallorca. Estos últimos aeropuertos perdieron, en proporción, menos viajeros domésticos, con cifras inferiores a las pérdidas medias del país: Palma de Mallorca (-46,3\%), Menorca, Fuerteventura y Lanzarote (-48\%), y Gran Canaria, Ibiza y Málaga, también por debajo de la media del conjunto. Este hecho incide en una idea ya indicada en líneas anteriores, en relación con el papel que ha jugado la demanda interior en el mantenimiento de la actividad del sector aéreo.

Resulta también relevante hacer referencia a la evolución de la conectividad para valorar en qué medida los aeropuertos perdieron conexiones internacionales, ligados a la escasa demanda inducida por las recomendaciones sanitarias en origen (tabla 10). Los resultados en relación con el mantenimiento de las rutas aéreas exteriores son algo menos negativos que lo que podrían anticipar los datos relativos al volumen de viajeros. Ciertamente, los aeropuertos sufrieron una pérdida de conectividad entre los veranos de 2019 y 
2020, pero no de una manera tan alarmante como las cifras de pasajeros y frecuencias. Las pérdidas de CC más significativas se dieron en los dos grandes aeropuertos del Estado, Madrid y Barcelona, que son aquellos que concentran gran parte de los vuelos transcontinentales, respondiendo a un amplio espectro de la demanda (tabla 10). La figura 10 muestra la variación de las frecuencias aéreas entre Madrid y Barcelona y los 20 destinos internacionales con mayor conectividad aérea de cada una de esas ciudades. En el caso de Madrid, por ejemplo, puede anotarse cómo en el verano de 2020 las principales rutas internacionales del 2019 continuaban operativas, aunque, experimentaron decrecimientos en la frecuencia superiores al 60\%.

Por otra parte, se observa que los aeropuertos con vocación turística tuvieron caídas de la conectividad internacional (CC) más moderadas. Cabe sospechar, en este sentido, que se trata de una estrategia comercial de las aerolíneas, manteniendo la ruta, aunque reduciendo las frecuencias, ya que en el proceso también influye la necesidad de mantener los slots 8 .

Tabla 10. Aeropuertos con CCA internacional superior a la media del país (2020). Coeficientes de conectividad 2019 y 2020, verano. Número de nodos internacionales para determinar el CC=259.

\begin{tabular}{|c|c|c|c|c|c|c|}
\hline Aeropuerto & $\begin{array}{l}\text { No conexiones } \\
\text { aéreas } \\
\text { internacionales. } \\
2019\end{array}$ & $\begin{array}{l}\text { No conexiones } \\
\text { aéreas } \\
\text { internacionales. } \\
2020\end{array}$ & $\begin{array}{l}\text { CC Internac. } \\
2019\end{array}$ & $\begin{array}{c}\text { CC Internac. } \\
2020\end{array}$ & $\begin{array}{c}\text { \% variación } \\
\text { pasajeros } \\
\text { internacionales } \\
(2019-2020)\end{array}$ & $\begin{array}{c}\% \text { variación } \\
\text { pasajeros } \\
\text { nacionales } \\
(2019-2020)\end{array}$ \\
\hline $\begin{array}{l}\text { TOTAL AEROP. } \\
\text { ESPAÑA }\end{array}$ & & & & & $-77,76$ & $-60,47$ \\
\hline Alicante & 86 & 79 & 33,20 & 30,50 & $-76,28$ & $-66,41$ \\
\hline Barcelona & 159 & 106 & 61,39 & 40,93 & $-79,51$ & $-65,65$ \\
\hline Fuerteventura & 47 & 41 & 18,15 & 15,83 & $-68,00$ & $-48,03$ \\
\hline Girona & 37 & 32 & 14,29 & 12,36 & $-91,49$ & $-12,20$ \\
\hline Gran Canaria & 75 & 49 & 28,96 & 18,92 & $-68,17$ & $-52,92$ \\
\hline Ibiza & 62 & 54 & 23,94 & 20,85 & $-86,71$ & $-55,89$ \\
\hline Lanzarote & 42 & 37 & 16,22 & 14,29 & $-72,99$ & $-48,10$ \\
\hline Madrid & 142 & 104 & 54,83 & 40,15 & $-75,34$ & $-64,05$ \\
\hline Málaga & 87 & 87 & 33,59 & 33,59 & $-86,52$ & $-58,47$ \\
\hline Menorca & 44 & 35 & 16,99 & 13,51 & $-89,90$ & $-49,59$ \\
\hline $\begin{array}{l}\text { Palma de } \\
\text { Mallorca }\end{array}$ & 119 & 105 & 45,95 & 40,54 & $-93,60$ & $-46,34$ \\
\hline Sevilla & 57 & 40 & 22,00 & 15,44 & $-75,02$ & $-63,31$ \\
\hline \multirow[t]{3}{*}{$\begin{array}{l}\text { Tenerife** } \\
\text { (destino) }\end{array}$} & 71 & 60 & 27,41 & 23,17 & & \\
\hline & Tenerife Norte & & & & $-80,79$ & $-51,72$ \\
\hline & Tenerife Sur & & & & $-69,06$ & $-74,55$ \\
\hline Valencia & 35 & 55 & 13,51 & 21,24 & $-74,64$ & $-60,25$ \\
\hline $\begin{array}{l}\text { Resto aerop. } \\
\text { españoles }\end{array}$ & & & & & $-86,86$ & $-63,51$ \\
\hline
\end{tabular}

Fuente: Resultados de la investigación a partir de Comber International Guides -OAG para el cálculo del CC; Ministerio de Transportes, Movilidad y Agenda urbana 2021 en relación al volumen de pasajeros nacional e internacional.

8 El reglamento 95/93 de la UE exige que las aerolíneas que operan en aeropuertos coordinados (donde la demanda excede la capacidad durante periodos de tiempo significativos y resulta imposible resolver la situación a corto plazo) cumplan con un $80 \%$ de ejecución sobre la programación en cada ruta, medida en series de cinco slots (Cinco Días, 2021). 
Tasa de variación del número de frecuencias mensuales (2015-2019). Selección de los 20 destinos con mayor conectividad aérea desde Madrid

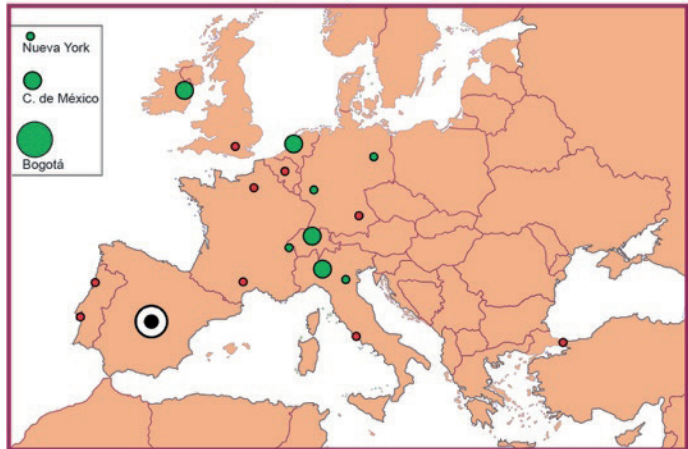

Tasa de variación del número de frecuencias mensuales (2015-2019). Selección de los 20 destinos con mayor conectividad aérea desde Barcelona

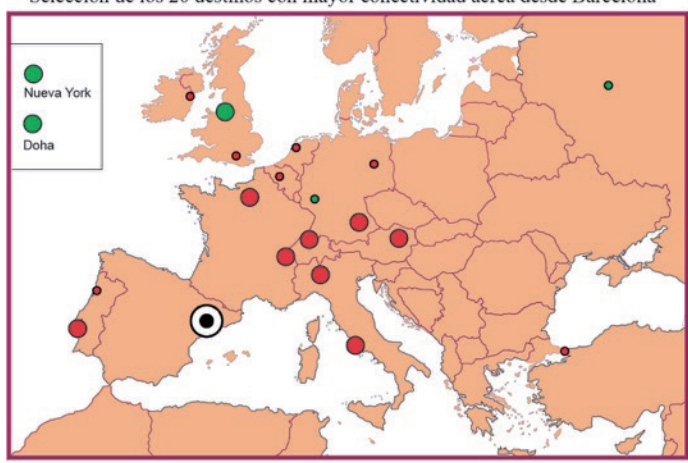

Tasa de variación del número de frecuencias mensuales (2019-2020). Selección de los 20 destinos con mayor conectividad aérea desde Madrid

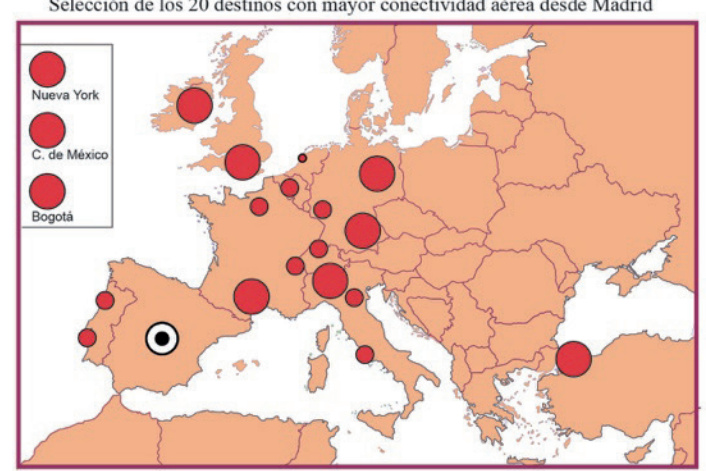

Tasa de variación del número de frecuencias mensuales (2019-2020). Selección de los 20 destinos con mayor conectividad aérea desde Barcelona

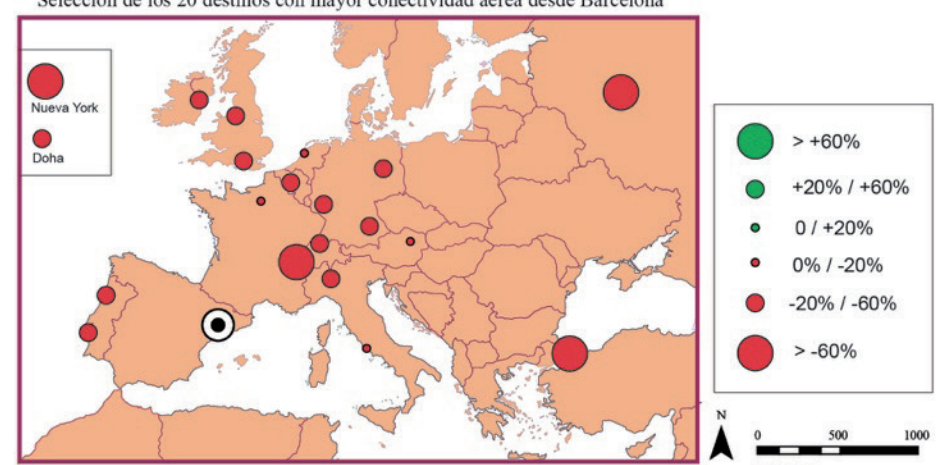

Figura 10. Tasa de variación de las frecuencias aéreas a los 20 principales destinos internacionales en los aeropuertos de Madrid (arriba) y Barcelona (abajo). Evolución 2015-2019 (izquierda) y 2019- 2020 (derecha). Fuente: Elaboración propia a partir de los resultados de la investigación; fuente primaria: Comber International Guides -OAG.

\section{DISCUSIÓN}

A continuación, se muestran algunas ideas que pretenden presentar una reflexión sobre los hechos descritos en estas páginas, pero especialmente, sobre las incógnitas que la pandemia ha abierto en relación con el sector de los viajes aéreos. En este sentido, el análisis realizado presenta los cambios para un periodo muy concreto, pero al tratarse de un proceso en marcha, todavía no pueden extraerse conclusiones generales sobre lo sucedido.

Se debe, en primer lugar, señalar algunas limitaciones del estudio. Principalmente, para el análisis de la evolución de la intensidad de las relaciones domésticas entre nodos sería muy interesante haber dispuesto de datos de tráfico de pasajeros entre pares de ciudades. Se ha contado con datos de conexiones y frecuencias, pero es cierto que a veces no reflejan en toda su complejidad la magnitud del cambio. Por otra parte, metodológicamente, en la elaboración de los coeficientes de conectividad ajustados (CCA) quizá deba revisarse el umbral de $250 \mathrm{~km}$ de competencia entre aeropuertos, fundamentalmente en lo que concierne a los vuelos domésticos. No obstante, se estima que los resultados utilizando umbrales algo inferiores tampoco divergirían excesivamente de los obtenidos.

En términos generales, se ha puesto de manifiesto que la trayectoria del sistema de transporte aéreo en España en el extenso periodo estudiado ha tenido como consecuencia la conformación de una red muy madura y vertebrada, con una trayectoria continuada desde hace casi medio siglo. Se aprecia también una concentración de la actividad en una decena de aeropuertos, en relación con las localizaciones turísticas y con los dos hub estatales, Barcelona y Madrid. En este contexto, la irrupción de la crisis sanitaria supuso, en un primer momento, una caída de la actividad sin precedentes, con un reinicio de las operaciones paulatino y donde, a fecha de hoy, todavía no se han alcanzado las cifras de partida. Las últimas noticias al respecto señalan, a escala mundial, una recuperación de la actividad aérea más rápida de lo esperado (Hosteltur, 2021), aunque para el caso de España es necesario disponer de datos que confirmen esta tendencia. También es una incógnita cómo se desarrollará en el medio-largo plazo la recuperación del sector de la aviación 
civil comercial en otros sistemas aéreos nacionales tras la pandemia y si habrá cambios irreversibles. Para el caso de Japón, Corea o China se ha mostrado que el sector de los vuelos domésticos se revitalizó antes que los vuelos internacionales ( $\mathrm{Ng}$ et al., 2021; Kim \& Sohn, 2022; Sun et al., 2021b). En consecuencia, se ha constatado que los viajes nacionales demostraron una mayor resistencia y dominaron los escenarios de recuperación del tráfico, particularmente en China y Rusia, donde el número de pasajeros nacionales a finales de 2020 ya había alcanzado cifras cercanas a los niveles previos a la pandemia (Aeroespacial, 2021). No obstante, debido a su prolongada duración y la incidencia de las diferentes olas es necesario disponer de una perspectiva temporal de amplio alcance.

Pero, la magnitud de las cifras trasciende la movilidad física de aeronaves y personas, al demostrarse la imbricación y la simbiosis del sistema de transporte con las dinámicas sociales y económicas y los posibles cambios o la generación de nuevas lógicas a la hora de decidir realizar un desplazamiento utilizando el avión. Las transformaciones son evidentes, por ejemplo, en el ámbito del teletrabajo y la necesidad a futuro de desplazamientos de ejecutivos y altos empleados de las empresas. Ello obliga a replantear en qué circunstancias será necesario un trayecto físico y la utilización de aeronaves (Comisión Europea, 2020). También es una incógnita en qué términos se restablecerá la actividad turística mundial. Un reciente informe de Amadeus (2021a), señala que el sector de los viajes se está reactivando en relación con las siguientes claves motivacionales: búsqueda de viajes a destinos o experiencias épicas (turismo experiencial), desplazamientos para visitar a amigos y familiares, opciones más sostenibles y responsables de turismo (ecoturismo y turismo solidario), la preferencia por destinos que han sido localizaciones de series y películas y por último, la reactivación de los viajes de negocios. Pese a estas predicciones, y en relación con el último caso, parece que no todos los modelos señalan la reactivación de los mismos en el largo plazo y así, algunos auguran que por causa de la pandemia se producirá una caída, con respecto a las previsiones iniciales, de entre un 14 y un 45\% (Mason, 2021). Por otra parte, diferentes modelos indican que en el futuro, una vez restablecida la movilidad a escala mundial, los principales aeropuertos (hubs globales) volverán a sufrir congestión y una crisis importante de capacidad (Gelhausen et al., 2021), con lo que podría haberse desperdiciado la oportunidad de incidir en la racionalidad y sostenibilidad del sector de los viajes aéreos.

Otras cuestiones que forman parte del debate actual están en relación con el futuro de las compañías y las medidas necesarias para favorecer la recuperación del sector desde el punto de vista de la activación de la demanda. El lamentable estado de cuentas en el que han quedado las aerolíneas, no solo las españolas, por efecto de la pandemia augura posibles quiebras o nuevas restructuraciones. Por ejemplo, la empresa propietaria de Iberia y Vueling, IAG, perdió 6.923 millones de euros a consecuencia de la crisis. También ha sido muy polémico el rescate por parte del Gobierno de España de la empresa Air Europa, por una cifra de 475 millones de euros (Cordero, 2021). Igualmente, ha tenido importante repercusión mediática la retirada de sus operaciones en Girona -lo que ha significado que este aeropuerto esté técnicamente sin actividad-y en los aeropuertos canarios (Lanzarote, Las Palmas de G.C., Tenerife) por parte de la compañía Ryanair. Este es un hecho que ya había anticipado esta aerolínea, pero que la crisis sanitaria ha acelerado (Rovira, 2020).

Así, resulta interesante el papel regulatorio, de restauración de la confianza y para garantizar las conectividades regionales que puede tener en el futuro la iniciativa política, ya que esta crisis ha hecho desaparecer algunas rutas regionales y también algunas aerolíneas (Xuan et al., 2021). Este aspecto ya ha sido puesto en valor, por ejemplo, en los casos de Japón ( $\mathrm{Ng}$ et al., 2021) o Corea del Sur (Kim \& Sohn, 2022). También es significativo cómo las ayudas recibidas por muchas compañías aéreas, fundamentales para la supervivencia del sector durante la primera ola de la pandemia por ejemplo en el caso europeo, pueden "cambiar las reglas de competencia entre empresas y las perspectivas de éxito en el futuro de las aerolíneas, porque si bien se proporciona recursos, también se limita el margen de maniobra para desarrollar estrategias, operaciones y las decisiones de gestión, como en la elección de rutas, la determinación de los hubs y los encargos de aviones y tecnología" (Albers \& Rundshagen, 2020 en Cifuentes \& Faura, 2021, p. 239).

Por otra parte, aunque las aerolíneas comerciales tradicionales han mostrado su vulnerabilidad a la crisis, se cuenta también con ejemplos en los que compañías han solventado el periodo con beneficios. Se trata de negocios dedicados al sector de vuelos privados o particulares para empresas, directivos o personas de alto 
poder adquisitivo (Cordero, 2021). El tipo de servicio que se ofrece resulta también muy conveniente para garantizar la recomendada "distancia social", evitando la masificación de aeropuertos y aeronaves.

En relación con esta idea, también el sector profesional del transporte aéreo incide en la recuperación de la confianza, garantizando vuelos seguros desde el punto de vista sanitario, renovando también el prestigio de las aerolíneas (Cifuentes \& Faura, 2021). Estas se han adaptado implementando medidas como las propuestas por la Universidad de Harvard, esto es: el sistema de ventilación y de renovación periódica del aire en las cabinas, el uso de mascarillas, la desinfección de los aviones, la monitorización de los pasajeros y la educación y concienciación. Además, el sector se ha adecuado a las nuevas necesidades, ofreciendo mayor flexibilidad en las reservas -cancelaciones, cambios de vuelo, reintegro del precio del pasaje- (Xuan et al., 2021), aumentando las experiencias con poco contacto (low-touch) tanto en aeropuertos como en hoteles, permitiendo a los viajeros realizar sus trámites en el aeropuerto de manera remota a través de sus teléfonos móviles (Amadeus, 2021 b), u ofreciendo servicios sanitarios de diagnóstico rápido en los aeropuertos (PCRs) para presentar en aquellos destinos que lo solicitan obligatoriamente (Hosteltur, 2021b).

En el caso concreto de España, otra variable que debe ser considerada en relación con el restablecimiento de la actividad aérea es que el tráfico aéreo doméstico experimenta una fuerte competencia con el transporte ferroviario de alta velocidad (AVE). Muchos de los enlaces aéreos peninsulares, especialmente aquellos de carácter radial, habían visto retroceder la demanda ya antes de la pandemia ante el desarrollo de esta modalidad de transporte, que adquiere gran competitividad en trayectos inferiores a los 600-700 kilómetros (Díez-Pisonero, 2016). Esta no debe ser entendida solo en términos de tiempo total de desplazamiento, sino también en relación con cuestiones de comodidad, disponibilidad de frecuencias y puntualidad del servicio (Jánez, 2015). A ello se suma la liberalización del sector ferroviario con la entrada de compañías competidoras de RENFE en el mercado (SNCF o Ilsa), añadiendo la variable tarifa o precio del billete en esta difícil ecuación, lo que augura un nuevo reto a la continuidad de la actividad de las compañías aéreas en las rutas peninsulares, y con ello la actividad en algunos aeropuertos menores (Cinco Días, 2020).

Es interesante también anotar que las cuestiones ambientales (eficiencia energética, resiliencia frente a situaciones climáticas adversas) están cobrando protagonismo en la elección del ferrocarril de alta velocidad frente al avión (Prusi \& Lonza, 2018). Para el caso de Europa la opción del tren como medio de transporte más sostenible y coherente con el Pacto Verde Europeo y con la Acción de la Unión Europea por el clima parece ser una iniciativa interesante (European Union- Agency for Raylways, 2020). No obstante, el ferrocarril de alta velocidad también presenta algunos inconvenientes que no pueden subestimarse, como la altísima inversión en el tendido de las rutas, los impactos en los paisajes y en los hábitat naturales, o el efecto túnel; aparte, se pueden estar subestimando los esfuerzos del sector de la construcción aeronáutica para diseñar aeronaves que reduzcan considerablemente las emisiones de $\mathrm{CO}_{2}$ (Eurocontrol, 2021), lo que proporcionará artefactos mucho más eficientes energéticamente y sostenibles en un futuro no muy lejano.

Conviene, por último, para el caso concreto de la red estatal de aeropuertos poner de manifiesto su disimetría y cuestionar la viabilidad de aquellos más modestos, lo que puede haberse agravado por el impacto de la pandemia. Es decir, es preciso conocer hasta qué punto la oferta actual de estas instalaciones es dependiente de las ayudas públicas y por cuánto tiempo las diferentes administraciones podrán mantenerlas. Del mismo modo, será necesario discutir sobre el modelo de gestión aeroportuaria. Frente al modelo público instaurado en la actualidad, donde la gestión de todos los aeropuertos públicos es implementada por AENA, la Unión Europea promueve otro modelo más descentralizado, cada vez más presente en países vecinos, donde exista una unidad gestora para cada infraestructura aeroportuaria (Directiva UE 96/67; Unión Europea, 1996).

\section{CONCLUSIONES}

La conectividad aérea española ha evolucionado significativamente durante los últimos 45 años, estudiados en estas líneas, consolidándose una red muy tupida y vertebrada. Así, frente a la estructura bicéfala de 1970, 
articulada por dos centros dominantes en un sistema manifiestamente concentrado, se ha evolucionado a otro donde, aunque Madrid y Barcelona siguen dominando las relaciones domésticas e internacionales, aparecen centralidades emergentes para la estructuración del territorio asociadas a la revalorización de núcleos regionales (Henneberg et al., 2007).

Respecto a la red internacional, aunque Madrid sigue teniendo el CC más elevado del país por su condición de hub (principal puerta de entrada y salida aérea), lo verdaderamente significativo es el crecimiento experimentado en un gran número de aeropuertos como consecuencia de la entrada de España en la Unión Europea, la gran especialización turística del país o la expansión de las compañías de bajo coste, entre otros factores.

Partiendo de esta trayectoria, el impacto de la COVID-19 sobre el transporte aéreo está suponiendo un verdadero punto de inflexión en la historia aeronáutica, independientemente de la escala de análisis y de las métricas tenidas en consideración. En España, las frecuencias y conexiones aéreas de todos sus aeropuertos se han visto mermadas durante los meses más duros del confinamiento, aunque es importante señalar que una operatividad suficiente de la red ya estaba restablecida en el verano de 2020.

Con este panorama, es fundamental aportar certidumbre en materia de salud y seguridad para la reconstrucción de la confianza de los usuarios. Algunas medidas, ya citadas, se han llevado a efecto en la mayor parte de los aeropuertos del mundo, como la desinfección de terminales, el uso de mascarillas, guantes y geles sanitarios, el control del aforo de tiendas y restaurantes, el distanciamiento social, etc. Una prueba de que las compañías aéreas y los aeropuertos ya están aplicando con éxito estos protocolos es que el riesgo de transmisión a bordo es bajo (Wyman, 2020).

Pero, en vista del temor a constantes rebrotes y olas en todo el mundo y la mutabilidad del virus de la COVID-19, no es posible predecir con exactitud cuándo se levantarán la totalidad de las restricciones a los desplazamientos, cuándo se volverá a una situación "de normalidad" o prepandémica o si algunas transformaciones serán irreversibles. A estos retos, enfocados en garantizar certidumbre en salud y seguridad, debe añadirse la consideración de la función de servicio público que también tiene el sector de la aviación, en muchos casos subestimada. El retroceso experimentado desde la primavera de 2020 justifica la necesidad de velar por la sostenibilidad en un sector indispensable para garantizar la interacción económica y social.

\section{Agradecimientos}

Los autores quieren expresar su reconocimiento y agradecer a los/as revisores/as el esmero en la revisión del manuscrito y sus valiosas y constructivas recomendaciones.

\section{Declaración responsable y conflicto de intereses}

Los autores/as declaran que no existe ningún conflicto de interés en relación con la publicación de este artículo. Todas las tareas realizadas (obtención de fuentes, tratamiento de la información, elaboración del marco teórico, obtención e interpretación de resultados, redacción de los apartados, elaboración del material gráfico y cartográfico) en el manuscrito se han repartido al 50\% entre ambos autores. El diseño metodológico ha recaído en el Dr. Díez-Pisonero.

\section{REFERENCIAS}

ABC World Airways Guide (1970). Thos Skiner and Co. October 1970. London. World flights database (all flights, to/from all airports worldwide).

ABC World Airways Guide (2015). Digital Comber International Guides -OAG (all flights, to/from all airports worldwide; november). 
ABC World Airways Guide (2020). Digital Comber International Guides -OAG (all flights, to/from all airports worldwide; august). AENA (2015, 2019, 2020, 2021). AENA Estadísticas. Pasajeros, Operaciones y Carga. AENA. http://www.aena.es/csee/Satellite?pagename=Estadisticas/Home

Aeroespacial (2021). El tráfico internacional de pasajeros cae un 60\% en 2020, según la OACI. Aeroespacial. https://actualidadaeroespacial.com/el-trafico-internacional-de-pasajeros-cae-un-60-en-2020-segun-la-oaci/

Agnew, J. (2001). The new global economy: time-space compression, geopolitics, and global uneven development. Journal of world-systems research, VII,2, 133-154. https://doi.org/10.5195/jwsr.2001.16.

Albers, S. \& Rundshagen, V. (2020). European airlines' strategic responses to the COVID-19 pandemic (January-May, 2020). Journal of air transport management, 87, 101863. https://doi.org/10.1016/j.jairtraman.2020.101863.

Amadeus (2021a). Seis tendencias que revitalizarán el espacio de los viajes en 2022. In: Amadeus. https://amadeus.com/ es/articulos/blog/seis-tendencias-que-revitalizaran-el-espacio-de-los-viajes-en-2022

Amadeus (2021b). COVID-19. Impacto y respuesta de Amadeus. In: Amadeus, Informe Global Amadeus 2020. https://corporate.amadeus.com/documents/es/recursos/informacion-empresarial/documentos-corporativos/informes-globales/2020/covid-19-impacto-y-respuesta-amadeus.pdf

Antón, F.J. \& Córdoba, J. (1999). La liberalización del transporte aéreo en España. Boletín de la Asociación de Geógrafos Españoles, 19, 113-132.

Atlas Magazine (2020). Impact of Covid-19 on the aviation sector. Report. https://www.atlas-mag.net/en/article/impactof-covid-19-on-the-aviation-sector

Bel, G. \& Fageda, X. (2006). Aeropuertos y Globalización: Opciones de gestión aeroportuaria e implicaciones sobre el territorio. IERMB. Universidad Autónoma de Barcelona.

Cano, G. (1980). El transporte aéreo en España. Ariel.

Cifuentes-Faura, J. \& Faura-Martínez, U. (2021). Situation of European airlines caused by COVID-19: restrictions, government subsidies and future prospects. Aviation, 25(4), 232-240. https://doi.org/10.3846/aviation.2021.15882.

Cinco Días (2020). La liberalización ferroviaria, un motor para la economía y la nueva movilidad. Cinco Días. https://cincodias.elpais.com/cincodias/2020/12/23/companias/1608755148_754350.html

Cinco Días (2021). La normativa europea de 'slots' mete presión sobre el futuro de Air Europa. Cinco Días. https://cincodias.elpais.com/cincodias/2021/11/05/companias/1636139071_872193.html

Chi, J. \& Baek, J. (2013). Dynamic relationship between air transport demand and economic growth in the United States: A new look. Transport Policy, 29, 257-260. https://doi.org/10.1016/j.tranpol.2013.03.005

Comisión Europea (2020). Telework in the EU before and after the COVID-19: where we were, where we head to. European Commission. https://ec.europa.eu/jrc/sites/jrcsh/files/jrc120945_policy_brief___covid_and_telework_final.pdf

Cordero, D. (2021). Gestair: la aerolínea española que capeó el temporal de la pandemia. El País. https://elpais.com/economia/2021-09-21/gestair-la-aerolinea-espanola-que-capeo-el-temporal-de-la-pandemia.html

Córdoba, J., Gago, C. \& Serrano, M. (2007). Transporte aéreo y espacialidad diferencial. En S. Gutiérrez \& J. Sanz (Eds.), Homenaje al Profesor J.M. Casas Torres (pp. 45- 64). Universidad Complutense.

Córdoba, J. \& Gago, C. (2010). Latin American cities and globalisation: change and permanency in the context of development expectations. Urban Studies, 47(9), 2003-2021. https://doi.org/10.1177/0042098010372680

Cumings, B. (1999). Still the American century. Review of International Studies, 25, 271-299. https://doi.org/10.1017/ S0260210599002715

Díez-Pisonero, R. (2016). El aeropuerto y la ciudad en los escenarios de la globalización: una simbiosis necesaria y cambiante (Tesis doctoral). Universidad Complutense, Madrid.

Dobruszkes, F. \& Van Hamme, G. (2011). The impact of the current economic crisis on the geography of air traffic volumes: an empirical analysis. Journal of transport geography, 19(6), 1387-1398. https://doi.org/10.1016/j.jtrangeo.2011.07.015.

Eurocontrol (2021). Plane and train: Getting the balance right. Aviation Sustainability Unit. Think Paper 11, 3 June 2021. https://www.eurocontrol.int/sites/default/files/2021-06/eurocontrol-think-paper-11-plane-and-train-right-balance.pdf

European Union- Agency for Raylways (2020). Report: Fostering the railway sector through the European Green Deal. ERA1234. https://www.era.europa.eu/sites/default/files/events-news/docs/fostering_railway_sector_through_european_green_deal_en.pdf 
Exceltur (2020). Impacto de la COVID-19 sobre el sector turístico español. Perspectivas Turísticas, nº 73, junio. https://www. exceltur. org/wp-content/uploads/2020/10/Informe-Perspectivas-N73-Balance-empresarial-y-escenario-impacto-Covid-19.pdf

Forer, P. (1978). A place for plastic space. Progress Human Geography, 2, $230-267$. https://doi. org/10.1177/030913257800200203

Gago, C. (2003). Región, Política y Transporte aéreo (Tesis doctoral). Universidad Complutense, Madrid.

Gámir, A. \& Ramos, D. (2011). Los pequeños aeropuertos regionales de la España peninsular: dinámicas recientes y perspectivas de futuro. Ería, 77- 102.

Gelhausen, M.C., Berster, P, \& Wilken, D. (2021). Post-COVID-19 Scenarios of Global Airline Traffic until 2040 That Reflect Airport Capacity Constraints and Mitigation Strategies. Aerospace, 8(10), 300. https://doi.org/10.3390/aerospace8100300

Graham, B. (1995). Geography and air transport. Wiley.

Harvey, D. (1983). Teorías, leyes y modelos en geografía. Alianza.

Henneberg, J.M., Tapiador, F.J. \& Campos, A. (2007). La eclosión de los aeropuertos regionales españoles. Universidad de Castilla-La Mancha, Lleida y Zaragoza. Fundación Abertis.

Hernández Luis, J.Á. (2010). El transporte aéreo interinsular como factor de cohesión territorial en las Islas Canarias. Revista Transporte y Territorio, 2, 38-67. https://doi.org/10.34096/rtt.i2.233

Hosteltur (2021a). El transporte aéreo se recupera de la pandemia más rápido de lo esperado. Hosteltur. https://www. hosteltur.com/lat/147511_el-transporte-aereo-se-recupera-de-la-pandemia-mas-rapido-de-lo-esperado.html

Hosteltur (2021b). La seguridad sanitaria, principal prioridad para Vueling. Hosteltur. https://www.hosteltur.com/142334_ la-seguridad-sanitaria-principal-prioridad-para-vueling.html

IATA (2020). El impacto del Covid-19 en la aviación europea. IATA. https://www.vadeaviones.com/2020/08/13/el-impactodel-covid-19-en-la-aviacion-europea/

IATA (2021). Key to Air Cargo Resilience Post Pandemic: Cooperation, Safety, Sustainability, Modernization. IATA. https://www. iata.org/en/pressroom/2021-releases/2021-10-12-01/

Inglada, V. \& Rey, B. (2004). Spanish air travel and the September 11 terrorist attacks: a note. Journal of Air Transport Management, 10, 441-443. https://doi.org/10.1016/j.jairtraman.2004.06.002

Ito, H. \& Lee, D. (2005). Assessing the impact of the September 11 terrorist attacks on U.S. airline demand. Journal of Economics and Business, 58, 75-95. https://doi.org/10.1016/j.jeconbus.2004.06.003

Ishutkina, M. \& Hansman, R.J. (2008). Analysis of Interaction between Air Transportation and Economic Activity. The 26th Congress of ICAS and 8th AIAA ATIO (p. 8888). https://doi.org/10.2514/6.2008-8888

Janelle, D.J. (1969). Spatial reorganization: A model and concept. Annals of the Association of American Geographers, 59, 348-364. https://doi.org/10.1111/j.1467-8306.1969.tb00675.x

Jánez, J.F. (2015). Una visión actualizada de la competencia entre el tren de alta velocidad y el avión. Revista de Alta Velocidad, 3, Octubre, 19-32.

Kim, M. \& Sohn, J. (2022). Passenger, airline, and policy responses to the COVID-19 crisis: The case of South Korea. Journal of air transport management, 98, 102144. https://doi.org/10.1016/j.jairtraman.2021.102144

Knowles, R. (2006). Transport shaping space: differential collapse of time-space. Journal of Transport Geography, 14, 407425. https://doi.org/10.1016/j.jtrangeo.2006.07.001.

Larsen, J., Urry, J. \& Auxhausen, K. (2006). Mobilities, networks, geographies. Ashgate. https://doi. org/10.1080/17450100600726654

Mason, K.J. (2021). Corona Markiert Eine Zäsur bei Geschäftsreisen. Airlines.de. 23- 08-2021. https://www.airliners.de/ airlinegeschaeftsmodelle-88-corona-markiert-zaesur-geschaeftsreisen/61658

Muñoz, R. (2021). AENA duplica pérdidas en el primer semestre hasta los 346,4 millones. El País, 28- 07- 2021. https:// elpais.com/economia/2021-07-28/aena-duplica-perdidas-en-el-primer-semestre-hasta-los-3464-millones.html

Ng, K.T., Fu, X., Hanaoka, S. \& Oum, T.H. (2022). Japanese aviation market performance during the COVID-19 pandemic-Analyzing airline yield and competition in the domestic market. Transport Policy, 116 (2022) 237-247. https:// doi.org/10.1016/j.tranpol.2021.12.006

OACI (2020). ICAO Report on the Effects of COVID-19 on Civil Aviation, 17 December 2020. ICAO. https://www.icao.int/sustainability/Documents/COVID-19/ICAO\%20COVID\%202020\%2012\%2017\%20Economic\%20Impact.pdf 
OACI (2021a). Effects of Novel Coronavirus (COVID-19) on Civil Aviation: Economic Impact Analysis, 17 September 2021. ICAO. https://www.icao.int/sustainability/Documents/COVID-19/ICAO\%20COVID\%202021\%2009\%2007\%20Economic\%20Impact\%20TH\%20Toru.pdf

OACI (2021b). Air Cargo. Priority brief. ICAO. https://www.icao.int/sustainability/Documents/ICAO-PRIORITY-BRIEF_ Air-Cargo_2021.04.19.FINAL.pdf

OACI (2021c). El volumen total de pasajeros en 2020 se redujo un 60 \% y el asalto de la COVID-19 a la movilidad internacional no se detiene. ICAO. https://www.icao.int/Newsroom/Pages/ES/2020-passenger-totals-drop-60-percent-as-COVID19-assault-on-international-mobility-continues.aspx

OECD (2021). OECD Economic Outlook, Volume 2021 Issue 2: Preliminary version. OECD. https://doi.org/10.1787/66c5ac2c-en Omic, J. \& Van Mieghem, P. (2010). Pandemics and networks: the case of the Mexican flu. World Congres on Engineering \& Computer Science (WCECS 10), 20-22 October 2010, San Francisco, USA.

Oprea, M. (2010). The effects of global economic crisis on the air transport of passengers in Europe and in Romania. GeoJournal of Tourism and Geosites, 5(1), 52-61.

Prussi, M. \& Lonza, L. (2018). Passenger aviation and high speed rail: a comparison of emissions profiles on selected European routes. Journal of Advanced Transportation, 2018. https://doi.org/10.1155/2018/6205714

Relp, E. (1976). Place and Placelessness. Londres: Pion.

Ribeiro, S.P., Silva, A.C., Dáttilo, W., Reis, A.B., Góes-Neto, A., Alcantara, L.C J. \& Azevedo, V.A.C. (2020). Severe airport sanitarian control could slow down the spreading of COVID-19 pandemics in Brazil. PeerJ, 8, e9446. https://doi. org/10.7717/peerj.9446

Rovira, M. (2020). La salida de Ryanair del aeropuerto de Girona deja en el aire 100 empleos. El País. https://elpais.com/espana/catalunya/2020-11-08/la-salida-de-ryanair-del-aeropuerto-de-girona-deja-en-el-aire-100-empleos.html

Serrano, J.M. (1999). Tráfico aéreo de pasajeros, turismo y red aeroportuaria en España a finales del siglo XX. Algunas consideraciones. Cuadernos de Turismo, 4, 73-88.

Serrano, J.M. \& García, R. (2015). Local low-traffic airports in Spain: problems and the necessary reorganisation of the territorial network. Boletín de la Asociación de Geógrafos Españoles, 67, 251-274.

Stein, J. (2001). Reflections on time, time-space compression and technology in the nineteenth century. In: J. May \& N. Thrift. Timespace: Geographies of Temporality (106-119). Routledge.

Sun, X., Wandelt, S., Zheng, C. \& Zhang, A. (2021a). COVID-19 pandemic and air transportation: Successfully navigating the paper hurricane. Journal of Air Transport Management, 102062. https://doi.org/10.1016/j.jairtraman.2021.102062

Sun, X., Wandelt, S., Fricke, H., \& Rosenow, J. (2021b). The Impact of COVID-19 on Air Transportation Network in the United States, Europe and China. Sustainability, 13(17), 9656. https://doi.org/10.3390/su13179656

Sorupia, E. (2005). Rethinking the role of transportation in tourism. In Proceedings of the Eastern Asia Society for Transportation Studies, 5, 1767-1777.

Unión Europea (1996). Directiva 96/67/CE del Consejo de 15 de octubre de 1996 relativa al acceso al mercado de asistencia en tierra en los aeropuertos de la Comunidad. Unión Europea. https://op.europa.eu/en/publication-detail/-/ publication/14ae9263-70dd-479a-9f5c-c1a1f40c148f/language-es/format-PDFA1B

Urry, J. (2000). Sociology Beyond Societies: Mobilities for the Twenty-first Century. Routledge.

Villarroya, J.M., Maudos, J., Monsálvez, J.M.P., Pastor, J.M. \& Martínez, L.S. (2006). Productividad e internacionalización: el crecimiento español ante los nuevos cambios estructurales. Fundación BBVA.

Vizcaíno, M.L. (2015). Evolución del turismo en España: el turismo cultural. International journal of scientific management and tourism, 1(4), 75-95.

Wensveen, J.G. \& Leick, R. (2009). The long-haul low-cost carrier: A unique business model. Journal of Air Transport Management, 15(3), 127-133. https://doi.org/10.1016/j.jairtraman.2008.11.012

Wyman, O. (2020). El impacto inmediato del coronavirus en el transporte aéreo será peor que el del 11S. Cotizalia Empresas. https:// www.elconfidencial.com/empresas/2020-05-25/impacto-inmediato-coronavirus-transporte-aereo-peor-11s_2609296/

Xuan, X., Khan, K., Su, C.W. \& Khurshid, A. (2021). Will COVID-19 Threaten the Survival of the Airline Industry? Sustainability, 13(21), 11666. https://doi.org/10.3390/su132111666 


\title{
Tendencias de investigación en Geografía Económica. Estudio bibliométrico de la Web of Science (1920-2020)
}

\section{Research trends in Economic Geography. Bibliometric study of the Web of Science (1920-2020)}

\author{
María Pilar Alonso-Logroño \\ pilar.alonso@udl.cat (10000-0002-4327-623X \\ Departament de Geografia i Sociologia. Universitat de Lleida. \\ Plaza Víctor Siurana, 1. 25003 Lleida, España \\ Nuria Bautista-Puig \\ nbautist@bib.uc3m.es@0000-0003-2404-0683 \\ Department of Industrial Management, Industrial Design and Mechanical Engineering. \\ University of Gävle. Kungsbäcksvägen 47, 801 76, Gävle, Suecia. \\ Universidad Carlos III de Madrid. Calle Madrid, 26. 28903 Madrid, España
}

INFO ARTÍCULO

Recibido: 20-12-2021

Revisado: 18-01-2022

Aceptado: 19-01-2022

\section{PALABRAS CLAVE}

Análisis bibliométrico Geografía Económica

Web of Science

Topic modelling

\section{KEYWORDS}

Bibliometric analysis

Economic geography

Web of Science

Topic modelling

\begin{abstract}
RESUMEN
Una de las primeras tareas para abordar cualquier trabajo académico es revisar las publicaciones llevadas a cabo sobre el tema. En este artículo se presenta una metodología que permite analizar las tendencias científicas en una disciplina a través de un análisis bibliométrico. En concreto, se examina su utilidad para estudiar los trabajos en el campo de la Geografía Económica; para ello se ha elegido como base de datos para su análisis la Web of Science (WoS). Con un conjunto de 4,307 publicaciones se analizan varios indicadores bibliométricos como la evolución de la producción científica, los agentes involucrados (países y organizaciones) y temas abordados, con el objetivo de ver la trayectoria del volumen de trabajos y las especializaciones temáticas de la Geografía Económica desde 1920 a la actualidad.
\end{abstract}




\section{INTRODUCCIÓN}

El incremento de la producción científica y la facilidad que ofrecen las redes provoca que el investigador, al revisar el tema sobre el que va a trabajar, se tenga que enfrentar al problema de la masificación de información bibliográfica. Puede verse desbordado si no utiliza herramientas adecuadas a la hora de realizar una búsqueda de los materiales que precisa. Para solventar este problema se puede acudir a la bibliometría, disciplina que permite, mediante el uso de herramientas, la identificación de la producción científica de una determinada temática, un actor (análisis de las publicaciones de un determinado país o institución) u otros niveles de análisis (por ejemplo, centrándose en las publicaciones de una o varias revistas especializadas) (Broadus, 1987). A través de los análisis bibliométricos se pueden analizar y caracterizar las distintas disciplinas, obteniendo información relevante de su trayectoria, de los patrones de colaboración, del impacto o la evolución de las temáticas, entre otras dimensiones.

Cada día son más frecuentes los estudios bibliométricos para conocer en profundidad las diferentes disciplinas, así como la identificación precisa de su producción y sus características. En el caso de la materia geográfica, algunas de sus ramas han tenido ya acercamientos de este tipo de análisis, sometiendo a una revisión sus producciones científicas. Así, Wang \& Liu (2014) trabajaron en una exploración bibliográfica sobre los estudios rurales en Geografía Humana, también Gorraiz, Gumpenberg \& Glade (2016) analizaron cuatro ramas de Geografía (Geoecología; Geografía Social y Económica; Demografía y Geografía de la población; Geografía Económica), entre las conclusiones que obtienen destacan que estas ramas tienen unas estrategias de publicación muy heterogéneas e individuales, incluso en el mismo campo de investigación. En 2019 un trabajo de Zhu, Jin \& He (2019) analiza la producción científica en Geografía Económica, centrándose sobre todo en la búsqueda de la línea central que ha seguido esta disciplina, indicando su gran variedad temática. En 2018 Kanai, Grant \& Lam (2018) utilizaron los análisis bibliométricos para el estudio de las temáticas urbanas. En 2019 Atienza et al. publicaron un trabajo apoyado en 55 revistas de la Web of Science (WoS) que se centra en estudiar a través de estudios bibliométricos las relaciones temáticas entre la Geografía y la Economía y la interdisciplinariedad de sus revistas.

Otros trabajos analizan la internacionalidad de la disciplina geográfica. Gutiérrez y López-Nieva (2001) en un estudio de una selección de 19 revistas de Geografía Humana de la WoS, determinaron que la mayoría no tienen un perfil internacional, sino que está más fragmentada en comunidades nacionales. En esta misma línea, Müller (2021) concluye que los productores del conocimiento en Geografía son anglófonos, mientras que la consumidores son cada vez más multilingües, situación que ocasiona que se pierdan la diversidad de conceptos, temas, estilos o localizaciones epistémicas que deberían constituirse como el distintivo de cualquier disciplina.

Recientemente en España también se han publicado algunos trabajos bibliométricos que aportan una información sobre algunas temáticas específicas en Geografía, como el trabajo de Salvador y Escolano (2018) sobre la revistas de Geografía indexadas en la WoS; en un artículo de Ródenas, Seguí-Pons \& Ruiz Pérez (2021), se analiza una revista concreta, "Journal of Transport Geography" entre 1993 y 2020, mostrando cómo las herramientas bibliométricas también tienen utilidad para diferentes unidades de análisis, por ejemplo, de revistas. Así mismo, en el trabajo de Corral y Espejo (2020), sus autores realizan un estudio de los artículos publicados en la revista Cuadernos Turísticos. En cualquier caso, no son muchos los análisis que encontramos desde una perspectiva bibliométrica en la disciplina geográfica, cuando realmente dada la variedad de temáticas y metodologías que se recogen detrás de ella, resulta necesario profundizar en esa diversidad interna que recogen sus contribuciones.

En este contexto, el objetivo de este artículo es presentar la utilidad de los análisis bibliométricos, para ello se toma el ejemplo de la producción científica de la Geografía Económica, dada la pluralidad temática que caracteriza a esta rama de la Geografía (Rosenman et al., 2020). Resulta útil acercarse a las técnicas que ofrece la bibliometría a la hora de ver resultados del estado de la cuestión del tema a abordar, y al que este trabajo intenta contribuir.

La estructura del artículo es la siguiente, tras la introducción, la sección 2 presenta la reflexión sobre la irregular trayectoria de la Geografía Económica y la necesidad de análisis que ayuden a aclarar su trayectoria, 
la sección 3 presenta la metodología de investigación 3. La sección 4 presenta los principales resultados. Finalmente, la sección 5 es el apartado de discusión y conclusiones que se derivan del análisis realizado.

\section{LOS CAMBIOS EN LOS ENFOQUES Y TEMÁTICAS DE LA GEOGRAFÍA ECONÓMICA}

En muchas disciplinas su trayectoria y enfoques son bastante lineales, ajustándose a una sucesión de paradigmas en cuanto a sus objetivos de estudio. En el caso de la Geografía vemos que los distintos cambios metodológicos han generado una evolución interna bastante convulsa, donde no es tan fácil ver una ruptura entre temas y metodologías. La Geografía ha pasado de ser la disciplina descriptiva del territorio, a ser una ciencia analítica y reflexiva, pero sin olvidar sus orígenes. Sin duda, las etapas que le ha tocado pasar han llevado a la Geografía a plantear métodos de trabajo nuevos, a acercarse a temáticas novedosas, que dieran respuestas a los problemas territoriales que una sociedad cambiante motivaba a realizar (Unwin, 1992).

Esta situación de diversidad que ha ido viviendo la Geografía plantea una necesidad de acercarse a las temáticas que los distintos trabajos han abordado y que las diferentes ramas de esta disciplina han ido abriendo a lo largo del tiempo. Es necesario tener presentes las aportaciones que se han ido realizando desde la Geografía e ir centrando las temáticas y las formas de trabajar a la hora de buscar aquellos trabajos que resulten útiles en las tareas a trabajar. Por ello, las aportaciones que se hagan sobre los análisis de la trayectoria de cuestiones y métodos que se han desarrollado a lo largo del tiempo son particularmente útiles en este campo de trabajo, donde a veces la diversidad puede parecer un caos, cuando realmente de ese caos surge la razón de la Geografía, el territorio y sus cambios.

La Geografía se ha visto en su trayectoria muy influida por los distintos cambios de paradigmas de la ciencia, planteados por Kuhn (1970), quien proporcionó una piedra angular en la discusión de las revoluciones de paradigmas. Destacó que un paradigma se crea cuando un individuo o grupo produce una síntesis o teoría que aporta más beneficios, tiene nuevas soluciones para los problemas y puede atraer a la mayoría de los científicos y profesionales de la próxima generación y alienta a los científicos a ver su participación en la investigación de manera diferente. Esto conducirá gradualmente a la desaparición de paradigmas anteriores, ya que el nuevo paradigma tiene más éxito que los anteriores. No obstante, el nuevo paradigma se enfrentará a desafíos y habrá científicos que se adherirán al viejo paradigma obstinadamente y, en muchos casos, desalientan la adopción de un nuevo paradigma. Sin embargo, habrá disciplinas, como la Geografía, en las que la convivencia y el pluralismo sea las que las defina y terminen definiéndola (Rosenman et al., 2020).

En este contexto, en este artículo se toma una de las ramas de la Geografía, la Geografía Económica, para comprobar esa convivencia y pluralismo, ya que es una de las disciplinas que ha ido pasando en su trayectoria por enfoques muy diversos en el tratamiento de los distintos temas que ha ido trabajando (Sánchez-Hernández, 2021). Los aportes que se han ido realizando en la Geografía Económica se han ajustado a los distintos paradigmas científicos, asumiendo los cambios en los intereses temáticos, en los modelos de acercamientos a los problemas planteados y también a las posibles soluciones ofertadas.

Pero, en esta disciplina, la ruptura de los distintos paradigmas científicos no es radical, sino que se observa una coexistencia entre enfoques teóricos y metodológicos, que hace que internamente no existan unos cambios radicales, sino una suma y una convivencia de temáticas (Méndez, 1997). Esto complica las búsquedas de los estados de la cuestión de los temas que se abordan. En la trayectoria de esta rama geográfica a los temas clásicos se han ido sumando otros derivados de la adopción de los planteamientos metodológicos, y también como resultado de los propios cambios en los tipos de funcionamientos de los sistemas económicos imperantes. Aunque la Geografía Económica a veces pueda dar la imagen de una rama poco consolidada, por sus diversos ámbitos y centros de trabajo (Rosenman et al., 2020), pero en realidad esta situación debe considerarse como un enriquecimiento.

Es necesario tener siempre presente que la Geografía Económica es una rama que se ha ido redefiniendo, ajustándose no solo a los cambios de los distintos paradigmas científicos, sino también en sus adaptaciones ha estado muy condicionada por las diversas situaciones sociales, políticas y económicas que han ido aconteciendo. Los investigadores que han trabajado en ella han tenido que adecuarse a los cambios y 
de ahí el posible "caos" temático que pueda parecer que presenta esta rama, que no es más que el fruto del propio carácter dinámico en la relación entre los procesos económicos y el desarrollo de los territorios, así como sus problemáticas.

Por tanto, en la trayectoria de esta rama de la Geografía, no existe una evolución lineal, donde observar que tras un paradigma le sustituye otro, sino que hay una superposición de diferentes escuelas de pensamiento que van nutriéndola de perspectivas, metodologías y donde se van añadiendo temas de trabajo, pero sin olvidar los anteriores (Sánchez-Hernández, 2021). Van surgiendo nuevos campos a la vez que se mantiene el interés por los anteriores. Por ello, es necesario mantener en la perspectiva de análisis, los enfoques más tradicionales, pero también los más recientes.

Los principales enfoques de la Geografía Económica parten de su consolidación como disciplina científica a finales del siglo XIX coincidiendo con una serie de acontecimientos: el Congreso Internacional de Geografía en 1875 donde se instituyó como rama de la Geografía; la publicación en Gran Bretaña de primer manual de Geografía Económica, "Handbook of comercial geography” de Chisholm en 1889 o la institucionalización como disciplina universitaria en la Universidad de Cornell en EE. UU. en 1893. En esta primera etapa de la Geografía Económica institucionalizada, los análisis de cuestiones económicas empezaron a tener autonomía en los trabajos de los geógrafos. Las temáticas principales que se trabajan se apoyan en la descripción y en las corrientes imperantes del historicismo y del determinismo ambiental, que otorgaban un papel importante a la relación de la condiciones del medio físico con las ocupaciones de la población, pero siempre bajo la perspectiva de realización de inventarios de los recursos naturales vinculados con las actividades económicas con el determinismo ambiental (minería, agricultura, industrias,...). Los objetivos de las aportaciones de esta etapa se centraron en un proyecto de tipo ambiental, donde imperaba la relación entre recursos naturales y desarrollo económico (Sánchez-Hernández, 2021).

Pero, los años cincuenta del siglo XX, los análisis regionales apoyados en la descripción son dejados al margen por un grupo de geógrafos que empiezan a plantear una aproximación de tipo cuantitativo. En la reivindicación de esta postura se defiende el uso de teorías y modelos para explicar los problemas territoriales de la localización. En este planteamiento los geógrafos económicos se implican de manera importante, y buscan esta postura como base para explicar la localización y la organización espacial derivada de la actividad económica. La estadística se convierte en una de las herramientas principales que utilizan, frente a la observación que manejan los geógrafos más tradicionales. Sin embargo, el exceso en el uso de las matemáticas también tuvo su respuesta entre los geógrafos, que ven la necesidad de preocuparse por los problemas de la organización social y los recursos económicos, donde temas de segregación económica, de pobreza, de mercados laborales o de reestructuración de la actividad industrial, pasan a preocupar a los geógrafos que se engloban bajo el paradigma de la Geografía Radical.

También desde los años 1980 se asiste a movimientos donde la cultura se convierte en el centro de las explicaciones y aparecen temas como el género en los diferentes mercados laborales, las redes sociales para la formación de economías alternativas, paisajes económicos vinculados a las presencias de determinadas actividades, entre otros. La Geografía Económica sufrió un enriquecimiento en el que factores sociales, políticos o psicológicos se introdujeron en la explicación de los diferentes procesos. En la que se puede considerar la tercera de las fases de la trayectoria de la Geografía Económica, con todo el anterior bagaje de corrientes mencionado y a las que se van sumando en las últimas décadas nuevos proyectos como el proyecto estructuralista, en que las explicaciones de los procesos se centran en la búsqueda de la interrelación entre estructuras globales y trayectorias locales. A estas nuevas corrientes también se le suma el reencuentro de la Geografía Económica y la Regional, mediante una reformulación de su relación, y también los argumentos de la Geografía Económica Evolucionista, en el que interesa el paisaje económico (Sánchez Hernández, 2021), cuyos estudios se caracterizan por relacionar los fenómenos que ocurren en la economía con principios biológicos propios de las ciencias naturales.

Encontramos por tanto una adición de proyectos aparentemente heterogéneos que se pueden albergar bajo el paraguas de "nuevas geografías económicas", donde lo que cobra importancia es la explicación de factores y procesos económicos sobre el espacio cambiante, en donde se hablara del espacio bajo el paraguas de economías de mayor desarrollo (ganadores) y de espacios más atrasados (perdedores), que 
generaran desequilibrios territoriales, ya que los espacios ganadores estarán conectados por redes, frente a las regiones marginales que estarán excluidas. Preocupaciones asociadas a temas que se van sumando al quehacer geográfico, donde surgen unidades de análisis como los distritos industriales o la globalización organizada a partir de las multinacionales o la innovación, pero también otros temas como las prácticas económicas alternativas y bajo este paraguas siembre un proyecto ambiental que resulta clave (Sánchez Hernández, 2021).

Estas tres fases de perspectivas adoptadas desde la Geografía Económica han acumulado metodologías diversas que van desde técnicas cualitativas con entrevistas, observación participante o encuestas, así como temáticas variadas, que se han ido añadiendo y que están presentes en los estudios más actuales y que se pueden seguir a través de los estudios bibliométricos. La Geografía Económica no ha sido una rama que haya avanzado en paradigmas descartando lo anteriores, sino que ha ido enriqueciéndose, sumando perspectivas, en un proceso de hibridación (Sánchez Hernández, 2021), donde es necesario profundizar en lo hecho y en lo que se está haciendo dentro de esta rama del conocimiento para ayudar a comprender con su trayectoria el funcionamiento de la economía sobre los territorios.

En este contexto, la aproximación a la investigación en Geografía Económica, disciplina con una trayectoria bastante divergente en cuanto a sus aportaciones, exige tener conocimiento de lo que estudia, de cuáles son sus principales contenidos temáticos, de cómo están evolucionando. Por ello los estudios bibliométricos son una solución ya que permiten observar y definir cronologías y temáticas que se han ido trabajando en esta rama, que se presenta como una materia muy abierta, e incluso desordenada, en cuanto a los contenidos que ha ido abordando.

\section{METODOLOGÍA}

Para el acercamiento a la trayectoria temática de la Geografía Económica, se utilizó un enfoque bibliométrico, es decir un análisis cuantitativo de las producciones científicas. Los pasos que se siguieron para ello fueron los siguientes: (i) Formulación de una estrategia de búsqueda para identificar la producción científica sobre Geografía Económica; (ii) Recopilación de datos y procesamiento de información; (iii) Definición y análisis mediante el uso de indicadores bibliométricos.

(i) Formulación de una estrategia de búsqueda. Para esta fase se diseñó una táctica de búsqueda para la recuperación de la producción de la rama de Geografía seleccionada, indagando en los campos de título, resumen y palabras clave (campo TS). Para esta búsqueda, se utilizaron las bases de datos de la Colección principal de la Web of Science (WOS), es decir, la Science Citation Index (SCI), Social Science Citation Index (SSCI) y Arts and Humanities Citation Index (A\&HCI). Se consideraron todos los años que contienen estas bases y se incluyeron todas las tipologías documentales. A pesar de las limitaciones de esta base de datos (Gómez-Caridad \& Bordons, 1996), su elección permitió una recopilación de aquellos trabajos indexados en las revistas incluidas en dicha base. La estrategia utilizada fue la siguiente:

\section{- Geografía económica: TS="economic-geography" AND TS="econom* geography"}

Esta estrategia de búsqueda permitió identificar la literatura básica (core), es decir, aquellos documentos relacionados de forma explícita con la Geografía Económica presente en la base de trabajos elegida para este análisis (WoS). El motivo de la elección de esta base es porque es una base de datos multidisciplinar, formada por una amplia colección de bases de datos bibliográficas, citas y referencias de publicaciones científicas de cualquier disciplina del conocimiento, siendo una de las bases de referencia para este tipo de estudios (Salvador \& Escolano, 2018).

(ii) Recuperación de resultados científicos y procesamiento de información. En esta segunda fase se descargaron los datos de las publicaciones de la WoS obtenidos de la consulta (en formato *.txt) y se exportaron a una base de datos relacional creada con MySQL, en la cual se ingresaron todos los registros. 
(iii) Definición de indicadores bibliométricos. Se analizaron los siguientes indicadores para el conjunto recopilado:

a) Patrones de investigación:

- Evolución anual de la producción científica y tasa de crecimiento promedio acumulada (o CAGR) medida a través de la siguiente fórmula.

$$
C A G R=\left(\sqrt[n-1]{\frac{x_{n}}{x_{1}}}-1\right) * 100
$$

Dónde y son los valores de inicio y final del período estudiado.

- Producción por instituciones y países: valores absolutos e Índice de Actividad que evalúa el grado de especialización de un país en un determinado tema (Frame, 1977), representando la contribución porcentual de cada país a la producción total de WoS, en comparación con el porcentaje de contribución en el tema analizado. La fórmula se detalla a continuación:

$$
A I=\frac{G \cdot E c o n \cdot A c}{G . E c o n . \text { WoS }}, \frac{\text { Total produccion Ac }}{\text { Total produccion WoS }}
$$

Dónde:

G.Econ. Ac es el total producción total de un actor (país) sobre un tema (Geografía Económica) en la WoS;

G.Econ.WoS es la producción total en Web of Science en Geografía Económica $(n=4307)$;

Total producción Ac es la producción total de un actor (país) en WoS en el mismo período;

Total producción WoS es el número total de documentos en WoS durante el período ( $n=67.546 .640)$,

Para este análisis, se han considerado las instituciones normalizadas de la WoS. Los datos posteriormente fueron mapeados con el software ArcGIS.

- Patrones de colaboración (nacional / internacional / sin colaboración). La colaboración nacional ocurre cuando al menos dos instituciones del mismo país contribuyen en el trabajo; colaboración internacional cuando hay instituciones de más de un país, y sin colaboración significa que el autor/es es/son de una sola institución.

- Impacto. Este apartado recopila aquellos trabajos en Geografía Económica que han tenido un mayor impacto, medido en número de citas totales.

b) Especialización temática:

- Categorías Web of Science (WoS). Este análisis permite mostrar un esquema de categorización de diferentes áreas de conocimiento de la WoS'1. Todos los libros y revistas incluidos en la colección principal de esta base de datos se asignan al menos a una de estas categorías. Las áreas de investigación se dividen en cinco grandes categorías (Artes y Humanidades; Ciencias de la Vida y Biomedicina; Ciencias Físicas; Ciencias Sociales; Tecnología) que a su vez se dividen en múltiples subáreas de investigación.

- Definición de temas mediante técnica de topic modelling, mediante los títulos y los abstracts de las publicaciones de los documentos recopilados mediante la estrategia de búsqueda realizado. Esta técnica probabilística permite identificar y aprender "temas" de un corpus de documentos.

1 Áreas de la Web of Science: http://images.webofknowledge.com/WOKRS522_2R1/help/es_LA/WOS/hp_research_areas_easca.html 
Con esta metodología cada documento es entendido como un conjunto de palabras (uni-gramas) que pueden combinarse en conjuntos o sacos de palabras (bags of words o topics) formados por aquellas que aparezcan más juntas de manera más frecuente (mayor co-ocurrencia). Mediante la selección de un umbral de probabilidad, cada documento se encuadra en uno o varios temas. Mediante este análisis un tema se define como una distribución de probabilidad sobre un vocabulario, donde las palabras con una alta probabilidad para el mismo tema tienden a tener una coocurrencia frecuente en los mismos documentos. Para realizar este análisis, primero se procedió a una depuración de los datos (eliminación de stopwords, espacios, etc.) mediante el software R (R Core Team 2020) y el uso del paquete tm (Feinerer \& Hornik, 2020). Para el análisis del topic modelling, se entrenó el dataset mediante el modelo Latent Dirichlet Allocation (LDA) en Python y se decidió utilizar un total de 15 clústeres de temas ya que este valor facilitaba la interpretación de los resultados. Además, se analizó la intensidad de los temas del período 1980 a 2020, para observar los cambios más recientes.

- Mapa de coocurrencias de palabras clave utilizando la herramienta VOSviewer (Van Eck y Waltman, 2017) para identificar grupos temáticos dentro del panorama científico. El tamaño de los nodos del mapa muestra la frecuencia de cada uno de los keywords obtenidos, los enlaces (links) las relaciones de co-ocurrencia entre dos términos (cuantas más veces aparecen juntos, tienen una conexión más grande) y los clústers (colores) indican la afinidad de los temas.

- Identificación de los Hot topics. Este tipo de análisis permite ver cuáles han sido los temas que han llamado más la atención en la literatura científica (medido por el aumento repentino del número de citaciones) utilizando el algoritmo de Kleinberg (2003). Para su identificación en el dataset de Geografía Económica se utilizó el software CiteSpace².

Explorar todos estos aspectos, a través de la base de datos de WoS, permite comprender mejor la configuración de la diversidad temática de la Geografía Económica, ver cuáles han sido las líneas más citadas, las instituciones que han aportado más trabajos de esta disciplina, etc. Con esta aproximación se quiere comprobar la utilidad de los estudios bibliométricos para conocer todos estos aspectos de referencia sobre las aportaciones científicas de una disciplina, como la Geografía Económica, que como se ha comentado, es cambiante y donde la hibridación de los proyectos científicos la caracteriza (Sánchez Hernández, 2021).

\section{RESULTADOS}

\subsection{Patrones de investigación}

Tras la consulta, descarga y análisis de la producción científica de Geografía Económica indexada en la WoS se identificaron 4.307 documentos en el período 1920-2020, con un crecimiento acumulativo medio de $8.12 \%$ (figura 1). En cuanto a la evolución de la producción científica, esta disciplina acumula un gran número de publicaciones a partir de los años 2000 (80,8\% de su producción). Sin duda, dentro de la explicación de esta trayectoria está la propia relevancia reciente alcanzada por las publicaciones en revistas indexadas en esta base de datos, que se ajustan a los requerimientos de evaluación de muchos concursos de promoción del profesorado o para evaluar la calidad de las publicaciones de las instituciones académicas. Los investigadores, por presiones de los sitemas de evaluación de la investigación, empiezan a buscar las revistas contenidas en las bases de datos indexadas, y que evalúan el factor de impacto. En cualquier caso, la explicación de este incremento también está relacionado con el recuperado interés de los economistas regionales de la que ellos denominan “Nueva Geografía Económica” (Krugman, 1997) y cuya literatura justificativa también es muy prolífica entre las revistas de esta base.

2 http://cluster.cis.drexel.edu/ cchen/citespace/ 
En este sentido, aun siendo conscientes de que nuestra búsqueda puede tener un cierto sesgo por aquí, no invalida el objetivo del trabajo, ya que con el análisis de los topic modelling y los Mapa de coocurrencias, se llega a encontrar los temas de trabajo que esconden estos trabajos que en principio se definen tanto en títulos, palabras clave o resumen por la presencia de las palabras de los términos definidos en la estrategia utilizada. Todo ello justifica que Geografía Económica empieza a tener un peso en las aportaciones de esta base de manera más notable desde el comienzo del siglo XXI, progresión que ha ido al alza, registrando en 2020 el mayor número de aportaciones, con casi 300 documentos. Esto demuestra que estamos ante una disciplina en crecimiento en la producción científica, con un importante dinamismo en las dos primeras décadas del siglo XXI.

Además de comprobar el crecimiento de los trabajos publicados en esta base de datos es interesante saber cuáles son las instituciones a las que pertenecen los investigadores que aportan estos trabajos; así en la tabla 1 se muestra el top 10 de las instituciones más prolíficas en esta rama. La mayor parte de las organizaciones son Universidades del Reino Unido y Estados Unidos, aunque también encontramos instituciones de Países Bajos, Suecia o Canadá. Todos ellos son centros de alto nivel en cuanto a las producciones y concentración de investigadores. La primera institución académica con más número de trabajos de Geografía Económica que publica en la WoS es la University of London (Reino Unido) con más de 180 documentos, seguida de la University of Oxford (Reino Unido) con 93. Es de destacar el número de instituciones inglesas con trabajos publicados en la WoS, así de las 10 primeras 5 son del Reino Unido.

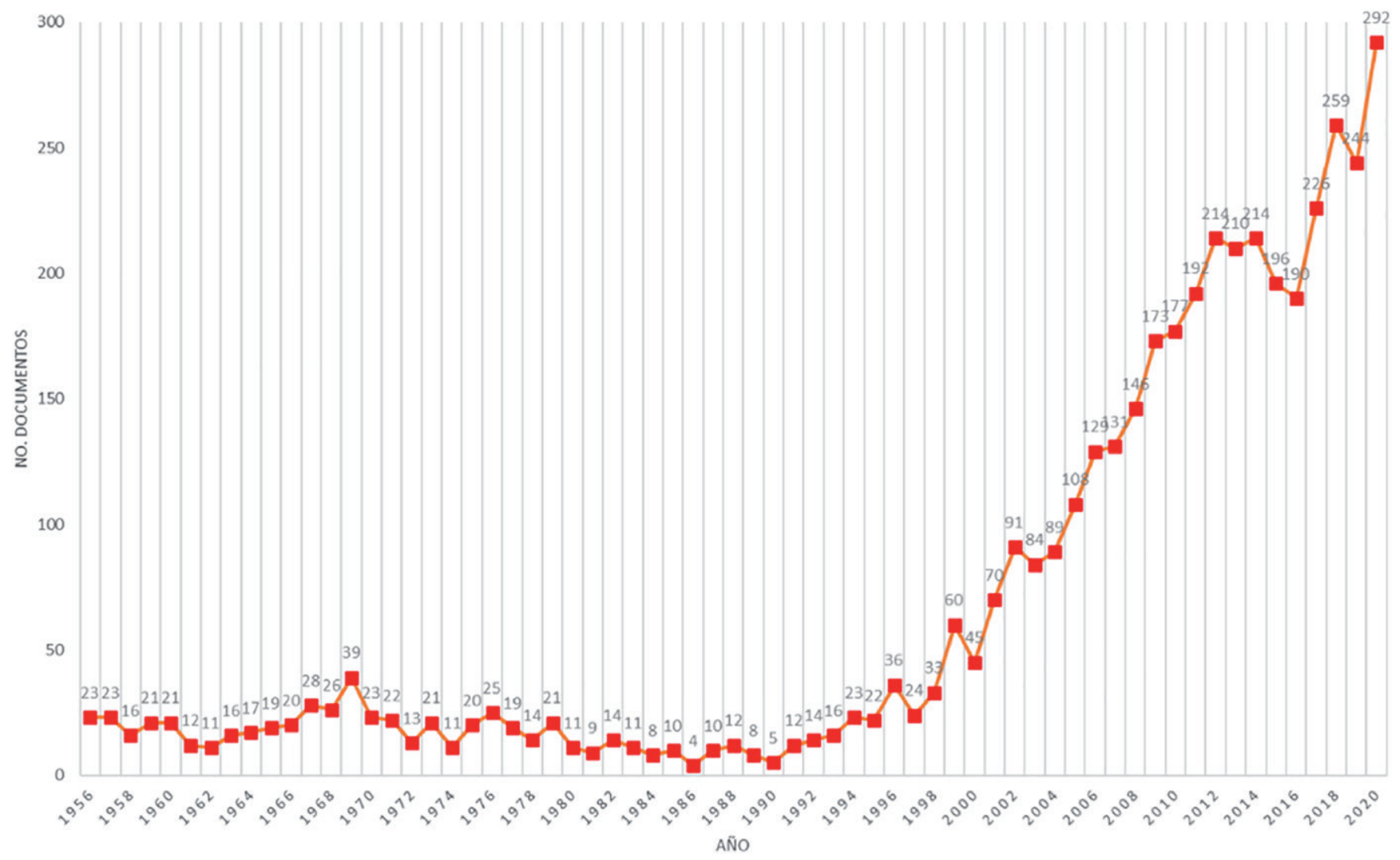

Figura 1. Distribución de publicaciones de Geografía Económica (1956-2020). Fuente: WoS. Elaboración propia. Nota: los cuatro documentos anteriores a 1956 no se muestran por ser discontinuos en el tiempo. 
Tabla 1. Top-10 instituciones en Geografía Economía.

\begin{tabular}{|l|c|}
\hline \multicolumn{1}{|c|}{ Institución } & G. Económica \\
\hline \multicolumn{1}{|c|}{ No. Docs. } \\
\hline University of London (Reino Unido) & 185 \\
\hline University of Oxford (Reino Unido) & 93 \\
\hline Utrecht University (Países Bajos) & 89 \\
\hline London School Economics Political Science (Reino Unido) & 85 \\
\hline University of California System (Estados Unidos) & 85 \\
\hline University of Cambridge (Reino Unido) & 73 \\
\hline Lund University (Suecia) & 67 \\
\hline University of Toronto (Canadá) & 65 \\
\hline National University of Singapore (Singapur) & 62 \\
\hline Newcastle University (Reino Unido) & 61 \\
\hline
\end{tabular}

Fuente: WoS. Elaboración propia.

Otra información que se obtiene del análisis realizado es la procedencia por países de los autores de los documentos analizados. Esta información se plasmó sobre un mapa donde se observa que países como Gran Bretaña, Estados Unidos, China o Alemania las que más número de documentos tienen publicados en el periodo analizado. Sobre todo, cabe destacar los dos primeros países, con más de 900 documentos cada uno. Sin embargo, al analizar por índice de actividad se observa una mayor especialización en el tema en el conjunto de sus aportaciones científicas en la WoS en comparación a las de otros campos en países como Noruega, Suecia, Finlandia, Chile, Eslovenia o Singapur (figura 2). España ocupa el lugar 21 del ranking por indice de actividad, lo que la sitúa en un campo de interes significativo, pero donde hay que mencionar la interrelación disciplinaria con las publicaciones de economistas espaciales, como más adelante se señala.

\subsection{Colaboración}

Si consideramos los patrones de colaboración de los autores que publican artículos relacionados con Geografía Económica, 898 documentos (20,8\%) son en colaboración internacional, 772 en colaboración nacional (17,2\%) y 2.637 sin colaboración (61.2\%). Si consideramos los últimos 20 años es la colaboración internacional la que ha crecido de forma más significativa (con un crecimiento de un 15,5\%), denotando una mayor colaboración con autores de ámbito internacional (figura 3), aunque el tipo de patrón predominante es el de autorías del mismo centro, con esa tendencia reciente apuntada, que en 2020 es bastante significativa. En esto quizás el aislamiento presencial y la mayor utilización de las redes para trabajar también puede ser un elemento explicativo.

\subsection{Impacto}

En términos de impacto, medido por el número de citas absolutas de los trabajos recopilados, la tabla 2 muestra los más altamente citados, con más de 1.000 citas. Lidera el ranking el trabajo de Krugman (1991) en el que desarrolla un modelo de análisis de los patrones de localización de actividades de centro-periferia en función de los costes de transporte y las economías de escala atendiendo a patrones de los procesos de industrialización. Por otro lado, le sigue el trabajo de Porter (1998) en el que habla de los clústeres y la economía de competición 
y Boschma (2005) con un análisis crítico de la proximidad espacial y la innovación. De los 7 trabajos tomados como ejemplo de temáticas de la cabecera con mayor índice de impactos, muestra la gran variedad de temáticas que se acogen dentro de la Geografía Económica.

De estos trabajos salvo 2 que están hechos con la implicación de geógrafos, el resto son investigadores de otras disciplinas con lo cual hay que valorar que no todos los trabajos aportados en el patrón de búsqueda están planteados desde la disciplina geográfica. Pero también hay que valorar la interrelación de las materias afines, y para la Geografía Económica la Economía lo es, ya que lo importante es ver las temáticas que bajo este paraguas preocupan a la sociedad y que son los que se abordan en todos estos trabajos.

Junto con los autores más citados también es de interés saber cuáles son las revistas más utilizadas para presentar los trabajos obtenidos mediante la estrategia de búsqueda realizada. Para ello la tabla 3 representa a las revistas con más de 50 documentos. Es de destacar que la mayoría de las revistas ocupan los primeros cuartiles del ranking del Journal Citation Reports (edición 2020), en el área de Geografía, lo que está indicando que se encuentran en revistas de relevancia dentro de su ámbito de conocimientos si se atiende a la citación de los trabajos de estas revistas.

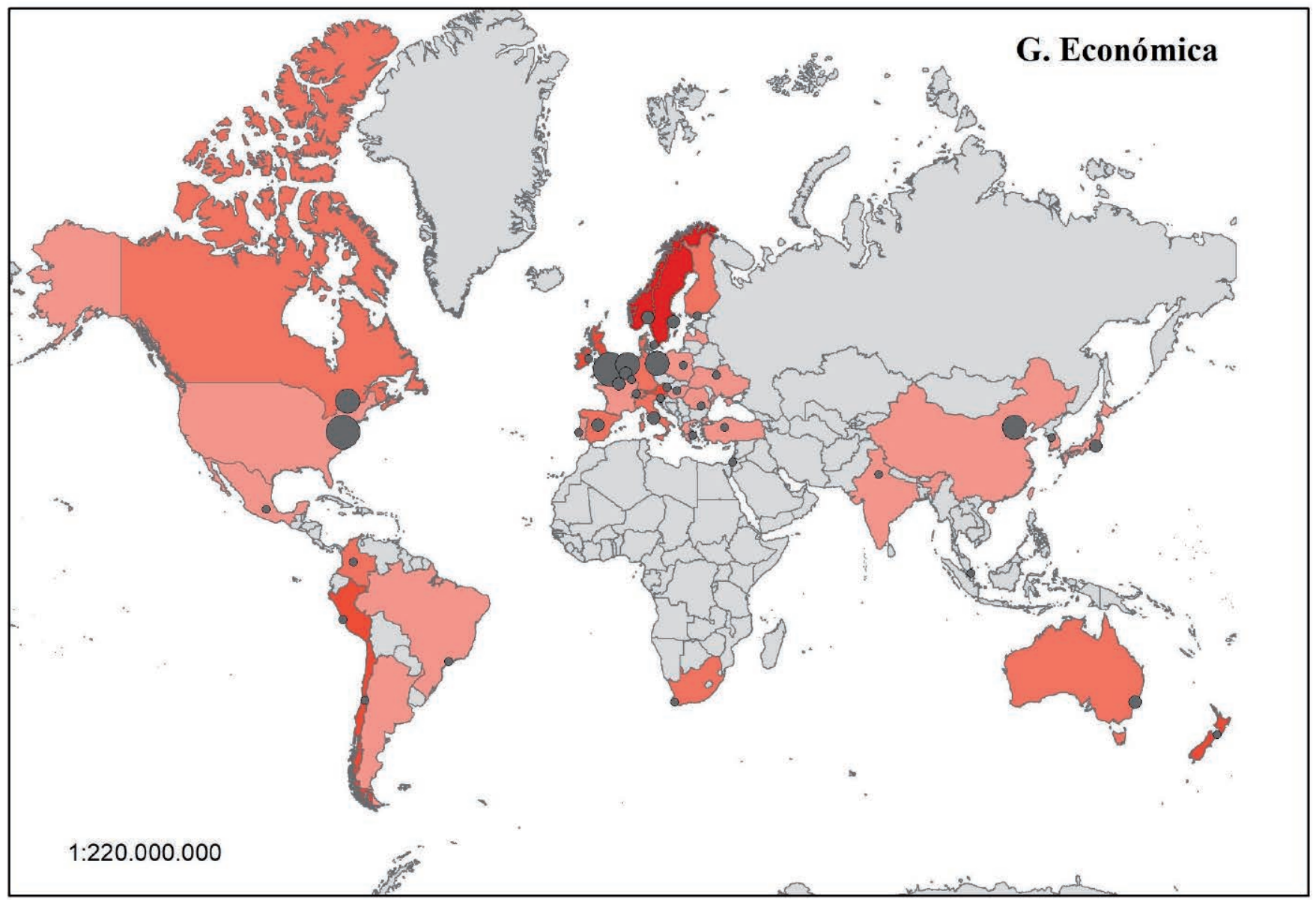

\section{Índice de actividad $\mathbf{N}$. documentos}

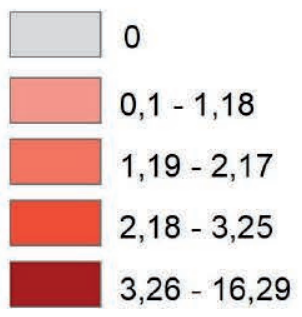

- $1-89$

- $90-182$

$183-332$

$333-982$

Figura 2. Distribución de la producción científica de G. Económica (>5 docs.) e Índice de Actividad 1920-2020. Fuente: WoS, ArcGis. Elaboración propia. 


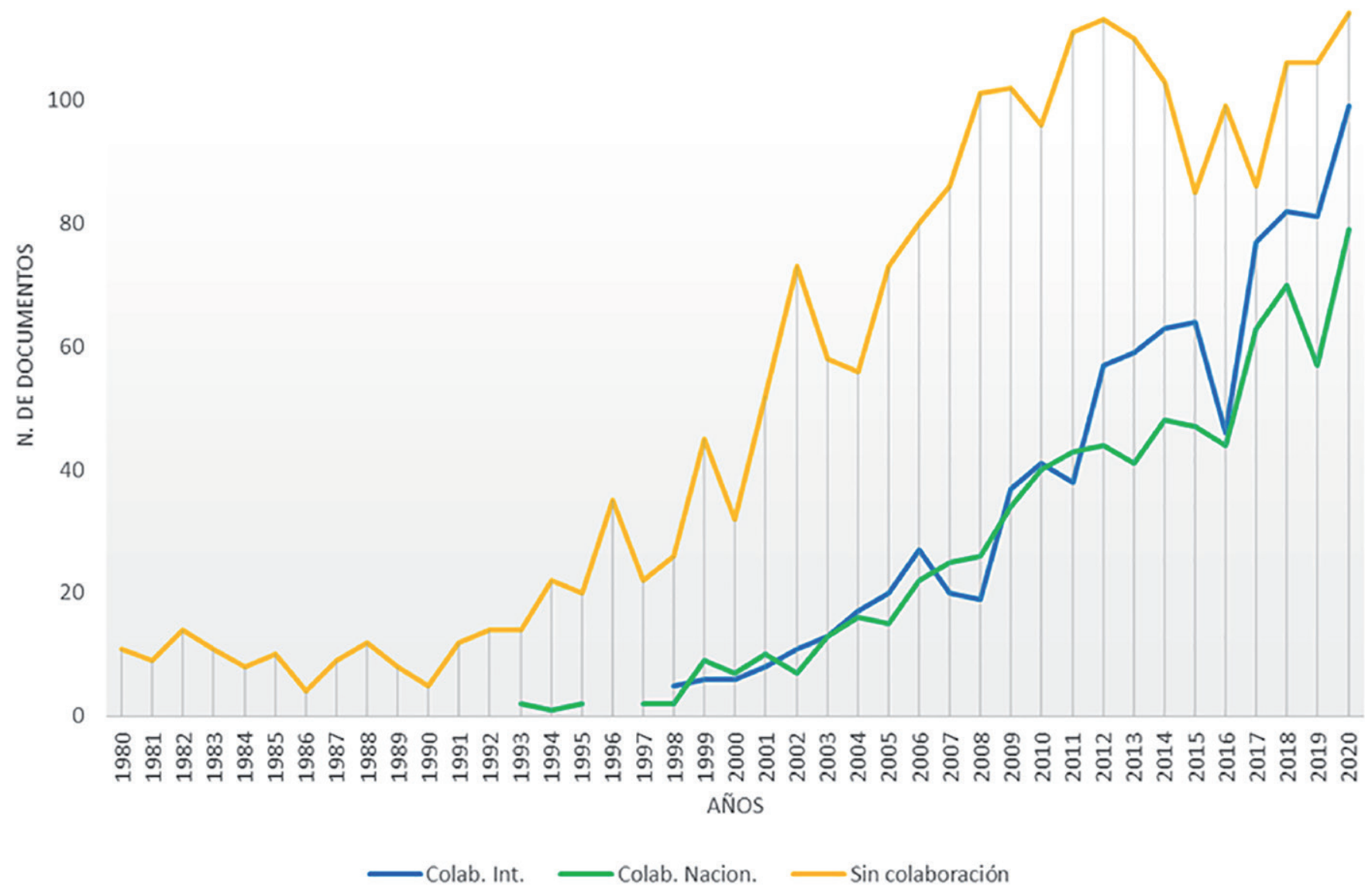

Figura 3. Evolución de los documentos en colaboración (nacional, internacional y sin colaboración) de 1980 a 2020. Fuente: WoS. Elaboración propia.

Tabla 2. Artículos altamente citados en Geografía Económica (>1000 citas).

\begin{tabular}{|l|c|}
\hline \multicolumn{1}{|c|}{ Trabajo } & \multicolumn{1}{|c|}{ Número de citas } \\
\hline $\begin{array}{l}\text { Krugman, P. (1991). Increasing returns and economic geography. Journal of } \\
\text { political economy, 99(3), 483-499. }\end{array}$ & 3.877 \\
\hline $\begin{array}{l}\text { Porter, M. E. (1998). Clusters and the new economics of competition (Vol. } \\
\text { 76, No. 6, pp. 77-90). Boston: Harvard Business Review. }\end{array}$ & 2.960 \\
\hline $\begin{array}{l}\text { Boschma, R. (2005). Proximity and innovation: a critical assessment. } \\
\text { Regional studies, 39(1), 61-74. }\end{array}$ & 1.857 \\
\hline $\begin{array}{l}\text { Porter, M. E. (2000). Location, competition, and economic development: } \\
\text { Local clusters in a global economy. Economic development quarterly, 14(1), } \\
\text { 15-34. }\end{array}$ & 1097 \\
\hline $\begin{array}{l}\text { Markard, J., Raven, R., \& Truffer, B. (2012). Sustainability transitions: An } \\
\text { emerging field of research and its prospects. Research policy, 41(6), 955- } \\
\text { 967. }\end{array}$ & 1.112 \\
\hline $\begin{array}{l}\text { Owen-Smith, J., \& Powell, W. W. (2004). Knowledge networks as channels } \\
\text { and conduits: The effects of spillovers in the Boston biotechnology } \\
\text { community. Organization science, 15(1), 5-21. }\end{array}$ & \\
\hline $\begin{array}{l}\text { Martin, R., \& Sunley, P. (2006). Path dependence and regional economic } \\
\text { evolution. Journal of economic geography, 6(4), 395-437. }\end{array}$ & 1.085 \\
\hline
\end{tabular}

Fuente: WoS. Elaboración propia. 
Tabla 3. Revistas donde más trabajos se publican (> 50 publicaciones). Entre paréntesis se indica el cuartil de cada revista según el JCR 2020.

\begin{tabular}{|c|c|c|}
\hline Revista & Número de documentos & $\%$ \\
\hline Journal Of Economic Geography (1Q) & 239 & 5,55 \\
\hline Economic Geography (1Q) & 224 & 5,20 \\
\hline Environment and Planning A-Economy And Space $(2 \mathrm{Q})^{*}$ & 176 & 4,09 \\
\hline Regional Studies (1Q) & 174 & 4,04 \\
\hline European Planning Studies (2Q) & 120 & 2,79 \\
\hline Tijdschrift Voor Economische En Sociale Geografie (2Q) & 105 & 2,44 \\
\hline Geoforum (1Q) & 101 & 2,35 \\
\hline Progress In Human Geography (1Q) & 97 & 2,25 \\
\hline Professional Geographer (3Q) & 88 & 2,04 \\
\hline Geography (2Q) & 79 & 1,83 \\
\hline Journal Of Regional Science (2Q) & 78 & 1,81 \\
\hline Regional Science And Urban Economics(2Q) & 72 & 1,67 \\
\hline Papers In Regional Science (2Q) & 70 & 1,63 \\
\hline $\begin{array}{l}\text { Annals Of The Association Of American Geographers (sin } \\
\text { determinar) }\end{array}$ & 64 & 1,53 \\
\hline Annals Of Regional Science (2Q) & 57 & 1,49 \\
\hline Zeitschrift Fur Wirtschaftsgeographie (3Q) & 54 & 1,32 \\
\hline
\end{tabular}

Fuente: WoS. Elaboración propia.

Nota: la Revista Environment and Planning A-Economy And Space engloba su producción, así como la antigua denominación de la revista (Environment And Planning A, EPA).

\subsection{Especialización por categorías de áreas de revista}

La Geografía Económica centra su producción en la categoría WoS de 'Geografía' (2.454 documentos, 56,98\%), así como Economía (1.876 documentos, 43,56\%) (figura 4). La siguiente categoría es 'Estudios Medioambientales' así como los temas urbanos, denotando el interés por el medio ambiente y el foco en los núcleos urbanos en la producción científica de esta rama. Esto sugiere que son temas que abordan la interacción entre el espacio y la economía.

\subsection{Topic modelling}

La tabla 4 resume los 15 clústeres de temas identificados mediante técnicas de topic modelling de la producción científica en Geografía Económica. En estas agrupaciones de palabras que se agrupan en distintos trabajos, se observa cómo unos temas son más sobre mercados/comercios (Topic 0, Topic 2, Topic 4), otros se centran más en espacios rurales (Topic 8 ) o urbanos (Topic 6, Topic 9) o incluso en temas de emprendimiento (Topic 14). Sin embargo, tal y como se observa en la figura 5 que muestra la intensidad de esos clústers en los últimos cuarenta años (período 1980-2020), no todos los temas han atraído el mismo interés. Temas espaciales (por ejemplo, regiones en vías de desarrollo como África (Topic 11) o China (Topic 6) o el emprendimiento (Topic 14) tuvieron más relevancia en los años 80-90; sin embargo, el análisis institucional o incluyendo a la sostenibilidad (Topic 5) o el transporte (Topic 4) han cobrado más relevancia recientemente, a partir del año 2000. 

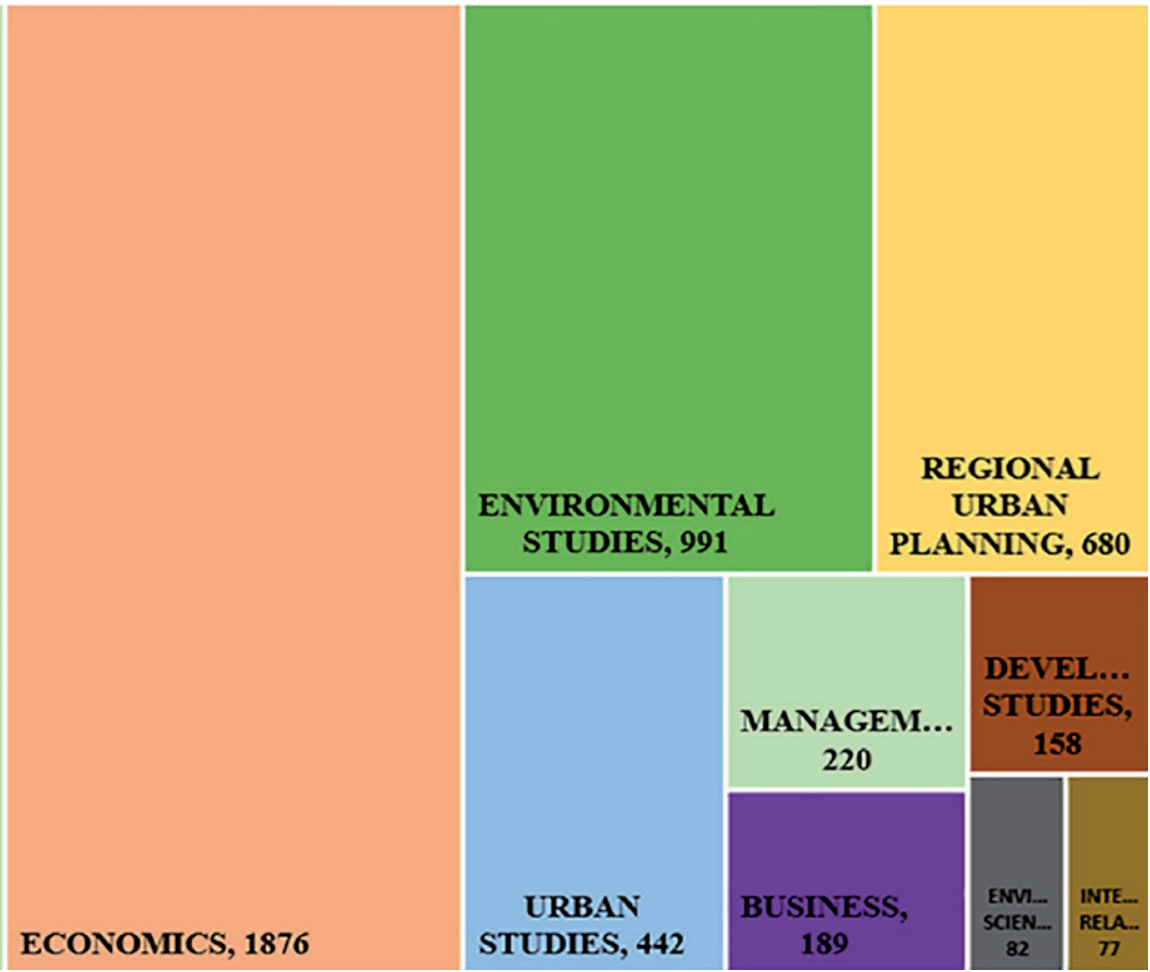

Figura 4. Distribución de Geografía Económica por categorías WoS. Fuente: WoS, Elaboración propia.

Un análisis pormenorizado de los clústers, permite por ejemplo mostrar cómo en la década de los 1990, hubo un importante número de trabajos centrados en los cambios de localización industrial asociados al crecimiento chino (Topic 6), o como los temas más de recursos medioambientales preocuparon en los 1980 (Topic 14), pero disminuyen su interés en las décadas siguientes.

La figura 6 muestra los mapas de coocurrencia de palabras clave para identificar los temas de interés de cada una de las disciplinas. El tamaño de los nodos del mapa muestra la frecuencia de cada uno de los keywords obtenidos, los enlaces (links) las relaciones de coocurrencia entre dos términos (cuantas más veces aparecen juntos, tienen una conexión más grande) y los clústers (colores) indican la afinidad de los temas. Al analizar los últimos 40 años, se observa que ha habido un cambio de interés en las temáticas. En un primer período predominaba el tema de los mercados y de la actividad económica en general, en un período más reciente se han incluido aspectos como la gobernanza, las redes o la innovación (figura 6, tabla 5).

Tabla 4. Resumen de los temas identificados por topic modelling.

\begin{tabular}{|l|l|}
\hline \multicolumn{1}{|c|}{ Temas } & \multicolumn{1}{c|}{ Conceptos } \\
\hline Topic 0 & $\begin{array}{l}\text { Firma; comercio; región; efecto; aglomeración; industria; productividad; regional; país; artículo; } \\
\text { resultado; modelo; crecimiento; nivel; fabricación; alto; espacial; evidencia; rendimiento; factor }\end{array}$ \\
\hline Topic 1 & $\begin{array}{l}\text { Conocimiento; innovación; red; firma; grupo; investigar; local; industria; proximidad; social; formación; } \\
\text { artículo; proceso; rol; diferente; tecnológico; negocio; creación; ajustado; dato }\end{array}$ \\
\hline Topic 2 & $\begin{array}{l}\text { Ubicación; empresa; ambiental; gas; negocio; mne; aceite; multinacional; investigar; política; firma; } \\
\text { energía; empresa multinacional; extranjero; análisis; estrategia; emisión; ruso; Rusia; inversión }\end{array}$ \\
\hline Topic 3 & $\begin{array}{l}\text { Trabajador; modelo; turismo; isla; impacto; renovable; movilidad; base; espacial; resultado; lugar de } \\
\text { trabajo; elección; labor; región; caso; variable; centrar; viaje; pérdida; ingreso }\end{array}$ \\
\hline Topic 4 & $\begin{array}{l}\text { Modelo; mercado; costo; comercio; transporte; efecto; sueldo; aglomeración; economía; espacial; papel; } \\
\text { aumento; país; precio; calificar; ubicación; casa; acceso; coste de transporte; competencia }\end{array}$ \\
\hline
\end{tabular}




\begin{tabular}{|c|c|}
\hline Temas & Conceptos \\
\hline Topic 5 & $\begin{array}{l}\text { Grupo; desarrollo; enfoque; artículo; social; investigar; industrial; economía; proceso; institucional; } \\
\text { artículo; trabajo; sostenibilidad; cambio; concepto; industria; política; sendero; perspectiva; práctica }\end{array}$ \\
\hline Topic 6 & $\begin{array}{l}\text { China; regional; espacial; desarrollo; sendero; ciudad; cambio; análisis; industrial; patrón; crecimiento; } \\
\text { papel; región; evolución; resultado; perspectiva; industria; nivel; Chino; aglomeración }\end{array}$ \\
\hline Topic 7 & $\begin{array}{l}\text { Firma; Servicio; inversión; extranjero; país; industria; impuesto; enlace; actividad; economía; exportar; } \\
\text { financiero; aglomeración; región; artículo; negocio; sector; internacional; empresa; ubicación }\end{array}$ \\
\hline Topic 8 & $\begin{array}{l}\text { Rural; periferia; ubicación; geográfico; área; recurso; subsidiario; industrial; espacial; planta; local; país; } \\
\text { modelo; actividad; región; concentración; sector; distrito; agricultura }\end{array}$ \\
\hline Topic 9 & $\begin{array}{l}\text { Ciudad; urbano; espacial; crecimiento; regional; efecto; artículo; hsr; desarrollo; modelo; migración; } \\
\text { impacto; China; local; europeo; derrame; resultado; accesibilidad; red; región }\end{array}$ \\
\hline Topic 10 & $\begin{array}{l}\text { Global; red; producción; cadena; valor; turismo; firma; internacional; investigar; gobernancia; } \\
\text { estratégico; local; valor global; mercado; perspectiva; producción global; artículo; gpn; enfoque; actor }\end{array}$ \\
\hline Topic 11 & $\begin{array}{l}\text { Africano; diversidad; mundo; papel; pueblo; desarrollo; futuro; Expresar; labor; Japonés; problema; } \\
\text { histórico; área; clase; movimiento; historia; regalo; cotidiano; población; trabajo }\end{array}$ \\
\hline Topic 12 & $\begin{array}{l}\text { Economía; creativo; financiero; investigar; industria; artículo; global; mercado; político; espacio; artículo; } \\
\text { cultural; red; práctica; geógrafo; industria creativa; análisis; espacial; comprender; trabajo }\end{array}$ \\
\hline Topic 13 & $\begin{array}{l}\text { Regional; innovación; política; desarrollo; región; sistema; industria; conocimiento; proceso; pah; papel; } \\
\text { desarrollo regional; diversificación; industrial; evolutivo; perspectiva; estudio; base; artículo; enfoque }\end{array}$ \\
\hline Topic 14 & $\begin{array}{l}\text { Alemán; emprendimiento; Banco; de emprendedor; bosque; Sur; recurso; deuda; mercado; empresario; } \\
\text { venta minorista; Alemania; recurso natural; lugar; este; natural; ecología; proceso; labor; norte }\end{array}$ \\
\hline
\end{tabular}

Fuente: WoS. Elaboración propia.

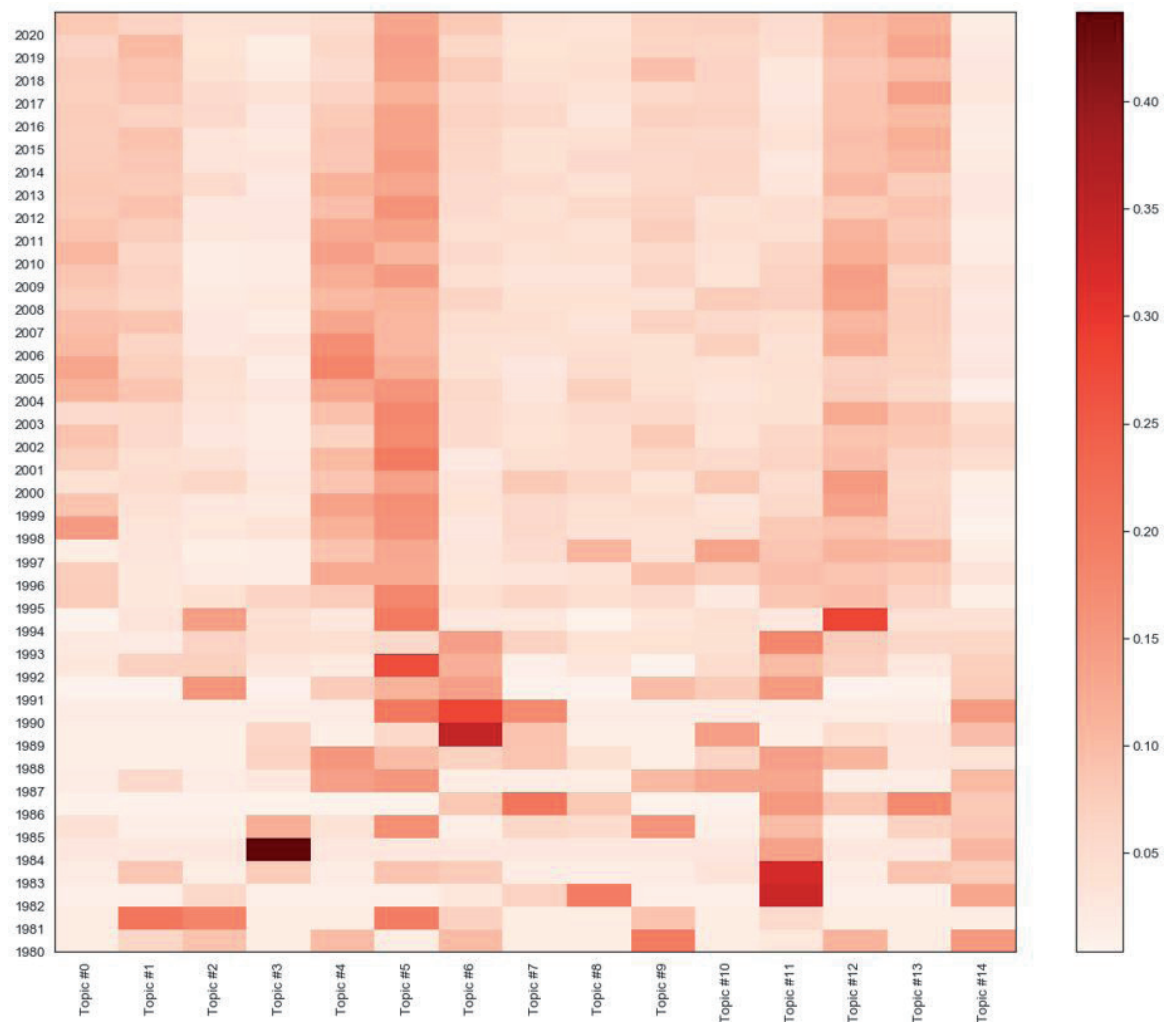

Figura 5. Evolución de la intensidad de los temas de 1980 a 2020. Fuente: WoS, elaboración propia. 


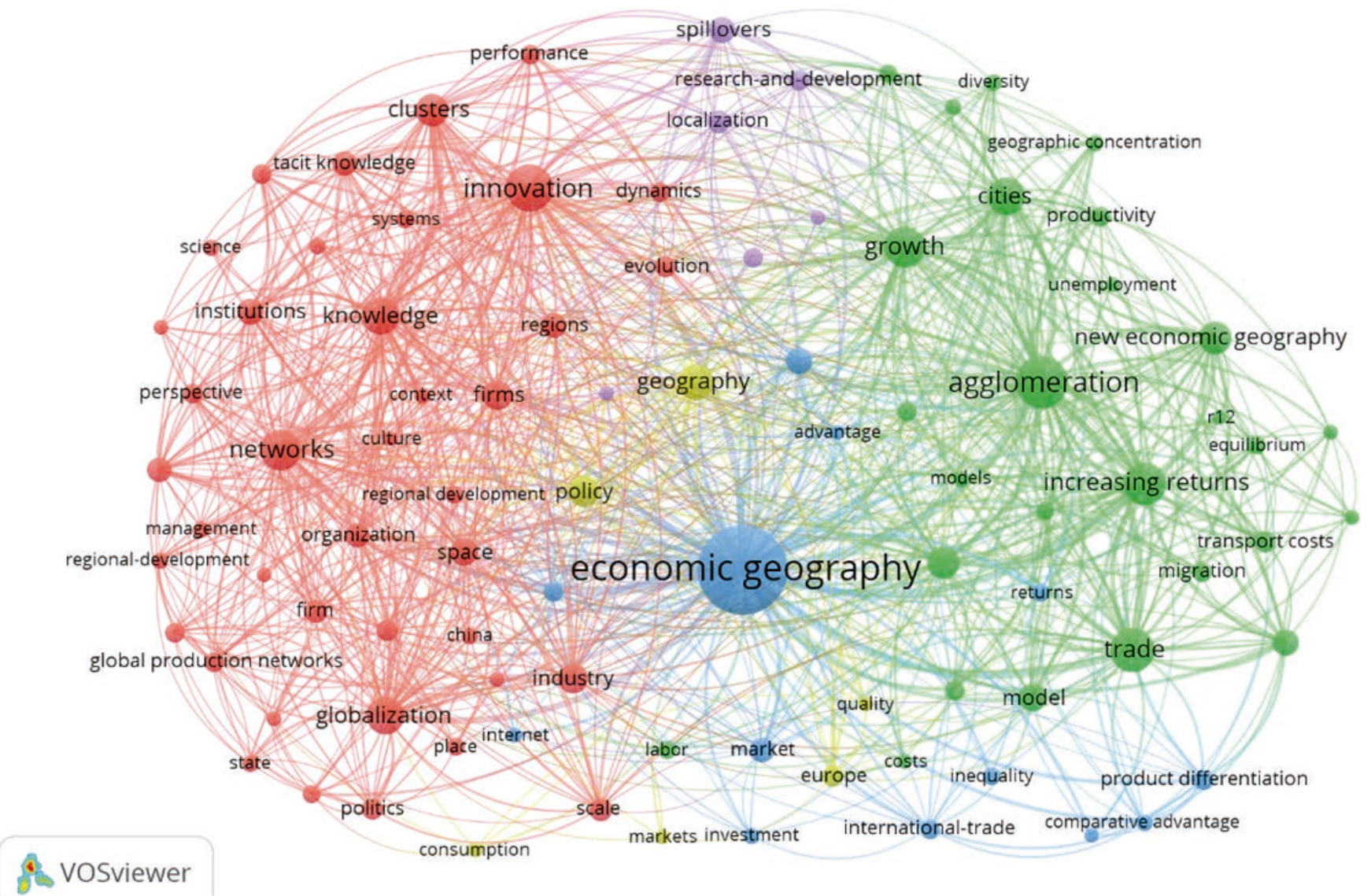

Figura 6. Mapas de coocurrencias de palabras clave de geografía económica en el período 2000-2010 (a) y 2010-2020 (b). Fuente: WoS, VOSViewer. Elaboración propia.

Tabla 5. Resumen de los clústeres obtenidos con los temas de interés.

\begin{tabular}{|c|c|c|c|}
\hline Geografía & $\mathrm{N}^{\circ}$ Cluster & Etiqueta & Términos más frecuentes \\
\hline \multirow{5}{*}{ Económica (2000-2009) } & \#1 (Rojo) & Redes e innovación & $\begin{array}{l}\text { Innovación (155); Redes (116); } \\
\text { Conocimiento (100) }\end{array}$ \\
\hline & \#2 (Verde) & Actividad económica & $\begin{array}{l}\text { Aglomeración (187); Comercio (134); } \\
\text { Rendimientos crecientes (128) }\end{array}$ \\
\hline & \#3 (Azul) & Inversión y mercado & $\begin{array}{l}\text { Geografía económica (551); } \\
\text { Competición (46); Mercado (40) }\end{array}$ \\
\hline & \#4 (Amarillo) & Políticas & Geografía (92); Política (66); Europa (30) \\
\hline & \#5 (Morado) & $\begin{array}{l}\text { Externalidades e } \\
\text { invetigación }\end{array}$ & $\begin{array}{l}\text { Derrames (45); Localización (39); } \\
\text { Investigación-Y-Desarrollo (29) }\end{array}$ \\
\hline \multirow{4}{*}{ Económica (2010-2020) } & \#1 (rojo) & Actividad económica & $\begin{array}{l}\text { Geografía económica (1211); } \\
\text { Crecimiento (279); Aglomeración (274) }\end{array}$ \\
\hline & \#2 (verde) & Gobernanza & $\begin{array}{l}\text { Globalización (156); Gobernanza (125); } \\
\text { Redes de producción globales (113) }\end{array}$ \\
\hline & \#3 (azul) & Redes e innovación & $\begin{array}{l}\text { Innovación (400); Conocimiento (281); } \\
\text { Redes (191) }\end{array}$ \\
\hline & \#4 (amarillo) & Dinámicas industriales & $\begin{array}{l}\text { Geografía (186); Dinámica (165); } \\
\text { Evolución (157) }\end{array}$ \\
\hline
\end{tabular}

Fuente: WoS, VOSViewer. Elaboración propia. 


\subsection{Hot Topics}

La tabla 6 muestra detección de ráfagas en las 35 palabras clave de todo el conjunto de datos trabajados sobre Geografía Económica. Sobre cada concepto, se indica la fuerza de su ráfaga, el período de inicio y fin de la ráfaga, además de la evolución temporal (en rojo el período y duración de la ráfaga). "Impacto" $(13,77)$, "nueva geografía económica" $(13,65)$, "aumento del rendimiento" $(13,4)$, "organización" $(12,43)$ y "comercio" $(11,78)$ son las palabras que tienen los valores de citación más altos. Sin embargo, si se comprueba temporalmente esta información, las palabras clave "organización" o "comercio internacional", tienen más importancia en los años 90 mientras que conceptos como "sostenibilidad", o "urbanización" han atraído más atención recientemente (desde 2018).

Table 6. Top-35 de las keywords con mayor ráfaga de citación.

\begin{tabular}{|c|c|c|c|c|}
\hline Kw & Fuerza & Inicio & Fin & $1956-2020$ \\
\hline Impact & 13,77 & 2016 & 2020 & \\
\hline New economic geography & 13,65 & 2005 & 2012 & \\
\hline Increasing return & 13,4 & 1998 & 2011 & \\
\hline Organization & 12,43 & 1994 & 2006 & \\
\hline Trade & 11,78 & 1998 & 2006 & \\
\hline Monopolistic competition & 10,3 & 1998 & 2009 & \\
\hline International trade & 8,93 & 1999 & 2006 & \\
\hline Dynamics & 8,92 & 2017 & 2020 & \\
\hline Transport cost & 8,84 & 2005 & 2010 & \\
\hline Resilience & 8,5 & 2014 & 2018 & \\
\hline Creation & 8,49 & 2017 & 2020 & \\
\hline Scale & 7,99 & 2001 & 2010 & \\
\hline Innovation system & 7,98 & 2016 & 2020 & \\
\hline Product differentiation & 7,89 & 2001 & 2009 & \\
\hline Global value chain & 7,68 & 2015 & 2020 & \\
\hline Path dependence & 7,66 & 2013 & 2017 & \\
\hline Localization & 7,54 & 2004 & 2010 & \\
\hline Offshore wind & 7,52 & 2016 & 2020 & \\
\hline Embeddedness & 7,14 & 2003 & 2008 & \\
\hline Power & 7,13 & 1999 & 2005 & 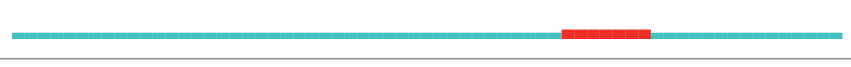 \\
\hline Return & 7,13 & 2005 & 2010 & \\
\hline Relatedness & 6,86 & 2016 & 2020 & \\
\hline Agglomeration & 6,63 & 2010 & 2011 & \\
\hline District & 6,59 & 1994 & 2003 & \\
\hline
\end{tabular}




\begin{tabular}{|c|c|c|c|c|}
\hline $\mathrm{Kw}$ & Fuerza & Inicio & Fin & $1956-2020$ \\
\hline Specialization & 6,54 & 2004 & 2010 & \\
\hline Equilibrium & 6,43 & 2005 & 2011 & \\
\hline Multinational enterprise & 6,36 & 2015 & 2018 & - \\
\hline Competition & 6,27 & 2002 & 2004 & - \\
\hline Manufacturing industry & 6,26 & 2010 & 2014 & \\
\hline $\begin{array}{l}\text { Evolutionary economic } \\
\text { geography }\end{array}$ & 6,26 & 2017 & 2020 & \\
\hline Path creation & 6,19 & 2018 & 2020 & - \\
\hline $\begin{array}{l}\text { Regional innovation } \\
\text { system }\end{array}$ & 6,13 & 2016 & 2020 & \\
\hline Flexibility & 6,11 & 1993 & 2003 & \\
\hline China & 6,09 & 2017 & 2020 & \\
\hline Life cycle & 6,08 & 2013 & 2018 & \\
\hline Dependence & 5,91 & 2014 & 2020 & \\
\hline Regional policy & 5,84 & 2009 & 2012 & \\
\hline Diversification & 5,84 & 2016 & 2020 & \\
\hline Institutional change & 5,82 & 2015 & 2018 & \\
\hline Value chain & 5,78 & 2013 & 2020 & \\
\hline Wage & 5,42 & 2005 & 2012 & \\
\hline Emergence & 5,42 & 2017 & 2020 & - \\
\hline Sustainability & 5,26 & 2018 & 2020 & \\
\hline Urban & 5,24 & 2018 & 2020 & \\
\hline Sustainability transition & 5,23 & 2016 & 2018 & 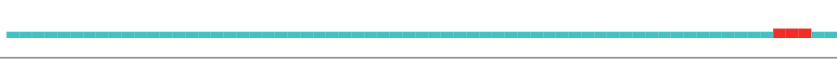 \\
\hline
\end{tabular}

Fuente: WoS. Elaboración propia.

\section{DISCUSIÓN Y CONCLUSIONES}

El análisis bibliométrico ofrece al investigador un punto de partida para abordar su investigación ya que le permite encontrar datos sobre la producción científica del tema que va a abordar. En este trabajo, tomado como ejemplo una disciplina que ha pasado por múltiples tendencias y temáticas como es la Geografía Económica, se intenta ver cómo dentro del pluralismo interno existen unas tendencias en las producciones científicas, que terminan reflejando las necesidades de análisis que implica una economía cambiante en los territorios. Esto permite ver que la diversidad temática que presenta una disciplina no supone que no tenga centros de trabajo que la definan, sino que los temas que preocupan a sus investigadores son cambiantes porque la economía lo es.

La Geografía Económica constituye una de las ramas de la geografía que, por su propio objetivo de estudio, las interrelaciones del funcionamiento de la economía y el territorio en diferentes escalas, provoca que los temas que abordan sean además de numerosos, cambiantes en enfoques y en preocupaciones. Sin 
embargo, no existen muchos estudios bibliométricos que analicen su producción científica, y las distintas temáticas de la propia disciplina, brecha de investigación que este estudio cubre.

El número de referencias encontrados en los criterios de búsqueda realizados son altos, a pesar de que la metodología utilizada es restrictiva, centrándose en el 'core' de las publicaciones y no se ha utilizado otras tipologías documentales como otros estudios que se centran en libros (Gorraiz et al., 2016) o en el análisis de la producción de las revistas en Geografía Económica (Foster et al., 2007). Además, los resultados obtenidos del número de publicaciones sugieren que a pesar de que la investigación sobre este tema parece tener una larga tradición, hay una concentración de publicaciones en los años más recientes, denotando un interés creciente sobre la Geografía Económica en los últimos años. A pesar que este crecimiento se encuentra generalizado en todas las áreas de conocimiento (Hu et al., 2020), este crecimiento está en línea con otros estudios (por ejemplo, Wang \& Liu (2014), que muestran que la parte económica es una gran contribuidora por ejemplo en los estudios de estudios territoriales como el ámbito rural.

El análisis realizado observa también una evolución positiva de los patrones de colaboración internacional, aunque estos siguen siendo menores, predominando las colaboraciones dentro de los mismos centros y dentro del mismo país (colaboración nacional). Este hecho reafirma las conclusiones de trabajos anteriores en las que se afirma que la Geografía Económica no tiene un carácter muy internacional (Gutiérrez \& López-Nieva, 2001 y Müller, 2021). También es interesante destacar la buena situación de las publicaciones analizadas en términos de impacto (por número de citas), lo que indica que los trabajos examinados están en revistas de las primeras posiciones de este ranking por citaciones, lo que sin duda favorece su mayor difusión. Sobre las temáticas abordadas mediante el análisis del topic modelling, los resultados obtenidos permiten ver como de variados son los temas y sobre todo lo que destaca es cómo hay momentos que interesan más unos que otros, así en los últimos años se aprecia como temas vinculados al transporte o la sostenibilidad están presentes en los trabajos analizados.

Por otro lado, los resultados muestran el carácter anglocéntrico (Reino Unido y Estados Unidos) de las instituciones que publican en geografía económica, en línea con estudios anteriores (Gutiérrez \& López-Nieva, 2001; Wing \& Liu, 2014; Foster et al., 2007) que muestran como se marginalizan a las comunidades no hablantes de inglés, a pesar de que la mayoría de lectores son consumidores son cada vez más multilingües (Müller, 2021). Sin embargo, este hecho puede estar relacionado con la selección de la base de datos WoS., que produce un sesgo hacía publicaciones en inglés. Sin embargo, los estudios por índice de actividad demuestran que otros países están especializados en el tema como los países nórdicos, han adquirido una especial importancia sobre todo porque las temáticas recientes asociadas a temas de innovación, emprendimiento han sido muy abundantes en estos países. Se asocian así temas de interés con espacios donde determinados procesos económicos presentan una novedad en su funcionamiento o en las preocupaciones sociales, algo que los resultados permiten mostrar.

En cualquier caso y como analizan Atienza et al. (2019), las interrelaciones temáticas entre los trabajos de los economistas y los geógrafos económicos resulta difícil de separar, como se ha podido comprobar en los resultados obtenidos con aportaciones de economistas incluidos en esta búsqueda. Si interesara separar los trabajos de ambos tipos de disciplina sería necesario en los criterios de búsqueda introducir algún discriminador que permita refinar la búsqueda si sólo queremos aportaciones realizadas desde el ámbito de los geógrafos. Aunque la interdisciplinariedad en este caso también ayuda a centrar cuáles son las temáticas que más preocupan a los investigadores que trabajen la interrelación entre economía y el espacio. Pero para este trabajo de acercamiento a los temas que se han abordado desde la geografía económica los patrones de búsqueda se consideran correctos, de hecho, los trabajos que aparecen como más citados son trabajos muy conocidos y utilizados en los trabajos de los geógrafos.

El trabajo realizado es una aproximación a la temática, en la que cabe señalar algunas limitaciones. Primero, identificamos los artículos relacionados explícitamente con la Geografía Económica, es decir, el 'núcleo' que incluyen tanto en el título, resumen como palabras claves los términos. En este sentido, puede haberse omitido artículos relacionados con el tema que no incluyan explícitamente la estrategia de búsqueda utilizada. Además, el uso de la base de datos WoS puede omitir otros trabajos no presentes en ellas, así como otra tipología de documentos (informes) que puedan resultar de interés para el análisis en la trayectoria de 
este campo. Un análisis más completo exigirá comprobar si esto mismo ocurre en otras bases bibliográficas donde se incorporen producciones en lenguas latinas, francesas e italianas, poco presentes en la base sobre la que se ha realizado esta aproximación.

Pero el objetivo era ofrecer una primera aproximación al interés de las técnicas de trabajo de la bibliometría cuando el investigador se enfrenta a campos de trabajo con una trayectoria compleja. En investigaciones futuras, se incluirán otras técnicas de búsqueda (métodos de expansión a través de citas directas), además de la definición de un marco teórico con un análisis basado en contenido de los artículos. Igualmente, en futuros estudios podrían complementarse con métodos de investigación cualitativa (entrevistas, encuestas) con investigadores del ámbito para conocer más sus motivaciones en la especialización en Geografía Económica. En cualquier caso, el método seguido demuestra la utilidad que tienen este tipo de acercamiento a las producciones científicas, y en definitiva la importancia de la interdisciplinariedad de las ciencias para ofrecer mejores resultados.

\section{Agradecimientos}

Se agradece el apoyo de financiación del proyecto "Innovación Socioeconómica y estrategias post-pandemia en los espacios metropolitanos de Valencia y Zaragoza" (PID2020-112734RB-C31), financiado por MCIN/ AEI/10.13039/501100011033/.

\section{Declaración responsable y conflicto de intereses}

Las autoras declaran que no existe ningún conflicto de interés en relación con la publicación de este artículo. Las autoras manifiestan que el presente artículo es fruto de un trabajo colaborativo y ambas han participado de forma equilibrada en la revisión bibliográfica, el diseño de la metodología, la realización del análisis gráfico y la redacción del artículo.

\section{REFERENCIAS}

Atienza, M., Ronda-Pupo, G. A., \& Phelps, N. (2019). Bridges over troubled water? Journals, geographers and economists in the field of economy and space 1980-2017. Environment and Planning A: Economy and Space, 51(8), 1800-1823. https://doi.org/10.1177/0308518X19866213

Broadus, R. N. (1987). Toward a definition of "bibliometrics". Scientometrics, 12(5-6), 373-379. https://doi.org/10.1007/ BF02016680.

Corral-Marfil, J. A. \& Espejo Marín, C. (2020). Evolución y análisis bibliométrico de la Revista Cuadernos de Turismo (19982019). Cuadernos de Turismo, (46), 531-565. https://doi.org/10.6018/turismo.451951

Feinerer, I, \& Hornik, K (2020). tm: Text Mining Package. R package version 0.7-8. https://CRAN.R-project.org/package=tm

Foster, J., Muellerleile, C., Olds, K., \& Peck, J. (2007). Circulating economic geographies: Citation patterns and citation behaviour in economic geography, 1982-2006. Transactions of the Institute of British Geographers, 32(3), 295-312. https://doi.org/10.1111/j.1475-5661.2007.00239.x

Frame, J. D. (1977). Mainstream Research in Latin America and the Caribbean. Interciencia, 2(3), 143-148. https://ci.nii. ac.jp/naid/10017095290/en/

Gómez-Caridad, I. \& Bordons, M. (1996) 'Limitaciones en el uso de los indicadores bibliométricos para la evaluación científica'. Política Científica, 46(10), 21-26, ISSN 1133-0554

Gorraiz, J., Gumpenberger, C., \& Glade, T. (2016). On the bibliometric coordinates of four different research fields in Geography. Scientometrics, 107(2), 873-897. https://doi.org/10.1007/s11192-016-1864-y.

Grün B, Hornik K (2011). Topicmodels: An R Package for Fitting Topic Models. Journal of Statistical Software, 40*(13), 1-30. https://doi.org/10.18637/jss.v040.i13 
Gutiérrez, J., \& López-Nieva, P. (2001). Are international journals of human geography really international? Progress in Human Geography, 25(1), 53-69. https://doi.org/10.1191/030913201666823316

Hu, X., Leydesdorff, L., \& Rousseau, R. (2020). Exponential growth in the number of items in the WoS. ISSI News/etter, $16(2), 32-38$.

Kanai, J. M., Grant, R., \& Jianu, R. (2018). Cities on and off the map: A bibliometric assessment of urban globalisation research. Urban Studies, 55(12), 2569-2585. https://doi.org/10.1177/0042098017720385

Kleinberg, J. (2003). Bursty and hierarchical structure in streams. Data mining and knowledge discovery, 7(4), 373-397. https://doi.org/10.1023/A:1024940629314

Krugman, P. (1997). Desarrollo, geografía y teoría económica. Antoni Bosch.

Kuhn, T. S. (1970). The structure of scientific revolutions (2nd ed.). The University of Chicago Press.

Méndez Gutiérrez del Valle. R. (1997). Geografía económica. La lógica espacial del capitalismo global. Arial.

Müller, M. (2021). Worlding geography: From linguistic privilege to decolonial anywheres. Progress in Human Geography, https://doi.org/10.1177/0309132520979356.

Ródenas Serra, P., Seguí-Pons, J., \& Ruiz Pérez, M. (2021). A bibliometric analysis of Journal of Transport Geography (1993-2020). Boletín de la Asociación de Geógrafos Españoles (90). https://doi.org/10.21138/bage.3105

Rosenman, E., Loomis, J., \& Kay, K. (2020). Diversity, representation, and the limits of engaged pluralism in (economic) geography. Progress in Human Geography, 44(3), 510-533. https://doi.org/10.1177/0309132519833453

Salvador Oliván, J. A., \& Escolano Utrilla, S. (2018). Comparison of bibliometric indicators in journals of geography indexed in Web of Science. Boletín de la Asociación de Geógrafos Españoles, (76), 131-152. https://doi.org/10.21138/ bage.2518.

Sánchez Hernández, J. L. (2021). El desarrollo teórico de la Geografía Económica en el siglo XXI: hacia la hibridación de los proyectos científicos de la disciplina. Boletín De La Asociación De Geógrafos Españoles, (89). https://doi.org/10.21138/ bage.3080

Unwin, T. (1992): The place of geography, Longman Scientific \& Technical. Londres. (traducción: El lugar de la Geografía, Omega, 1995).

Van Eck, N. J., \& Waltman, L. (2017). Citation-based clustering of publications using CitNetExplorer and VOSviewer. Scientometrics, 111(2), 1053-1070. https://doi.org/10.1007/s11192-017-2300-7

Wang, J., \& Liu, Z. (2014). A bibliometric analysis on rural studies in human geography and related disciplines. Scientometrics, 101(1), 39-59. https://doi.org/10.1007/s11192-014-1388-2.

Zhu, S., Jin, W., \& He, C. (2019). On evolutionary economic geography: a literature review using bibliometric analysis. European Planning Studies, 27(4), 639-660. https://doi.org/10.1080/09654313.2019.1568395 


\title{
Etude de la dynamique spatio-temporelle de la forêt des Ait Daoud ou Ali (Haut Atlas central, Maroc) en utilisant les techniques géospatiales
}

\author{
Study of the spatio-temporal dynamics of the Ait Daoud ou Ali (Central High \\ Atlas, Morocco) Forest using geospatial techniques
}

\section{Estudio de la dinámica espacio-temporal del bosque de Ait Daoud ou Ali (Alto Atlas Central, Marruecos) mediante técnicas geoespaciales}

\author{
Aïman Hili \\ a.hili@usms.ma 0000-0003-2220-6360 \\ Rachid Bissour \\ bissour1983@usms.ma 0000-0002-5391-9921 \\ Farid Jaa \\ farid.jaa@usms.ac.ma@0000-0002-7158-5080 \\ Hanane Reddad \\ h.reddad@usms.ma 0000-0002-6238-165X \\ Yassine El Jouhary \\ yassineeljaouhary02@gmail.com @ 0000-0002-1534-4944
}

Faculté des Lettres et des Sciences Humaines, Université Sultan Moulay Slimane.

Avenu Ibn khaldoun, B.P. 524 Beni Mellal, Maroc

INFO ARTÍCULO

A reçu: 04-07-2021

Revu: 21-01-2022

Accepté: 21-01-2022

\section{MOTS CLÉS}

Classification supervisée

NDVI

Étude diachronique La forêt des Ait Daoud ou Ali Haut Atlas central

Maroc

\section{RESUME}

Depuis longtemps l'Homme cherche l'exploitation des ressources naturelles à des fines quotidiennes. Ainsi, le développement scientifique et technologique actuel lui a facilité et lui a donné des vraies opportunités pour la surexploitation de ces ressources en général et du couvert végétal en particulier. Afin de montre cette exploitation nous voulons, dans le présent article, étudier l'évolution du couvert végétal de la forêt des Ait Daoud ou Ali, située dans le Haut Atlas central sur une superficie de 30860 ha, entre 1972, 1999 et 2020, en se basant sur la télédétection et l'outil SIG. Pour ce qui concerne la méthodologie de travail, l'étude multi-chronique de la dynamique du couvert végétal de la zone d'étude, repose sur l'analyse spatio-temporelle et le traitement des images satellitaires par la télédétection spatiale. En effet, dans le présent papier nous avons opté cette démarche qui s'appuie sur l'utilisation des données des images du satellite de LandSat de trois types; il s'agit des images de type MSS, ETM et Oli, pour trois dates 1972, 1999 et 2020 (période de 48 ans) pour identifier les différences spatiales du couvert végétal entre les trois dates choisies. En effet, l'étude de la dynamique du couvert végétal de la forêt des Ait Daoud ou Ali entre 1972, 1999 et 2020, a montré une variation spatio-temporelle très importante, liée essentiellement à plusieurs facteurs (naturels et humaines). La comparaison des résultats de la classification des images Landsat, a montré un recul et une dégradation importante du couvert végétal entre 1972 et 1999 de $12 \%$ de la surface totale de la zone d'étude. Cette dégradation est justifiée par l'intervention de plusieurs facteurs, notamment les conditions climatiques et les périodes sèches qu'a connu le Maroc à cette période. Pour la deuxième période (1999-2020), le traitement a montré une progression du couvert végétal de l'ordre de $10 \%$. Dans cette étude, nous avons mis en évidence l'impact des facteurs naturels et notamment les actions anthropiques sur la dynamique de la forêt des Ait Daoud ou Ali située dans Haut Atlas Central, en se basant sur l'utilisation des techniques géospatiales qui nous ont permis d'avoir des informations très précises relatives à la dynamique spatio-temporelle du couvert végétal. 


\section{KEYWORDS}

Supervised classification
NDVI

Diachronic study

The Ait Daoud ou Ali Forest

Central High Atlas

Morocco

\section{PALABRAS CLAVE}

Clasificación supervisada

NDVI

Estudio diacrónico

Bosque de Ait Daoud ou Ali

Alto Atlas Central

Marruecos

\section{ABSTRACT}

For a long time, Man has been looking for the exploitation of natural resources for daily purposes. Thus, the current scientific and technological development has facilitated and given him real opportunities for the overexploitation of these resources in general and the plant cover in particular. In order to show this exploitation, we want, in this article, to study the evolution of the vegetation cover of the forest of Ait Daoud or Ali, located in the Central High Atlas on an area of 30860 ha, between 1972, 1999 and 2020, based on remote sensing and GIS tool. Regarding the methodology of work, the multi-chronic study of the dynamics of the vegetation cover of the study area, is based on the spatio-temporal analysis and processing of satellite images by remote sensing space. Indeed, in this paper we have opted for this approach which is based on the use of data from LandSat satellite images of three types; these are the images of type MSS, ETM and Oli, for three dates 1972, 1999 and 2020 (period of 48 years) to identify the spatial differences of the vegetation cover between the three selected dates. Indeed, the study of the dynamics of the vegetation cover of the forest of Ait Daoud or Ali between 1972, 1999 and 2020, showed a very important spatio-temporal variation, linked essentially to several factors (natural and human). The comparison of the results of the classification of Landsat images, showed a decline and a significant degradation of vegetation cover between 1972 and 1999 of $12 \%$ of the total area of the study area. This degradation is justified by the intervention of several factors, including climatic conditions and dry periods that Morocco has experienced in this period. For the second period (1999-2020), the treatment showed an increase in vegetation cover of about $10 \%$. In this study, we have highlighted the impact of natural factors and especially anthropic actions on the dynamics of the forest of Ait Daoud or Ali located in the Central High Atlas, based on the use of geospatial techniques that have allowed us to have very precise information on the spatio-temporal dynamics of plant cover.

\section{RESUMEN}

Durante mucho tiempo, el hombre ha tratado de explotar los recursos naturales para fines cotidianos. Así, el desarrollo científico y tecnológico actual ha facilitado y le ha dado oportunidades reales para la sobreexplotación de estos recursos en general y de la cubierta vegetal en particular. Para mostrar esta explotación queremos, en el presente artículo, estudiar la evolución de la cubierta vegetal del bosque de Ait Daoud o Ali, situado en el Alto Atlas central sobre una superficie de 30.860 ha, entre 1972, 1999 y 2020, basándonos en la teledetección y la herramienta SIG. En cuanto a la metodología de trabajo, el estudio multicrónico de la dinámica de la cubierta vegetal de la zona de estudio se basa en el análisis espacio-temporal y el procesamiento de imágenes de satélite por teledetección espacial. En este trabajo, hemos optado por este enfoque, que se basa en la utilización de datos de imágenes de satélite LandSat de tres tipos: imágenes MSS, ETM y Oli, para tres fechas 1972, 1999 y 2020 (período de 48 años), con el fin de identificar las diferencias espaciales de la cubierta vegetal entre las tres fechas seleccionadas. En efecto, el estudio de la dinámica de la cubierta vegetal del bosque de Ait Daoud o Ali entre 1972, 1999 y 2020, mostró una variación espacio-temporal muy importante, esencialmente ligada a varios factores (naturales y humanos). La comparación de los resultados de la clasificación de las imágenes Landsat mostró una importante disminución y degradación de la cubierta vegetal entre 1972 y 1999 del $12 \%$ de la superficie total del área de estudio. Esta degradación se justifica por la intervención de varios factores, especialmente las condiciones climáticas y los periodos de sequía que vivió Marruecos durante este periodo. En el segundo período (1999-2020), el tratamiento mostró un aumento de la cubierta vegetal de alrededor del 10\%. En este estudio, hemos puesto de relieve el impacto de los factores naturales y, en particular, de las acciones antrópicas en la dinámica del bosque de Ait Daoud o Ali, situado en el Alto Atlas Central, basándonos en el uso de técnicas geoespaciales que nos han permitido disponer de información muy precisa sobre la dinámica espacio-temporal de la cubierta vegetal. 


\section{INTRODUCTION}

Depuis longtemps, l'Homme cherchait à exploiter les ressources naturelles à des fins quotidiens (Bouiadjra et al., 2011; Labhar, 1998) pour assurer sa vie et ses besoins. Ainsi, le développement scientifique et technologique actuel lui a facilité et lui a donné des vraies opportunités pour la surexploitation des ressources naturelles en général et du couvert végétal en particulier. Pour cela, la protection des ressources naturelles en générale et la ressource forestière en particulier est devenue aujourd'hui, dans le contexte global des changements climatiques et l'émergence de la notion de développement durable, un défi majeur à travers la proposition des lois (loi 11-03, loi 12-03 et loi 22-07) et aussi par la création des aires protégées et des parcs nationaux (Hili \& El Khalki, 2017). Cela venait dans le but de créer un certain équilibre bioécologique et de faire face aux changements climatiques que ce soit à l'échelle globale ou locale.

Vu l'apport de la télédétection spatiale et des outils SIG, notamment dans le croisement des cartes, la détection des zones de dégradation et les zones de progression de la forêt, l'utilisation de ces outils est devenue très intéressante dans les études de la dynamique spatio-temporelle du couvert végétal (Hili \& Abdelaziz, 2021; Gansaonré et al., 2020; Bissour et al., 2018; Sbai et al., 2018; Bouzekraoui et al., 2016; Daoui \& Fatemi, 2014; Brou, 2010; Mahamane et al, 2007.; Hountondji et al., 2004; Nguessan, et al., 2003; Demaze, 2003).

En effet, les études qui ont été réalisées sur la dynamique du couvert végétal (Hili \& Abdelaziz, 2021; Gansaonré et al., 2020; Bissour et al., 2018; Sbai et al., 2018; El Mazi et al., 2018; Raogo, 2018; Diop et al., 2018; Bouzekraoui et al., 2016; Daoui \& Fatemi, 2014; Soro et al., 2014; Tra Bi, 2013; Bouiadjra et al., 2011; Dawson et al., 2011; Brou, 2010; Mahamane et al., 2007; Demarteau et al., 2007; Hammi, 2007; Ouloukoi et al.; 2006; Jeffrey et al., 2006; Cabid et al., 2005; Hountondji et al., 2004; Carmen Salazar Conde et al., 2004; Nguessan, et al., 2003; Demaze, 2003; Dupouey et al., 1999; Labhar, 1998; Thimonier, 1994; Benabid, 1985; Lecompte, 1986; Michel \& Ruelan, 1967), ont montré que ce dernier est souvent influencé par plusieurs facteurs, notamment le climat, la topographie (les pentes, l'exposition des versants et les altitudes) la lithologie, la pédologie, et bien entendu les actions anthropiques que ce soit conscientes ou inconscientes.

Pour ce fait, nous proposons cette étude multi-chronique de la forêt des Ait Daoud ou Ali, située dans le Haut Atlas central calcaire (Royaume du Maroc). Vu que cette région d'étude se situe dans le Haut Atlas central et caractérisée par un contexte naturel et humain très diversifié, que ce soit du point de vue géographique, topographique, géologique, climatique et anthropique, ou aussi de point de vue de sa couverture végétale.

L'objectif de ce travail est l'application des techniques de traitement géospatial sur des données géographiques, et l'évaluation de l'apport de la télédétection spatiale pour la quantification de la dynamique spatio-temporelle du couvert végétal de la forêt des Ait Daoud ou Ali sur une période de quarante-huit ans entre 1972, 1999 et 2020. Cette approche méthodologique consiste à détecter les changements (régression ou progression) dans le couvert végétal, à partir du calcul de l'Indice de Végétation par Différence Normalisé, appelé aussi NDVI (Normalized Difference Vegetative Index), et d'une classification supervisée des images satellitaires de différentes dates (1972, 1999 et 2020). Ainsi, les résultats obtenus dans cette étude et d'autres études venions par la suite (sur la commune d'Aghbala (Hili et al., 2021) et sur la forêt des Ait Bouzid), vont nous permettre d'évaluer l'efficacité des lois et programmes réalisés pour la protection et le sauvegarde du couvert végétal forestier marocain en général et de la zone d'étude en particulier.

\section{LA ZONE DE L'ETUDE}

Sur le plan administratif, la forêt des Ait Daoud ou Ali fait partie de la région de Beni Mellal-Khénifra (carte 1), elle s'étend sur six communes rurales, il s'agit des communes de Larbaa n'Ait Ouqabli, commune de Tiffert n'Ait Hamza et Tagleft (couvrant la majeure partie de la zone de l'étude), et partiellement sur les communes de Isekssi, Tabaroucht et la commune de Boutferda. En général, la forêt est délimitée et côtoie dans sa partie Est par la forêt des Ait Abdi, au Sud par les deux forêts d'Anergui et des Ait Isha et à l'Ouest par la forêt des 
Ait Atta Noumallou. Superficiellement, elle couvre sur une superficie de 53785 ha, et classée parmi les forêts les plus importantes de la région (Direction Régional des Eaux et Forêt, Beni Mellal., 2010). En effet, la forêt abrite une population légale de l'ordre de 21220 habitants (Haut-Commissariat au Plan (HCP), 2014). La zone la plus peuplée au niveau du territoire de la forêt est celui situé au centre de la commune de Tagleft, suivi par le centre de la commune de Larbaa n'Ait Ouqabli. Cette situation confère à la forêt des conditions très favorables à la fois à l'évolution et à la dégradation des ressources forestières.
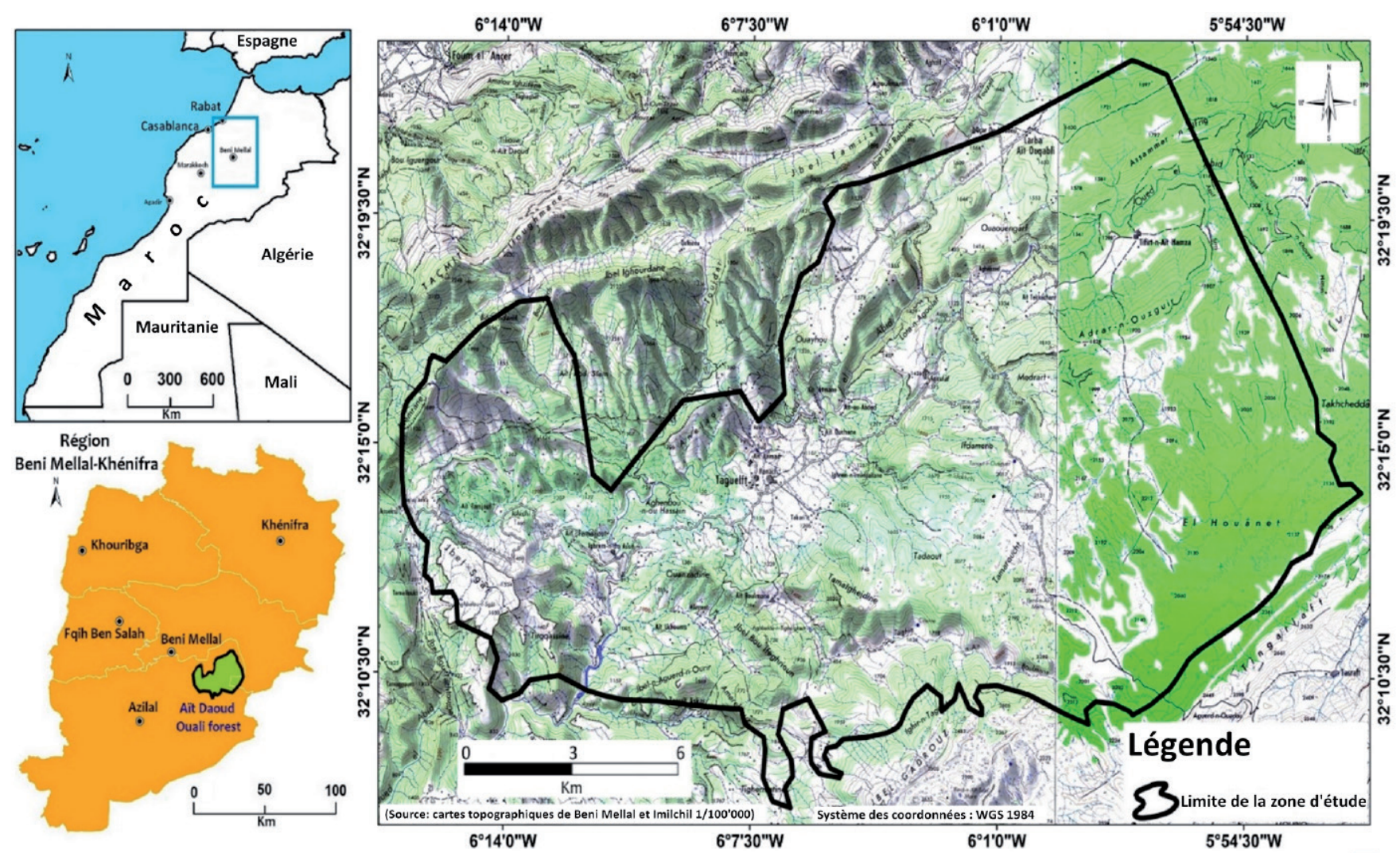

Carte 1. Situation géographique de la forêt des Ait Daoud ou Ali. Source: Élaboration des auteurs

En effet, la spatialisation de la dynamique de la forêt est prouvée par l'influence de plusieurs facteurs naturels et anthropiques. Concernant les conditions topographies, notre terrain d'étude se situe au centre du Haut Atlas Central, sur une tranche altitudinale comprise entre 893 m et 2137 m, qui est marquée souvent par l'accidentée de ces versants. L'analyse de la base de données de la carte des tranches d'altitude montre la dominance des tranches qui varient entre $1500 \mathrm{~m}$ et plus de $2100 \mathrm{~m}$, avec une superficie de l'ordre de 49.6\%. Ces altitudes s'étendent notamment sur la partie Sud-Est de la zone de l'étude. Les reliefs les plus remarquables dans lesquels s'étend la forêt des Ait Daoud ou Ali sont le synclinal de Tagleft, le plateau d'El Houanet et les vallées et les gorges de l'Oued El Abid. La densité du couvert végétal de la forêt est souvent considérable seulement au niveau des versants d'orientation Nord et Nord-Ouest, et au long de la vallée profonde de l'Oued El Abid, et quelques vallées de ses affluents (Aqqa n'Tzanit). Alors que, les terrains presque plats sont souvent occupés par des champs de cultures (Bissour, 2019). Cette diversité de reliefs et de topographie a joué et joue encore un rôle très important et primordial dans la répartition spatiale du couvert végétale et des essences forestières de la forêt des Ait Daoud ou Ali.

Ainsi, l'analyse des classes des pentes qui occupent la zone de la forêt, nous permet de déceler une quasi dominance des pentes moyennes et faibles avec, respectivement, $36 \%$ et $26 \%$ de la superficie totale de la zone de l'étude. Alors que la classe des pentes forte et très fortes n'occupe que $38 \%$ de la surface de la zone. Quant à l'exposition des versants, les versants les plus dominants sont les versants exposés vers le Nord et vers l'Est, le Sud et vers le Sud-Est. Ces versants représentent $52.7 \%$ de la superficie totale de la forêt. 
D'un point de vue géologique, le contexte géologique du terrain d'étude est marqué par la prédominance des formations jurassiques perméables, constituées essentiellement par des sédiments détritiques continentaux (les couches rouges de Bathonien), notamment au niveau du synclinal de Tagleft (Bissour, 2019). Les couches Bajociennes sous-jacentes constituent un aquifère important qui draine les eaux du secteur des Ait Ouqabli. Ce bassin est séparé de celui de Ouaouizerht par le seuil de Jbel Bou Tachtuine-Abbadine, qui est une ride anticlinale complexe et étroite, de direction Nord-Sud (Monbaron, 1982), se déversant vers l'Ouest. Les couches rouges des deux bassins se redressent et se terminent en biseau à l'approche de ce seuil (Bahzad, 1982). Dans la partie Est de la forêt des Ait Daoud ou Ali, le terrain, qui correspond au plateau d'El Houanet, est dominé par des couches calcaires marneux très gélifs et karstiques, ce qui a favorisé et favorise encore le développement d'une multitude de formes karstiques de petites tailles et d'autres de grandes à très grandes tailles (Couvreur, 1988).

Pour ce qui concerne le climat, vu l'effet direct du climat sur l'évolution et la distribution de couvert végétal (Sbai et al., 2018; Dawson et al., 2011; Brou, 2010; Hountondji et al., 2004; Lecompte et Alexandre, 1996), l'analyse climatique semble très importante dans ce genre d'étude, pour cela nous avons utilisé les données de la station des Ait Ouchène (la station des Ait Ouchène est installée dans la zone de la forêt, près du centre de Tagleft sur l'Oued El Abid, mais ne mesure pas les données de la température), et les données de la station de Tillouguit (située au Sud de la forêt, au niveau du centre de la commune de Tilouguit et sur l'Oued Ahançal, l'un des principaux affluents de l'Oued El Abid), pour une période de 30 ans (entre 1986 et 2016). Selon la classification d'Emberger, les deux stations montrent que la zone de la forêt appartient à l'étage bioclimatique de végétation semi-aride avec un hiver frais (pour la station des Ait Ouchène à Tagleft) et hiver très froid pour la station de Tilouguite (Combe, 1977; Couvreur, 1988), alors que la partie Est de la forêt qui s'étend sur le plateau d'El Houanet le climat est de type Sub-Humide avec un hiver très froid (Bissour, 2019). La méthode de Bagnouls et Gaussen (1957) appliquée sur la série de données thermométriques et pluviométriques fournies par la station de Tilouguite, pour mettre en évidence les mois humides et les mois secs, en faisant une analyse fréquentielle mensuelle, montre que les mois secs s'étalent d'Avril à Octobre avec des fréquences dépassant 54\%, et que les années qui présentent 6 et 9 mois secs sont les plus fréquentes (26\%) (Bissour \& El Khalki, 2018).

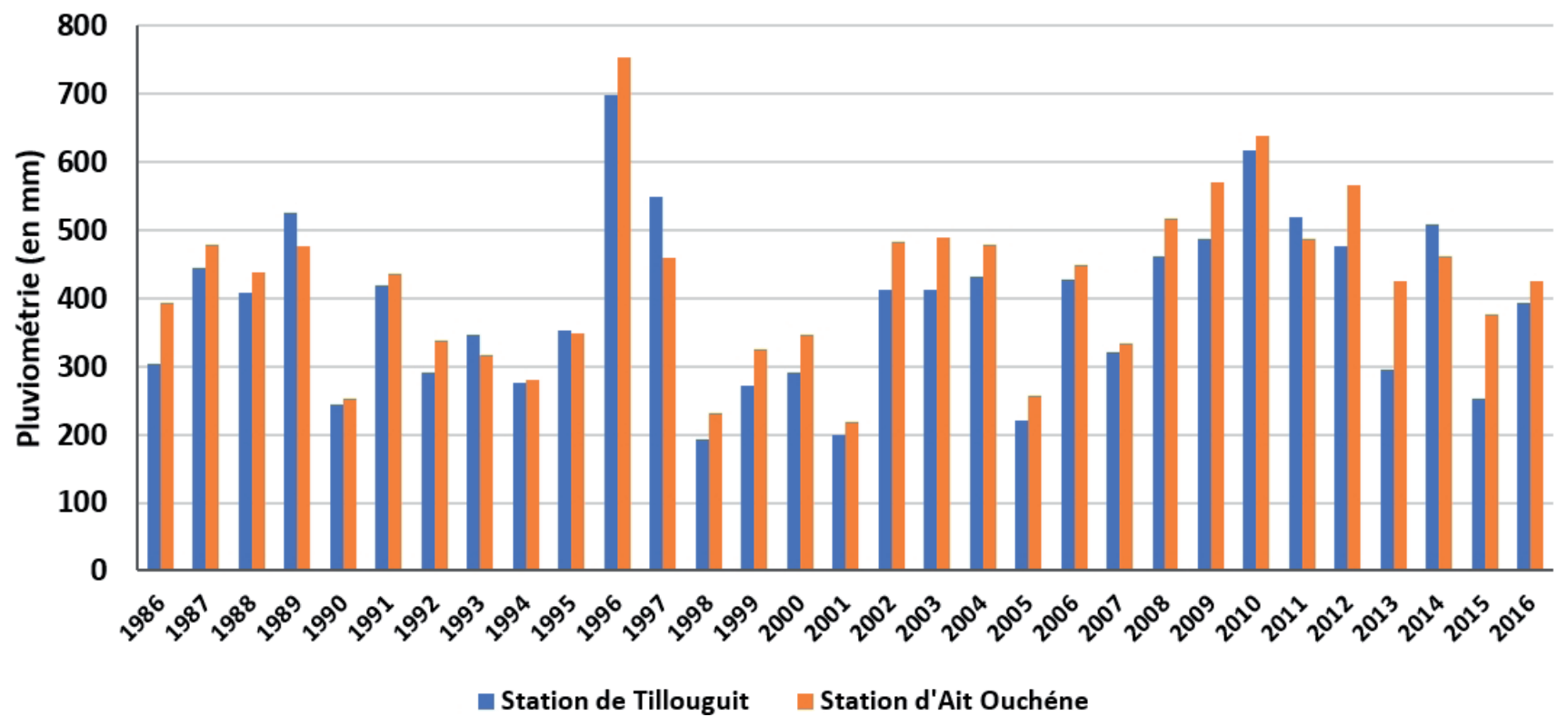

Figure 1. Evolution de la pluviométrie moyenne annuelle aux stations de Tillouguit et Ait Ouchène entre 1986 et 2016. Source: Élaboration des auteurs. 
L'analyse des données de précipitations annuelles des stations étudiées montre une variation importante des précipitations interannuelles (figure 1), où la moyenne interannuelle enregistrée au niveau de la station de Tillouguite atteint $379 \mathrm{~mm}$ et la station des Ait Ouchène enregistre durant la même période $420.7 \mathrm{~mm}$. Ainsi, les valeurs annuelles les plus élevées pour les deux stations sont enregistrées pendant les deux années 1996 et 2010 , avec respectivement $697.6 \mathrm{~mm}$ et $616.8 \mathrm{~mm}$ à la station de Tillouguite, et $752.5 \mathrm{~mm}$ et $639.2 \mathrm{~mm}$ à la station des Ait Ouchène. Il faut noter aussi que la zone de la forêt des Ait Daoud ou Ali reçoie annuellement des masses très importantes de la neige qui durent plusieurs mois, notamment au niveau du plateau d'El Houanet qui est dominé par des monts et des crêtes dépassant 2600m d'altitude.

En effet, la relation entre ces facteurs est très intime et directe vu qu'il y a un impact sur l'évolution du couvert végétal. Concernant le climat, elles agissent d'une manière directe sur la répartition du couvert végétal et par conséquent sur leur stabilité. L'impact du choc des gouttes d'eau ouvre la voie au ruissellement par une série de modifications de l'état de surface du sol, au fil de temps l'effet de ces modifications devient de plus en plus importants, avec la pente les effets du ruissellement deviennent plus graves, et menacent par conséquent la stabilité et la fixation des sols et de la végétation.

Tous ces facteurs, i) anthropiques (densité de la population et ses activités) et ii) naturels tel que le climat, la topographie, la lithologie ont contrôlé et contrôlent d'une manière ou autre et interviennent à la distribution spatiale et la dynamique du couvert végétal à l'échelle de la forêt des Ait Daoud ou Ali et les autres zones forestières du Haut Atlas central.

\section{METHODOLOGIE}

\subsection{Données utilisées}

Généralement, l'étude multi-chronique de la dynamique du couvert végétal ou forestier, repose sur l'analyse spatio-temporelle et le traitement des images satellitaires par la télédétection spatiale. En effet, dans le présent papier nous avons opté cette démarche qui s'appuie sur I>utilisation des données des images du satellite de LandSat de trois types; il s'agit des images de type MSS, ETM et Oli, pour trois dates (période de 48 ans) (tableau 1). Ainsi, l'utilisation conjointe de la technique de télédétection spatiale et les outils SIG nous permet i) d'identifier les différences spatiales entre les trois dates choisies (1972, 1999 et 2020) et ii) de valider les résultats de classification obtenus.

En effet, pour toute étude multi-chronique de la végétation, il est très intéressant de bien choisir la date de prise de vue, parce que les caractéristiques du terrain varient souvent d'une année à l'autre et d'une saison à l'autre dans la même année. Donc, la difficulté dans ce genre d'étude c'est de distinguer et d'identifier la végétation naturelle notamment forestière. Pour ce fait, et afin d'augmenter la précision spatiale et radiométrique nous avons i) choisi la période de la saison sèche (de juin à septembre), parce que la majorité des cultures (notamment les céréalicultures) durant cette saison deviennent sèches; ainsi, ii) l'absence des nuages durant cette période sèche (de juin à septembre) rend la qualité des images satellites acquises plus élevée.

Tableau 1. Caractéristiques des images satellites utilisées.

\begin{tabular}{|l|c|c|c|c|}
\hline \multicolumn{1}{|c|}{ Nom du satellite } & Date acquisition & Range & Path & Résolution spatiale \\
\hline MSS (LANDSAT 1) & $08 / 09 / 1972$ & 38 & 216 & 30 \\
\hline ETM (LANDSAT 5) & $27 / 07 / 1999$ & 38 & 201 & 30 \\
\hline OLI (LANDSAT 8) & $08 / 06 / 2020$ & 38 & 201 & 30 \\
\hline
\end{tabular}

Source: Élaboration des auteurs 
Afin de justifier les résultats de l'évolution spatio-temporelle du couvert végétal de la forêt des Ait Daoud ou Ali, nous avons élaboré une carte de degré de risque de la dégradation potentiel (carte 4). L'élaboration de cette carte a été i) appuyée sur la superposition de toutes les cartes des facteurs naturels (tel que la cartes des pentes, des tranches d'altitude, d'exposition des versants (cartes topographiques Beni Mellel et Imilchil $1 / 100$ '000), carte de la spatialisation des précipitations (données de 4 stations cimatiques pour une période de 31 ans), de la lithologie (carte géologique de Beni Mellal et Imilchil 1/100'000) et la carte du couvert végétal (les images LandSat)), ayant une influence directe et indirecte sur l'évolution du couvert végétal, ainsi cette carte ii) classe la zone de l'étude en zones à risque allant de risque faible au risque très élevé. Dans l'objectif de vérification des résultats, nous avons utilisé cette carte comme référence cartographique pour valider sur le terrain les zones de progression et les zones de recul réelles.

Pour monter l'impact des pratiques humaines sur la dynamique du couvert forestier de la forêt des Ait Daoud ou Ali, nous avons préparé et rempli 120 questionnaires, destiné à la population locale ayant un contact direct avec la forêt et aux gestionnaires de la forêt (Direction Régionale des Eaux et Forêts, la commune, Direction provinciale de l'Agriculture).

\subsection{Les aspects méthodologiques}

Avant de procéder à la classification des trois images satellitaires retenues, et pour assurer un bon seuillage et une bonne visualisation des images, lors des traitements, nous avons fait quelques corrections radiométriques. Par la suite, nous avons élaboré deux types de composition colorées des images satellitaires, la première concerne la composition fausse colorée, qui permet de mettre en évidence le couvert végétal (il apparait en rouge), et la deuxième composition a pour but la visualisation d'une image en couleurs naturelles (RVB = Rouge, Vert, Bleu), afin de l'utiliser dans la classification sous un logiciel de de télédétection et/ou SIG.

Nombreuses sont les méthodes utilisées dans les études de classification de la dynamique du couvert végétal: I'Indice de Végétation par Différence Normalisée (NDVI: Normalised Difference Vegetation Index), Indice de Végétation Résistante à l'Atmosphère (ARVI: Atmospherically Resistant Vegetation Index), Indice de Surveillance de l'Environnement Mondial (GEMI: Global Environment Monitoring Index), Indice de Végétation Ajustée au Sol Transformé (STAVI: Tranformed Soil Adjusted Vegetation Index); Indice de Végétation Ajustée au Sol Modifié (MSAVI: Modified Soil Adjusted Vegetation Index), (Qi et al., 1994; Rondeaux et al., 1996; Bouiadjra et al., 2011). Par contre, dans notre travail, nous avons procédé à calculer l'Indice de Végétation par Différence Normalisée (NDVI) afin de bien identifier les zones d'extension du couvert végétal et forestier pour les différentes dates choisies. Ainsi, la méthode de classification adoptée pour cette étude est celle de la classification supervisée (ou dirigée), et pour éliminer les très petits polygones de classification et améliorer les résultats de classification nous avons procédé à la méthode de (Maximum Likelihood). Quant aux classes choisies pour la classification supervisée, nous avons retenu deux classes: le couvert végétal et le sol nu. Pour valider les résultats de la classification nous avons calculé la séparabilité entre les deux classes pour éliminer toute confusion entre les deux classes. Le niveau de séparabilité obtenu entre les deux classes est très satisfaisant. En outre, pour mener à bien la classification supervisée des images et obtenir des résultats avec haute précision nous avons procédé à i) la vérification des différentes classes sur le terrain (plusieurs sorties de terrain), ii) la comparaison des résultats de la classification sur les logiciels de télédétection et le logiciel de SIG.

Concernant l'élaboration de la carte de degré de risque de la dégradation de la forêt de la zone d'étude, elle consiste en l'identification, l'évaluation et l'intégration des facteurs physiques de base, tels que la topographie (pentes et exposition des versants à partir des cartes topographiques de Beni Mellal et Imilchil 1/100'000), la lithologie (carte de Beni Mellal et Imilchil 1/100'000), et le couvert végétal (images LandSat 1972-1999-2020) et travail de terrain, afin de fournir des informations sur l'état potentiel de la dégradation des versants ainsi les facteurs responsables à la dégradation de la forêt. 


\section{RESULTATS}

\subsection{Classification du couvert végétal de la zone d'étude}

Après avoir identifié les classes retenues, nous avons pris plusieurs échantillons en se basant sur les signatures spectrales du couvert végétal et des surfaces dépourvues de végétation. En effet, le traitement des images a montré une variation très importante de l'extension spatiale et de la superficie du couvert végétal entre les trois dates prédéfinies 1972, 1999 et 2020 (carte 2).

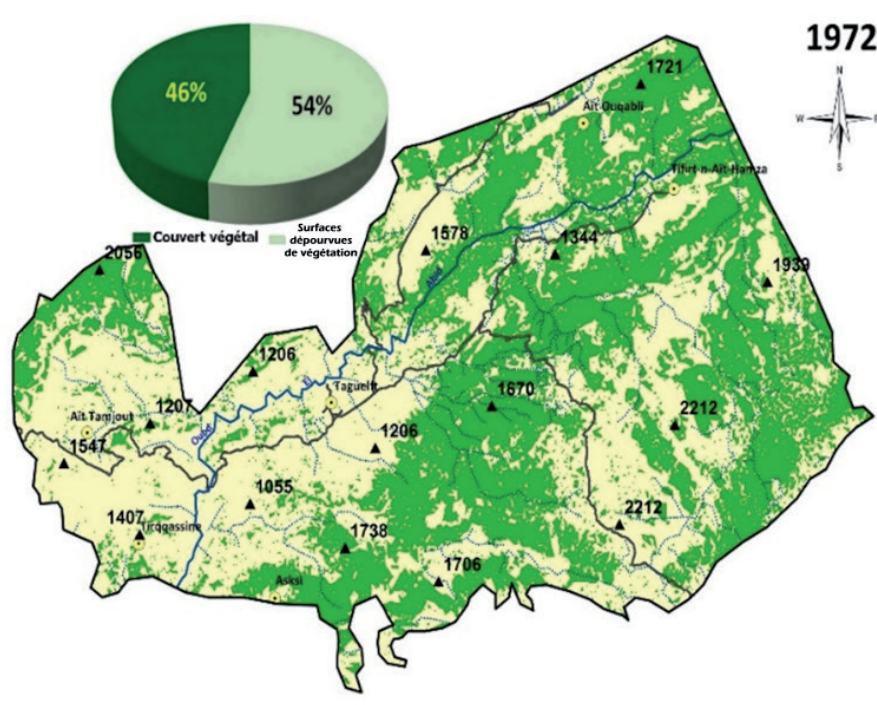

\section{Légende}

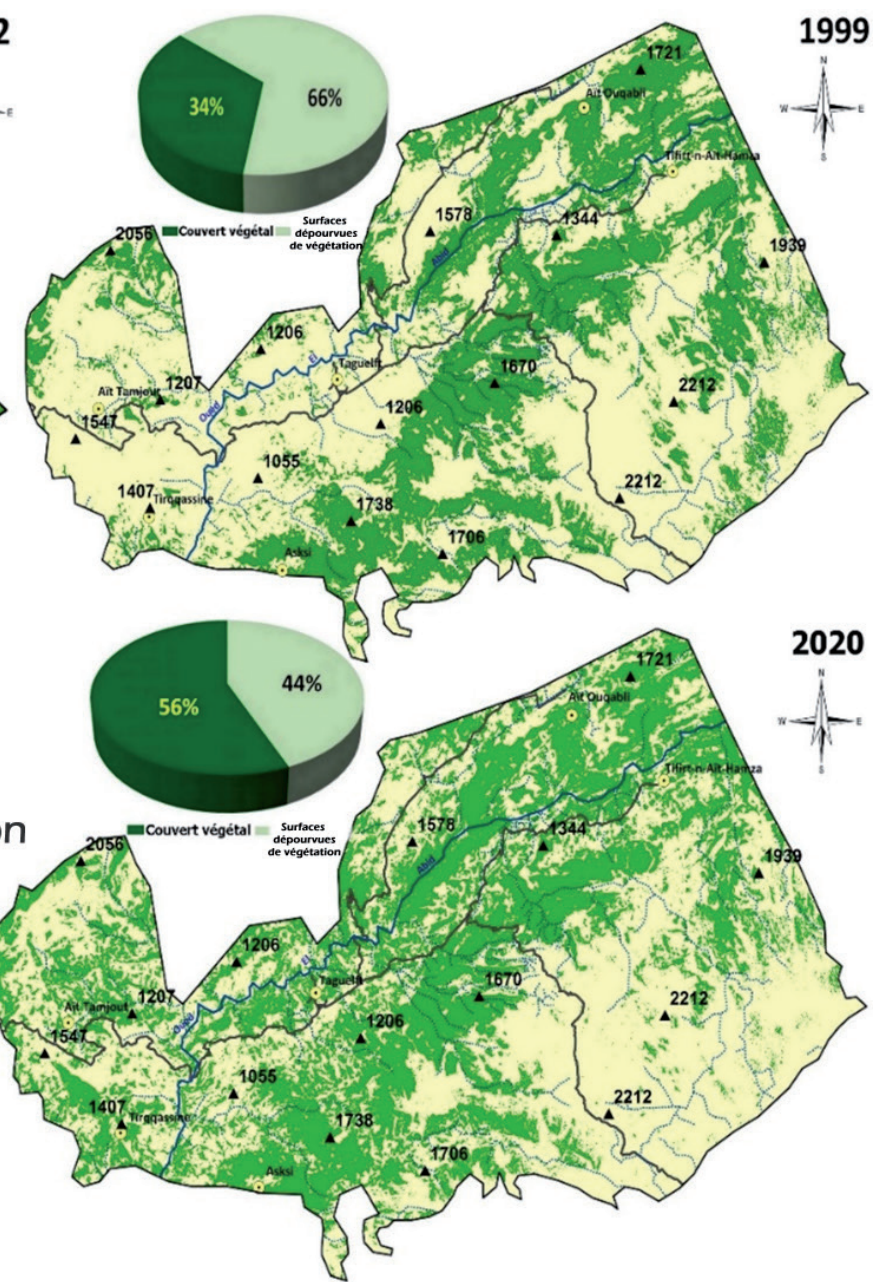

Carte 2. Dynamique du couvert végétal de l'image Landsat 1972, 1999 et 2020. Source: Élaboration des auteurs.

A la lumière des cartes de la classification, nous observons une dynamique spatio-temporelle très remarquable. Cette dynamique est résumée dans un grand recul du couvert végétal entre les deux années 1972 et 1999. Les zones qui ont connu une importante régression de la superficie du couvert forestier sont la partie Sud-Est et la partie Nord-Ouest de la zone de l'étude. En revanche, le couvert végétal de la forêt des Ait Daoud ou Ali a connu une progression entre les deux années 1999 et 2020, notamment au long de la direction et l'alignement Sud-Ouest Nord Est (spécialement au centre de la zone d'étude et sur les alentours des douars Asksi et Ait Tamjout d'une part, et sur les centres des communes de Taguelft, des Ait Ouqabli et de Tifirt n'Aït Hamza d'autre part).

Pour bien concrétiser et évaluer la dynamique du couvert végétal entre les trois dates retenues, nous avons représenté des résultats quantitatifs des variations du couvert végétal et des surfaces dépourvues de végétation tirés de la classification supervisée dans le tableau 2. On remarque qu'en 1972, superficie du couvert végétal à l'échelle de la zone de la forêt était de l'ordre de 14195.6 ha, et il se concentre essentiellement 
dans la partie centre et la partie Est de la zone de l'étude. En revanche, la partie Ouest, qui conforme le synclinal de Tagleft et la vallée de l'Oued El Abid, a connu une dominance des surfaces dépourvues de végétation dont la superficie est de 16664,4 ha. Quant à la classification effectuée pour l'année 1999, le couvert végétal montre un recul très important de point de vue surfacique par rapport à l'année 1972. Les zones ayant connues cette importante régression sont la partie centre et la partie Sud-Ouest de la zone de la forêt des Ait Daoud ou Ali. En effet, la superficie de la forêt a été réduite avec 12\% de la surface totale par rapport à l'année 1972. Par ailleurs, les surfaces dépourvues de végétation ont enregistré une progression très remarquable, dont ils atteignent 3703.2 ha.

Tableau 2. Changement du couvert végétal en 1972, 1999 et 2020.

\begin{tabular}{|c|c|c|c|c|}
\hline \multirow{2}{*}{ Années } & \multicolumn{2}{|c|}{ Couvert végétal } & \multicolumn{2}{|c|}{ Surfaces dépourvues de végétation } \\
\hline & ha & $\%$ & $h a$ & $\%$ \\
\hline 1972 & 14195,6 & 46 & 16664,4 & 54 \\
\hline 1999 & 10492,4 & 34 & 20367,6 & 66 \\
\hline 2020 & 17281,6 & 56 & 13578,4 & 44 \\
\hline Variation entre 1972-1999 & $-3703,2$ & -12 & 3703,2 & 12 \\
\hline Variation entre 1999-2020 & 6789,2 & 22 & $-6789,2$ & -22 \\
\hline Variation entre 1972-2020 & 3086 & 10 & -3086 & -10 \\
\hline
\end{tabular}

Source: Élaboration des auteurs.

En effet, pendant les années 80, le Maroc a connu le déficit pluviométrique le plus important avec des périodes de sécheresse pénible (Hili et al., 2020; Bissour et al., 2018; Hanchan, 2014; Wassenburg et al., 2013; Benassi, 2008; Stour \& Agoumi, 2008; Karrouk, 2003), ces conditions ont influencé directement la répartition spatiale des précipitations, et par conséquent la spatialisation et l'évolution du couvert végétal. Pour cela, pendant ces années, les ressources naturelles en général, et le couvert végétal en particulier ont enregistré une surexploitation très abusive.

Quant à la classification effectuée pour l'image Landsat 2020, l'analyse de la carte obtenue de la dynamique du couvert végétal nous permet de souligner une importante progression de la densité de la forêt des Ait Daoud ou Ali. Les zones concernées par cette progression sont les alentours du centre de la commune de Tagleft, la partie Ouest près du douar des Ait Tamjout. Cette progression est de l'ordre de 10\% par rapport à l'année 1999. En revanche, nous remarquons sur la partie Sud-Est de la zone d'étude un remarquable recul du couvert végétal, malgré que les versants sont exposés vers le Nord et vers l'Ouest, où les sols sont riches en matière organique et en humidité. Normalement, la justification de cette progression est la déclaration de plusieurs lois, qui visent la protection de l'environnement.

Dans ce sens, le Royaume du Maroc a participé au "Sommet de la Terre" à Rio de Janeiro en 1992, delà et en raison de sa position géographique, le Maroc a proposé plusieurs actions de reboisement et autant de réglementations et de lois pour la conservation et la protection de la nature en général, et la richesse de sa diversité biologique en particulier à travers la création des aires protégées et des parcs nationaux.

Après la déclaration des lois (la loi 11-03 relative à la protection et à la mise en valeur de l'environnement, la loi 12-03 relative aux études d'impact sur l'environnement, et notamment la loi 22-07 relative aux aires protégées), nous avons remarqué une progression de la superficie du couvert végétal en faveur de la surface des surfaces dépourvues de végétation (carte 3). Cette augmentation est prouvée par l'intérêt donné à la protection et à la sauvegarde de la biodiversité à travers les différentes actions menées par les autorités chargées par la conservation des zones forestières (Direction des Eaux et Forêts). Malgré les efforts menés pour la protection, le reboisement et la progression enregistrée entre 1999 et 2020, le terrain de l'étude a enregistré encore un recul général entre 1972 et 2020 de l'ordre de 10\%. 


\subsection{La dynamique spatio-temporelle du couvert végétal}

Afin de montrer les zones de recul et de progression, nous avons élaboré les cartes de la dynamique du couvert végétal de zone de la forêt des Ait Daoud ou Ali, en croisant les trois cartes (1972-1999-2020) pour ressortir la carte de la dynamique spatio-temporelle de cette zone (carte 3). Dans ces cartes nous avons retenu quatre classes: surfaces dépourvues de végétation, la forêt, les zones de recul ou de dégradation et les zones de progression ou de croissance du couvert végétal et forestier.
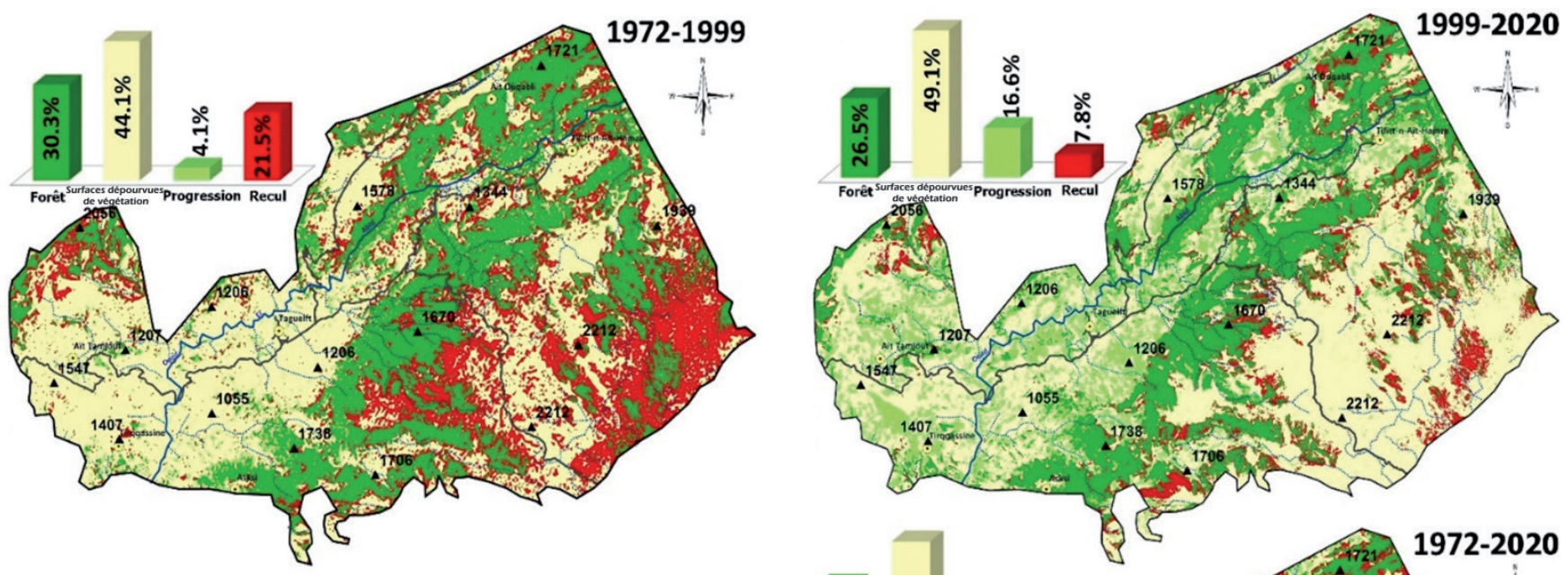

\section{Légende}

Zones de progression

Zones de recul

Surfaces dépourvues de végétation(Zones de stabilité)

Couvert végétal (Zones de stabilité)

$\Omega$ Limite de la forêt

$\sim$ Cours d'eau permanent

Cours d'eau temporaire

Réseau routier

- Ponits d'altitude

- Centres
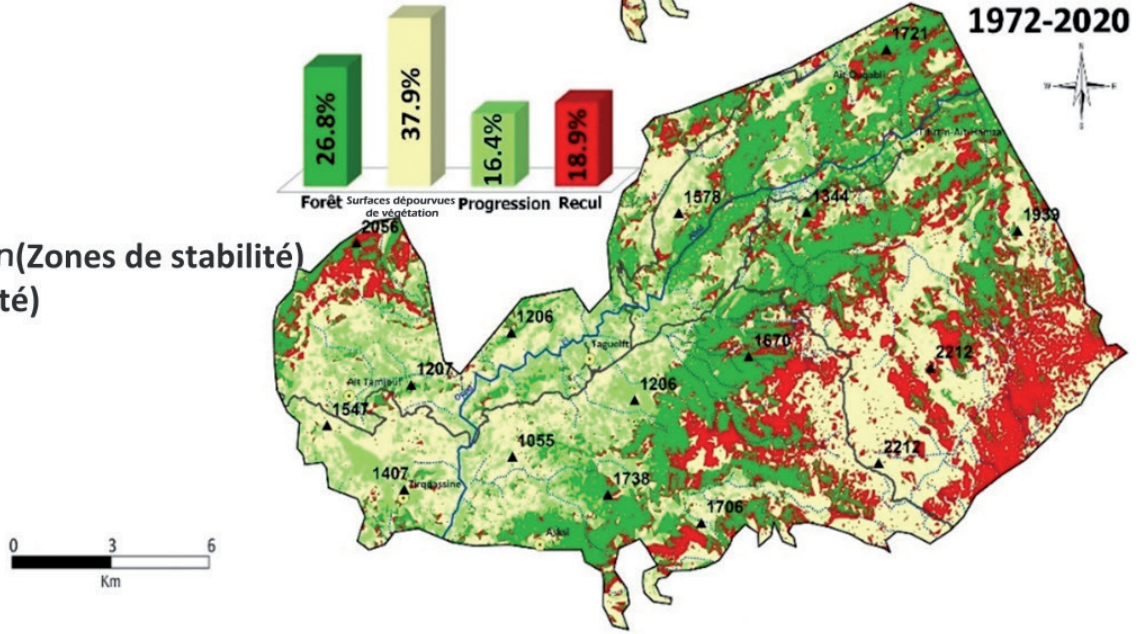

Carte 3. Zones de progression et de recul du couvert végétal de la forêt des Ait Daoud ou Ali. Source: Élaboration des auteurs.

Quant à la première carte, qui concerne l'évolution du couvert végétal entre 1972 et 1999, l'analyse des résultats de la carte nous permet de distinguer un recul important du couvert végétal notamment au centre, au Sud-Est et au Nord-Est de la zone de la forêt. En effet, ce recul marque une dégradation des zones couvertes autrefois par la forêt avec $21.5 \%$. Par contre, la progression de la forêt a touché des zones très limitées qui ne dépassent pas $4.1 \%$. Ainsi, les zones de stabilité (la forêt et les surfaces dépourvues de végétation) couvrent respectivement $30.3 \%$ et $44.1 \%$ (graphique de la carte 3, année 1972-1999).

Concernant l'analyse des résultats de la dynamique du couvert végétal des Ait Daoud ou Ali entre 1999 et 2020, durant cette période (période de promulgation des lois de la protection de la biodiversité et de l'environnement), les surfaces dépourvues de végétation ont régressé en faveur des surfaces de progression de la forêt avec $16.6 \%$ notamment dans la partie centrale de forêt près de Tagleft et au Nord du douar Asksi, et à l'Ouest près des douars des Ait Tamjout et de Tirqqassine. Par ailleurs, les surfaces de recul et de dégradation ont enregistré une diminution au profit des surfaces dépourvues de végétation avec $7.8 \%$ notamment dans la partie Sud-Est de la zone. 
En effet, l'analyse des données de la classification de la période étudiée de 48 ans (entre 1972 et 2020), a montré que le couvert végétal de la zone d'étude a régressé dans l'ensemble en faveur des surfaces de reculs avec $18 \%$, par contre les surfaces dépourvues de végétation ont enregistré une régression en faveur des zones de progression avec $16 \%$.

Afin de vérifier et de valider les résultats de traitements des images (régression et/ou progression), nous avons i) effectué plusieurs sorties de terrain, dont nous avons enregistré une grande disposition spatiale entre la classification de l'évolution du couvert végétal, le degré de risque de la dégradation potentielle et la réalité de terrain. Ainsi, ii) ce constat a été vérifié par la comparaison des résultats de classification élaborée à l'aide de la Télédétection Spatiale (RS) et les Systèmes d'Information Géographique (GIS), dont nous avons noté une précision globale du traitement très satisfaisante (tableau 3).

Tableau 3. Comparaison des résultats de classification effectuée sur (RS) et (GIS).

\begin{tabular}{|c|c|c|c|c|c|c|}
\hline & \multicolumn{2}{|c|}{$\begin{array}{c}\text { Classification supervisée sur RS } \\
\text { "Region of interest (ROI)" }\end{array}$} & $\begin{array}{c}\text { Classification supervisée sur GIS } \\
\text { "Maximum Likelihood } \\
\text { Classification" }\end{array}$ & \multicolumn{2}{|c|}{ Différence } \\
\hline Années & $\begin{array}{c}\text { Couvert } \\
\text { végétal \% }\end{array}$ & $\begin{array}{c}\text { Surfaces } \\
\text { dépourvues de } \\
\text { végétation \% }\end{array}$ & $\begin{array}{c}\text { Couvert } \\
\text { végétal } \\
\%\end{array}$ & $\begin{array}{c}\text { Surfaces } \\
\text { dépourvues de } \\
\text { végétation \% }\end{array}$ & $\begin{array}{c}\text { Couvert végétal } \\
\%\end{array}$ & $\begin{array}{c}\text { Surfaces } \\
\text { dépourvues de } \\
\text { végétation \% }\end{array}$ \\
\hline 1972 & 45,82 & 54,17 & 46,1 & 53,9 & $\mathbf{0 , 2 8}$ (soit 86 ha) & $\mathbf{0 , 2 7}$ (soit 83 ha) \\
\hline 1999 & 34,13 & 65,85 & 33,82 & 66,17 & $\mathbf{0 , 3 1}$ (soit 96 ha) & $\mathbf{0 , 3 2}$ (soit 99 ha) \\
\hline 2020 & 56,04 & 43,94 & 55,78 & 44,21 & $\mathbf{0 , 2 6}$ (soit 80 ha) & $\mathbf{0 , 2 7}$ (soit 83 ha) \\
\hline
\end{tabular}

Source: Élaboration des auteurs.

La comparaison des résultats de la classification élaborée sous les deux logiciels, montre une faible différence de classification entre $0.26 \%$ et $0.32 \%$ entre les surfaces traitées et calculées. Pour ce fait, nous remarquons que le couvert végétal en 1972 s'étend sur une superficie de l'ordre de 45.82\% en utilisant l'outil "Region of Interest", et une superficie de $46.1 \%$ avec la méthode de "Maximum Likelihood Classification" sous l'outil SIG, avec une différence de $0.28 \%$. De même, les surfaces dépourvues de végétation enregistrent un écart de 83 ha soit $0.27 \%$. Pour la classification effectuée pour l'image de l'année 1999, la différence entre les zones a augmenté vers $0.31 \%$ pour le couvert végétal, et $0.32 \%$ pour les surfaces dépourvues de végétation. En revanche, pour l'année 2020, le couvert végétal représente un écart de $0.26 \%$ (soit 80 ha), et les surfaces dépourvues de végétation ont enregistré une variation de $0.27 \%$ soit 83 hectares.

En fait, l'existence de ces zones de différence est liée notamment à la présence de plusieurs pixels à la limite entre les zones du couvert végétal et les surfaces dépourvues de végétation. Dans ce sens, nous avons essayé de corriger au maximum les valeurs digitales de plusieurs pixels pour qu'ils reflètent la réalité du terrain et respectent les limites réelles de la forêt et des surfaces dépourvues de végétation.

\subsection{La dégradation potentiel du couvert végétal de la zone d'étude}

Pour vérifier la dynamique du couvert végétal de notre zone d'étude nous avons élaboré la carte de degré de risque de la dégradation potentiel du couvert végétal (carte 4). En effet, la superposition des facteurs naturels ayant une influence directe et indirecte sur l'évolution du couvert végétal nous a permet de hiérarchiser la carte de risque en potentiel faible à plus élevé (carte 4).

En effet, la carte 4, nous renseigne sur l'état de dégradation potentiel de la zone étudiée. D’après cette carte, nous constatons que la zone de la forêt est caractérisée par une dégradation potentielle très élevée. 


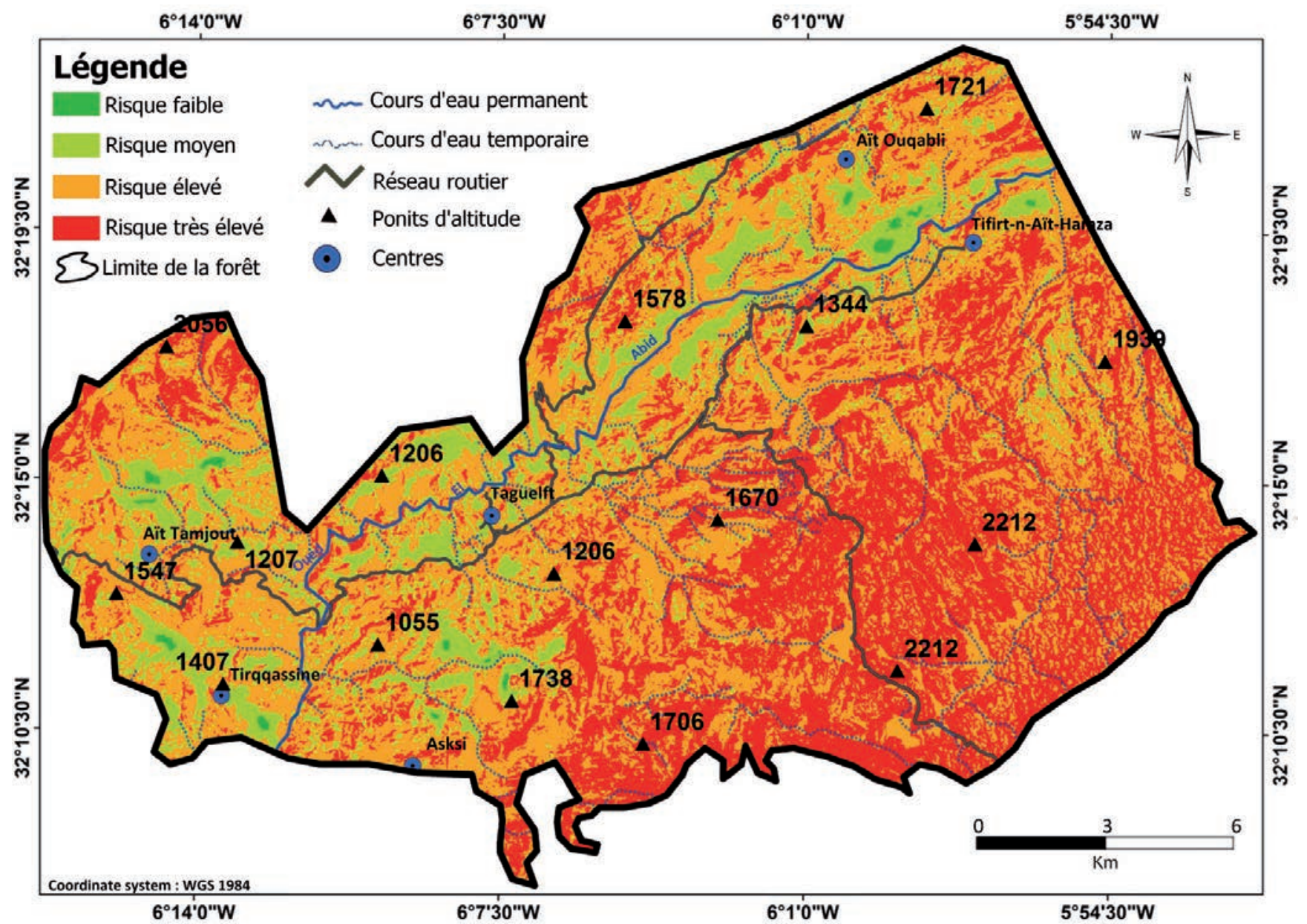

Carte 4. Degré de risque de la dégradation potentiel de la forêt des Ait Daoud ou Ali. Source: Élaboration des auteurs.

\subsection{Les pratiques anthropiques touchant l'intégrité de couvert végétal de la zone d'étude}

Pour monter le rôle des interventions humaines dans notre zone d'étude Les sorties de terrains et l'analyse de cette carte de degré de risque de la dégradation, montrent une grande coïncidence entre les zones à risque élevé et très élevé qui couvrent une superficie qui représente $72.3 \%$ avec les zones de recul, notamment à l'Est et au Sud-Est de la zone d'étude (Sud de Tifirt-n-Aït Hamza, Est d'Asksi, et Sud-Est de Taguelft). En revanche, les zones à risque faible (représentent $7.2 \%$ de la surface de la zone de la forêt) et moyen (couvrent 20.7\%) se coïncident avec les zones de stabilité et les zones de progression, cette coïncidence est bien visible à l'Ouest de Tifert n'Aït Hamza (Sud des Ait Ouqabli), au Nord d'Asksi, et Ait Tamjout, et au Sud-Ouest de Taguelft.

Généralement, les faibles quantités de précipitations, la topographie accidentée, la lithologie calcaire (Bissour, 2019) sont autant des facteurs qui sont à l'origine de la dynamique et l'évolution du couvert végétal. Outre les facteurs naturels, nous avons essayé d'évaluer l'effet des interventions anthropiques, l'analyse des données du questionnaire, nous a permis de dégager les actions et les interventions inappropriées les plus utilisées par l'Homme amenant à la dégradation du couvert végétal (Tra Bi,2013), l'utilisation du bois pour le charbonnage, pour la construction des maisons et pour le chauffage. De même, la population exerce une grande action négative sur la forêt par le surpâturage, et par l'effet de la déforestation et la conversion des terrains forestiers en des zones agricoles (Bouzekraoui et al., 2016; El Mazi et al., 2018). Ceci est bien claire dans les environs du douar d'Aglef (Plateau d'Aglef) et aux alentours du centre de Tifert n'Ait Hamza).

D’après la figure 2, nous remarquons que 32.1\% de la population locale (questionnée) utilise les bois issus de la forêt des Ait Daoud ou Ali pour le chauffage et la cuisine. Ce pourcentage a pour origine le climat dur qui règne dans la zone de la forêt, notamment dans les parties Sud et Est, où les précipitations nivales sont 
très importantes pendant les périodes estivales et les minimas des températures sont souvent inférieurs à $0^{\circ} \mathrm{C}$ pendant les périodes humides, et peuvent durer plusieurs mois. De même, $29.7 \%$ de la population exerce un surpâturage au milieu de la forêt, ce problème pèse lourdement lorsque le troupeau comporte un nombre considérable de tète (plus de 200 têtes), et surtout s'il comporte des chèvres (figure 3), qui peuvent atteindre les parties supérieures des arbres et mangent notamment les nouveaux bourgeons des branches.

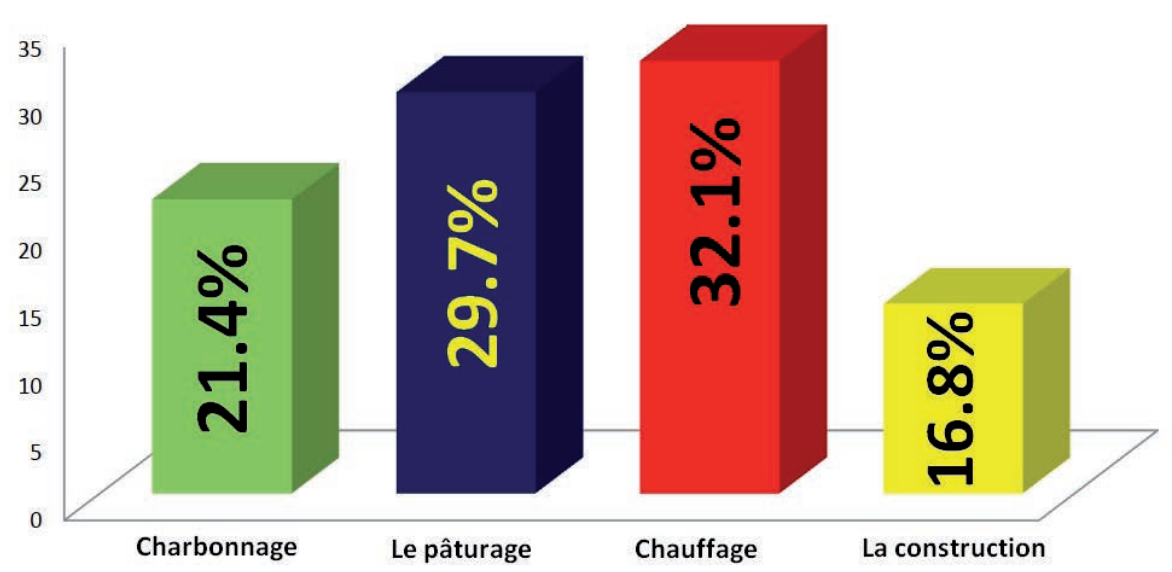

Figure 2. Actions anthropiques dégradant le couvert végétal de la zone d’étude. Source: Élaboration des auteurs.

Outre cela, $21.4 \%$ de la population pratiquent le charbonnage notamment avec le chêne vert, car il est examiné et considéré comme un bois très excellent pour cette opération. Selon les responsables des Eaux et Forêts rencontrés, plus de $210 \mathrm{Kg} / \mathrm{st}$ du bois sont exploités pour le charbonnage. Cette action est exercée par la population locale pour des fins commerciaux, dont le charbons produit est souvent destiné aux centres ruraux (Tagleft, Larbaa n'Ait Ouqabli, Tifert n'Ait Hamza, Ouaouizerht, Aghbala, El Ksiba) et villes comme Beni Mellal dans la plaine de Tadla. Malgré les efforts déployés par les autorités chargées de la protection et la garde de la forêt pour lutter contre le charbonnage illégal et non autorisé, le charbonnage continue à exercer son effet négatif sur la forêt des Ait Daoud ou Ali, en attendant que la population locale dispose d'autre ressources économiques. Enfin, 16.8\% coupe le bois de la forêt pour la construction des maisons (figure 4). Cette portion est due généralement à la nature et type des constructions, dont la population n'utilise que les sols (argiles ou marnes), des pierres et du bois pour la construction de leurs abris.

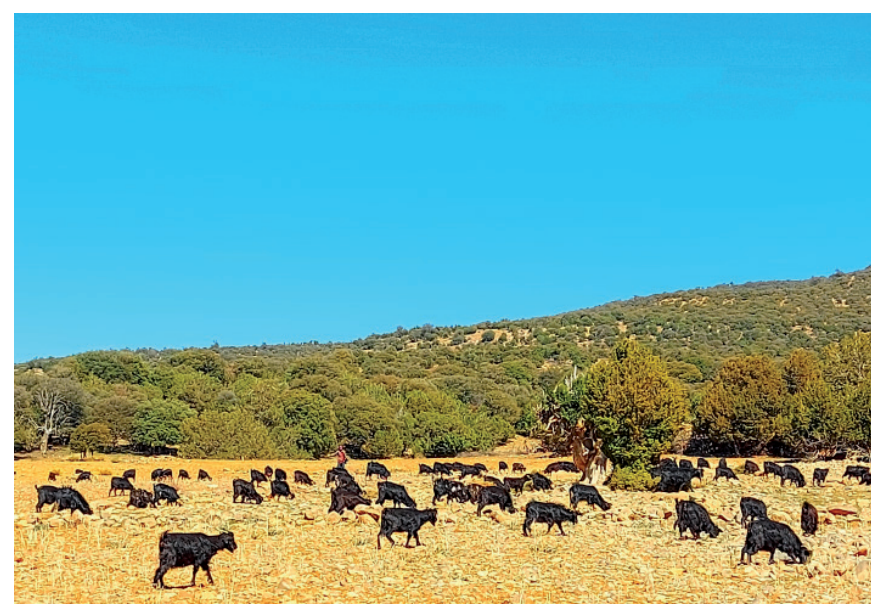

Figure 3. Le surpâturage des chèvres dans la forêt. Source : Hili, 2020.

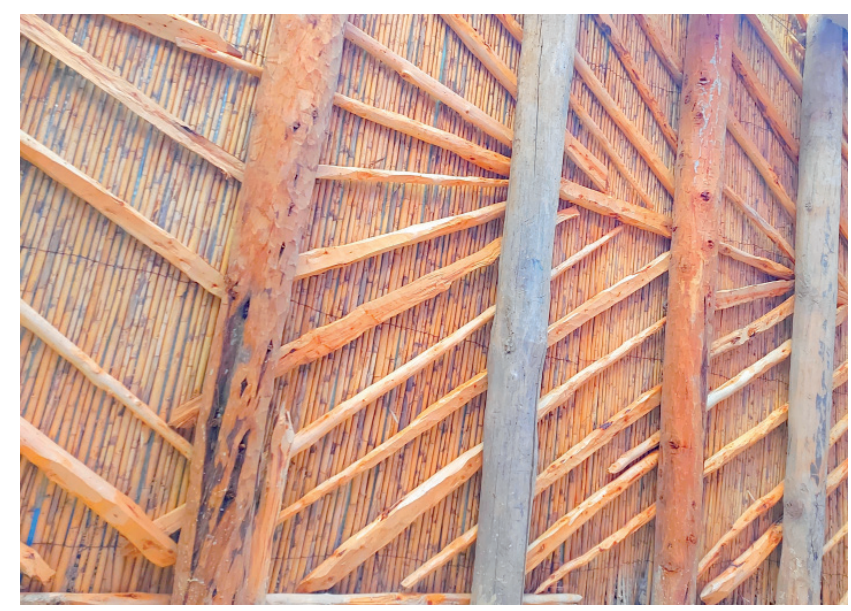

Figure 4. La construction des maisons. Source: Hili, 2020. 


\section{DISCUSSION}

En général, la répartition et la dynamique du couvert végétal au Maroc (Hili \& Abdelaziz, 2021; Bissour et al., 2018; Sbai et al., 2018; El Mazi et al., 2018; Bouzekraoui et al., 2016; Daoui \& Fatemi, 2014; Tra Bi, 2013; Hammi, 2007; Labhar, 1998; Benabid, 1985; Lecompte, 1986; Michel \& Ruelan, 1967) comme les autres pays du monde (Gansaonré et al.; 2020, Raogo, 2018; Diop et al., 2018; Soro et al., 2014; Bouiadjra et al., 2011; Dawson et al., 2011; Brou, 2010; Mahamane et al., 2007; Demarteau et al., 2007; Ouloukoi et al., 2006; Jeffrey et al., 2006; Cabid et al., 2005; Hountondji et al., 2004; Carmen Salazar Conde et al., 2004; Nguessan, et al., 2003; Demaze, 2003; Dupouey et al., 1999; Thimonier, 1994) sont liées aux changements environnementaux et/ou interventions anthropiques, dans notre terrain d'étude, deux types de causes possibles peuvent expliquer ces changements observés du couvert végétal entre les trois dates étudiées.

Pour la période entre 1972 et 1999, les changements observés du couvert végétal sont liés aux facteurs naturels notamment les conditions climatiques défavorables qu'a connu le Maroc (les périodes de la sécheresse) en général et de la zone d'étude en particulier. Cette période a été marqué par un stress climatique et hydrique très remarquable qui a touché la dynamique spatio-temporelle du couvert végétal dans cette zone. En revanche, entre 1999 et 2020, le Maroc en général a enregistré une augmentation de la démographie, ce qui a changé les besoins et les pratiques de l'Homme, pour cela malgré la promulgation des lois de la protection de la biodiversité et de l'environnement, les interventions de l'état (reboisement) et les conditions climatiques plus ou moins favorables les actions anthropiques ont laissé un impact majeur sur la dynamique et la répartition du couvert végétal (Hili \& Abdelaziz, 2021; Bouzekraoui et al., 2016; Tra Bi, 2013; Nguessan et al., 2003). Les principaux résultats ont indiqué un vrai recul du couvert végétal issue à une dégradation de plus en plus importante du milieu liée notamment à la demande intense sur le bois et aussi aux pratiques anthropiques (le pâturage, charbonnage, agropastorale, ...).

En effet, l'étude de la dynamique spatio-temporelle du couvert végétal de la forêt des Ait Douad ou Ali a montré que les facteurs naturels tels que le climat (précipitations - surtout nivales-, température, etc.), la topographie (notamment les altitudes, l'exposition des versants et les pentes), la lithologie sont autant de facteurs qui ont influencé et influencent encore la répartition spatiale et la dynamique du couvert végétal de la forêt des Aït Douad ou Ali.

Ainsi, l'évolution des pratiques anthropiques (le pâturage, charbonnage, ...) sur le territoire d'étude est considérée comme un facteur très important pour expliquer la dynamique du couvert végétal de la forêt des Ait Daoud ou Ali observée pendant ces dernières 48 ans. Dans ce sens, nous avons distingué quatre usages principaux qui peuvent être responsables à la dégradation du couvert végétal dans notre zone d'étude, ces quatre actions sont variables dans le temps et dans l'espace selon les besoins de l'Homme.

Il faut dire que les études que nous avons mené sur la dynamique spatio-temporelle du couvert végétal sur quelques zones de la région de Beni Mellal-Khènifra, notamment sur la commune d'Aghbala (en cous de publication) et sur la forêt des Ait Bouzid (fera l'objet d'un autre article), penchent vers une tendance d'une forte dégradation et d'une forte régression du couvert végétal dans les trois zones (forêt des Ait Daoud ou Ali, commune d'Aghbala, la forêt des Ait Bouzid). Cette tendance de dégradation est liée essentiellement dans ces trois zones aux actions anthropiques inappropriées, très intensives et inconscientes.

\section{CONCLUSION}

La classification multi-chronique $(1972,1999$ et 2020) menée dans ce travail a montré que la zone de la forêt des Ait Daoud ou Ali a connu une évolution très remarquable durant les 48 ans dernières.

Durant cette période, notamment entre 1972 et 1999, nous avons enregistré un fort recul de la superficie du couvert végétal en faveur des surfaces dépourvues de végétation avec $12 \%$ au Sud-Est de la zone d'étude. Cette diminution, est impliqué dans un contexte climatique particulier, où le Maroc a connu des longues périodes de sécheresse (les années 1980). Après cette période, notamment entre 1999 et 2020, le Maroc s'est engagé à proposer et adopter plusieurs réglementations et lois, pour la protection de la nature en général, 
et de la richesse de sa diversité biologique en particulier. Certes, cette politique a donné ces fruits quelques années plus tard (même si qu'elle reste très modeste à l'échelle du Haut Atlas Central et à la région de Beni Mellal-Khénifra en particulier). Sur la zone de la forêt qui fait objet de cette étude, nous pouvons remarquer une progression du couvert végétal (en général) avec $22 \%$. Malgré cette progression, l'aire de l'étude enregistre encore une perte de $10 \%$ de son couvert végétal.

Les résultats de classification obtenus sont satisfaisants, sa validation a été vérifiée par l'observations directes de la spatialisation des zones lors des sorties de terrains, et aussi par la comparaison des résultats obtenus de la classification de l'outil "Region of Interest" utilisé sous les outils de la télédétection spatiale, avec celle de la classification "Maximum Likelihood Classification" effectué à l'aide des Systèmes d'Informations Géographiques. L'étude de ces deux méthodes a montré une précision élevée du traitement globale, avec une faible différence entre les zones qui varie entre $-0.26 \%$ et $0.32 \%$.

En général, il faut dire que l'évolution spatio-temporelle du couvert végétal est influencée et liée essentiellement à la conjonction de plusieurs facteurs naturels (le climat, les altitudes, l'exposition des versants et les pentes, la lithologie) et anthropiques.

Cette étude a mis en évidence l'impact des actions anthropiques notamment l'utilisation du bois pour le charbonnage, pour la construction des maisons, pour le chauffage (utilisation socio-économique de la ressource forestière) ainsi que l'impact de surpâturage et l'activité agricole dans la zone forestière (agroforestier), vu que l'activité principale de la population locale se résume dans l'agriculture et l'élevage). L'utilisation des techniques géospatiales nous a permis d'avoir des informations très précises relatives à l'évolution spatio-temporelle de recul et aussi de la progression du couvert végétal dans la forêt des Ait Daoud ou Ali.

Pour cela, on peut considérer que la méthode utilisée dans cette étude, qui associer à la fois l'analyse, l'interprétation visuelle et les traitements numériques, est satisfaisante et opérationnelle, elle peut donc être appliquée sur l'ensemble des études dédiées au suivi de la dynamique spatio-temporelle du couvert végétal.

\section{Signalement responsable et conflit d'intérêts}

Tous les auteurs s'engagent à divulguer tout conflit d'intérêts existant ou potentiel en relation avec la publication de notre article. De même, les tâches effectuées par les auteurs sont i) pour Aïman HILI, Rachid BISSOUR et Yassine El Jouhary, ils ont fait la collecte des données (cartes, images satellites, précipitations, ...), l'analyse des données, les sorties de terrain, l'élaboration des cartes et des bases de données, et la vérification des résultats sur le terrain; ii) pour les auteurs Aïman HILI, Fardi JAA et Hanane REDDAD ils ont fait l'orientation et l'encadrement du travail, l'analyse des données, la correction du manuscrit et la validation des résultats.

\section{RÉFÉRENCES}

Bahzad, H. (1982). Recherches hydrologiques et hydrochimiques sur quelques karsts méditerranéens: Liban, Syrie et Maroc. Livre deuxième. (Thèse de doctorat d'état), Université d'Aix-Marseille II, Institut de Géographie.

Benabid, A. (1987). Les grands écosystèmes terrestres et leur préservation. G.E.M. Rabal, 4, 77-190.

Benassi, M. (2008). Drought and climate change in Morocco. Analysis of precipitation field and water supply. In A. López-Francos (ed.). Drought management: scientific and technological innovations (pp.83-86). CIHEAM, 2008. Options Méditerranéennes: Série $A, \mathrm{n}^{\circ} 80$.

Bissour, R. (2019). Ressources en eau de l'oued El Abid amont barrage Bin El Ouidane et agriculture irriguée: Caractérisation, quantification et valorisation. Cas du périmètre irrigué de Beni Moussa (Région Beni Mellal - Khénifra). (Thèse de doctorat). Université Sultan Moulay Slimane, Beni Mellal, Maroc.

Bissour, R., \& El Khalki, Y. (2018). Fluctuations pluviométriques et leurs impacts sur le régime hydrologique du bassin versant de l'oued El Abid en amont du barrage de Bin El Ouidane (Haut Atlas Central). Acte du colloque Climat, Eau et Société (CES'2015); De la gestion des ressources en eau à la gestion des systèmes aquatiques, 1, 11-26.

Bissour, R., El Khalki, Y., \& Hili A. (2018). Apport de la télédétection spatiale à l'étude diachronique de la dynamique de l'occupation du sol dans le bassin versant de l'Oued El Abid, (Haut Atlas central, Maroc). Actes du colloque International des utilisateurs du SIG, Oujda. 
Bouiadjra, S., El Zerey, W., \& Benabdeli, K. (2011). Étude diachronique des changements du couvert végétal dans un écosystème montagneux par télédétection spatiale: cas des monts du Tessala (Algérie occidentale). Varia, 5, 211225. https://doi.org/10.4000/physio-geo.2048

Bouzekraoui, H., El Khalki, Y., Mouaddine, A., Lhissou, R., El Youssi, M., \& Barakat, A. (2016). Characterization and dynamics of agroforestry landscape using geospatial techniques and field survey: a case study in central High-Atlas (Morocco). Agroforestry Systems. 90 (6), 965-978. https://doi.org/10.1007/s10457-015-9877-8

Brou, T. (2010). Variabilité climatique, déforestation et dynamique agrodémographique en Côte d'Ivoire. Sécheresse, 21(1e), 1-6. https://doi.org/10.1684/sec.2010.0266

Cabid, M., Zak, M., R., Cingolani, A., Cáceres, D. \& Díaz, S., (2005). Cambios en la cobertura de la vegetación del centro de la Argentina. ¿Factores directos o causas subyacentes? https://www.researchgate.net/profile/Daniel-M-Caceres/publication/323548160.

Carmen Salazar Conde, E., Zavala Cruz, J., Castillo Acosta, O., et Cámara Artigas, R. (2004). Evaluación espacial y temporal de la vegetación de la Sierra Madrigal, Tabasco, México (1973-2003). Investigaciones Geográficas, Boletín del Instituto de Geografía, 54. 7-23.

Combe, M. (1977). Haut Atlas calcaire. Ressources en eau du Maroc, domaines atlasiques et sud-atlasiques. Tome III. Notes et mémoires du Service Géologique. Maroc, n²31, 116-139.

Couvreur, G., (1988). Essai sur l'évolution morphologique du Haut Atlas central calcaire (Maroc). Notes et Mémoires du Service géologique, $\mathrm{n}^{\circ} 318$.

Daoui, K., \& Fatemi, Zea. (2014). Agroforestry systems in Morocco: the case of olive tree and annual crops association in Saïs region. In M. Behnassi et al (eds.) Science, policy and politics of modern agricultural system (281-290). Springer. https://doi.org/10.1007/978-94-007-7957-0_19

Dawson, IK., Vinceti, B., Weber, JC., Neufeldt, H., Russell, J., Lengkeek, AG., Kalinganire, A., Kindt, R., Lilles, JPB. \& Roshetko, J. (2011). Climate change and tree genetic resource management: maintaining and enhancing the productivity and value of smallholder tropical agroforestry landscapes: a review. Agroforestry Systems, 81, 67-78. https://doi. org/10.1007/s10457-010-9302-2

Demarteau, M., Francois., L. Cheddadi, R. \& Roche., E. (2007). Réponses de Cedrus atlantica aux changements climatiques passés et futurs. Geo-Eco-Trop, 31, 105-146.

Demaze, M.T. (2003). Caractérisation et suivi de la déforestation en milieu tropical par télédétection. Application aux défrichements agricoles en Guyane française et au Brésil. Télédétection, 3(5 ), 477-478.

Diop, A., Hyacinthe. S., Cheikh, D., Elysée, N., Honoré, D. \& Bienvenu, S. (2018). Dynamique d'occupation du sol des zones humides urbanisées de Dakar (Sénégal) de 1942 à 2014. VertigO - la revue électronique en sciences de l'environnement, 18. https://doi.org/10.4000/vertigo.20120

Direction Régionale des Eaux Et Forêts, Beni Mellal. (2010). Etude d'aménagement de la forêt des Ait Daoud Ouami, Rapport de synthèse.

Dupouey, J.-L., Thimonier A., Lebourgeois F., Becker M., F.Picard J. \& Timbal J. (1999). Changements de la végétation dans les forêts du nord-est de la France entre 1970 et 1990. Rev.For.Fr.LI, 2, 219-230. https://doi.org/10.4267/2042/5432

El Mazi, M., Saber, E. \& Houari, A. (2018). Evolution spatio-temporelle des écosystèmes forestiers dans les massifs numidiens de la chaîne rifaine (Maroc): cas de Jbel Outka. Geo-Eco-Trop, 42 (1), 133-146.

Gansaonré, R.N., Benewindé, J.-B., Zoungrana \& Isidore Yanogo, P. (2020). Dynamique du couvert végétal à la périphérie du Parc W du Burkina Faso. Belgeo. https://doi.org/10.4000/belgeo.40786

Hammi, S. (2007). Evolution des recouvrements forestiers et d'occupation des sols entre 1964 et 2002 dans la haute vallée des Ait Bougumez (Haut Atlas central, Maroc). Sécheresse, 18, 1-7.

Hanchan, M. (2014). Impact du changement climatique sur les précipitations au Maroc: de la modélisation prospective à l'observation des séries temporelles actuelles. Cas de Taza et Berkine. Actes du colloque, Taza et son arrière-pays: ressources territoriales et perspectives du développement durables (95-118).

Hili, A., Bissour R. \& El Khalki, Y. (2020). The influence of climatic variations on geotourism in the National Parc of Tazekka (middle eastern north Atlas), which adaptation? Actes du colloque international Climat, Eau et Société (CES'2019) (71-76).

Hili, A. \& Abdelaziz, R. (2021). Apport du SIG et de la télédétection à l'étude de la dynamique du couvert végétal dans la commune d'Aghbala, province de Beni Mellal. Revue GéoDev, (accepté, en cours de publication) - Texte en arabe. 
Hili, A. \& El Khalki, Y. (2017). Les paysages karstiques du Parc National de Tazekka (Moyen Atlas nord oriental, province de Taza): inventaire, évaluation et valorisation pour un développement territorial durable et intégré. Karstologia,70, 43-52.

Hountondji, Y.C., Ozer, P. \& Nicolas, J. (2004). Mise en évidence des zones touchées par la désertification par télédétection à basse résolution au Niger. Cybergeo: European Journal of Geography, Environnement, Nature, Paysage, 291,1-18. https://doi.org/10.4000/cybergeo.2761

Jeffrey, A., Mcneel, Y. \& Schroth, G. (2006). Agroforestry and biodiversity conservation-traditional practices, present dynamics, and lessons for the future. Biodiversity and Conservation, 15, 549-554. https://doi.org/10.1007/s10531005-2087-3

Karrouk, M.S. (2003). Dynamiques des climats au Maroc. (Thèse de doctorat d'état). Université Hassan II, FLSH Ben M'sick Casablanca.

Labhar, M. (1998). Les milieux forestiers et pré-forestiers du Moyen Atlas central nord occidental: Approche Géographique, phytoécologique et dynamique. (Thèse de Doctorat d'Etat). Université Libre de Bruxelles.

Lecompte, M. (1986). Biogéographie de la montagne marocaine: le Moyen Atlas central. Mémoires et documents de Géographie. Edit. CNRS.

Lecompte, M., \& Alexandre, F. (1996). Discontinu et continu de la végétation et du milieu: De la théorie des étagements en altitude à la phytoclimatologie dynamique. L'Espace géographique, 25(3), 261-272. https://doi.org/10.3406/spgeo.1996.995

Loi n 11-03. (2003). La loi relative à la protection et à la mise en valeur de l'environnement. Bulletin Officiel.

Loi $n^{\circ}$ 12-03. (2003). La loi relative aux études d'impact sur l'environnement. Bulletin Officiel.

Loi $n^{\circ} 22-07$. (2010). La loi relative aux aires protégées. Bulletin Officiel.

Mahamane, A., Mahamane, S., Yacoubou, B., Issaka, A., Ichaou, A., \& Saley, K. (2007). Analyse diachronique de l'occupation des terres et caractéristiques de la végétation dans la commune de Gabi (région de Maradi, Niger). Sécheresse, 18(4), 296-304.

Michel, C. \& Ruelan, A. (1967). L'agriculture et les forêts au Maroc. Les cahiers de la recherche agronomique, $\mathrm{n}^{\circ} 24, \mathrm{R}^{2} \mathrm{bat}$, Maroc, Chapitre IV (103-140).

Monbaron, M. (1982). Un relief anti-bathonien enfoui sur la ride du Jbel La'bbadine (Haut Atlas central, Maroc): conséquences pour la chronologie de l'orogenèse atlasique. Bull. Ver. Schweiz. Petroleum-Geol. u. -Ing., 48(114), 9-25.

Nguessan, É., Bellan, M.F. \& Blasco, F. (2003). Suivi par télédétection spatiale d'une forêt tropicale humide protégée soumise à des pressions anthropique. Télédétection, 3 (5), 443 -456.

Ouloukoi, J., Mama, V.J. \& Bernadin, A.F. (2006). Modélisation de la dynamique de l'occupation des terres dans le département des collines au Benin. Télédétection. 2006, 6(4), 305-323.

Perritaz, L. (1995). Contribution à l'étude géomorphologique et hydrogéologique d'un Karst perché en domaine méditerranéen: le plateau des Aït Abdi: Haut Atlas central calcaire, Maroc. (Thèse doctorat). Université Fribourg. https://doi. org/10.3406/karst.1996.2372

Qi, J., Chehbouni, A., Huete, A.R., Kerr, Y.H., et Sorooshian, S. (1994). A Modified Soil Adjusted Vegetation Index. Remote Sensing of Environment, 48, 119-126. https://doi.org/10.1016/0034-4257(94)90134-1

Raogo, N. G. (2018). Dynamique du couvert végétal et implications socio-environnementales à la périphérie du parc W/Burkina Faso. VertigO - la revue électronique en sciences de l'environnement, 18(1) https://doi.org/10.4000/vertigo.20249.

Rondeaux, G., Steven, M. \& Baret, F. (1996). Optimization of Soil-Adjusted Vegetation Indices. Remote Sens. Environ, 55, 95-107. https://doi.org/10.1016/0034-4257(95)00186-7

Sbai, A., Lasgaa, H. \& Sabri, M. (2018). Contribution de la télédétection dans l'étude et l'évolution spatiotemporelle du couvert végétal: cas du couloir de Taourirt - El Aioun et ses bordures montagneuses (Maroc oriental). Actes du coIloque International des utilisateurs du SIG, Oujda (245-250).

Soro, G., Ahoussi, E.K., Kouadio, E.K., Soro, T.D., Oulare, S., Saley, M.B., Soro, N. \& Biemi, J. (2014). Apport de la télédétection à la cartographie de l'évolution spatio-temporelle de la dynamique de l'occupation du sol dans la région des Lacs (Centre de la Côte d'Ivoire). Afrique Science, 10(3), 146-160.

Stour, L. \& Agoumi, A. (2008). Sécheresse climatique au Maroc durant les dernières décennies. Hydroécol. Appl. Tome 16 (pp. 215-232). https://doi.org/10.1051/hydro/2009003 
Thimonier, A. (1994). Changements de la végétation et des sols en forêt tempérée européenne au cours de la période $1970-$ 1990: rôle possible des apports atmosphériques. Sciences de l'environnement. Université Paris XI Orsay. 〈tel-02923657〉.

Tra Bi, Z.A., (2013). Etude de l'impact des activités anthropiques et de la variabilité climatique sur la végétation et les usages des sols, par utilisation de la télédétection et des statistiques agricoles, sur le bassin versant du Bouregreg (Maroc). (Thèse de doctorat). Université Félix Houphouët-Boigny (Abidjan, Côte d'Ivoire).

Wassenburg, J.A., Immenhauser, A., Richter, D.K., Niedermayr, A., Riechelmann, S., Fietzke, J., Scholz, D., Jochum, K.P., Fohlmeister, J., Schröder-Ritzrau, A., Sabaoui, A., Riechelmann, D.F.C., Schneider, L. \& Esper, J. (2013). Moroccan speleothem and tree ring records suggest a variable positive state of the North Atlantic Oscillation during the Medieval Warm Period. Earth and Planetary Science Letters. http://dx.doi.org/10.1016/j.epsl.2013.05.048 


$$
\begin{gathered}
\text { Summary } \\
\text { of } \\
\text { Articles }
\end{gathered}
$$

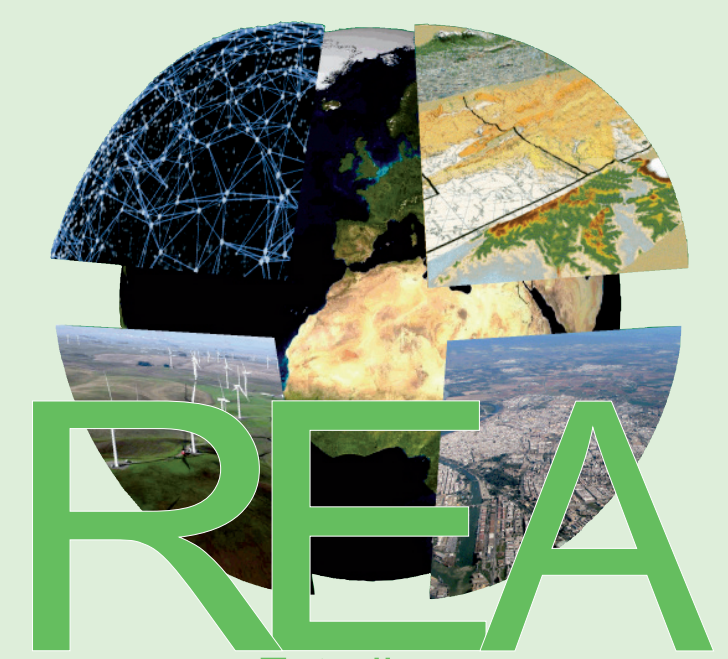

Revista de Estudios Andaluces 


\title{
Gentrification process of a degraded space turned into a cultural showcase. The case of the Historic Center of Malaga
}

\author{
Hugo Castro-Noblejas \\ hugocastro@uma.es@0000-0002-8975-7506 \\ Juan Francisco Sortino-Barrionuevo \\ francis.sortino@uma.es @0000-0002-3643-4228 \\ Sergio Reyes-Corredera \\ sergioreyes@uma.es @ 0000-0002-2760-6489
}

Departamento de Geografía. Facultad de Filosofía y Letras. Universidad de Málaga. Campus Teatinos. Bulevar Louis Pasteur s/n. 29071 Málaga, España

\author{
KEYWORDS \\ Gentrification \\ Urban center \\ Urban processes \\ Residential transformation \\ Malaga
}

The deterioration and subsequent transformation of historic urban centres has been one of the most analysed phenomena in the field of urban geography in recent decades at an international level.

Malaga, a city in the south of the Iberian Peninsula, on the Mediterranean coast, has become the sixth largest Spanish municipality in terms of total population, largely due to the effect of tourist activity since the mid-20th century. Although a series of profound architectural, functional and social transformations have been perceived in the Historic Centre of Malaga in recent decades, these processes had not yet been systematically analysed, although there have been partial studies in the municipality, such as the one carried out in the district called "SoHo" (Borondo, 2015).

This work aims to determine if the Historic Centre of Malaga has presented a gentrification process from the last third of the 20th century to the beginning of the 21 st century, comparing the behaviour of this possible phenomenon in the different areas that make up this area of the city. A secondary objective is to provide a geographical vision, with a transversal contribution on a detailed micro-territorial scale, to the scientific production focused on urban processes that considers social, economic and environmental aspects.

Specifically, the administrative units that roughly coincide with the limits of the old Muslim city have been studied: the census tracts of 2906701, 2906702 and 2906703. When possible, it has been deepened to the census section unit scale: 2906701001 (Atarazanas Market), 2906701002 (surroundings of Calle Larios), 2906702001 (Alcazaba-Paseo del Parque), 2906703001 (central area), 2906703002 (surroundings of Plaza de San Pedro) and 2906703003 (around the Palacio de Valdeflores), although some information comes from external information with other delimitations (DonDeNegocios, 2016).

The methodological proposal has consisted in obtaining a series of demographic, socioeconomic and real estate indicators and an integrated analysis of them, taking into account their temporal evolution. The 
order in which the variables are analysed allows us to verify the patterns of gentrification and to nuance and separate them spatially during the analysis. In the first place, first indications of gentrification are collected in the study area using criteria of social hierarchy of the population at the census section level; Later, the socioeconomic characteristics are studied in depth, placing particular interest in the population that arrives and leaves the study area. Finally, the urban transformation that accompanies the previous indications is recognised through the variables of real estate and public spaces.

Regarding demographic and socioeconomic variables, 1) the temporal evolution of the population at the census section scale between 1981 and 2019; 2) the evolution of the demographic structure through the ratio of the values of the different population cohorts for the years 2001, 2011 and 2019; 3) the evolution of the volume of foreigners for the period 2001-2019 through the location coefficient, comparing the presence of foreigners in the Historic Centre with that of the total in the municipality between 2001 and 2011 and $2019 ; 4)$ the at-risk-of-poverty rate of households and 5) the Gini index to measure income inequality of the population for the year 2011.

Regarding the characterization and evolution of the housing stock and the home, 6 ) the evolution of the price of built land, measured in $€ / \mathrm{m}^{2}$, in the period 2001-2012 was taken into account; 7) the process of demolition-rehabilitation of the house based on the interpretation of an annual sequence of plans from 1956 to 2016 in which the demolitions are counted; 8) the year of construction of the houses, taking the house as a unit; 9) the evolution in the state of the building allows to detect if there is a process of abandonment and reforms; 10) the size of the dwelling; 11) the household structure and 12) the tenure system. These last variables have been measured by taking the values of the census sections from the total value of the study area for the years 2001 and 2011.

The last block of variables used deals with the variables on services and facilities, in which we examine 13) the evolution in the supply of commerce and hotels and restaurants, broken down according to the Spanish National Classification of Economic Activities, in the Historic Centre of Malaga for the period 2001-2016), 14) the evolution of the number of premises for each group of activities, expressed by means of an index in base 100 and 15) an account of the evolution of cultural facilities in this urban area, also considering their spatial distribution. The methodological proposal tries to connect the results following a chronological logic and local, national and international socio-economic processes, as the asymmetry of the data, despite its richness, prevents the application of a quantitative methodology.

The interpretation of the results makes it possible to detect, from the demographic dimension, signs of gentrification from fluctuations in the total size of the population, with a negative trend from which it has not recovered with the growing presence of tourism in the area and with the transformation of the population structure, tending towards a rejuvenation and a greater presence of foreign inhabitants, a pattern repeated in other large globalized western cities such as Barcelona (Sargatal, 2000; López-Gay, 2018) or Madrid (Sorando \& Leal, 2019). These demographic fluctuations occur simultaneously with the variations in the socioeconomic condition of the inhabitants, where fairly high inequality values are observed, according to the Gini index and the at-risk-of-poverty rate in 2011, which reflect the contrasts typical of a population. gentrification without ending in an economic stage marked by the crisis of 2008 (Sorando \& Leal, 2019). On the other hand, the transformations of the housing stock also reflect patterns such as the reduction in the size of the home associated with the increase in the price of land, the numerous demolitions and, instead, new constructions, which mean the passage of a housing stock particularly degraded to one in good condition, in a context of intensive rehabilitation. This translates into a phenomenon typical of gentrification: the increase in the income gap due to the increase in the difference between the capitalized rent of the land given its current use (previous price of the land) and the potential rent of the land that can be capitalized through a new use of it (Smith, 1987). Finally, this set of transformations has interacted favouring an evident functional metamorphosis of the study area, which is reflected in the typology of commercial activity and in the increase in restaurants and hotels, as has been detected in the Historic Centre of Seville (Jover, 2019); as well as in the growing cultural equipment promoted by public administrations, emulating planning proposals similar to those of Bilbao (Angulo-Baudin et al., 2017) or London (Davidson, 2008) and which leads to a loss of urban identity, already identified in the city of Malaga (García et al., 2019). 
Consequently, public-private investments have favoured the continuity in the indirect expulsion of lower-income groups, who cannot access property due to gentrification and, subsequently, also to the touristification of the Historic Centre. This phenomenon is reflected in the increase in the number of empty houses and the price of houses or the change of businesses and facilities that working-class families suffer when their neighbourhood is transformed, as has happened in London (Davidson \& Lees, 2005).

With these results, it is concluded that the Historic Centre of Malaga has become a cultural showcase, as has been promoted by public entities since the last decades of the 20th century, in order to reconvert the productive model of the Historic Centre. However, this strategy has led to an intense process of gentrification with the territorial imbalances that it entails, and which has led to and favoured other more recent processes such as touristification.

The development of gentrification does not manifest itself in a spatially homogeneous way. The central sections show an earlier and tenuous gentrification than the sections on the left bank of the Guadalmedina River 2906701001 (area of the Atarazanas Market) and 2906703003 (around the Palacio de Valdeflores). These last two areas undergo a very intense evolution of transformation between the late 1990s and early 2000s. These changes are reflected demographically in a rejuvenated population, male and with a higher proportion of foreigners than the other sections, as well as by the accelerated process of demolitions and rehabilitation of the residential park.

The detection in the present study of other subsequent urban processes such as touristification opens the opportunity to address them in future research. To better understand the profound territorial transformations that are taking place in the city and the consequences that they may have in the medium and long term, it would be interesting to differentiate and assess the relationships between both phenomena. In addition, a path of investigation on gentrification is opened that extends the study unit to the surrounding neighbourhoods of the Historic Centre. 


\title{
Nuclear heritage of the south of Spain. Diagnosis and proposals
}

\author{
Juan Antonio Muñoz-Castillo \\ juanantonio.munoz@iesaverroes.org (10000-0002-9755-5541 \\ Departamento de Geografía e Historia. Instituto de Educación Secundaria "Averroes" de Córdoba. \\ C/ Motril, s/n. 14013 Córdoba, España \\ Jorge Olcina-Cantos \\ jorge.olcina@ua.es @ 0000-0002-4846-8126 \\ Departamento de Análisis Geográfico Regional y Geografía Física. Universidad de Alicante. \\ Campus de San Vicente del Raspeig s/n. 03690 Alicante, España
}

\author{
KEYWORDS \\ Nuclear heritage \\ Andalucía \\ Badajoz \\ Uranium \\ Radioactive wastes
}

In Southern Spain there is a firm relationship with all parts of the nuclear power process. Uranium mines and purifying plants, a nuclear waste depot, a non-started nuclear plant and a place that suffered an aerial-nuclear incident integrate the set named "Nuclear Heritage in Southern Spain". Andújar (the Virgen de la Cabeza mines and the former Uranium Purifying Plant "General Eduardo Hernández Vidal"), Cardeña (the Venta del Cerezo mines), El Cabril (the former uranium mines, and the nuclear waste depot by ENRESA), Palomares-Sierra Almagrera lands (that suffered the "Spanish broken arrow" in January 17th 1966), Valdecaballeros (the non-birth nuclear power plant at the Extremaduran Siberia) and La Haba (former uranium mines and purifying plant) integrate this set. A set lacking a geographical synthesis study that opens door to further research that can be extrapolated to other regions of Spain.

\section{OBJECTIVES}

1. Delimit the infrastructures that make up the Nuclear Heritage in Southern Spain.

2. Carry out a diagnosis of the state of the same, without forgetting the historical route that explains its evolution and current state.

3. Prepare action proposals to value this nuclear heritage, which minimizes the generally negative perception that accompanies these places in relation to the danger associated with uranium. 


\section{METHODOLOGY}

The work aims to create a database on the elements of the Nuclear Heritage in Southern Spain, their trajectory, strengths and weaknesses. And from this analysis, make a series of proposals that allow a sustainable development of projects that improve the prospect of these places.

\section{RESULTS}

There have been analyzed six places: Andújar (FUA and former uranium mines), Cardeña (former uranium mines), El Cabril (former uranium mines and nuclear waste depot), Palomares (site of a "broken arrow" incident), La Haba (former uranium mines and plant) and Valdecaballeros (non-started nuclear power plant). Mostly of them, with the unique exception of Palomares (closely to the Eastern Almerian Mediterranean coast, more known as Levante Almeriense), placed in the inner Spain. And with the exception of Andújar -an "agro-city"-, the other places are inside the set named "Emptied Spain".

Andújar has a dual nuclear heritage: the former mines in the north and northeast surrroundings of the Sanctuary of Our Lady of "La Cabeza" and the former uranium refining plant -FUA- "General Hernández Vidal". First, at the mountains about $45-50 \mathrm{~km}$. north and northeast from the municipal capital, and last-the FUA- closely to the urban area from the municipal capital. In itself, Andújar is a region with at least four different landscapes. The mining and quarrying tradition has been millenary at the mountains of Sierra Morena and the north riverside of the Guadalquivir river.

The uranium mines operated from 1955 to 1970. On the other hand, the FUA "General Hernández Vidal" after two years of building, operated from November 1959 to July $15^{\text {th }} 1981$, after which it underwent a waiting period and a "test bed", before being dismantled and sealed between 1991-94. Its location was logistically unbeatable, but radiologically, worse impossible.

The human drama experienced by the former FUA workers, exposed to extremely high doses of radiation without the proper security measures, far exceeds any analysis. They were not well treated by the hierarchies of nuclear in Spain. In addition, the sealing work of the FUA and the old uranium mines accelerated after the declaration of the Sierra of Andújar as a Natural Park. There are very few publications even technical, on this space. But it is the paradigm of "what should not to be done" when setting up a uranium concentrates factory.

The Cardeña's uranium mines case is very similar-in part- to the previous. The Cardeña and Andújar mountain ranges are separated by the embedded Yeguas river and are geologically and physiographically the same. This uranium mines -that surrounded the small township of Venta del Cerezo- were producing minerals between 1953 to 1970. And later were abandoned until their restoration and sealing in 1998. They were the first uranium mines well studied, and at their restoration, were the most influenced by the UMTRA plans.

The declaration of a Natural Park of Cardeña and Montoro mountains spurred the sealing and restoration works. But it has not yet taken place, and not for lack of initiatives, the take-off of this town, not lacking in environmental attractions. There is very little written about Cardeña, and it would be worth a greater diffusion of its values.

El Cabril is, with no doubts, the biggest element of the set named "Nuclear Heritage in Southern Spain". It is located in the northwest of the province of Córdoba and has been involver for more than a century, first with uranium mining, and in the last six decades with the storage and management of radioactive waste. It is a unique and exemplary facility in this industrial activity of environmental management, as welle as the site of numerous scientific experiments, both related to its activity and to other branches.

El Cabril is located on the eastern slope of the Sierra Albarrrana, a Precambrian and Caledonian base, with extremely poor soils and subsoils with rare minerals. No one lives for more than 15 kilometers around. And all the next towns are losing population since many years ago. Mining activities started in 1918, were stopped by the Spanish Civil War between 1936-1939, and after the war were re-started by private enterprises like BRESA, EPALE, and later, by the public JEN and the private AISLAMIC. Uranium mines were exploited 
until 1961, and mica mines were exploited until the end of 1975. From 1961 to 1985 the radioactive waste warehouse was operated by the Spanish JEN (Joint of Nuclear Energy). Since 1986 is operated by ENRESA (National Radioactive Waste Enterprise, S.A.), constituting its main facility, unique in its function in Spain, and the main $\mathrm{R}+\mathrm{d}+\mathrm{i}$ in the Nortwestern province of Córdoba. It has three modules of concrete cells for low and medium level (radioactive) waste another four cells for very low level waste. And its investigative and innovative activity is incessant.

However, despite ENRESA's effort to publicize its work, something is wrong with the communication policy. Being the best Nuclear Heritage facility in Southern Spain, it has an environmental and leisure potential to be developed.

Palomares is a town situated at the Southeast part of the municipal area of Cuevas de Almanzora, in Eastern province of Almería. Since January $17^{\text {th }} 1966$, it has part of the Nuclear Heritage in Southern Spain after the air crash of to USAF airplanes (one B-52 and a KC 135 "Stratotanker"), when four B24 H bombs were landed off from the B-52. Two of them burnt, but the other two were rescued -one, 80 days later, from the sea-. The plutonium, instead the decontamination works by the USAF troops during the next year, radioactivity has conditioned the life of this agricultural town and its surrounding places. Specially the former mining zone of Sierra Almagrera, when in 2009 was discovered a zone when the "radioactive spray" detached from the two bombs that burnt, fell.

To this day, the plots affected by radioactivity have been fenced off, expropriated and subjected to surveillance by JEN/ENRESA/CIEMAT. And in the same way, the locals who have presented traces of plutonium in their blood and radioactivity, even though some of them are unusually healthy. Palomares, due to its proximity to the coas -with a notable sustainable tourism- and its powerful intensive agriculture under plastic, is perhaps the exception within the whole.

Valdecaballeros is a small town situated at the Northwestern province of Badajoz, at the region named "the Extremaduran Siberia". Between 1975 and 2001 this town and its surroundings, lived around a project of nuclear power plant that was stopped at first in 1991, and later, cancelled and dismantled in 2001. The project would have been a development chance to that extremely poor and underpopulated region. The "jabalines" (Valdecaballeros' inhabitants) say that "the future of this town was killed without the nuclear power plant".

At the same province of Badajoz, between the regions of Las Vegas Altas and La Serena, there is a small town named La Haba. It's the opposite case to Valdecaballeros. There was uranium mining between 1953 and 1991, and especially dangerous, an open heaven uranium mine-La Marilozana- that extender radioactivity to the town. And between 1975 and 1993, an "experimental" uranium refining plant, that produced "yellow cake" to nuclear power plants. There was radioactive containers until 1993, and many people at town has died for have been exposed to high doses of radioactivity. It's usual to listen, at this town, that "uranium has killed it".

\section{CONCLUSIONS}

- The study of the double case of Andújar -minas de la Sierra and FUA in its outskirts-, shows evident results of the aforementioned (stigmatization of a territory) from the study of the mines and their trajectory, and the analysis of the taboo subject that they represent the tragedy of the FUA with its consequences of this day. There are clear analogies between the Cardeña-Venta del Cerezo mines and those in the north and north-west surroundings of the Sanctuary of Nuestra Señora de la Cabeza in the Sierra de Andújar.

- The evolution experienced by El Cabril has been outstanding in the last decades. This town has gone from being a place of uranium, mica and beryl mines to the headquarters of the Centralized Storage of Waste with very low, low and medium radioactivity in Spain. Due to its importance and significance after some years relegated to the background by the truncated ATCE project (2013-2020), El Cabril is 
the main asset of ENRESA/CIEMAT, and it still has new possibilities, with the development of sports activities and environmental.

- In Palomares, the work carried out through the "Indalo Project" has been analyzed highlighting the positive initiatives that have allowed to improve the perception of this town as a prominent area of avant-garde agricultural development and residential tourism, since the plane crash occurred of nuclear effects on January $17^{\text {th }}, 1966$.

- Very different is the case of the province of Badajoz, which has experienced two diametrically opposed realities. On the one hand, in Valdecaballeros great hope was enlightened to leave behind its centuries-old scarce development with the unfinished nuclear power plant project, which has given rise to a rather uncertain future. On the other hand, the case of La Haba, where the "uranium fever" extracted from its mines and transformed into its "experimental" ENUSA factory followed the cessation of activity in 1991 and the subsequent tragedy of deaths caused by contact with different radioactive elements. 


\title{
Trail system classification of the conservation unit Pau-Ferro Forest State Park, Areia, Paraíba, Brazil
}

\author{
Valéria Raquel Porto de Lima \\ valeriaraquelportodelima@servidor.uepb.edu.br @ 0000-0001-7744-3502 \\ Universidade Estadual da Paraíba. Rua Baraúnas, 351 \\ Bairro Universitário - Campina Grande-PB. CEP 58429-500 Brasil \\ Jean Oliveira-Campos \\ jean.oliveira@academico.ufpb.br@0000-0002-2874-754X \\ Universidade Federal da Paraíba. Cidade Universitária \\ João Pessoa-PB. CEP 58051-900 Brasil
}

\begin{abstract}
KEYWORDS:
Atlantic Forest

Conservation Unit

Park

Track system
\end{abstract}

\section{INTRODUCTION}

The implementation of conservation units to safeguard biodiversity constitutes man's main reaction face to the degradation of ecosystems in Brazil and the world (Myers et al., 2000; Primack \& Rodrigues, 2001; Aguiar et al., 2013). The main juridical instrument of creation from Conservation Units in Brazil is the Law 9.985, of 2000, which institutes the National System of Conservation Units (SNUC), of which establishes parameters and categories of management with different protection degrees, that is divided into Units of Integral Protection and Units of Sustainable Use.

The category Park is in the group of integral protection units whose basic objective is to preserve nature, being allowed only the indirect use of its natural resources, educational activities, scientific and recreational. In Paraíba state, among the conservation units of the Atlantic Forest, Pau-Ferro Forest State Park, in Areia municipality, shelters one of the greatest fragments, it is one of the most representatives of the Northeast region (Tabarelli \& Santos, 2004). It is a fragment of Seasonal Forest Semi deciduous Montana (Ombrophylous Forest), situated on the eastern slope of the Plateau of Borborema, in a condition of refuge or altitude swamp (Veloso et al., 1991; Ab'Saber, 2003; Tabarelli \& Santos, 2004; Bétard et al., 2007; Medeiros \& Cestaro, 2019).

Although it has such importance, the UC still doesn't have the trails mapping, nor the extension of them, demonstrating the visitation activities happen into informal conditions, i.e., without infrastructure and necessary orientations. This conjuncture prevents measuring and estimating the impacts of the said activity at the unit, considering that is not known for sure where it happens.

Because it is an important touristic place of Brejo Paraibano, the elaboration of such a product will pronounce, in a more assertive way the touristic potential, and will elicit the realization of research and environment educational practices, points that are among the goals pursued by the Park category. Given the above, this article proposes mapping the trails of Pau-Ferro Forest State Park and its difficulty classes, aiming to provide contributions to the survey of touristic potentials and dissemination of the area's importance to protect biodiversity. 


\section{METHODOLOGY}

The municipality of Areia located at Paraíba state, seated on the wet edge of Borborema Plateau in a condition of altitude swamp. The Pau-Ferro Forest State Park is located in the rural area of the municipality, presenting an area of 607.96 hectares. The protected area was created on October 19, 1992, as an Ecological Reserve and recategorized to the state domain park category, through a State Decree No. 26.098, of August 4, 2005, starting to form the Pau-Ferro Forest State Park (Decree No. 26.098, of August 4, 2005, 2005).

Given the above, for the work development at the Conservation Unit was used the following materials: radar image with a Digital Terrain Model - MDE with a resolution of $12.5 \mathrm{~m}$ ALOS/PALSAR; Sentinel-2 satellite image, MSI sensor; the cartographic base of Brazil, Northeast, Paraíba and the municipality of Areia; polygon in shapefile format of the Conservation Unit; portable GPS device model Etrex Garmin Vista; Android GPS Essentials app version 4.4.27; Photographic camera; and ArcGIS Software version 10.2 $®$ and Excel.

The fieldwork took place on August 10, 11 and 29, 2019, and March 10, 2020. With aid of a local tourist guide, all trails were crossed and a photographic record of the main attractions along the paths was taken. All the trails, as well as all attractions, were recorded in the portable GPS and also in GPS Essentials automatically. The visit in March was accomplished aiming to verify the updates suffered by the trails.

The GPS data were manipulated in ArcGIS software to the elaboration of the trail map, while the application's trails were used for their validation. Subsequently, the paths of the trails were superimposed with maps of altitude and declivity generated from the MDE, and, later, was done the extraction of information that was used for the elaboration of graphics.

To map the classes of difficulties presented by the trails, was used the methodology adapted by Silva (2016), Silva, Lima and Panchaud (2016), and Silva and Palhares (2020), which is based on the attribution of grades, overlapping and summation of the environmental variables' declivity, vegetation coverage, terrain conditions and water drainage, with geoprocessing use, to verify the trails degrees of difficulty.

For this purpose, with the ArcGIS use, the variables' declivity, vegetation coverage, terrain conditions and water drainage were divided into classes, later received grades from 1 to 4 and were reclassified as very easy, easy, moderate and difficult - according to the difficulties that offer to the trails' accomplishment. The declivity and drainage were obtained from the MDE processing in ArcGIS software, the latter was generated from the curves of the terrain level.

The vegetation coverage information was obtained from the supervised classification of a Sentinel-2 satellite image, in the ArcGIS software, using the Maximum Likelihood classifier, where the following classes were found: high vegetation, medium vegetation, and lower vegetation. The terrain conditions, in turn, were obtained from the vegetation coverage, given that the obstacles found on the surface of the trails refer, in the study area, to fallen trees, which are more frequent in areas with high vegetation.

All the environmental variables were generated in raster format, in which, after assigning grades, it was realized their summation using ArcGIS. Subsequently, the product obtained from the summation was reclassified based on the final grades and converted to shapefile format. Finally, the shapefile archive, with the difficulty classes, was used to cut out the mapped trails, allowing to verify the difficulty levels found in them.

\section{MAIN RESULTS}

In total, were mapped 4 trails, 2 integrations that connect the trails, and 4 main points of the landscape that works as tourist attractions (map 2). The mapped trails were Trilha Inicial, Trilha do Cumbe, Trilha das Flores and Trilha da Barragem, while the mapped integrations are named Integração 1 and Integração 2 . The attractive points, therefore, are Munguba, Cachoeira, Barragem and Casarão.

Throughout the trails, most of the time, the visitors' field of vision is limited by the stalks and crowns of the trees, being common the sighting of birds and mammals. The soil, in turn, appears without vegetation coverage for most of the path and is also verified stretches with organic covers, such as seedlings, leaves, branches, fruits, and animal waste that inhabit the area. Open-air sections also occur, where the field of vision 
is expanded, these, however, are situated in clearings located in the central portion of the Park, as well as in the southern portion, where the vegetation is smaller.

In relation to the classes of difficulty presented by the trails, it was found that the highest percentage of the Park's trails is classified as "easy", given that the class comprises $67.41 \%$ of the trail system. The "very easy" class occupies $16.49 \%$ and manifests itself significantly in the northern and southeastern portions. The routes classified as moderate occupy $15.96 \%$ and occur mostly in the central and southern parts of the area. On the other hand, the routes classified as "difficult" have the lowest representation in terms of distance, occupying only $0.13 \%$ of the system, having their occurrence restricted to the central portion, where is located Integração 2.

The predominance of the easy difficulty class also reveals the non-requirement of physical conditioning for the traffic. However, as the class is distributed in fragments on the trail system, it is necessary to observe whether the difficulty classes that are present in between them do not constitute obstacles to visitors. The recommendation is strengthened when dealing with the central portion of the Park, where is found the difficult class, although in a smaller percentage.

\section{CONCLUSION}

The Pau-Ferro Forest State Park has a system consisting of 4 trails, 2 integrations, and four points in the landscape that works as main tourist attractions, in which most of the routes are classified as easy, i.e., they do not require greater physical effort for their realization. In addition, the Park is surrounded by residents who develop sustainable economic activities associated with the Conservation Unit, such as ecotourism, with the possibility of expansion to a greater number of people.

This conjuncture reinforces the tourist potential of the Conservation Unit to receive several groups of visitors at the same time, as well as consolidating itself as one of the most appropriate spaces for the achievement of visiting and of interpreting trails in the state of Paraíba, in addition to contributing to the income of local residents. These aspects are reinforced by the fact that it is one of the greatest remaining Atlantic Forest in the state in altitude swamp, and is home to endangered species. In this way, the dissemination of the area's importance, the increase in number of visitors, and the implementation of adequate structures to maintain visitation can raise financial resources and new perspectives for protecting the area. 


\title{
Resilience of the urban tourist market in the face of the COVID-19 crisis. The case of Malaga
}

\author{
Beatriz Benítez-Aurioles \\ bbaurioles@uma.es (1) 0000-0002-4224-9184 \\ Facultad de Ciencias Económicas y Empresariales. Universidad de Málaga. \\ Calle El Ejido, 6. 29013 Málaga, España
}

\author{
KEYWORDS \\ Resilience \\ Urban tourism \\ COVID-19 \\ Hotels \\ Airbnb \\ Impacts
}

\section{INTRODUCTION}

The COVID-19 pandemic has caused an unprecedented crisis that has hit tourism particularly hard. However, in 2021, the progressive advance of vaccination and the lifting of the restrictions that had been decreed to try to contain the spread of the virus allowed, to a certain extent, the recovery of tourist activity. In this context, the analysis of the resilience of urban tourism, which has received increasing attention from an academic point of view, has a special relevance given the open debate, before the pandemic, about the pressure that tourism was exerting on certain cities.

\section{OBJECTIVES}

The objective of this article is to analyze the resilience of urban tourism in the face of the COVID-19 crisis, taking the city of Malaga as a reference. The convenience of supporting the study in the analysis of supply, demand and prices as basic vectors that determine the functioning of any market is proposed. In this context, it is relevant to first determine whether urban tourism is recovering and, if so, to what extent the characteristics it had before the pandemic are being reproduced.

\section{METHODOLOGY}

Among the various methodological approaches that can be adopted for the study of urban tourism, the theoretical framework provided by the economic analysis is relevant to know the basic vectors that condition the operation of the tourism market. Furthermore, given the differences between the conventional accommodation market and the p2p market for short-term rentals, a separate analysis is appropriate.

Regarding the data used, for the conventional tourist accommodation market, we will turn to the Hotel Occupancy Survey that is published regularly by the National Institute of Statistics (INE) and, additionally, we will base ourselves on the barometer published by Exceltur the treatment of some variables related to the 
profitability of the hotel. For its part, given the scarcity of official data, we will use the information InsideAirbnb collects and makes available to interested parties via scrapings from Airbnb listings (whose leadership, among the platforms dedicated to the commercialization of private homes in the short term, is indisputable). This database, despite its limitations, allows a good approximation to the basic variables that determine the operation of the $p 2 p$ market and, in particular, of prices.

The choice of the city of Malaga as the area of our study is justified, not only by the absolute and relative importance of tourism in generating income and employment (Malaga places it among the top urban destinations in Spain), but also by the weight of the p2p market for tourist accommodation, which has frequently been pointed out as the catalyst for negative impacts associated with overtourism.

The time frame that we have taken as a reference is the period between September 2018 and the same month in 2021, that is, before the pandemic and once the tourism sector has shown signs of recovery.

\section{RESULTS AND DISCUSSION}

The analysis of the conventional accommodation market has shown evident signs of recovery as of spring 2021. On the demand side, the leading role acquired by national tourism is noteworthy. In fact, it is the national tourist demand that has led the recovery that the sector has experienced and that is even more evident since May 2021. It is true that, since then, there has also been an increase in both the number of travelers and overnight stays by foreigners, although without reaching pre-pandemic levels. On the other hand, the number of travelers and overnight stays by national tourists registered significant growth, even exceeding the figures of previous years. Everything points to the fact that residents in Spain substituted international trips for national ones, which, unlike what happened before the pandemic, has surpassed tourist activity by foreigners, both in terms of travelers and hotel overnight stays. which accredits the capacity of national tourism to compensate for the drop in international tourism. It is also worth noting the increase of the average stay in hotels up to historical figures, which could be connected to the change in behavior caused by national tourists.

On the supply side, the recovery of the conventional accommodation market as of mid-2021 is also confirmed. The estimated number of rooms reached its historical highs in summer 2021, which suggests that not only the reopening took place of hotel establishments that had closed during the pandemic, but there were also new additions to the market. The fact that, despite this growth in the number of estimated rooms, their degree of occupancy has also grown, is logically explained by the recovery in tourist demand. Indeed, the fact that there has been a rise in the Average Daily Rate (ADR) and Revenue per Available Room (RevPAR) since spring 2021 suggests that the intensity of demand recovery has offset the supply increase, and, consequently, explains the rise in prices in the conventional accommodation market. The end result was an increase in employment in the hotel sector during 2021 to levels very close to those it had before the pandemic. The resilience of urban tourism in the city of Malaga was not limited to conventional market (hotels) but is also manifested in the p2p market. Indeed, although there is a decrease in the number of accommodations comparing the data from September 2019 with that from the same month of 2021, this does not necessarily amount to an effective reduction in the market-as the analysis performed indicates that, in the face demand recovery, there has been a more intensive use of available accommodation; so that, ultimately, tourist pressure exerted by the p2p market may be recovering to pre-pandemic levels. In this sense, the p2p market for tourist accommodation shows similar resilience patterns to that of the conventional market; and, more specifically, a strong recovery in demand as of May 2021.

On the other hand, the preponderance of the commercialization of entire homes and that of hosts that supply more than one accommodation in the $\mathrm{p} 2 \mathrm{p}$ market is confirmed. In other words, the trend seems to be strengthening towards a market where the supply is in hands of professionals and is basically dedicated to the short-term renting of entire homes. In many cases, the supply even comes from companies that comprehensively manage the rental of the apartments on behalf of the actual owners. The reduction in the percentage of bookings that can be made instantly, which could be indicative of the greater interest of the 
hosts in selecting the type of tourist they receive, is also noteworthy. All this could ultimately explain certain changes in the price formation process in the p2p market for tourist accommodation after the pandemic.

From the econometric estimates made with data from before (September 1, 2019) and after the pandemic (September 30, 2021), it can be deduced that, when the homes supplied are entire (rather than shared) and the number of accommodates is higher, the accommodation price is higher and maintains the same influence, in quantitative terms. Likewise, the number of reviews per listing, which could be considered an approximation to demand, maintains the same value and inverse relationship with price. Distance, on the other hand, appears to lose relevance: while having the expected sign with high statistical significance before the pandemic, it loses its statistical significance and influence in determining the prices of accommodation after it. However, perhaps the most notable changes occurred in the parameters associated to the variables related to the hosts and their reservation policy. In this sense, the Superhost label loses influence on the price, while the number of listings per host gains it. We additionally remark the change in the sign of the parameter linked to instant booking, which has a direct influence on the price at the end of the period.

\section{CONCLUSIONS}

Faced with the crisis caused by COVID-19, the resilience of urban tourism has been confirmed, at least in the city of Malaga, both in the conventional market (hotels) and in the p2p market (Airbnb) as we verify that the basic variables that characterize both markets have shown clear signs of recovery as of spring 2021. The characteristics of this recovery have some practical implications for both the private and public spheres. Thus, the leading role that national tourism has had in the tourist demand for hotel accommodation and the lengthening of stays can serve as a basis for the articulation of promotional campaigns by private managers especially aimed at resident tourists in Spain. On the other hand, the resurgence of the $\mathrm{p} 2 \mathrm{p}$ market for tourist accommodation reopens the debate on the carrying capacity of cities and the relevance of its regulation. 


\title{
Does a visit to a blue-green space evoke positive feelings? Blue and green spaces survey in Shkodra' Lake, Albania
}

\author{
Samel Kruja \\ samel_kruja@universitetipolis.edu.al (1) 0000-0003-2717-138X \\ Polis University. Rr. Bylis 12, Tirane-Durres Highway, Km 5.1051 Tirana, Albania \\ Olta Braçe \\ oltabrace@msn.com @ 0000-0001-6335-5085 \\ Polytechnical University of Tirana. Rr. Muhamet Gjollesha, 54, Tirana, Albania
}

\author{
KEYWORDS \\ Blue space \\ Green space \\ Urban planning \\ Health \\ Mood \\ Well-being
}

Urbanism promotes numerous changes in human behavior that influence human health, as smoking, traffic accidents, mortality and adult obesity (World Health Organization, 1998). However, urban environments contain infrastructures that can help reduce the serious health consequences of urban living. Due to the great benefits provided by nature, both in theoretical and practical aspects during the last two decades, there has been a growing interest in nature-based ecological health promotion initiatives (Hartig et al., 2014). Building, protecting, maintaining, and growing blue and green spaces (BGS) are the targets of new strategies.

Previous studies have demonstrated the benefits of blue and green spaces on the mental health of the population. The availability of and access to green and blue spaces has shown to be associated with improved mental health (Sturm \& Cohen, 2014; Wood et al., 2017). Evidence suggests that exposure to green spaces is associated with decreased stress levels and pleasant feelings due to physiological reactions to a relaxed state (Hazer et al., 2018; Honold et al., 2016).

Nonetheless, empirical, and qualitative research shows that using blue spaces in urban areas has a favorable impact on both physical and mental health. Several studies have demonstrated that blue space, particularly turbulent water bodies, can protect and promote health by masking road noise (Jeon et al., 2010) and mitigate summertime temperatures (Völker et al., 2018).

Although the relationship between blue and green spaces and human health is intricate, the understanding of their dynamics, the amount of information and data on health and well-being, as well as access to blue and green spaces, varies from different countries.

The aim of this study is to reduce the gap between the understanding of the complex relationship between blue and green spaces, and the positive effects on mood feelings in the population of Shkodra. In 
Albania, studies relating to the impact of blue and green spaces on the well-being of the population have been limited and poorly explored.

Shkodra is an ancient town of 2500 years old and one of the most important cities of Albania. It is situated in the northwest of Albania, with a surface area of $872,71 \mathrm{~km}^{2}$. The lake of Shkodra with $369 \mathrm{~km}^{2}$, the largest lake in Albania and Montenegro, is located on the west of the city of Shkodra and serves as a border between the two countries (Sadori et al., 2014), with $149 \mathrm{~km}$ of it belongs to Albania. Both countries put their decisions and procedures for managing this region into action, using national legislation and international accords to preserve this area. The Albanian side of Shkodra' Lake and the green areas surrounding, is a protected area and one of the most important national and international ecosystems, proclaimed Managed Nature Reserve as well as Ramsar Area (Albanian Government Decision No.684, dated 11/02/2015, while the Montenegrin side is proclaimed National Park in 1983 (Government Report, 2020).

The lake frames the historic and artistic town of Shkodra, a tranquil and relaxing environment, reflecting the effect of the water that elegantly surrounds it. It is also rich in cultural and historical monuments, which stretch along an important part of this managed nature reserve. Many visitors pass through the impressive Buna River delta to reach Lake Shkodra. Many others choose to take a cycling tour to fully immerse themselves in the natural environment of the area. During the summer, several lakeside resorts offer excellent alternatives to visitors thanks to their clear waters and proximity to the city. Visitors should not miss the waterfront restaurants offering the famous Carp fish in a variety of meals.

Population data presented in this paper are preliminary data extracted from an online cross-sectional survey on BGS carried out in Shkodra' city. Respondents have been asked to complete the survey via the platform Google Form, from April to May 2021. During this period, Albania was open to all citizens and visitors, with some restrictions in place, such as masks required outside and inside certain buildings and institutions, no gatherings of more than 50 people, and public movement prohibited from 10:00 p.m. to 5:00 a.m. The questionnaire used in the study was prepared by an interdisciplinary panel formed by urban planner, geographer, psychologist, and environmental scientist. The questionnaire provided 68 questions, designed in 3 main sections: 1) General information, 2) Natural environment information, 3) Self-reported health information. To improve the clarity of the questions before launching the survey, a pilot study was conducted. After the validation and cleaning process, a representative sample ( $95 \%$ level of confidence) of 530 respondents was obtained. This survey targeted people over 16 years old and was disseminated to the public using social media platforms.

Descriptive statistics were used to analyze such as indicators (1) sociodemographic characteristics; (2) frequency of visits in BGS in the last 4 weeks; (3) time spending during the visit; (4) activities carried out during the visit; (5) type of accompaniment; (6) the reason for not visiting BGS and the quality of BGS. The SPSS software platform was used for the statistical analyses. The frequency, percentage, mean and standard deviation calculations were used to calculate data from the sample. The Chi-square test was used to analyze association of visits frequency in blue space with the people mood. There exists any statistical significance when $\mathrm{p}$-value was $\mathrm{P}<0.05$.

According to the analysis of the sociodemographic variables, the mean age of the respondents was 30.32 \pm 12.971 . It can be observed that the population sample was young, with $63.4 \%$ between 16 and 31 years old, $23.4 \%$ between 32 and 48 years old, $12.6 \%$ between 49 and 64 years old, and only $0.6 \%$ over 65 years old, including $76.2 \%$ of women and $23.8 \%$ of men.

Regarding employment status, 55.8\% were working at the time of the survey, 30.2\% were students, $1.9 \%$ were unemployed, $1.1 \%$ were homemakers followed by $0.8 \%$ retired, and $0.2 \%$ disabled. It is interesting to remark that only $14.7 \%$ of the respondents had not visited Shkodra' Lake during the last four weeks of whom $43.5 \%$ for lack of time, $37.1 \%$ for living too far from this area, and only 3.8\% for describing it as an overpopulated area.

In terms of frequency of visits to Shkodra Lake, 30.9\% had visited once or twice in the last four weeks, $28.1 \%$ several times a week, $26.2 \%$ had visited only once a week and $14.7 \%$ had not made any visits in the last four weeks. 
Concerning the type of accompaniment during the visits, $37.9 \%$ visited Shkodra' Lake with friends, $14.2 \%$ with wife/husband or boyfriend/girlfriend, $13.4 \%$ with children, $8.5 \%$ with parents, $5.8 \%$ with another adult, and $2.8 \%$ alone. In their visits, the respondents spent approximately 60 minutes at the Shkodra' Lake BGS as follows: $31.1 \%$ cycling, $18.3 \%$ consuming food and drink, $8.9 \%$ walked or played with children, $4.3 \%$ engaged in quiet activities (e.g., reading, meditating), $0.8 \%$ walked with a dog, $0.6 \%$ went swimming and $0.2 \%$ used this time for fishing.

In terms of quality, $46.6 \%$ of the people who had visited during the last 4 weeks rated this area as good quality, $29.8 \%$ rated it as acceptable, $14.8 \%$ considered Shkodra' Lake as very good quality and only $7.5 \%$ thought that the quality of this area was bad or very bad.

In terms of mood after the visits to Shkodra' Lake, there are significant differences between positive feelings with the visit $(p=0.032)$ and feeling part of nature $(p=0.004)$. It is generally observed that regardless of the frequency of visits $87.6 \%$ felt tranquility and $87.6 \%$ felt safe.

The current study found a correlation between people's mood and visits to blue and green spaces (BGS), in a way that people who visited Shkodra' Lake more frequently demonstrated higher positive feelings. Therefore, the results of this study confirm the results acquired from previous studies claiming the benefits of visits to BGS on mood and well-being of people (White et al., 2013; Su Sugiyama et al., 2008; Pretty et al., 2005).

Referring to the methodology, one of the limitations of this study is conducting the survey using an online platform which created biases in the obtained sample, in order to better identify gaps in research on the benefits of blue and green spaces on the population health and well-being.

The results of this study reinforce the importance of BGS as a community resource to promote good health. Therefore, local governments who are often in charge of the design and maintenance of BGS could address community health problems by improving and creating BGS.

Although the health benefits of BGS have been demonstrated, such findings have probably not been sufficient to persuade decision makers to act. It is essential to emphasize that improving BGS is likely to be a practical health promotion effort that local governments can undertake. 
SUMMARY OF ARTICLE: HTTPS://DX.DOI.ORG/10.12795/REA.2022.I43.06

\title{
Environmental public policies and sustainable tourism development in Ecuador's protected areas
}

\author{
Iván Mendoza-Montesdeoca \\ imendozam@espam.edu.ec @ 0000-0001-7632-144X \\ Escuela Superior Politécnica Agropecuaria de Manabí (ESPAM MFL). \\ Matriz de Calceta. Avda. 10 de agosto, $n^{\circ} 82$ y Granda Centeno. Ecuador \\ Manuel Rivera-Mateos \\ manuel.rivera@uco.es@0000-0003-2780-380X \\ Universidad de Córdoba. Plaza del Cardenal Salazar, 1. 14071 Córdoba, España \\ Yamil Doumet-Chilán \\ ndoumet@espam.edu.ec @ 0000-0003-4295-5270 \\ Escuela Superior Politécnica Agropecuaria de Manabí (ESPAM MFL). \\ Matriz de Calceta. Avda. 10 de agosto, $n^{\circ} 82$ y Granda Centeno, Ecuador
}

\author{
KEYWORDS \\ Tourism \\ Environmental policies \\ Protected Areas \\ Natural spaces \\ Sustainable tourism development \\ Ecuador
}

\section{INTRODUCTION}

Critical analysis of public policies on environmental conservation, management, and tourism development in the protected natural areas of Ecuador to detect their dysfunctions, contradictions, and problems of applicability.

The scientific bibliography consulted coincides in pointing out the need to know how planned actions and strategies are being carried out in the development models proposed in protected natural spaces. With this, comparative analyzes can be established and lessons learned and reference cases of good practices can be extrapolated, to a greater or lesser extent, to other territories. Likewise, it is also essential to specify whether these models are truly framed within the principles and objectives of a sustainability policy, especially with the obligation to provide guarantees for the conservation of natural heritage and allow greater opportunities for participation to local communities.

\section{METHODOLOGY AND SOURCES OF INFORMATION}

A predominantly exploratory research methodology with a descriptive-analytical approach is used when studying and systematizing the different regulations, actions and guidelines existing and implemented by international and national organizations with competencies in environmental conservation and sustainable development. These are systematized and analyzed through the main documents of interest that include principles, strategic guidelines, and specific rules of application. 
Through primary and secondary sources and internal documentation of various Administrations we have identified the most visible effects and impacts that these policies have generated in the protection and/or valorization of the natural heritage, as well as in the tourist development compatible with the conservation of these spaces, the generation of complementary income and economic diversification for local communities.

\section{ENVIRONMENTAL SIGNIFICANCE AND TOURIST SUSTAINABILITY OF THE PROTECTED NATURAL AREAS OF ECUADOR}

The importance of Ecuador's protected areas as a fundamental support for its tourism offer is explained by being one of the 17 countries with the greatest biodiversity in the world and by occupying the second place in number of endemic species, in addition to having 17 different ecosystems and 35\% of its territorial extension covered by undisturbed biomes, especially in the Amazon region. Its National System of Protected Areas (SNAP) covers, in fact, 13.64\% of the national territory, with a total of 64 protected areas and an area of $18,401,927$ hectares. Biological diversity is therefore fundamental for national economic development and is a fundamental element of their national and regional strategies for sustainable tourism development, at least at the level of theoretical discourse, given the great potential, still insufficiently explored, and of the benefits derived from the conservation of the natural environment and the maintenance of its eco-cultural and indigenous identity marks to become a first-rate tourist destination.

This country is part of the $30 \%$ of the countries with the greatest potential in the world for tourism development, taking into account the quality and diversity of its natural and cultural resources. Currently, there are 3,366 tourist attractions registered at the national level, of which 3\% are located in the island region of the Galapagos, $28 \%$ in the Coastal region, $53 \%$ in the Andes and $17 \%$ in the Amazon, while $51 \%$ of these attractions correspond to cultural manifestations and $49 \%$ to natural sites. For the Ministry of the Environment (2020) the natural spaces that are part of the National System of Protected Areas (SNAP) have been experiencing in recent years an acceptable level of influx of visitors and at a good pace thanks to the presence of national visitors, which represent $95 \%$ of the total, while international demand is only $5 \%$. The most up-todate total number of visitors is 368,309 people in all the country's conservation areas (MAE, 2020).

\section{RESULTS. ENVIRONMENTAL POLICIES AND THEIR ORIENTATION TOWARDS SUSTAINABLE TOURIST DEVELOPMENT}

The direct and indirect threats that fail to conserve these spaces provide important ecosystem services and have a natural heritage that serves as a basic support for sustainable tourism. These can find their turning point if efficient decision-making is adopted in the matter, such as the planning and management of the territory and a collaborative governance system with agents from the private sector, the productive fabric and the local community itself, promoting a commitment between the parties in terms of sustainability.

In the legislation studied, only very generic mentions are made to the planning and management of protected areas, without expressly considering that the National System of Protected Areas of Ecuador forms a non-homogeneous territorial group and with certainly different physical, geological or environmental characteristics according to zones. On the other hand, the levels of socioeconomic development in their areas of influence are also very different according to territories.

Likewise, it is important to point out that not all the protected areas legally declared as such in the country have been assigned stimulus functions to the strategies of sustainable development of activities such as tourism, since in Ecuador there are territories whose declaration responds exclusively to the environmental preservation of areas of special fragility. To this we must add the growing problem of land use and land control conflicts, which in certain cases reaches a worrying dimension that makes it difficult to implement planning and sustainability strategies. 
Lastly, the fact that in protected areas where environmental education and recreational-tourism activities and scientific tourism can be carried out in principle, the Ministry of Tourism of Ecuador is not actively participating, not even in the Planning and managing sustainable tourism projects is limiting the State's capacity to actively promote the initiatives of rural communities, in the areas of influence of these spaces, and to properly guide them according to sustainability criteria.

\section{DISCUSSION}

The strategic vision of the Ministry of Tourism on the basic pillar of tourism quality in Ecuador must be adapted to the specific territorial characteristics of protected natural areas and must be accompanied in parallel by environmental planning and the regulation of uses and management and governance systems, as well as the implementation of quality and sustainability standards. Connectivity in terms of public transport, access, multimodality of non-motorized means, etc. with national and international markets, is another priority, but the accessibility support infrastructures in different regions of the country, especially in coastal areas, present serious deficiencies as a result of: a) an excessively centralized policy in the attention to the needs of large cities, b) a limited management capacity and applicability of comprehensive development projects at the local and provincial level and, c) strong limitations to national and foreign investment in the tourism sector

In this sense, despite the fact that Ecuador has risen in the ranking of performance in tourism competitiveness since 2009, when it ranked 96th according to the World Economic Forum, in 2019 it continued to occupy a low position in said ranking (70/140). In addition, in the last five years, it has been losing competitiveness and and the values of variables such as employment, tourism arrivals and tourism and environmental sustainability have fallen.

\section{CONCLUSIONS}

We concluded that Ecuadorian regulations on the conservation of protected areas present notable points of collision and lack of coherence or coordination with tourism policies. This is the consequence of two main factors: 1) the lack of a broad strategic vision and comprehensive territorial planning of these territories as sustainable tourist destinations and, 2) the lack of a framework for management, planning and collaborative planning between the different local agencies and agents that affect these spaces.

The diagnosis carried out on the management and planning of these protected areas reveals the existence of important information deficits regarding most of the aspects related to the tourist development of these territories, the incidence of this activity in the socio-economic and business structure of their area of influence, the territorial impacts of an environmental and sociocultural nature or even on the same profile of the current and/or potential demand, that seeks tourist-recreational activities in direct contact with the natural environment. 


\title{
The importance of dynamic capabilities in the reformulation of an innovative competitive advantage. Case study of Cordoba technology companies
}

\author{
María Amalia Trillo-Holgado \\ maru.trillo@uco.es@0000-0002-1626-8066 \\ Carolina León-Urban \\ d22leurc@uco.es@0000-0002-3862-6784 \\ Rocío López-Caballero \\ d22locar@uco.es @0000-0003-2701-9951
}

Universidad de Córdoba (Área de Organización de Empresas). Edificio Gregor Mendel (C5), $3^{a}$ planta.

Campus de Rabanales. Ctra. Madrid-Cádiz, Km. 369. 14071 Córdoba, España

\author{
KEYWORDS \\ Competitive advantage \\ Dynamic capabilities \\ Innovation \\ Case study
}

The Theory of Resources and Capabilities is not able to explain how companies renew their competences to adapt to the changing environment and maintain their competitive advantages. For this reason, in recent decades, a new perspective has been developed in the literature on strategic management, which has been given the name of Dynamic Capabilities (Teece, 2007). This perspective arises to improve the explanatory capacity of the Theory of Resources and Capabilities with respect to the sustainable nature of competitive advantage in rapidly changing environments. It considers the evolving nature of the firm's resources and capabilities in relation to changes in the environment in which the firm operates (Wang \& Ahmed, 2007). Firms that have achieved success in such competitive environments are those that have demonstrated responsiveness in the moment, and rapid and flexible product innovation (Teece et al., 1997).

The study of the phenomenon of dynamic capabilities has been approached from various theoretical perspectives or approaches. Most prominent are the innovation approach, the capability building approach and the contingent approach. This implies that as the perspective from which the study phenomenon is analysed changes, the conclusions reached in each analysis are different. However, all perspectives have in common the relationship with the need to rethink competitive advantage in order to address the market, as explained below.

From a contingent approach, dynamic capabilities are defined as capabilities that make it possible to respond to changes in the environment (Zajac et al. 2000). The innovation approach refers to the firm's ability to develop new solutions (Teece \& Pisano, 1994). And, in the capability building theory, capabilities are conceived as those that enable the modification of the firm's current competencies or organisational routines (Oliver \& Holzinger, 2008). 
Although the three currents respond to different schemes, they cannot be considered mutually exclusive. In this sense, both the innovation stream or approach and the contingent perspective seem to define dynamic capabilities in terms of their outcomes or effects, innovation and state of adaptation, respectively. However, although the definitions that make up each approach differ in the way they are stated, two common aspects can be identified: the ability of the firm to remain adapted to rapidly changing environments. Both aspects highlight the need to take into account not only the external (environment) and internal (resources and capabilities) factors of the organisation, but also the evolution of both factors over time and the way in which firms adjust between them. This is done through the "strategic fit" between internal and contextual factors (Zajac et al., 2000; Rindova \& Kotha, 2001) to try to explain the achievement of a sustainable competitive advantage by firms operating in dynamic environments with unpredictable change.

Teece et al. (1997) stated that "dynamic capabilities reflect the organisational ability to achieve new and innovative forms of competitive advantage". The development and use of dynamic capabilities influences the level and scope of a firm's innovation, enabling it to remain adaptive to a changing environment. Successful firms in the marketplace are those that can demonstrate the ability to respond in a timely manner and innovate products quickly and flexibly, along with the managerial capacity to effectively coordinate and redeploy internal and external competencies. Therefore, this paper will focus on the innovation approach to articulate the relationship between the development and use of organisations' dynamic capabilities and their efforts to innovate, which has a major impact on the strategic management of the firm, as Teece (2014) points out, given that the firm that fails to innovate is doomed to exit the market.

The definition of dynamic capabilities proposed in this research is as follows: a company's ability to renew and update its competencies in response to changes in the environment in which it operates, enabling it to develop new processes, products or services in order to maintain or expand its competitive advantages.

The strategic resources most commonly related to innovation capability are (Leonard and Sensiper 1998; Oke et al. 2009): human capital, leadership, culture, and structures and systems.

Regarding the dynamic capabilities needed for innovation, according to the literature analysing knowledge management are (Grant, 1996; Zahra \& George, 2002; Lavie, 2006): knowledge creation, knowledge absorption, knowledge integration and knowledge reconfiguration. This relates to general organisational learning capabilities on which the literature is less focused, as stated by Ipek (2019).

Moreover, as Zahra (2021) points out, researchers have hardly studied the fundamental question of how entrepreneurial firms manage their resources for competitive advantage.

On the other hand, the factors that cause dynamism in the environment, scattered in the literature, have been classified into three main blocks: supply factors (raw materials, technology, new competitors), demand factors (consumers) and factors related to the macroeconomic environment (government policy and economic turbulence).

Market dynamics require organisations to develop new capabilities and use them to develop innovative products, services and processes to gain competitive advantage. If the innovation is a process innovation (introduction of a significant change in the production technology of a good or service), a competitive advantage of cost leadership will be achieved, and if it is a product or service innovation (introduction of new or significantly improved products or services), a competitive advantage of product or service differentiation will be achieved.

Methodologically, a model is constructed through which certain variables and indicators are identified to help managers explain how those resources and capabilities that intervene to a greater extent in the development of new processes, products or services are related to the reconfiguration of the company's competitive advantage.

The model is composed of four elements: strategic resources, dynamic capabilities, innovation and competitive advantage. Innovation is considered to be both process and product or service innovation, whether incremental or radical. Feedback is established between the dynamic capabilities of the company, described above, and its competitive advantage (cost leadership or differentiation), contributing to the evolution of the company in its environment. 
To corroborate the usefulness of the model, an exemplary case study is carried out within the technology sector based on a public and a private company.

So, It is provided a strategic tool to the manage the dynamic capabilities that are part of the process of developing an innovative competitive advantage in the company. Both constructs feedback on each other and enable the evolution of the entity. In addition, it is highlighted different ways of acting in practice, both in the public and private sector.

In the companies studied, it has become clear how their competitive advantage is reconfigured according to their dynamic capabilities, a process that can be extrapolated, in general terms, to other companies in different sectors or countries.

In the knowledge capture stage, the importance of collaborative behaviour stands out. The integration of this knowledge takes place through training and regular meetings. The organisational culture is a basic support for the company's strategy, where the strengthening of the collaborative spirit is necessary for the development of innovations. That reaffirms the scientific literature on the subject, which explains how business strategy, together with dynamic capabilities, determines a sustainable competitive advantage in a global environment. On the other hand, it also confirms the fact that specific innovation activities support dynamic capabilities and their interrelationships in terms of complementary or substitutive effects. Moreover, in both public and private companies, the culture of the organisation has been strengthened by the innovations. And, in both companies there are ways to measure the level of customer satisfaction.

In terms of knowledge absorption, investment in R\&D\&I is particularly relevant, which in the case of public companies could be more profit-driven than in the case of private companies.

Periodic knowledge integration meetings might be more frequent in the case of the innovative private company.

In the case of knowledge reconfiguration, concrete mechanisms for the search of market opportunities are highlighted.

The implementation and evolution of dynamic capabilities is carried out by deploying the company's resources but, in the cases analysed, the importance given to people is essential.

In the case of private companies, customer orientation is freer from political issues and bureaucratic procedures.

In short, the innovations developed by both companies have contributed to the reconfiguration of their competitive advantages. The service innovation of the public company has strengthened the integral, innovative and exclusive nature of its services provided to public bodies, and the process innovation has made it possible to increase the quality of these services due to the acquisition of servers that have increased the storage capacity of its clients' data. On the other hand, in private enterprise, both its service innovation and process innovation have improved the quality of its services, both in terms of reliability because customers have the guarantee of a back-up line for data transmission, and in terms of functionalities due to the characteristics of its services adapted to the needs of its customers.

For future research, it is proposed to extend the study to a broad sample of companies and, as noted in the introduction to this work, to quantify the reaction time of one type of company and another. It would also be interesting to determine the percentage of R\&D\&I dedicated to each process and type of company. 


\title{
Observed and projected changes in the types of bioclimatic regimes in Argentina
}

\author{
Valeria Soledad Duval \\ valeria.duval@uns.edu.ar @ 0000-0001-9048-3058 \\ Universidad Nacional del Sur-CONICET \\ 12 de Octubre.1098. CP 8000 Bahía Blanca, Argentina \\ Rafael Cámara-Artigas \\ rcamara@us.es@0000-0003-1046-3749 \\ Universidad de Sevilla. Cl Doña María de Padilla s/n. 41004 Sevilla, España
}

Departamento de Geografía Física y Análisis Geográfico Regional, Facultad de Geografía e Historia,

\section{KEYWORDS \\ Bioclimatic mapping \\ Climate change \\ Ecoregions \\ Physical geography}

In Argentina, there is no in-depth study of the bioclimatic classification of the territory. There are also no research carried out on the subject on a national scale, in the past and in the future. That is why the objective of this work is to elaborate bioclimatic maps of Argentina in three periods of time (Last Glacial Maximum, current situation and climate change scenario RCP8.5 of 2070) and analyze their changes. This work is an essential contribution due to the relationship between bioclimatic mechanisms and the distribution of plant formations. In this way, the connection between both variables can be known. On the other hand, the multitemporal analysis allows making projections on the impact that the increase in greenhouse gases (GHG) has on the distribution of bioclimatic mechanisms.

To meet this objective, the CCSM4 (Community Climate System) model was selected and used for the Last Maximum Glacier and the future climate change scenario. Based on the methodology of bioclimatic balances, we operated with the monthly temperature and precipitation rasters to obtain the necessary variables for the identification of bioclimatic regimes. From them, the monthly and annual rasters of paralysis of plant activity due to temperature and paralysis of plant activity due to water were obtained. Then, on the basis of them were generated the conditional rasters of tropicality, subtropicality and temperate and cold zones of Argentina. As a result, the subtypes of bioclimatic regimes were obtained, where their nomenclature conforms to the thermal designation followed by the water denomination and its ombrotermal type.

Among the results it was recognized that during the Last Glacier Maximum the surface was larger than the current one since the continental shelf was overexposed in this period, due to the decrease of the sea level. 16 types of bioclimatic regimes (TBR) were recognized and 64 subtypes (TBRs). During this period, it was observed that the most extended thermal type was the cryophyllos, followed by the mesocryophyllos and the hypercryophyllos. The euritermophyllos was developed in the northern sector, mainly central and east and was the smallest. There is no record of the thermophyllos for that period. The cryo mesophyllo TBR 
was the largest and was distributed mainly in the center of the current country and in part of the Argentine Sea. The cryo xerophyllo was another bioclimatic regime of great expansion to the South of the continent during this period. In relation to the TBRs associated with the polar zones, the hypercryo mesophyllo was the largest area and extended in the western sector, linked to the Andes Mountain and in the southern zone, in the current Tierra del Fuego and Falkland Islands.

In the current TBR map, changes were detected in relation to the map of the Last Glacier Maximum, both in the land surface and in the bioclimatic regimes, as a product of the post-glacial period. As a first analysis, 17 TBRs and 75 subtypes were observed. Currently, it is the eurothermophyllo (subtropical bioclimates) that occupy the most area of the country. In the Last Glacier Maximum, this was reduced to the Central-East zone and now this limit extended to the South. Euritermo mesophyllo was recognized as that TBR that predominates in the east of the country. On the other hand, among the cryophyllos (temperate-cold bioclimates), the cryo tropophyllo is the one that acquires greater relevance. These TBRs are mainly developed in Patagonia. In the mesocriophyllos and hypercriophyllos (subpolar and polar bioclimates) a reduction of their surface was observed being relegated to the South of the country in the area of Tierra del Fuego and Falkland Islands and in the Andes Mountain Range. Then euritermophyllos and cryophyllos predominate, relative to the thermophyllos (tropical) types that are absent.

Based on this bioclimatic relationship, a combination of Argentina's ecoregions was performed. In the subtropical domain, the TBR that is most often present in the ecoregions is the euritermo mesophyllo in its different ombroclimas situations. The TBR euritermo tropophyllo, with a contrasting rainfall seasonality, is represented in the Yungas and partially in the Chaco Seco. Euritermo Xerophyllo and hyperxerophyllo is present in the ecoregion of Montes de Sierras y Bolsones. Regarding the cold -temperate type cryophyllos bioclimates, they are distributed in conditions of paralysis of plant activity due to water in the Puna (cryo xerophyllo and cryo hyperxerophyllo) and in the Estepa Patagónica (cryo tropophyllo and cryo xerophyllo).

There are two situations with cryo mesophyllo bioclimates, in the Monte de Llanura y Mesetas and in Pampa and Espinal more southern. In sub-polar medium conditions with micro-mesophyllo bioclimates only the South Atlantic Islands are found under conditions of dry sub-humid ombroclima and in the Bosques Patagónicos in hyperhumid to sub-humid-dry ombroclima. In this same medium but with paralysis of plant activity due to temperature, the Altos Andes (Mesocryo xerophyllo and hyperxerophyllo) are located, and in the Estepa Patagónica more southern with semiarid mesocryo tropophyllo bioclimate. The bioclimates of the tropical domain are not currently represented in Argentina.

The TBR map of the future climate change scenario selected the year 2070. The purpose of this mapping is to analyze how the current TBR would be modified with the influence of these gases in the atmosphere, in a scenario where their concentration is high (RCP 8.5). This map shows a total of 19 TBRs and 73 TBRs. The mesophyllo, tropophyllo and xerophyllo TBRs (tropical bioclimates) appear in this mapping, being absent in the previous ones. They are distributed in the north-east and north-central parts of the country.

As a result of the emergence of new TBR in the north of the country, the types associated with euritermophyllo TBR would be displaced further south, encompassing part of Northern Patagonia, in the provinces of Río Negro, Chubut and Mendoza. The euritermo mesophyllo rate would continue to prevail. The types linked to the cryophyllo bioclimates would be mainly spread in Patagonia, whose northern boundary was modified and is limited to the central and southern sector. Also in the area linked to the Andes Mountain, in the northwest of the country. In the rest of the provinces of Patagonia the cryophilic TRBs predominate and the mesocryophyllos and hypercryophyllos would be found in the sector of the mountains. The types linked to mesocryophyllos and hypercryophyllos bioclimates would be reduced on their surface.

If the TBR of the Last Glacier Maximum is compared with the current situation and the climate change scenario with RCP 8.5 for 2070, some significant modifications are observed. While the cryophyllo was the largest during the Last Glacier Maximum, in the current map and in the 2070 scenario, it is the eurythermophyllo, the one with the greatest predominance. On the contrary, the tropophyllo appears as a new thermal type that is visualized with a large surface in the year 2070. The eurythermophyllo, during this period, increases its surface although not as significantly as from the first to the second map. 
Considering the current period with the climate change scenario of the year 2070 , increases and decreases in TBRs are observed between both periods. The tropophyllo bioclimate in the tropical domain by 2070, would reach an area of $147,152 \mathrm{~km}^{2}$ and the mesophyllo $111,146 \mathrm{~km}^{2}$, both located in northern Argentina, bordering Brazil and Paraguay. Tropical and subtropical TBR are increased. In contrast, all TBRs in the temperate-cold, sub-polar and polar categories would suffer surface losses.

As conclusions, the spatial transformations of bioclimatic regimes in the selected periods, which can be explained as a product of climate change, are highlighted in this paper. In Argentina, this phenomenon is characterized by an increase in average annual temperatures, mainly in Patagonia, and by variation in precipitation by region, increasing in the central-eastern zone of the country and decreasing in the region of Cuyo. These changes have intensified in recent centuries, also affecting bioclimatic regimes. The most significant are shown on the basis of the thermal condition, increasing the types of the tropical and subtropical environments and decreasing the surface of the temperate-cold and subpolar environments. This new pattern of bioclimatic regimes in the future climate change scenario would also affect the range of plants and consequently plant formations in Argentina.

On the other hand, the importance of the elaboration of bioclimatic maps at the national level was recognized as it is essential to define the distribution of living beings in a territory. In particular, the methodology of TBR is a great contribution in the research on this topic since it has as advantages its use and application in different scales of analysis and in different temporalities. In addition, its cartographic representation allows to quickly see the information on the bioclimatic regimes of a territory and establishes models to be able to define possible scenarios for the future under high concentrations of GHGs. Finally, studies on different problems can be derived from the application of this methodology in regions and provinces of the country. 


\title{
Air transportation and the COVID-19 pandemic: Towards a change of the path in the spanish airport network?
}

\author{
Roberto Díez-Pisonero \\ rdpisonero@ghis.ucm.es @ 0000-0002-7817-628X \\ Cándida Gago-García \\ cgago@ucm.es@0000-0003-2315-7943 \\ C/ Profesor Aranguren s/n. Ciudad Universitaria. 28040 Madrid, España
}

Departamento de Geografía, Facultad de Geografía e Historia. Universidad Complutense de Madrid.

\author{
KEYWORDS \\ Air transportation \\ COVID-19 \\ Airports \\ Air connectivity \\ Spain
}

The COVID-19 coronavirus pandemic has been a deep setback for the global economy in general, and in the aviation industry in particular, as it is directly affected by the numerous restriction and containment measures to stop the spread of the virus.

Unlike previous crises (Gulf wars, terrorist attacks of 9/11, financial crisis of 2008), the deep recession caused in the sector has led many experts to classify it as the worst in the entire history of commercial aviation, with notable effects on all study metrics: while the prediction of world traffic for 2020, before the declaration of the pandemic by the WHO in March 2020, was 9.4 billion passengers, the figure declined to 3.8 billion (ICAO, 2020). According to some authors, this crisis is even worse than the scenario generated after the 9/11 terrorist attacks, when the airline industry took about a decade to fully recover (Wyman, 2020).

The outbreak of the coronavirus in Wuhan (China) and its rapid expansion to the rest of the world forced many countries to implement restrictive and containing measures to stop the spread of the virus, which has dealt a very violent blow to the entire airline industry. Within days, nearly all flights were cancelled, airports closed, the global fleet on the ground, and thousands of employees laid off. The confinement and closure of borders decreed almost simultaneously by governments around the world to contain the Covid-19 outbreak resulted in a reduction in all study metrics.

In this sense, the first objective of this work is to present and quantify the impact of the pandemic on the commercial aviation sector on a global scale and by major world regions, based on official data and statistics from the main organizations of the aeronautical industry (IATA, ICAO, EUROSTAT, AENA). According to the different monthly studies that the IATA has been publishing on its website during the course of the pandemic, and according to the estimates for the month of December (2020), it is confirmed that the possible impact of COVID-19 on the air travel industry will be very high, although the real impacts will depend on the duration and magnitude of the outbreak, containment measures, the degree of consumer confidence in air travel, economic conditions and the progress of the vaccination process, among other factors. It is, therefore, that 
the authorities warn that a return to normality is not on the agenda for the foreseeable future, since the industry is expected not to return to the activity levels of 2019 until 2024 (IATA, 2020).

Secondly, the work aims to evaluate Spanish airport connectivity (domestic and international) and, consequently, analyze the degree of national structuring between urban systems (national connectivity) and the evolution of the participation of many of the Spanish airports in the global scenario during the pandemic (international connectivity), through a diachronic analysis, with a "photograph" of the years 1970, 2015, 2019 and 2020. The first two years (1970-2015), 45 years apart, offer an adequate time frame to understand and visualize the trajectories that have occurred in the Spanish airport network. These must be essentially related to the restructuring of the sector, with special emphasis on the consequences derived from the liberalization process and the increase in international tourism (Díez-Pisonero, 2016). The consideration in the analysis of the last period, years 2019-2020, aims to show and evaluate the pre-pandemic situation (2019) and the impact of the COVID-19 pandemic on the airport network (2019-2020).

Data on connections and frequencies between pairs of cities, both domestic and international traffic, have been used for the analysis, extracted from those known in the sector as ABC Guides; in 1970, in paper format "ABC World Airways Guide, October 1970" and, in 2015, 2019 and 2020, in digital format "Comber International Guides Database - OAG". The data refer in any case to the months of the end of summer (August and September).

These have been subjected to a statistical treatment, using for the analysis the calculation of a topological connectivity coefficient (Córdoba and Gago, 2010). For the interpretation, data on air frequencies between pairs of cities have also been used, when logic recommends it, from the aforementioned sources.

Regarding the first period (1970-2015), it can be corroborated how in these 45 years the degree of cohesion of the system has evolved favorably, both nationally and internationally, since the number of links and air frequencies has increased considerably, consolidating a very dense and vertebrate network. Thus, in the face of the two-headed structure of 1970 articulated by two dominant centers in a manifestly centralist system, it has evolved to another where, although Madrid and Barcelona continue to dominate internal relations, new emergent centralities appear to be linked to a revaluation of central regional structures in the national territory's organization.

It is in the international network where a profound metamorphosis has been observed. While in 1970, when Spain still had a great regulation of air traffic and Iberia exercised the role of flag company with the main hub in Madrid, Spanish international traffic was entirely directed by the capital of the country. The rest of the Spanish cities did not register any connection outside our borders, except for tourist destinations (archipelagos and the Mediterranean coast), but only through charter flights. In this way, if a passenger wanted to go abroad by plane at that time, they had to go through Madrid first in most cases. This is why it is considered that the Spanish network was strongly polarized.

However, in 2015, the situation is very different, with a generalized growth experienced in a large number of airports as a consequence of the liberalization of the sector, the entry of Spain into the European Union, the great tourist specialization of the country, the internationalization of the Spanish economy in the European and world context, its progressive consolidation as a connecting bridge with Ibero-American countries or the generalization of low-cost companies, among other factors.

Regarding the second period analysed, the impact of COVID-19 on air transport is assuming a true turning point in aeronautical history, regardless of the scale of analysis and the metrics taken into consideration. In Spain, the frequencies and air connections of all its airports have been reduced during the hardest months of the confinement, not having achieved the "expected recovery in the summer of 2021", although there is an evident growth with respect to the first year of the pandemic. This trajectory already speaks to us of a far-reaching impact and, at least, in the case of Spain, of a slow recovery process. The analysis carried out presents the changes for a very specific period, but as it is an ongoing process, no general conclusions can yet be drawn about what happened.

Against this background, it is essential to provide certainty in health and safety to rebuild trust in society. Some measures have been implemented in most of the world's airports, such as the disinfection of terminals, the use of masks, gloves, and disinfectant gels, the control of the capacity of shops and restaurants, so- 
cial distancing, etc. The airlines have also adapted in this sense, implementing measures such as those proposed by Harvard University, that is: the ventilation system and periodic air renewal in the cabins, the use of masks, the disinfection of airplanes, passenger monitoring, and education and awareness. In addition, the sector has adapted by offering greater flexibility in reservations, for example, increasing experiences with little contact (low-touch) in both airports and hotels, allowing travelers to carry out their procedures at the airport remotely through from their mobile phones, or offering rapid diagnosis health services at airports (PCRs) to present at those destinations that require it. Proof that airlines and airports are already applying these measures successfully is that the risk of transmission on board is low (Wyman, 2020).

But, in view of the fear of new outbreaks and waves around the world, it is not possible to predict exactly when all restrictions on movement will be lifted and when it will return to a pre-COVID "normal" situation. It is, for this reason, that we believe that future challenges that should prioritize the action strategy in the field of air transport should focus on guaranteeing certainty in health and safety. Thus, despite the setback experienced during the last year as a consequence of the pandemic, experience justifies the need to continue investing in an essential sector to guarantee economic and social interaction. 


\title{
Research trends in Economic Geography. Bibliometric study of the Web of Science (1920-2020)
}

\author{
María Pilar Alonso-Logroño \\ pilar.alonso@udl.cat 100000-0002-4327-623X \\ Departament de Geografia i Sociologia. Universitat de Lleida. \\ Plaza Víctor Siurana, 1. 25003 Lleida, España \\ Nuria Bautista-Puig \\ nbautist@bib.uc3m.es@0000-0003-2404-0683 \\ Department of Industrial Management, Industrial Design and Mechanical Engineering. \\ University of Gävle. Kungsbäcksvägen 47, 801 76, Gävle, Suecia. \\ Universidad Carlos III de Madrid. Calle Madrid, 26. 28903 Madrid, España
}

\begin{abstract}
KEYWORDS
Bibliometric analysis

Economic geography

Web of Science

Topic modelling
\end{abstract}

Economic geography is one of the major branches of Geography and studies economic activity and factors affecting them. This field was formerly created as a scientific discipline at the end of the 19th century, coinciding with the launch of the first handbook in 1889 and with the institutionalization as a discipline at the University of Cornell (United States) in 1893. In this stage, the main focus of the discipline was on the regional analysis (e.g. physical environment with population occupations). Later, in the fifties, the research approach changed to the location and the local organization from the economic activity (e.g. by using quantitative approaches such as statistics). In the eighties, culture and social movements became prominent and the focus was on labour markets and social networks, among others. Overall, the field has passed from being a descriptive discipline of the land to a more analytical and reflective one with a paradigm change through the years. In this regard, tools are needed for analysing the evolution of a scientific discipline, being bibliometrics an ideal to tackle this analysis. Although there are some studies that analyse the scientific output and the evolution, not many analyse the evolution of the topics discipline, a research gap that this study covers. In this context, the objective of this article is to present the usefulness of the use of bibliometric tools to do this analysis.

This article presents a methodology that allows analysing scientific trends in a discipline through a bibliometric analysis. Specifically, Economic Geography is used as a case study. Documents were collected in in the Web of Science (WoS) database by using an ad-hoc strategy. With a set of 4,307 publications, various bibliometric indicators divided into patterns of research (evolution of scientific production, scientific output by countries and institutions, collaboration patterns and impact) and the thematic specializations (WoS categories, definition of cluster topics by using a topic modelling approach, keywords co-occurrence networks and hot topics identification) are analysed from the period 1920 to 2020. Different software was used for the publication patterns (ArcGIS) and thematic specialization (e.g. CiteSpace, R software). 
In terms of research, the evolution shows the scientific production is concentrated recently, since the 2000 s (80.8\% of its production). The most prolific institutions that are publishing papers on Economic Geography are Anglo-Saxon (the United Kingdom and the United States); however, Nordic countries (e.g. Norway, Sweden) show greater specialization in the subject by using an activity index. More precisely, the most prolific institutions are the University of London (United Kingdom), University of Oxford (United Kingdom) and Utrecht University (The Netherlands). Regarding collaboration patterns, 21\% of the documents are in international collaboration, which is also the one that has grown most significantly in the last years in the last forty years (with a growth of 15.5\%). By checking the impact, regional studies on urban and rural areas, industrial clusters, and spatial proximity and innovation (e.g. patterns of location center-periphery according to the transport costs) are the ones that have a major number of citations.

Regarding thematic specialization, Geography and Economics constitute the main areas in which this research is published; however, other research fields are prominent (e.g. Urban Studies, Environmental Studies), indicating the interaction between space and economics. By using a topic modelling approach to determine the topics of the articles, 15 clusters were defined. Markets/businesses constitute a topic whereas other focus on spaces (rural and urban) and entrepreneurship issues. However, the intensity over time shows a different pattern. In this sense, in the last twenty years, markets and economic activity were more prominent in the early years whereas topics related to institutions, sustainability-oriented, networks (e.g. transport) and urbanization have become more relevant recently. This indicates the change of discourses over time. Last, "Impact" (13.77), "new economic geography" (13.65), "increased performance" (13.4), "organization" (12.43) and "trade" (11.78) are the keywords that are considered as 'hot topics' in the field.

In the discussion section, it is remarked that the number of records collected by using the search criteria are high, despite the fact that the methodology used is restrictive, focusing on the 'core' of the publications and other documentary typologies have not been used, such as other studies that focus on books (Gorraiz et al., 2016) or in the analysis of the production of journals in Economic Geography (Foster et al., 2007). In addition, the results obtained from the number of publications suggest that although research on this topic seems to have a long tradition, there is a concentration of publications in recent years, denoting a growing interest in this field in recent years. Although this growth is generalized in all areas of knowledge (Hu et al., 2020), this growth is in line with other studies (for example, Wang \& Liu, 2014), which show that the economic part is a great contributor, for example, in the studies of territorial studies such as the rural area.

The analysis also shows a positive evolution of international collaboration patterns, although these continue to be smaller, with collaborations within the same centers and within the same country (national collaboration) predominating. This fact reaffirms the conclusions of previous works in which it is stated that Economic Geography does not have a very international behaviour (Gutiérrez \& López-Nieva, 2001; Müller, 2021).

On the other hand, the results show the Anglocentric character (United Kingdom and United States) of the institutions that publish in economic geography, in line with previous studies (Gutiérrez \& López-Nieva, 2001; Wing \& Liu, 2014; Foster et al., 2007) that show how non-English-speaking communities are marginalized, despite the fact that the majority of readers are consumers and are increasingly multilingual (Müller, 2021). However, this fact may be related to the use of Web of Science database, which produces an English-publication bias. However, in terms of specialization some countries stand out (e.g. Nordic countries) with topics associated with innovation and entrepreneurship. In this way, topics of interest are associated with spaces where certain economic processes present a novelty in their operation or in social concerns, something that the results allow us to show.

In terms of topics, as also is pointed out by Atienza et al. (2019), the thematic interrelationships between the studies of economists and economic geographers are difficult to separate, as also attested by the results the collaboration between both fields. Although interdisciplinarity in this case also helps to focus on the issues that most concern researchers who work on the interrelationship between economy and space.

As a conclusion, this study helps to understand the path of the Economic Geography research field. The bibliometric analysis offers a starting point to get an overview of a research field, as it allows collecting and analysing data on the scientific production of a specific subject. In this study, a greater scientific effort in recent years is observed, as well as an increase of international collaboration along with the evolution of the 
different themes in this regard. Thus, the method followed shows the usefulness for the various topics that you want to work on.

Some limitations of this study should be noted. First, we identify documents explicitly mentioning Economic Geography ('core publications' that include this term in the title, abstract and keywords). In this regard, articles related to the topic that do not explicitly include the search strategy used may have been omitted. Furthermore, the use of the Web of Science database may omit other works (for example, publications in Spanish language), as well as other types of documents (reports) that may be of interest for the analysis of this field. In future research, other search techniques (direct citations expanding method) will be included. As well, a more complete analysis will require checking whether this same happens in other bibliographic bases where productions in Latin, French and Italian languages are incorporated, little present in the basis on which this approach has been made. In addition, future studies could be complemented with qualitative research methods (interviews, surveys) with researchers in the field to learn more about their motivations in their specialization towards Economic Geography. 


\title{
Study of the spatio-temporal dynamics of the Ait Daoud ou Ali (Central High Atlas, Morocco) Forest using geospatial techniques
}

\author{
Aïman Hili \\ a.hili@usms.ma@0000-0003-2220-6360 \\ Rachid Bissour \\ bissour1983@usms.ma@0000-0002-5391-9921 \\ Farid Jaa \\ farid.jaa@usms.ac.ma@0000-0002-7158-5080 \\ Hanane Reddad \\ h.reddad@usms.ma@0000-0002-6238-165X \\ Yassine El Jouhary \\ yassineeljaouhary02@gmail.com @ 0000-0002-1534-4944
}

Faculté des Lettres et des Sciences Humaines, Université Sultan Moulay Slimane. Avenu Ibn khaldoun, B.P. 524 Beni Mellal, Maroc

\author{
KEYWORDS \\ Supervised classification \\ NDVI \\ Diachronic study \\ The Ait Daoud ou Ali Forest \\ Central High Atlas \\ Morocco
}

For a long time, Man has sought to exploit natural resources for daily purposes (Bouiadjra et al., 2011; Labhar, 1998) to ensure his life and his needs. Thus, the current scientific and technological development has facilitated and given him real opportunities for the overexploitation of natural resources in general and plant cover in particular. For this, the protection of natural resources in general and the forest resource in particular has become today, in the global context of climate change and the emergence of the concept of sustainable development, a major challenge through the proposal of laws (Law 11-03, Law 12-03 and Law 22-07) and also through the creation of protected areas and national parks (Hili \& El Khalki, 2017). This came with the aim of creating a certain bio-ecological balance and facing climate change whether at the global or local scale.

Considering the contribution of spatial remote sensing and GIS tools, especially in the crossing of maps, the detection of degradation areas and areas of forest progression, the use of these tools has become very interesting in studies of the spatio-temporal dynamics of vegetation cover (Hili \& Abdelaziz, 2021; Gansaonré et al., 2020; Bissour et al. 2018; Sbai et al. 2018; Bouzekraoui et al. 2016; Daoui \& Fatemi 2014; Brou 2010; Mahamane et al. 2007; Hountondji et al. 2004; Nguessan et al. 2003; Demaze 2003).

Indeed, the studies that have been conducted on the dynamics of the vegetation cover (Hili \& Abdelaziz, 2021; Gansaonré et al., 2020; Bissour et al., 2018; Sbai et al., 2018; El Mazi et al., 2018, Raogo, 2018, Diop et al., 2018, Bouzekraoui et al, 2016, Daoui \& Fatemi, 2014, Soro et al., 2014; Tra Bi, 2013; Bouiadjra et al., 2011; Dawson et al., 2011; Brou, 2010; Mahamane et al., 2007; Demarteau et al., 2007; Hammi, 2007; Ouloukoi 
et al., 2006; Jeffrey et al, 2005; Hountondji et al, 2004; Carmen Salazar Conde et al, 2004; Nguessan, et al, 2003; Demaze, 2003; Dupouey et al, 1999; Labhar, 1998; Thimonier, 1994; Benabid, 1985; Lecompte, 1986; Michel \& Ruelan, 1967), have shown that the latter is often influenced by several factors, notably climate, topography (slopes, exposure of slopes and altitudes), lithology, pedology, and of course anthropic actions, whether conscious or unconscious.

For this reason, we propose this multi-chronic study of the Ait Daoud or Ali forest (with an area of 53785 ha), located in the central limestone High Atlas (Kingdom of Morocco). Given that this study area is located in the central High Atlas and characterized by a natural and human context very diverse, whether geographically, topographically, geologically, climatically and anthropically, or also from the point of view of its vegetation cover.

The objective of this work is the application of geospatial processing techniques on geographical data, and the evaluation of the contribution of spatial remote sensing for the quantification of the spatio-temporal dynamics of the vegetation cover of the forest of Ait Daoud or Ali over a period of forty-eight years between 1972, 1999 and 2020. This methodological approach consists in detecting changes (regression or progression) in the vegetation cover, from the calculation of the Normalized Difference Vegetative Index (NDVI), and a supervised classification of satellite images of different dates (1972, 1999 and 2020). Thus, the results obtained in this study and other studies that came afterwards (on the commune of Aghbala (Hili et al., 2021) and on the forest of Ait Bouzid), will allow us to evaluate the effectiveness of the laws and programs carried out for the protection and the safeguard of the Moroccan forest cover in general and the study area in particular.

The multi-chronic classification (1972, 1999 and 2020) conducted in this work has shown that the area of the forest of Ait Daoud or Ali has experienced a very remarkable evolution during the last 48 years. During this period, particularly between 1972 and 1999, we recorded a strong decline in the area of vegetation cover in favor of surfaces devoid of vegetation with $12 \%$ in the southeast of the study area. This decrease is involved in a particular climatic context, where Morocco has experienced long periods of drought (the 1980s). After this period, especially between 1999 and 2020, Morocco has committed to propose and adopt several regulations and laws, for the protection of nature in general, and the richness of its biological diversity in particular. Certainly, this policy has borne fruit a few years later (even if it remains very modest at the scale of the Central High Atlas and the region of Beni Mellal-Khénifra in particular). In the area of the forest that is the subject of this study, we can note a progression of the vegetation cover (in general) with $22 \%$. Despite this progression, the study area still records a loss of $10 \%$ of its vegetation cover.

The classification results obtained are satisfactory, its validation was verified by direct observations of the spatialization of areas during field trips, and also by comparing the results obtained from the classification of the tool "Region of Interest" used under the tools of spatial remote sensing, with that of the classification "Maximum Likelihood Classification" carried out using Geographic Information Systems. The study of these two methods showed a high accuracy of the overall treatment, with a small difference between the areas that varies between $-0.26 \%$ and $0.32 \%$.

In general, it must be said that the spatio-temporal evolution of the vegetation cover is influenced and linked essentially to the conjunction of several natural factors (climate, altitudes, exposure of the slopes and the lithology) and anthropic.

This study has highlighted the impact of anthropic actions including the use of wood for timber, for the construction of houses, for heating (socio-economic use of the forest resource) as well as the impact of overgrazing and agricultural activity in the forest area (agroforestry), given that the main activity of the local population is in agriculture and livestock) The use of geospatial techniques has allowed us to have very precise information relating to the spatio-temporal evolution of retreat and also of the progression of the vegetation cover in the forest of Ait Daoud or Ali.

For this, we can consider that the method used in this study, which combines both the analysis, visual interpretation and digital processing, is satisfactory and operational, it can therefore be applied to all studies dedicated to monitoring the dynamics of space-time vegetation cover. 


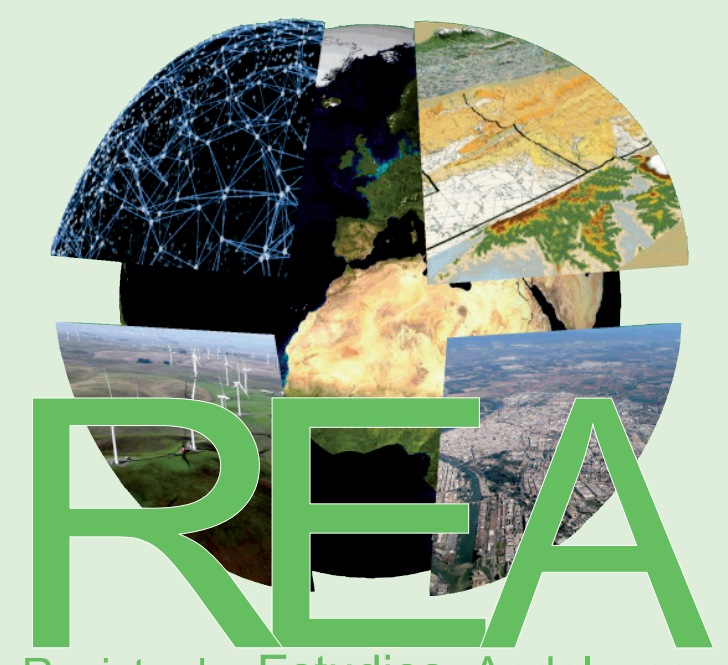

Revista de Estudios Andaluces 